\title{
Fostering Experimental Competences Using
}

\author{
Complementary Resources
}

[Fomento de las competencias experimentales utilizando recursos complementarios]

\author{
Natércia Maria Pereira Machado Lima \\ PhD Thesis Supervisors \\ Professor Clara Neves Cabral da Silva Moreira Viegas PhD \\ Professor Francisco José García Peñalvo PhD
}
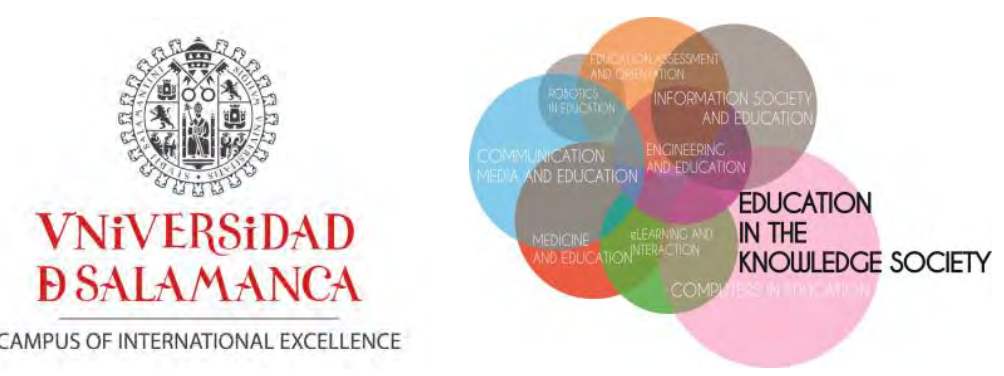

Education in the Knowledge Society PhD Programme

Salamanca, July 2020 

Francisco José García Peñalvo, PhD, Full Professor in the Department of Computer Science and Automation at the University of Salamanca (Salamanca, Spain) and Clara Neves Cabral da Silva Moreira Viegas, PhD, Professor in the School of Engineering at the Polytechnic of Porto (Porto, Portugal), as supervisors of the PhD thesis entitled "Fostering Experimental Competences Using Complementary Resources" developed by Natércia Maria Pereira Machado Lima

Hereby declare that

This PhD Thesis presents enough merits (theoretical and practical ones) evaluated through the proper assessment, publications and original proposals to be presented and defended publicly.

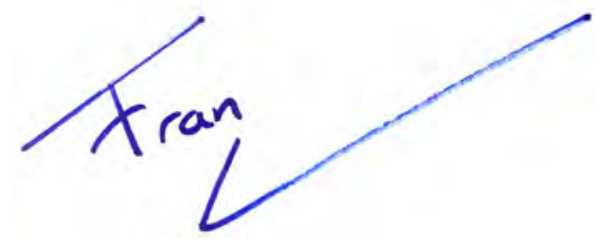

Francisco José García Peñalvo, PhD

University of Salamanca

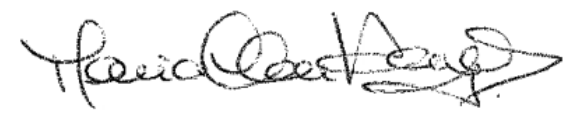

Clara Neves Cabral da Silva Moreira

Viegas, PhD

Polytechnic of Porto 

Fostering Experimental Competences Using Complementary Resources

[Fomento de las competencias experimentales utilizando recursos complementarios]

\author{
PhD Thesis \\ Candidate \\ Natércia Maria Pereira Machado Lima \\ Supervisors \\ Professor Clara Neves Cabral da Silva Moreira Viegas PhD \\ Professor Francisco José García Peñalvo PhD
}

July 2020 

$\mathscr{J}_{0}$ my sister Carla 

Whatever the results, whether successful ar not, the important thing is that in the end each one can say:

"I did what I could".

Louis Pasteur, 1822-1895 (Biologist) 



\section{ACKNOWLEDGEMENTS}

$\mathrm{T}$

his is the end of a hard, difficult, long but also challenging and motivating five years long journey. It would be impossible to go through this path without the support of several institutions and persons without whom I am sure I could not reach its end. So, it is with great joy and satisfaction that I am writing it, as I have decided, since the beginning, this would be the last thing to be done.

First of all, I would like to thank to my thesis supervisors: Clara (Professor Maria Clara Neves Cabral da Silva Moreira Viegas) and Francisco (Professor Francisco José García Peñalvo).

My deepest and eternal gratitude to my friend Clara (for over 30 years, now) and also my colleague (both from the Physics Department of ISEP and the research centre CIETI-LABORIS). First, to challenge me to this Project and believe (and make me believe) I was able to succeed. Secondly for being always there and treating me with all due respect and patience. Thank you for your support, for all the discussions, suggestions and sharing your expertise and experience with me. I am a really "lucky girl"!

My sincere thanks to Francisco for all his support, guidance, quick answers to all my doubts and the careful review of this thesis. My appreciation to you, also as the Coordinator of the Doctoral Program Education in the Knowledge Society, for all your initiatives, especially the Doctoral Consortium in the TEEM conferences. It has been a pleasure to attend and participate in it, all these years. I have learned a lot with the discussions with the colleagues and the other researchers. A special word of gratitude to Ana Santos and Alicia García Holgado, for clarifying some of my doubts.

Institutionally speaking, I want to thank to: USAL, especially the Faculty of Social Sciences; to P.Porto/ISEP, in particular to the Physics Department, not forgetting my colleagues, with a special word of gratitude to Arcelina for believing in my capabilities as a researcher; to CIETILABORIS, for all the support, including the financial support (through the FCT project UIDB/04730/2020). Thank you to all my colleagues from LABORIS, for the support and availability, with a special emphasis to Gustavo (Professor Gustavo Ribeiro da Costa Alves) for inviting me to this Research Centre and involving me in its projects. He was the first to talk me into doing a $\mathrm{PhD}$ and kept challenging me along the time. 
Thank you to the VISIR community (this great family started by professor Ingvar Gustavsson) and the VISIR+ Project members. Thanks for all the discussions and opportunities to share practice insights involving VISIR.

I cannot forget all the teachers and students that participated in this project. Without them and their collaboration I would not have data to conduct this study. Thank you to all of them especially the ones who I had the opportunity to keep informal contacts.

On a more personal note, I must thank my family and my friends for their support and encouragement.

First, my thanks to my parents for teaching me the value of work, responsibility, resilience and effort and for their investment in my education. Although I know they suffered with my absence (I am aware that I was not always there for you), I also know they are happy and very proud for this accomplishment.

Finally, I present my deepest gratitude to my close family -my husband (Rui) and my three children (Estefânia, Carolina and Henrique)- for all their patience, support and words of encouragement, trying to cheer me up in my worst moments. A special word of gratitude to Carolina for her help with some word and image issues. My apologies to all of you, for my "absences" through this long and arduous 5 years' period, especially in the last few months. I know I was not always in my best mood and all of you have suffered with it ("it is always about the thesis")! 


\section{ABSTRACT}

$\mathrm{T}$ The use of ICT in the academic context is a reality, in the world we live in. The young generation of students is digital native, being immersed in a virtual world during a considerable part of their day. This has an impact in their life, including on their education. In undergraduate engineering education laboratory classes are an integral part of its curriculum. These days, many laboratory classes combine traditional hands-on labs with online labs (remote and virtual labs) and several experimental resources. A "blended" or "hybrid" approach to experimental learning seems the most effective to (students') experimental learning and the development of competences. Still this technologically mediated resource affects the way students learn and in the literature there is still a lack of works, considering the characterization of didactical implementations using a "blended" or "hybrid" approach and its impact in students' learning and the way they construct their knowledge. In the Electric and Electronic Engineering topic and using the remote laboratory VISIR there are really very few works, reported in literature, describing some small scaled didactical experiments.

The problematic which motivated this work was the need to understand the impact of different didactical approaches using this methodology (simultaneous use of several experimental resources) has on students' academic results. Ultimately this work intends to contribute to fill a gap identified in the literature: identify factors (including some eventual students' characteristics) which affect students' learning and engagement in the electric and electronic circuits topic using the remote lab VISIR along with other complementary resources.

To accomplish this end, four research questions where posed, each of them taking into account a set of factors in a specific field of inquiry and its influence on students' results. The first research question approached the way the several experimental resources could be combined and its effect on students. The second dealt with the influence of the proposed VISIR tasks characteristics on students' results. The third tackled important teacher mediation traces that could be linked to better students' performance. And finally, the last research question investigates if there were students' characteristics that were more associated with good learning outcomes and engagement.

Considering the former objectives, it was chosen a multi-case study research methodology, using a mixed method approach, resourcing mainly to questionnaire, interview, documental analysis and observation as data gathering methods, and statistical analysis (descriptive and inferential) and content analysis, as data analysis techniques. 
A large-scale study analysis was conducted, including 26 courses (in a total of 43 didactical implementations using VISIR, as some of the courses have undergone more than one course implementation edition), comprising 1794 students and involving 52 different teachers. This study took place in several Higher Education Institutions (and at a minor extent, in some Technological and High Schools) in Argentina, Brazil and Portugal. In the southern hemisphere these didactical implementations happened in the 2016 and 2017 academic years while in the northern hemisphere it was possible to collect data from three semesters between 2016/17 and 2018/19 academic years. The study focused on analysing each didactical implementation (their characteristics, teachers' usage and perception) and the matching students' results (usage, academic results and perception). Ethical questions to guarantee both students' and teachers' privacy was taken care of, when using the data of the participants. The former data was only used for the purposes of this study and the state of the participation was reflected anonymously, which can be observed both in the information collected for the analysis as well as in the transcripts along the text.

The study included the analysis of the collected data from various sources, the interpretation of its results using several analysis techniques, and the convergence in a process of triangulation. These results, after discussed with literature, allowed to answer in the most possible complete way the four research questions. Based on them, conclusions were drawn to identify factors that may foster students' learning and engagement.

The study also contributed to the advancement of knowledge in this research area. It allowed to conclude that VISIR and this methodology can be as useful for introductory courses as for more advanced ones (dealing with this thematic) as long as teachers plan the didactical implementation according to the type of course and students' background. Plus, this methodology based upon VISIR can be applied with high success to courses that do not have an experimental component, nor its contents are directly related to the Electricity and Electronics topic. In these courses VISIR can be used with the purpose of contextualization, providing more interesting and appealing learning environments (e.g. theoretical mathematical courses). Finally, both teachers' perception and students' results suggest VISIR target public seems to be the students that require more support in their learning, that is, the students still struggling with difficulties than the more proficient students. 
KEYWORDS: Engineering Education, curricular design, experimental practices, VISIR, simulations, hands-on labs, remote labs, teacher mediation, teacher reflection, students' learning, students' characteristics, students' engagement, didactical implementations. 



\section{RESUMEN}

l uso de las TIC en el contexto académico es una realidad en el mundo en que vivimos. La
generación de los jóvenes estudiantes es nativa digital y está inmersa en un mundo virtual durante una parte considerable de su día a día. Esto tiene un impacto en su vida, incluyendo su educación. En los grados de ingeniería, las clases de laboratorio son una parte importante de sus planes de estudios. Actualmente, muchas clases prácticas combinan laboratorios tradicionales (hands-on) con laboratorios online (remotos y virtuales) y varios recursos experimentales. Un enfoque blended o hybrid parece ser el más efectivo para el aprendizaje experimental (de los estudiantes) y la adquisición de competencias. Aun así, estos recursos mediados tecnológicamente afectan la forma como los estudiantes aprenden. En la literatura todavía faltan trabajos que consideren la caracterización de implementaciones didácticas usando un enfoque blended o hybrid y su impacto en el aprendizaje de los estudiantes y la forma como construyen su conocimiento. En relación con la Ingeniería Eléctrica y Electrónica y el uso del laboratorio remoto VISIR, hay muy pocos trabajos en la literatura que describen algunas (pequeñas) implementaciones didácticas.

La problemática que motivó este trabajo fue la necesidad de comprender el impacto de diferentes aproximaciones didácticas, que utilizaran el uso simultáneo de varios recursos experimentales, en los resultados académicos de los estudiantes. En última instancia, este trabajo tiene la intención de contribuir a llenar el siguiente vacío en el estado de la cuestión: identificar factores (incluyendo posibles características de los estudiantes) que afecten el aprendizaje y la participación del estudiante en el tema de circuitos eléctricos y electrónicos utilizando el laboratorio remoto VISIR junto con otros recursos complementarios.

Para lograr este fin, se plantearon cuatro preguntas de investigación, cada una de ellas teniendo en cuenta un conjunto de factores en un tópico específico y su influencia en los resultados de los estudiantes. La primera pregunta aborda la forma en cómo se podían combinar los diversos recursos experimentales y su efecto en los estudiantes. La segunda se refiere a la influencia de las características de las tareas VISIR propuestas en los resultados de los estudiantes. La tercera se centra en las importantes características de la mediación docente que podrían estar asociadas a un mejor rendimiento de los estudiantes. Y, finalmente, la última pregunta investiga si hay características de los estudiantes que se puedan asociar más con los buenos resultados de aprendizaje y compromiso. 
Teniendo en cuenta los objetivos anteriores, se eligió una metodología de investigación de estudio de casos múltiples, utilizando una aproximación metodológica mixta, recurriendo principalmente a cuestionarios, entrevistas, análisis documental y observación como métodos de recopilación de datos y análisis estadístico (descriptivo e inferencial) y análisis de contenido, como técnicas de análisis de datos.

Se realizó un estudio a gran escala, que incluyó 26 cursos (en un total de 43 implementaciones didácticas usando VISIR, ya que algunos de los cursos realizaron más de una edición de implementación), abarcando 1794 estudiantes e involucrando 52 docentes diferentes. Este estudio se realizó en varias instituciones de enseñanza superior (y, en menor medida, en algunas escuelas tecnológicas y secundarias) en Argentina, Brasil y Portugal. En el hemisferio sur, estas implementaciones didácticas ocurrieron en los años académicos 2016 y 2017, mientras que en el hemisferio norte fue posible recopilar datos de tres semestres entre los años académicos 2016/17 y 2018/19. El estudio se centró en analizar cada implementación didáctica (sus características, uso y percepción de los docentes) y los resultados de los estudiantes correspondientes (uso, resultados académicos y percepción). Se garantizó la privacidad tanto de los estudiantes como de los docentes al utilizar los datos de los participantes. Los datos obtenidos solo se utilizaron para los fines de este estudio y la participación fue anónima, lo que se puede observar tanto en la información recopilada para el análisis como en las transcripciones a lo largo del texto.

El estudio incluyó el análisis de los datos recogidos de diversas fuentes, la interpretación de sus resultados utilizando varias técnicas de análisis y la convergencia en un proceso de triangulación. Estos resultados fueron discutidos con los de la literatura, permitiendo responder, de la manera más completa posible, a las cuatro preguntas de investigación. Con base en estos resultados, se sacaron conclusiones para identificar los factores que pueden fomentar el aprendizaje y la participación de los estudiantes.

El estudio también contribuyó para el avance del conocimiento en esta área de investigación. Permitió concluir que VISIR y esta metodología pueden ser tan útiles para los cursos introductorios como para los más avanzados (que abordan esta temática) siempre que los docentes planifiquen la implementación didáctica de acuerdo con el tipo de curso y los conocimientos previos de los estudiantes. Además, esta metodología basada en VISIR puede aplicarse con gran éxito a cursos que no tengan un componente experimental o contenidos directamente relacionados con el tema de Electricidad y Electrónica. En estos cursos, VISIR se puede utilizar con el propósito de contextualizar, proporcionando entornos de aprendizaje más interesantes y atractivos (por ejemplo, en cursos matemáticos teóricos). Finalmente, tanto la 
percepción de los docentes como los resultados de los estudiantes sugieren que el público objetivo de VISIR parece ser más los estudiantes que requieren de apoyo en su aprendizaje y no tanto los estudiantes más competentes.

PalabRas ClaVE: Educación en Ingeniería, diseño curricular, prácticas experimentales, VISIR, simulaciones, laboratorios prácticos, laboratorios remotos, mediación docente, reflexión docente, aprendizaje de los estudiantes, características de los estudiantes, participación de los estudiantes, implementaciones didácticas. 



\section{INDEX}

Acknowledgements.................................................................................................................

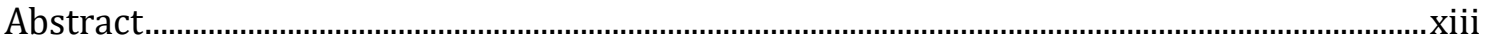

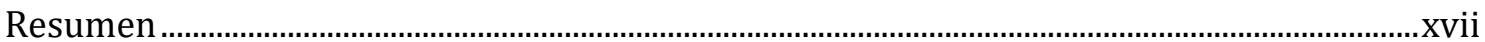

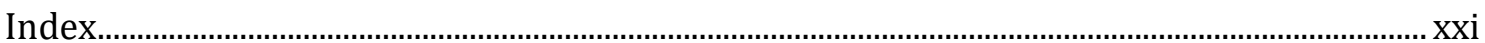

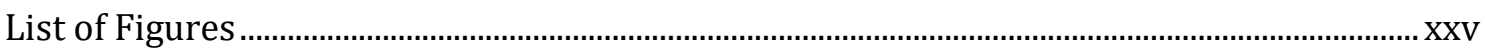

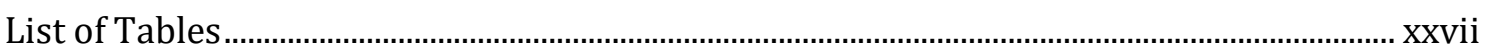

List of Abbreviations and Acronyms..........................................................................................

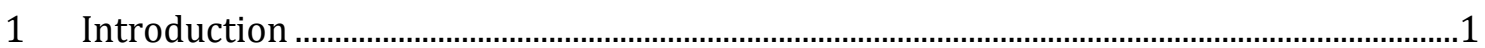

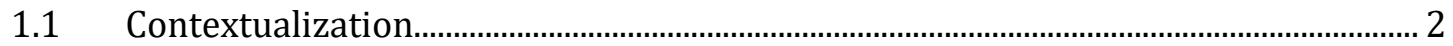

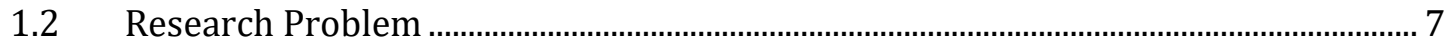

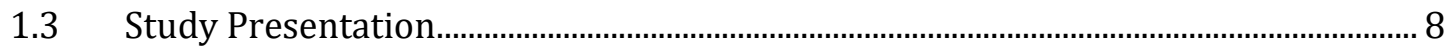

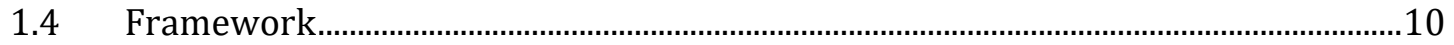

1.5 Document Structure .......................................................................................................12

2 State of the art

2.1 The Role of Experimental Work in Engineering Education ..........................................15

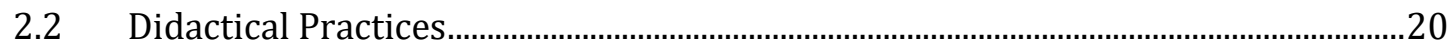

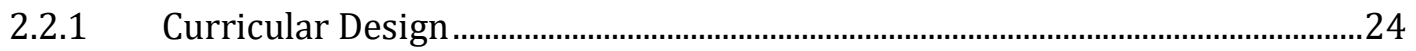

2.2.2 Teacher Mediation....................................................................................................

2.2.3 Practice Reflection.................................................................................................. 40

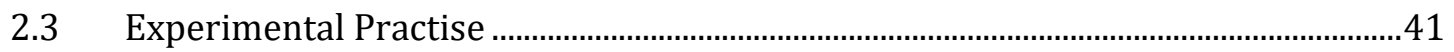

2.3.1 Hands-on Laboratories............................................................................................ 43

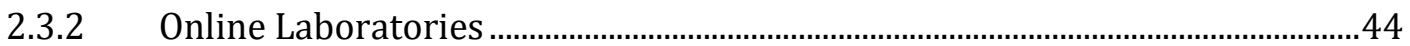

$2.4 \quad$ Students' Learning ...........................................................................................................

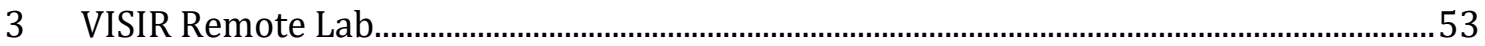

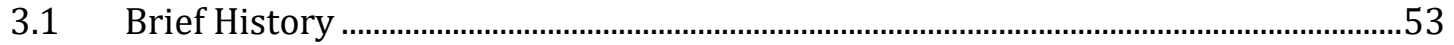




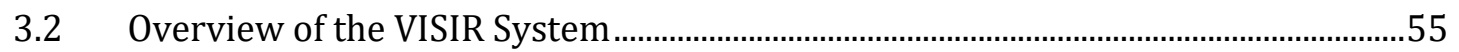

3.3 VISIR Usage State of the Art up to 2016 - Literature Review ………………………....59

3.4 The VISIR+ Project ...............................................................................................................61

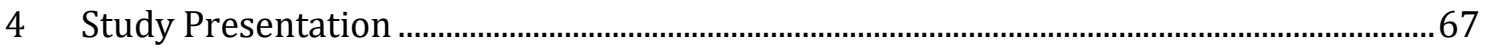

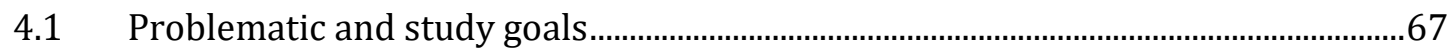

4.2 Research Methodology ..................................................................................................

4.3 Case Studies Characterization …………………...............................................................

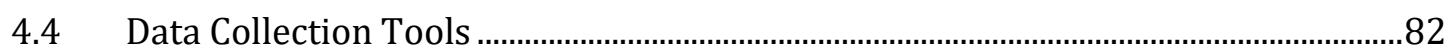

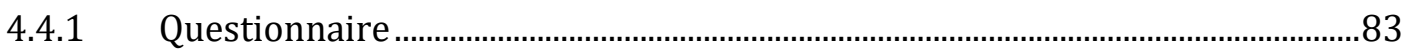

4.4.2 Interviews and Informal Contacts …………………………………………........... 87

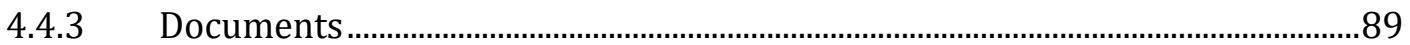

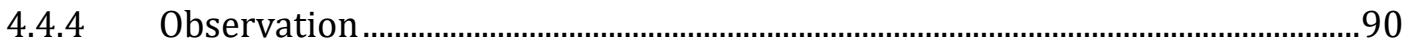

4.5 Data Analysis Techniques ............................................................................................91

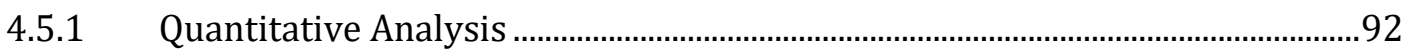

4.5.2 Qualitative Analysis .........................................................................................94

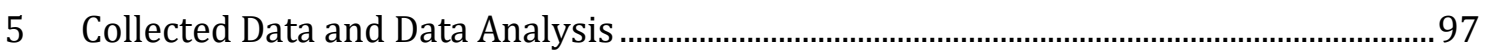

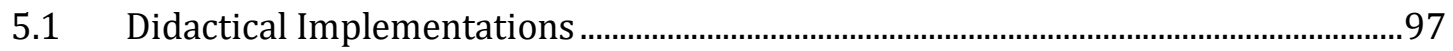

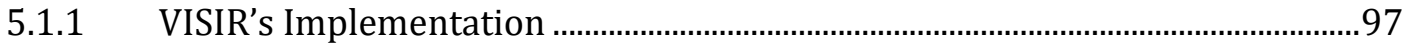

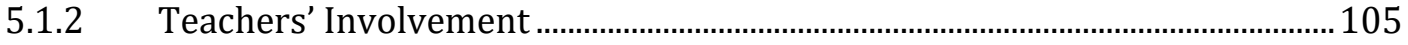

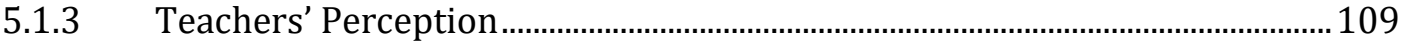

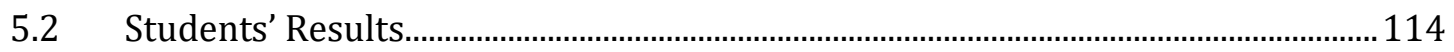

5.2.1 Academic Performance............................................................................................. 114

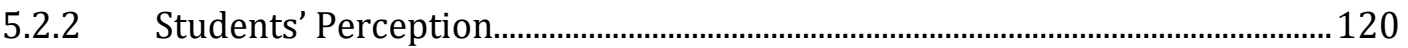

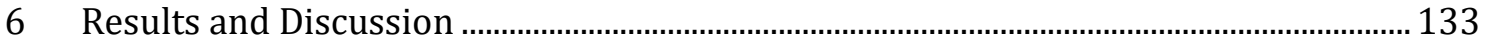

6.1 Didactical Implementation Results ......................................................................... 133 
6.1.1.1 Didactical Implementations Iterations ………………………………........ 134

6.1.1.2 Simultaneous Resources Analysis ...................................................................138

6.1.1.3 Level of Competence and Type of Task...............................................................142

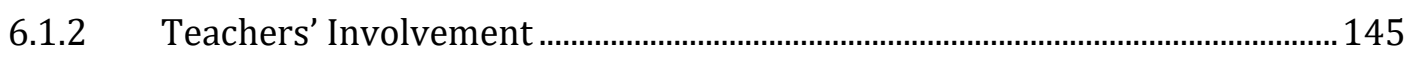

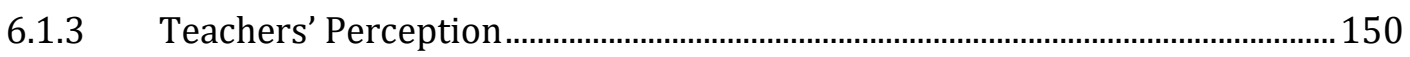

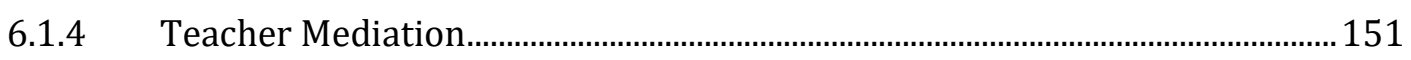

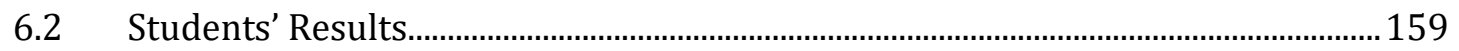

6.2.1 Academic Performance...........................................................................................

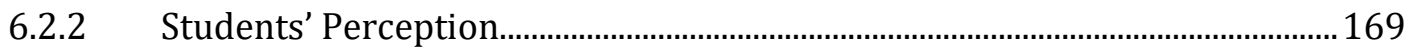

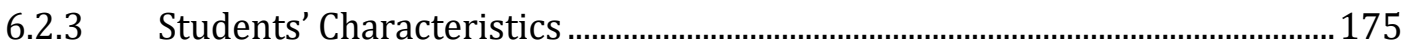

6.2.4 Academic Performance and Students' Perception ............................................... 178

6.3 Didactical Implementation/Students' Results ........................................................... 185

6.3.1 Simultaneous Use of Resources and Students' Results .....................................185

6.3.1.1 Synthesis of the Results Obtained in Simultaneous Use of Resources and Students' Results 195

6.3.2 Tasks Characteristics and Students' Results 197

6.3.2.1 Synthesis of the Results Obtained in Tasks Characteristics and Students' Results 207

6.3.3.1 Synthesis of the Results Obtained in Teacher Mediation and Students' Results

6.3.4 Students' Characteristics and Students' Results. 226

6.3.4.1 Synthesis of the Results Obtained in Students' Characteristics and Students' Results 237 


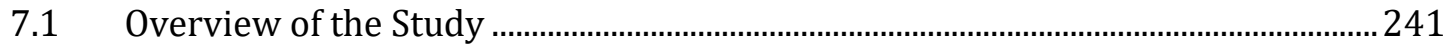

7.2 General Conclusions .................................................................................................. 243

7.3 Problems and Limitations of the Work ……………………………………………..... 251

7.4 Future Directions..................................................................................................... 252

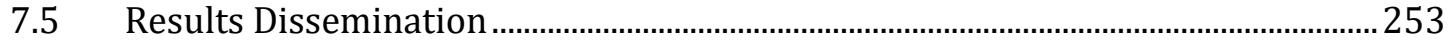

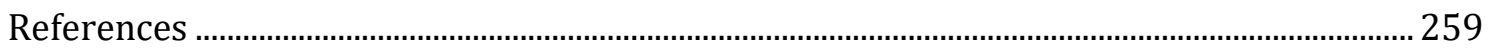

Appendix A - Student's Satisfaction Questionnaire ……................................................................. 281

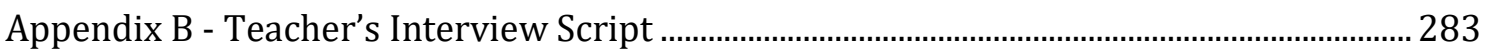

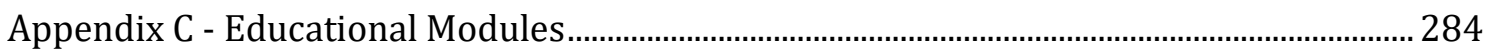

Appendix D - Target Course Fact File ............................................................................................. 286

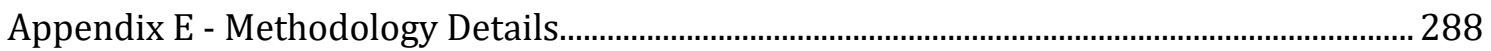

Appendix F - Summary of the Analyses Involving each Case ........................................................2 289

Appendix G - Mann-Whitney Test Results for Teachers............................................................... 290

Appendix H - Correlations by Didactical Implementation ............................................................ 291

Appendix I - Mann-Whitney and Student's T-Test Results for Students ...................................300 


\section{LIST OF FIGURES}

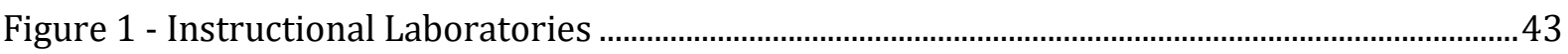

Figure 2 - VISIR Virtual Breadboard .................................................................................................... 56

Figure 3 - Interfaces of the Instruments - VISIR System ......................................................................56

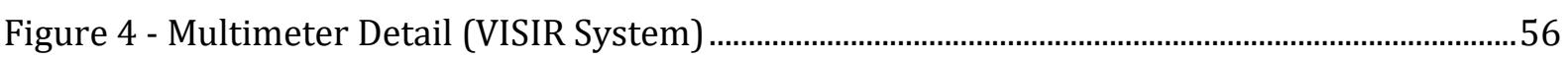

Figure 5 - VISIR at ISEP: Overview (left) and a Switching Matrix Detail (right)................................58

Figure 6 - Level of Competence Teachers Wanted Students to Develop ..............................................99

Figure 7 - VISIR Support during the Semester ..................................................................................... 101

Figure 8 - Tasks (Number and Regime) by Education Level................................................................ 103

Figure 9 - VISIR Tasks Attributes by Education Level .................................................................................104

Figure 10 - Teachers' Perception of Students' Satisfaction with VISIR ……......................................109

Figure 11 - Teachers' Satisfaction with VISIR ………….......................................................................110

Figure 12 - Students' Background........................................................................................................ 117

Figure 13 - Students' preference for remote labs versus hands-on labs …………..........................123

Figure 14 - Students' Answers to Questions Q13 and Q18 ………………………………………......124

Figure 15 - Combination of Experimental Resources used in the Didactical Implementations.. 139

Figure 16 - Competence Level/ Type of Task............................................................................................143

Figure 17 - Influence of Students' Background and Students' Success on Students' Grades and

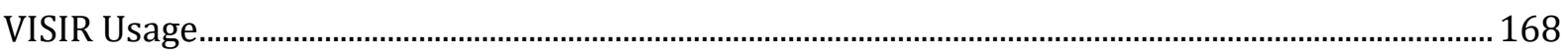

Figure 18 - Q7 and Q11 Students' Answers by Course Level................................................................177

Figure 19 - Influence of Experimental Resources Combination and Teachers Designed Support on Students' Academic Performance 192

Figure 20 - Influence of Experimental Resources Combination and Teachers Designed Support in

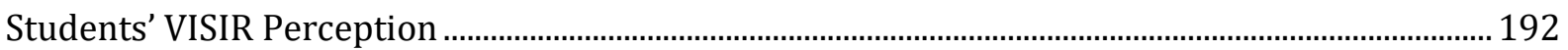

Figure 21 - Influence of Task Characteristics on Students' Academic Performance........................ 204

Figure 22 - Influence of Task Characteristics in Students' VISIR Perception................................... 204

Figure 23 - Students' Answers to Q16, by Number of Course Implementation Edition ................. 221

Figure 24 - Dominant Mediation Traces on Students' Results ..............................................................225

Figure 25 - Contributions to the Advancement of Knowledge.............................................................249

Figure 26 - Recommendations for a System of Best Experimental Practices .....................................2 250 



\section{LIST OF TABLES}

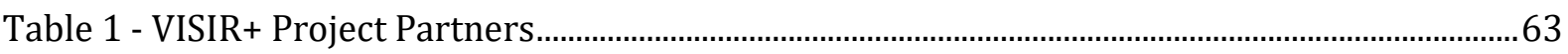

Table 2 - Dimensions and Categories of Analysis**................................................................................. 74

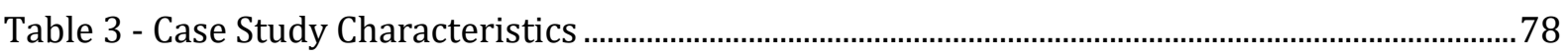

Table 4 - Additional Resources Used by Implementation ....................................................................

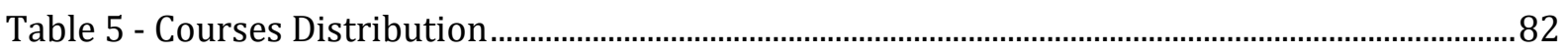

Table 6 - Student's Questionnaire Internal Consistency Analysis (Cronbach alpha), by Case........86

Table 7 - Student's Questionnaire Internal Consistency Analysis (Cronbach alpha) by Topic ......87

Table 8 - Collected Data to Tackle each RQ .....................................................................................91

Table 9 - Didactical Implementation Characteristics .................................................................................98

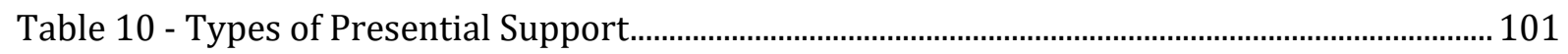

Table 11 - Number of VISIR Tasks by Topic ………….......................................................................... 102

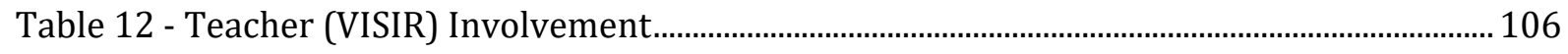

Table 13 - Teacher (VISIR) involvement Characterization.................................................................107

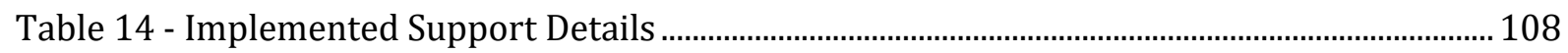

Table 15 - Teacher Open Question Quality Assessment (positive and negative factors (in shadow)

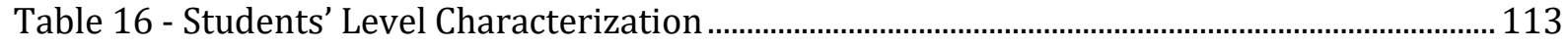

Table 17 - Students' Academic Performance Characterization ..............................................................115

Table 18 - Students' Academic Performance Characterization by Topic............................................118

Table 19 - Students' Perception of VISIR …………...............................................................................121

Table 20 - Students' Perception of VISIR by Topic................................................................................122

Table 21 - Students Quality Assessment on the Open Questions (identified positive and negative factors (in shadow)) .............................................................................................................................. 126

Table 22 - Students Quality Assessment on the Open Questions by Topic (identified positive and negative factors (in shadow)) .........................................................................................................129

Table 23 - Course Implementation Editions: main Modifications ………...........................................137

Table 24 - Experimental Resources Combination Details.....................................................................139

Table 25 - VISIR and Hands-on Usage Arrangement........................................................................... 141

Table 26 - Tasks Type 2 Detailed Characterization ........................................................................................ 144

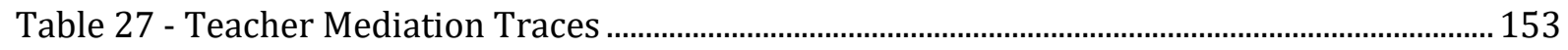

Table 28 - Students' Grades Correlations with VISIR Usage (Global Analysis).................................161 
Table 29 - Students' Grades Correlations with VISIR Usage (by topic).

Table 30 - Correlation between F1 and F2 (Globally and by Topic)...

Table 31 - Students' Academic Performance and Students' VISIR Perception Correlations (Global Analysis) 179

Table 32 - Students' Academic Performance and Students' VISIR Perception Correlations (by Topic). 180

Table 33 - Correlation between Simultaneous Use of Resources and Students' Results . 186

Table 34 - Correlation between Tasks and Level of Competence with Students' Results 198

Table 35 - Correlation between Factors related to Teacher Mediation Traces with Students' Results 209

Table 36 - Correlation between Teachers' VISIR Usage and Students' VISIR Usage 212

Table 37 - Correlation between Teachers' Satisfaction and Students' Satisfaction (with VISIR)214

Table 38 - Teacher Mediation Traces and Students' Academic Results

Table 39 - Correlation between Q16 Answers Distribution and Students' Results. 221

Table 40 - Correlation between Students' Characteristics and Students' Results 227

Table 41 - "Students' Level" (According to Teachers' Perception) and Students' Academic Performance. 236

Table 42 - Correlation between Q7 and Q11 Answers Distribution with Students' Results 237 


\section{LIST OF ABBREVIATIONS AND ACRONYMS}

ABENGE - Brazilian Association of Engineering Education

ABET - Accreditation Board for Engineering and Technology

$\mathrm{AC}$ - alternate current

AP partners - Associate partners

APA - American Psychological Association

ASEE - American Society for Engineering Education

BSU - Batumi Shota Rustaveli State University

BTH - Blekinge Institute of Technology

CIETI - Centre for Innovation in Engineering and Industrial Technology

CISPEE - International Conference of the Portuguese Society for Engineering Education

CLADI - Congreso Latinoamericano de Ingenería

COBENGE - Congresso Brasileiro de Educação em Engenharia

CONFEDI - Federal Council of Deans of Faculties of Engineering

CONICET - National Council for Technical and Scientific Research

CoP - Community of Practice

CUAS - Carinthia University of Applied Sciences

DC - direct current

DI - Didactical Issues

EDUNINE - IEEE World Engineering Education Conference

EE - Electricity and Electronics

EU partners - European HEI partners

exp.at - Experiment@ International Conference

FCT - Portuguese Foundation for Science and Technology

FH Campus Wien - FH Campus Wien University of Applied Sciences

GPL - General Public License

HE - Higher Education

HEI - Higher Education Institutions

HOS - Higher order skills

IAOE - International Association of Online Engineering

ICT - Information and Communication Technology

IFC Araranguá - Federal Institute Catarinense, Araranguá 
IFC C. Sombrio - Federal Institute Catarinense, Campus Sombrio

IFSC - Federal Institute of Santa Catarina, Florianopolis

I-I - indirect-interaction

IIT-M - Indian Institute of Technology Madras

ILO - Intended Learning Outcomes

ILS - Intelligent Learning System

IMCL - International Conference on Interactive Mobile

INTED - International Technology, Education and Development Conference

IoE - Internet of Everything

IoLT - Internet of Learning Things

IoT - Internet of Things

IPS - Higher Polytechnic Institute Gral. San Martín

IRICE - Research Institute in Educational Sciences of Rosario

ISEP - P.Porto School of Engineering

LA - Latin American

LA partners- Latin American HEI partners

LABORIS - Research Group in Systems Testing

LMS - Learning Management System

MOOC - Massive Open Online Course

MOODLE - Modular Object-Oriented Dynamic Learning Environment

NI - National Instruments

NTL - non-traditional labs

PC - personal computer

P.Porto - Polytechnic of Porto

PILAR - Platform Integration of Laboratories based on the Architecture of visiR

PLE - Personal Learning Environment

PLP - Personal Learning Pathway

PUC-Rio - National Distance Education University

REV - International Conference on Remote Engineering \& Virtual Experimentation

RQ - Research Question

SATC - Santa Catarina Coal Industry Charitable Association

S-E - student-equipment interaction

S-I - student-instructor interaction

SIG - Special Interest Group 
SLA - Student Learning Approaches (student approaches to learning)

SLR - systematic literature review

SPSS - Statistical Package for the Social Sciences

SRL - self-regulated learning

S-S - student-student interaction

SSQ - Student's Satisfaction Questionnaire

STEAM - Science, Technology, Engineering, Arts, and Mathematics

STEM - Science, Technology, Engineering, and Mathematics

TA - training actions

TAEE - Technology Applied to Electronics Teaching

TEEM - International Conference on Technological Ecosystems for Enhancing Multiculturality

TI - Technical Issues

TL - traditional labs

TR - Teacher-Researcher

UCP - Catholic University of Petropolis

UDEUSTO - University of Deusto

UERJ - State University of Rio de Janeiro

UFSC - Federal University of Santa Catarina, Araranguá

UNED - National Distance Education University

UNIVALI - Vale do Itajaí University

UNR - National University of Rosario

UNSE - School of Exact Sciences and Technologies - National University of Santiago del Estero

UTN FRRo - National Technical University

VINNOVA - Swedish Governmental Agency for Innovation Systems

VISIR - Virtual Instrument Systems in Reality

VRLs - Virtual and Remote Laboratories

VRLs - Virtual and Remote Labs 



\section{INTRODUCTION}

$\mathrm{T}$ his digital age strains the need of rethinking the traditional teaching and learning. The development of digital networks and Internet dissemination from the second half of the 1990s broadened the available information and access to different tools. These technological innovations also facilitate the learning process on a time that is marked by an ongoing increase in the volume of knowledge. In about one generation the learning environments and conditions have radically changed leading to a revolution in teachers' role. Modern teachers must not be enclosed in the knowledge components. In fact, they must design, develop and implement effective learning environments, supported by Information and Communication Technology (ICT). They need to establish the necessary bridges to reach these actual cosmopolitan, curious and demanding students and prepare them for their professional demands. In the twenty-first century, these concerns about education particularly their impact in science education are international. Modern society is more globally aware of the importance of science and technology in everyday life. These changes caused a tremendous impact in the way experimentation takes place in the science laboratory nowadays. The central role of experimenting in science and engineering education is unquestionable. Still one moved from an exclusive traditional hands-on lab to developing competences also through the usage of online labs (remote and virtual labs), combining these resources in diverse ways. The central purpose of an engineering is definitely to interact with nature, shaping it by the development of products, systems and equipment, for the benefit of mankind; however, the way these interactions take place have changed and further research is needed to determine more efficient and sustainable ways to interact with nature. Experimentation is therefore a central key in science education and specially in engineering.

The uncertainties and questioning about this particular item are not a limitation but the driving force beneath this research project which aim is to contribute to the knowledge development in this area. Using varied contexts such as: educational setting, students' background, type of course, teachers' experience with remote labs, resources used, learning goals, etc. and also including external factors such as socio-cultural and/or political, the aim of this work is to better understand how and which students' learning outcomes are affected by the simultaneous use of different experimental resources. Analysing the data from 43 didactical implementations supported by the remote laboratory VISIR (Virtual Instrument Systems in Reality) -involving 1734 students and 52 teachers- the target is to identify the factors that affect students' learning in the electric and electronic circuits topic. Ideally the goal is to identify common traces, in "resources", "tasks", and "mediation" and be able to understand which 
combinations - according to some "students' characteristics" - produce good results, contributing to the definition of a system of best practices.

This chapter describes the problematic tackled in this PhD work as well as the thoughts and ideas that lead to it. In that sense, after a brief contextualization of this study, it is presented the research problem and, within it, the four research questions (RQs) addressed in this thesis. The methodology used to conduct this study and answer the research questions is briefly referred as well as the designed work plan to achieve this goal. Finally, in the last subsection it is explained the document structure.

\subsection{Contextualization}

In the last 50 years the human population has nearly triplicated. This period was accompanied by huge advances in most areas of knowledge: science, engineering and technology, including the Internet burst. In about 30 years one goes from almost no Internet -in the beginning of the $80 \mathrm{~s}$ - to nowadays, where the Internet has the potential to address many challenges of the modern world. Although this technology is by no means a panacea, it can benefit individuals as well as organizations and countries, contributing to improve the social well-being and economic development. The present times are defined by the Internet of Things (IoT) (Atzori, Iera, \& Morabito, 2010): physical devices around the world that are (or can be) now connected to the Internet, generating, collecting and sharing data. Anything with a sensor can become part of a IoT, thanks to cheap processors and wireless networks (León, Hernández-Serrano, \& Soriano, 2010; Rose, Eldrdge, \& Chapin, 2015). With IoT everything can be online and accessible from home automation mechanisms through health monitoring medical devices to educational platforms Internet of Everything (IoE) (Kang, Kim, \& Choo, 2017)- connecting people, process, data and things -making the most of these connections, turning information into valuable actions. When applied to Education -adoption of these technologies in a massive way, engaging students in and beyond classrooms- is known in literature as the Internet of Learning Things (IoLT) (CISCO, 2013; Prasanna, 2017). Naturally, IoT raises important challenges, namely: security issues, privacy considerations, ethical or legal questions that must be considered (Rose et al., 2015).

Education, promotion of knowledge construction and competences development in a formal or informal way (Griffiths \& García-Peñalvo, 2016), has undergone considerable changes in the last decades, especially since the 80s, including the Bologna Process (Crosier \& Parveva, 2013) in the beginning of this century. The use of ICT in education forced a shift from traditional teaching -typical a teacher-oriented (theory-oriented)- to student-centred didactical strategies 
(Valcke, Sang, Rots, \& Hermans, 2010). This technology is nowadays used in various formats: faceto-face (classrooms), blended and distance education (García-Peñalvo, 2015a). Moreover, the coronavirus has shown the gap between the theoretical technology penetration in education and the real one (García-Peñalvo, 2020) The digital age has influenced our daily lives and demands rethinking of traditional teaching and learning, leading to a change in students' and teachers' roles . Nowadays -and in opposition to the 80s where it was common belief that teachers (when finishing their degree) already knew everything- teachers are committed to lifelong learning, professional reading/research and collaboration (Gray \& Campbell-Evans, 2002; Soini, Pietarinen, \& Pyhältö, 2016) and are permanently challenged to revise their practices and adapt them to students' needs (Núñez Pardo \& Téllez, 2015). In fact, education main goal is to create a society able to manage conflicts in the right way, establishing fair interpersonal relationships based on empathy and respect of rights and duties (García-Peñalvo, Fernández-Hermo, Fidalgo-Blanco, \& Sein-Echaluce, 2014; Zahonero Rovira \& Martín Bris, 2012). Therefore, teachers have the role, as educators, to help in the transmission of those values. Beside theoretical-practical knowledge teachers must promote the development of generic or soft skills. Nowadays, employees generally agree that graduates have solid theoretical-practical knowledge in their field of specialization but they are less satisfied with the development of some of those soft skills such as: communication, team working, time management, problem-solving, learning aptitude or the ability to manage stress and heavy workloads (Hernandez-March, Martin Del Peso, \& Leguey, 2009; Stiwne \& Jungert, 2010). Some consider that this new generation of graduates -"Peter Pan Generation" (Martín Del Peso, Rabadán Gómez, \& Hernández March, 2013), grown in a rather protected environmentunlike the previous generations, lacks some maturity and motivation, putting high priority on comfort, their personal life and free time (Hernandez-March et al., 2009).

Engineering education has solid needs of experimental competence development regardless the area (Feisel \& Peterson, 2002a; Feisel \& Rosa, 2005; Gustavsson et al., 2009; Jara, Candelas, Puente, \& Torres, 2011). These competences were traditionally developed in hands-on (local) laboratories. Lab experiments allow students to efficiently apply theoretical concepts to practical situations -observe and explore real-world situations- as well as handling instruments, equipment and data. This practice contributes to build and consolidate knowledge and competences (Feisel \& Rosa, 2005; Gustavsson et al., 2009; Jara et al., 2011).

In the last decades, there was a general dramatically growth of the number of students attending higher education while staff, funding resources and the physical resources available have not proportionally augmented (Magin \& Kanapathipillai, 2000). At the end of the last century, the American Society for Engineering Society recommended engineers should "re-think the objectives of laboratory instruction and experiments, and find innovative ways for satisfying 
objectives" (Magin \& Kanapathipillai, 2000). Moreover, with the democratization of education, Higher Education Institutions (HEI) have to accommodate students that are more diverse in their background, motivations and capabilities as well as in the jobs and positions they will have after graduating (Kehm \& Teichler, 1995). Simultaneously, with the Bologna Process, the laboratory time was reduced in most European Engineering Schools and the number of students per class increased, due to economic restrictions. About the same time scientists started developing virtual (computer simulations) and remote laboratories. Online labs/experimentation are one of the new paths that targets at improving both learning quality and teaching methodologies. They allow students to practise some experimental skills in different manners - giving them freedom to organize their own learning activities according to the perception of their own learning needs, extending access to the learning resources and potentiating their autonomous work, time management and responsibility (Brinson, 2015; Gustavsson et al., 2011; Ma \& Nickerson, 2006). In fact, online labs combine benefits from "learning by doing" approaches with the main advantages of these learning spaces: accessibility, availability and safety (Marques et al., 2014). The use of these technologies allows teachers to diversify their classes in a simple way, without having to think about the typical logic, safety and cost issues associated with hands-on labs, reaching more students, as they diversify the methods and techniques used in class (Richardson, 2011). At the same time they are likely to appeal young students as they are a generation of digital natives (Prensky, 2001). Remote labs can be shared and pooled across the web, promoting the collaborative work between institutions and fomenting communities of practice (Alves, Fidalgo, et al., 2016). As a matter of fact, remote labs emerge as one of the main instructional technologies adopted and valued in undergraduate engineering education, corresponding to one of the major shifts in engineering education in the last 100 years (Froyd, Wankat, \& Smith, 2012).

Nowadays there is still some controversy about this new technology efficacy on students' experimental learning. Some studies consider online labs as educational hindrances (Dewhurst, MacLeod, \& Norris, 2000; DiBiase, 2000) while many others consider them useful resources as a complement to hands-on (Brinson, 2015; Corter, Esche, Chassapis, Ma, \& Nickerson, 2011; Gustavsson et al., 2009; Heradio, de La Torre, et al., 2016; Restivo \& Alves, 2013). Still students' learning performance cannot be endorsed to the type of resource alone. Many other factors have a tremendous impact in students' experimental learning such as: motivation, peer collaboration, appropriate feedback (Corter et al., 2011; Ma \& Nickerson, 2006) as well as teacher mediation role in leading students to productive engagement in the task (Cunha, Saraiva, Santos, Dinis, \& Lopes, 2014; Sarabando, Cravino, \& Soares, 2016). Naturally, students also have responsibility in their learning process, that is studying also depends on student-based factors including motivation, study skills, habits and attitudes (Biggs \& Tang, 2007; Crede \& Kuncel, 2008). 
Nevertheless, teachers are often using these resources instead or as a complement to the traditional hands-on labs to build and consolidate knowledge and competences. A "blended" or "hybrid" approach to experimental learning -a combination of hands-on labs, simulation and remote lab- seems to the most effective (Brinson, 2015, 2017; Corter et al., 2011; Corter, Nickerson, Esche, Chassapis, \& Ma, 2007; Heradio, de La Torre, et al., 2016), although some students express preference for traditional hands-on labs (Brinson, 2017; Corter et al., 2007). This poses new trends regarding pedagogical and didactical issues, as its use, on their own, may even be prejudicial -some of these tools are quite complex and not immediately understandable to students, leading them to frustration and dropping out the task (Sticker, Lookabaugh, Santos, \& Barnes, 2005). So two aspects that must be taken into account when using these tools are the technology-mediated interface and the physical and psychological distance from the lab equipment and figure out these factors influence in students' learning outcomes (Gorham \& Zakahi, 1990; Lindsay \& Good, 2005).

On the other hand, students need to understand the major differences of the type of measurements obtained from these different resources: model results from simulations versus real experimental results from hands-on and remote labs. The remote labs have the advantage of working with real things. Still they are not a perfect solution: the underlying technology of the laboratory (as the interface of the equipment) may influence learning effectiveness (Corter et al., 2011; Nickerson, Corter, Esche, \& Chassapis, 2007). Recent studies present evidence that the use of these technology-enabled lab formats can be effective in students' learning outcomes, as long as teachers realize the associated educational objectives of each of them may be different (Lustigova \& Novotna, 2012; Ma \& Nickerson, 2006); each method allows the developing of different (and maybe complementary) competences. So, teachers should be aware of this fact when deciding which method or combination of methods to use. It is crucial to design the course curriculum based on the learning outcomes teachers want their students to develop (Biggs \& Tang, 2007). For this planning, teachers must take into account not only the teaching methods but also the resources they will be using, and design students' activities accordingly.

Although in literature there are already some experiences describing the simultaneous use of these resources, in most cases just two of these are used (remote labs versus hands-on labs or simulations versus hands-on labs) (Corter et al., 2007; Nickerson et al., 2007; Sicker, Lookabaugh, Santos, \& Barnes, 2005) or no distinction is made between the type of online labs (remote or virtual) that is being used (Brinson, 2015). Many of these comparative studies are small-scaled, particularly for remote labs (Ma \& Nickerson, 2006) and no significant and consistent difference between hands-on, simulation and remote labs stand out with respect to content knowledge or the ability to solve problems measured by the results of test or reports (Ma \& Nickerson, 2006; 
Nickerson et al., 2007). And above, in some of these experiences students are split into groups and each group just experiences a single lab format (Corter et al., 2011).

In the Electric and Electronic Engineering topic, there are already some small scaled didactical experiments, reported in literature, using the three simultaneous experimental resources -extended to all students- based upon the remote laboratory VISIR (Virtual Instrument Systems in Reality)(Alves, Viegas, Lima, \& Gustavsson, 2016; Lima, Alves, Viegas, \& Gustavsson, 2015; Viegas, Lima, Alves, \& Gustavsson, 2014). In fact, in the EE (Electricity and Electronics) area, many authors have been developing studies addressing students' learning outcomes based upon the remote lab VISIR (Alves et al., 2011; Claesson \& Håkansson, 2012; Fidalgo et al., 2012; GarcíaZubía et al., 2020; García-Zubía, Gustavsson, et al., 2011; García-Zubía, Hernández, Gustavsson, \& Alves, 2011; Marques et al., 2014; Tawfik, Monteso, García-Loro, Sancristobal, et al., 2015; Tawfik, Sancristobal, Martín, et al., 2012), initiated in 1999, at the Blekinge Institute of Technology (BTH) in Sweden (Gustavsson, Zackrisson, \& Olsson, 2004). VISIR is a combination of open source software packages and commercial equipment from National Instruments (NI) for creating, wiring and measuring electronics circuits online. It can be considered a remote workbench with the same instruments and components that are available on a hands-on electric and electronic circuits lab, similar in all engineering schools(Gustavsson, Zackrisson, Nilsson, et al., 2008). BTH research group is still responsible for maintaining and updating the VISIR distribution that is available as open source. Nowadays, VISIR is installed in seventeen different Higher Education Institutions, in twelve different countries (Argentina, Austria, Brazil, Costa Rica, Georgia, Germany, India, Morocco, Portugal, Spain, Sweden and United States of America) (Alves, Felgueiras, et al., 2018; García-Zubía et al., 2020) and it has well served several thousands of students (Salah, Alves, Abdulazeez, Guerreiro, \& Gustavsson, 2015; Tawfik, Sancristobal, Martín, Gil, Pesquera, Losada, et al., 2011; Tawfik et al., 2013). But until the end of 2015 civil year, before the blast of the VISIR+ Project (Alves, Fidalgo, et al., 2016), VISIR was installed just in eight HEI in six countries. The VISIR+ Project intended to disseminate VISIR in Latin American (LA) countries (Argentina and Brazil) by installing a system in five HEI, to be used not only for these HEI but also for other secondary/technological/higher education institutions. It also aimed to define and develop a set of educational modules comprising hands-on, virtual and VISIR remote lab, together with calculus, following an enquiry-based teaching and learning technology (at least, in some extent).

Until the end of 2015, thousands of students had already used VISIR, with effective learning gains (Tawfik, Sancristobal, Martín, et al., 2012). In some cases VISIR was used along the handson lab, although in the majority these 2 experimental resources usage was not extended to all the students involved in the implementations (Alves et al., 2011; Costa-Lobo et al., 2011; Marques et 
al., 2014). Up to then there were very few works in literature reporting this resource usage simultaneously with simulation and hands-on lab, together with calculus, except for the small scale didactical experiments already referred in this section (Alves, Viegas, et al., 2016; Lima, Alves, Viegas, et al., 2015; Viegas et al., 2014).

For this study, the gathered data, mostly in the scope of the Project, allowed the conduction of an analysis in several different contexts in order to better understand how and which students' learning outcomes are affected by the use of these simultaneous resources. It also allowed exploring other factors which somehow may compromise students' engagement, motivation and learning outcomes. This work intends to contribute to fill this gap: identify factors which affect student' experimental learning in the electric and electronic circuits topic using remote lab VISIR as a complementary educational resource.

\subsection{Research Problem}

The underlying problematic that can be tackled in this thesis project is to better understand how and which students' learning outcomes are affected by the use of different experimental resources (hands-on, simulation and remote labs) together with calculus, in class and assessment.

To achieve this goal, an empirical approach in different contexts such as demographic, educational experience and background of participants, type of courses, resources and developed tasks was considered. As the tasks involve circuit analysis, besides the type/level of competence one has also to distinguish between DC (direct current) and AC (alternate current): AC circuit analysis and calculus imply using vector and complex numbers notations, being quite more challenging than DC analysis. The complexity of analysing so different contexts makes it impossible to make simple comparisons. So, several insights must be taken into consideration, considering both teachers' involvement and perception as well as students' academic performance, involvement and perception, including also external factors, such as socio-cultural and/or political factors, teacher mediation traces or other contextual influences. Using a study case research methodology, the results are first analysed for each case. However, this richness of contexts also allows to pursue more complex questions, that may be independent of context. This work presents a search for more efficient practices using simultaneous experimental resources which may conduct to good learning achievements.

Considering this problematic, the main goal of this work aims to study four research questions (RQs): 
* RQ1: In which way the use of simultaneous resources (hands-on, simulation and remote labs along with calculus), contributes to promote students' learning and engagement?

* RQ2: Are there VISIR tasks characteristics that affect students' learning and engagement?

- RQ3: Are there teacher mediation traces that can be linked to better students' learning and engagement?

* RQ4: Are there students' characteristics that can be associated to students' learning and engagement?

\subsection{Study Presentation}

To study and answer the four RQs addressed in this work a large-scale analysis was conducted, involving 43 didactical implementations that took place in 26 different courses of several education levels comprising 52 different teachers and 1794 students. These implementations took place in several higher education Institutions (and at a minor extent, in some technological and high schools) in Argentina, Brazil and Portugal. They occurred in the 2016 and 2017 academic years for the Latin American countries and between 2016/17 and 2018/19 academic years for Portugal. Different didactical approaches were used by the teachers involved, according to several factors such as the level of education, course topic, course characteristics, students background, resources used, learning goals or implemented tasks. The study focused on analysing each didactical implementation (their characteristics, teachers' usage and perception) and the correspondent students' results (usage, academic results and perception). Most courses just had one didactical implementation (one semester), but seven of them undergone two editions (two semesters) and four of them three editions (three semesters); in these situations, the evolution on consecutive editions is also analysed.

To conduct this research work, it was used a mixed methods approach, that is, it will be incorporated in a unique research study, methods of collecting and analysing data from the quantitative and qualitative approach. The former data will be collected from various sources, analysed and merged following an integration approach (Creswell, 2013; García-Peñalvo, Moreno López, \& Sánchez-Gómez, 2018).

Considering this project involves studying 43 didactical implementations in diverse contexts, in order to analyse the effect of these different approaches in the students' learning process, a research strategy of multiple case study was defined. It is the most appropriate to the understanding, exploration and description of complex contexts in which several factors are 
implicated (Papachroni \& Lochrie, 2017; Zainal, 2007). Each case represents a different course where VISIR was implemented, "a specific instance that is frequently used to illustrate a more general principle" (Cohen, Manion, \& Morrison, 2007). They are descriptive and detailed with a narrow focus, combining objective and subjective data, establishing cause and effect - observing effects in real context, recognizing that contexts are a powerful determinant for both causes and effects (Cohen et al., 2007). The epistemological paradigm that presided over the work was necessarily interpretative which implies not only a mere description of the didactical implementations, teachers' and students' involvement and perception along students' academic results, but a significant analysis of all the factors/contexts that might enable knowledge and understanding of reality. (McDonough \& McDonough, 1997). Assuming that the research study cannot be understood without considering the influence of the varied contexts involved, this is the most appropriate methodology.

A key issue in this research method, as Cohen and colleagues (2007) state, is the selection of information: it should be collected/recorded not only typical (representative) occurrences but also unrepresentative or even critical incidents, as they can be crucial to the understanding of the case. Plus, the data collection must be extensive and drawn from multiple sources such as direct or participant observations, interviews, archival records or documents, physical artefacts and audio-visual materials (Williams, 2007). In order to accomplish this, this work involved diversified data which included quantitative and qualitative data. A set of tools for collecting data, developed and validated by the research team involved in the VISIR+ Project (in which the doctoral student was included) was used: teachers pre and post implementation forms; educational modules, teacher's interview and student's questionnaire along with teachers' and students' informal comments(Alves, Fidalgo, et al., 2016; Pozzo, Borgobello, \& Pierella, 2019). These tools allowed to characterize the courses (such as: degree, academic year, course curricula, schedules, students) where VISIR was implemented as well as to get detailed information how VISIR was implemented (including: complementary resources used, support materials, task characteristics, assessment) on each course. It also allowed to evaluate both teachers' and students' satisfaction with VISIR, as well as teachers' opinion about students' satisfaction with the resource. Other collected data consisted on the recordings of VISIR's system registering how many times students and teachers accessed it and detailed students' academic results.

The collection of "multiple sources of evidence allows research to develop on several fronts -to investigate various aspects of the same phenomenon" (Yin, 2014), classifying this method as triangulation. Data triangulation allows to obtain a more assertive and comprehensive view of the phenomenon to be known. In this study, it has been used data from diverse sources to corroborate the same topics. 


\subsection{Framework}

This research work was made within the University of Salamanca PhD Programme on Education in the Knowledge Society (García-Peñalvo, 2013, 2014, 2015b) in the area Engineering Education. The doctoral student is a full member of the Research Group in Systems Testing, (LABORIS) -part of the Centre for Innovation in Engineering and Industrial Technology (CIETI)- from the research line Remote Laboratories and Engineering Education (“CIETI Research Group," n.d.). CIETI research centre is formally recognized by the Portuguese Foundation for Science and Technology (FCT) and is hosted at School of Engineering (ISEP), Polytechnic of Porto (P.Porto). P.Porto/ISEP was the VISIR+ Project Coordinator, in which most researchers from LABORIS were involved. As a staff member of the Project, she had the opportunity not only to be involved in the development of the data collection tools but also to be part of the team that participated in the training actions (TA) (Viegas et al., 2017): sessions to share VISIR experiences, render its advantages and contextualize their implementations taking into account LA teachers' needs. She also was deeply involved in the data collection process interacting with the teachers (that were developing the didactical implementations) in several ways. Also, she had the opportunity to meet some of them in person and visit several Institutions, where the implementations took place. She participated in the Project meetings as well as in several Conferences where the Project results were disseminated. In parallel, she also implemented VISIR in her own classes (held at ISEP), along with hands-on lab supported by calculus, and used the same data collection tools, assuming the dual role of Teacher-Researcher (TR) (Gray \& Campbell-Evans, 2002).

In this context, a work plan was designed to achieve the research objectives based on the following activities:

* Perform a systematic literature review (SLR) considering VISIR until 2016. The purpose of this review was to evaluate VISIR implementation and usage in order to better understand the state of the art regarding VISIR's didactical implementations impact (Lima, Viegas, Alves, \& García-Peñalvo, 2016b, 2016a). The results of this review contributed to the evaluation of the remote lab VISIR in terms of didactical implementations, including educational goals, learning achievements and competences. And to a less extent some technical aspects that could be improved in VISIR itself and consequently improve its interaction with students. This systematic literature review -the first step of this thesis project- confirmed the lack of studies in the usage of simultaneous experimental resources, supported on VISIR, and its impact in students' learning outcomes and reinforced the pertinence of this research. Section 3.3 will address the results of this work. 
* Collect the relevant data, using the developed tools as well as other mechanisms, of the didactical implementations that took place in LA during 2016 and 2017 academic years in both semesters. As the data was being collected it was starting to be organized, partially analysed and in some cases, disseminated. In fact, there were some publications in several topics, namely: using VISIR to contextualize mathematics (Lima, Viegas, Zannin, Marques, Alves, Felgueiras, Fidalgo, et al., 2017; Lima, Zannin, et al., 2017); students' perception of the difference between simulation and remote labs (Lima, Viegas, Zannin, Marques, Alves, Felgueiras, Costa, et al., 2017); the analysis of the didactical implementations that took place in a LA HEI, considering both students' academic results and perception about VISIR with the courses and didactical implementation characteristics (Viegas, Pavani, et al., 2018).

* Design, develop and implement VISIR along with hands-on lab and supported by calculus in the course "Applied Physics" in ISEP, Portugal. This didactical implementation took place in the second semester of 2016/17, 2017/18 and 2018/19 academic years. Collect and organize the relevant data using the same collection tools that were developed in the scope of the VISIR+ Project. The impact that the teacher reflection -considering three perspectives: literature review, her own didactical practices, her research results upon her and others teachers' practices- had in the implementation design and shaped the modifications made in the subsequent course editions also led to a publication (Lima, Viegas, \& García-Peñalvo, 2019a).

* Organize the collected data considering the 43 didactical implementations, involving 52 teachers and 1794 students. This global data organization, taking into account all the factors that were considered in this study, was a very arduous and time-consuming procedure. Two main files were developed: the first to summarize the didactical implementation characteristics as well as teachers' perception about VISIR, based on their answers to a guided interview at the end of the didactical implementation; the second the students' (individual) academic performance (including grades by component and final grade) and perception (the last based on a student's questionnaire composed of 20 closed questions and 2 open questions). These files also considered the course characteristics, teachers' and students' VISIR usage and other contextualization factors.

* Perform data analysis, considering each didactical implementation and the overall results involving the 43 didactical implementations and the respective academic community (teachers and students). It started by a descriptive analysis and then inference statistics (bivariate and multivariate) was performed to try to find out 
possible associations between didactical implementation characteristics and students' academic results. The first results of the global analysis of the didactical implementations that took place in LA - cross analysing their characteristics with teachers' perception about student acceptance and performance with VISIR as well as teachers' satisfaction with VISIR - were already published (Lima, Viegas, \& GarcíaPeñalvo, 2019c, 2019b; Lima, Viegas, Marques, Alves, \& García-Peñalvo, 2018).

The fulfilment of the five phases previously described will, hopefully, serve as guidelines to answer the four research questions.

\subsection{Document Structure}

This thesis is organized in seven chapters followed by two sections (references in the APA (American Psychological Association) format and nine appendices). This chapter (Chapter 1) provides a short introduction to the doctoral thesis, comprising its justification and contextualization. Here the pursued objectives/goals are explained as well as the research methodology used to accomplish it.

Chapter 2 yields the theoretical framework for this study based on a literature review of the vectors upon which this project has evolved. It starts by emphasising the importance of the laboratory classes in undergraduate engineering education and their purposes, including an historical perspective of its evolution. It is complemented by a comparison between the different type of available experimental resources -hands-on labs, simulations and remote labs- after a brief definition of each of them. It emphasises the actual trend for an "hybrid" or "blended" approach and the different learning and teaching environments that have emerged. It also comprises a section about the role of the didactical practices (with a special focus on experimental practices) emphasising the importance teachers design didactical practices according to the learning outcomes they want their students to achieve. It is also explored teacher mediation and its impact in students' learning as well as teacher reflection (about his practices) as a key element of teacher professional development and improvement. Several external factors, issues, attitudes and habits -referred in literature- that somehow can influence students' learning are also addressed in the last section.

Chapter 3 is dedicated to VISIR remote lab potentialities since its release in 1999 and its usage and dissemination results along these 20 years. A description of the VISIR main characteristics and architecture, including types of access and setups, is briefly addressed. Afterwards, the main results from the systematic literature review (SLR) (Kitchenham \& Charters, 
2007) about VISIR until 2016 -the first step of this research work- are summarized. Finally, it also contextualizes the VISIR+ Project and its importance not only for the data collection and this study, but mainly for the dissemination of the remote labs and pedagogical practices based upon the use of several experimental resources, including VISIR.

Chapter 4 describes the problematic tackled in this thesis project and the four research questions it addresses. It then describes the research methodology -a multi-case study- chosen to carry out this research work. It also presents the main characteristics of the courses where the didactical implementations occurred, in a total of 26 cases comprising 43 didactical implementations and involving 52 different teachers and 1794 students. Finally, it also includes a summary of the data collection tools as well as the data analysis techniques.

Chapter 5 presents the collected data, applying the several collection tools, used through this work. It starts by displaying some descriptive statistics of the population/samples. The didactical implementation characteristics are exhibited in parallel with teachers' involvement and perception of VISIR and the students' results (academic performance, involvement and perception). Then the previous data are analysed: a descriptive analysis is conducted to describe the relevant quantitative data while the qualitative data is systematized applying a content analysis methodology. By the former data analysis techniques, the didactical implementations and students' results are thorough characterized.

In Chapter 6 a deeper analysis of the data presented (and briefly analysed) in the previous chapter is pursued. These further analyses are carried out, considering the results of the didactical implementations, the student results and later their interaction: the impact the different didactical implementations have on students' results. During the all chapter, the obtained results in this work are compared with literature. Correlations between the former factors, parametric and nonparametric difference tests, qualitative analysis of students' questionnaires and teachers' interviews as well as some informal comments reported by both respondents will be considered to further investigate the association between the didactical implementation characteristics in students' results. It will be detailed the way the different experimental resources combination and the VISIR tasks characteristics (proposed and developed by students) has on students' results. It will also be considered the influence of teacher mediation in (and out the classroom) as well as the importance of some students' characteristics on students' academic performance and perception of the tool. The last section gathers the achieved results and discusses their overall interconnection to address each of the four research questions.

Finally, in Chapter 7 an overview of the study is presented as well as the main conclusions derived from this research project. In addition, the main limitations of this study are approached 
and an outline for future work, to endorse the results found, is made as well as some final recommendations for those who intend to use VISIR in their practices.

To close, nine appendices -presenting some additional information about this study- have been included 


\section{STATE OF THE ART}

$\mathrm{T}$

his chapter defines the vectors upon which this work was developed, addressing the major ideas that substantiate the knowledge of the scientific community about the role of the experimental work in engineering, the role of didactical practices and also the importance of understanding how students' learning might be affected. It starts by substantiating the importance of experimental work in undergraduate engineering education, presenting a brief historical perspective, since its beginning to the twenty-first century. If traditionally this type of work was conducted just in hands-on labs, nowadays, with the development of new technologies, students have the opportunity to practice and develop experimental skills in different learning environments like virtual and remote laboratories. A definition of each type of experimental resource and its (comparative) advantages/disadvantages will be presented, considering its relevance for this study. The theoretical framework and empirical principles which served as pillars for this work is explored. Since the experimental work helps students to develop their knowledge, teachers need to design didactical practices which may allow the desired learning outcomes. This design includes curricular design and adequate teacher mediation to put it in practice. An important element, part of the professional development, is the teacher reflection about his didactical practices as a process of improving continuously. Different opportunities to implement effective learning strategies according to student's needs are in depth considered, based in the literature. This chapter is concluded with an overview of what the literature states about students' learning especially the impact that the online experimental resources may have in their learning experience.

\subsection{The Role of Experimental Work in Engineering Education}

Engineering is, since its origin, a practical profession where doing is the key. In its early beginning, preceding the existence of formal engineering schools, engineering was actually taught in practice, in an apprenticeship program (Feisel \& Rosa, 2005). Those apprentices learned their profession by doing; they had to design, analyse and build the intended products, whatever they were. So clearly, the focus of engineering, back in that time, was on practice.

Nowadays engineering is still a practical job and the general goal of engineering education is to prepare students to become engineers, that is, to practice engineering. At the end of their education, graduates are expected to have not only a solid theoretical-practical knowledge in their field of specialization, but also have appropriate soft skills, such as communication, teamwork, 
time management, problem-solving, learning aptitude and the ability to manage stress or heavy workloads (Froyd et al., 2012; Stiwne \& Jungert, 2010). Engineers must be able to apply the theoretical mathematical and science concepts to solve real-life problems, such as designing, building and assessing machines, structures, software systems and technologies using the three resources humankind has at its disposal: energy, materials and information (Board on Engineering Education, 1995; Feisel \& Rosa, 2005). Today's engineering deal with extra challenges -the general instability and the rapid changes characterizing the last decades of the last century and the twenty-first century- being its role more important than ever. Their responsibility has also increased as they are required to design "sustainable systems that consider as crucial inputs the environmental impact of their manufacture and use, their accessibility to people of diverse ethnicity and physical abilities, their safety, and their recyclability" (Board on Engineering Education, 1995).

Engineering education is, these days, considered by many, an engineering service and being so, it has to find appropriate mechanisms to be effectively delivered. Plus, the technology boom of the last decades has a great influence on the way young people learn -a generation of native digitals- and due to several social factors these young students seem to feel some apathy and fear concerning STEM (Science, Technology, Engineering, and Mathematics) (Ramírez-Montoya, 2017) and STEAM (Science, Technology, Engineering, Arts, and Mathematics) courses in general (Conde et al., 2019; Jurado, Fonseca, Coderch, \& Canaleta, 2020; Prensky, 2001). These changes in society -economic, technological, social and cultural- have a tremendous impact in engineering education and practice. Engineering education must make an effort to reply to these changes and challenges in order to "shape the nature and quality of life in the twenty-first century" (Board on Engineering Education, 1995).

Since the early days of formal engineering education, the experimental work -developed traditionally in instructional hands-on laboratories- had a crucial role, being an essential part of undergraduate and, in some cases, graduate programs (Cooper, 2000; Gustavsson et al., 2011, 2009; Jara et al., 2011; Ma \& Nickerson, 2006; Peterson \& Feisel, 2002). Brinson (2015) goes a step further: he considers that hands-on experiences in the science laboratory play the central role. Laboratory classes provide a number of valuable learning opportunities to students in a way that is difficult to reproduce through other teaching approaches. Students gain a better understanding of theory, having the chance to illustrate and validate theoretical concepts; they are introduced to professional practice, handling with instruments and equipment, obtaining and interpreting data, dealing with uncertainties involved in non-ideal situations, while developing experimental skills; they also have the opportunity to develop social and teamwork skills in a technical environment. As Gustavsson (2011) stated, in order to become engineers, students have 
to become "fluent in the language of nature and a successful designer, and for that engineering students must perform numerous experiments practice laboratory work". The lab environment, by the variety of elements it deals, assists students to construct and strengthen their knowledge and it is expected that students get engaged in the laboratory activities/experiments to take the most of it. The most of the lab learning from a particular lab experiment takes place, not during the actual lab experiment, but afterwards when students compile the results, analyse and discuss it, and hopefully understand it (Corter et al., 2007).

Since the creation of engineering schools, the emphasis on laboratories has varied over the years. Even literature about laboratory instruction was scarce during the last two decades of the last century, although in these last few years it has substantially increased (Feisel \& Peterson, $2002 \mathrm{~b}$ ). As a matter of fact, since the beginning of formal engineering education a pressure between theory and practice emerged. The first engineering school founded in the USA (United States of America), back in 1802, was the U. S. Military Academy and its purpose was to train and create military engineers. It combined the rigor of the mathematical model theory with practice. Civilian engineering schools emerged in Europe before that -in 1707 it was founded the Czech Technical University, the oldest technical university ("11 of The Oldest Engineering Schools In The World That Shaped The Field," n.d.)- and during the nineteenth century many engineering schools popped up a little all over the world. These schools combined theory trough classroom learning with hands-on practice in the physical laboratory. These institutions developed curricula that high valued the laboratory instruction and to support it, applied considerable funding resources to build new physical structures to accommodate the engineering laboratories. Both laboratory and practical work environment were a considerable part of the engineering education program. These engineering programs maintained the laboratory work and fieldwork as integral parts of the programs, supported by science and mathematics theory and concepts until the end of the Second World War. During the War and as a direct result of it, great inventions occurred, most of them developed by scientists rather than engineers. As a result, a committee considered that the engineers that were being trained in these schools were too oriented to practice and recommended reinforcing work in basic sciences like mathematics and physics at the expense of the laboratory work. Engineering courses became more theoretical and in the seventies there was a significant decline in the funding for technology and engineering education and the number of students looking for this type of courses also diminished. Lots of schools started struggling with difficulties and to reduce the costs some decided to reduce the time and courses devoted to lab work. So by the eighties it was clear that engineering schools were not aligned with industry necessities (and labour market in general) that required professionals with more practical skills (Feisel \& Rosa, 2005). This gap was recognized nearly the end of the twentieth century, by several 
panels, commissions and organizations, including ASEE (American Society for Engineering Education). However, although they have made a recommendation that the lab work should be strengthened (including instrumentation replacement and refurbishments, when necessary), they also considered it would be difficult for some institutions to support the cost of their handson labs and recommended they should adopt cost effective approaches, taking advantage of the new technologies (Feisel \& Peterson, 2002b; Feisel \& Rosa, 2005; Magin \& Kanapathipillai, 2000).

Other factors have also contributed for both the reduction of hands-on lab time and the quality of the laboratory experiment: (i) the democratization of education in the last decades of the last century (Kehm \& Teichler, 1995) which caused a dramatically increase in the number of students but not in the staff or funding resources to support it (Magin \& Kanapathipillai, 2000); (ii) due to cost constraints, the number of students per lab class also increased, so the number of students who actually have the possibility to interact with the apparatus is really reduced; most students assume the role of observers, as a good percentage of lab experiments are performed in groups of 3 or 4 students; (iii) these hands-on labs have also become more difficult to set up and support -the equipment is more complex and sophisticated and so its cost has also increased-and requires more broadly educated technical staff, which is also expensive to hire; (iv) most institutions cannot keep hands-on labs open as many hours as it would be appropriate to cope for this amount of students (Magin \& Kanapathipillai, 2000). Plus, some students feel the need to use these labs, out of class time, accordingly to their perceived learning needs, which may contribute to boost their autonomy and responsibility which is also one of the goals of the Bologna process (Crosier \& Parveva, 2013); (v) the engineering school staff, including teachers, has also changed and led to a diminished quality laboratory experience; until 30 years ago, most engineering teachers had either worked in industry or engaged in job consultancy having a great inclination towards the practical and field work; in the last decades, most of teachers come from more scientific and theoretical backgrounds with a great aptitude for research, but not as much to practice engineering with their students or promoting hands-on laboratory instruction. This academic shift to rewarding research activity has contributed to the creation of an exceptional academic research community that, in many cases, is so overwhelmed that is difficult to take the time and effort to invest in quality undergraduate laboratory instruction. Plus, this type of work is not equally rewarded for career purposes, particularly in universities (Feisel \& Peterson, 2002b; Feisel \& Rosa, 2005).

The ongoing digital transformation (Kutnjak, Pihiri, \& Furjan, 2019; Negreiro \& Madiega, 2019; Tibilova, Ovcharenko, \& Potapova, 2020), including the technological advancements in the information processes and communication, that has been affecting people's daily lives for the last decades had naturally reached education with the incorporation of ICT. In fact, the integration of 
the personal computer (PC) in the laboratory contributed to the lab instruction quality. It allowed to counterbalance some of the costs in the equipment and its usage in data acquisition, data reduction, design assistance, and simulations contributed to improve the laboratory experience. The development of computers in the last decades turned them in a world-wide tool absolutely essential to engineering professionals. In the last two decades of the twentieth century, engineering schools started to integrate computers from classrooms to laboratories. The handson instructional labs have changed a lot as computers allowed some level of automation, being used to control experiments, acquire data and then analyse it and even present the obtained results. About the same time, with the Internet development and dissemination, the first effective simulations and later the remote labs were developed and also introduced as a complement or even as a replacement of hands-on labs. In fact, the expansion of distance education courses motivated the development of remote laboratories and, at a lesser extent, simulations. Simulations are computational models -accurate or simplified- widely used to illustrate phenomena that are not easily observed and used many times as pre-lab experiment to give students an idea of what they will find in the real experiment or as complement or replacement for hands-on lab. Remote labs are real labs, providing really measurements and data, accessible through the Internet, mediated by some kind of interface.(Feisel \& Peterson, 2002b; Feisel \& Rosa, 2005; Magin \& Kanapathipillai, 2000; Peterson \& Feisel, 2002; Tchoshanov, 2013). Nowadays, teachers are often using these resources -in undergraduate and graduate engineering programsparticularly as a complement to the traditional hands-on lab.

While there seems to be general agreement that laboratory work is an integral and essential part of undergraduate engineering courses, used with different aims for students' learning, often these goals are only implied but not properly communicated to students nor their importance. In fact, usually little is said about what they are expected to accomplish. Still it is well known from literature that an effective learning system must be supported by clear learning objectives, that somehow should be assessed (Biggs \& Tang, 2007). But, until very recently there was not made a real effort to define a set of objectives concerning engineering instructional labs, nor there was a consensus on its objectives, although there were clearly defined objectives for the Engineering degrees. This difficulty in defining a clear purpose for the role of instructional laboratories had two main problems: (i) designing a lab experiment without a clear instructional objective may sometimes result but others may be completely inefficient; (ii) incorporate some innovation in lab (including using the Internet, simulations and remote labs) was difficult as there were no stimulus to it and no principles to effectively assess it (Feisel \& Rosa, 2005). This problem concerning instructional labs role and specific goals become clear and cumbrous when distance education programs began questioning about accreditation. 
To help solving this problem ABET (Accreditation Board for Engineering and Technology) with the help of the Sloan Foundation -a foundation that had given great support to the development of distance-learning (Crisol-Moya, Herrera-Nieves, \& Montes-Soldado, 2020; GarcíaPeñalvo \& Seoane-Pardo, 2015; Gros \& García-Peñalvo, 2016)- decided to sponsor a colloquy. The event took place in California, between 6 and 8 January 2002, with a group of over 50 participants, including the steering committee, the ABET staff, the Sloan Foundation representatives and distinguished engineering educators, representing a variety of institutions and areas/topics. The goal of the colloquy was to, independently of the experimental resource used, give answer to the question: What are the fundamental objectives of engineering instructional laboratories? On the colloquy last day, a list of thirteen learning objectives applicable to laboratory experiments over the entire undergraduate learning program was presented. All the objectives starting with the statement "By completing the laboratories in the engineering undergraduate curriculum, you will be able to...." ("ABET," n.d.). Then, each objective was firstly defined, for simplicity, by a one or two words title (to afford easy reference) and then by a brief explanatory simple text to clarify it (“ABET," n.d.; Feisel \& Peterson, 2002a; Feisel \& Rosa, 2005; Peterson \& Feisel, 2002).

Finally, after a long journey, a set of clear objectives to undergraduate laboratory instruction was defined. These objectives might help teachers to build appropriate learning environments and then assess their effectiveness.

\subsection{Didactical Practices}

The etymological origin of the term didactics comes from the Greek word Didaskein, which means to instruct, to teach. Considering its definition, there is a saying "Didactics is as old as times" (Tchoshanov, 2013), as when someone is teaching another person, the setting already suggests didactics. The need to learn and transmit knowledge from one generation to the next is imperative to the development of society, but for many years this process occurred trough the circumstances of life and work. Within human history, the existence of institutions -schools, colleges, universities- which main focus is learning is a relatively recent phenomenon and mass participation in those is definitely very recent (Billett, 2014).

It was Jan Amos Comenius (1592-1670) -considered by many, the Didactics father- that gave Didactics its pedagogical character by defining it, in his book Didactica Magna (1657), as the art of teaching. The Czech educator and philosopher fought the medieval system, bringing innovation to education. He was the first academic to respect the child's intelligence and feelings defending the teaching of "everything for everyone" and bringing the inductive method to school. He defended principles like: "children must learn to know and investigate things themselves", 
"bring social reality to the classroom, making use of the most advanced technological means available" and "schools must be cheerful, equipped with illustrative materials and staffed with sympathetic teachers". Most of these principles, including "learning should be approached by the senses and by doing" came from Comenius' practical experience as a teacher (Cordasco, 1976) and are still so up to date.

Since Comenius to the 21st century, there was a great evolution in the didactics concept, well documented in the educational literature, addressing the transition of the traditional concept of didactics to the modern or digital age didactics. Cachapuz and colleagues (2001) consider that an important obstacle for the development of Didactics as an autonomous field of knowledge, was the belief that teaching is a simple activity for which one only needs scientific knowledge in a specific topic and some practice. They also pointed out the necessity of teachers' involvement in the development of the new didactical knowledge construction and the importance of valuing Didactics as a research discipline (in which teachers should also be involved as researchers) that can effectively have a positive impact in the education policies (Cachapuz, 1994; Cachapuz et al., 2001). Tchoshanov (2013) proposed to define Didactics "as science, engineering and art of teaching and learning", recognizing this way its scientific, technological and artistic character.

The last decades are characterized by revolutionary changes due to the intensive implementation of new digital technologies in education and society in general. These new technologies contributed to the democratization of knowledge and access to open education. These new technologies, nowadays widely used in education, lead us to digital age didactics or eDidactics (D’Angelo, 2007b). Classical/traditional Didactics and e-Didactics share analogous theoretical foundations and its main goal is still focused on teaching and learning quality with the aim of developing the required/expected level of students' competences (D'Angelo, 2007b; Margolinas \& Drijvers, 2015; Tchoshanov, 2013). The main difference between the two is a paradigm shift from teaching to engineering of learning; e-Didactics is commonly defined as "an ICT-integrated didactics with a focus on engineering of learning" (Tchoshanov, 2013).

Classical Didactics and e-Didactics certainly have a wide superimposition area, but they also have their own specificities. These differences include: delivery format, teachers' and students' role, dominant mode of learning, primary learning and teaching space, instructional material, mode and means of communication and information access (D'Angelo, 2007a; Fantin, 2015; Sell \& Rüütmann, 2015; Varela, 2013).

Teachers nowadays -the digital age- have to somehow combine the competences of a teacher (Casillas Martín, Cabezas González, \& García-Peñalvo, 2020), a didactician (someone who is familiarized with the learning theory and research-based teaching) and an engineer, in the sense of having knowledge and aptitude to design and construct effective learning environments. 
Tchoshanov (2013) refers to these modern teachers as teacher-engineers although in literature the more common designation is reflective teachers (Biggs \& Tang, 2007; Cachapuz, 1994; Fagundes, 2016; Lopes, Silva, et al., 2012; Philipsen, Tondeur, McKenney, \& Zhu, 2019). In fact, nowadays, teachers are expected to learn throughout their career and are permanently challenged to revise their practices and adapt them to students' needs (Núñez Pardo \& Téllez, 2015). These reflective teachers think and reflect on their own practice and develop strategies based on it, considering their students/classes/school reality as an object of research, reflection and analysis. Each experience, critical incident, or failure is considered by a reflective teacher as a learning experience, so he can improve continuously.

Constructivism -a series of principles about knowing and learning that highlights the active role of learners in constructing their own knowledge- has its roots in the eighteenth century. The constructivism view of learning is reflected in the developmental theories of several authors, from which stand out Piaget (Piaget, 1972) and Vygotsky (Vygotsky, 1978). The first in his theory cognitive constructivism revealed that the individual's reaction to experience influences learning (leading to success or failure, depending on the reaction). The second in his theory social constructivism, stated that interaction with others play a crucial role in the construction of significant meaning from the experience: meaning is co-constructed.

The key idea of constructivism -in opposition to the positivism model, that dominated Higher Education (HE) for centuries, in which it was believed individuals passively received knowledge- is that knowledge cannot be simply transmitted to students, but merely facilitated by the teacher/instructor. The instructor can merely create the best didactical conditions for successful construction of knowledge and understanding but, being aware that as knowledge construction is an individual process, different individuals may show up with their own unique understanding. The constructivist model of learning is the actual accepted model for HE learning, which means the traditional instructional practices must be reviewed and teacher, as a facilitator of student knowledge construction, should set up experiments that induce students to construct knowledge by themselves. In that process -which is more important than the result- student prior knowledge, beliefs, preconceptions and misconceptions, accordingly to evidence provided by the experiences, may be adjusted or even rejected. Considering the influence of social interaction in knowledge construction, it becomes imperative to understand how dialogue -teachers/students and students/students- can be used to enhance student learning (Biggs \& Tang, 2007; Dufresne, Gerace, Leonard, Mestre, \& Wenk, 1996; Prince \& Felder, 2006; Scott, Mortimer, \& Aguiar, 2006; Tchoshanov, 2013).

Implementation of constructivism ends up with the traditional teacher centred classroom, appealing to the rethinking of teaching and learning approaches, encouraging the use of a student 
centred dialogue. Although the theory "does not prescribe how one should teach, it does carry implications for curriculum and instruction" (Dufresne et al., 1996). Considering the curriculum, its emphasis is on major ideas and concepts and not in basic knowledge; learning and teaching is a flexible process supported by multiple resources; students' learning, and understanding is facilitated by the teachers. In fact, learning objectives, teaching -resources used, tasks/activities proposed and teacher mediation- and assessment are closely connected.

The purpose of teaching is students' learning (Lopes, 2004). First of all, it is necessary to understand how teaching can be improved and teachers' and students' roles in this process. And then, the most important, to understand and thorough which factors affect students' learning.

Teaching does not involve direct transfer of information to students (gathering ever more information), but organizing student activities, helping them to grasp that information in relation to their own experience (Biggs, 1999; Prosser, Ramsden, Trigwell, \& Martin, 2003; Ramsden, 1992). Accordingly to Laurillard (2013), teaching in undergraduate HE is "essentially a rhetorical activity, seeking to persuade students to change the way they experience the world through understanding the insights of others. It has to create the environment that enables students to embrace the twin poles of experiential and formal knowledge". Considering it, teachers should recognize their role in mediating between both their experience and their experience account so that students develop knowledge based on someone else's experience of the world (TinocoGiraldo, Torrecilla Sánchez, \& García-Peñalvo, 2020). Considering teachers' role as a mediator between the "world and the learner", the same author argues that it is teachers' responsibility to create the conditions -the learning environments- in which this understanding and knowledge construction is possible, providing the appropriate learning activities (aligned with the learning objectives teachers pursue: "specific and concrete statements on what students are expected to learn" (Ramsden, 1992)) and guiding students in this process.

As students have different preferences for how they receive and process new information, due to their individual differences (Kirschner \& Van Merriënboer, 2013; Richardson, 2011), teachers can effectively reach more students, if they diversify the methods and techniques used in the classroom and also in the assessment (Biggs \& Tang, 2007; Laurillard, 2013; Ramsden, 1987, 1992). Several recognized authors believe HE teachers have the main responsibility for students' learning, as they limit students' choices in how and what they can learn. Still, teachers should foment students sense of responsibility by engaging them in active participation in classes and tasks, cooperation, respecting the others as well as the rules, being deeply involved in the construction of their own knowledge and their self-regulation and self-assessment (Cunha, Lopes, Cravino, \& Santos, 2012; Lopes, Cunha, et al., 2012). As a final remark, the effectiveness of teaching and the quality of students' learning are intrinsically connected (Biggs \& Tang, 2007), so "the point 
of departure for teaching is students experience of learning - not the teachers' experience of teaching" (Prosser et al., 2003)

Considering the didactical vectors affecting students' learning, in the literature it was found a pattern regarding the fundamental features to be taken into account as theoretical principles of this study: curricular design (in order for students develop the intended learnings) (Biggs \& Tang, 2007; Lopes, 2004; Lopes, Silva, et al., 2008; Ramsden, 1992; Viegas, 2017b; Viegas, Lopes, \& Cravino, 2009), teacher mediation (how this design was planned and then was delivered in practice) (Cunha et al., 2014; Lopes, Cravino, Branco, Saraiva, \& Silva, 2008; Lopes, Silva, et al., 2010, 2012; Viegas, 2017b) and reflection upon practice (generating a continuous improvement of the process)(Lopes, 2004; Ramsden, 1992; Redish, 2003). Focusing in these three features simultaneously is a major advantage since it allows us keeping in mind students' learning is highly dependent on the way students work in the classroom (Felder, Woods, Stice, \& Rugarcia, 2000). Even starting from the same curricular design -which includes not only the course contents but also the competences that teachers pursue as well as the proposed tasks (to achieve it), including the provided contexts- some teacher mediation traces may allow better results considering students' learning. As literature has showed, the reflection upon these practices is always a powerful tool for improving practices, adequate them for the specific context, and ultimately achieve positive impact in students' results (Biggs \& Tang, 2007; Lopes, Silva, et al., 2012; Ramsden, 1987).

\subsubsection{Curricular Design}

Course curriculum is a concept that can be interpreted in multiple ways with regard to its content and the innumerable ways and varied perspectives on its construction and development (Roldão \& Almeida, 2018). It is important, that in the complex teaching-methodological and scientificeducational process, it exists an effective instrument regarded as a normative document and a regulatory factor of the former process -the curriculum- on the design of which it depends the process of efficiently teaching (Druzhinina, Belkova, Donchenko, Liu, \& Morozova, 2018). It can, in a simplest way, be defined as a set of learnings -considered socially needed in a given time and context- that is up to the school to organize and guarantee (Roldão \& Almeida, 2018).

In HE curriculum design is perceived as a "planned and dynamic process that reveals values and principles regarding learning, knowledge and disciplines as well as the cultural and political goals of higher education" (Druzhinina et al., 2018). The curriculum design or curriculum organization of a course comprises the coordination -the ways in which the curriculum components are structured- and the methodological development proposal for the course. It 
includes the description of the programmatic contents (the topics), the definition of the competences and learning goals that are intended to be reached. But also the design of effective and meaningful learning environments including the resources to be used, the design of tasks with which it is intended to develop the pursued learnings and the definition of appropriate assessment tools (Biggs \& Tang, 2007; Prasad et al., 2018; Ramsden, 1992; Tchoshanov, 2013). Simultaneously, appropriate mediation traits should also be designed to implement the curriculum (Lopes, Silva, et al., 2010, 2012).

In this study, the principle concept adopted -to student learning and teaching- is that of the social constructivism model, as explained in the previous section. So for each module/course the learning outcomes students are supposed to achieve must be clearly defined and they must be perfectly aligned with meaningful and relevant teaching and learning activities (Ausubel, 2000; Biggs \& Tang, 2007). In order to enhanced students' motivation, attention and engagement, the learning material should be at a level of students' zone of proximal development (Vygotsky, 1978), the level at which they could learn and understand new material with a certain level of support and scaffolding. Additionally, the assessment instruments (such as: exams, tests, questionnaires, etc.) and the assessment tasks also have to be lined up with the proposed activities/tasks (GarcíaPeñalvo, Corell, A., Abella-García, \& Grande, 2020). The tasks should provide the designed learning outcomes, so that students may build their knowledge towards the foresee learning outcomes. This way, at the end of the module/course students should have learned and master the relevant knowledge and developed adequate skills and competences in order to move to the next level in their studies. As stated in literature "curriculum design is a very important part of creating a contextually relevant and responsive teaching and learning environment for both lecturers and students" (Biggs \& Tang, 2007).

In the next paragraphs, a theoretical foundation based in the literature will be presented for the main steps followed in a curriculum development process: (1) selection and organization of the contents; (2) defining the learning objectives; (3) choosing the resources used in the teaching/learning process; (4) proposing adequate tasks and experiences; (5) choosing appropriate assessment instruments and tasks.

Teacher mediation, both the designing of students' tasks and also of some teacher mediation traces that promote students' engagement in the former tasks (in and out the classroom), but mostly its implementation in the classroom will be discussed in section 2.2.2.

(1) Content is highlighted as having a major importance both for learners and the society, so it should be critically analysed. In order to make decisions regarding the objective choice of curricular content, it is also important to consider the form that this selection takes, in view of its 
purposes, that teaching should always promote: appropriation and intelligent use of (content) knowledge, in all its dimensions, by students. (Druzhinina et al., 2018; Roldão \& Almeida, 2018).

In a curriculum consisting of modules -considered one of the most effective approaches used in the content development- its content is structured and has a clear sequence. A modular design "subdivides a system into smaller parts (modules) that can be independently created and then used in different systems to drive multiple functionalities" (Baldwin \& Clark, 2000). Furthermore, it is flexible and capable to take individual educational paths of students into account. If the course content (modular structured or not) is framed in terms of relevant, authentic, meaningful and contextualized problems and tasks -that students need to solve- it is more likely that they get productively engaged in the course and succeed. If the course content is personally meaningful for the student, he/she "builds up the knowledge base needed for deep learning and, motivationally, develops the expectations that give confidence in future success" (Biggs \& Tang, 2007). On the other hand, if students dislike the content being taught, teachers need to do an extra effort in involving students' and promote their participation in the learning activities.

The teacher should design and produce or select the learning materials and activities according to students' prior knowledge and experiences. Addressing it, he tries to evaluate and record students understanding of previous learned facts, concepts, procedures and experience, mobilizing it in order they learn new material and construct deep knowledge (Biggs \& Tang, 2007; Prince \& Felder, 2006; Ramsden, 1992; Tchoshanov, 2013). Teachers should also take into account some other strategies: right level of difficulty, contiguity and minimizing cognitive workload (Lopes, 2004; Ramsden, 1992; Tchoshanov, 2013). The right level of difficulty signifies that the learning material should not be too easy nor too difficult. If it is too difficult students may quit, while if it is too easy students may not feel challenged enough (Ambrose, Bridges, DiPietro, Lovett, \& Norman, 2010; Chang \& Bell, 2002; Lopes, 2004; Viegas, 2017a; Viegas et al., 2009). The right level of difficulty should also be applied to assignments and assessment so students can effectively complete it, with some effort and/or support. Contiguity is associated with introducing closely in time and space concepts and ideas that need to be connected, for instance presenting simultaneously corresponding words and images. And finally the strategy of minimizing cognitive load advises to split complex learning material into smaller portions, so students assimilate it better (Biggs \& Tang, 2007; Ramsden, 1992; Tchoshanov, 2013). A final remark, institutions and teachers should be careful when developing the course contents, as "there is little doubt that most courses in all universities contain more content than students can handle" (Biggs \& Tang, 2007), considering the pressure to include more and more content. 
The increasing abundance of freely learning material: lectures, videos, texts and other, on the Internet and/or some institutional repositories (Ferreras-Fernández, 2018; González-Pérez, Glasserman Morales, Ramírez-Montoya, \& García-Peñalvo, 2017; Ramírez-Montoya, 2015), allowed students to have access to an extensive and often high-quality content. Nowadays, content (materials) is no longer scarce, yet teaching, as explained in the previous paragraphs is much more than content deliver (Veletsianos, 2016).

(2) Objectives: In the social constructivism alignment, the language is tending to shift from curriculum objectives or objectives (Biggs, 1999; Ramsden, 1992) to learning outcomes or intended learning outcomes (ILO) (Biggs \& Tang, 2007). The former authors believe ILO is a better term because it accentuates more (than the previous term objectives) that the focus is in what students have to learn rather than what the teacher has to teach. In literature, both terms coexist along with the term learning objective (Tchoshanov, 2013) or simply (learning) goal (Prosser et al., 2003), but ILO turns absolutely clear that the outcomes are from students' perspective: when reading a good ILO (that is, well written), the students will know what to do and how well to do in order to meet it. ILO can be made at three levels: institutional level, degree program level and course level (Biggs \& Tang, 2007).

In the previous paragraphs it was realized that the curriculum starts by defining a list of contents topics that are considered appropriate for students to learn. Then those topics must be converted into outcome statements that teaching/learning activities, as well as the designed assessment tasks, must address. All the components -learning outcomes, teaching/learning activities and assessment- must be aligned and support each other (Biggs \& Tang, 2007; Druzhinina et al., 2018; Nicol, 2008; Tchoshanov, 2013; Viegas, 2017a). Still in this perspective of constructive alignment, in which students should have some freedom to construct their own knowledge, the teaching and assessment tasks should always permit for desirable but unintended (not defined) leaning outcomes (Biggs \& Tang, 2007). This is much likely to occur considering students' role in this model, leading students into deep learning. In fact, students are encouraged by teachers, through the setup of favourable learning environments (that will be explored in section 2.2.2) to participate in the construction of their own knowledge, sharing with the teachers the responsibility of achieving the designed learning outcomes (Biggs \& Tang, 2007; Tchoshanov, 2013).

The design stage is focused on the development of students' learning pathway based on the learning outcomes. Learning outcomes should be designed using the appropriate (cognitive) terminology -a learning verb such as: identify, apply, explain, compare, reflect- and a set of about six intended learning outcomes is enough for a one semester course. An ILO "is a statement 
describing what and how a student is expected to learn after exposure to teaching" (Biggs \& Tang, 2007). This teaching framework grasps decisions all the time to achieving or assessing the intended learning outcomes, in order to be able to effective (good) teaching: make the majority of students to achieve the ILO, using the level of cognitive processes needed.

The selection of teaching strategies should be adapted to the triad: learning outcomes, teaching/learning activities and assessment. Teacher strategies are defined as "a generalized plan for a lesson which includes structure, instructional objectives and an outline of planned tactics, necessary to implement the strategies" (Issac, 2010). In a simpler way, they can be regarded as the methods used to convey information to students and are supposed to "encourage students to relate to the subject matter they are studying in a purposeful way" (Ramsden, 1992).

(3) Resources The chosen teacher strategies imply a careful choice of resources, making the most of the new technologies currently available. But the starting point is that teachers have to work with the material/resources they have -relevant to the topic and learning objectives- and make the best use of it to engage and motivate students. Typically, teachers have at their disposal lectures, recitation/practice classes and laboratory classes. Respectively, they are traditionally used to present the theoretical background, to solve paper and pencil exercises and to perform experimental work.

Traditional expositive lectures -based on contents exposition- and at a minor extent the other type of traditional classes might have worked in the past, but they do not work so well today. In fact, they do not fulfil today's needs anymore and must be adapted and rearranged in order to create teaching contexts where nowadays students can get more involved.

Some institutional factors, like limitation of both physical and personal resources and or cost constraints dictate to lectures with a large number of students. Mass lecturing makes constructivism alignment more difficult to implement, but not impossible. To turn it easier, the lecturer should find and use resources that potentiate students' learning. These resources may include traditional ones like the white board, textbooks, lecture notes and power point projection, but also the use of digital tools, web resources, videos, software, tutorials, recordings, social media applications, amongst others. It is important that the teacher uses resources that challenge students and lead them to participate in class (for instance by projecting a power point with conceptual questions, that students answer, using an automatic clicker voting system). The former resources can be included in the LMS (Learning Management System) course page (Greenberg, 2002) course page, so students can use it after (or before) the classes. The use of these varied resources can help teachers in alternate between necessary moments of expositive teaching (when possible visual focused, with the visual aid of pictures, diagrams, graphs and schemes to 
students look at) with short engagement tasks, for keeping students' attention (Biggs \& Tang, 2007; Tchoshanov, 2013). Finally, a lecture should not finish before getting students to review what has been learned during the class -with a conceptual map or a diagram, for example- as this "leads to much better and lasting retention than simply finishing and dismissing the students" (Biggs \& Tang, 2007).

Recitation/practice classes involve, typically, relatively small groups of students (under 30), which turn things easier. To foment students' interaction a special attention to students positioning in the classroom should be considered. The spatial organization or layout of the classroom (the arrangement of tables and chairs) affects not only the number of students that can interact with each other and/or the teacher but also the quality of that interaction. If possible, leave the traditional organization setup and use "new" classroom setups, such as U-shaped arrangement of the tables or square work tables with several students (Cardellino, Araneda, \& García Alvarado, 2018). The use of computers, e-learning tools and/or traditional (in paper) resolution of exercises in class, can in this type of spatial organization, foment peer interaction, group work and discussion (Viegas et al., 2009). In this type of class, with a small number of students it is easy to change the direction of the class -"a spur-of-the-moment" change (Biggs \& Tang, 2007)- maybe in a response to a student question, which would be more difficult in a lecture.

The importance of lab work in engineering education was already discussed in section 2.1. Laboratory classes have, nowadays, the traditional hands-on approach that can be complemented by simulation and remote labs. The hands-on traditional class can be potentiated involving students deeply in their knowledge construction process, giving them more responsibility as it will be more detailed in section 2.3.

Simulations and remote labs provide alternative learning spaces where students can develop experimental (and other) skills. Simulations allow students the possibility of learning contents online, helping them to better understand the concepts they have learned. Remote labs allow students to obtain real data and give the possibility of comparing these results with theoretical calculations and the results obtained with other experimental resources. These resources release lab time for hands-on work, where students learn by doing, usually in group work. The combination of these experimental resources (analysing and comparing data obtained with the different resources, explaining its differences, etc.) promotes higher performance and deep understanding (Pinto et al., 2014; Sell \& Rüütmann, 2015; Veletsianos, 2016). A comparative study between these experimental resources will be presented in section 2.3.

The resources described in the former paragraphs can and should be used by teachers in several ways: (i) integrating it into knowledge constructions/development; (ii) creating learning activities to accomplish specific educational outcomes; (iii) applying it to "spontaneous" learning, 
(iv) fomenting interaction, communication and cooperation between students (Tchoshanov, 2013; Veletsianos, 2016).

(4) Tasks When designing a task, its goals and the corresponding intended learning outcome -that students are supposed to achieve after completing it- must be clearly defined and students must be aware of it (knowing what to do to complete it). The principles, including type of language and structuration, used for this design are similar to what was described when considering learning objectives and ILO (course) design.

Another essential factor when designing learning tasks is building didactical situations: "a purposefully designed fragment of teaching that aims at engaging students in a learning task, problem, and/ or activity" (Tchoshanov, 2013), that provide students opportunities to develop scientific, social and professional competences endorsing them to accept challenges in a steady base. Competence can be defined as combination of knowledge, skills and behaviour features adequate to the context- to improve performance (Conceição \& de Sousa, 2012; Estella \& Vera, 2008; Roldão, 2003). In order to develop competences, the student must be able to mobilize the necessary knowledge, making the necessary connections between concepts and procedures (Biggs \& Tang, 2007; Lopes, Cravino, et al., 2008; Viegas, 2017b). The notion of competence contributes to a new meaning of school, concerned with the preparation of all students for life. In the limit, a competence based education helps students to develop competences that they do not yet possess, but are able to achieve, helping them to facilitate their learning (Dias, 2010). So, in order to promote students' learning, the groups or type and level of competences teachers expect their students to develop with specific tasks -included in the ILOs teachers expect students to achieve after completing it- should be taken in to consideration in the task design (Lopes, 2004). It is important to have a perfect adjustment between the type/level of competence teachers pursue and the type of designed task in order to its successful development.

Tasks need to be valued by students and be attainable, so several concerns should be taken into account when proposing tasks to students. Primarily they should provide challenge, interest and motivation to learn (Ambrose et al., 2010; Chang \& Bell, 2002; Cunha et al., 2014; Druzhinina et al., 2018; Lopes, 2004; Nicol, 2008; Viegas, 2017b), by relating the material being presented to students' personal experience (inside and outside the classroom)(Silverman \& Forum, 1988). The (learning) tasks proposed to students should be relevant, based, as much as possible, in real-life contexts/situations (adapted to students) (Lopes, 2004; Prasad et al., 2018; Roldão \& Almeida, 2018; Viegas, 2017b). The former tasks generate real challenges to students, in which they can effectively support their learning, allowing students to interpret, reason and discuss possible solutions (Biggs \& Tang, 2007; Lopes, 2004; Ramsden, 1987; Viegas et al., 2009), mobilizing 
students' prior knowledge (Biggs \& Tang, 2007; Viegas et al., 2009). They should be constructive, sequential and inter-linked and aligned with each other and the intended learning outcomes(Biggs \& Tang, 2007; Druzhinina et al., 2018; Nicol, 2008).

The tasks should also vary in content and complexity and the type of tasks should be diversified (quizzes, open-ended questions, experimental work, project work, homework, exploring videos, e-learning tasks), helping the students to "develop multiple layers of competence including facts, procedures, concepts and models and to connect these layers" (Tchoshanov, 2013).

Teachers must be careful and not propose too many tasks to students to guarantee they do not get overload with work.

Teachers should also consider in dividing the tasks into individual and group tasks (to develop autonomous work or to make use of peer collaboration, which improves students confidence and the perceived benefits in learning), set some of the tasks for students to be done at their own time (guiding them in setting up a work plan), set some of the tasks linked to homework (for instances for lectures or lab classes to compel them to work proactively in lab), considering optional or mandatory (for instances, online tasks for self-evaluation) depending on the goal and students' motivation.

It takes time and extra involvement to get engaged in tasks that address higher level outcomes, so this type of tasks should consider time and eventually space constraints carefully. This type of tasks, which requires students to use and engage with higher-order cognitive processes is more adequate as to be performed towards the end of the course. In fact, learning tasks should become progressive more difficult over the course period.

Learning tasks create a link between learning objectives and learning outcomes and to guarantee that link is effectively established, learning tasks should have the characteristics described in the previous paragraphs.

(5) Assessment The term assessment, in education, "refers to the wide variety of methods or tools that educators use to evaluate, measure, and document the academic readiness, learning progress, skill acquisition, or student educational needs" ("The Glossary of Education Reform," 2015). Assessment has a regulation function, of processes and/or results, as it allows -teachers, students and society- to understand the extent to which students' learning approaches to what is expected, according to the designed learning objectives (Lopes, Cravino, et al., 2008; Lopes, Silva, et al., 2012; Roldão \& Almeida, 2018). It may comply mainly four phases, conducted basically by the teacher: (i) the design of the appropriate assessment instruments; (ii) information gathering, in multiple and varied ways of students' learning: knowledge, competences and attitudes (effort, 
engagement, autonomy, etc.); (iii) analysis of the collected information, to provide students feedback how he is doing and how he can improve and teachers can also use that feedback to make the necessary improvements/adjustments in the teaching process; and finally (iv) judge/grade students (Lopes, Silva, et al., 2012)

The role of (formative) assessment to help develop students' learning, with even more emphasis in students developing their practical and experimental skills (Felder et al., 2000), is well established in the scientific and educational community, being one of the key issues that has a major impact in the effectiveness of learning. Nowadays, assessment has a broader meaning, being also understood as a way of motivating and engaging students and even change their approach to learning (Dufresne \& Gerace, 2004; Earl, 2006; Viegas, 2017a; William, 2011). Its goal is much more than just grading students, but rather verify whether a student's learning meets the intended outcomes, strengthening student's responsibility for the process and outcome of learning (Tchoshanov, 2013).

Teachers tend to regard the ILOs as the main pillar in an aligned teaching system, that is a system in which the assessment is designed and connected to the learning objectives and content (Biggs \& Tang, 2007; Tchoshanov, 2013), but typically students have a different perspective. The former consider assessment is a necessary evil, to be conducted at the end of the learning process and what and how students learn depend basically on how (and about what contents) they think they will be assessed (Biggs \& Tang, 2007). So assessment practices must enlighten students about what and how they should be learning to avoid a "backwash"(Elton, 1987). The former author created this term to highlight the effects assessment has in students' learning: assessment having a greater influence in students' learning than the curriculum itself. If assessment is aligned to what students should be learning backwash has a positive effect as it boosts adequate learning. If, on the other hand, the teaching occurs in an exam-dominated system, where strategy becomes more important than substance, students learn for the exam, leading to surface knowledge ("memorization that allows reproduction of learned material" (Crede \& Kuncel, 2008)) and backwash as negative effect (Biggs \& Tang, 2007). To avoid negative backwash teachers must keep in mind, when designing the assessment tasks that they should comprise a reliable representation of the course ILOs, demanding a quality of performance that the assessment tasks require.

In the previous paragraphs it was described why assessment, which is inevitable, should be diversified and now two more reasons for assessment are provided: formative assessment -has a crucial role in effective teaching- to provide feedback during learning; and summative assessment, to provide an indicator of how well students have learned when instruction has been completed (Ambrose et al., 2010). The two types of assessment, respectively assessment for learning and assessment of learning, have different functions and purposes (Earl, 2006; William, 2011). 
Formative assessment or formative feedback happens during the learning process (ideally in several moments), rather than at the end and is in the top of the list of those factors leading to good learning. It tells students how well they are doing and what might need improving (Black \& Wiliam, 1998; Earl, 2006; Hattie \& Timperley, 2007; Viegas, Lopes, \& Cravino, 2010; William, 2011). It is interactive with teacher, generating differentiated teaching strategies and learning opportunities for helping distinct students move frontward in their learning. Feedback will be fully explored in section 2.2.2, and in this section the focus will be mainly summative assessment and assessment tasks. Summative assessment -assessment of learning- happens after learning (at the end of a task, a module, a course), informing students how well they have learned what they were supposed to have learned. It is designed to deliver evidence of achievement and is translated into statements or symbols (like numerical grades) about how well students have learned and its registers (many times) are public. In this process, a variety of methods can be used. It is up to the teacher to choose the method that best suits the purpose of the assessment in that particular context (Earl, 2006; Lopes, Silva, et al., 2012; Tchoshanov, 2013; Viegas et al., 2010).

Teachers should design authentic and performance assessment tasks (both formative and summative and not too difficult nor to easy) aligned to the ILOs they intend to address. An adequate assessment task should provide information how well a student has reached the ILOs addressed by the task and how well the task itself was performed. Assessment tasks should also support student learning, so teachers should design and propose several different formats of tasks, considering students' individual differences and preferences as well as the type of knowledge they intend to approach (Biggs \& Tang, 2007; Tchoshanov, 2013). Their contribution to the final grade should also be defined: students tend to make little effort in they do not see the immediate point of it (like some extra points in the final grade) and if the task is or not mandatory to pass the course/module.

The planning of the assessment design in course curricula assumes a major importance and research suggests a changing from traditional assessment to authentic assessment, changing its dimensions from: (i) focusing on a single measure to more varied assessment tasks, such as: multiple-choice questions, presentations, individual and group projects, lab reports, reflective journal, case study, portfolio and final projects; (ii) discrete to continuous: one to various tasks along the course; (iii) from isolated to interdisciplinary, for instances a project involving several courses; (iv) from primarily quantitative to qualitative and integrated assessment; (v) from prescribed and standardized to flexible and open (Biggs \& Tang, 2007; Felder et al., 2000; Roldão \& Almeida, 2018; Tchoshanov, 2013).

Strategies of self-assessment and peer-assessment as well as group assessment (group tasks) and random assessment (pick up just a reduced number of the tasks students have to 
deliver to assess, but the same number for all the students) should also be considered. Self and peer-assessment allow students to learn from an evaluator's perspective (good judgement is vital for their future work), provide an opportunity to reflect while engaging them in the process of good learning. All the former can cut down the teachers' assessment load, speeding up assessment procedures, while maintain the integrity of the process (Biggs \& Tang, 2007; Tchoshanov, 2013).

The revised dimensions emphasize characteristics of authentic assessment, that could facilitate effective learning environments being "rooted in a belief that all students can learn, and that the teacher's role is to find a range of ways to ensure that this learning happens"(Earl, 2006).

In order to achieve the connection between learning objectives, course content and assessment of learning outcomes, the teacher selects the appropriate resources and designs the appropriate learning activities, assignment tasks and course deliverables. He also guarantees student learning is assessed not only by test results but also by the efforts he made to attain progress and his attitudes during the process, shifting from categorizing students through judgements but using the assessment tasks as opportunities to enhance the learning process.

Developing formative situations that incorporate all these factors, giving importance to the created interactive learning environment that foments students' participation and considers teachers' attention and support to students' learning are crucial factors helping students "to move in a connected way from where they are to a more efficient and abstract approach" (Tchoshanov, 2013).

\subsubsection{Teacher Mediation}

As already described in the previous sections students' learning is a complex process depending not only on the quality of the didactical sequences in which they were involved, but also on the interactions between the learner and the learning environment, including with teacher and colleagues (Wei et al., 2019). As previously referred, learning is a social process (Vygotsky, 1978), so the human interactions in the knowledge construction -as people learn from one another via collaboration, observation, imitation and modelling- are prevalent and a suitable comprehension of learning is impossible without considering its social dimension, particularly when we are dealing with academic learning (in so different contexts) (Rosa \& Rosa, 2007).

Teacher mediation, accordingly to Lopes (2004) and cited by Viegas (2017b) "incorporates all teachers' actions that may stimulate desirable development of students' knowledge and competences". In this sense teacher mediation is one dimension of teachers' work (in and out the classroom), which plays a crucial role in students' learning development such as the way teaching is organized and presented, adequate learning experiences are provided and most of all how their 
actions facilitate and support the students' achievements. This former support, by no means, signifies teacher is doing students work (Mazur, 1997), as students productive work is vital in their learning. Efficient teacher mediation can be mainly considered a two stage process: (i) the curriculum preparation: designing students' tasks and teacher mediation characteristics in order to promote students engagement in the proposed tasks, in and out the classroom; (ii) implementation in the classroom: if students feel empathy with the teacher and the former is able to promote a social environment where students are comfortable enough to express and discuss their ideas (even if they think they are "stupid" ideas) and in which they feel they have an active role they become more actively engaged which promotes learning and the development of competences (Lopes, 2004; Lopes, Viegas, \& Cravino, 2010; Viegas, 2017b). In order to comply with an insightful mediation, teachers must look upon students' role in the development of the scientific knowledge during class as primordial, valuing their opinions, prior knowledge, questions or suggestions. (Cunha et al., 2014; Lopes, 2004; Lopes, Cravino, et al., 2008; Lopes, Silva, et al., 2008, 2012; Lopes, Viegas, et al., 2010; Pinto et al., 2014; Viegas, 2017b). Even if the course curricular design is well planned and includes a set of perfectly established mediation guidelines, the way teachers addresses those guidelines and implement the curriculum in the classroom depend on the teacher. In practice, teachers adapt them according to their experience, their own didactic interpretation, personality (conservative/progressive), scientific expertise, professional knowledge and even factors like empathy with students and time and effort devoted to students' monitoring (Cunha et al., 2014; Lopes, Silva, et al., 2008; Viegas, 2017b). Cunha and colleagues (2014) refer that "the capacity of integrate the results of the research in science education can improve teachers explicit professional knowledge", making them more attentive to certain mediation traces that affect students' productive engagement in the classroom. All these factors have influence in the students' learning process, helping them in the process of connecting theories, practices and justifications of phenomena, both from the theory to the observable-world and vice-versa (Pinto et al., 2014).

In literature, the most referred teacher mediation aspects or traces, through actions and languages include: class environment, classroom interaction characteristics and the promoted dialogue (Dufresne et al., 1996; Scott et al., 2006; Seoane-Pardo \& García-Peñalvo, 2008; Viegas et al., 2009), teachers support (including structuring of students' work) and autonomy fostered to students (Lopes, 2004; Lopes, Silva, et al., 2010), teachers' effort to contextualize and scaffold students' learning, propose (and keep) authentic/real tasks as a challenge(Cunha et al., 2012; Lopes, Silva, et al., 2010; Lopes, Viegas, et al., 2010; Viegas, 2017b), the work really demanded to students (Viegas, 2017a; Viegas et al., 2009) and teachers' use of assessment and feedback (Hattie \& Timperley, 2007; Lopes, 2004; Roldão, 2003; Viegas, 2017a). 
In this section the focus will be in some of the former mediation characteristics in the classroom grouped in three vectors which are more relevant to this study: (1) learning environment created and authority given to students; (2) task presentation to students and the support provided in order to keep the task authentic; (3) timely and adequate feedback provided which may help students progress in their work. For its importance in this work, each one of those aspects will be presented more thoroughly and grounded in literature in the next paragraphs.

(1) Learning environment and authority. The key to create and sustain an effective learning environment is communication (teacher/student/teacher and student/student). This is true either is a face-to face course, hybrid or online course, although in the last two some extra effort must be made to promote synchronous and/or asynchronous communication through the use of digital and social networks (Veletsianos, 2016). Accordingly to Tchoshanov (2013) "the classroom culture should be built around meaningful content-focused communication and discourse whether it is a reflection on student's own learning and thinking or discussion with peers on comparing and contrasting different methods of problem solving". Accordingly, to the same author, teachers must help students to productively interact, creating an environment of communication and collaboration, involving all students in meaningful discussions contributing to the development of students' critical thinking. As an example of getting students engaged in learning, the teacher can foment group discussions, by for instances proposing a provoking question and asking students to participate in the discussion; in the discussion process teacher has the role of monitoring students' comments, sustain the discussion (capitalizing students' reasoning, providing clarification, exploration by setting counterexamples or opposition points of view) and when a solution to the question is achieved, teacher should synthesize and bring a closure to the discussion. The former activity and others -small group brain storm activities, a one-three minutes' essay, a simple calculus exercise or write a comment about a specific topic, either individually or in groups (Biggs \& Tang, 2007; Mazur, 1997; Ramsden, 1992; Tchoshanov, 2013)- are interesting for all type of classes, including lectures. They allow to break up long period of lecture (of talking and writing on the board); for this type of class, the former type of activities should be brief (typically no more than five minutes) as their main focus is restoring students' attention.

Teachers should set up a social learning environment based on a positive culture of success, that is, on the principle that all students can learn. This type of environment encourages students to be productive engaged in the course, performing the designed (varied) learning activities (Biggs \& Tang, 2007; Engle \& Conant, 2002). Classes become much more interesting (both for 
teachers and students) as students have an active role in class (Biggs \& Tang, 2007; Felder et al., 2000; Lopes, Viegas, et al., 2010; Silverman \& Forum, 1988; Viegas, 2017b; Viegas et al., 2009). These environments should also promote the development of scientific and social competences, giving students more responsibility and allowing students to work cooperatively and collaboratively with peers (Felder et al., 2000; Pea, 2004).

The teachers discourse (dialogic and interactive) must be clear, keeping eye contact with students while talking and using visual aids (Dufresne et al., 1996; Scott et al., 2006). Teachers should, as much as possible, relate the concepts being presented to the students' personal experience. An empathy climate that promotes the social interaction, where students feel at ease exposing their doubts, making questions and discuss their ideas with their peers and the teacher, assuming a participative role in the classroom contribute to students' engagement and success (Lopes, Cravino, et al., 2008; Lopes, Silva, et al., 2012; Lopes, Viegas, et al., 2010). Teachers should avoid sarcastic comments and/or cynicism as these behaviours do not contribute to proper task engagement (Biggs \& Tang, 2007) and should praise students' creative answer/solution even if incorrect (Silverman \& Forum, 1988). When possible the spatial organizational of classroom should also be rethought to foment peer interaction and active and collaborative learning methodologies.

Students should be given an adequate control -autonomy and responsibility- of their activity (which is not feasible if the task is not totally revealed in the beginning), allowing them more authority towards a productive engagement.

(2) Task presentation and support. "A task is the work demanded from students, that they must perform to reach, within a certain time, an answer to a question or other kind of request" (Lopes, Cravino, et al., 2008). When presenting a task to students, whatever the kind of task (assignment, class-question, experimental activity, etc.) the language used in the task formulation and presentation must be clear and adequate to students and course level and teachers should clarify any doubts students may have due to the linguistic formulation (Lopes, Silva, et al., 2012). Students must know from the beginning, what the purposes of the task are and what exactly is expected from them to accomplish an answer or solution (Cunha et al., 2014). The way the task is presented (completely revealed at the beginning or bit by bit to students in different times), the resources they may use to develop it, the time they have to reflect and complete it and the type of task affect students' engagement. The teacher must further demonstrate that the task is intrinsically worthwhile and valued, remembering that deep engagement in a task takes time. 
Teachers should be aware on the work really demanded from students -in or out of the classroom- to complete the task, as sometimes it can be (slightly) different from the teacher initial intentions (Lopes, Cravino, et al., 2008; Lopes, Silva, et al., 2012; Lopes, Viegas, et al., 2010).

Teachers should allow students to work at their own pace -keeping the task authentic until they find a solution- giving them the necessary support (clues and guidance in crucial moments), but avoiding the natural temptation of doing the students job ("explain everything, every time a student has a question" (Lopes, Viegas, et al., 2010)) (Mazur, 1997; Viegas, 2017b; Viegas et al., 2009).

(3) Timely and adequate feedback. Teachers should also provide students with useful (and well-timed) information of their personal accomplishments, that is, feedback on progress. This is important for motivating students and to the development of deep learning: "knowing where you are going, and feedback telling you how well you are progressing, heightens expectations of success" (Hattie \& Timperley, 2007). Feedback is an integral part of the learning process and the former authors define it as "information provided by an agent (e.g. teacher, peer, book, parent, self, experience) regarding aspects of one's performance or understanding". Feedback is thus a consequence of performance and the information provided just become feedback if it has an effect on students' future performance, helping them answering questions about their learning goals, when necessary reorienting students towards those learnings (Viegas et al., 2009, 2010). It is being discussed the feedback for learning: "where they stand, where they are going and how to get there" (Black \& Wiliam, 1998; Viegas, 2017a).

When students get engaged in a learning task, they produce their own feedback about their progress, by monitoring, reflecting and assessing their evolution. But not all students have the same degree of awareness of those processes, although the generation of appropriate inner feedback can be reinforced by asking them to reflect on a continuous basis on their progress and/or to comment or grade their colleagues works (peer feedback/assessment). If well structured, this feedback can complement that delivered by teachers while also contributes to the development of several skills -monitor, manage, evaluate- which are important for their profession and lifelong learning (Nicol, 2008). There are many ways in which teachers can provide feedback to students and for student to receive it from teachers (and/or peers).

Feedback in one of the most critical influences in students' learning and works both ways: for students and for teachers. It provides relevant information to students: how and what they understand (or not) -their state of learning- encountering information and directions they must follow to improve and complete the tasks. Teachers can understand their students' needs and evolution and perceive what they should do next to enhance students' engagement and learning 
(Lopes, 2004; Viegas et al., 2009, 2010). For instances some activities (conceptual questions, discussions, etc.) promoted during class, can provide valuable feedback for teachers: if from the promoted activities teachers realize from students answers that "a large amount of difficulties and misconceptions appeared" (Viegas et al., 2009), it is up to teachers to revise those contents and concepts to help students overcome their difficulties(Biggs \& Tang, 2007; Lopes, Viegas, et al., 2010). The feedback during the learning process helps to maintain the alignment between the course learning objectives and assessment, although giving and receiving feedback requires many skills from teachers and at a minor extent from students also. It is required "high proficiency in developing a classroom climate, the ability to deal with the complexities of multiple judgements, and deep understandings of the subject matter to be ready to provide feedback about tasks" (Hattie \& Timperley, 2007). Teachers need time and resources to provide personalized and on time feedback before frustration takes over. Considering the time factor, Clariana and colleagues (2000) suggest that complex tasks should have delayed feedback while simple tasks should have immediate feedback, accordingly to the degree of processing involved in each type of task.

Accordingly to Hattie \& Timperley (2007), there are four levels of feedback: about the task (FT), about the processing of the task (FP), about self-regulation (SR) and about the self as a person (FS), being the first three interrelated and the last the least effective. FT provides information about the task development: (i) can distinguish between correct and wrong answers; it is the most common -corrective feedback- and addresses mainly surface knowledge; (ii) give information, provide cues and directions about strategies, addressing more deep knowledge. Many teachers combine both types of feedback. FP is more powerful when it helps students reject incorrect hypothesis leading them, through clues and tips, to move to new directions for searching and organising. SR is effective when students understand the importance that autonomy, responsibility, effort and engagement have in their learning process. FS is effective, if teachers produce assertive comments about students' performance that may somehow potentiate their self-esteem and the belief, they are able to be productive engaged in the task.

Feedback to be effective needs to be clear, positive, meaningful -providing alerts to students (when a major difficult is detected and proposing a way of trying to overcome it, by, for instances a presential meeting), discussing students work, providing cues or reinforcement- and compatible with students' prior knowledge. It also implies that students drive active information processing and that the goals of the task are clear (to students) and the task complexity is adequate to their knowledge (Lopes, Cravino, et al., 2008; Lopes, Silva, et al., 2012; Viegas et al., 2009, 2010). Feedback should not be based in negative comments or punishment; as it may be considered a threat to the person at self-level (Hattie \& Timperley, 2007). Effective feedback may help students 
to gain confidence to execute and complete the proposed tasks, being a powerful tool for enhancing learning.

\subsubsection{Practice Reflection}

Teacher and student learning are tightly interconnected in many ways as teachers can and should also learn in the classroom environment. In fact, classroom is a privileged contextualized learning space, where everyday practices of teachers' work take place. Although it is clear that teachers learn through formal professional development programs, the learning from the classroom learning at work- is not granted, as it depends on teachers' active efforts. Literature shows that teacher learn by trying on different and/or new teaching methods, by doing and reflecting about their experiences either individually and/or with colleagues (Fagundes, 2016; García-Peñalvo, Alarcón, \& Domínguez, 2019; Philipsen et al., 2019; Soini et al., 2016). The developed learning activities may lose their intrinsic meaning without reflection on the experience. Núñez and colleagues (2015) consider reflecting has a crucial role in teachers progress (professional and personal) "since it leads to a process of self-recognition of his performance and to a self-evaluation that simultaneously allows him to make changes and implement innovations not only to the methodological approach, but also to the selection and development of meaningful contextualized materials". Refection refers to teachers discerning about their practice both during the teaching process (in the classroom) and outside the learning environment. According to Schön (1983), the first is "reflection in action", dominated by tacit and intuitive knowledge ("knowledge in action") and the second is "reflection on action", which implies examining actions and events and create innovative solutions and develop new strategies.

Reflection is a key aspect in teachers' professional development, allowing them to use their observations to initiate the process of transformation. While reflecting in the teaching context, teachers are focused in what really happens in the classroom and not in what they hoped to happen. The reflection process allows teachers -reflective teachers- to devote time to learn and inquiry about their practices and didactical approaches. The reflective inquiry about their practice gives them the opportunity to move from reflection (in the experience), to description, analysis and finally to action (Gray \& Campbell-Evans, 2002; Núñez Pardo \& Téllez, 2015). Reflection allows teachers to take more informed and conscious decisions regarding their practices and the resources they use and tasks they design, implement and assess and is also a strategic aspect of a teacher professional development (Núñez Pardo, Ramos, \& Téllez, 2006).

The success of teacher reflection depends upon his own reflective ability and the instruments he uses to aid him during his reflection activity (Lopes, Silva, et al., 2012), such as: 
audio records, documents produced both by students and teachers, field notes, diaries, informal contacts or discussions with both teachers and students. Reflective practice can be formally encouraged as action research or action learning, in which "the target of action research is the teaching of the individual teachers herself or himself" (Biggs \& Tang, 2007). The former authors use the term transformative reflection, considering it more appropriate: "theory makes us aware that there is a problem and it helps to generate a solution to that problem". Although it can be an individual activity, it can be enhanced if teacher share his knowledge, beliefs and practices with peers and experts (Biggs \& Tang, 2007; Philipsen et al., 2019; Schön, 1983). In fact, students, a colleague with the role of "critical friend" or an expert (that can provide informed advice) can help in this reflection, as sometimes is difficult for the teachers themselves to identify teaching aspects that might be improved. Students feedback about this context can be obtained -anonymouslywith a simple questionnaire (open questions) asking about what aspects of teaching they appreciate and which ones they would like to be changed. A "critical friend": colleagues from the same department with similar assumptions about good teaching could visit each other classes to observe. Ultimately, they may also receive advice from experts in teaching. All these different perspectives may contribute to better practices (Biggs \& Tang, 2007).

Expert reflective teachers must have experience and deep content knowledge about their course, focusing on what the student does and how that relates to teaching. They constantly reflect on how they might continuously improve their teaching, assuming their research about teaching (and their practices) as triggering their professional development. Adjusting the teaching (in one or more items) may enhance it (sometimes it will take some time and several iterations) but definitely enriches both teaching experience and teaching theory (Biggs \& Tang, 2007).

The reflection process, involving teachers and students, also serves as evaluation of the curriculum as a whole and the mediation traces implemented in the classroom, which can and should make part of the ongoing processes of curriculum alignment and renewal.

\subsection{Experimental Practise}

In the former section it was discussed several types of didactical practices. In this section, taking into account the theme of this thesis project, the focus will be in understanding more profoundly how and which students' learning outcomes are affected by the use of different experimental resources (hands-on, simulated and remote labs) which constitute the experimental practices.

An instructional laboratory is a place where a student goes to perform an experience -an instructional laboratory experience- "personal interaction with equipment and tools leading to the accumulation of knowledge and skills required in a practical-oriented profession" (Peterson 
\& Feisel, 2002). Students perform a lot of instructional experiments during their entire undergraduate program to accomplish the thirteen learning objectives associated with laboratory instruction (Feisel \& Peterson, 2002b, 2002a; Peterson \& Feisel, 2002). These objectives can be grouped in four dimensions: conceptual understanding, design skills, social skills and professional skills (Ma \& Nickerson, 2006) and each of them will be briefly addressed in the next paragraphs:

* Conceptual understanding: the laboratory environment is most appropriate for illustrating and validating analytical concepts, allowing students the opportunity to reprise information taught earlier and/or understand material that had not been grasped before. The variety of elements existing in a laboratory (apparatus, devices, locations) challenges students, allowing them learning by doing (including mistakes), under the support of a teacher, assisting students in the assimilation of information and knowledge construction.

* Design skills: laboratory activities enhance students' ability to solve open-ended problems, designing, building or developing new artefacts or processes to, for instances, meet client requirements or society problems.

* Social skills: laboratory classes are the type of class where group work is dominant, in which social aspects like interdependence, cooperation and collaboration are really important. Students have to defend their points of view, respecting others, being exposed to different learning contexts, solving specific problems/tasks. They learn how to be productively engaged in group engineering-activities.

* Professional skills: laboratory classes allow students to develop skills with instrumentation, including the development of these skills to operate it independently in the future; they allow students the opportunity to be exposed to situations similar to what is expected in the professional practice, including the difficulties and uncertainties involved in the processes. It is important students realize the real world does not always behave accordingly to the theoretical models and they need to develop the adequate technical skills to deal with it. It is also important that they adopt values and attitudes of an engineer.

Nowadays, students can perform experiences not only in the traditional hands-on laboratories, but also in online laboratories: remote laboratories and virtual laboratories (simulations) (Sancristobal et al., 2012; Tawfik, Sancristobal, Martin, Diaz, \& Castro, 2012; Williams \& Neto, 2012), as identified in Figure 1 (accordingly to the type of data and access). Each of them has its own characteristics and a set of advantages and disadvantages, that have already been extensively reported in literature (Alves, Fidalgo, et al., 2016; Alves, Fidalgo, Marques, 
Viegas, Felgueiras, Costa, Lima, Castro, et al., 2018; Bochicchio, Longo, Vaira, \& Zappatore, 2015; Brinson, 2015, 2017; Corter et al., 2011, 2007; Faulconer \& Gruss, 2018; Feisel \& Rosa, 2005; Gomes \& Bogosyan, 2009; Gustavsson, 2011; Heradio, de La Torre, et al., 2016; Lustigova \& Novotna, 2012; Ma \& Nickerson, 2006; Nickerson et al., 2007; Post, Guo, Saab, \& Admiraal, 2019; Restivo \& Alves, 2013; Shea \& Bidjerano, 2013; Sicker et al., 2005; Veletsianos, 2016; Williams \& Neto, 2012). In the next sections (and based on the previous works) they will be briefly described and their main advantages/disadvantages (comparatively to each other) will be considered.

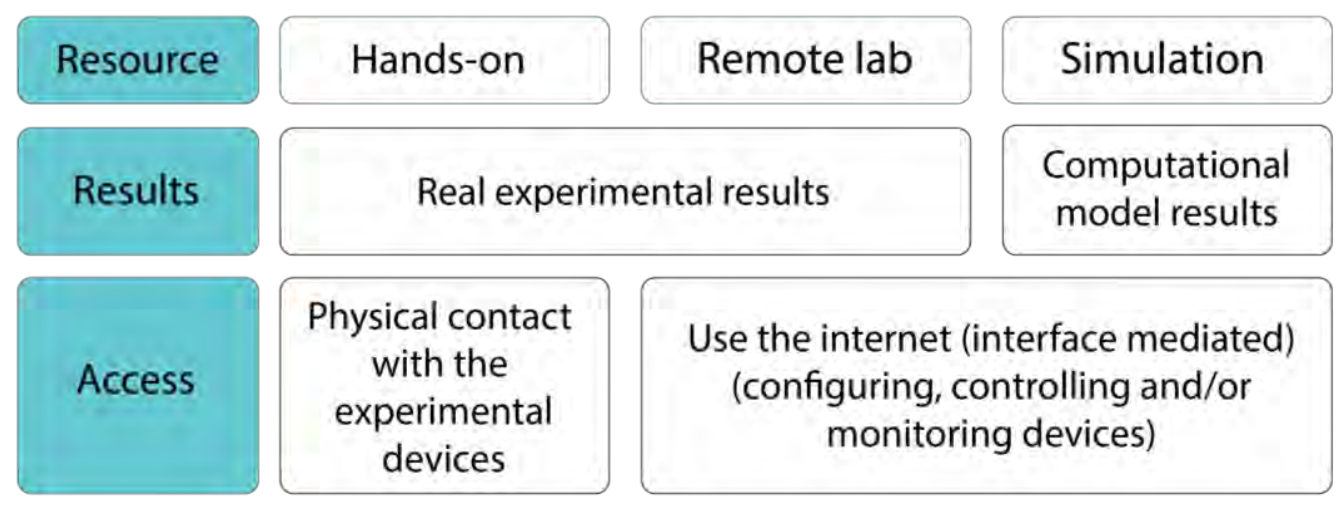

Figure 1 - Instructional Laboratories

\subsubsection{Hands-on Laboratories}

Hands-on labs are the traditional instructional laboratories and still the most common for undergraduate engineering students, offering students the opportunity to experiment with real equipment, physically set up at the same room where both students and teachers are.

They are considered the corner stone of engineering education as they provide the students: (i) the opportunity to deal with data with "unexpected clashes": data that is different from students were expecting accordingly to the theoretical models; (ii) the chance to handle and physically interact -touch sensory feedback- with instrumentation. These two aspects are essential for students to understand the role of experimentation: learning by doing and learning by the failure. Naturally, they promote interaction between teacher/students/equipment and facilitate cooperative and collaborative work, as all elements are physically located at the same place.

As already explained in section 2.2.1, to further involve students in their knowledge construction process, giving them more responsibility, teachers may propose/implement: (i) students previous preparation of their lab work before the lab class, in which they could be asked 
some questions about it; (ii) the lab experiments being aligned with the theoretical concepts covered in lectures; (iii) using less guided experiments (avoiding detailed lab scripts composed of a set of precise instructions, which students have to execute without much reflection) and use more unstructured guides, based on simple lab devices, that allow students to demonstrate or interpret theoretical concepts; (iv) when possible, a lab project with the aim of solving a specific problem, addressing the course contents. The former promote the development of autonomous work as well as collaborative teamwork (if the lab problems are solved in group with the delivery of a team report), including the development of other soft skills (Biggs \& Tang, 2007; Cunha et al., 2012; Lopes, Viegas, et al., 2010; Viegas et al., 2009).

Its major disadvantages are usually linked with constraints related with space, time, cost and security. They require a suitable space, with specific infrastructure features, to set up the equipment and accommodate students and teachers. Usually they are not 24 hours/7 days per week available and typically students have to comply with class schedules or luckily usufruct some course laboratory open hours (for those institution that have the necessary technical staff). Another important disadvantage is the high laboratory maintenance costs: equipment requires regular maintenance, by qualified technical staff that is also, in some cases, required to supervise experiments. These constraints usually have implications in the number of students per class being too high (as the number of students per group). In these cases, typically one student runs the apparatus and the other(s) just watch. Depending on the type of lab, security may be a crucial factor (type of equipment and/or components), implying special conditions and typically a lower number of students per class, leading to higher costs.

These accessibility and availability constraints render this type of resource impractical for distance learning education.

This type of labs is nowadays increasingly "interfaced" by computers and/or ICT, either to control experiments and/or acquire and/or analyse data, so the difference to the NTL (nontraditional labs) may become somehow blurred.

\subsubsection{Online Laboratories}

Online laboratories are based on lab experiments that can be efficiently delivered through the Internet, typically with a lower cost and can be assessed from anywhere at any time. Traditionally they are classified into two different types -simulation or virtual laboratories and remote laboratories- defined as:

- Simulations: are the imitations of real laboratory procedures/experiments (as realistic as possible) but they do not have a real physical existence. They rely on mathematical 
and computational models, so the obtained data is not real, but derived from a computational model. As the resulting data are based on mathematical calculations, each time a measurement is carried out students get the same answer. Usually, its architecture includes a computer server, which hosts a set of simulations. Students, using their own computers, access remotely the server, by sending input over a network. After receiving it, the server sends feedback, using the same network to students' computer.

* Remote laboratory: it is a really physically laboratory apparatus that is located remotely from the student. For the experiment execution there is a need of a communication mean (Internet) between the user and the remote equipment and usually also requires a particular user interface. The user has the possibility to configure, control and/or monitor the physical parameters of a real experiment, obtaining real data (typically, with different values each time a measurement is carried out) and in real-time, although they perform this configuration through a technologymediated interface. Its architecture involves a computer server connected to real equipment. Students, using their own computers and through Internet access, perform actions (like assembling a circuit) using some specific software remotely. These inputs are transmitted to the computer server that is directly connected with real equipment. After receiving the feedback from the equipment, the computer server sends it directly to students.

Both types of online labs have some common advantages: (i) lower operating and maintenance costs (particularly simulation, that requires neither a physical space nor maintenance); (ii) availability (24 hours/7 days) and accessibility: students can access it (individually or with other students that can be even located in geographical distant places) as many times as they need it and from any place, as long as they have access to Internet; (iii) safety: students can use it without the fear of hurting themselves or damaging the equipment; (iv) growth potential and class size: it can be used in different type of classes (including lectures), with different goals, with simplicity; (v) involving students deeply in their learning process (autonomy, time management, responsibility); (vi) supervision: students perform experiments without the need of supervision; (vii) increases students access to particularly expensive equipment; (viii) adequate for distance learning education, including MOOC (Massive Open Online Courses) (García-Peñalvo, Fidalgo-Blanco, \& Sein-Echaluce, 2017, 2018); (ix) support life-long learning; (x) meet special needs of disabled students; (xi) promote cooperation between researchers and institutions; (xii) sustainability: reduces enormously the damaged components and/or 
equipment, reducing the environmental impact (less electronic waste); (xiii) the lab sessions can be easily recorded and shared online in e-learning environments, potentiating learning.

Each of it -simulations and remote labs- has its own set of advantages/disadvantages:

* Simulations: (i) perform experiments and allow to "observe" phenomena that are not possible to be performed nor easily visualized in a traditional hands-on lab; (ii) useful for an introduction and/or preparation to a lab class, to test a formula or a concept, although they are not appropriate to investigate a truly real behaviour of nature; (iii) flexible time flow, allowing for different rates: slow microseconds into minutes or the other way around, speed up months into seconds (allowing the "observation" of phenomena like the movement of molecules); (iv) the student can stop, restart and reexamine the experiment under new conditions, allowing students freedom to explore and experiment; (v) most are designed as single-user applications, so teachers should bear it in mind when using it, to prevent students' isolation.

* Remote labs: (i) multiplexing capacity: some of these resources allow several users at the same time; (ii) they can be easily integrated in a LMS (some even have their own LMS system, although in some cases a very simple one) allowing a much easy students' management (through the e-learning platform). All students' information is registered by the system including the number of accesses and the activities they accessed, facilitating the assessment procedure; (iii) it is easier to implement an ILS (Intelligent Learning System) (Myneni, Narayanan, Rebello, Rouinfar, \& Pumtambekar, 2013) that leads students in their own learning pathway -Personal Learning Environment (PLE) (Humanante-Ramos, García-Peñalvo, \& Conde-González, 2015; Wilson et al., 2007)and create their own PLP (Personal Learning Pathway) (Gillet, Jon, Sotiriou, \& Salzmann, 2013) in accordance with the constructivism theory; (iv) can be shared between Institutions and also provide experimental work to those institutions where no real labs exist or for some reason (as military conflicts or a pandemic) cannot use it; creation of Federations of Labs (Gustavsson et al., 2011): a creation of a portal where several institutions share their remote labs and educational resources, allowing these students to increase enormously the resources they can use.

Some authors also consider the existence of another type of online labs: hybrid labs (Frerich, Kruse, Petermann, \& Kilzer, 2014). The definition of this type of lab is not (yet) clearly established in the literature. In fact, they are "created" by combining features from remote labs with virtual labs (simulations), that is they mix real and virtual components. This way, they try to 
appropriate some of the advantages of remote and virtual labs (Gomes \& Bogosyan, 2009; Rodriguez-Gil, García-Zubía, Orduña, \& Lopez-Ipiña, 2017; Zutin, Auer, Maier, \& Niederstätter, 2010). Some other authors consider hybrid labs as also combining features from hands-on labs with (local) simulations (Rivera \& Petrie, 2016).

As each resource (hands-on labs, remote labs, simulation) has its own advantages and disadvantages, each potentiating the developing of different competences, teachers should be aware of it when deciding which resource or combination of resources to use. In fact, a "blended" or "hybrid" approach to experimental learning -a combination of hands-on labs, simulation and remote lab- seems to the most effective (Brinson, 2015, 2017; Corter et al., 2011, 2007; Heradio, de La Torre, et al., 2016).

\subsection{Students' Learning}

Students may learn from different resources and through different methods. Although to their individual differences they may have different preferences for a specific resource and/or method and/or teaching strategies, it is well studied in literature that teachers can reach more students, potentiating their learning, if they create an effective social learning environment, in which students interact with their peers, the teachers and the environment. Encouraging the necessity to know, rousing students' curiosity, building on students' prior knowledge as well as diversifying methods and teaching techniques in the classroom are all things that teachers can try to do (including other features described in section2.2). Several authors defend that this diversification is particularly important because students have different learning styles (visual, sensing, inductive, active or global) (Çardak \& Selvi, 2016; Felder et al., 2000; Larkin-Hein \& Budny, 2001; Prince \& Felder, 2006; Richardson, 2011; Silverman \& Forum, 1988); if teachers do not diversify the teaching techniques they may fail their intention of reaching all students which may "lead to poor student performance, professional frustration and a loss to society of many potentially engineers" (Silverman \& Forum, 1988). Other authors, like Kirschner (2013) defend that learning styles are "an urban legend in education" and one should focus on the bottom things students have in common, not denying their individual differences and preferences for this or that approach, that, depending on the context, may be or not be realized in practice. In fact, teachers have to deal with an interaction between personal and contextual factors (Biggs \& Tang, 2007).

Accordingly to what was explained in section 2.2, the overall student success in learning largely depends on how well the assessment is designed and connected to learning objectives and content. But it does not depend exclusively on teachers' responsibility and ability on creating an accessible knowledge teaching context including informed decision making and good 
management of the overall process. At the undergraduate level teachers have, in fact, the major responsibility for what and how their students learn, but students also have responsibilities: choosing (or not) to go to the lectures, concentrating, working hard, seeking true knowledge (and not just pass the test) and use available web resources. Teachers can help students "learn how to learn" (Novak, 2002), but effective studying, and consequently learning, also depends on studentbased factors including: (i) cognitive, metacognitive and motivational skills; (ii) student approaches to learning; (iii) study skills, habits and attitudes; (iv) reflective thinking (Biggs \& Tang, 2007; Crede \& Kuncel, 2008; Prince \& Felder, 2006; Richardson, 2011).

Learning is a complex behavioural process that directs students' behaviour towards the fulfilment of the designed learning objectives. As previously described, active learning increases students' motivation and participation in their learning process with positive results towards the construction of meaningful and deep knowledge (Lopes, Viegas, et al., 2010). When students consciously control their learning process, that is when they become academic self-regulated which is a gradual process- they get cognitively, motivationally and behaviourally more active in their learning processes, taking control of their own learning (Schunk \& Zimmerman, 1998; Zimmerman, 2000). Students are assigned with more responsibility, confidence, strategies and empowerment for their own learning (Nicol, 2008; Novak, 2002; Redaelli \& Lima Jr, 2013). Selfregulated learning (SRL) is important, if not essential, for effective learning and efficacy. Accordingly to Zimmerman (2000) "the observation of models, imitations, and enactive experience with increasing independence are the most important sources for becoming a selfregulated learner". Still, biological, developmental, contextual, and other individual differences may condition learners in becoming self-regulated learners in all contexts. Several factors including: goal orientation, intrinsic motivation, task-value, self-efficacy, future time perspective and the learning environment, have implications in students' development of SRL (Artino, 2008; Brandmo \& Berger, 2013; Redaelli \& Lima Jr, 2013). Learning environments and task value that promote SRL were already been addressed in previous sections. Intrinsic motivation is the ideal, but not common. It characterizes the student that learn by the pleasures of it, engaging easily in tasks, independently of the reward. For the other common students with extrinsic motivation, the key is to ensure learning activities (tasks) that are meaningful and worthwhile (Biggs \& Tang, 2007). Self-efficacy is related to motivational beliefs which the individual has to achieve a goal. It is a motivational process that somehow has control in someone's achievements (Redaelli \& Lima Jr, 2013). As a conclusion, "students who hold adaptive motivational beliefs tend to use more SRL strategies and, as a result, outperform their less-adaptive counterparts" (Artino, 2008).

Metacognition is another important factor and is considered to be one of the key approaches to promote student's thinking about their learning (Crede \& Kuncel, 2008; Novak, 2002; 
Tchoshanov, 2013), "being exclusively focused on the cognitive aspects of learning and thinking and their regulation" (Brandmo \& Berger, 2013). This principle -learning about learning, including adapting study behaviours to the demands of a particular task- suggests some strategies to foster students self-monitoring activities: learning to plan, monitor success, involving students in identifying and correcting errors, recognize unsuccessful problem approaches, promote and scaffold students' discussions and encourage students to seek and offer help -cooperative and collaborative learning- in more challenging proposed tasks like projects or experimental work (Artino, 2008; Novak, 2002; Redaelli \& Lima Jr, 2013; Tchoshanov, 2013). Students with high metacognitive skills are characterized for being highly involved in their learning process (Crede \& Kuncel, 2008).

Students tend to embrace different approaches to studying -"student approaches to learning" (SLA)- depending upon the content, the context and the requirements of specific learning tasks (Biggs \& Tang, 2007). Students opt for different paths of carrying out learning tasks: a deep approach is driven by students' intrinsic motivation and commitment to learning and aims to understand material and integrate it with students' prior knowledge towards deep knowledge construction; a surface approach is driven by one's extrinsic motivation and aims to memorize and reproduce those materials for assessment leading to surface knowledge; a strategic motivation is focused in reaching good grades, by any means but typically based on an organized study routine (Biggs \& Tang, 2007; Crede \& Kuncel, 2008; Ramsden, 1992; Richardson, 2011). The option for choosing a SLA "may be related both to students' perceptions of their academic environment and to their conceptions of learning and their conceptions of themselves as learners" (Richardson, 2011).

Study skills, habits and attitudes also have impact in students' learning. The first is related to students possessing appropriate studying techniques and practices and includes: capacity to manage time and space, allocate the necessary resources to develop the learning tasks, aptitude to organize, condense and incorporate material. Study habits are related to establishing study routines like the frequency of study sessions but also include revision of material, self-testing and rehearsal of learned material. Study attitudes are connected to a positive attitude towards studying and education in general (Crede \& Kuncel, 2008; Gettinger \& Seibert, 2002).

Students reflection (about their own learning (including causal attributions for their failures and/or successes) and their perception of teaching/learning conditions and activities) may also have an important role in students' learning and self-monitoring (Artino, 2008; Biggs \& Tang, 2007), leading to correct their attitudes and behaviours.

Students' learning habits as well as students' reflection must be rethought in order to contribute to the development of the 21st century engineer competences that include 
competences associated to sustainability and social responsibility as well as collaborative teamwork (Conde-González, Colomo-Palacios, García-Peñalvo, \& Larrueca, 2018), communication (Chidambaram, Mugundhan, \& Rao, 2020), creativity and innovation (Bourgeois-Bougrine, Buisine, Vandendriessche, Glaveanu, \& Lubart, 2017), critical thinking (Shanta \& Wells, 2020), problem solving (Pease, Vuke, June Maker, \& Muammar, 2020), and decision-making (Wendell, Wright, \& Paugh, 2017). In fact, the former are key competences essential for a 21st century engineer and their learning encompass the development of the former competences as much as the theoretical and technical knowledge and analytical skills (Al-Bahi, Taha, \& Turkmen, 2013; Lapek, 2017; Samavedham \& Ragupathi, 2015).

Therefore, meaningful learning construction is a continuous process, depending on several of the factors approached in the previous paragraphs. Still the quantity and quality of relevant knowledge possessed by the learner and the degree of his effort to integrate new knowledge with existing relevant knowledge -facilitated by proper teacher mediation- in a constructive aligned teaching and learning system have a major impact in the process (Novak, 2002). Students anxiety -based on perceptions of low competence- either to studying or assessment, may compromise students' learning (Crede \& Kuncel, 2008).

All the factors previously considered influence students' learning either in a face-to-face, blended or distance learning environment. Although the focus of this study is in presential learning environments, it was not used only traditional hands-on labs, but also online labs: virtual labs (simulations) and remote labs. When one embraces these new lab formats two extra elements are introduced: a technology-mediated interface and physical and psychological separation from the laboratory equipment. The sense of separation between students and the hardware (mental perception of hardware) -more than the physical separation itself- is a key factor. The interface intends to close the psychological distance, although this achievement is dependent on the type of interface. The access mode (hands-on, remote, virtual labs) is an aggregation of innumerable other important variables and the change from the proximal mode (hands-on labs) to nonproximal modes (online labs) is a complicated shift. These two extra elements affect the mode students construct their learning and teachers should be aware of it for both minimizing its negative features and potentiating the positive ones. Promoting collaborative social environments (both with other students and the instructor), emphasising the task goals for online experiments and support students with timely feedback are important aspects to get the full value of these learning online experiences (Bright, Lindsay, Lowe, Murray, \& Liu, 2008; Lindsay \& Good, 2005; Shea \& Bidjerano, 2013).

Another important feature, somehow linked to the previous ones, is the type of interaction that occur in these different laboratory-based learning environments. The design of these 
environments needs to account for the level of these interactions, as they determine students' satisfaction and their engagement in the laboratory. As already seen in section 2.2, learners' performance is highly influenced by the interactions between the learner and the learning environment. In instructional hands-on laboratories, the learning environment includes: the student themselves, other students, the teacher and/or instructor and the lab equipment (which may include components, computers and manuals). It was clear in literature that three types of interaction occurred: student-student interaction (S-S), student-instructor interaction (S-I), and student-equipment interaction (S-E) (Lal, Lucey, Treagust, \& Mocerino, 2018; Lowe, Member, Murray, Lindsay, \& Liu, 2009; Shea \& Bidjerano, 2013) and more recently another type of interaction was added: indirect- interaction (I-I), referring to students listening or observing and learning to interactions in which they are not direct participants: either other students interactions between themselves or with the teacher (Lal et al., 2019; Wei et al., 2019). In a handson laboratory, where all these elements are present at the same physical space, all of them occur. In online laboratories these interactions are not exactly the same: they may be modified or even absent and it is up to the instructor -which role in these online environments is even more important- to consider its social context and promote the adequate support and foment collaboration and interaction (preferably all types), using technology innovations. These include: provide the necessary support documents (considering the equipment and lab tasks) and support during the lab usage, arrange for a common space (using ICT) where students and teachers can interact and communicate and foment collaborative and team work (Lal et al., 2019; Serdyukov \& Serdyukova, 2011). 



\section{VISIR REMOTE LAB}

$\mathrm{T}$

his chapter initiates with a brief history of VISIR, over his 20 years of existence and then a very simple description of VISIR system including a summary of its architecture, types of access and setups is presented. Afterwards, the main results from the literature review about VISIR until 2016 -the first step of this research work- are summarized and finally the VISIR+ Project is fully described. The Project description allows to contextualize its importance not only for the data collection and this study, but also for the dissemination of the remote labs and pedagogical practices based upon the use of VISIR along with other experimental resources.

\subsection{Brief History}

The remote laboratory VISIR emerged from a feasibility study started in 1999, at the Blekinge Institute of Technology (BTH) in Sweden, although it was only launched on 10 March 2004. VISIR is a combination of open source software packages and commercial equipment from National Instruments (NI), released under a GNU General Public License (GPL), for remotely creating, wiring and measuring electronics circuits on a breadboard, supporting a wide range of electronic circuit components (Gustavsson et al., 2004). Nonetheless, the platform is not limited to electrical experiments; VISIR laboratories for acoustics and mechanical vibration experiments are online in BTH (Gustavsson, Zackrisson, \& Lundberg, 2014; Tawfik et al., 2013). BTH, together with NI in the USA and Axiom EduTECH in Sweden launched the VISIR Project at the end of 2006, the project being financially supported by BTH and the Swedish Governmental Agency for Innovation Systems (VINNOVA) (Tawfik et al., 2013). Professor Ingvar Gustavsson -VISIR's "father"- goal was to foment cooperation amongst HEI and other organizations -creating a VISIR Consortiumdeveloping software modules using open source technologies for online remote laboratories. BTH research group is still responsible for maintaining, updating as well as installing VISIR system(s).

Up to now, and after BTH, VISIR was installed in sixteen different Higher Education Institutions, in eleven different countries, starting in Europe, but nowadays distributed over four continents (Alves, Felgueiras, et al., 2018; García-Zubía et al., 2020), in a total of seventeen nodes:

* Argentina: National University of Rosario (UNR) and School of Exact Sciences and Technologies - National University of Santiago del Estero (UNSE).

* Austria: Carinthia University of Applied Sciences (CUAS) and FH Campus Wien University of Applied Sciences (FH Campus Wien). 
- Brazil: Federal Institute of Santa Catarina, Florianopolis (IFSC); Federal University of Santa Catarina, Araranguá (UFSC) and Pontifical Catholic University of Rio de Janeiro (PUC-Rio).

* Costa Rica: National Distance Education University (UNED).

* Georgia: Batumi Shota Rustaveli State University (BSU).

* Germany: TU Dortmund University.

* India: Indian Institute of Technology Madras (IIT-M).

* Morocco: Hassan 1er University, Settat.

* Portugal: School of Engineering (ISEP), Polytechnic of Porto (P.Porto).

* Spain: National Distance Education University (UNED) and University of Deusto (UDEUSTO).

* United States of America (USA): University of Georgia, Athens, GA.

The International Association of Online Engineering (IAOE) created a Special Interest Group (SIG) around VISIR to foster the collaboration within the community and to foment the project dissemination (Salah et al., 2015; Tawfik et al., 2013). The existence of this community, which is quite wide and active is a major advantage: VISIR users -students, teachers and researchersfrequently come up with different requirements and/or identify constraints and problems that were not predicted by VISIR developers. This feedback is often used to add new features and introduce improvements to the system interface and operation, promoting VISIR's evolution and improvement (Fidalgo et al., 2012). In fact, VISIR SIG evolved from a group of researchers interested to improve and spread VISIR system to a larger community also focused on sharing best practices as well as develop knowledge in this topic (remote labs, particularly for Engineering Education). So VISIR SIG can now be considered a CoP (Community of Practice) (O' Keeffe, 2017): "groups of people who share a concern, a set of problems, or a passion about a topic, and who deepen their knowledge and expertise in this area by interacting on an ongoing basis" (Wenger, Mcdermott, \& Snyder, 2002). In the last few years this CoP was able to contribute to a series of technical improvements in VISIR (hardware and software) as well as outreaching several thousand students and hundreds of teachers, not only from the HEI where VISIR is installed, but also from Middle East (Odeh et al., 2015); this last using a VISIR system from other HEI (ISEP). In fact, the highest goal of this VISIR's CoP is to create a federation of VISIR laboratories that could be accessed by any partner and would include a free-access repository for sharing learning resources. The VISIR+ Project (that will be described in section 3.3) was the first step in that direction and the PILAR (Platform Integration of Laboratories based on the Architecture of visiR) Project (2016-2019) consolidated it. The PILAR Project aim was "enhancing practical instructive scenarios -in particular electronics practical experimentation- at different educational levels -[...] 
specifically through VISIR remote laboratory- and improving the repository, efficiency and accessibility of these educational resources" (García-Loro et al., 2019). In these projects, each partner was simultaneous a supplier and a user: each partner/user has access to many more resources (experiments, data, etc.) than those provided by his own institution, potentiating knowledge, but PILAR goal is to open the federation to other partners in Europe. A few months from the end of the PILAR project, the first version of the PILAR lessons repository (supported by MOODLE (Modular Object-Oriented Dynamic Learning Environment)) is already being used: this pilot course includes 15 different experiments and more than two hundred students are already using/testing it (García-Loro et al., 2019).

In the Electric and Electronic Circuits area, VISIR is the best and well known remote laboratory, the longest-running and also the most documented, with more than one hundred technical and scientific publications (Felgueiras et al., 2019; García-Zubía et al., 2020), for which this CoP had a crucial role. In effect, VISIR was recognized as the best remote controlled laboratory by the Executive Committee of Global Online Laboratory Consortium, in 2015 ("IAOE: Winners for the GOLC Online Laboratory Award, 11 February 2015," n.d.). VISIR is also the first remote lab in the world serving a Massive Open Online Course (MOOC) on industrial electronics, developed by the Spanish National Distance Education University (UNED) (Tawfik et al., 2014).

\subsection{Overview of the VISIR System}

VISIR may be considered as a remote workbench, equipped with the same instruments that exist in a hands-on laboratory for conducting experiments with electric and electronic circuits. These workbenches are similar everywhere in the world: usually in each, there is a breadboard and components, provided by the instructor, and students use them to mount the electrical/electronic circuits and to connect the test probes, as determined in the lab instruction procedure. Using VISIR, an identical simulation of the real equipment and instruments appears (a virtual breadboard and photographs of the components/instruments) on the student PC (personal computer) screen. Students using the mouse instead of their fingers, may adjust the instruments to position components on the breadboard and to do the wiring to assemble the circuits (clicking on the buttons or rotating knobs). The corresponding real components are mounted in sockets in a switching matrix and the measurement results, through the instruments virtual front panels, are displayed in the students' PC screen. So, as long as the student has a PC or more recently a handheld device, such as a smartphone or tablet, he has the ability to access to this real electronic lab (his "individual" lab workbench), at any location, by using Internet and a web-based userinterface by means of a web browser and Flash Player installed as a plug-in (Gustavsson, 
Zackrisson, Bartunek, et al., 2008; Gustavsson, Zackrisson, Håkansson, Claesson, \& Lagö, 2007). VISIR system allows students to perform experiments in a very similar way to the hands-on lab, almost giving them the impression they are working in the real lab: a virtual breadboard (where he performs the connections) and interfaces of the instrument panels (which include animated controls and displays and with which users are able to interact) as shown in Figure 2, Figure 3 and Figure 4.

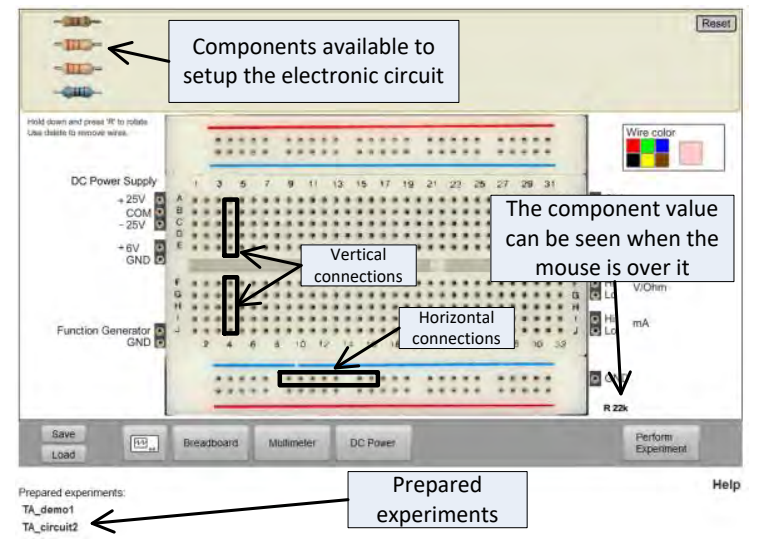

Figure 2 - VISIR Virtual Breadboard

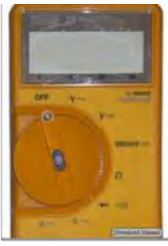

Multimeter

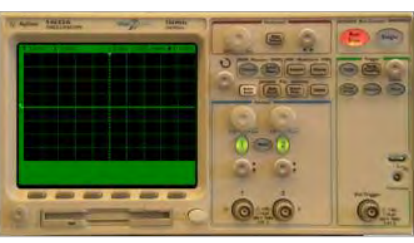

Oscilloscope

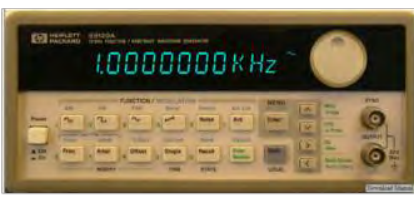

Function Generator

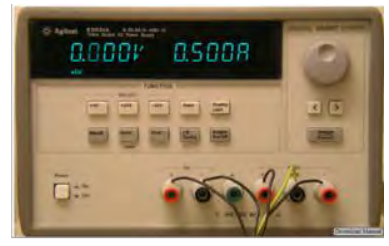

DC Power

Figure 3 - Interfaces of the Instruments - VISIR System

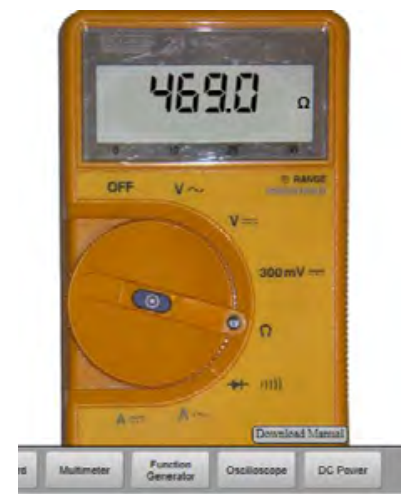

Figure 4 - Multimeter Detail (VISIR System) 
Students have the possibility to perform a set of experiments -different circuits with diverse types of components (see Figure 2: Prepared experiments, in the bottom left corner)- preconfigured by the system administrator, accordingly to teachers request. Moreover, students can construct, wire and test those circuits without the worry of burning components or hurting themselves. Another important feature to be considered is that the system allows several users at the same time (comparable to a lab equipped with lots of traditional workbenches) up to a threshold limit of 60 simultaneous users (Alves, Fidalgo, et al., 2016). This multiplexing capacity is one relevant pedagogical aspect, not typical amongst remote labs (García-Zubía et al., 2017). In fact, when students press the button "Perform Experiment" (Figure 2, bottom right corner), the circuit is sent to the workbench, which creates the defined circuit and performs the experiment (in fractions of one second) returning the results to the user. For instances, if the purpose was to measure the resistance of a particular resistor, the multimeter measurement result appears as exhibited in Figure 4.

Mainly, VISIR allows three types of didactical setups depending on the allowed level of students' autonomy while performing the tasks:

* Pre-designed circuit: students' interaction with the tool is minimal -they just perform the measurements- as all the connections and setups were already performed by the teacher; it can be used to teach students how to measure current and voltage, for instances.

* Pre-defined circuit, where the students design the circuit on their own -similar to the experience they do in the hands-on lab- making the connection and the measurements, but they have access to a limited number of components (defined in advance by the teacher).

* Non-defined circuit: students have freedom to fully design the circuits to solve a specific lab assignment -they can choose components from a components list, then add the components to the breadboard and to conclude make the necessary connections with the measurement equipment- making the necessary measurement, to autonomously solve the assignment.

VISIR is a client server architecture, where measurements are carried out using a server (Figure 5). The hardware architecture of the VISIR project consists basically of a PC-based platform, relay switching matrix and PXI chassis from National Instruments. These three hardware components are connected through several types of cables. The PC-based platform is a computer sever that hosts several software packages/programs to provide functionality for the other two components. The NI instrumentation platform is where all the instruments required for 
practice are integrated. The function of the switching matrix -a stack of printed circuit boards- is to allow the interconnection amongst the different electronic components such as resistors, capacitors and diodes, as well as to connect the laboratory equipment to the circuit, in order to introduce signals/supply (function generator and power supply) or to perform measurements (oscilloscope and multimeter) (Rodriguez-Gil, Orduña, García-Zubía, \& López-de-Ipiña, 2012; Tawfik, Monteso, García-Loro, Losada, et al., 2015).

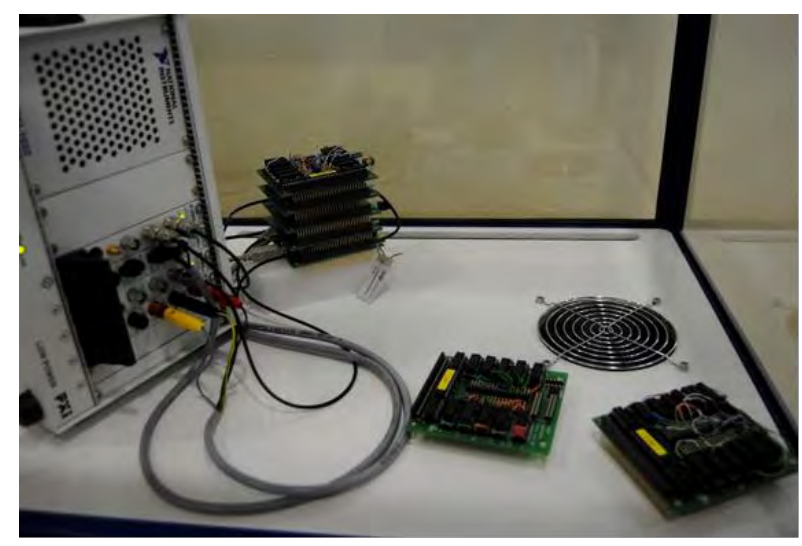

VISIR System at ISEP

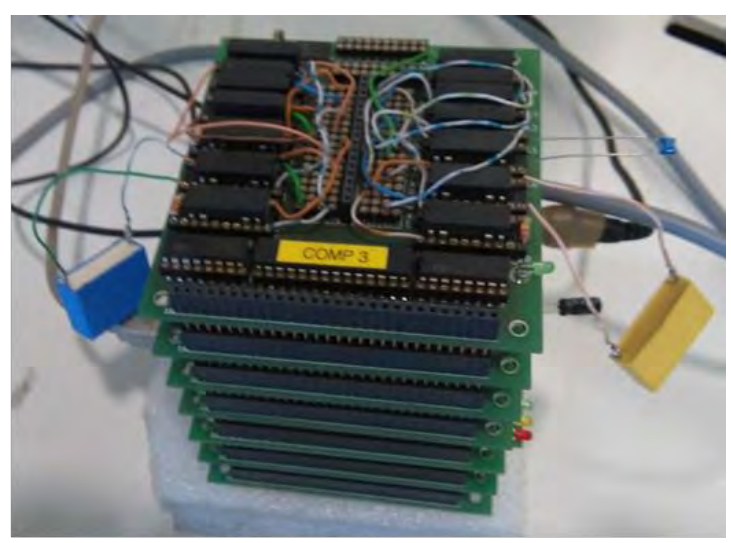

Switching Matrix

Figure 5 - VISIR at ISEP: Overview (left) and a Switching Matrix Detail (right)

The software architecture is responsible for displaying and handling the breadboard as well as the instrument front panels, so students can assemble the circuit and observe the measured comeback. It is probably the most complex part, as it is divided into several virtual servers, having each of them a specific function (García-Loro et al., 2019; Rodriguez-Gil et al., 2012; Tawfik, Monteso, García-Loro, Losada, et al., 2015). All these software modules are anchored in the PCbased platform:

* (Open labs) Web Interfaces: provides the basic remote experimentation layers, including the initial webpages, user authentication and authorization, etc., as well as a database, used to store users, circuit and other information. Nowadays, the text resources available in VISIR web interfaces are accessible in several languages, including English, Portuguese and Spanish.

* Experiment Client/Web Server: is connected to the measurement server and provides the experiment user-interface (the simulated workbench where the user assembles the circuit, accordingly to Figure 2), accessible through any browser. In brief, it is where the user designs the experiment. 
* Measurement Server: it is a software application, running in another (distinct) computer and works with the equipment server, in order to provide the real time measurements to the user. Verifies connection received by users and manages the queue of users before sending them to the equipment server.

* Equipment Server: deals with the hardware and the circuit-wiring robot, being in charge of the direct control of the physical equipment. Configures the instruments and physically constructs the circuits.

VISIR has its own LMS although it can be integrated with other platforms, such as Open Labs projects and Social Networks (Gustavsson et al., 2007). It has four different user account types: administration account, teacher account, student account and guest account. Each user account has its own features, privileges and limits, setting the availability of the lab contents. The account associated to the lab organizer and distributor is the administrator account with privileges of creating contents in the user interface, uploading files, creating and deleting courses and add the responsible for the course, assigning teacher accounts and modifying and/or removing user accounts. Teacher's accounts are linked to the course(s) for which each teacher is responsible and its main privileges are adding and removing experiments as well as student accounts and making schedule reservations for a group of students. Student's accounts allow to access the experiments of a specific course: select experiments (with a previously defined list of components), select instruments and make a schedule student reservation. Finally, the guest account is a public trail account, that can be accessed by anyone who wants to try VISIR (Tawfik, Sancristobal, Martín, Gil, Pesquera, Losada, et al., 2011).

\subsection{VISIR Usage State of the Art up to 2016 - Literature Review}

In 2016, an initial SLR was conducted in order to understand and systematize the scientific research using VISIR's approach, done until May 2016 (Lima et al., 2016b, 2016a). This SLR recognised the lack of studies considering the effect of the usage of simultaneous experimental resources, supported on VISIR, in the learning process and students' learning outcomes. It allowed to identify some gaps in literature, considered in this research project. Actually, the main goal of this SLR was to identify common outcomes and indicators of consistent results found in the different didactical approaches, based upon VISIR. From the 86 papers initially considered, 32 were rejected and from the remaining 54 throughout analysis, two main lines of research were identified: Technical Issues (TI) and Didactical Issues (DI). TI considered papers which main focus was the software/hardware VISIR components description and/or other technical issues. In DI all 
papers describing VISIR implementations and usage in specific courses presenting the resulting outcomes were considered.

Even though not pursued in this work, the TI line of research also allowed the identification of some weaknesses and constraints (Lima et al., 2016b, 2016a).

Considering the DI research line -the focus of this work- there were identified and analysed 22 cases, covering more than 4400 students, from different educational levels and backgrounds. Each case represented a different course where VISIR was implemented and the type of didactical interventions carried out were also very diverse (although in most cases, very briefly described) as well as the knowledge and level of competence development.

From this analysis it was concluded VISIR system is a useful learning resource -to be used as a complement to hands-on lab and/or simulation or as a tool for distance learning- for teaching and learning electricity and electronics. It is well accepted by students, although some considered it more appropriate for introductory courses. The major conclusions of this work address various strengthens considering VISIR usage, although it was also identified some constraints that should be considered when planning a didactical implementation using VISIR. Still, it is very difficult to isolate VISIR's contribution to these results from the other resources used in each case.

The major VISIR strengthens found are (contributing to):

* A gain in students' learning and/or performance.

* Improve students' competences, including not only experimental competences, but also problem-solving skills and critical thinking.

* Increase students' motivation and enthusiasm.

* Boost students' confidence in hands-on lab.

The main constraints are:

* Teacher experience and attention to VISIR is required. In fact, this factor plays a crucial role, in several ways:

- Before the didactical implementation: teacher needs to spend some time getting familiarized with the tool, not only to give assistance to his students' eventual initial difficulties but also to arouse students' enthusiasm and perception of VISIR utility.

○ Prepare an introductory activity and/or support material: to help students to get familiarized with the tool.

○ Ensure students support: during the task execution period this support is very important to keep students engaged and prevent dropping out the tasks. 
* VISIR tasks contribution to final grade: VISIR engagement is conditioned by the assessment, so VISIR tasks should be assessed and contribute to students' final grade.

* Set up VISIR tasks accordingly to the learning goals and students' knowledge on the topic, to avoid frustration.

In this SLR there was one small scale case, in which the didactical intervention was detailed described, including course curriculum and design. The didactical implementation was designed accordingly to the learning outcomes teachers wanted students to develop and the proposed tasks were aligned with it and clearly specified. In this case, VISIR was used along simulation and handson labs and supported by calculus and an enquiry-based methodology was applied. This kind of work is likely to be more helpful to other teachers who want to use VISIR, as it incorporates an accurate and detailed description how VISIR was integrated in the course curriculum and the type of teacher mediation that was used. It also details the obtained results.

\subsection{The VISIR+ Project}

The VISIR+ Project -Educational Modules for Electric and Electronic Circuits Theory and Practice following an Enquiry-based Teaching and Learning Methodology supported by VISIR- is an ERASMUS+ project, launched in November 2015 and concluded in Abril 2018. This project was a predictable outcome of the European CoP around VISIR. The cooperative and institutional ties created, along the time, between the European Countries VISIR users (HEI and researchers) made them explore together the possibility of creating a consortium/project to replicate in LA (Argentina and Brazil) the level of cooperation and novelty associated with VISIR in Europe. In fact, the VISIR+ Project main goal was to spread VISIR usage in Argentina and Brazil, providing technical and didactical support (Alves, Fidalgo, et al., 2016).

With the help of the five European HEI partners (EU partners) a VISIR system was installed in the five Latin American HEI partners (LA partners) and it was -and still is being- used not only by the owner institution (the one, in which, VISIR is installed), but also for other secondary/professional/higher education institutions (Associate partners (AP partners)). VISIR+ Project specific objectives comprised (Alves, Fidalgo, Marques, Viegas, Felgueiras, Costa, Lima, Kulesza, et al., 2018; Viegas, Alves, et al., 2018):

* Enrich teachers' course curricula, on electric and electronic circuits, by using several simultaneous resources (both in class and in assessment): hands-on, simulation and remote labs. 


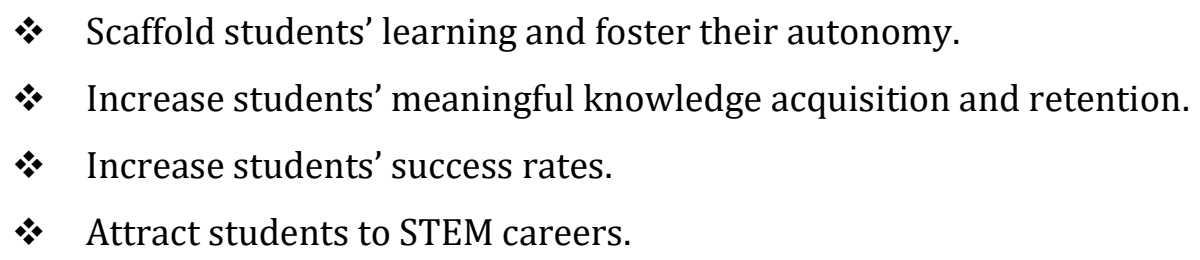

* Scaffold students' learning and foster their autonomy.

* Increase students' meaningful knowledge acquisition and retention.

* Increase students' success rates.

* Attract students to STEM careers.

These objectives hopefully will contribute to achieve the aims and respond to the challenges identified by ABENGE (Brazilian Association of Engineering Education) and CONFEDI (Federal Council of Deans of Faculties of Engineering).

Both ABENGE and CONFEDI have identified the need to adopt ICT based education tools at HEI to enhance the quality of the teaching and learning methodologies, shifting to a student centred approach, aiming for self-regulated learning, learn-by-doing and learn everywhere and at any time scenarios, coping with a new generation of digital natives. Remote labs, in particular VISIR, serve these purposes and expectantly will contribute to increase the number of students that opt for STEM-related degrees (as they can also be used at the lower levels of education) and reduce the number of dropouts in the initial years of these degrees.

The installation of a VISIR system in each LA partner is of vital importance as it contributes to an increased sense of ownership by the local teachers and students, facilitating its adoption, namely within lesson plans and tasks and as an activity contributing both for formative and summative assessment. Students have the possibility to access VISIR from any device connected to Internet, including mobile devices, motivating them to do more experiments and as a result increasing their motivation, performance and success.

Another important premise of the project was the tutoring relationship established between EU and LA partners and afterwards between LA partners and AP partners (keeping the support/supervision of EU partners). Indeed, each LA partner had an EU partner that shared with him his expertise and experience in the topic, providing the didactical support needed to carry on the didactical implementations (Alves, Fidalgo, Marques, Viegas, Felgueiras, Costa, Lima, Kulesza, et al., 2018; Viegas, Alves, et al., 2018). The first training action (TA1) goal was to introduce VISIR and its capabilities -a session where all partners were put together to allow that all EU partners shared their expertise with all LA partners- so LA partners could start using it, in their own HEI, in one pilot course. Then, prior to the boom of didactical implementations, during the second semester of the 2016 academic year, LA teachers had the opportunity to attend a TA (TA2) at their own institution organised by each EU partner tutor. The purpose of this TA was to address teachers' needs, particularly to those implementing VISIR in their courses/classes. In the following academic year, as LA partners were already using VISIR in their courses for one or two semesters (depending on the cases) they were the ones who delivered a TA (TA3) in their AP partners. These TA involved the LA partner teachers who have been using VISIR on their courses 
and their main goal was sharing their own contextualized experiences and involving more teachers/courses (from the LA and AP partners) in the project.

The technical support, including VISIR installation and organizing training technical workshops, was warranted by a single EU partner (BTH) for all LA partners. The EU partners, LA partners and the AP partners, together with its main characteristics are summarized in Table 1.

Table 1 - VISIR+ Project Partners

\begin{tabular}{|c|c|c|c|c|c|c|c|}
\hline \multirow{2}{*}{ 离 } & \multicolumn{7}{|c|}{ Institution Characteristics } \\
\hline & Name & Country & $\begin{array}{l}\text { Public/ } \\
\text { Private }\end{array}$ & $\begin{array}{l}\text { Education } \\
\text { Level (s) }\end{array}$ & $\begin{array}{l}\text { University/ } \\
\text { Polytechnic }\end{array}$ & $\begin{array}{l}\text { Number of } \\
\text { Students }\end{array}$ & Other \\
\hline \multirow{5}{*}{ EU } & P.Porto/ISEP & $\mathrm{Pt}$ & Public & $\mathrm{HE}$ & Polytechnic & $18,500 / 6,500$ & $\mathrm{BSc} / \mathrm{MSc}$ \\
\hline & UNED & Es & Public & $\mathrm{HE}$ & University & 260,000 & $\begin{array}{l}\text { E-learning Institution } \\
\mathrm{BSc} / \mathrm{MSc} / \mathrm{PhD}\end{array}$ \\
\hline & UDEUSTO & Es & Private & $\mathrm{HE}$ & University & 11,000 & $\mathrm{BSc} / \mathrm{MSc} / \mathrm{PhD}$ \\
\hline & BTH & $\mathrm{Se}$ & Public & $\mathrm{HE}$ & University & 5,900 & $\mathrm{BSc} / \mathrm{MSc}$ \\
\hline & CUAS & At & Public & $\mathrm{HE}$ & University & 1,700 & $\mathrm{BSc} / \mathrm{MSc}$ \\
\hline \multirow{5}{*}{ LA } & IFSC & $\mathrm{Br}$ & Public & $\begin{array}{l}\text { Secondary } \\
\text { Technological } \\
\text { HE }\end{array}$ & Polytechnic & 24,000 & Technical/BSc/MSc \\
\hline & UFSC & $\mathrm{Br}$ & Public & $\mathrm{HE}$ & University & 34,000 & $\mathrm{BSc} / \mathrm{MSc} / \mathrm{PhD}$ \\
\hline & PUC-Rio & $\mathrm{Br}$ & Private & $\mathrm{HE}$ & University & 15,000 & $\mathrm{BSc} / \mathrm{MSc} / \mathrm{PhD}$ \\
\hline & UNSE & $\mathrm{Ar}$ & Public & $\begin{array}{l}\text { Technological } \\
\text { HE }\end{array}$ & University & $12,000 / 1,200$ & $\begin{array}{l}\text { Technical/ } \\
\mathrm{BSc} / \mathrm{MSc} / \mathrm{PhD}\end{array}$ \\
\hline & UNR & $\mathrm{Ar}$ & Public & $\mathrm{HE}$ & University & 74,500 & $\mathrm{MSc} / \mathrm{PhD}$ \\
\hline \multirow{8}{*}{ AP } & $\begin{array}{l}\text { IFC C. } \\
\text { Sombrio }\end{array}$ & $\mathrm{Br}$ & Public & $\begin{array}{l}\text { Secondary } \\
\text { HE }\end{array}$ & Polytechnic & & UFSC \\
\hline & IFC Araranguá & $\mathrm{Br}$ & Public & $\begin{array}{l}\text { Secondary } \\
\text { Technological } \\
\text { HE }\end{array}$ & Polytechnic & & UFSC \\
\hline & IPS & $\mathrm{Ar}$ & Public & $\begin{array}{l}\text { Secondary } \\
\text { Technological }\end{array}$ & & & UNR \\
\hline & SATC & $\mathrm{Br}$ & Private & $\begin{array}{l}\text { Basic } \\
\text { Secondary } \\
\text { Technological } \\
\text { HE }\end{array}$ & University & 5,000 & UFSC \\
\hline & UNIVALI & $\mathrm{Br}$ & Private & $\begin{array}{l}\text { Basic } \\
\text { Secondary } \\
\text { Technological } \\
\text { HE }\end{array}$ & University & 24,000 & IFSC \\
\hline & UERJ & $\mathrm{Br}$ & Public & $\begin{array}{l}\text { Basic } \\
\text { Secondary } \\
\text { HE }\end{array}$ & University & 43,000 & PUC-Rio \\
\hline & UCP & $\mathrm{Br}$ & Private & $\begin{array}{l}\text { Technological } \\
\text { HE }\end{array}$ & University & 5,000 & PUC-Rio \\
\hline & UTN FRRo & $\mathrm{Ar}$ & Public & $\begin{array}{l}\text { Technological } \\
\text { HE }\end{array}$ & University & 70,000 & UNR \\
\hline
\end{tabular}

The EU and LA partners were already briefly presented in section 3.1. The AP partners, in which courses VISIR was incorporated and teachers used the data collection tools are summarized in Table 1 (in the last column of the table are registered the LA partners tutors). The acronyms used stand for: IFC C. Sombrio (Federal Institute Catarinense, Campus Sombrio), IFC Araranguá (Federal Institute Catarinense, Araranguá), IPS (Higher Polytechnic Institute Gral. San Martín), 
SATC (Santa Catarina Coal Industry Charitable Association), UNIVALI (Vale do Itajaí University), UERJ (State University of Rio de Janeiro), UCP (Catholic University of Petropolis), UTN FRRo (National Technical University). The table also includes information about the country (Portugal (Pt), Spain (Es), Sweden (Se), Austria (At), Brazil (Br) and Argentina (Ar)), the type of institution (public/private; university/polytechnic, if HEI), the number of students and the education level. Some universities are responsible for several education levels (and not only the typical HE level); the secondary level, in all cases, although equivalent to high school qualification, is vocational or professional. In the last column is listed the type of qualification each EU and LA partners can confer.

The VISIR+ Project had two more partners: the Research Institute in Educational Sciences of Rosario (IRICE), part of the National Council for Technical and Scientific Research (CONICET) of Argentina and ABENGE. The first was responsible for the quality monitoring and the second for the dissemination and exploitation.

In a short period of time (2016-2018) VISIR was installed in 5 HEI in LA and was used by nearly 2,000 students (from LA and AP partners), with about 50 implementations in courses from diverse education levels, involving about 60 teachers. Still, although some of these teachers have used VISIR in their courses, they did not follow the project premises and/or collected data -they tried it just in one experiment or for illustrating some concepts- as they were not familiarized with the resource. Nonetheless, it was possible to collect data from 40 didactical implementations, involving 51 teachers and reaching 1595 students. This VISIR usage was tagged along the didactical implementation results dissemination. In fact, the Project results dissemination -both didactical implementations as well as some particular or global issues concerning the Project"was thought to act as an extra motivational factor for those teachers willing to include the VISIR remote lab in their course instructional plan" (Alves, Fidalgo, Marques, Viegas, Felgueiras, Costa, Lima, Kulesza, et al., 2018). These results -mainly concerning a particular issue of a didactical implementation, such as: contextualization, VISIR tasks description (including assessment), students' acceptance of VISIR, institutional policies and Project particular issues- were presented in conferences like: REV (International Conference on Remote Engineering \& Virtual Experimentation), EDUNINE (IEEE World Engineering Education Conference), exp.at (Experiment@ International Conference), TAEE (Technology Applied to Electronics Teaching), CLADI (Congreso Latinoamericano de Ingenería), COBENGE (Congresso Brasileiro de Educação em Engenharia), TEEM (International Conference on Technological Ecosystems for Enhancing Multiculturality), IMCL (International Conference on Interactive Mobile), CISPEE (International Conference of the Portuguese Society for Engineering Education) and INTED (International Technology, Education and Development Conference). In these conferences, there were also 
presented some more generalist papers and two of these papers (CISPEE'16 and TEEM'16) have been awarded as the best paper(s) in their categories. Under VISIR+ Project's scope four book chapters have also been published and there was also a publication comparing consecutive implementations results in a specific LA HEI in an international journal.

In the scope of the VISIR+ Project about 30 works have been published, some involving directly the PhD student (as first author) and already referenced in section 1.4, including (Lima et al., 2016b, 2016a, 2019a, 2019c, 2018; Lima, Viegas, \& García-Peñalvo, 2017; Lima, Viegas, Zannin, Marques, Alves, Felgueiras, Costa, et al., 2017; Lima, Viegas, Zannin, Marques, Alves, Felgueiras, Fidalgo, et al., 2017; Lima, Zannin, et al., 2017). Most of the publications involving the other researchers will be referred along this work, still in this section some of them will be mentioned due to their relevance for the construction of this work. Several different topics have been covered and some of these works have been accomplished and fulfilled through the project. Considering the different topics and just the most "complete" published versions:

* Generalist papers: reflection about a community of practice based upon VISIR, including the description of the VISIR project regarded as the first step to the development of a federation of VISIR Nodes (Alves, Fidalgo, et al., 2016) and a detailed description of the VISIR+ Project (Alves, Fidalgo, Marques, Viegas, Felgueiras, Costa, Lima, Castro, et al., 2018; Alves, Fidalgo, Marques, Viegas, Felgueiras, Costa, Lima, Kulesza, et al., 2018); a work comparing VISIR potential and two virtual labs (Branco, Coelho, \& Alves, 2017).

* Project VISIR+ specific features: description of the process of training actions (sessions to contextualize VISIR didactical implementations and address teachers' needs) and its impact on the didactical implementations (Pozzo, Dobboletta, García-Loro, et al., 2017; Viegas, Alves, et al., 2018); data collection tools design and implemented for collecting the relevant data of the didactical implementations (Pozzo, Dobboletta, Viegas, et al., 2017).

* Didactical implementation descriptions: considering several different courses, in different countries, institutions, levels of education. Most of the works were focused in one or two particular aspects of the didactical implementations as for many teachers it was their first experience with VISIR. Others were more thorough studied, but in none the didactical intervention was detailed described and/or its results fully analysed (Evangelista et al., 2018; García-Zubía et al., 2017; Marchisio, Crepaldo, Del Colle, \& Lerro, 2018; Pavani, Lima, Temporão, \& Alves, 2017; Rocha Roque et al., 2017; Soria et al., 2017). 
* VISIR "dissemination": workshops to promote the development of remote lab competences in (high school) physics teachers in Costa Rica and disseminate remote lab experimentation supported by VISIR (Arguedas-Matarrita et al., 2017). Design and development of a repository containing didactical resources, including videos and lab guides, to support teachers' electric and electronic circuits practices using VISIR (Pereira et al., 2017).

This Project was the promoter of the installation of the Costa Rica VISIR system. One researcher from this institution -a teacher/PhD student- got to know the VISIR remote lab as his PhD supervisor was one of the UNR team members. He attended a TA at UNR and was so interested in VISIR that he promoted a similar local TA at his own institution. They were so enthusiastic about it, that made the necessary arrangements to possibly for a VISIR node in Costa Rica, which was already installed. 


\section{STUdy PRESENTATION}

$\mathrm{T}$

he use of online laboratories (remote and virtual) in education is growing exponentially, however scientific studies on the educational effectiveness of these resources in students' learning outcomes are less prevalent. This chapter describes the problematic tackled in this work, its pertinence and the research questions (RQs) that it addresses. Then the research methodology chosen to conduct this research project is presented and the case studies are thoroughly characterized. To conclude, the data collection tools, and the data analysis techniques are approached.

\subsection{Problematic and study goals}

The use of online education is expanding, and it is expected to proceed this way in the next years, being critical to institutional long-term strategy. Nonetheless, the adoption of remote laboratories and virtual laboratories in educational didactical practices has been primarily driven by factors like: the growth of the number of students, economical restrictions (insufficient staff, funding and physical resources), safety issues (Magin \& Kanapathipillai, 2000) and adoption of the Bologna Process in Europe (lab time reduction along the increase of the number of students per class) (Crosier \& Parveva, 2013; Romero, Guenaga, García-Zubía, \& Orduña, 2014). The quality of learning was not the major reason for these online labs usage and at the beginning there was not any idea if these different resources impacted the students' learning outcomes. Clearly, some specific learning outcomes may be enhanced or hindered by these online resources, although in the early days when these tools started being used, there was no adequate study considering its efficacy in the learning process. In the meantime -since 2005, the production of scientific papers regarding online labs has grown considerably- and nowadays there are more than four thousand papers considering VRLs (Virtual and Remote Laboratories) (Heradio, de La Torre, et al., 2016). Still most of these publications are mainly technical (detailed description of the remote lab including the procedure and/or difficulties to set it up): these technologies are built up mainly by engineers, who usually write about technical design matters rather than educational evaluation issues. There are, however, in the literature many published papers about the comparable advantages of these new technologies (to traditional labs) in engineering education (Heradio, de la Torre, \& Dormido, 2016; Heradio, de La Torre, et al., 2016), even though scientific studies on the educational effectiveness of VRLs are significantly less prevailing (Post et al., 2019). Still, several meaningful important studies have been carried out and confirm the efficacy of online labs 
-NTL (non-traditional labs) can be at least as effective as TL (traditional labs)- advocating that a "hybrid" or "blended" approach looks like the most effective to experimental learning (Brinson, 2015, 2017; Corter et al., 2011, 2007; Heradio, de La Torre, et al., 2016; Nickerson et al., 2007; Restivo \& Alves, 2013). As each type of laboratory has its own strengths and weaknesses, the challenge is to combine NTLs and TLs to pursuit and reach specific learning outcomes. Brinson (2015) -in his revision work of 56 studies related to this topic- suggests that a combination of TL and NTL (he does not distinguish between remote labs and virtual labs) may improve both students' satisfaction and competences development, but "the results of blended lab studies are mixed and no consensus exists yet regarding best practices, so this is a fascinating and important avenue of further research". Several works concluded that although students prefer hands-on labs, that does not prevent them from learning the relevant concepts in NTL as well or better they do in TL (Brinson, 2017; Corter et al., 2011, 2007). Corter and colleagues (2007) point out the importance of coordination, communication between students and collaborative work when using NTL as they believe this type of work may have contributed to the found learning outcomes and consider further research is needed to address this perception. In a more recent work, the same author considered the type of resource as just one factor affecting learning outcomes and identified other factors that play important roles: the difficulty of the experiment, the time devoted to the tasks and the type of collaborative work, suggesting that "future researchers may want to examine how educational goals can be achieved through the improvement of a group's collective learning process" (Corter et al., 2011). More recently, Brinson (2017), in another study where he further characterizes literature considering learning outcomes in TL versus NTL, concludes that more empirical studies, special quantitative ones are necessary "in an attempt to overcome confounding factors related to cultural and national differences as well as it is necessary to determine if pedagogical effectiveness of lab type varies according to grade level and discipline in order to determine a system of best practices". In a very recent work, Post and colleagues (2019) -based on a literature review between 2013 and 2017- concluded that "evaluation of educational benefits of remote labs in higher education is only superficial in the articles published so far and more rigorous empirical research should be conducted to obtain a more comprehensive picture of learning benefits of remote labs in different disciplines within HE".

In most cases, remote labs were not used simultaneously with other resources, such as, simulation and hands-on lab, except for some small scale didactical experiments (Jara et al., 2011). Up to the end of 2015 civil year and considering VISIR usage along other experimental resources (simulation and hands-on labs) and supported by calculus, as already referred in section 1.1 and further detailed in section 3.3, there were very few works in literature except for some small scale didactical implementations (Alves, Viegas, et al., 2016; Lima, Alves, Viegas, et al., 2015; Viegas et 
al., 2014). More recently, and in the scope of the VISIR+ Project, even though there was a boom of publications, the majority was focused on specific aspects of the didactical implementations, students/teachers/institution satisfaction with VISIR and/or other particular issues considering its usage as described in section 3.4.

Using some of the data collected in the VISIR+ Project this problematic started being addressed in some studies from which several works related to this thesis project have been published as described in section 1.4. As the data was being gradually collected some particular issues have been addressed including: VISIR usage to contextualize mathematics, students' perception of the difference between simulation and remote labs and the different type of results obtained, a qualitative analysis of one course didactical implementation and how teacher reflection shaped the modifications made in the subsequent course editions. As the data collection was increasing and this research work was progressing it was possible to start studying the factors that impacted students' learning outcomes, although at the beginning in a small-scale.

As the data collection from a particular HEI was nearly done, it was possible to compare students' results and perception as well as teachers' perception about this methodology, in the several courses where the didactical implementations occurred. In particular there was a publication which analysed the didactical implementations -using this kind of blended approachthat took place in this LA HEI (Viegas, Pavani, et al., 2018). In this work, students' academic results and perception bout VISIR were cross related with the type of courses and didactical implementation characteristics and some factors emerged.

The first results of the global analysis of the didactical implementations that took place in all LA partners and AP partners were already published (Lima et al., 2019c, 2018). Although it contributed to this topic -using TL and NTL simultaneously- this analysis just considered some courses features as well as some didactical implementation characteristics and teachers' involvement and perception. A more throughout analysis is required and students' academic results, involvement and perception about VISIR should also be considered.

From the contents of the previous paragraphs, it is clear there is a gap in the literature considering the impact that a "hybrid" or "blended" approach in experimental learning -in engineering education- has in students' learning outcomes. This PhD work intends to go a step forward in this topic, based upon a specific remote lab in the electric and electronic circuits topic, VISIR.

The underlying problematic that will be tackled in this work relates to a better understanding of the effects in students' learning outcomes by the use of different experimental resources (hands-on, simulation and remote labs) together with calculus, in class and assessment. This may be accomplished with the identification of factors which contribute or not to students' 
improvements on learning. Also, by identifying didactical mediation practices teachers might use in order to facilitate students' learning outcomes while using these blended experimental resources. And considering the impact of some eventual "students' characteristics" in this methodology.

In order to help advance the scientific knowledge regarding this problematic, four research questions were designed:

\section{* RQ1: In which way the use of simultaneous resources (hands-on, simulation and remote labs along with calculus), contributes to promote students' learning and engagement?}

* RQ2: Are there VISIR tasks characteristics that affect students' learning and engagement?

* RQ3: Are there teacher mediation traces that can be linked to better students' learning and engagement?

* RQ4: Are there students' characteristics that can be associated to students' learning and engagement?

To answer these RQs we must keep in mind the overall learning context is important, and an integral part of the learning process. So, several aspects must be considered, bearing in mind both teachers' and students' insights.

Students' learning performance cannot be endorsed to the type of resource alone, as many other factors affect students' lab cognitive learning (conceptual knowledge and technical skills) and affective learning (motivation, engagement, satisfaction). Factors like social interaction (with teachers/colleagues as well as surroundings/resources), students' background, satisfaction with the tool, time devoted to the task, assessment and type of feedback must be taken into account. As NTL are being used, one must keep in mind two extra factors: remote lab interface and the distance from the equipment.

Teachers' engagement, involvement (including support to students), and satisfaction (while using these resources) as well as their mediation role in the learning process must also be considered. Some mediation traces like defining learning goals and be able to design tasks accordingly to the students' knowledge development needs, warrantying that the task is challenging and clear to students and, giving authority to students and appropriate feedback may influence students' engagement and learning.

When teachers use several resources simultaneously, diversifying the teaching strategies, they are reaching more students and probably moving towards a student-centred approach and eventually promoting the use of formative and more continuous assessment tasks. These changes 
demand extra time and effort from the teacher and are likely to appeal more students. Nevertheless, students' attitudes concerning both NTL and TL are an essential factor.

Course characteristics and didactical implementation characteristics must also be considered. As its contents cover circuit analysis one has to distinguish between DC and AC: AC circuit analysis and calculus imply using vector and complex numbers notation, being quite more challenging than DC analysis.

Finally, external factors, such as economical, socio-cultural and/or political and other contextual influences may also compromise students' learning.

To answer the four RQs addressed in this work, a large-scale thoroughly analysis was conducted, involving 43 didactical implementations that took place in 26 different courses of several education levels involving 52 different teachers and 1794 students. These implementations took place in several HEI in Argentina, Brazil and Portugal, and, although at a minor extent, also in the secondary educational level in Argentina and Brazil and in the technological education level in Brazil. These implementations were carried out in 2016 and 2017 academic years in Argentina and Brazil, and between 2016/17 and 2018/19 academic years in Portugal. Different approaches were used taking into account the level of education, course topic, course characteristics, resources used, learning goals and implemented tasks. The study is focused in each didactical implementation (their characteristics, teachers' usage and perception) and students' results (usage, academic results and perception).

\subsection{Research Methodology}

The methodology phase is one of the most crucial in the development of a research project, shaping the whole process of data collection and analysis and so extra care should be taken when choosing it.

Educational research main goal is to explain, predict and/or control educational phenomena, originated by at least one question about a specific phenomenon of interest (Williams, 2007). The ultimate goal when choosing a particular research design -that allows the collection of adequate data for analysis- is to produce a trustworthy answer to the RQ. The analysis performed in this work relies on a multicase study research methodology and combines quantitative and qualitative data, that is, uses a mixed method approach.

The multicase study methodology was considered the most appropriate research strategy to deeply understand, through a meticulous analysis (Cohen et al., 2007), the impact of a "blended" or "hybrid" approach in laboratory learning in students (cognitive and behavioural) learning outcomes in such (many) different contexts. A multicase allows replicating the analysis of the 
phenomenon in different contexts (Yin, 2014), making it possible to make comparisons between the results. This choice is also justified by its potentiality to deal with multiple data sources documents, questionnaires, interviews and observations- converging in a process of triangulation, which is vital, considering case studies always have a subjective character (Papachroni \& Lochrie, 2017).

Accordingly to Leedy and Ormrod, and cited by Williams (2007), case studies try to "learn more about a little known or poorly understood situation". And to accomplish it, the data collection should be systematically and rigorous gathered (Cohen et al., 2007; Creswell, 2013) and the researcher should have, if possible a participant role or at least spend some time in the local, interacting with the population under study and the results or patterns found should connect with theory (Williams, 2007). This was accomplished by the researcher visit to some of the institutions involved in the Project as well as establish some informal contacts with several teachers.

Additionally, case studies come from the "real world" and their discernments may be straight understood and put to use, being "a step to action" (Cohen et al., 2007). Case studies are set in temporal, geographical and institutional contexts, with boundaries perfectly defined. Although they combine knowledge and inference, its results cannot be straightforwardly generalized (Cohen et al., 2007; Creswell, 2013). Still, they may corroborate or challenge the theoretical paradigms, contributing to the knowledge that one already has about a certain phenomenon. Since the data gathered so many different didactical implementations that took place in so different contexts, results could not be directly and simply compared with each other. Case study methodology takes this into account.

Considering the problematic tackled in this study, a mixed methodology was adopted, as it articulates a qualitative/interpretative approach with data resulting from quantitative and demographic variables. These methodologies are complementary and not mutually exclusive (Cohen et al., 2007). They allow researchers to combine -in each case study- quantitative and qualitative data as well as methods for analysing it, permitting to test and build theories (Creswell, 2013). As an example, in a specific data collection tool, like a questionnaire, researchers may incorporate closed questions to collect the numerical/quantitative data and open questions to gather the narrative/qualitative data. Or use several different collection tools, some designed to collect the quantitative data and others for the qualitative data. The quantitative data is mainly used to explain or predict -establishing causes and effects- a specific phenomenon. While the qualitative data contributes to get a comprehensive and thorough insight about the way things are and how participants perceive it. This was accomplished in this work.

In this research work a mixed method approach, with data collected from various sources (triangulation) is used in order to better understand the study topic -increasing the complexity, 
richness and rigor- contributing to its validity and external acceptability. Our mixed methodology design follows an integration approach, which permits a higher degree of combination as the two methods (quantitative and qualitative) are mingled nearly in all the stages of this research work. The research fluctuates between the deductive and inductive schemes (Hernández-Sampieri \& Mendoza, 2008).

The data collection tools, used in this research include questionnaires, interviews, document analysis and observations.

The participants in this study are the respective academic community (52 teachers and 1794 students) involved in the didactical implementations using traditional hand-on labs (TL) and non-traditional remote and virtual labs (NTL), supported by calculus in various institutions.

Each case represents a different course where VISIR was implemented. For each course, the analysed dimensions and categories are summarized in Table 2.

The first dimension of analysis, Didactical Implementation, intends to characterize teachers' intentions while designing the VISIR implementation and perceive how it was actually performed. It also means to characterize teachers' involvement in the implementation as well as their perception about students' satisfaction with VISIR and their own satisfaction with the tool; external factors that somehow may have had influence in the implementation are also pointed, accordingly to teachers' opinion.

The dimension Students' Results characterizes students' results in the former didactical implementations. Two categories are explored and analysed: students' academic performance and students' perception about VISIR are thoroughly considered. In fact, this perception is split in three components: their perceived learnings, their satisfaction with VISIR itself and their satisfaction with the support they felt they had while using VISIR. In this category it is also identified external factors, accordingly to students' point of view, that may have compromised the implementation success. 
Table 2 - Dimensions and Categories of Analysis**

\begin{tabular}{|c|c|c|}
\hline Dimensions & Categories & Factors \\
\hline \multirow{21}{*}{ Didactical Implementation } & \multirow{13}{*}{ VISIR's implementation } & VISIR usage in course contents (\%) \\
\hline & & Additional used resources (simulator/hands-on (number)) \\
\hline & & VISIR introduction (none/in class) \\
\hline & & VISIR designed support (support material/email/presential) \\
\hline & & Implementation competence goal level (level 1/level 2/level 3) \\
\hline & & Number of tasks using VISIR \\
\hline & & VISIR tasks attributes (type, DC/AC) \\
\hline & & VISIR tasks regime (individual/group; mandatory/not mandatory) \\
\hline & & VISIR tasks weight on final grade (qualitative/quantitative) \\
\hline & & VISIR use level (Basic/Intermediate/Advanced) \\
\hline & & Course implementation edition \\
\hline & & Education level (Secondary/Technological/Higher Education) \\
\hline & & Course level (EE majors/non-EE (other majors)) \\
\hline & \multirow{4}{*}{ Teachers' involvement } & Teacher implementation edition \\
\hline & & Number of teachers involved \\
\hline & & Teacher accesses in VISIR \\
\hline & & Implemented support \\
\hline & \multirow{4}{*}{ Teachers' perception } & Students' satisfaction with VISIR \\
\hline & & Teachers' satisfaction with VISIR \\
\hline & & External factors \\
\hline & & Students' level \\
\hline \multirow{8}{*}{ Students' Results } & \multirow{4}{*}{ Academic performance } & Students' background (previously addressed topics, first time in the course/VISIR) \\
\hline & & Students' grades (VISIR tasks, other tasks, lab, exam, final) \\
\hline & & Students' "success" (NF, dropout, HOS, passed the course) \\
\hline & & Students' accesses in VISIR \\
\hline & \multirow{4}{*}{ Students' perception } & Learning with VISIR \\
\hline & & Satisfaction with VISIR \\
\hline & & Satisfaction with support \\
\hline & & External factors \\
\hline
\end{tabular}

The identification of the analysis factors was mostly driven by research necessity of comparing results between the different contexts and characteristics in order to be able to tackle the designed RQs. Some (like: "external factors", "implemented support", “students' level") were driven by the results. "External factors", both in the teachers and students' perception category, were induced by the content analysis of the teachers' and students' open answers and are mainly related to problems with Internet connection. From the teachers' involvement and the teachers' perception categories, were driven respectively the factors "implemented support" and "students' level". Some of these factors are understandable through their names (Table 2), while others need to be further enlightened in order to fully clarify their meaning. 
Starting by the category VISIR's implementation, the factor "VISIR usage in course contents" refers to the percentage of course contents, in which VISIR was used.

The way VISIR was introduced to students (factor "VISIR introduction") was also characterised: none (no formal activity was planned); when an activity was developed during class time it was distinguished between 2 types: teachers explained the basis of VISIR doing some assembling and measurements (students played the role of observers) or while teachers were explaining VISIR and doing some assembling and measurements, students were doing the same type of assembling/measurement in their own computers (students played a participatory role). For simplicity they will be characterized by level: I1, I2 and I3, respectively.

The type of support (factor "VISIR designed support") teachers decided to use to accompany their students work during the task execution period, along the semester included: upload specific support material, such as tutorial videos or documents, in the LMS course page (material); answer students' doubts via email (email); perform the tasks during (ordinary or extra) class time or clarifying students' doubts either by monitors (older students trained to provide support) or the head teachers (or other teacher, in the cases where there was more than one teacher involved in the course) in their office hours. This presential support (presential), considering its particular features, was split in three types, respectively: class, monitoring and office hours. Several teachers opted for more than one type of support (material, e-mail, presential).

The "implementation competence goal level" associated to teachers' intentions while using VISIR into their didactical implementation design to pursue the task learning objectives, was classified in three levels(Lopes, 2004):

* Level 1 (L1): e.g. gather some data, perform some measurements, assemble the proposed experimental circuits, doing some calculus.

* Level 2 (L2): e.g. analyse data, compare the different types of data obtained (simulation data and real data), become proficient in experimental techniques, predict results, develop several soft skills (teamwork, cooperation, time management, communication).

* Level 3 (L3): e.g. design/plan the experiments; confront experimental data with the model data; understand the differences between simulation data and real data (obtained with hands-on labs and remote labs); develop research skills and critical thinking.

This competence level will be analysed both in terms of the teacher goal (intentions) and in terms of the tasks proposed to students (actually achieved). Taking into account, the tasks teachers designed upon VISIR usage ("VISIR tasks attributes"), it was considered: 
* DC/AC tasks: if the proposed task involved DC circuits and/or included AC circuits. AC circuit analysis and calculations imply using vector and complex numbers notation, being quite more demanding that DC analysis and calculations.

* Type of task: task type 1 (T1) involves doing some circuits assembling and some parameters measurements; in the task type 2 (T2) besides circuits assembling and parameters measurements, students were supposed to compare these results with the theoretical expected values and/or the results obtained with other experimental resources; in task type 3 (T3) students had to design circuits and after the assembling and parameters measurement they had to compare the results with the theory and the results obtained using other resources (simulation and hands-on labs).

Some teachers opted for proposing individual tasks while others opted for group tasks; in some cases, these tasks were mandatory to pass the course while in others they were not ("VISIR tasks regime"). The "VISIR tasks weight on final grade" also varied: some teachers opted for qualitative while others decided for quantitative weight, with different weights.

The VISIR usage within a course ("VISIR use level") was classified in three levels (basic (B), intermediate (I) and advanced (A)) according to the type of use when compared to the course syllabus and its mapping in the degree:

* Basic level: deals with the use of basic instruments, measuring mainly resistances, currents or voltages; deals basically with Ohm's and Kirchhoff's laws.

* Intermediate level: relates to $2^{\text {nd }}$ level reasoning like use of non-linear components and analysis, circuits frequency response and transistors polarization.

* Advanced level: complies with the use of VISIR with amplifiers (op-amps or transistor amplifiers) and other complex circuits.

The "education level" may be distinguished between secondary level (vocational or professional, although equivalent to high school qualification), technological (post high school degrees, typical 2 years long) and higher education.

"Course level" was classified in two levels: Electricity and Electronics (EE) majors and other majors (non-EE), according to whether or not its contents were related to the degree's scientific area of expertise The first (EE majors) can further be distinguished between: introductory (I) and scientific (S), respectively for basic contents of the scientific area and for more advanced contents. For example, a course on Circuit Analysis in an Electronics degree would be considered as an EE major course (introductory level) but the same course contents in a Civil degree would be classified as other majors. 
In the category Teachers' involvement, the factor "teacher implementation edition" makes reference to the number of course editions of each head teacher. The factor "implemented support" characterizes teachers' attention to students and the VISIR system, mainly during the VISIR task execution period, including the effort they may have made to accomplish it.

In the category Teachers' perception, three factors need to be further detailed: "students' satisfaction with VISIR", "teachers' satisfaction with VISIR" and "students' level". The first was classified in three levels: not satisfied, satisfied and completely satisfied accordingly to teacher comments about their perception about students' satisfaction with the tool. 'Teachers' satisfaction with VISIR" factor was assessed by 5 questions, included in the teachers guided interview (it will be explained in section 4.4.2.). "Students' level" refers to teachers' perception about the global general level of students, when starting that particular course: including if they have difficulties (at mathematics, for instances), lack of organization habits and/or soft skills or on the other hand have adequate prior knowledge.

In the category Academic performance, two factors need to be clarified: "students' background" and "students' success". Considering "students' background": it was measured if the contents covered with VISIR were being introduced for the first time or were previously addressed (in this or other course), if the students were or not freshman in the course and if they were using or not VISIR for the first time. In "students' success" factor, it was considered the number of students that did not show for the majority of classes and any assessment moment (NF) or had dropped out the course (dropout) as well as the number of students that teachers considered had developed higher order skills (HOS).

In the category Students' perception three factors: "learning with VISIR", "satisfaction with VISIR" and "satisfaction with support", were obtained by several questions included in a questionnaire that was delivered to the students, at the end of the didactical implementation (it will be explained in section 4.4.1).

\subsection{Case Studies Characterization}

The course characteristics in which the VISIR didactical implementations occurred are briefly summarized in Table 3 (split in three sub tables) by level of education: Secondary, Technological and Higher Education. These tables include information about the country: (Argentina (Ar), Brazil (Br), Portugal (Pt)), institution (previously characterized in section 3.4), implementation topic: accordingly, to the main focus of the course where the implementation occurred (Electricity, Electronics, Physics, Mathematics and Projects), major degree and course designation. 
Secondary Education

\begin{tabular}{|c|c|c|c|c|c|c|c|c|c|}
\hline \multirow{2}{*}{ 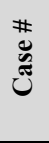 } & \multirow{2}{*}{ Ü } & \multirow{2}{*}{ Institution } & \multirow{2}{*}{$\begin{array}{c}\text { Implementation } \\
\text { Topic }\end{array}$} & \multirow{2}{*}{ Degree } & \multirow{2}{*}{ Course Name } & \multirow{2}{*}{ 离 } & \multicolumn{3}{|c|}{ Number } \\
\hline & & & & & & & $\begin{array}{l}\text { h/ } \\
\mathbf{w}\end{array}$ & $\mathbf{T}$ & St \\
\hline C1 & $\mathrm{Br}$ & $\begin{array}{c}\text { IFC C. } \\
\text { Sombrio } \\
\end{array}$ & Physics & Informatics & Physics & Non-EE & 2 & 1 & 65 \\
\hline $\mathrm{C} 2$ & $\mathrm{Br}$ & \begin{tabular}{|c|} 
IFC \\
Arananguá
\end{tabular} & Electricity & Electromechanics & Basic Electronics & $\mathrm{EE}$ & 2 & 1 & 25 \\
\hline C3 & $\mathrm{Ar}$ & IPS & Physics & $\begin{array}{l}\text { Constructor/ Industrial } \\
\text { Facilities/ Mechanics }\end{array}$ & Physics IV & Non-EE & 2 & 4 & 121 \\
\hline
\end{tabular}

\section{Technological Education}

\begin{tabular}{|c|c|c|c|c|c|c|c|c|c|}
\hline \multirow{2}{*}{$\begin{array}{l}\# \\
\text { \# } \\
\text { こ }\end{array}$} & \multirow{2}{*}{$\stackrel{\vec{E}}{\Xi}$} & \multirow{2}{*}{ Institution } & \multirow{2}{*}{$\begin{array}{c}\text { Implementation } \\
\text { Topic }\end{array}$} & \multirow{2}{*}{ Degree } & \multirow{2}{*}{ Course Name } & \multirow{2}{*}{ ల } & \multicolumn{3}{|c|}{ Number } \\
\hline & & & & & & & $\begin{array}{l}\mathbf{h} / \\
\mathbf{w}\end{array}$ & $\mathbf{T}$ & St \\
\hline $\mathrm{C4}$ & $\mathrm{Br}$ & SATC & Electricity & $\begin{array}{c}\text { Industrial Automation } \\
\text { Technologies }\end{array}$ & Circuits Theory & $\mathrm{EE}$ & 4 & 1 & 15 \\
\hline $\mathbf{C 5}$ & $\mathrm{Br}$ & IFSC & Electricity & Technical Electronics & Electricity I & $\mathrm{EE}$ & 6 & 3 & 164 \\
\hline C6 & $\mathrm{Br}$ & IFSC & Electricity & Technical Electronics & Electricity II & $\mathrm{EE}$ & 5 & 1 & 8 \\
\hline C7 & $\mathrm{Br}$ & ITAJAI & Electricity & Technical Electronics & Instrumentation & $\mathrm{EE}$ & 2 & 1 & 35 \\
\hline
\end{tabular}

\section{Higher Education}

\begin{tabular}{|c|c|c|c|c|c|c|c|c|c|}
\hline \multirow{2}{*}{ 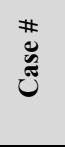 } & \multirow{2}{*}{ 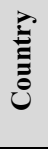 } & \multirow{2}{*}{ Institution } & \multirow{2}{*}{$\begin{array}{c}\text { Implementation } \\
\text { Topic }\end{array}$} & \multirow{2}{*}{ Degree } & \multirow{2}{*}{ Course Name } & \multirow{2}{*}{ ఫ్త } & \multicolumn{3}{|c|}{ Number } \\
\hline & & & & & & & $\begin{array}{l}\mathbf{h} / \\
\mathbf{w}\end{array}$ & $\mathbf{T}$ & St \\
\hline C8 & $\mathrm{Br}$ & UFSC & Mathematics & Computer/ Energy & Calculus IV & Non-EE & 4 & 1 & 124 \\
\hline C9 & $\mathrm{Br}$ & UFSC & Mathematics & Computer/ Energy & $\begin{array}{l}\text { Probabilities and } \\
\text { Statistics }\end{array}$ & Non-EE & 4 & 1 & 84 \\
\hline C10 & $\mathrm{Br}$ & SATC & Electronics & Mechatronic & Instrumentation I & Non-EE & 2 & 1 & 45 \\
\hline C11 & $\mathrm{Br}$ & IFSC & Electricity & Electronic & Circuits III & $\mathrm{EE}$ & 3 & 1 & 19 \\
\hline $\mathrm{C12}$ & $\mathrm{Br}$ & IFSC & Electricity & Electronic & Electronics II & $\mathrm{EE}$ & 4 & 1 & 18 \\
\hline $\mathrm{C} 13$ & $\mathrm{Br}$ & IFSC & Electronics & Industrial Electronics & $\begin{array}{l}\text { Amplifying } \\
\text { Structures }\end{array}$ & $\mathrm{EE}$ & 4 & 1 & 10 \\
\hline C14 & $\mathrm{Br}$ & PUC-Rio & Electricity & $\begin{array}{l}\text { Control \& Automation } \\
\text { / Electrical/ Computer }\end{array}$ & $\begin{array}{c}\text { Electric Circuits } \\
\text { Laboratory }\end{array}$ & $\mathrm{EE}$ & 8 & 2 & 59 \\
\hline C15 & $\mathrm{Br}$ & PUC-Rio & Projects & \begin{tabular}{|c|} 
Control \& Automation / \\
Electrical/ Computer
\end{tabular} & $\begin{array}{l}\text { Engineering } \\
\text { Introduction }\end{array}$ & $\mathrm{EE}$ & 4 & 4 & 20 \\
\hline C16 & $\mathrm{Br}$ & PUC-Rio & Electricity & \begin{tabular}{|c|} 
Chemical/ Civil/ \\
Environmental/ Materials \\
/Mechanical/ Production/ \\
Petrol/ Industrial
\end{tabular} & $\begin{array}{l}\text { General } \\
\text { Electricity } \\
\text { Laboratory }\end{array}$ & Non-EE & 3 & 4 & 442 \\
\hline $\mathrm{C} 17$ & $\mathrm{Br}$ & UERJ & Electricity & Electrical & $\begin{array}{c}\text { Electric and } \\
\text { Magnetic } \\
\text { Measurements } \\
\end{array}$ & $\mathrm{EE}$ & 4 & 2 & 50 \\
\hline C18 & $\mathrm{Br}$ & UCP & Electricity & Electrical & $\begin{array}{l}\text { Applied } \\
\text { Electricity }\end{array}$ & $\mathrm{EE}$ & 4 & 1 & 15 \\
\hline C19 & $\mathrm{Ar}$ & UNR & Electronics & Electronic & $\begin{array}{l}\text { Physics of } \\
\text { Electronic } \\
\text { Devices } \\
\end{array}$ & $\mathrm{EE}$ & 6 & 4 & 55 \\
\hline $\mathrm{C20}$ & $\mathrm{Ar}$ & UNR & Electricity & Electronic & Circuits Theory & $\mathrm{EE}$ & 6 & 5 & 91 \\
\hline $\mathrm{C} 21$ & $\mathrm{Ar}$ & UNR & Electronics & Electronic & $\begin{array}{l}\text { Devices \& } \\
\text { Electronic } \\
\text { Circuits I } \\
\end{array}$ & $\mathrm{EE}$ & 6 & 7 & 60 \\
\hline $\mathrm{C} 22$ & $\mathrm{Ar}$ & $\begin{array}{l}\text { UTN } \\
\text { FRRo }\end{array}$ & Physics & Electrical & Physics II & $\mathrm{EE}$ & 5 & 3 & 41 \\
\hline $\mathrm{C} 23$ & $\mathrm{Ar}$ & UNSE & Electronics & $\begin{array}{l}\text { Electronic/ Electrical/ } \\
\text { Electromechanical }\end{array}$ & Electronics 2 & $\mathrm{EE}$ & 7 & 2 & 13 \\
\hline $\mathrm{C} 24$ & $\mathrm{Ar}$ & UNSE & Electronics & $\begin{array}{l}\text { Electronic/ Electrical/ } \\
\text { Electromechanical }\end{array}$ & Electronics 3 & $\mathrm{EE}$ & 7 & 2 & 8 \\
\hline $\mathrm{C25}$ & $\mathrm{Ar}$ & UNSE & Physics & Electronic & Electronics 1 & $\mathrm{EE}$ & 6 & 2 & 8 \\
\hline $\mathrm{C26}$ & $\mathrm{Pt}$ & ISEP & Physics & Systems & Applied Physics & Non-EE & 6 & 1 & 199 \\
\hline
\end{tabular}


For the secondary and technological levels, the degree corresponds to the vocational/professional qualification they achieve; in HE level, the degree is a typical 5 years engineering degree, except for cases C13 and C26 (respectively a 7-semesters and a 6-semesters engineering degree). It also includes level regarding course contents (EE majors (EE) -from which just one case fits in the introductory level (I): case C18- and other majors (non-EE)), number of class hours per week $(\mathrm{h} / \mathrm{w})$ as well as the number of teachers (T) involved and the number of students (St) enrolled in the course. All implementations of the Latin American countries took place in the second semester of 2016 and/or first semesters of 2017 and/or second semester of 2017 academic years, except the first course edition of C14 course that took place in the first semester of 2016 academic year. Case C26 is in the northern hemisphere and considers three implementations in the second semester of the academic years 2016/17, 2017/18 and 2018/19. Several teachers were involved in more than one didactical implementation, so the total number of teachers of Table 3 is higher than 52 , which is the number of different teachers involved in the didactical implementations.

In the majority of the cases there was just a didactical implementation supported by VISIR and for most of them using also other resources, such as, simulations and hands-on labs. But in eleven cases (C3, C5, C8, C9, C10, C14, C16, C17, C19, C20 and C26), there were several subsequent implementations (two or three) and in some, teachers felt the need of doing some adjustments (in the subsequent didactical implementations), including in the additional resources used. Table 4 summarizes it, by implementation and also includes the number of course and head teacher edition and the number of teachers and students involved in each course edition. The last column displays the numbers of hands-on tasks performed in the hands-on lab, when this resource was used. These didactical implementation iterations will be further analysed in section 6.1.1.1.

In the LA institutions the majority of the didactical implementations took place in the second semester of 2017 academic year (which was the last semester for data collection accordingly to VISIR+ Project). Still teachers who implemented VISIR (along other experimental resources and supported by calculus) in their courses earlier, had the chance to go on using VISIR in the subsequent course editions. As it becomes clear from Table 4, there is nearly a perfect match between course and teacher edition number. There are still a few exceptions -C3, C8, C9 C22 and C25- for different reasons. In C3 second course edition, the course occurred simultaneously in three different degrees, with the same team of teachers for all of them, remaining the head teacher of the first course edition as the head teacher of one of them. This teacher not only used VISIR again in the second course edition, but also persuaded other teachers to use it. Cases C8 and C9 are mathematics courses: the teacher started to use VISIR in one of his courses and after this first didactical implementation he decided not only to go on using it in that course, but also using it in 
another course. C22 head teacher was part of the team of C3 first course edition: he got to know VISIR and this methodology and when he had the chance, he implemented it in his own course. C25 head teacher used VISIR in the first semester of 2017 academic year (case C23) and as he considered it a useful resource, he implemented it in another course (of his responsibility) in the subsequent semester (C25).

Table 4 - Additional Resources Used by Implementation

\begin{tabular}{|c|c|c|c|c|c|c|c|}
\hline \multirow{2}{*}{$\begin{array}{l}\text { \# } \\
\text { Ẽ } \\
\tilde{U}\end{array}$} & \multicolumn{2}{|c|}{ Implementation Edition } & \multicolumn{2}{|c|}{ Number } & \multicolumn{3}{|c|}{ Additional Resources } \\
\hline & Course & Head Teacher & Teachers & Students & Simulation & Hands-on & Number \\
\hline $\mathrm{C1}$ & 1 & 1 & 1 & 65 & No & Yes & 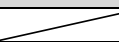 \\
\hline $\mathbf{C 2}$ & 1 & 1 & 1 & 25 & No & Yes & 2 \\
\hline \multirow{4}{*}{$\mathbf{C 3}$} & 1 & 1 & 2 & 37 & No & No & 0 \\
\hline & 2 & 2 & 3 & 23 & Yes & Yes & 1 \\
\hline & 2 & 1 & 3 & 28 & Yes & Yes & 1 \\
\hline & 2 & 1 & 3 & 33 & Yes & Yes & 1 \\
\hline $\mathrm{C} 4$ & 1 & 1 & 1 & 15 & Yes & Yes & 1 \\
\hline \multirow{3}{*}{ C5 } & 1 & 1 & 2 & 54 & Yes & Yes & 8 \\
\hline & 2 & 2 & 2 & 55 & Yes & Yes & 8 \\
\hline & 3 & 3 & 2 & 55 & Yes & Yes & 8 \\
\hline C6 & 1 & 1 & 1 & 8 & Yes & No & 0 \\
\hline C7 & 1 & 1 & 1 & 35 & Yes & Yes & 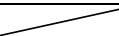 \\
\hline \multirow{3}{*}{ C8 } & 1 & 1 & 1 & 36 & Yes & No & 0 \\
\hline & 2 & 2 & 1 & 43 & Yes & No & 0 \\
\hline & 3 & 4 & 1 & 45 & Yes & No & 0 \\
\hline \multirow{2}{*}{ C9 } & 1 & 3 & 1 & 42 & No & Yes & 1 \\
\hline & 2 & 5 & 1 & 42 & No & Yes & 1 \\
\hline \multirow{2}{*}{$\mathrm{C10}$} & 1 & 1 & 1 & 31 & Yes & Yes & 4 \\
\hline & 2 & 2 & 1 & 14 & Yes & Yes & 4 \\
\hline C11 & 1 & 1 & 1 & 19 & Yes & Yes & 6 \\
\hline C12 & 1 & 1 & 1 & 18 & Yes & Yes & 6 \\
\hline $\mathrm{C13}$ & 1 & 1 & 1 & 10 & Yes & Yes & 5 \\
\hline \multirow{2}{*}{$\mathrm{C} 14$} & 1 & 1 & 1 & 23 & Yes & Yes & 10 \\
\hline & 2 & 2 & 2 & 36 & Yes & Yes & 10 \\
\hline C15 & 1 & 1 & 4 & 20 & Yes & Yes & 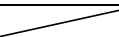 \\
\hline \multirow{2}{*}{$\mathrm{C} 16$} & 1 & 1 & 4 & 260 & No & Yes & 8 \\
\hline & 2 & 2 & 4 & 182 & No & Yes & 8 \\
\hline \multirow{2}{*}{ C17 } & 1 & 1 & 2 & 14 & Yes & Yes & 7 \\
\hline & 2 & 2 & 2 & 36 & Yes & No & 0 \\
\hline C18 & 1 & 1 & 1 & 15 & Yes & Yes & 2 \\
\hline \multirow{3}{*}{$\mathrm{C} 19$} & 1 & 1 & 4 & 15 & Yes & Yes & 12 \\
\hline & 2 & 2 & 4 & 23 & No & Yes & 12 \\
\hline & 3 & 3 & 4 & 17 & Yes & Yes & 12 \\
\hline \multirow{2}{*}{$\mathrm{C2O}$} & 1 & 1 & 5 & 36 & No & No & 0 \\
\hline & 2 & 2 & 5 & 55 & No & No & 0 \\
\hline C21 & 1 & 1 & 7 & 60 & No & Yes & 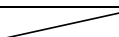 \\
\hline $\mathrm{C22}$ & 1 & 2 & 3 & 41 & Yes & Yes & 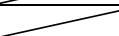 \\
\hline $\mathrm{C23}$ & 1 & 1 & 2 & 13 & Yes & Yes & 8 \\
\hline $\mathrm{C24}$ & 1 & 1 & 2 & 8 & Yes & Yes & 8 \\
\hline $\mathrm{C25}$ & 1 & 2 & 2 & 8 & Yes & Yes & 5 \\
\hline \multirow{3}{*}{$\mathrm{C26}$} & 1 & 1 & 1 & 76 & No & Yes & 7 \\
\hline & 2 & 2 & 1 & 62 & No & Yes & 6 \\
\hline & 3 & 3 & 1 & 61 & No & Yes & 6 \\
\hline
\end{tabular}

Teachers combined VISIR usage with simulation and hands-on lab, in the didactical implementations of their courses, but in three didactical implementations (C3 first course edition and C20 both course editions) VISIR was the only way for students to experiment with real equipment/instruments and components. In 24 didactical implementations teachers managed to 
use the three resources simultaneously and in the remaining 16 didactical implementations teachers used a combination of two resources: VISIR/simulation or VISIR/hands-on.

In some cases, students were able to use other resources or having classes in a somehow different environment. That was the case of HE students from IFSC -cases C11, C12 and C13where all type of classes (including lectures or theoretical classes) are taught in labs equipped with modern equipment and where students have access to the three experimental resources: simulation, hands-on and VISIR. All benches are equipped with a computer to access the online labs and a set of typical EE components and devices (to hands-on set ups), leaving space to work with paper and pencil. The benches are disposed in a format that promotes interaction and students can easily go from exploring a theoretical concept and/or problem solving to simulation (or other experimental resources) -accordingly to teachers' suggestion- to validate or test it. Students from PUC-Rio -cases C14 and C16- have access to the Maxwell System; in fact; VISIR was incorporated in this System. The Maxwell System (http://www.maxwell.vrac.puc-rio.br/) is an integrated platform that hosts an Institutional Repository that comprises several formats of digital contents including several types of courseware, such as hypermedia learning objects, videos, simulators and interactive books. Most of this courseware is in Open Access and students have free access to it (Pavani, Barbosa, Calliari, Lima, \& Cardoso, 2018). Besides this free access, teachers can also organize a "space" with the courseware they want their students to access, including the experiments using simulation and/or VISIR (just by clicking in the appropriate link) students have to perform, as it was the cases C14 and C16. Students from UNR -C19, C20 and C21have access to "FCEIA-UNR Electronics Physics Remote Lab" (http://labrem4a.fceia.unr.edu.ar), being available for students to be used freely (Lerro \& Protano, 2007). All students from Electronic Engineering use it in a physics course, prior to the courses where VISIR was integrated. Nowadays FCEIA-UNR is integrated not only in the LMS but also in Facebook and Twitter (Lerro \& Marchisio, 2016) and has been federated to WebLab-Deusto -an open source Remote Laboratory Management System (Orduña et al., 2012)- so UNR students also have access to these resources.

The number of students and teachers involved in the didactical implementations varies enormously. It goes from courses with 8 students to courses with 260 students and although a significant percentage of the didactical implementations just involves 1 teacher, there are other with several teachers to the maximum of 7 teachers. The number of class hours per week also presents a wide variability: from 2 to 7 hours/week within a semester of about 16 to 18 weeks, except for case $\mathrm{C} 26$ which semester is 11 weeks long.

Table 5 summarize the courses distribution, including the number of teachers and students involved, by education level, implementation topic, course level as well as VISIR use level. 
Table 5 - Courses Distribution

\begin{tabular}{|l|l|l|l|l|}
\hline \multicolumn{2}{|c|}{} & \multicolumn{3}{|c|}{ Number } \\
\cline { 3 - 5 } \multicolumn{2}{|c|}{} & Courses & Teachers & Students \\
\hline \multirow{4}{*}{ Education Level } & Secondary & 3 & 6 & 211 \\
\cline { 2 - 5 } & Technological & 4 & 6 & 222 \\
\cline { 2 - 5 } & Higher Education & 19 & 40 & 1361 \\
\hline \multirow{4}{*}{\begin{tabular}{l} 
Topplementation \\
\cline { 2 - 5 }
\end{tabular}} & Electricity & 12 & 22 & 941 \\
\cline { 2 - 5 } & Electronics & 6 & 15 & 191 \\
\cline { 2 - 5 } & Projects & 1 & 4 & 20 \\
\cline { 2 - 5 } & Mathematics & 2 & 1 & 208 \\
\cline { 2 - 5 } & Physics & 5 & 10 & 434 \\
\hline \multirow{3}{*}{$\begin{array}{l}\text { Course Level } \\
\text { VISIR Use Level }\end{array}$} & EE majors (I) & 1 & 1 & 15 \\
\cline { 2 - 5 } & EE majors (S) & 18 & 39 & 699 \\
\cline { 2 - 5 } & Non-EE majors & 7 & 12 & 1080 \\
\cline { 2 - 5 } & Basic & 15 & 23 & 1392 \\
\cline { 2 - 5 } & Intermediate & 8 & 23 & 318 \\
\hline & Advanced & 3 & 6 & 84 \\
\hline
\end{tabular}

As it can be observed, there is a big asymmetry in the courses distribution by education level, implementation topic and course level. Higher Education level embraces 19 courses involving 40 teachers and reaching 1361sudents. The other two levels of education present very similar distributions regarding the number of courses, teachers and students. Considering the distribution by implementation topic the majority lies in the electricity and electronics topics (EE topics) although the mathematics and physics topics covered 7 courses, involving 11 teachers and 642 students. Considering the distribution by course level: EE majors (introductory or scientific) and non-EE majors, the majority of students lies in the non-EE major courses (other majors), although most teachers (75\%) are from EE majors. The same analysis is valid for the number of courses: $73 \%$ are from EE majors. From these there was just a didactical implementation in the introductory level involving one teacher and 11 students. Considering VISIR use level, 58\% courses are from the basic level comprising $78 \%$ of the students. Just 3 courses are from the advanced level, considering VISIR usage, involving 3 teachers and 84 students.

\subsection{Data Collection Tools}

Under the scope of the VISIR+ Project, a set of tools for collecting data were internally developed and validated by the research team involved in the project. These tools included: a student's satisfaction questionnaire (SSQ), a teachers' interview script about their generic opinion about their didactical implementation practice using VISIR and their perception upon students' learning and satisfaction and two structured documents: educational modules and teachers pre and post implementation forms (teaching plans). This set of standardized instruments "meant that comparable information could be gathered to evaluate implementation in different contexts" (Pozzo et al., 2019). 
In the end of each didactical implementation, teachers were also asked to deliver information about (all) students detailed academic performance: grades by component, final grade, NF, dropouts and HOS. Also, the VISIR System records how many times (and when) students and teachers accessed it and that information was also registered. Other sources of spontaneous evidence like teachers and students casual contacts (either by email or personally) and some teacher's and student's informal interviews were also considered.

Observations made within the research context were also taken into account.

All these tools have been used in this research study and the next subsections describe it.

\subsubsection{Questionnaire}

According to the literature, questionnaires are one of the most recommended ways to collect opinions about a particular item or items, enabling data collection in a standardized way. The questionnaires are easily converted into statistical data, allow inferring results, from a sample to the general population (Pozzo et al., 2019). It is a widely used and an useful tool for collecting information, providing structured, often numerical data that can be used without the presence of the investigator (Cohen et al., 2007) and has several advantages, such as: in a short period of time one can get information about a large sample, data is easy to obtain and analyse and typically involves low costs (Pozzo et al., 2019). Questionnaires are instruments designed to access a person's internal dimensions, such as information or knowledge about a specific topic as well as values, preferences, attitudes or beliefs. In this way, a questionnaire is at all times an incursion into the respondent's life both in terms of time used to complete it as in the level of sensitivity or privacy associated to the questions (Cohen et al., 2007). A questionnaire can be composed by closed questions and/or open questions. Closed questions have the advantage of being easily answered by the respondents and the data analysis rapidly processed using a statistical software, being easily compared across respondents. On the other hand, open questions allow respondents to write and explain, as much as they wish and in their own words, what they think about a specific matter and are more appropriate to inspect complex issues. Considering data analysis, the data is difficult to code and classify -being a very time-consuming procedure- and hard to compare between participants, although very rich in contents. However, for its results to be acceptable, the questionnaire has to be validated.

In this work it was chosen a semi-structured questionnaire: a combination of a set of closed questions in a scale through which the respondents express their degree of approval or rejection about a given statement (assuming that a response on a scale corresponds to a quantitative 
measure of that same approval or rejection) with open questions designed to capture students' insight about a particular issue (Cohen et al., 2007).

It the scope of the VISIR+ Project it was designed a Student's Satisfaction Questionnaire (SSQ), as a satisfaction questionnaire reveals the most about the respondents opinion (Pozzo et al., 2019), being a standardized instrument that allows comparing data obtained in different contexts.

The questionnaire design addressed the dimensions that were being evaluated, under the scope of the VISIR+ Project: a technical dimensional and a pedagogical dimension. The technical dimension considered issues related to the remote lab VISIR accessibility, availability and security. The pedagogical dimension included: the access to support learning material (developed by teachers to help students in the learning process), the development of practical and reflective skills that promote significant learning, autonomous and self-regulated learning and the development of critical thinking and other higher orders competences (Pozzo, Dobboletta, Viegas, et al., 2017). The questionnaire was composed of 20 closed questions in a 4-level Likert agreement scale (1-I do not agree; 2-I partially agree; 3-I agree; 4-I fully agree) (Nemoto \& Beglar, 2013) and 2 open questions: What did you enjoy most about using VISIR? (Q21) What inconveniences did you find about using VISIR remote lab? (Q22) (the SSQ is displayed in Appendix A). The questionnaire was first developed in English and then translated to the native language of the students (Portuguese or Spanish), being this process a challenge as some terms/words used by the AngloSaxon speaking community are not common in the Portuguese and/or Spanish speaking countries. The process of validation included: revision from some researchers involved in the Project (including some experts on question construction), running a pilot test of the questionnaire to participants of a pilot course and finally checking its internal consistency.

So, at the end of the course implementation, students' opinions about the didactical experience and the main advantages/disadvantages of VISIR were collected. Student's satisfaction questionnaire was, depending on the cases, delivered on paper (in most cases) or made available via Moodle or through a Google forms, always in the native language of the students. For the sake of correlating students' answers with their academic results, students were asked to identify themselves through their academic ID numbers which was codified by their teachers in order to guarantee students privacy. It was explained to students that this identification was purely for research issues.

This study used part of these material, choosing the more relevant questions to this research. Considering the SSQ closed questions three factors of analysis were identified and studied: 
* F1 - Students' perceived learnings. It characterizes students perceived comprehension of the topic, including the use of theoretical concepts to explain experimental results and further apply it to real-life problems and their lab confidence abilities. It was addressed using questions Q2, Q14, Q16, Q18 and Q20.

* F2 - Students' satisfaction with VISIR. It refers to VISIR usage (availability, accessibility, easiness and suitability) and the perceived most value as well as asking for students' preference between this type of resource and hands-on labs. It was addressed using questions Q1, Q3, Q6, Q7, Q12, Q17 and Q18.

* F3 - Students' satisfaction with support. It expresses students' perceived assistance towards the VISIR system: LMS course page (support material, forums, etc.), VISIR manuals, lab guides as well as server issues and/or Internet connection. It was addressed using questions Q4, Q9, Q10 and Q15.

For the sake of this factor analysis Q3 and Q15 were "inverted" (as they were stated in the opposite form of what was being evaluated), Q18 was used for both F1 and F2 and questions Q5, Q8, Q11, Q13 and Q19 were not used, as they were not related to these factors.

A reliability analysis (Cronbach's alpha also referred as the alpha coefficient of reliability or simply the alpha) of the three factors, previously described, was performed. This step is essential to ensure the validity of the studied variables as Cronbach's alpha "provides a coefficient of interitem correlations, that is, the correlation of each item with the sum of all the other relevant items" (Cohen et al., 2007). This is a measure of the internal consistency amongst the items, that is, a way of realizing whether items on a variable's measurement scale measure the same construct. The coefficient ranges from 0 to 1 , and the closer to 1 , the more reliable the items that make up the scale, being unacceptable if Cronbach alpha < 0.5 (Pestana \& Gageiro, 2014).

The results from this test are displayed in Table 6. The table displays these results by case each course where VISIR was implemented- and in the cases where the course has undergone more than one didactical implementation, this factor analysis is also considered by course edition (each line represents a didactical implementation and the last line displays the overall course results). Table 6 last line presents the global results, considering all the collected data (from all students involved in all didactical implementations). The former table includes the case number and course name as well as the number of students enrolled in each course (N. St) and the number of students that answered the questions for each factor (NSQ). At the end of the didactical implementations, not all the teachers delivered the SSQ to their students nor all the students answered it. In fact, from the 1794 students involved in these implementations, we have data for this test for a little over 50\% (F1 - 53\%; F2 - 52\%; F3 - 51\%). 
Considering the analysis by case, it shows internal consistency in F1 and F2 for the majority of the cases (even though at a low level, for some of them) but, also for the majority, not in F3 (Cronbach alpha $<0.5$ ). For this reason, for the majority of the cases, F1 and F2 will be considered and F3 will only be qualitatively analysed. Considering the overall results, this analysis shows internal consistency in F1 and F2, but not in F3. So, F3 will only be qualitatively analysed.

Table 6 - Student's Questionnaire Internal Consistency Analysis (Cronbach alpha), by Case

\begin{tabular}{|c|c|c|c|c|c|c|}
\hline Case \# & Course Name & N St & NSQ & F1 & F2 & F3 \\
\hline C1 & Physics & 65 & & & & \\
\hline $\mathrm{C2}$ & Basic Electronics & 25 & & & & 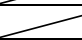 \\
\hline \multirow{5}{*}{$\mathrm{C} 3$} & \multirow{5}{*}{ Physics IV } & 37 & $33 / 29 / 26$ & 0.642 & 0.363 & $<0.2$ \\
\hline & & 23 & 23 & 0.666 & 0.767 & $<0.2$ \\
\hline & & 28 & $25 / 25 / 18$ & 0.617 & 0.302 & $<0.2$ \\
\hline & & 33 & $26 / 24 / 24$ & 0.413 & 0.341 & $<0.2$ \\
\hline & & 121 & $107 / 101 / 65$ & 0.565 & 0.473 & $<0.2$ \\
\hline $\mathrm{C4}$ & Circuits Theory & 15 & $8 / 8 / 9$ & 0.581 & $<0.2$ & 0.476 \\
\hline \multirow{4}{*}{ C5 } & \multirow{4}{*}{ Electricity I } & 54 & $13 / 13 / 12$ & 0.719 & 0.656 & $<0.2$ \\
\hline & & 55 & 26 & 0.694 & 0.493 & $<0.2$ \\
\hline & & 55 & 19 & 0.812 & 0.727 & 0.489 \\
\hline & & 164 & 43 & 0.753 & 0.617 & 0.275 \\
\hline C6 & Electricity II & 8 & $6 / 6 / 5$ & $<0.2$ & $<0.2$ & 0.587 \\
\hline C7 & Instrumentation & 35 & $10 / 9 / 9$ & 0.838 & 0.445 & 0.667 \\
\hline \multirow{4}{*}{ C8 } & \multirow{4}{*}{ Calculus IV } & 36 & 20 & 0.573 & 0.514 & 0.457 \\
\hline & & 43 & 34 & 0.686 & 0.537 & 0.624 \\
\hline & & 45 & 10 & 0.567 & $<0.2$ & $<0.2$ \\
\hline & & 124 & 64 & 0.655 & 0.487 & 0.473 \\
\hline \multirow{3}{*}{ C9 } & \multirow{3}{*}{ Probabilities \&Statistics } & 42 & 9 & 0.666 & 0.851 & 0.797 \\
\hline & & 42 & 9 & 0.409 & 0.384 & 0.282 \\
\hline & & 84 & 18 & 0.571 & 0.734 & 0.639 \\
\hline \multirow{3}{*}{ C10 } & \multirow{3}{*}{ Instrumentation I } & 31 & 29 & 0.852 & 0.671 & $<0.2$ \\
\hline & & 14 & 11 & 0.294 & $<0.2$ & 0.398 \\
\hline & & 45 & 40 & 0.786 & 0.574 & 0.239 \\
\hline C11 & Circuits III & 19 & 14 & 0.695 & 0.513 & $<0.2$ \\
\hline $\mathrm{C12}$ & Electronics II & 18 & $5 / 6 / 6$ & $<0.2$ & 0.347 & 0.731 \\
\hline C13 & Amplifying Structures & 10 & 4 & 0.936 & 0.682 & $<0.2$ \\
\hline \multirow{2}{*}{$\mathrm{C} 14$} & \multirow{2}{*}{ Electric Circuits } & 23 & & $>$ & $>$ & $\infty$ \\
\hline & & 36 & $16 / 17 / 17$ & 0.530 & 0.559 & 0.335 \\
\hline $\mathbf{C 1 5}$ & Engineering Introduction & 20 & 17 & 0.699 & 0.696 & 0.344 \\
\hline \multirow{3}{*}{$\mathrm{C} 16$} & \multirow{3}{*}{ General Electricity } & 260 & $254 / 250 / 253$ & 0.650 & 0.639 & 0.345 \\
\hline & & 182 & $132 / 126 / 131$ & 0.613 & 0.540 & 0.232 \\
\hline & & 442 & $386 / 376 / 384$ & 0.636 & 0.611 & 0.304 \\
\hline \multirow{2}{*}{ C17 } & \multirow{2}{*}{$\begin{array}{c}\text { Electric \& Magnetic } \\
\text { Measurements }\end{array}$} & 14 & $7 / 7 / 6$ & 0.329 & $<0.2$ & $<0.2$ \\
\hline & & 36 & & 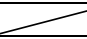 & 2 & 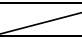 \\
\hline C18 & Applied Electricity & 15 & & 2 & 1 & 1 \\
\hline \multirow{4}{*}{ C19 } & \multirow{4}{*}{ Physics of Electronic Devices } & 15 & 15 & $<0.2$ & $<0.2$ & $<0.2$ \\
\hline & & 23 & 13 & 0.547 & 0.423 & $<0.2$ \\
\hline & & 17 & 17 & 0.453 & 0.748 & 0.598 \\
\hline & & 55 & 45 & 0.684 & 0.606 & $<0.2$ \\
\hline \multirow{3}{*}{$\mathrm{C20}$} & & 36 & 9 & 0.444 & 0.780 & 0.617 \\
\hline & Circuits Theory & 55 & 18 & 0.671 & 0.747 & $<0.2$ \\
\hline & & 91 & 27 & 0.576 & 0.754 & 0.249 \\
\hline $\mathbf{C 2 1}$ & Devices \& Electronic Circuits I & 60 & 12 & 0.661 & 0.850 & 0.540 \\
\hline $\mathbf{C 2 2}$ & Physics II & 41 & 17 & 0.733 & 0.536 & 0.700 \\
\hline $\mathbf{C 2 3}$ & Electronics 2 & 13 & 3 & 0.469 & 0.728 & 0.513 \\
\hline $\mathrm{C24}$ & Electronics 3 & 8 & 5 & 0.884 & 0.905 & 0.356 \\
\hline $\mathrm{C25}$ & Electronics 1 & 8 & 1 & 2 & 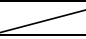 & 2 \\
\hline & & 76 & 19 & 0.633 & 0.319 & $<0.2$ \\
\hline C26 & & 62 & 38 & 0.610 & 0.651 & 0.332 \\
\hline $\mathrm{C20}$ & Applied Pnysics & 61 & $25 / 24 / 25$ & 0.211 & 0.685 & 0.244 \\
\hline & & 199 & $82 / 80 / 82$ & 0.550 & 0.606 & 0.233 \\
\hline & TOTAL & 1794 & $952 / 935 / 908$ & 0.658 & 0.639 & 0.307 \\
\hline
\end{tabular}


A reliability test -calculating Cronbach alpha for each factor- was also performed, considering the results clustered by education level, by implementation topic, by course level and by VISIR use level, as in chapters 5 and 6 , the results will be similarly analysed, by these topics. The test results are displayed in Table 7.

Table 7 - Student's Questionnaire Internal Consistency Analysis (Cronbach alpha) by Topic

\begin{tabular}{|c|c|c|c|c|c|c|}
\hline & & N St & NSQ & F1 & F2 & F3 \\
\hline \multirow{3}{*}{ Education Level } & Secondary & 211 & $107 / 101 / 65$ & 0.565 & 0.473 & $<0.2$ \\
\hline & Technological & 222 & $82 / 81 / 81$ & 0.758 & 0.544 & 0.330 \\
\hline & Higher Education & 1361 & $763 / 753 / 762$ & 0.658 & 0.661 & 0.322 \\
\hline \multirow{5}{*}{$\begin{array}{l}\text { Implementation } \\
\text { Topic }\end{array}$} & Electricity & 941 & $537 / 528 / 535$ & 0.662 & 0.643 & 0.317 \\
\hline & Electronics & 191 & 109 & 0.731 & 0.654 & $<0.2$ \\
\hline & Projects & 20 & 17 & 0.699 & 0.696 & 0.344 \\
\hline & Mathematics & 208 & 82 & 0.638 & 0.565 & 0.515 \\
\hline & Physics & 434 & $207 / 199 / 165$ & 0.585 & 0.519 & 0.302 \\
\hline \multirow{3}{*}{ Course Level } & EE majors (I) & 15 & & 2 & 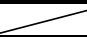 & 2 \\
\hline & EE majors (S) & 699 & $295 / 296 / 295$ & 0.730 & 0.701 & 0.288 \\
\hline & Non-EE majors & 1090 & $657 / 639 / 613$ & 0.628 & 0.607 & 0.316 \\
\hline \multirow{3}{*}{ VISIR Use Level } & Basic & 1391 & $797 / 778 / 751$ & 0.652 & 0.602 & 0.328 \\
\hline & Intermediate & 318 & $92 / 94 / 93$ & 0.708 & 0.824 & 0.423 \\
\hline & Advanced & 84 & $63 / 63 / 63$ & 0.708 & 0.619 & $0<0.2$ \\
\hline
\end{tabular}

Considering the same analysis by education level, by implementation topic, by course level and by VISIR use level the results are not very different: F1 and F2 show internal consistency for all topics except for the secondary education level while F3 shows internal consistency only for the mathematics implementation topic.

\subsubsection{Interviews and Informal Contacts}

A survey by interview is a very popular and flexible data collection tool that can present diverse different formats. In fact, "the number of types of interviews given is frequently a function of the sources one reads" (Cohen et al., 2007). An interview is particularly suitable for analysing the meanings that actors give to their practices and the readings they make of their own experiences, allowing -depending on the type of interview- individuals to talk openly about specific topics (Creswell, 2013). A guided interview, although the topics and issues to be covered are decided in advance, allows to collect the respondents' opinion about a specific topic in their own way (using their own words and terms). On the other hand, a closed quantitative interview comprises a bunch of questions with a predefined set of answers: respondents choose their answers from the previous fixed responses. Although very easy to analyse it has the disadvantage that respondents cannot fully share their experience (Cohen et al., 2007).

It the scope of the VISIR+ Project it was designed a teacher's interview -a "mixed method approach" script- a combination of a closed quantitative interview with a guided interview. 
According to the VISIR+ Project, the teacher's interview questions design also addressed the technical dimension and the pedagogical dimension. The technical dimension considered issues related to teachers' satisfaction with the remote lab, namely login procedure, interface and eventual server issues. The pedagogical dimension was again focused on identifying student centred didactical strategies contributing to students' autonomous work and enhancing the development of critical thinking and other higher order competences (Pozzo, Dobboletta, Viegas, et al., 2017).

The teacher's interview script was composed by 9 closed questions with three answer options (no, sometimes, yes) and a final open question asking for the main advantages/disadvantages of this resource (What advantages and disadvantages do you find in the use of remote lab VISIR?) ( Appendix B). These interviews intended to evaluate teachers' usage and satisfaction with VISIR, including the didactical aspects and VISIR main disadvantages/advantages. The interview questions were first developed in English and then translated to the native language of the teachers (Portuguese or Spanish).

Considering the large number of teachers and institutions involved, spread over a wide geographical area and for a two-year period, it was not technically possible to conduct this interview to all the involved teachers in a similar way. So, to ensure better equity and similar conditions, at the end of each didactical implementation, the interview script was sent by email to the head teachers, to collect their opinion about the didactical experience, in the teacher's native language. A factor -F2_T: Teachers' satisfaction with VISIR- addressing VISIR usage and adequacy to teacher's needs was identified. It was addressed by 5 questions: Q1, Q3, Q4, Q5 and Q8, in which Q3 was "inverted" as it was stated in the opposite form of what was being evaluated. For statistical analysis purposes the answers were converted to a numerical scale: no (1), sometimes (2) and yes (3).

All head teachers except for the cases $\mathrm{C} 1$ and $\mathrm{C} 17$ replied to the interview sent by email, in a total of 40 answers (93\%).

The informal conversational contacts emerged spontaneously, in some situations, much by students and teachers will to share their experience and/or opinion about VISIR. Even though this type of data organization and analysis can be a big challenge as one typically collects different information from different respondents and different questions, it can provide interesting and genuine insights about specific topics, increasing the richness of the study case analysis (Cohen et al., 2007). 


\subsubsection{Documents}

Documentation is an important source of (non-interfering) evidence for the case study (Yin, 2014). Documents allow to collect data by processes that do not involve the direct information from the participants (in this study: students and teachers), exhibiting several advantages: are always available, may be reviewed several times (usually at low cost) and are factual (may contain references and details important for the research). Documents may encompass events over time and in space although they can also bring difficulties, particularly if they were not designed to be research data, but were conceived for a different purpose and/or context (Cohen et al., 2007; Yin, 2014). Nonetheless, they should be studied "in their context, in order to understand their significance at the time" (Cohen et al., 2007).

Documents can take a multitude of forms, including records, timesheets, plans, technical documents, reports and statistics and samples of students' work. Some documents facilitate large samples to be addressed while others may catch individual facts and feelings (Cohen et al., 2007). From the documents that can be used for data collection one can use documents that were developed by the researcher (for the purpose of the study itself) and documents that naturally exist (or can be easily obtained) in the research context. This study includes both type of documents. The VISIR+ Project research team developed two documents:

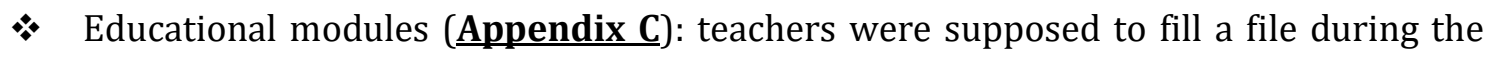
VISIR didactical implementation. The file included information considering basically three sheds: aim, resources and implementation. The first involved defining teachers' goals while using VISIR and the corresponding students' learning outcomes. The second meant identifying other complementary resources and stating which kind of support materials (learning resources) were developed to help students to complete the VISIR tasks. The third comprised the assessment plan (of VISIR tasks) and VISIR usage support (students had while using VISIR).

* Teachers pre and post implementation forms or target course fact file (teaching plans) ( Appendix D): a file containing detailed information about the target course where VISIR was being implemented. It contains information about the course (degree, academic year, background on EE), course curricula (contents, educational materials, teaching and learning strategies), schedules (type of classes, hours/week, teaching team) and students (number of students, freshman percentage, etc.). It also included a section where teachers were asked to comment students' general performance with VISIR. 
The documents obtained within the research context included:

* Information about students' performance: students' detailed academic results: grades by component, final grade, number of students who did not fulfil any kind of assessment during the semester (NF), number of dropouts, number of students who passed the course as well as where enrolled for the first time in the course/use VISIR and identify the students who developed HOS; all teachers have a grades file, although eventually it is not as detailed as it was asked in this research project.

* Information about VISIR usage: number of VISIR accesses for teachers as well as students.

The ultimate goal of these documents analysis was to throughout characterize the VISIR didactical implementations as well as students' academic performance and VISIR usage (both by teachers and students). To protect the anonymity of individuals/participants in the project, all names were withdrawn and replaced by aliases.

\subsubsection{Observation}

Observation can be considered a method of gathering information that goes along with the development of the research process itself. It can be defined as the set of procedures for obtaining and collecting meaningful reality data in the exact place where research takes place, that is, in situ. Instead of relying on others' judgement, the researcher can look directly on what is happening and use his own awareness to get more accurate data, without others interference. It is a useful tool for recording non-verbal behaviour and/or actions in a particular situation/context, allowing the researcher to achieve a better comprehension about the situation (Cohen et al., 2007). Considering the same author, one can distinguish between a systematic or structured observation and an unstructured observation. The latter is characterized for not having an agenda of issues but rather going into a situation and observe what is happening and later review those data to decide its significance for the research context. "Unstructured observation provides a rich description of a situation which, in turn, can lead to the subsequent generation of hypotheses" (Cohen et al., 2007).

In this work, some visits to the institutions involved were made, which allowed to conduct an unstructured observation and register some meaningful aspects (including critical incidents) considering the ongoing research. In some cases, it was possible to use direct observation of the teachers, in their work context or similar contexts, complemented by informal teachers' contacts, being participants aware of the researcher presence (as observer). In the early stages of this work, 
the researcher assumed the role of non-participant in observation, as she did not interact at all with the subject of the study at the time she was conducting the observation (Cohen et al., 2007). Additionally, as she decided at some point to implement VISIR (along with other resources and supported by calculus) in one of her courses, she became one of the actors/participants of this research project and considering her own course she assumed a participant role.

Some notes of these observations were made in situ -in field notes- and later on, in the research environment, these records were long-drawn-out leading to reflection. During the process of data analysis, they have been revisited and re-examined in an attempt of corroborating (or not) other data (triangulation). These observations include some teachers' behaviours and expressed ideas and/or comments about the didactical implementations and/or perception about VISIR as well as the target course LMS page contents.

All the tools, described in the previous subsections, facilitated the collection of relevant quantitative and qualitative data to tackle each RQ as summarized in Table 8.

Table 8 - Collected Data to Tackle each RQ

\begin{tabular}{|c|c|c|c|c|c|}
\hline & Collected Data & RQ1 & RQ2 & RQ3 & RQ4 \\
\hline \multirow{8}{*}{ 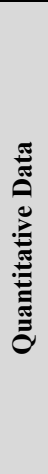 } & Course Characteristics (education level, EE/non-EE, edition number) & & & $\mathrm{X}$ & $\mathrm{X}$ \\
\hline & VISIR accesses (teachers and/or students) & $\mathrm{x}$ & $\mathrm{x}$ & $\mathrm{x}$ & $\mathrm{x}$ \\
\hline & VISIR tasks (number, regime, weight) & & $\mathrm{x}$ & & \\
\hline & Students' "Success" (NF, dropouts; HOS, passed the course) & $\mathrm{x}$ & $\mathrm{x}$ & $\mathrm{x}$ & $\mathrm{x}$ \\
\hline & Students' grades (per component and final) & $\mathrm{x}$ & $\mathrm{x}$ & $\mathrm{x}$ & $\mathrm{x}$ \\
\hline & Students' grades per type of tasks and DC/AC & & $\mathrm{x}$ & & \\
\hline & Student's Satisfaction Questionnaire (closed questions) & $\mathrm{x}$ & $\mathrm{x}$ & $\mathrm{x}$ & $\mathrm{x}$ \\
\hline & Teacher's closed quantitative Interview & & & $\mathrm{x}$ & \\
\hline \multirow{7}{*}{ 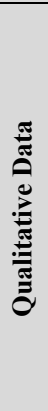 } & Course Curricula: contents, goals, resources, education materials, assessment tools & $\mathrm{x}$ & $\mathrm{x}$ & $\mathrm{x}$ & \\
\hline & Student's informal comments & $\mathrm{x}$ & $\mathrm{x}$ & $\mathrm{x}$ & $\mathrm{x}$ \\
\hline & Student's Satisfaction Questionnaire (open questions) & $\mathrm{x}$ & $\mathrm{x}$ & $\mathrm{x}$ & $\mathrm{x}$ \\
\hline & Teacher's interview and/or informal comments & $\mathrm{x}$ & $\mathrm{x}$ & $\mathrm{x}$ & $\mathrm{x}$ \\
\hline & VISIR tasks attributes (type, AC/DC) & & $\mathrm{x}$ & & \\
\hline & Type of support/feedback & $\mathrm{x}$ & & $\mathrm{x}$ & \\
\hline & Observations & $\mathrm{x}$ & $\mathrm{x}$ & $\mathrm{x}$ & $\mathrm{x}$ \\
\hline
\end{tabular}

\subsection{Data Analysis Techniques}

Although this research work follows an interpretative epistemological paradigm it was made an effort to conserve a critical attitude of reflection and continuous review of the interpretation of 
the data analysis results (Creswell, 2013), using several data sources and analysis techniques to guarantee triangulation and reduce the possible bias.

Data analysis is the process by which raw data gives rise to interpretation based on evidence. Quantitative analysis appeals to statistical analysis that can be performed using a software like SPSS (Statistical Package for the Social Sciences) (Marôco, 2018). Qualitative data analysis includes "organizing, accounting and explaining the data; in short, making sense of data in terms of the participants' definitions of the situation, noting patterns, themes, categories and regularities" (Cohen et al., 2007). Both types of analysis are equally important and "its use is entirely dependent on fitness for purpose" (Cohen et al., 2007).

\subsubsection{Quantitative Analysis}

Statistics is based on probability theory, and its goal is to build a mathematical framework that explains a specific phenomenon. Both descriptive statistics and inferential statistics were used in this work.

Descriptive statistics just describes the data -using the mean, mode, median, minimum and maximum values, the variance, standard deviation- and presents it, in tables and/or graphics. It simply reports the found results. It is used to systematize the collected data, being univariate. It describes the samples/population, accordingly to the considered variables and supports the subsequent analysis (Murteira, Ribeiro, Andrade e Silva, \& Pimenta, 2002). In this research work it has been used to analyse the quantitative data from the SSQs and the teachers' interviews as well as the number of VISIR accesses, students' grades and didactical implementation characteristics, facilitating the process of sample and population characterization.

Inference statistics, on the other hand, attempts to make predictions and inferences based upon the collected data, being typically more powerful (Murteira et al., 2002). These can be bivariate statistics (establish the relation between two study variables) or multivariate statistics (establish the relation between several groups and/or characteristics) and include: hypothesis testing, correlations, regression, difference tests and factor analysis (Cohen et al., 2007). In this work we have used mainly correlation, difference tests and independence tests.

Correlation is a bivariate analysis which purpose is to establish the extent to which two variables are statistically correlated. It has been used parametric (Pearson) and nonparametric (Spearman) correlation (Conover, 1999) to establish the possible relation/association between several study variables, including the implementation characteristics, teachers' involvement and teachers' perception with students' academic performance and their VISIR perception. The correlation coefficient -which can range in value from -1 to +1 - describes both the strength and 
the direction of the relationship. A value of -1 or +1 points to a perfect degree of association between the two variables, where the sign indicates its direction.

Difference tests look for the difference between the means of the study variables considering a particular factor. Before deciding which test to apply it is necessary to verify the normality as well as the skewness and the kurtosis of the variables in study/test variables to figure out if it should be used a parametric test or a nonparametric test. From the normality test results, ( $\mathrm{p}$ value smaller or bigger than 0.05 ), the null hypothesis is respectively supported or rejected (H0: the variables follow a normal distribution): (i) if the null hypothesis is supported it will be used an independent samples t-test (significance level 5\%). These parametric tests usually have more statistical power than nonparametric tests and thus are more likely to detect a significant effect when one truly exists. The student's t-test (or simply t-test) has the advantage of immediately allowing the researcher to find exactly where the differences might lie (by looking at the means). The null hypothesis, for this test, is defined (H0: there is no statistically significant differences between the means of the two groups). The t-test procedure implies first looking to the results of the Levene's test for equality of variances, to first find out if equal variances are or not assumed, depending on the value of sig (if sig $\leq 0.05$ equal variances are not assumed). That test allows to identify the row of data of the t-test that must be followed and if $p<0.05$, there is a statistically significant difference between the means of the two groups (and the null hypothesis of the t-test is not supported); (ii) if the null hypothesis (of the normality test) is rejected it will be used the Mann-Whitney $U$ test for two independent samples (significance level 5\%) -a nonparametric test or distribution-free test- that compares two sample means that come from the same population, and is used to test whether two sample means are equal or not. After defining the null hypothesis (H0: there is no statistically significant differences between the means of the two groups) and if the obtained $\mathrm{p}<0.05$ there is a statistically significant difference between the means of the two groups and the null hypothesis is not supported. Unfortunately, this test does not enable the researcher to identify clearly where the differences lie between the two groups, so the researcher must complement this test by cross tabulation if he wants to identify where the differences lie (Conover, 1999).

When the variables to be studied are categorical the Pearson's chi-square test $\left(\chi^{2}\right)$, or the chi-square test, is the most common used. This test is usually used for testing relationships between categorical variables. Typically, the data is disposed in a cross tabulation (a bivariate table); this type of table presents the distributions of the two categorical variables simultaneously and the chi-square independence test evaluates whether an association exists between the two variables, by comparing the observed distribution to the expected one if the variables were really independent of each other. The null hypothesis of the chi-square test is that there is no 
relationship between the categorical variables (in the population), that is, they are independent. If $\mathrm{p}<0.05$, one can conclude that the variables being studied are not independent of each other and there is a statistical relationship between them (Cohen et al., 2007).

\subsubsection{Qualitative Analysis}

Considering the qualitative data, which is vast in this research work, it has been used content analysis (Cohen et al., 2007) for the majority. The open questions (VISIR main advantages and disadvantages), both for the SSQs and the teachers' interviews, were qualitatively analysed, following the procedure of the grounded theory (Glaser \& Strauss, 2012).

Data reduction to manageable amounts is a key aspect in qualitative analysis. In fact, a big effort must be achieved to reduce large quantities of written data and a typical procedure to achieve it is content analysis. According to Cohen (2007) "content analysis is the process of summarizing and reporting written data -the main contents of data and their messages". Its goal is to achieve the maximum objective analysis possible. The first step of this process (prior to the analysis) is the definition of the categories of analysis -concepts, characteristics or qualities to be examined- usually resulting from theoretical constructs, although they can be adjusted, through the analysis (Williams, 2007). After this first step, the data (interviews, documents, observations) is codified -the texts are reviewed in order to code them and place them into categories- and then the counts of occurrences of words, codes and categories are done. A statistical analysis is applied as a way of the results being reported in a quantitative format. From this, the researcher is able to interpret the results, drawing conclusions about the patterns found. In this work it was used content analysis to analyse the qualitative data from the educational modules and the teacher pre and post implementation forms.

The major difference between content analysis and grounded theory is in the way categories are derived. In the first case they are usually derived from theoretical constructs (preordinate categories) in advance of the analysis while in the second method they are derived from the data itself. Grounded theory does not limit the interpretation to already known theories, but rather builds conclusions from the analysis of the collected data, respecting their shades and diversity in the construction of categories and subcategories (Cohen et al., 2007). Accordingly to Creswell (2014) "involves using multiple stages of data collection and the refinement and interrelationship of categories of information. Two primary characteristics of this design are the constant comparison of data with emerging categories and theoretical sampling of different groups to maximize the similarities". 
As a method of analysis of the SSQ open questions (Q21 and Q22) as well as the final open question of the teacher's guided interview, the grounded theory was chosen, which gives a fundamental importance to what the informant's report to build the analytical categories. In that sense, the researcher looks for semantic clusters within responses, in spite of the minor variants with which they were formulated or the internal aspects to which they refer. Therefore, it quantifies not the number of students/teachers, but the ideas expressed by them, as one person may have pointed more than one argument as regards interest and/or difficulty.

In general students tend to avoid answering open questions, so when they choose to do so, it is because they feel the need to express their opinion and usually what they write can be most meaningful in terms of identifying characteristics that are commonly (but independently) expressed. Each student may identify one or more aspects that were relevant to him/her. In this study, there was a high level of students who chose to answer these open questions: to Q21 there were 720 answers and 703 students answered Q22.

Teachers answered the open question included in the interview script in 93\% of the didactical implementations.

The qualitative analysis on what teachers and students report helped to build the analytical categories. This analysis was performed independently for the two type of respondents.

Two appendixes ( $\underline{\text { Appendix } \mathbf{E}}$ and $\underline{\mathbf{A p p e n d i x} \mathbf{F})}$ ) were included in the end of the thesis to further enlighten the reader about respectively the methodology details and the analyses procedures performed in each case. 



\section{Collected Data ANd Data Analysis}

$\mathrm{T}$

hroughout this chapter the data obtained using the collection tools described in the previous chapter -questionnaire, interviews, documents and observations- is presented and analysed. This data is presented in the most possible rigorous way (to avoid, as far as possible, uncontrolled factors and guarantee all the relevant information is revealed) and for now the least permeated by interpretation as possible. A descriptive analysis is conducted to describe the relevant quantitative data. The qualitative data is systematized applying a content analysis methodology. The student's satisfaction questionnaire (SSQ) open answers as well as the open answer from the teacher's guided interview is analysed by the procedure of grounded theory. By these procedures, the didactical implementations and students' results will be in depth characterized.

\subsection{Didactical Implementations}

In this section the data collected in the scope of the dimension Didactical Implementation (Table 2 , page 74) will be presented and detailed analysed, accordingly to the defined categories, each of them presented as a subsection of this one. As it was explained, since this study involved 43 didactical implementations in three countries and in 14 different educational institutions, the amount of required data was massive. Even though this allowed for a very rich set of data, it also provided some constrains in order to collect all type of data from all the 52 teachers involved. Hence, it was not possible to collect all the required data for all the implementations, being those missing data issues different from one implementation to the next.

\subsubsection{VISIR's Implementation}

Teachers introduced and used VISIR in their courses, which varied significantly in contents and level of difficulty, being some of them introductory courses (students' first contact with electric circuits) and some advanced ones, taking into account the learning goals they wanted to achieve. They intended to design tasks according to the competences they wanted their students to develop. Table 9 summarizes these implementation characteristics, where the first and second columns identify respectively the case number and the course edition number. 
Table 9 - Didactical Implementation Characteristics

\begin{tabular}{|c|c|c|c|c|c|c|c|c|c|c|c|c|c|c|}
\hline \multirow{2}{*}{\begin{tabular}{l}
$\#$ \\
\multirow{2}{*}{} \\
$\tilde{E}$
\end{tabular}} & \multirow{2}{*}{ 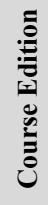 } & \multicolumn{3}{|c|}{ VISIR Design } & \multicolumn{4}{|c|}{ VISIR Introduction and Support } & \multicolumn{6}{|c|}{ VISIR Tasks } \\
\hline & & $\begin{array}{c}\text { Course } \\
\text { Content }\end{array}$ & $\begin{array}{c}\text { Comp. } \\
\text { Goal }\end{array}$ & $\begin{array}{c}\text { Use } \\
\text { Level }\end{array}$ & $\begin{array}{l}\text { Introd } \\
\text { uction. }\end{array}$ & $\begin{array}{l}\text { Mat } \\
\text { erial }\end{array}$ & Email & Pres. & $\mathbf{N}$ & $\begin{array}{l}\text { Wei } \\
\text { ght }\end{array}$ & $\begin{array}{c}\text { Gro } \\
\text { up }\end{array}$ & $\begin{array}{c}\text { Man } \\
\text { dato } \\
\text { ry }\end{array}$ & Type & $\begin{array}{l}\text { DC/ } \\
\text { AC }\end{array}$ \\
\hline C1 & 1 & $20 \%$ & L2 & B & I3 & No & No & Class & 2 & Q & Yes & No & $\mathrm{T} 2$ & $\mathrm{DC}$ \\
\hline C2 & 1 & $2 \%$ & L2 & B & I2 & No & No & Class & 1 & $\mathrm{Q}$ & No & No & T1 & DC \\
\hline \multirow{4}{*}{$\mathbf{C 3}$} & 1 & $16 \%$ & L2 & B & I2 & No & No & Class & 4 & Q & Yes & No & T1 & DC \\
\hline & 2 & $16 \%$ & L2 & B & I2 & No & No & Class & 3 & $19 \%$ & Yes & Yes & $\mathrm{T} 1$ & DC \\
\hline & 2 & $16 \%$ & L3 & $\mathrm{B}$ & $\mathrm{I} 1$ & Yes & No & Class & 3 & $19 \%$ & Yes & Yes & $\mathrm{T} 1$ & $\mathrm{DC}$ \\
\hline & 2 & $16 \%$ & L3 & $\mathrm{B}$ & $\mathrm{I} 3$ & 7 & 7 & $>$ & 3 & $19 \%$ & Yes & Yes & $\mathrm{T} 1$ & $\mathrm{DC}$ \\
\hline C4 & 1 & $20 \%$ & L2 & B & I2 & No & No & Class & 1 & Q & No & No & $\mathrm{T} 2$ & DC \\
\hline \multirow{3}{*}{ C5 } & 1 & $5 \%$ & L1 & B & I2 & No & No & Monit & 2 & $6 \%$ & No & No & T1 & DC \\
\hline & 2 & $15 \%$ & L1 & $\mathrm{B}$ & $\mathrm{I} 3$ & No & No & Monit & 2 & $6 \%$ & No & No & $\mathrm{T} 1$ & $\mathrm{DC}$ \\
\hline & 3 & $15 \%$ & L1 & B & I2 & No & No & Monit & 2 & $6 \%$ & No & No & T1 & DC \\
\hline C6 & 1 & $30 \%$ & L2 & $\mathrm{B}$ & $\mathrm{I} 2$ & Yes & Yes & No & 1 & $\mathrm{Q}$ & 7 & No & T1 & $\mathrm{DC}$ \\
\hline C7 & 1 & 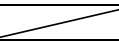 & L1 & $\mathrm{B}$ & I2 & $\mathrm{Na}$ & $\mathrm{Na}$ & $\mathrm{Na}$ & 3 & $\mathrm{Q}$ & 1 & No & $\mathrm{T} 2$ & $\mathrm{DC}$ \\
\hline \multirow{3}{*}{ C8 } & 1 & $20 \%$ & L3 & $\mathrm{B}$ & $\mathrm{I} 3$ & Yes & No & No & 1 & $10 \%$ & Yes & No & $\mathrm{T} 2$ & $\mathrm{AC}$ \\
\hline & 2 & $25 \%$ & L3 & $\mathrm{B}$ & $\mathrm{I} 1$ & Yes & No & No & 1 & $11 \%$ & Yes & No & $\mathrm{T} 2$ & $\mathrm{AC}$ \\
\hline & 3 & $25 \%$ & L3 & $\mathrm{B}$ & $\mathrm{I} 2$ & Yes & No & No & 1 & $10 \%$ & Yes & No & $\mathrm{T} 2$ & $\mathrm{AC}$ \\
\hline \multirow{2}{*}{ C9 } & 1 & $5 \%$ & L3 & $\mathrm{B}$ & I2 & Yes & No & No & 1 & $11 \%$ & No & No & $\mathrm{T} 2$ & $\overline{D C}$ \\
\hline & 2 & $30 \%$ & L3 & B & I2 & Yes & No & No & 1 & $10 \%$ & Yes & No & $\mathrm{T} 2$ & DC \\
\hline \multirow[b]{2}{*}{ C10 } & 1 & $15 \%$ & L1 & B & I3 & 7 & 1 & 1 & 1 & $10 \%$ & Yes & No & $\mathrm{T} 2$ & DC \\
\hline & 2 & $50 \%$ & L2 & B & I3 & 7 & $\gamma$ & $\gamma$ & 1 & $10 \%$ & Yes & No & $\mathrm{T} 2$ & DC \\
\hline C11 & 1 & $10 \%$ & L2 & A & I2 & Yes & Yes & No & 2 & $5 \%$ & No & No & $\mathrm{T} 1$ & $\mathrm{AC}$ \\
\hline $\mathrm{C} 12$ & 1 & $10 \%$ & L3 & I & I2 & 7 & $\Gamma$ & $\gamma$ & 2 & $\mathrm{Q}$ & $\gamma$ & No & $\mathrm{T} 1$ & $\mathrm{AC}$ \\
\hline C13 & 1 & $100 \%$ & L3 & $\mathrm{A}$ & I1 & Yes & No & No & 3 & Q & 7 & No & $\mathrm{T} 3$ & $\mathrm{AC}$ \\
\hline \multirow{2}{*}{ C14 } & 1 & 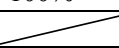 & L3 & I & I2 & Yes & No & No & 1 & 1 & 7 & $\gamma$ & $\mathrm{T} 2$ & $\mathrm{AC}$ \\
\hline & 2 & $100 \%$ & L3 & I & $\mathrm{I} 2$ & Yes & No & No & 3 & $15 \%$ & No & No & $\mathrm{T} 2$ & $\mathrm{AC}$ \\
\hline C15 & 1 & $25 \%$ & L1 & I & $\mathrm{I} 2$ & Yes & No & No & 4 & $27 \%$ & 7 & Yes & $\mathrm{T} 1$ & $\mathrm{AC}$ \\
\hline \multirow{2}{*}{ C16 } & 1 & $67 \%$ & L1 & $\mathrm{B}$ & $\mathrm{I} 3$ & Yes & No & Class & 4 & $20 \%$ & No & No & $\mathrm{T} 2$ & DC \\
\hline & 2 & $67 \%$ & L1 & $\mathrm{B}$ & $\mathrm{I} 3$ & Yes & No & Class & 4 & $20 \%$ & No & No & $\mathrm{T} 2$ & DC \\
\hline \multirow{2}{*}{ C17 } & 1 & $30 \%$ & 7 & I & I2 & Yes & No & No & 3 & 7 & 7 & $\gamma$ & $\gamma$ & 7 \\
\hline & 2 & $30 \%$ & 7 & I & 7 & & 7 & $\gamma$ & 2 & & & & & \\
\hline C18 & 1 & 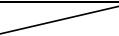 & - & B & & & 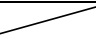 & & 7 & & 5 & 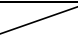 & & 7 \\
\hline \multirow{3}{*}{ C19 } & 1 & $6 \%$ & L3 & $\mathrm{A}$ & I2 & Yes & No & No & 1 & Q & No & No & T2 & $\mathrm{AC}$ \\
\hline & 2 & $25 \%$ & L2 & $\mathrm{A}$ & I2 & No & Yes & No & 1 & Q & No & Yes & $\mathrm{T} 2$ & $\mathrm{AC}$ \\
\hline & 3 & $25 \%$ & L2 & $\mathrm{A}$ & $\mathrm{I} 2$ & No & Yes & No & 1 & Q & No & Yes & $\mathrm{T} 2$ & $\mathrm{AC}$ \\
\hline \multirow{2}{*}{ C20 } & 1 & $17 \%$ & L3 & I & $\mathrm{I} 3$ & $\gamma$ & $\Gamma$ & 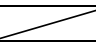 & 1 & Q & Yes & Yes & $\mathrm{T} 2$ & $\mathrm{AC}$ \\
\hline & 2 & $17 \%$ & L3 & I & $\mathrm{I} 3$ & 7 & 1 & 1 & 1 & Q & Yes & Yes & $\mathrm{T} 2$ & $\mathrm{AC}$ \\
\hline C21 & 1 & $6 \%$ & L1 & I & I2 & Yes & No & No & 1 & Q & No & No & $\mathrm{T} 2$ & DC \\
\hline $\mathrm{C22}$ & 1 & $10 \%$ & L2 & B & I2 & 7 & $\gamma$ & $>$ & 2 & Q & $\gamma$ & No & $\mathrm{T} 2$ & DC \\
\hline $\mathrm{C23}$ & 1 & $21 \%$ & L3 & I & $\mathrm{I} 3$ & No & Yes & No & 2 & $5 \%$ & No & Yes & $\mathrm{T} 2$ & DC \\
\hline C24 & 1 & $20 \%$ & L3 & I & $\mathrm{I} 3$ & No & Yes & No & 2 & $5 \%$ & No & Yes & $\mathrm{T} 2$ & DC \\
\hline $\mathrm{C25}$ & 1 & $20 \%$ & L3 & $\mathrm{B}$ & $\mathrm{I} 2$ & 7 & $\Gamma$ & $>$ & 2 & $\mathrm{Q}$ & No & Yes & $\mathrm{T} 2$ & DC \\
\hline \multirow{3}{*}{$\mathrm{C26}$} & 1 & $15 \%$ & L2 & B & I3 & Yes & Yes & Of_hs & 1 & $5 \%$ & Yes & No & $\mathrm{T} 2$ & $\mathrm{DC}$ \\
\hline & 2 & $15 \%$ & L2 & B & I3 & Yes & Yes & Of_hs & 1 & $10 \%$ & Yes & No & $\mathrm{T} 2$ & $\mathrm{DC}$ \\
\hline & 3 & $15 \%$ & L2 & B & I3 & Yes & Yes & Of_hs & 1 & $10 \%$ & Yes & No & $\mathrm{T} 2$ & DC \\
\hline
\end{tabular}

The implementation characteristics are essentially split by three mains focuses (the variables were already defined in section 4.2):

* VISIR design: (i) usage in course contents (\%); (ii) competence goal level (level 1 (L1), level 2 (L2), level3 (L3)) teachers pursued when they stated their course learning objectives related to students' work with VISIR tasks; (iii) VISIR usage level regarding course contents level (basic (B), intermediate (I), advanced (A)). 
* VISIR introduction and support: (i) the way VISIR was introduced to students: I1 (no formal activity was prepared) and when a formal presential activity was conducted, it was distinguished between I2 (teachers in class) and I3 (teachers and students in class); (ii) the type of support teachers provided their students, along the semester: upload specific support material (material); answer students' doubts via email (email); presential support split in three types: class (class), monitoring (monit) and office hours (of_hs).

* VISIR tasks: (i) the number of tasks involving VISIR (N); (ii) its contribution (W) to the courses final grade ( $Q$ means that it counts as qualitative information); (iii) if the tasks were developed in groups (G) or not; (iv) if the tasks were mandatory (M) or not (to pass the course); (v) the task type (T1, T2, T3); (vi) if the tasks were performed in direct current (DC) or alternate current (AC).

The extent of VISIR usage in course contents (in \%) varied from 2\% (a teacher simple experience in a very specific course topic) to $100 \%$, depending not only on the course syllabus but also with teachers' goal and experience using VISIR. Still in most implementations the extent of VISIR usage in course contents was between 15 to $25 \%$.

The level of competence (L1, L2, L3) teachers pursued when defining their learning objectives related to VISIR tasks is reported in Figure 6 -by VISIR use level and split by education level- and the connection between the level to the type of competence teachers identified was already described in section 4.2 .

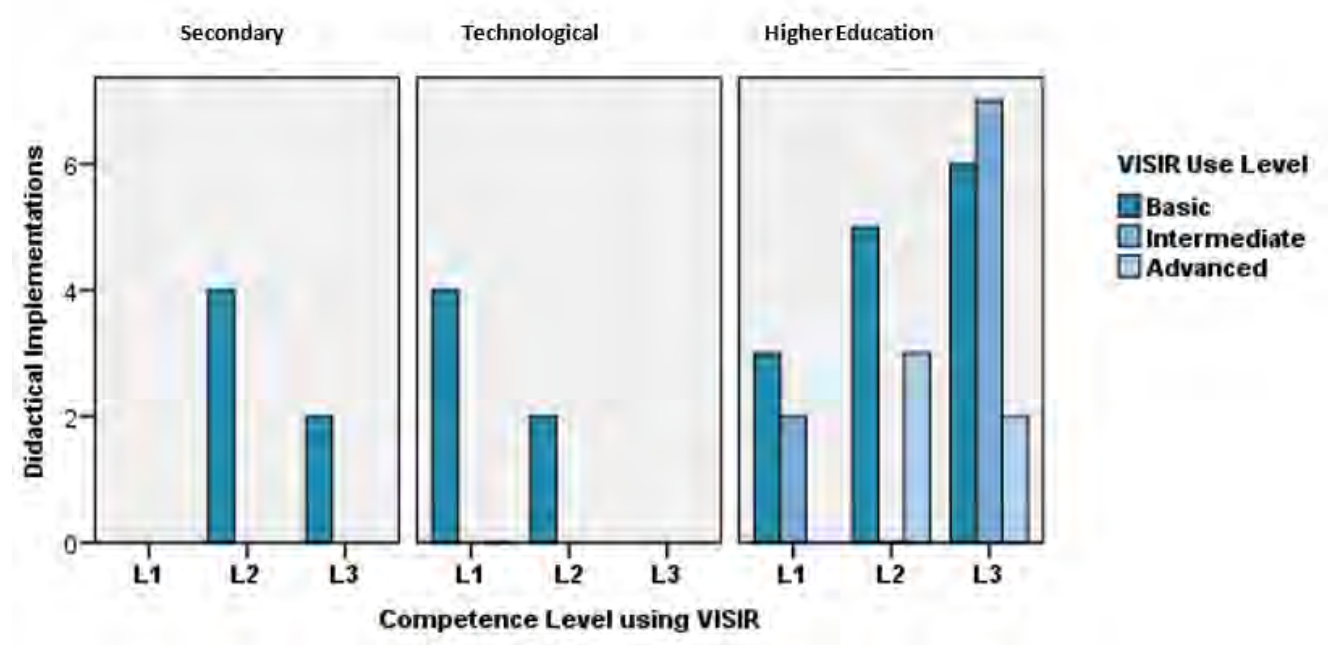

Figure 6 - Level of Competence Teachers Wanted Students to Develop

In all secondary education cases (except partially in the second course edition of case C3) teachers wanted their students to master experimental techniques and develop analysis 
competences (analyse and compare the data obtained using the different resources) and/or some soft skills (L2). In the technological level teachers were more cautious and wanted their students to mainly develop experimental competences (establish the proposed circuits and do some measurements and obtain data) and do some calculus while allowing the students to know and use several resources (L1). In cases C4 and C6 they wanted their students to develop level 2 (L2) competences. In these two levels of education the VISIR use level was basic, that is concerned the use of basic instruments for measuring components, currents or voltages applying basically simple laws (Ohm's and Kirchhoff's).

In $40 \%$ of the didactical implementations, teachers wanted students to develop higher order competences (level 3): all of these (except partially in the second course edition of case C3) are higher education course implementations. In all, these teachers wanted students to develop critical analysis and the ability of problem-solving: students were supposed to be able to confront model data with real data and explain its differences. In HE, the three VISIR usage levels coexist: B with 15 didactical implementations; I with 11 didactical implementations; and A with 5 didactical implementations. In fact, when teachers' goal is that students develop competence level 3 (L3) they consider VISIR usage from very simple circuits to advanced ones.

Teacher introduction to VISIR was mainly done in class, by teachers. That was the case for 38 out of the 43 didactical implementations: in 23, teachers decided to introduce VISIR in a class explaining the basics of the tool and doing some assembling and measurements while students were observing (I2). In 15 implementations teachers have introduced it in classes, but while they were explaining VISIR and doing some assembling and measurements, students were doing the same in their own computers, trying it by themselves (I3). In 3 implementations (one of the C3 and C8 course implementation editions and case $\mathrm{C} 13$ ) teachers did not develop any formal activity to introduce VISIR (I1): in C3 and C13 students were supposed to use the support material available in the LMS course page and explore the tool, by themselves; still, in case C3 the tasks involving VISIR were develop during class time. And for 2 implementations it was not possible to have that information.

Considering VISIR (designed) support along the semester, some teachers opted for uploading specific support material (47\%), such as tutorial videos or documents, in the LMS course page or decided to answer students' doubts via email $(21 \%)$ while others $(33 \%$ of the implementations) opted for diverse ways of presential support (Figure 7). Most teachers elected just one type of support, but in 5 didactical implementations teachers combined two types of support and in case C26 teacher was extremely cautious providing the three types of support. Although it is trusted that teachers accompanied students in their work with VISIR, for nearly 
$26 \%$ of the implementations, teachers did not specify the precise way in which this support was carried out.

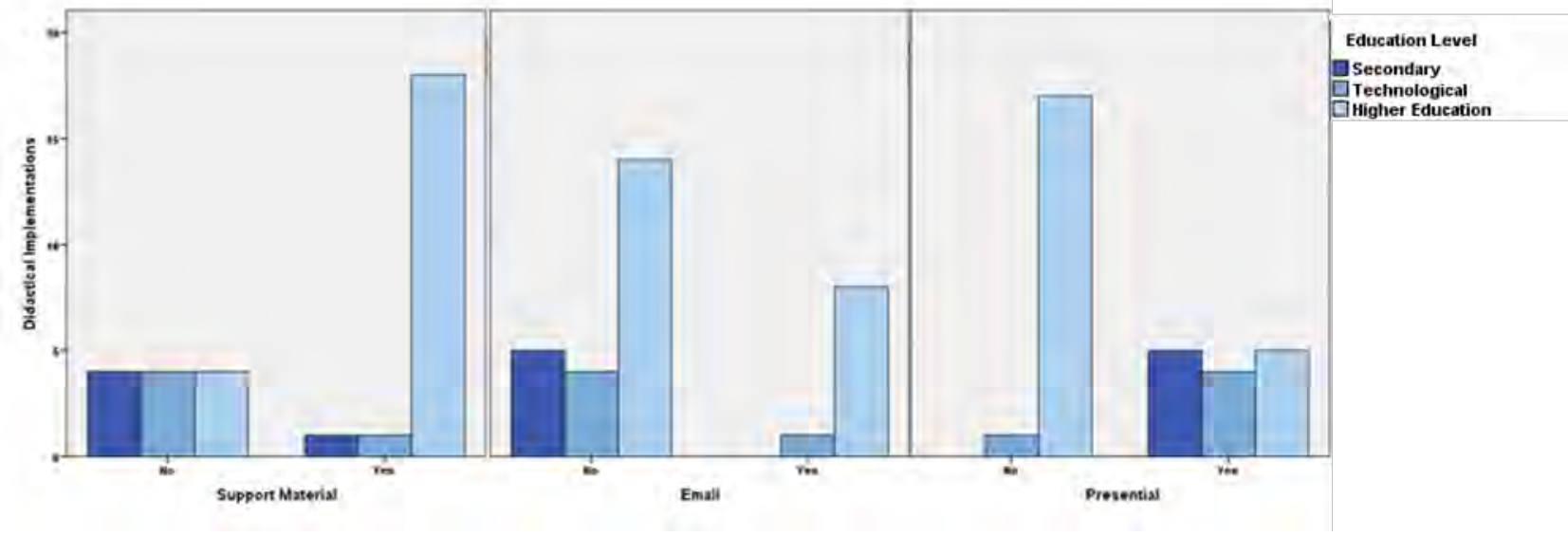

Figure 7 - VISIR Support during the Semester

The presential support, as already described in the previous chapter, was mainly performed in three different ways: in class (performing the tasks either during ordinary class time or extra class time), by allocating monitors to give support to students during the task execution period or teachers using their office hours to clarify students doubts (face-to face contact). Table 10 summarizes the cases or course implementation editions for which the former type of support occurred, detailing it. All secondary and technological course implementations, except case C6, opted for presential support, although not all in the same way: in the majority, all VISIR tasks were fully performed during class or extra class time (so with teachers' full support), although in the second course edition of C3 one of the VISIR tasks (very similar to the ones students have developed during class time) was performed autonomously by students as a homework/extraclass task; in case C5 the tasks were performed out of class time, but students had the support of a monitor, during the all task execution period. There were just two HE courses that opted for this type of support: in case C16, 2 out the 4 VISIR tasks were performed during class time and in case C26 teacher used her office hours to support students whenever they needed.

Table 10 - Types of Presential Support

\begin{tabular}{|c|l|c|}
\hline \multicolumn{2}{|c|}{ VISIR Presential Support } & Cases \\
\hline \multirow{2}{*}{ Class } & All tasks & $\mathrm{C} 1, \mathrm{C} 2, \mathrm{C} 3\left(1^{\mathrm{st}}\right), \mathrm{C} 4$ \\
\cline { 2 - 3 } & Not all tasks & $\mathrm{C} 3\left(2^{\text {nd }}\right), \mathrm{C} 16$ \\
\hline \multicolumn{2}{|c|}{ Monitoring } & $\mathrm{C} 5$ \\
\hline \multicolumn{2}{|c|}{ Office Hours } & $\mathrm{C} 26$ \\
\hline
\end{tabular}


The number of tasks involving VISIR varied between 1 and 4 and the average number of tasks by education level, by implementation topic and by course level as well as VISIR use level in course contents are summarized in Table 11.

Table 11 - Number of VISIR Tasks by Topic

\begin{tabular}{|l|l|l|}
\hline \multicolumn{2}{|c|}{} & \multicolumn{1}{c|}{$\begin{array}{c}\text { Average \# } \\
\text { VISIR Tasks }\end{array}$} \\
\hline \multirow{4}{*}{ Education Level } & Secondary & 2.7 \\
\cline { 2 - 3 } & Technological & 1.8 \\
\cline { 2 - 3 } & Higher Education & 1.7 \\
\hline \multirow{4}{*}{$\begin{array}{l}\text { Implementation } \\
\text { Topic }\end{array}$} & Electricity & 2.1 \\
\cline { 2 - 3 } & Electronics & 1.4 \\
\cline { 2 - 3 } & Projects & 4.0 \\
\cline { 2 - 3 } Course Level & Mathematics & 1.0 \\
\cline { 2 - 3 } & Physics & 2.1 \\
\hline \multirow{3}{*}{\begin{tabular}{l} 
VISIR Use Level \\
\cline { 2 - 3 }
\end{tabular}} & EE majors (I) & 1.8 \\
\cline { 2 - 3 } & EE majors (S) & 1.9 \\
\cline { 2 - 3 } & Non-EE majors & 1.9 \\
\cline { 2 - 3 } & Basic & 2.0 \\
\cline { 2 - 3 } & Intermediate & 1.6 \\
\hline
\end{tabular}

Analysing by educational level, the number of tasks shows some variability, decreasing from the lower to the higher levels of education. Examining by implementation topic, it is clear that the topic with more proposed tasks was projects, while the one with a lower number of tasks was mathematics. In fact, they respectively reached the maximum (4) and minimum (1) number of tasks proposed, which makes sense, as the first topic works exclusively with tasks and projects while in the second VISIR was used for mathematical concepts contextualization. Considering the analysis by course level and by VISIR use level, this number is very similar for both.

In terms of their weight contribution to final grade, in some cases they were merely qualitative, others had a quantitative contribution. The qualitative contribution was chosen by the majority of the teachers from the secondary and technological levels of education. In the secondary level of education just in the second course edition of case C3 teachers opted for a quantitative contribution (19\%), to the course final grade. In the technological level just in case C5 teachers opted for a quantitative contribution of $6 \%$, to the course final grade. In the HE level the majority (10 cases) opted for a quantitative contribution to the final grade, which varied from $5 \%$ to $27 \%$ weight; in four cases it was not possible to have information.

In $37 \%$ of the didactical implementations the proposed tasks were meant to be developed in group, allowing students the opportunity and time to discuss their ideas and communicate with others; all teachers from the secondary level of education (except in case C2) opted for this. In 40 $\%$ of the didactical implementations the tasks were meant to be performed individually: all teachers from the technological level opted for it. And for the remaining $23 \%$, there were no information. 
Just in nearly $26 \%$ of the didactical implementations teachers opted for mandatory task(s) involving VISIR (students had to deliver it, in order to be able to be approved in the course). Figure 8 summarizes the previous information by education level.

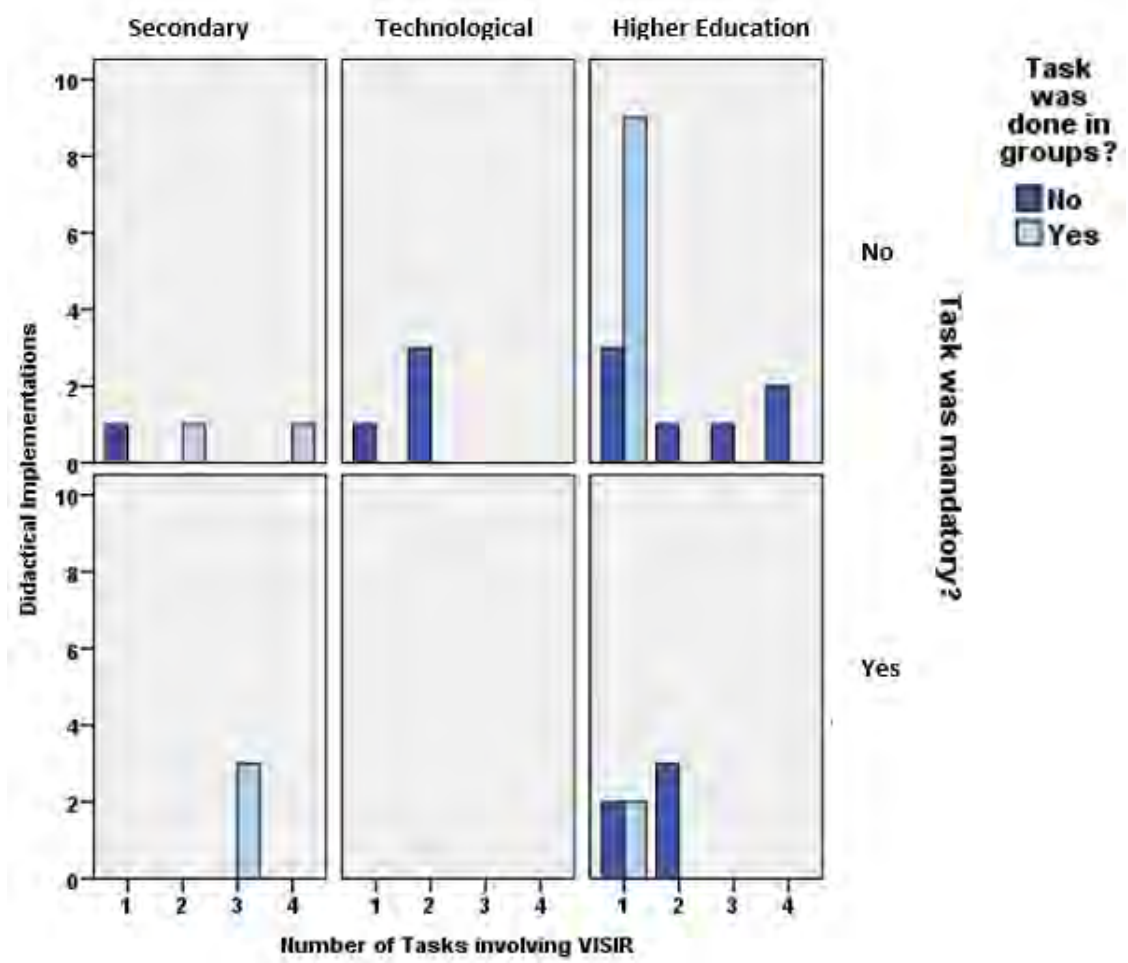

Figure 8 - Tasks (Number and Regime) by Education Level

In 12 implementations the VISIR tasks consisted of doing some electrical circuits assembling and some measurements (such as electrical current and voltage) (T1 task) (most secondary and technological teachers opted for it). In 27 didactical implementations, the tasks were more ambitious. In addition to circuits assembling and some measurements, students were supposed to compare those results with the theoretical expected results and/or the results obtained with other resources: simulation and/or hands-on (T2 task). This last category covers mainly higher education course implementations, although not all higher education teachers opted for this type of task in their courses: some of them opted for the simpler one (T1 task). In case $\mathrm{C} 13$, the teacher was determined that students had to design a circuit to solve a specific problem and then compare the results with the theoretical ones as well as with the results obtained with other experimental resources (T3 task). Tasks involving AC circuits are quite more challenging than DC circuits, as AC analysis and calculus involves using more complex mathematics concepts, such as complex numbers notation. Teachers only opted for it in $14 \mathrm{HE}$ didactical implementations (Figure 9). For 3 implementations (cases C17 and C18) it was not possible to have information about the type of tasks (T1, T2, T3 and DC/AC). 

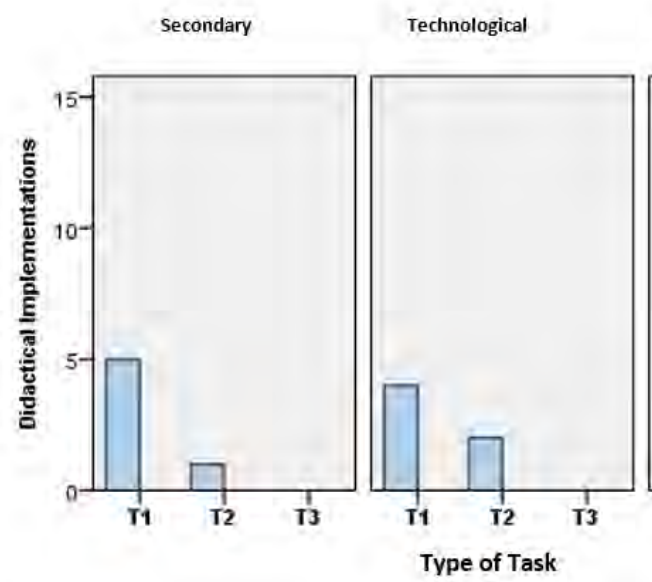

Higher Education

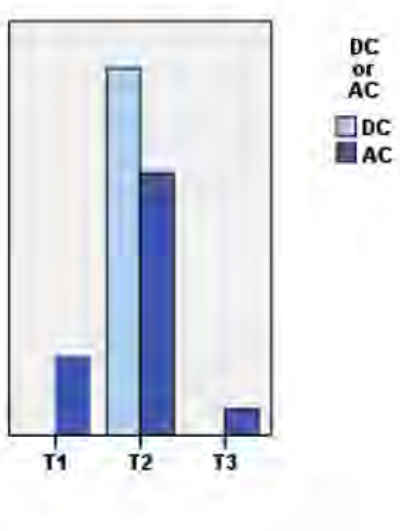

Figure 9 - VISIR Tasks Attributes by Education Level

After completing the tasks, students had to deliver an individual or group report, which accordingly to the type of proposed task could be a simple work or elaborated one, to succeed in making all the results comparisons and analysis requested. In all the cases, except cases C5, C12 and C20, students' VISIR grade was basically the grade they obtained in those reports combined (at some extent) with teachers' perception of students' performance and involvement during the task execution period. In cases C5, C12 and C20, students' VISIR grade was obtained in a different way. After delivering the report students had also to:

* Case C5: students had to present one of the experiments (and results) performed in the VISIR remote lab.

* Case C12: students had to present one of the experiments they performed during the semester. Still, they could choose between presenting an experiment performed in the hands-on lab or one performed in the VISIR. The majority opted for presenting and defending a hands-on experiment. VISIR was introduced nearly the end of the semester and not all students were confident using it, so this defence was optional.

* Case C20: students individually arranged a timetable (extra class) with the teacher. The teacher asked students some questions about the activities they have developed with VISIR, the only experimental resources used in this course.

Students' VISIR grade was a combination of the report(s) with the former summarized activities.

As previously described in this section, the 43 didactical implementations presented a wide variety of characteristics which is natural taking into account, we are dealing with different levels 
of education and different type of courses. Plus, they were designed and implemented by teachers with different backgrounds and teaching experiences to students from also varied contexts. Teachers opted for different and specific strategies on implementing this methodology -using several experimental resources based upon VISIR and supported by calculus- accordingly to the (available) resources and their needs.

\subsubsection{Teachers' Involvement}

Teachers' usage of VISIR is vital in order to closely attend students and efficiently recognize their difficulties and doubts, readily helping them overcoming it. Furthermore, without teachers' encouragement to use it and suitable justification about its utility, students have more difficulty to overcome the initial challenges VISIR (as any new tool) might pose to a new user. Table 12 characterizes teacher involvement considering VISIR usage: it shows the teacher implementation edition (for each head teacher the number of course editions made) and the number of teachers' accesses (total and per task) into the system, including the task preparation phase and the support given along the semester. It was not possible to have data for the former factor in some cases by different reasons. In the beginning and before LA partners have their own VISIR system installed, in some didactical implementations it was used a EU partner VISIR system and in some cases it was not created a specific user account for the teacher, but instead he accessed the system through a guest account (used simultaneously by several users). Later, although teachers were accessing their own VISIR systems (that in the meantime have been installed) through an individual user account, some VISIR systems were not installed with the option of registering each access and, when detected, it was not possible to make the correction on time. Although most teachers just developed one didactical implementation supported by VISIR, there were a few that kept on using it (in the same or other courses): teachers involved in cases C3, C10, C14, C16, C17, C22 and C25 had two editions; teachers involved in cases C5, C19 and C26 had three editions and the head teacher of cases C8 and C9 was responsible for 5 editions. It is clear that the number of VISIR accesses per task shows a wide range of variability from 3 to 85 accesses per task (being this minimum and maximum value obtained in case C20: 85 accesses per task in the first course edition and 3 in second subsequent edition). Considering the courses in which there was more than one didactical implementation $(\mathrm{C} 3, \mathrm{C} 5, \mathrm{C} 8, \mathrm{C} 9, \mathrm{C} 10, \mathrm{C} 14$, C16, C17, C19, C20 and C26) the number of accesses per task tends to diminish or be similar, from one implementation to the next. The only exceptions are for case C5, C19 and C26. 
Table 12 - Teacher (VISIR) Involvement

\begin{tabular}{|c|c|c|c|}
\hline \multirow{2}{*}{ 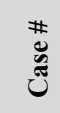 } & \multirow{2}{*}{$\begin{array}{l}\text { Teacher } \\
\text { Implementation } \\
\text { Edition }\end{array}$} & \multicolumn{2}{|c|}{ Number (VISIR) } \\
\hline & & Total Accesses & Accesses/task \\
\hline $\mathrm{C1}$ & 1 & 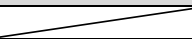 & 2 \\
\hline $\mathrm{C2}$ & 1 & 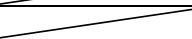 & 2 \\
\hline \multirow{4}{*}{ C3 } & 1 & 19 & 4.8 \\
\hline & 2 & 13 & 4.7 \\
\hline & 1 & 16 & 5.3 \\
\hline & 1 & 12 & 4 \\
\hline $\mathrm{C4}$ & 1 & 2 & 2 \\
\hline \multirow{3}{*}{ C5 } & 1 & 2 & 2 \\
\hline & 2 & 19 & 9.5 \\
\hline & 3 & 37 & 18.5 \\
\hline C6 & 1 & 2 & 2 \\
\hline C7 & 1 & 21 & 7 \\
\hline \multirow{3}{*}{$\mathrm{C} 8$} & 1 & 15 & 15 \\
\hline & 2 & 25 & 25 \\
\hline & 4 & 6.5 & 6.5 \\
\hline \multirow{2}{*}{ C9 } & 3 & 12 & 12 \\
\hline & 5 & 6.5 & 6.5 \\
\hline \multirow{2}{*}{ C10 } & 1 & 9 & 9 \\
\hline & 2 & 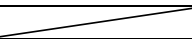 & 2 \\
\hline C11 & 1 & 31 & 15.5 \\
\hline $\mathrm{C12}$ & 1 & 27 & 13.5 \\
\hline $\mathbf{C 1 3}$ & 1 & 32 & 10.7 \\
\hline \multirow{2}{*}{ C14 } & 1 & 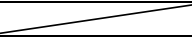 & 2 \\
\hline & 2 & 21 & 7 \\
\hline $\mathrm{C15}$ & 1 & 41 & 10.3 \\
\hline \multirow{2}{*}{ C16 } & 1 & 99 & 24.8 \\
\hline & 2 & 83 & 20.8 \\
\hline \multirow{2}{*}{ C17 } & 1 & 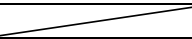 & 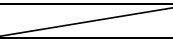 \\
\hline & 2 & 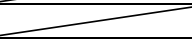 & 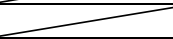 \\
\hline C18 & 1 & 2 & 2 \\
\hline \multirow{3}{*}{ C19 } & 1 & 6 & 6 \\
\hline & 2 & 8 & 8 \\
\hline & 3 & 9 & 9 \\
\hline \multirow{2}{*}{$\mathrm{C20}$} & 1 & 85 & 85 \\
\hline & 2 & 3 & 3 \\
\hline $\mathrm{C21}$ & 1 & 12 & 12 \\
\hline $\mathrm{C22}$ & 2 & 2 & 2 \\
\hline $\mathrm{C23}$ & 1 & 44 & 21.8 \\
\hline $\mathrm{C} 24$ & 1 & 26 & 12.8 \\
\hline $\mathrm{C25}$ & 2 & 20 & 10 \\
\hline \multirow{3}{*}{$\mathrm{C} 26$} & 1 & 8 & 8 \\
\hline & 2 & 13 & 13 \\
\hline & 3 & 15 & 15 \\
\hline
\end{tabular}

The number of teachers involved in each didactical implementation varied from 1 to 7 , although in half of the cases there was just one teacher involved in each didactical implementation. This variation, in the majority of the cases, does not reflect a head teacher option in involving (or not) a team of (specific) teachers in a didactical implementation, considering his belief that it would promote better results. In the majority of the cases the number of teachers involved (and which) was planned by the department header considering organization and/or institutional constraints, including the number of students enrolled in the course, the number and type of classes per week, laboratory and other resources availability and teachers' background and profile. 
Teacher VISIR usage characterization was also summarized by education level, by implementation topic and by course level as well as VISIR use level in course contents. Table 13 summarizes these results.

Table 13 - Teacher (VISIR) involvement Characterization

\begin{tabular}{|c|c|c|c|}
\hline & & \multicolumn{2}{|c|}{ Average \# } \\
\hline & & Teachers & $\begin{array}{l}\text { VISIR } \\
\text { Accesses/Task }\end{array}$ \\
\hline \multirow{3}{*}{ Education Level } & Secondary & 2.2 & 4.7 \\
\hline & Technological & 1.5 & 11.7 \\
\hline & Higher Education & 2.3 & 15.2 \\
\hline \multirow{5}{*}{$\begin{array}{l}\text { Implementation } \\
\text { Topic }\end{array}$} & Electricity & 2.1 & 20.5 \\
\hline & Electronics & 2.9 & 11.1 \\
\hline & Projects & 4.0 & 10.3 \\
\hline & Mathematics & 1.0 & 13.0 \\
\hline & Physics & 2.0 & 8.1 \\
\hline \multirow{3}{*}{ Course Level } & EE majors (I) & 1.0 & \\
\hline & EE majors (S) & 2.5 & 15.3 \\
\hline & Non-EE majors & 1.8 & 11.6 \\
\hline \multirow{3}{*}{ VISIR Use Level } & Basic & 1.7 & 11.5 \\
\hline & Intermediate & 3.0 & 20.7 \\
\hline & Advanced & 2.8 & 9.8 \\
\hline
\end{tabular}

Analysing by education level, the average number of teachers shows some variability (being lower in the technological level), although the number of VISIR accesses per task, which shows a wide range of variability, increases from the lower level of education to the higher level. Assuming that as the level of education increases, the proposed VISIR tasks are more demanding, it seems natural teachers (with very different profiles) require more time to prepare, implement and support those tasks during their execution period. Examining by implementation topic, it is clear that the topic with a higher number of teachers is projects and the one with a lower number of teachers (in fact, just one teacher) is mathematics. Teachers from electricity present a much higher number of VISIR accesses per task opposing to physics teachers that exhibit the lowest number.

Considering the analysis by course level, it is clear that EE majors present a larger number of accesses per task to VISIR system when compared to non-EE majors. Considering the average number of teachers involved, it is higher at the EE majors (S). In the EE majors (I), there is just one course. Analysing by VISIR use level, the average number of teachers is lower at the basic level and higher at the intermediate level. Also, this level stands out exhibiting an average number of VISIR accesses per task twice as large as the other levels. Still, one must consider in detail the influence (for this result) of case C20 (first course edition) which had 85.0 VISIR accesses per task. Taking out this number, the average number of VISIR accesses per task in the intermediate level decreases to 11.5 (just 8 cases fit in this level and there is not data about this parameter for all of them). If the same procedure is carried on considering course level, the average number of VISIR 
accesses per task differences amongst course levels also fade away. Although, at a less extent, these differences also get smoother if implementation topic and education level are considered. Concluding teachers' VISIR usage -the number of VISIR accesses per task- is similar respectively amongst course level and VISIR use level.

In section 5.1.1, it was already detailed the different forms -uploading specific material, clarifying doubts via email, several ways of presential support- teachers accompanied students in their work with VISIR. Now, it is intended to somehow have some clues about the implemented support, which is related to teachers' attention to students and the VISIR system, during the VISIR task execution period. This categorization was carried out (when possible) considering teachers' comments about some features and details related to their involvement in the VISIR didactical implementation, connected both to the task preparation phase and/or the task execution period. For the majority of the cases it was not possible to have this data, but for the cases and/or course implementation editions for which it was possible, the data is displayed in Table 14.

Table 14 - Implemented Support Details

\begin{tabular}{|l|l|}
\hline \multicolumn{1}{|c|}{ Implemented Support Details } & \multicolumn{1}{c|}{ Cases } \\
\hline High level of time/experience & C20, C26 \\
\hline Head teacher trained monitors to assist students & C5 \\
\hline Head teacher had some resistance to the VISIR system & $\mathrm{C} 12$ \\
\hline Heightened attention to the VISIR system & $\mathrm{C} 3, \mathrm{C} 8\left(2^{\text {nd }}\right), C 9\left(1^{\text {st }}\right), \mathrm{C} 26\left(3^{\text {rd }}\right)$ \\
\hline Heightened attention to students & $\mathrm{C} 3\left(2^{\text {nd }}\right), C 16, C 19\left(2^{\text {nd }}, 3^{\text {rd }}\right), C 26\left(2^{\text {nd }}, 3^{\text {rd }}\right)$ \\
\hline
\end{tabular}

In two cases teachers referred that they spent quite a large amount of time to get familiarized with the tool -for being able to assist students in overcoming their difficulties- and/or also to prepare adequate educational material. In case $\mathrm{C} 5$, the head teacher trained a team of monitors (older students) that were available to support students, clarifying their doubt. On the other hand, C12 head teacher implemented VISIR in his course (by his Institution suggestion), but as he did not feel comfortable with the tool, maybe because he did not have enough time to get familiarized with it, he showed up some resistance to VISIR. In several didactical implementations, teachers were particularly attentive to the VISIR system, trying (ahead) the circuits that were proposed to students during the task execution period, to make sure everything was working properly. In some, teachers made a special effort in tutoring students -allowing them time, but monitoring their difficulties, in a general way, to prevent frustration- and/or paying attention to students' comments about the VISIR system. 
From the category teachers' involvement analysis, it gets clear that the "number of teachers involved" in each didactical implementation presents a meaning variation, mainly due to organizational constraints. Several teachers were involved in quite a few didactical implementations -"teacher implementation edition"- either in the same course (several course editions) or in other courses. Although the number of "teachers' VISIR accesses per task" shows a wide range of variability amongst cases, it is noteworthy that this number tends to decrease, from one course edition to the subsequent ones, in courses that have undergone several editions. This VISIR usage also seems to be connected to the education level. Several teachers were particularly cautious in the "implemented support" they provided to students, during their work with VISIR, as summarized in Table 14.

\subsubsection{Teachers' Perception}

Teachers' perception about students' satisfaction with VISIR was split it in 3 levels of hierarchy (from 1 to 3 ). This categorization was carried out considering teachers' comments about students' general acceptance and satisfaction with VISIR (this data was obtained for 37 didactical implementations). The results -displayed in Figure 10, by education level- show the majority were satisfied (level 2).

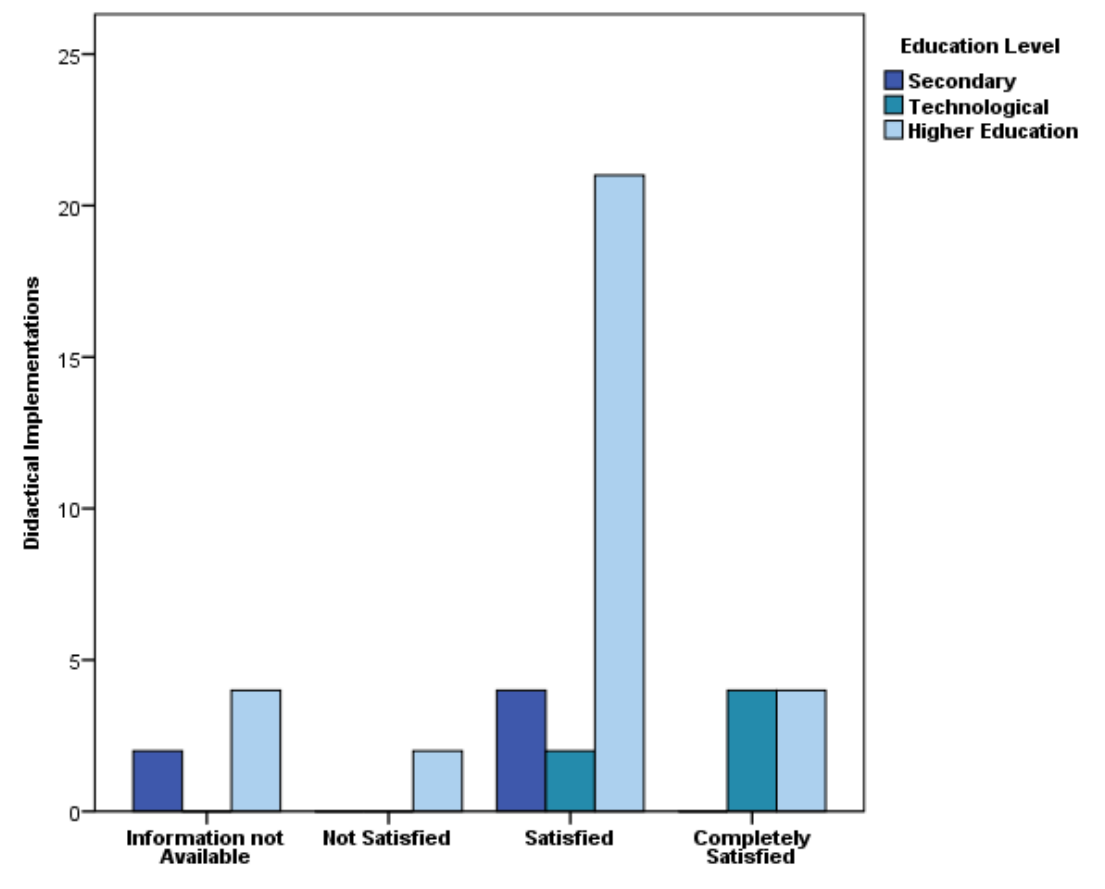

Figure 10 - Teachers' Perception of Students' Satisfaction with VISIR

Just in cases C11 and C14 (second course edition) teachers reported students disliked (and/or did not consider it a valuable resource) the tool (level 1). In the majority, teachers 
testified students were motivated, challenged and enthusiastic with the tool (level 2), which naturally lead to a good performance with it. In cases C5 (in the three course editions), C7 and C10 (second course edition) teachers commented students were highly engaged and really devoted to the tool (level 3) and that after using VISIR, students felt much more at ease in the hands-on lab, being faster and performing less mistakes.

At the end of the didactical implementation, the head teachers were asked to reply to a guided interview, sent by email. All, except for the cases C1 and C17, replied to the interview, in a total of 40 answers (although not all answered all the questions). The teachers that used VISIR in more than one course or in which the course has undergone several subsequent didactical implementations replied to this interview more than once (according to the number of courses/implementation editions): the answers were very similar from one implementation to the other, although in some new features were reported.

The factor F2_T: Teachers' satisfaction with VISIR (defined in section 4.4.2) was computed as the median of the questions Q1, Q3, Q4, Q5 and Q8 (ㅁppendix B). Teachers' satisfaction with the tool itself was evaluated by Q1, Q3, Q5 and Q8 (easiness, server issues, difficulties to log in and user friendly) and adequacy to teacher's needs was evaluated by Q4 (components suitable). Questions Q3, Q5 and Q8 had answers: 1, 2 and 3; Q4 had just the choices 2 and 3 and for Q1 all 39 answers were in the value 3. The results are displayed in Figure 11 and it is clear that teachers were very satisfied with the tool, except for one of the second editions of case C3 (a secondary level course).

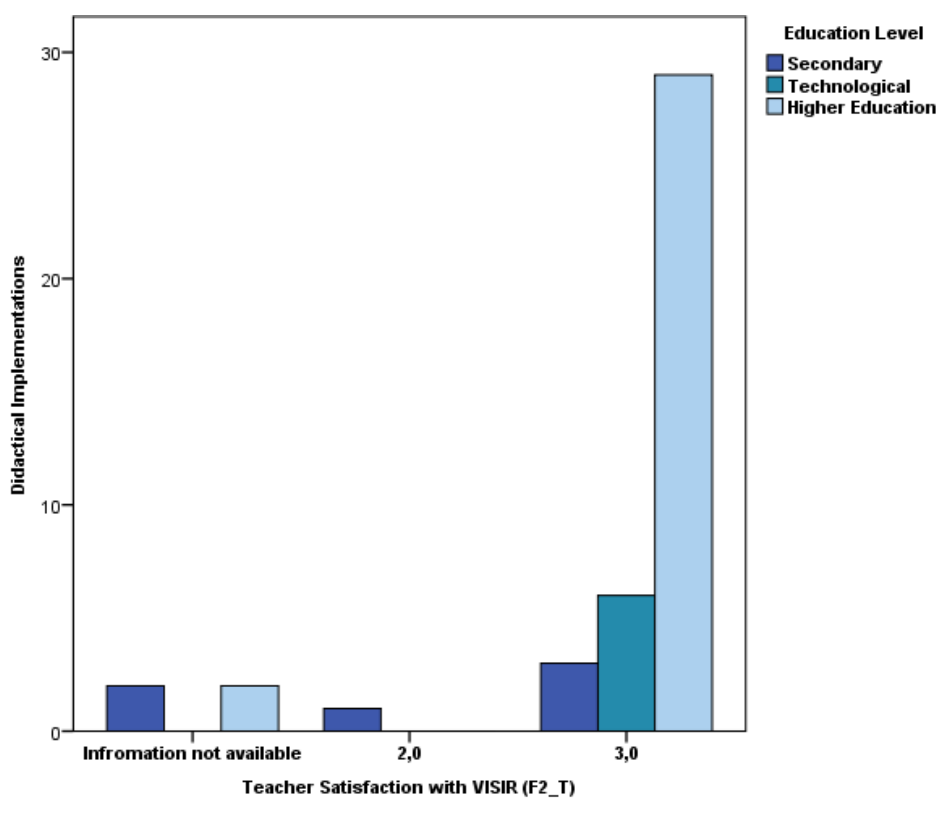

Figure 11 - Teachers' Satisfaction with VISIR 
The other four closed questions, included in the interview (in Appendix B): Q2, Q6, Q7 and Q9 had respectively 39, 38, 37 and 39 answers. The descriptive statistics of the collected answers to these questions revealed:

* Q2: in 78\% of the implementations, teachers considered this methodology, supported by VISIR, allowed them to increase the number of the experiments.

* Q6: in $66 \%$ of the implementations, teachers stated the use of VISIR contributed to the increase of the calculus exercises performed by students.

* Q7: the majority (68\%) indicated that this methodology did not contribute to increase the usage of open experiments.

* Q9: in $42 \%$ of the didactical implementations, teachers did not feel the need to use VISIR manuals as this resource allowed them intuitively to assign experiments.

A qualitative analysis of the open question (What advantages and disadvantages do you find in the use of VISIR?) of the teachers' guided interview was also carried out. The qualitative assessment of the answers to the open question allowed the identification of 10 factors, considering directly teacher satisfaction: 6 positives and 4 negatives. Table 15 summarizes these factors, according to teachers' identification about VISIR main advantages and disadvantages, in which was also included the factor "external factor".

Table 15 - Teacher Open Question Quality Assessment (positive and negative factors (in shadow)

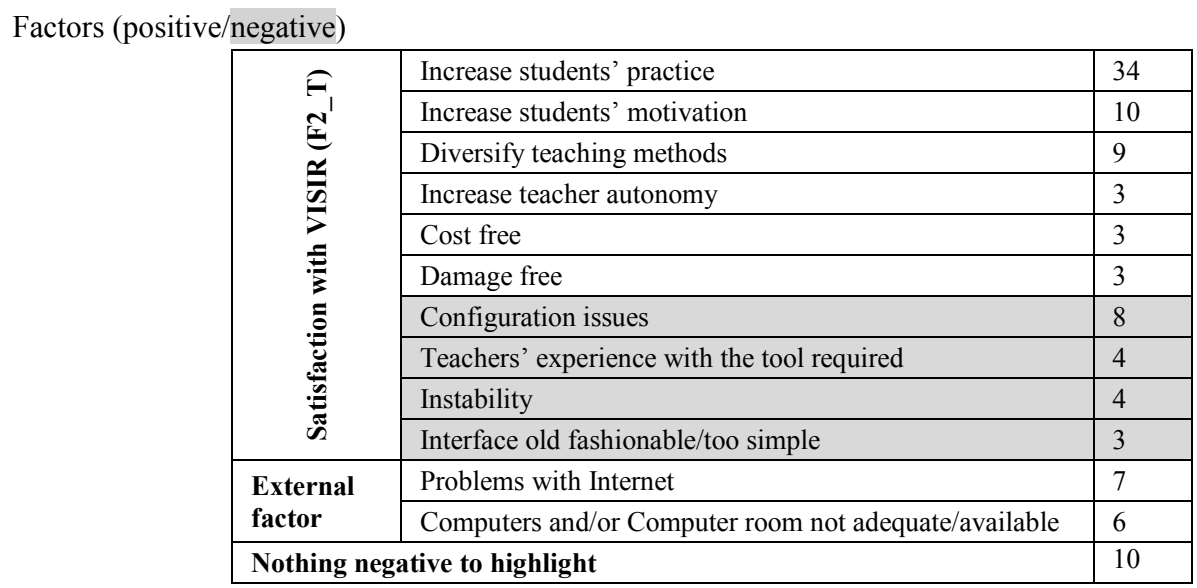

The former factor was reckoned into account for teachers' comments that may compromise their satisfaction and usage of the tool, like problems with Internet and computers and/or computer room not adequate/available, but was due to factors not directly related to VISIR. That was the case of the head teacher of one of the C3 second course editions, which reported the availability of the computer lab is necessary. A good active Internet connection is required all the 
time of use. From this comment (corroborated by the other head teachers' comments), one can infer that he did not have access to the best conditions, which may have contributed to his low satisfaction with VISIR (F2_T). He was the only teacher who just achieved level 2 satisfaction (all the others attained level 3).

Some teachers believed there was no negative factors about VISIR and considering its importance the factor "nothing negative to highlight" was also considered.

The most mentioned positive factor was "increase students' practise", which accordingly to teachers own words included, assembling more circuits and/or several times, learning by doing mistakes, explore and illustrate theoretical concepts and compare measurements/results made with different resources. The second and third most referred factors were 'increase students' motivation" -VISIR was considered an attractive technology to native digital students- and "diversify teaching methods" -diversification of the teaching-learning process- with the opportunity of using this resource as a complement in different types of classes, with several groups of students simultaneously. The other positive factors were "increase teachers' autonomy", as they do not depend on lab/instruments availability and/or an assistant for handson lab and "cost free" and "damage free", respectively no need to buy components and/or instruments and security issues.

The most referred negative factor was "configuration issues", related to specific aspects about VISIR functioning: dependence on a configuration file to perform an experiment (due to the need of prior assembly) and restriction of components (number and type) and nodes. Another referred negative factor was "instability", referring to unstable performance, including some operating issues and problems with the server. The mathematics topic teacher (cases C8 and C9) even made the comment although the performance of the remote lab was unstable at times, I wouldn't say it stopped students from using it, leading to the assumption that this negative factor may not have had a direct impact in students' VISIR usage. Teachers also mentioned 2 more negative factors: "teachers' experience with the tool required": being a new tool, teachers need to spend some time to gain the knowledge and confidence to use it, help students overcame their initial difficulties and stimulate students' perception of VISIR utility; the interface is "old fashionable/too simple": VISIR was launched in 2004 and although during this period it has undergone some changes and updates, the interface may be considered a little old fashionable not only for this generation of digital native students, but also for some teachers.

One teacher also commented students did not complete the proposed tasks in due time and another mentioned his students had some difficulties (mainly at the beginning) in using the system due to low electrical content knowledge. As these are not directly related to VISIR and were hardly mentioned, they were not listed in Table 15. 
The results highlight teachers consider VISIR a valuable resource. In fact, in 10 didactical implementations teachers did not mention any negative factor.

In the cases where it was possible and based upon teachers' comments about their perception of students' general characteristics when starting that course, it was characterized students' level. The results for the 9 cases, where this characterization was possible, are exhibited in Table 16.

Table 16 - Students' Level Characterization

\begin{tabular}{|l|l|l|}
\hline \multicolumn{2}{|c|}{ Students' Level Characterization } & \multicolumn{1}{c|}{ Cases } \\
\hline \multirow{3}{*}{ Difficulties } & prior knowledge & $\mathrm{C} 5, \mathrm{C} 11$ \\
\cline { 2 - 3 } & several skills/competences & $\mathrm{C} 3, \mathrm{C} 5$ \\
\cline { 2 - 3 } & working habits & $\mathrm{C} 3, \mathrm{C} 11$ \\
\hline \multirow{2}{*}{ Interested } & $\mathrm{C} 8, \mathrm{C} 9, \mathrm{C} 19, \mathrm{C} 26\left(1^{\text {st }}, 2^{\text {nd }}\right)$ \\
\hline Good & $\mathrm{C} 8, \mathrm{C} 9, \mathrm{C} 14, \mathrm{C} 16, \mathrm{C} 26$ \\
\hline
\end{tabular}

In some cases, teachers sensed students had difficulties mainly by three motifs: (i) students did not have the adequate prior knowledge either in the course topic or in the needed mathematics concepts; (ii) students did not have some of the soft skills properly developed, such as: oral and written communication and/or did not have adequate reasoning and problem solving competences; (iii) students did not have adequate working habits. In some other cases teachers felt students were interested (in learning) and/or were good students (until the beginning of that course their results in the previous courses were good and they had adequate prior knowledge).

From the data analysis to the category teachers' perception, it is clear both 'teachers' perception of students' satisfaction with VISIR" as well as "teachers' (own) satisfaction with VISIR" (F2_T) were really good (respectively with two and one exception). This perception was corroborated by the qualitative analysis of the open question (included in the teachers' interview) in which teachers identified much more positive features than negative ones related to VISIR. Teachers considered the former tool as a valuable resource, contributing to motivate students and enhance their engagement, being adequate to their practices. Teachers also perceived that in some cases students started the courses with some type of difficulty -"students' level"- which could somehow compromise students' success, although this perception also alerted teachers to the need of paying extra attention to these students. In other cases, teachers recognized students had the adequate prior knowledge and were good and/or interested students. 


\subsection{Students' Results}

In this section all the data collected in the scope of the dimension Students' Results (Table 2, page 74) will be presented and detailed analysed. It was not always possible to collect all the data for all the cases/students. The data will be presented and analysed, accordingly to the two defined categories, each presented as a subsection of this one.

\subsubsection{Academic Performance}

Table 17 summarizes students' academic performance by didactical implementation (considering several courses (cases) have undergone more than one course edition). The last line of Table 17 summarizes these results for the overall students involved in the 43 didactical implementations, for which it was possible to have some or all the data. The first two columns identity respectively the case number and the course edition number. The following columns display the number of freshman, that is the number of students that were enrolled in the course for the first time (Fresh), the number of students that did not fulfil any kind of assessment (NF) or have dropped out the course (Drop) as well as the number of students that teachers consider had developed higher order skills (HOS). The subsequent column indicates if the topics that were introduced using VISIR have been addressed before (in this course or a previous one) or if it was the first-time students were being introduced to it.

Students (individually or in group, depending on the cases) accessed VISIR several times. When students performed group tasks the number of VISIR accesses for each student was considered to be the total number of accesses of all the group members (assuming they worked together, representing a valid VISIR experience for each one). This data was supposed to be easy to get for all students/cases, as all students were thought to have their own individual ID to access VISIR system and VISIR systems have the possibility to register those accesses. But in the beginning and before LA partners had their own VISIR system, some used EU partners VISIR systems through guest accounts and in some this guest account was created for the course (and not one for each student). Then, in some Institutions, the VISIR systems were not installed with that option and so it was not possible to have that information. In some, although the VISIR systems were suitably installed, it was not created an individual ID for each student, but a user account for each course, used by all the enrolled students. When students accessed VISIR exclusively during class time (or in extra presential class time allocated to perform the VISIR task), it was considered the number of VISIR accesses was the same for all students (constant) and equal to the number of classes/extra class sessions where the VISIR activity took place. When the VISIR 
tasks were not performed during class time and students could access freely to VISIR that information became unavailable. The average characterization of this VISIR usage (both total and per task) is also summarized in Table 17.

Table 17 - Students' Academic Performance Characterization

\begin{tabular}{|c|c|c|c|c|c|c|c|c|c|c|c|c|c|c|}
\hline \multirow{2}{*}{ 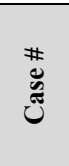 } & \multirow{2}{*}{ 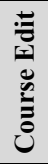 } & \multicolumn{4}{|c|}{ Number of Students } & \multirow{2}{*}{$\begin{array}{l}\text { Topics } \\
\text { Before }\end{array}$} & \multicolumn{2}{|c|}{$\begin{array}{c}\text { Average } \\
\text { VISIR } \\
\text { Accesses }\end{array}$} & \multicolumn{5}{|c|}{ Average Grade (\%) } & \multirow{2}{*}{$\begin{array}{l}\text { Pass } \\
(\%)\end{array}$} \\
\hline & & Fresh & NF & Drop & HOS & & Total & /Task & $\begin{array}{l}\text { VISIR } \\
\text { Tasks }\end{array}$ & $\begin{array}{l}\text { Other } \\
\text { Tasks }\end{array}$ & Lab & Exam & Final & \\
\hline $\mathrm{C1}$ & 1 & 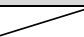 & & 7 & 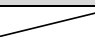 & 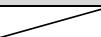 & 7 & 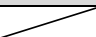 & 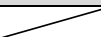 & $>$ & & 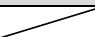 & 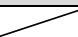 & 7 \\
\hline $\mathrm{C2}$ & 1 & 7 & 7 & 7 & 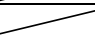 & 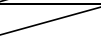 & 7 & 7 & 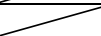 & 7 & & 7 & 7 & 7 \\
\hline \multirow{4}{*}{ C3 } & 1 & 37 & 0 & 0 & 6 & No & 4.0 & 1.0 & 68.2 & 70.3 & No & 70.7 & 76 & 100 \\
\hline & 2 & 23 & 0 & 0 & 4 & No & 6.3 & 2.1 & 61.2 & 67.0 & No & 68.0 & 69.1 & 100 \\
\hline & 2 & 28 & 0 & 0 & 6 & No & 11.8 & 3.9 & 76.6 & 64.6 & No & 69.7 & 76.8 & 85.7 \\
\hline & 2 & 33 & 0 & 0 & 6 & No & 5.4 & 1.8 & 78.7 & 76.7 & No & 76.5 & 76.4 & 100 \\
\hline C4 & 1 & 15 & 7 & 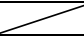 & $\infty$ & 2 & 7 & 2 & 2 & 2 & & 2 & 1 & 7 \\
\hline \multirow{3}{*}{ C5 } & 1 & 37 & 20 & 0 & 4 & No & 7 & 7 & 7 & 7 & & & 57.1 & 40.7 \\
\hline & 2 & 33 & 23 & 0 & 7 & No & 2.0 & 1.0 & 100 & No & No & 39.4 & 64.3 & 43.6 \\
\hline & 3 & 40 & 18 & 1 & 10 & No & 3.6 & 1.8 & 73.5 & 76.1 & No & 43.8 & 60.4 & 29.1 \\
\hline C6 & 1 & 0 & 2 & 0 & 2 & No & 1 & 7 & 90.0 & 80.0 & No & 7 & 78.3 & 75.0 \\
\hline C7 & 1 & & 7 & - & $\sigma$ & 7 & 3.9 & 1.3 & 7 & 7 & 5 & 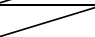 & 5 & 7 \\
\hline \multirow{3}{*}{ C8 } & 1 & 2 & 6 & 0 & 9 & No & $>$ & 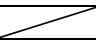 & 90.6 & 73 & No & 63.0 & 63.7 & 63.9 \\
\hline & 2 & 43 & 0 & 1 & 5 & No & 3.6 & 3.6 & 82.2 & 82.5 & No & 44.6 & 54.7 & 62.8 \\
\hline & 3 & 39 & 0 & 2 & 10 & No & 6.3 & 6.3 & 86.4 & 78.6 & No & 51.2 & 60.3 & 75.6 \\
\hline \multirow{2}{*}{ C9 } & 1 & 42 & 2 & 2 & 9 & No & 3.4 & 3.4 & 94.1 & 83.6 & No & 62.1 & 70.4 & 81.0 \\
\hline & 2 & 27 & 4 & 2 & 7 & No & 2.8 & 2.8 & 83.1 & 79.0 & No & 53.2 & 57.9 & 59.5 \\
\hline \multirow[b]{2}{*}{ C10 } & 1 & 31 & 2 & 0 & 12 & No & $\overline{7}$ & 7 & 7 & 7 & & 7 & 70.6 & 80.6 \\
\hline & 2 & 13 & 2 & 0 & 10 & No & 7 & $\Gamma$ & 86.7 & 89.2 & No & 65.5 & 68.6 & 64.3 \\
\hline C11 & 1 & 15 & 1 & 0 & 1 & 1 & 6.2 & 3.1 & 42.5 & 77.6 & 62.9 & 52.2 & 52.1 & 52.6 \\
\hline $\mathbf{C 1 2}$ & 1 & 7 & 0 & 4 & 1 & No & 3.5 & 1.7 & 7 & 1 & & 1 & 69.3 & 72.2 \\
\hline C13 & 1 & 7 & 6 & 0 & 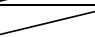 & No & 17.2 & $\begin{array}{l}5.8 \\
\end{array}$ & 1 & 1 & & 7 & 70.0 & 40.0 \\
\hline \multirow{2}{*}{ C14 } & 1 & 1 & 7 & 7 & 1 & Yes & 7 & 7 & 1 & 1 & & 1 & 7 & 1 \\
\hline & 2 & 23 & 0 & 3 & 1 & Yes & 9.1 & 3.0 & 62.9 & 80.2 & 64.8 & 47.7 & 7 & 55.6 \\
\hline $\mathbf{C 1 5}$ & 1 & 20 & 3 & 0 & 7 & No & 17.3 & 4.3 & 7 & 7 & 7 & 7 & 76.9 & 85.0 \\
\hline \multirow{2}{*}{ C16 } & 1 & 251 & 1 & 3 & 1 & No & 8.9 & 2.3 & 85.7 & 94.6 & 95.5 & 72.6 & 7 & 93.8 \\
\hline & 2 & 177 & 1 & 0 & 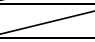 & No & 6.4 & 1.6 & 86.4 & 95.2 & 92.1 & 77.8 & $\gamma$ & 97.8 \\
\hline \multirow[b]{2}{*}{$\mathbf{C 1 7}$} & 1 & 1 & 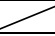 & 7 & 1 & Yes & 10.3 & 3.4 & 1 & 1 & & 1 & 1 & 1 \\
\hline & 2 & 7 & & 7 & 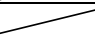 & Yes & 7 & 7 & 7 & 7 & & 1 & 7 & \\
\hline C18 & 1 & 7 & 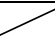 & 7 & $\Gamma$ & No & 7 & 7 & 7 & & & & 7 & \\
\hline \multirow{3}{*}{ C19 } & 1 & 15 & 0 & 4 & 3 & Yes & 7.4 & 7.4 & 100 & 7 & 75.7 & 7 & 81.8 & 73.3 \\
\hline & 2 & 10 & 2 & 0 & 8 & Yes & 6.9 & 6.9 & 86.4 & 7 & 79.3 & 1 & 82.9 & 91.3 \\
\hline & 3 & 17 & 0 & 2 & 4 & Yes & 15.5 & 15.5 & 100 & 74.1 & $\begin{array}{l}71.5 \\
\end{array}$ & 7 & 82.7 & 88.2 \\
\hline \multirow[b]{2}{*}{$\mathbf{C 2 0}$} & 1 & 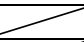 & 15 & 11 & 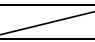 & Yes & 6.3 & 6.3 & 78.6 & 7 & & 7 & 70.0 & 25.0 \\
\hline & 2 & 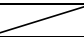 & 17 & 9 & $\Gamma$ & Yes & 13.3 & 13.3 & 90.8 & 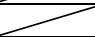 & & $\Gamma$ & 72.8 & 52.7 \\
\hline $\mathrm{C} 21$ & 1 & 60 & 7 & 7 & $\Gamma$ & Yes & 9.7 & 9.7 & 7 & 7 & $\tau$ & 7 & 7 & 7 \\
\hline C22 & 1 & 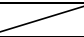 & & $=$ & 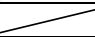 & 7 & 7 & 7 & 7 & 7 & 5 & 7 & 7 & 7 \\
\hline $\mathrm{C23}$ & 1 & 13 & 2 & 0 & 10 & Yes & 6.1 & 3.1 & 81.8 & No & No & 69.6 & 72.8 & 76.9 \\
\hline $\mathrm{C24}$ & 1 & 8 & 1 & 0 & 6 & Yes & 3.1 & 1.6 & 92.9 & No & No & 70.0 & 72.9 & 87.5 \\
\hline $\mathrm{C} 25$ & 1 & 7 & 0 & 1 & 3 & No & 1 & 1 & 1 & 7 & 1 & 1 & 1 & 12.5 \\
\hline \multirow{3}{*}{$\mathrm{C26}$} & 1 & 41 & 15 & 3 & 6 & No & 2.4 & 2.4 & 78.3 & No & 65.8 & 47.9 & 53.7 & 65.8 \\
\hline & 2 & 41 & 8 & 1 & 8 & No & 7.4 & 7,4 & 80 & No & 57.6 & 36.2 & 54.1 & 64.5 \\
\hline & 3 & 46 & 7 & 12 & 10 & No & 12.8 & 12.8 & 72.0 & 61.3 & 58.2 & 47.7 & 57.0 & 54.1 \\
\hline Total & & 1178 & 158 & 61 & 161 & 7 & 7.3 & 4.1 & 82.7 & 84.6 & 81.6 & 62.9 & 65.1 & 73.3 \\
\hline
\end{tabular}

In the same table students' academic results are also considered: the average grade obtained in each evaluation component (a "No" in a component grade means that there is not a specific grade for that component) along with the final grade and the percentage of students that had success on the course show up in the last column. The final grade as well as the grades obtained in each component and some additional information characterizing students' "success" 
were delivered by the teacher (teacher grade file). However, despite our effort and reiterated requests, some teachers did not deliver at all that information or it was not complete. Plus, in some cases (in which teachers delivered that information) it was difficult to have the information about the VISIR grade in a very precise way: a few teachers considered students achieved $100 \%$ in that component) if they fully delivered the proposed activity and/or $50 \%$ if they delivered half of it and obviously were not graded if they did not deliver nothing; but still, its contribution to students' final grade was merely qualitative. In some others, that also opted for VISIR task as a qualitative contribution. it was not possible to quantify it at all.

As it can be observed in Table 17, the percentage of students that was enrolled in each course for the first time shows a wide range of variability: from cases where all the students were freshman (C3, C8 (second edition), C9 (first edition), C10 (first edition), C15, C19 (first and third editions), C21, C23 and C24) to a case -C6- where all students were repeating the course. In fact, from the 1377 students for which we have the information about this parameter, 1178 are freshman (86\%). The number of students that did not fulfil any kind of assessment also varies amongst the cases: from 0 students in cases C3, C8 (second and third editions), C12, C14, C19 (first and third editions) and C25 to about $40 \%$ of $\mathbf{N F}$ in all editions of case $\mathrm{C} 5$ and in the second course edition of C20. The number of students who dropped out the course is zero in courses from the secondary level of education and one (in total) in the technological level. In the HE level, this number presents some variability, being low in the majority of the cases. The exceptions are cases C12, C19 (1 ${ }^{\text {st }}$ course edition), C20 and C26 (3 $3^{\text {rd }}$ course edition), where the percentage of students that dropped out varies between $16 \%$ to $30 \%$. The information about the number of students that teachers consider had develop HOS is missing for many didactical implementations. Still this number is in the majority of the cases between 10 to 20\%, reaching very high values (around $75 \%$ ) for cases C10 (second edition), C23 and C24.

Students' background was also characterized by 2 more items: if the topics covered by VISIR (electrical and electronic circuit contents) were or not previously addressed and if students were using VISIR for the first time (as they could eventually have used it in another course or could be repeating the course). The results are displayed in Figure 12. 

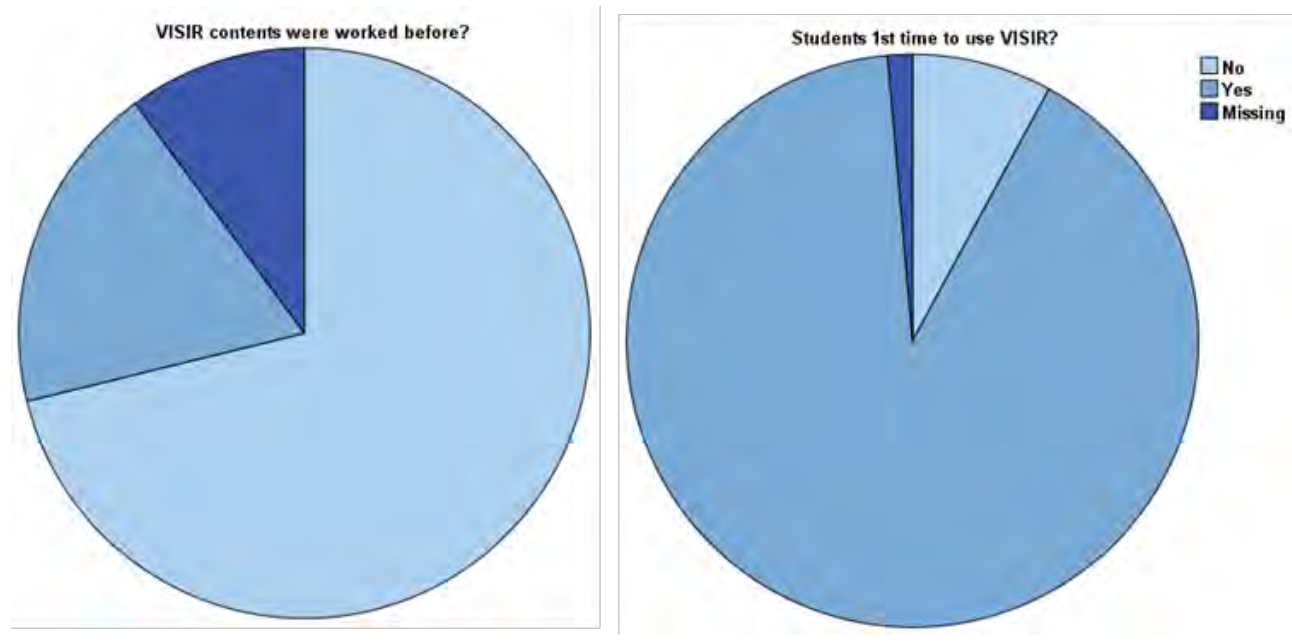

Figure 12 - Students' Background

For the majority of the students (76\%) it was the first time these topics were addressed and just 142 students (8\%) had already used the remote lab VISIR before.

The average number of students' VISIR accesses per task varies enormously: from 1.0 (cases C3 (first edition) and C5 (second edition)) to 15.5 (case C19 (third edition). It was not possible to collect this information (number of students' accesses) for some didactical implementations involving 371 students. Considering the students for which it was possible to collect this information, $21 \%$ did not access VISIR, at least using their own individual ID log register (if the tasks were individual); if the tasks were done in group the individual accesses of each student was the sum of the accesses of all group members: in these cases, students may have accessed VISIR using just the ID of one of the group elements.

The grades obtained in each component as well as the final grade also show a wide range of variability, although this variety is not similar for all components. In general, students achieved good results in the VISIR component -over $80 \%$ in the majority of the cases-although in case C11 the average grade was $42.5 \%$. The average other tasks grade was quite good, varying from $61.3 \%$ to $95.2 \%$, although just in three didactical implementations this average grade was below $70 \%$. Although in the majority of the implementations there was a hands-on component (traditional lab), that component did not always have a distinct grade as it can be observed in Table 17. Still for the cases where this grade exists and is known, the results were pretty reasonable, being excellent in case C16. The average exam grade is the component where the students achieved worse results, except students from the secondary level for which the average grade was about the same in all components as well as the final grade. In fact, there are 7 didactical implementations where the average exam grade is below $50 \%$ and just in 5 didactical implementations the result is equal or over $70 \%$ (but below $80 \%$ ). The average final grade also 
presents a wide-ranging from $52.1 \%$ (case C11) to around $82 \%$ (case C19). The percentage of students that had success in the course also exhibits an extensive variety: from $12.5 \%$ (case C25) to $100 \%$ (case C3).

Considering the results displayed in the last line of Table 17 it is clear the average grades obtained in the VISIR tasks, other tasks and laboratory are very similar in opposition to the exam grade and final grade (alike between them) that are clearly lower, although $73.3 \%$ of the students have passed the courses.

Students' academic performance was also summarized by education level, by implementation topic and by VISIR use level in course contents. Table 18 summarizes these results. Still when the results are considered by these topics, one must bear in mind that the information that is missing for some students -particularly the number of students that teachers consider had developed higher order skills (HOS)- may have an enormous impact. So, in those cases, a reference will be made.

Table 18 - Students' Academic Performance Characterization by Topic

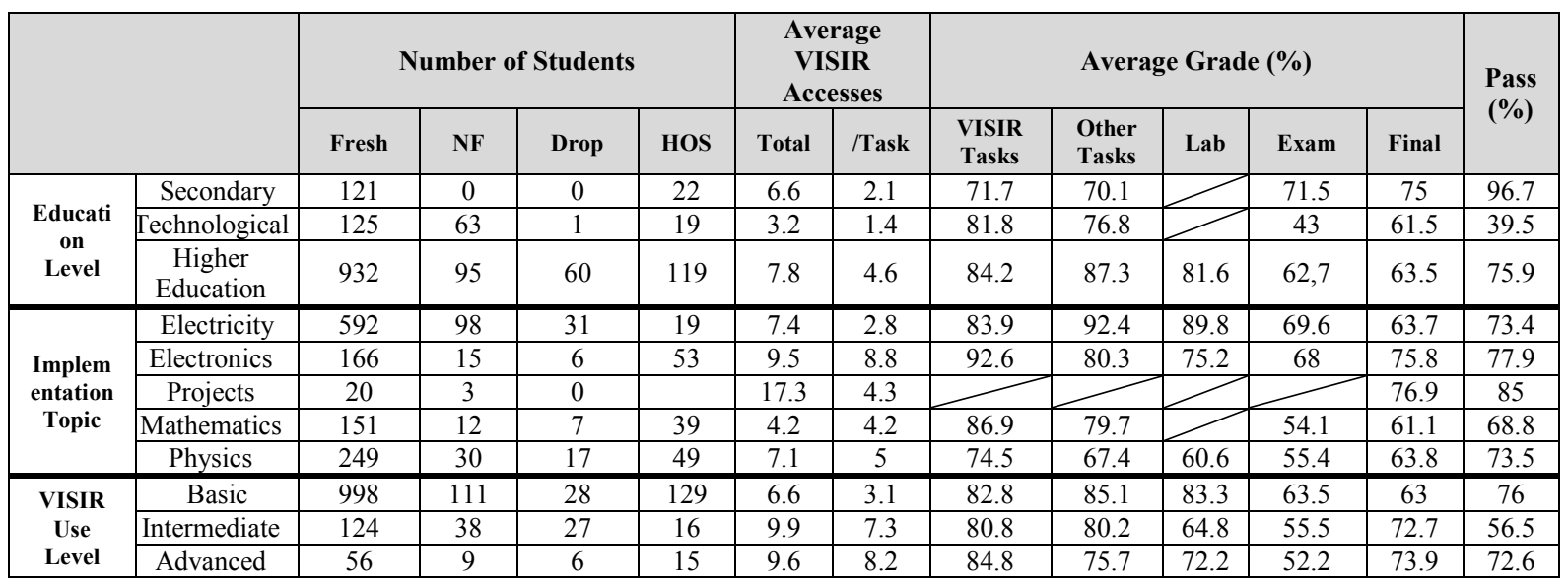

Considering the analysis by education level it is clear students from the secondary education level achieved a higher level of success on the courses while students from the technological level had a high level of failures. Considering the students for which we have information, students from the secondary fulfilled the assessments and did not dropout the course, reaching good grades in the exam leading to a success rate of $97 \%$, with a good average final grade. In the technological level for which we lack the information for $23 \%$ of the students, there is a high percentage of students that did not completed any kind of assessment (28\%), leading to a very low course success rate; in fact, the majority (60\%) failed the course, although the majority (of students) that fulfils the proposed activities has success. Students from higher education are the ones with better grades in the VISIR component as well as in the other tasks and the lab. They also had a higher average number of VISIR accesses per task in opposition to the 
technological level which had the lowest. In the HE level, the percentage of NF and dropouts is low, respectively $7 \%$ and $5 \%$, although that information is lacking for $14 \%$ of the students. Considering the percentage of students enrolled in the course for the first time in each level there is information that is missing; if we neglect it, that is consider the valid percentage (not considering the missing values) this value (the number of students enrolled in the course for the first time) reaches $100 \%$ for the secondary level, while 33\% of the technological students are repeating the course. Despite all this, the number of students that developed HOS, accordingly to teachers' perception, does not differ significantly amongst levels.

Considering the same type of analysis by implementation topic these differences in students course rate of success fade up. Students from electronics are the ones who reached a better average grade in the VISIR component, although the average grade obtained in this component was good for all implementation topics. In fact, except for the electricity topic, the VISIR average grade was the best (of all partial grades and final grade). Students from electronics present a much higher number of VISIR accesses per task opposing to the electricity students that exhibit the lowest number. In view of the number of freshmen, and although we just have the information for all students in mathematics and projects, the topic which presents a higher number of students repeating the course is physics in opposition to projects where all the students are freshman. Mathematics topic presents the lowest number of students that did not complete any kind of assessment as well as the lowest number of students that dropped out the course, respectively $6 \%$ and $4 \%$. Considering the number of students that teachers consider having developed HOS the number of students for which there is no information is really high; still that percentage is higher in electronics.

Considering the analysis by VISIR use level the number of VISIR accesses per task increased with the level of VISIR usage, although the grades obtained in the VISIR component are about the same in the three levels. In the advanced level students obtained a higher final average grade, although the partial grades and the exam grade were lower than the corresponding in the basic level. In fact, in the basic level students got the higher rate of course success. The percentage of students that is repeating the course is considerably higher on the advanced level than in the lower levels (although there is not information for all students in all levels); it is also in this level that teachers identified a higher percentage of students that developed HOS, although for the intermediate level we just have that information for $7 \%$ of the students. The intermediate level has a noteworthy higher number of students that did not fulfil any kind of assessment and dropped out the course. 
From the data analysis to the category academic performance and considering the overall results from the 1794 students involved in the former didactical implementations it is incontestable that their average grades were good specially in the VISIR tasks, other tasks and the lab component. Their exam and final grades are noteworthy lower although their rate of success (in the courses) is quite acceptable. Considering "students' background", the majority was introduced to these EE topics for the first time, being also their first contact with VISIR. These results represent the average results of the students involved in the 43 didactical implementations and naturally not all of them achieved similar success rates. In fact, there were a few courses that presented an outstanding number of NF students (C5, C20) and/or dropouts (C20) and/or a really low value of success (C20, C25). The "number of students' VISIR accesses per task" displayed a wide range of variability; their "VISIR grades" were, for the majority of the didactical implementations, above 80\%, although in one case their average VISIR grade achieved a really low value $(42.5 \%)$.

The previous analysis showed the secondary "education level" students were the ones who achieved a higher level of success contrasting with the technological courses in which the number of NF and failures was really high. Students from the implementation topic electronics were the ones who accessed more VISIR and also where better grades in the VISIR tasks were achieved. An equivalent scenario is noticeable for the students in which "VISIR use level" was advanced.

\subsubsection{Students' Perception}

At the end of each didactical implementation, students were asked to fill up a student's satisfaction questionnaire (SSQ), in their native language. The SSQ was delivered in most cases in paper, although in some didactical implementations teachers opted for making it available on the LMS (Learning Management System) course page or via a GOOGLE form. The SSQ, as detailed described

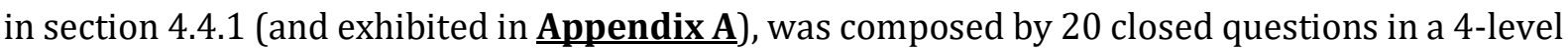
Likert agreement scale (1-I do not agree; 2-I partially agree; 3-I agree; 4-I fully agree) and two open questions asking for students' opinion about VISIR main advantages and disadvantages. Using 15 out of the 20 closed questions of the SSQ three factors, considering students' perception about VISIR, were studied. These factors were computed as the median (central tendency) of the questions that were used to address each of them. The three factors (described in section 4.4.1) are:

* F1 - Students' perceived learnings. There were used 5 questions (Q2, Q14, Q16, Q18 and Q20) addressing students perceived comprehension of the subject and their lab confidence skills. 
* F2 - Students' satisfaction with VISIR. There were 7 questions (Q1, Q3, Q6, Q7, Q12, Q17 and Q18) addressing VISIR usage and its perceived most value.

* F3 - Students' satisfaction with support. There were 4 questions (Q4, Q9, Q10 and Q15) addressing the perceived assistance towards the system.

This factor analysis is summarized, by didactical implementation in Table 19, in which the third column exhibits the number of students enrolled in the course. The last line of the table summarizes these results for the overall students involved in the 43 didactical implementations that answered the SSQ (F1: 952 answers; F2: 935 answers; F3: 908 answers).

Table 19 - Students' Perception of VISIR

\begin{tabular}{|c|c|c|c|c|c|}
\hline \multirow{2}{*}{ 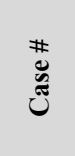 } & \multirow{2}{*}{ 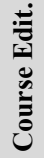 } & \multirow{2}{*}{$\begin{array}{l}\text { Number } \\
\text { Students }\end{array}$} & \multicolumn{3}{|c|}{ Students' Perception (median) } \\
\hline & & & F1 & F2 & F3 \\
\hline C1 & 1 & 65 & 2 & 2 & $\infty$ \\
\hline $\mathbf{C 2}$ & 1 & 25 & 2 & 2 & 2 \\
\hline \multirow{4}{*}{ C3 } & 1 & 37 & 3 & 3 & 3,5 \\
\hline & 2 & 23 & 3 & 3 & 3 \\
\hline & 2 & 28 & 3 & 3 & 2 \\
\hline & 2 & 33 & 3 & 3 & 2.75 \\
\hline $\mathrm{C4}$ & 1 & 15 & 3 & 3 & 2.5 \\
\hline \multirow{3}{*}{$\mathrm{C5}$} & 1 & 54 & 3 & 3 & 2.5 \\
\hline & 2 & 55 & 3 & 3 & 2.5 \\
\hline & 3 & 55 & 3 & 3 & 2.5 \\
\hline C6 & 1 & 8 & 3 & 3 & 2 \\
\hline C7 & 1 & 35 & 4 & 4 & 2.25 \\
\hline \multirow{3}{*}{ C8 } & 1 & 36 & 3 & 3 & 3 \\
\hline & 2 & 43 & 3 & 3 & 3 \\
\hline & 3 & 45 & 2.5 & 2 & 2.5 \\
\hline \multirow{2}{*}{ C9 } & 1 & 42 & 3 & 3 & 2.5 \\
\hline & 2 & 42 & 3 & 3 & 2.5 \\
\hline \multirow{2}{*}{$\mathrm{C} 10$} & 1 & 31 & 3 & 3 & 2.5 \\
\hline & 2 & 14 & 3 & 3 & 3 \\
\hline C11 & 1 & 19 & 3 & 2 & 2.5 \\
\hline C12 & 1 & 18 & 3 & 3 & 2.5 \\
\hline C13 & 1 & 10 & 3.5 & 3 & 3 \\
\hline \multirow{2}{*}{$\mathrm{C} 14$} & 1 & 23 & $=$ & $=$ & \\
\hline & 2 & 36 & 2 & 1 & 2 \\
\hline C15 & 1 & 20 & 3 & 2 & 2.5 \\
\hline \multirow{2}{*}{$\mathrm{C} 16$} & 1 & 260 & 3 & 2 & 2.5 \\
\hline & 2 & 182 & 3 & 2.5 & 2.5 \\
\hline \multirow{2}{*}{ C17 } & 1 & 14 & 3 & 4 & 2.5 \\
\hline & 2 & 36 & $=$ & $=$ & $\longrightarrow$ \\
\hline C18 & 1 & 15 & 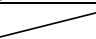 & 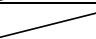 & 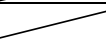 \\
\hline \multirow{3}{*}{ C19 } & 1 & 15 & 3 & 3 & 3 \\
\hline & 2 & 23 & 3 & 3 & 3 \\
\hline & 3 & 17 & 2 & 2 & 2,5 \\
\hline \multirow{2}{*}{ C20 } & 1 & 36 & 3 & 3 & 3 \\
\hline & 2 & 55 & 3 & 3 & 2.5 \\
\hline C21 & 1 & 60 & 3 & 3 & 2.75 \\
\hline $\mathrm{C22}$ & 1 & 41 & 3 & 3 & 3 \\
\hline $\mathrm{C23}$ & 1 & 13 & 2 & 2 & 1.5 \\
\hline C24 & 1 & 8 & 3 & 3 & 2.5 \\
\hline $\mathrm{C25}$ & 1 & 8 & 3 & 3 & 3.5 \\
\hline \multirow{3}{*}{$\mathrm{C26}$} & 1 & 76 & 3 & 3 & 3 \\
\hline & 2 & 62 & 3 & 3 & 3 \\
\hline & 3 & 61 & 3 & 3 & 3 \\
\hline Total & & 1794 & 3 & 3 & 2.5 \\
\hline
\end{tabular}


The results on the three factors of analysis (F1, F2 and F3) appear in shadow, when the calculated Cronbach alpha of these factors was below 0.5 (not consistent).

Although F2 is in some cases a little lower than F1, in most didactical implementations F1 and F2 achieve the same value of 3. That is also the value that we get, when the overall students that answered the SSQ are considered, showing students were satisfied with VISIR and believe it was a useful resource that helped them in their (perceived) learning. There are still some cases that stand out (in a negative and positive way), reaching different values of F1 and F2. Students from case C7 are the ones who were more enthusiastic about VISIR while students from case C14 (second course edition) did not appreciate the resource: although they considered their perceived learning was low, they were even more unhappy with the tool itself. The calculated Cronbach alpha for F3 was below 0.5 , for the majority of the implementations. However, it is noticeable from the results exhibited in Table 19, that this value is typically lower than F1 and F2; students did not feel so satisfied with support as they did with the resource itself and their perceived learnings with it.

The factor analysis F1, F2 and F3 was also summarized by education level, by implementation topic and by VISIR use level in course contents. Table 20 summarizes these results.

Table 20 - Students' Perception of VISIR by Topic

\begin{tabular}{|c|c|c|c|c|c|}
\hline & & \multirow{2}{*}{$\begin{array}{l}\text { Number } \\
\text { Students }\end{array}$} & \multicolumn{3}{|c|}{ Students' Perception (median) } \\
\hline & & & F1 & F2 & F3 \\
\hline \multirow{3}{*}{$\begin{array}{l}\text { Education } \\
\text { Level }\end{array}$} & Secondary & 211 & 3 & 3 & 3 \\
\hline & Technological & 222 & 3 & 3 & 2.5 \\
\hline & Higher Education & 1361 & 3 & 3 & 2.5 \\
\hline \multirow{5}{*}{$\begin{array}{c}\text { Implementation } \\
\text { Topic }\end{array}$} & Electricity & 941 & 3 & 3 & 2.5 \\
\hline & Electronics & 191 & 3 & 3 & 2.5 \\
\hline & Projects & 20 & 3 & 2 & 2.5 \\
\hline & Mathematics & 208 & 3 & 3 & 3 \\
\hline & Physics & 434 & 3 & 3 & 3 \\
\hline \multirow{3}{*}{$\begin{array}{l}\text { VISIR Use } \\
\text { Level }\end{array}$} & Basic & 1392 & 3 & 3 & 2.5 \\
\hline & Intermediate & 318 & 3 & 3 & 3 \\
\hline & Advanced & 84 & 2.5 & 2.5 & 2.5 \\
\hline
\end{tabular}

Students' perceived learnings (F1) as well as students' satisfaction with VISIR (F2) are nearly constant for all considered topics and equal to each other. Once again, F3 tends to have a lower value. In projects, F2 has a lower value and in the advanced VISIR use level, F1 and F2 assume both also a lower value. In projects, students have used several types of resources, including other remote labs (and some more sophisticated). So, naturally VISIR did not cause a big impression on them. The advanced VISIR use level just comprises three cases -C11, C13 and C19- and in the third course implementation edition of case C19, both F1 and F2 lowered from the value 3 (achieved in the first two course editions) to the value 2 . It is precisely the former value 
that is responsible for this lower perception in the advanced VISIR use level. Still this lower perception seems to be related with some problems/constraints on a specific course edition.

Considering the factor F2 - satisfaction with VISIR, a detailed analysis of the answers to one of the questions Q3 (preference for remote labs to hands-on experiments) is illustrated in Figure 13 , by education level and split by VISIR use level. It is clear that the majority prefer remote labs. This preference is particularly high for the students from the secondary: $72 \%$ answered 3 or 4 , expressing their agreement or fully agreement with I prefer remote labs to hands-on experiments. Just for the VISIR use level intermediate, HE students quantified their agreement/fully agreement with the previous statement in $40 \%$, while $41 \%$ expressed their disagreement (answer 1) with it. Students from electricity implementation topic express a similar opinion.

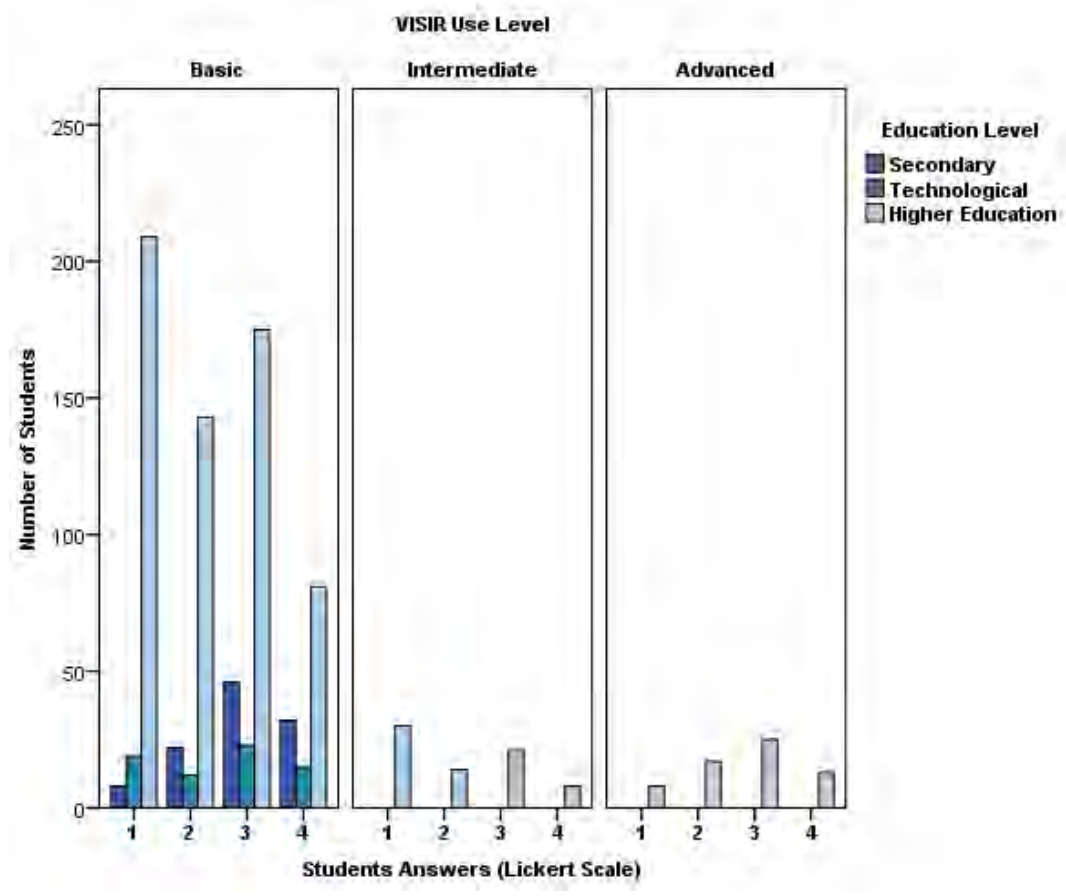

Figure 13 - Students' preference for remote labs versus hands-on labs

This methodology -using several experimental resources- allows students to practice some experimental skills in a different manner, but to take the most of it, they need to understand the major differences of the type of data (measurements) gathered while using it. Still, some students do not really understand it and "this difficulty is not even acknowledged by some, who think they did understand it" (Lima, Viegas, Zannin, Marques, Alves, Felgueiras, Costa, et al., 2017). Considering its importance, students' answers to questions Q13 (I could see the differences between results obtained by simulations and remote labs) and $\mathbf{Q 1 8}$ (I could see similarities between experimenting with remote and hands-on labs) were analysed and its results are illustrated in Figure 14 (by education level and split by VISIR use level). 

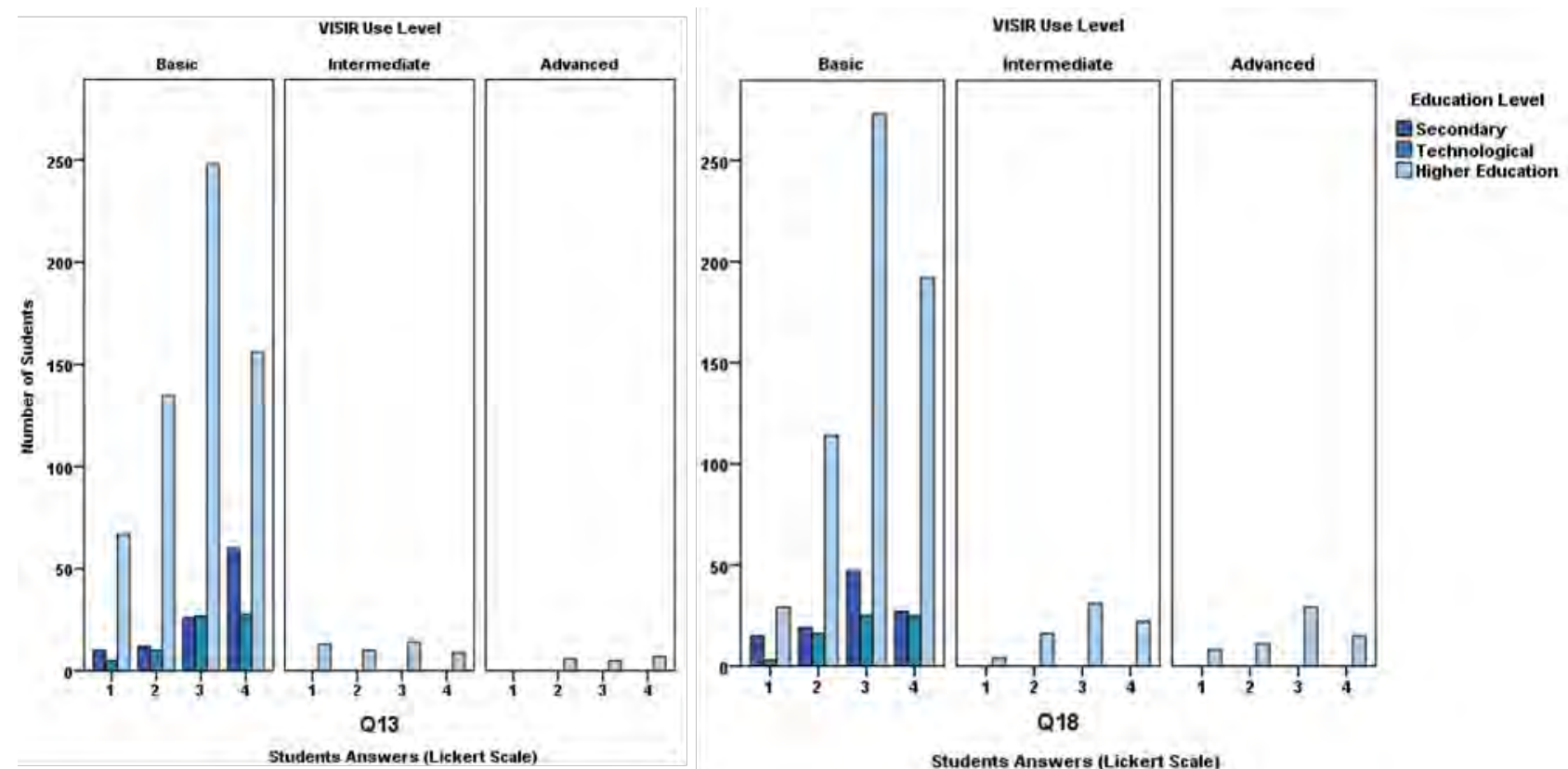

Figure 14 - Students' Answers to Questions Q13 and Q18

It is clear, from Figure 14, the majority of the students considers they have understood it (answered 3 or 4, stating their agreement or fully agreement), respectively $68 \%$ and $74,5 \%$ of all students that answered Q13 (848 answers) and Q18 (921 answers). A minority of students answered 1 (disagreement), respectively $11 \%$ and $6 \%$. Analysing by education level, these results do not differ a lot, although students from the secondary and technological levels are even more sure they understood the differences between the results obtained by simulation and remote labs. However, students from the secondary level achieved a lower value considering their answer to Q18. Considering the VISIR use level, students from the intermediate level did not understand so well the differences between the results obtained by simulation and remote labs (49\% answered 3 or 4 in the Likert scale).

It was carried out a qualitative assessment of the open questions, included at the end of the Student's Satisfaction Questionnaire (SSQ): Q21 (What did you enjoy most about using VISIR remote lab?) and Q22 (What inconveniences did you find about using VISIR remote lab?). In general students are not particularly attracted to this type of open questions, as although they can express their opinions freely, this type of answer requires introspection and effort. So, when they choose to answer it, is because they feel the need to express their opinion and usually what they write can be extremely meaningful. Each student may identify as many features as they considered being more relevant to him/her.

In this study, in most of the courses, a great number of students chose to answer these open questions: relatively to the ones who had answered the SQ (959 (out of 1794) students, although 
not all of them answered all the questions, even just considering the closed questions: 76\% answered Q21 and 73\% answered Q22. The overall analysis of these two questions allowed the identification of 5 positive factors (which denote students' satisfaction with VISIR) and 13 negative factors (which denote students' dissatisfaction). Several of these 13 negative factors can be linked together ("problems in understanding at the beginning" / "problems in understanding"; "insufficient preparation from classes" / "insufficient material support"; "time allocated" / "circuits limitation"), resulting in just 10 factors. Nevertheless, considering the number of expressed opinions, there were 907 positive remarks and 555 negative ones. An "external factor", related to problems with Internet connection, that generally describes problems like, in students' own terms, a long time to upload, it does not open in some browser, difficulties to login, was also reported by 89 students. Several students answered "nothing", "nothing in particular" and "everything" to Q21. Even though the first two answers have very similar words, these answers can have completely different meanings: the first is an expression that the student did not like anything at all about VISIR; the second expressing there is nothing to highlight. The third answer means students liked everything about VISIR. Considering the answer to Q22 the answers "none" and "everything" also showed up. Again, extra care was taken analysing these answers: "none" means there is nothing to highlight while the second means students did not like anything about VISIR. So, to contemplate these answers, the factors "nothing positive to highlight" (9 answers) and "nothing negative to highlight" (146 answers) were also considered, suggesting respectively they did not find anything interesting in the resource and they truly appreciated VISIR and all its potentialities. Although some courses have undergone two or three course editions, with, in some cases, differences from one to the other, these results are exposed by case. Their answers distribution amongst the identified factors may be observed in Table 21, split by education level, in which the last column expresses the total number of opinions, by factor. 
Table 21 - Students Quality Assessment on the Open Questions (identified positive and negative factors (in shadow))

\begin{tabular}{|c|c|c|c|c|c|c|c|c|c|c|c|c|c|c|c|c|c|c|c|c|c|c|c|c|}
\hline \multirow{3}{*}{\multicolumn{2}{|c|}{ ctor }} & \multirow{2}{*}{\multicolumn{4}{|c|}{ Technological }} & & & & & & & & & & & & & & & & & & & \\
\hline & & & & & & \multicolumn{18}{|c|}{ Higher Education } & \multirow{2}{*}{ 苛 } \\
\hline & & ¿ & ヘ & ४ & 5 & 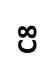 & 8 & 웝 & $\vec{\exists}$ & ปี & $\stackrel{m}{y}$ & $\underset{U}{J}$ & 군 & $\stackrel{\square}{3}$ & 겅 & 겁 & ర్రి & $\dot{\widetilde{U}}$ & $\tilde{ช}$ & $\tilde{\widetilde{U}}$ & 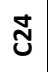 & กี & đั & \\
\hline \multirow{4}{*}{ 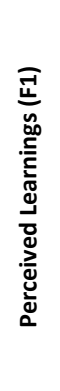 } & $\begin{array}{l}\text { Better/more complete } \\
\text { understanding }\end{array}$ & 1 & 7 & 1 & 1 & 23 & 1 & 4 & 0 & 0 & 0 & 1 & 1 & 62 & 3 & 3 & 9 & 8 & 6 & 2 & 0 & 1 & 7 & 141 \\
\hline & $\begin{array}{l}\text { Problems in } \\
\text { understanding at the } \\
\text { beginning }\end{array}$ & 0 & 2 & 0 & 0 & 5 & 0 & 1 & 0 & 0 & 0 & 0 & 0 & 22 & 0 & 8 & 1 & 1 & 0 & 0 & 0 & 0 & 2 & 42 \\
\hline & $\begin{array}{l}\text { Problems in } \\
\text { understanding }\end{array}$ & 0 & 7 & 0 & 0 & 12 & 0 & 0 & 0 & 1 & 0 & 0 & 2 & 81 & 0 & 10 & 1 & 0 & 3 & 0 & 0 & 0 & 1 & 118 \\
\hline & Time allocated & 0 & 0 & 0 & 0 & 0 & 0 & 0 & 0 & 0 & 0 & 0 & 0 & 3 & 0 & 2 & 0 & 2 & 0 & 0 & 0 & 0 & 0 & 7 \\
\hline \multirow{9}{*}{ 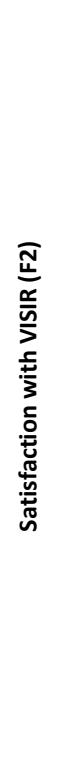 } & $\begin{array}{l}\text { Access from } \\
\text { anywhere/ anytime }\end{array}$ & 0 & 8 & 0 & 2 & 14 & 5 & 3 & 6 & 5 & 4 & 0 & 8 & 159 & 3 & 15 & 9 & 10 & 5 & 0 & 1 & 1 & 14 & 272 \\
\hline & No fear of damaging & 2 & 6 & 0 & 1 & 7 & 2 & 6 & 1 & 0 & 1 & 2 & 1 & 53 & 1 & 4 & 4 & 2 & 1 & 0 & 1 & 0 & 33 & 128 \\
\hline & $\begin{array}{l}\text { The potential of the } \\
\text { equipment }\end{array}$ & 6 & 28 & 5 & 3 & 36 & 10 & 23 & 6 & 1 & 1 & 1 & 4 & 128 & 4 & 38 & 15 & 7 & 8 & 2 & 1 & 1 & 32 & 360 \\
\hline & $\begin{array}{l}\text { Doing/sharing with } \\
\text { colleagues }\end{array}$ & 0 & 0 & 0 & 0 & 0 & 0 & 0 & 0 & 0 & 0 & 0 & 0 & 3 & 0 & 1 & 0 & 0 & 0 & 0 & 1 & 0 & 1 & 6 \\
\hline & $\begin{array}{l}\text { Problems with server } \\
\text { connection }\end{array}$ & 0 & 0 & 0 & 0 & 0 & 0 & 5 & 0 & 0 & 0 & 0 & 0 & 11 & 0 & 0 & 0 & 0 & 0 & 1 & 2 & 0 & 0 & 19 \\
\hline & $\begin{array}{l}\text { Poor interface/old } \\
\text { fashionable/too simple }\end{array}$ & 0 & 0 & 0 & 0 & 1 & 0 & 0 & 2 & 2 & 4 & 4 & 2 & 25 & 0 & 2 & 0 & 0 & 0 & 0 & 1 & 0 & 2 & 45 \\
\hline & Errors not explained & 0 & 0 & 0 & 1 & 2 & 0 & 0 & 2 & 0 & 0 & 0 & 0 & 19 & 0 & 0 & 1 & 1 & 0 & 0 & 0 & 0 & 3 & 29 \\
\hline & Operating Issues & 2 & 14 & 4 & 6 & 26 & 10 & 9 & 3 & 0 & 0 & 5 & 2 & 33 & 4 & 14 & 14 & 3 & 0 & 3 & 1 & 0 & 13 & 166 \\
\hline & Being in English & 0 & 1 & 0 & 1 & 2 & 0 & 0 & 0 & 0 & 0 & 0 & 0 & 0 & 0 & 0 & 0 & 0 & 0 & 0 & 0 & 0 & 2 & 6 \\
\hline \multirow{5}{*}{ 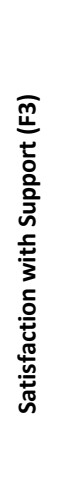 } & $\begin{array}{l}\text { Insufficient } \\
\text { preparation from } \\
\text { classes }\end{array}$ & 0 & 0 & 0 & 0 & 0 & 0 & 0 & 0 & 0 & 0 & 0 & 1 & 12 & 0 & 0 & 0 & 0 & 0 & 0 & 0 & 0 & 1 & 14 \\
\hline & $\begin{array}{l}\text { Insufficient material } \\
\text { support }\end{array}$ & 1 & 1 & 0 & 0 & 2 & 0 & 0 & 0 & 0 & 0 & 0 & 5 & 26 & 0 & 5 & 1 & 0 & 0 & 1 & 0 & 0 & 2 & 44 \\
\hline & $\begin{array}{l}\text { Lack of permanent } \\
\text { assistance }\end{array}$ & 0 & 0 & 0 & 0 & 2 & 0 & 0 & 0 & 0 & 0 & 0 & 0 & 17 & 0 & 0 & 0 & 0 & 0 & 0 & 0 & 0 & 0 & 19 \\
\hline & $\begin{array}{l}\text { Preference for } \\
\text { traditional labs' }\end{array}$ & 0 & 0 & 0 & 0 & 1 & 1 & 0 & 1 & 0 & 0 & 0 & 0 & 10 & 0 & 1 & 1 & 0 & 0 & 0 & 0 & 1 & 4 & 20 \\
\hline & Circuits Limitation & 0 & 1 & 1 & 0 & 0 & 0 & 3 & 2 & 4 & 0 & 0 & 0 & 3 & 1 & 4 & 3 & 2 & 0 & 0 & 1 & 0 & 1 & 26 \\
\hline \multicolumn{2}{|c|}{$\begin{array}{l}\text { External factor: problems } \\
\text { with internet connection }\end{array}$} & 1 & 12 & 0 & 0 & 9 & 2 & 5 & 1 & 0 & 0 & 0 & 0 & 46 & 1 & 2 & 3 & 0 & 0 & 0 & 2 & 0 & 5 & 89 \\
\hline \multicolumn{2}{|c|}{ Nothing negative to highlight } & 4 & 14 & 1 & 1 & 7 & 6 & 7 & 1 & 0 & 0 & 1 & 0 & 58 & 1 & 5 & 3 & 5 & 12 & 0 & 1 & 0 & 19 & 146 \\
\hline \multicolumn{2}{|c|}{ Nothing positive to highlight } & 0 & 0 & 0 & 0 & 0 & 0 & 0 & 0 & 0 & 0 & 5 & 1 & 3 & 0 & 0 & 0 & 0 & 0 & 0 & 0 & 0 & 0 & 9 \\
\hline
\end{tabular}


Globally (considering all students' answers) the most referred positive factor was "the potential of the equipment" -360 out of the 740 who opted to answered Q21 (47\%) chose it- while the second most mentioned factor was "access from anywhere/anytime", chosen by $36 \%$ of the students. In third, although very far away from the first two, comes the factor "better/more complete understanding" (19\%). Regarding the negative aspects about VISIR the most referred factor was "operating issues": 24\% of the students (166 out of the 703 students who answered Q22) pointed it out. In second it was the combination of "problems in understanding at the beginning" (42 answers) and "problems in understanding" (118 answers); 23\% of the students revealed they felt some difficulties in understanding/working with the system, although some of them were able to overcome it. The third most mentioned negative factor was "poor interface/old fashionable/too simple", mentioned by a minor of $6.4 \%$ students. Factors like "being in English" (1\%), "time allocated" (1\%) and "circuits limitation" (4\%) were also mentioned by the students. The VISIR system has the option of choosing several operating languages, including English -but also the native languages of the students from these countries- still that was not clear for some students. Although students can use VISIR for how much time they want, some teachers allocated a specific period of time for students to complete a task: clearly that time was not enough for some of them. VISIR system has a set of (limited) components that teachers or technicians make available for students: in some teachers did not consider so many options as students expected.

The three most referred positive factors are similar for all considered cases, although not exactly by the same order of relevance. Still, in some the factor "no fear of damaging" replaces the factors positioned in second and third place.

Considering the negative factors, the scenery is quite different, depending on the cases and also the education level. In fact, the distribution among negative factors is quite heterogeneous. The second most negative factor, identified in the global analysis, the combination of "problems in understanding at the beginning" with "problems in understanding", gained importance mainly because the cases C5, C8, C16 and C19 answers. Analysing closely these cases, it can be noticed that all of them also reported significant "operating issues" and the majority also "problems with Internet connection". These two former referred factors probably lead students to have a hard time in their first contacts with VISIR making it difficult to understand it. Students from cases C16 and C19 also mentioned "insufficient preparation from classes" and/or "material support", which turned these students work even more difficult. Still, in general, students did not complain about VISIR support (either material support or class preparation), suggesting VISIR introduction and support were adequate in most cases. Considering the third (global) factor "poor interface/old fashionable/too simple", its importance also came basically from the answers of 5 cases: C11, C12, C13, C14 and C16; in fact, 12 cases (out of the 22 for which there were answers) did not even 
mention it. Cases C11, C12 and C13 are one intermediate and two advanced HE courses from IFSC with a small number of students and even smaller number of answers. In the three cases, students have classes in labs equipped with modern equipment and based upon the use of three experimental resources: simulation, hands-on and VISIR. In case C12 as the activity was optional and at the end of the semester most students did not really have the time to explore/use VISIR. In case $\mathrm{C} 13$ this factor is the only negative factor students reported in their comments -I believe that the oscilloscope could be more modern, with colours and options more up to date... as in the benchthey all made reference to the same problem connected to the oscilloscope and its cursor. In fact, a suggestion to modify the oscilloscope layout has already been reported in literature (Marques et al., 2014), for being considered a factor that could hinder students' satisfaction with VISIR (Fidalgo et al., 2014). Cases C14 and C16 are from PUC-Rio, where students have lots of available resources, including the Maxwell system. Some students' answers seem to indicate students did not clearly understand Q22 and seem to be evaluating both VISIR and Maxwell systems: site interface obsolete, Maxwell was a little confusing, I found the site confusing and had difficulties finding the tools, Maxwell site is not intuitive and the interface is really bad. Some of these answers lead to the assumption they were evaluating both systems and not only VISIR.

Considering the education level, the first and second most referred negative factors were the same as the ones identified in the global analysis, although in the HE level their order was changed. The third most referred factor for HE 1 kept "poor interface/old fashionable/too simple". In the technological level the third most mentioned factor was "circuits limitations", "insufficient material support" and "being in English" (the three with exact the same number of answers). These students have a more practical component in their courses and probably wanted to explore VISIR more, although they somehow felt the need for more support in that challenge.

A quality assessment of the open questions was also carried out by implementation topic and VISIR use level to further understand it. This distribution is summarized in Table 22. 
Table 22 - Students Quality Assessment on the Open Questions by Topic (identified positive and negative factors (in shadow))

\begin{tabular}{|c|c|c|c|c|c|c|c|c|c|c|}
\hline & & & $\operatorname{Imp}$ & ementation & opic & & & Use & & \\
\hline Fact & rs (positive / negative) & Math. & Electricity & Electronics & Physics & Projects & B & 1 & A & $\circ$ \\
\hline & $\begin{array}{l}\text { Better/more complete } \\
\text { understanding }\end{array}$ & 24 & 85 & 17 & 14 & 1 & 114 & 24 & 3 & 141 \\
\hline 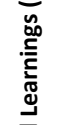 & $\begin{array}{l}\text { Problems in } \\
\text { understanding at the } \\
\text { beginning }\end{array}$ & 5 & 25 & 10 & 2 & 0 & 32 & 2 & 8 & 42 \\
\hline 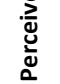 & $\begin{array}{l}\text { Problems in } \\
\text { understanding }\end{array}$ & 12 & 90 & 10 & 4 & 2 & 104 & 4 & 10 & 118 \\
\hline & Time allocated & 0 & 3 & 4 & 0 & 0 & 3 & 2 & 2 & 7 \\
\hline & $\begin{array}{l}\text { Access from anywhere/ } \\
\text { anytime }\end{array}$ & 19 & 192 & 33 & 20 & 8 & 211 & 36 & 25 & 272 \\
\hline & No fear of damaging & 9 & 70 & 14 & 34 & 1 & 111 & 11 & 6 & 128 \\
\hline & $\begin{array}{l}\text { The potential of the } \\
\text { equipment }\end{array}$ & 46 & 197 & 72 & 41 & 4 & 280 & 35 & 45 & 360 \\
\hline$\stackrel{\frac{a}{5}}{\sum}$ & $\begin{array}{l}\text { Doing/sharing with } \\
\text { colleagues }\end{array}$ & 0 & 3 & 2 & 1 & 0 & 4 & 1 & 1 & 6 \\
\hline 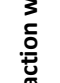 & $\begin{array}{l}\text { Problems with server } \\
\text { connection }\end{array}$ & 0 & 11 & 8 & 0 & 0 & 16 & 3 & 0 & 19 \\
\hline 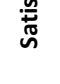 & $\begin{array}{l}\text { Poor interface/old } \\
\text { fashionable/too simple }\end{array}$ & 1 & 33 & 7 & 2 & 2 & 28 & 9 & 8 & 45 \\
\hline & Errors not explained & 2 & 23 & 1 & 3 & 0 & 25 & 2 & 2 & 29 \\
\hline & Operating Issues & 36 & 85 & 30 & 13 & 2 & 117 & 32 & 17 & 166 \\
\hline & Being in English & 2 & 2 & 0 & 2 & 0 & 6 & 0 & 0 & 6 \\
\hline & $\begin{array}{l}\text { Insufficient preparation } \\
\text { from classes }\end{array}$ & 0 & 12 & 0 & 1 & 1 & 13 & 1 & 0 & 14 \\
\hline$\frac{7}{2}$ & $\begin{array}{l}\text { Insufficient material } \\
\text { support }\end{array}$ & 2 & 29 & 6 & 2 & 5 & 32 & 7 & 5 & 44 \\
\hline $\begin{array}{l}5 \\
\frac{5}{3} \\
c\end{array}$ & $\begin{array}{l}\text { Lack of permanent } \\
\text { assistance }\end{array}$ & 1 & 17 & 0 & 0 & 0 & 19 & 0 & 0 & 19 \\
\hline 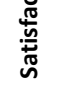 & $\begin{array}{l}\text { Preference for } \\
\text { traditional labs' }\end{array}$ & 2 & 12 & 1 & 5 & 0 & 17 & 1 & 2 & 20 \\
\hline & Circuits Limitation & 0 & 15 & 10 & 1 & 0 & 9 & 11 & 6 & 26 \\
\hline $\begin{array}{l}\text { Exte } \\
\text { inter }\end{array}$ & $\begin{array}{l}\text { nal factor: problems with } \\
\text { net connection }\end{array}$ & 11 & 64 & 9 & 5 & 0 & 80 & 6 & 3 & 89 \\
\hline & thing negative to highlight & 13 & 84 & 18 & 31 & 0 & 129 & 11 & 6 & 146 \\
\hline & othing positive to highlight & 0 & 8 & 0 & 0 & 1 & 3 & 6 & 0 & 9 \\
\hline
\end{tabular}


Considering the analysis by implementation topic, the three most referred positive factors continued to be: "the potential of the equipment", "access from anywhere/anytime" and "better/more complete understanding", although the order was not always the same. The only exception was for the physics topic where the factor "no fear of damaging" stood out in second place (replacing "better/more complete understanding"). The negative factors varied a little, particularly for the topic projects. The first two factors remain the same (as the ones identified in the global analysis) for all topics (although not always by the same order), except projects. The third most negative factor was different for each implementation topic, reflecting somehow students' different profiles: for electricity topic (includes most students from PUC-Rio) remained "poor interface/old fashionable/too simple". For mathematics several factors like "errors not explained" and "insufficient material support" had the same value ( 2 answers), with very little expressivity. In fact, the mathematics teacher implemented VISIR in two different courses (one with two editions and the other with three editions) and the material support was prepared in advance and made available in the LMS courses page. "Circuits limitation" was the third factor for electronics students. These students being from an EE major probably wanted to explore more the resources and felt they did not have as many components as they wanted to fully explore it. Physics students considered it was "preference for traditional lab features". Project students are from a "special" PUC-Rio course completely based in hands-on projects (with the aid of several resources, including remote labs) with the aim of "showing Engineering to students". VISIR was just one more remote lab and probably did not provoke no special enthusiasm, although the most negative referred factor -"insufficient material support"- is not directly connected to VISIR. Students identified another three negative factors (all with the same number of answers): the combination of "problems in understanding at the beginning" and "problems in understanding", "poor interface/old fashionable/too simple" and "operating issues".

Considering the analysis by VISIR use level, some features also stood out. In the advanced level, although the two most referred positive factors were kept unchanged, the third most referred factor was not similar to the other levels. The elected factor was "no fear of damaging". This result was intriguing at first, as these were proficient students used to assemble complex circuits. This may reveal that precisely because they were working with complex and expensive equipment and components, the risk of burning or damaging had a significant impact. VISIR allowed them to practice freely without that risk. Considering the most referred negative factors, they kept unchanged for the advanced level, although not exactly by the same order. In the basic level, the first two negative factors were also the same (of the global analysis), but the third most referred factor was "insufficient material support". In the intermediate level, the first and the third 
more referred factors kept unchanged, but the second most referred negative factor was "circuits limitation".

In this study involving so many courses, students and different contexts the three more often mentioned positive factors were: 1) "the potential of the equipment", 2) "access from anywhere/anytime", 3) "better/more complete understanding". When narrowing the analysis by topic, as detailed in the previous paragraphs, the order amongst them sometimes changed and in some situations one of these factors was replaced by "no fear of damaging". The three most negative factors referred by students were: 1) "operating issues", 2) "problems in understanding" and 3) "poor interface/old fashionable/too simple". In some situations, the three factors did not appear by the same order and in some situations the order of one of these factors was replaced, depending on the type of students/courses by "insufficient material support" or "circuits limitation" or "preference for traditional lab features".

From this analysis -students' perception- it is perceptible students appreciated the tool. They considered it was useful in their "learning process" (F1) and they were "satisfied with its potentialities" (F2) -accessibility, availability and security- although they were not so satisfied with the "VISIR support" (F3). There were still two cases that stood out: C7 and C14. In the first case students really appreciated VISIR and in the second students' satisfaction with the tool was really low. Even though, in general, students expressed their satisfaction with VISIR they also found some inconveniences and constraints about it that should be considered. VISIR sometimes has some instability and its interface could actually benefit from a renewal.

The majority of students manifested their preference for remote labs. They also trust they understand the differences between the results obtained by simulation and remote labs as well as understand the similarities between experimenting with remote labs and hands-on labs. 



\section{RESUltS AND DisCUSSION}

$\mathrm{T}$ his chapter presents the results of the relations between the analysed data previously presented in order to realize if the encountered differences between groups are significant and how could they help in the understanding of the persecuted problematic. These results will be detailed considering those dimensions and categories of analysis previously described (Table 2 , page 74). Correlations between factors, categories and between dimensions will also be pursued. For instance, correlations between students' VISIR usage and perception of the tool with their academic results. Possible associations between students' satisfaction with VISIR with teachers' satisfaction with VISIR as well as students' and teachers' usage of the resource will also be explored. Parametric and nonparametric difference tests will be performed to investigate the effect that some factors have in students (VISIR usage and perception as well as grades) and teachers (usage and perception if the tool). To conclude it will be thoroughly explored the possible correlations between didactical implementations characteristics, teacher mediation traces, tasks features (including level of competence) and students' characteristics with students' academic performance and perception of the tool.

\subsection{Didactical Implementation Results}

In this section the results considering the data collected in the scope of the dimension Didactical Implementation will be explored, considering mainly the defined categories, in an attempt to gather results to address the research questions (RQs).

\subsubsection{VISIR's Implementation}

As already described in the previous chapter, these 43 implementations cover a wide range of contexts, including: country, education level, degree, course, teachers' professional profiles and students' background. These varied contexts had an enormous impact in the didactical implementations teachers designed, developed and implemented in their courses. These differences in the didactical implementations approaches included: "course level", "resources used", "VISIR use level" as well as "\% of VISIR usage in course contents", the "level of competence" and the "tasks features" implemented to achieve it, the "number of VISIR tasks" as well as its "regime" and "contribution to final grade" and the "type of support" teachers gave to students not only during the introductory activity (to get them acquainted with the tool) but also during the 
task execution period. This information was already presented by didactical implementation, which main characteristics are detailed in Table 4 (page 80) and Table 9 (page 98) and an analysis of the data was also already carried on in the previous chapter.

It was intended to figure out if there was any correlation between some of the factors mentioned in the previous paragraph- considered in this category, namely: "VISIR usage in course contents (\%)", "implementation competence goal level", "number of tasks using VISIR", "VISIR tasks attributes" (type of task: T1, T2, T3), "education level", "VISIR use level" and "course level". It was found: (ii) a positive correlation (moderate) between the number of tasks involving VISIR and the VISIR usage in course contents (\%): $r_{P}=0.440(p=0.004 ; N=40)$. This result indicates that when teachers use VISIR in a larger amount of course contents the number of tasks also increases to address all the topics; (ii) a positive correlation (strong) between the education level and the type of tasks involving VISIR: $r_{S P}=0.641(p<0.001 ; N=40)$. This result indicates that, naturally, at higher levels of education teachers design and propose to students VISIR tasks that tend to be more complex and demanding;

In this section and considering the richness of contexts and the nuances in the way VISIR was implemented in these 26 courses, a deeper evaluation oriented to the factors of analysis will be performed: (i) an analysis of the courses that have undergone several implementation editions; (ii) the way VISIR was combined with other experimental resources; (iii) ascertain between the level of competence teachers pursued and the actual competence level demand of the proposed VISIR tasks. The former analyses will be approached in the next subsections.

\subsubsection{Didactical Implementations Iterations}

In eleven courses there were several successive didactical implementations: two course editions for cases C3, C9, C10, C14, C16, C17 and C20 and three course editions for cases C5, C8, C19 and C26. All are HE courses except C3 and C5 that are respectively a secondary and a technological course. In the majority of the cases, there were no noteworthy changes in the subsequent course editions, but in some cases, for different reasons teachers felt the need to introduce changes in the subsequent didactical implementations. For all cases, except C26, these modifications were mainly derived from teacher reflection upon his practices. In fact, teacher reflection about his practices, both during the teaching process and outside the learning environment play a crucial role in teacher aptitude in trying on different teaching methods as well as developing new strategies, including innovative solutions (Fagundes, 2016; Philipsen et al., 2019; Soini et al., 2016). Undeniably expert reflective teachers need to have experience and deep content knowledge about their courses (Biggs \& Tang, 2007) and not all of them achieve the same 
degree of success in this reflection activity (Lopes, Silva, et al., 2012). In case C26, the subsequent modifications were derived not only from teacher reflection about her own practices, but also from teacher reflection upon literature review and her research activity. In the former case teacher assumed the dual role of Teacher-Researcher (TR) (Gray \& Campbell-Evans, 2002).

For all the involved teachers, the first course implementation edition corresponded to teachers first didactical implementation (edition) based upon VISIR in the scope of the VISIR+ Project, except for the mathematics teacher when he decided to implement VISIR in another of his courses (C9), C22 course (the head teacher of this course was involved in the C3 first course edition, as assistant teacher) and C25 course (this teacher was involved in the previous semester in $\mathrm{C} 22$, also as head teacher). The main changes in the subsequent course implementation editions can be inferred from Table 4 (page 80) and Table 9 (page 98). Still, the next paragraphs will further analyse the influence of the course implementation edition (deeply connected to the teacher implementation edition) -somehow connected to teacher's experience- in some other VISIR's implementation factors, derived mainly by teacher reflection upon his practices. These subsequent modifications, when noteworthy, are detailed in the next paragraphs:

* Case C3: in its first course edition, the head teacher implemented 4 simple tasks using VISIR, to be fully performed during class time -its weight in final grade was qualitative and the proposed VISIR tasks were not mandatory- being the remote lab the only way for students to experiment with real equipment/instruments and develop experimental competences. In its second edition, C3 course occurred simultaneously in 3 different degrees, with the same team of teachers for all of them, remaining the head teacher of the first course edition in one of them. This teacher got familiarized with the tool and perceiving its advantages not only used it again but convinced other teachers to use it and gave them support. From the first course implementation to the second, VISIR weight in the final grade gained considerable importance (19\%) and it also became mandatory. Although the number of VISIR tasks was reduced from 4 to 3 , the tasks were more complex (although the same type (T1)) and one of them was assigned as homework. Additionally, in these three simultaneous implementations, they used combinations of experimental resources: not only the remote lab VISIR, but also handson lab and simulation. Curiously, the type of activity chosen to introduce VISIR was different for each of them and the support provided during the task execution period was also different. The head teacher of the first course edition considered that for this level of education, students highly value the inclusion of ICT in lessons and "VISIR proved a useful tool to spur interest on learning DC circuits" (Evangelista et al., 2017). All involved teachers remarked that the VISIR didactical implementation should be 
carefully planned -bearing in mind students usual interest in working in groups and being defied- and that the experiments students are supposed to perform should be previously thoroughly tested to guarantee everything is working properly and avoid students' frustration and dropouts (Evangelista et al., 2018, 2017).

* Case C5: teacher incremented VISIR usage in course contents from 5\% in the first edition to $15 \%$ in the subsequent editions. He considered VISIR motivated students, being an important aid tool also for the hands-on lab: students were more at ease, spending less time assembling the circuits and doing less mistakes.

* Cases C8 and C9: teacher incremented VISIR usage in course contents in both cases, respectively from $20 \%$ to $25 \%$ and $5 \%$ to $30 \%$. Teacher found VISIR so interesting for mathematical contextualization that he decided to use it in other math's course (C9) in a similar way. Considering more closely the guidelines of the VISIR+ Project, in C9, he also involved the use of simultaneous resources, in this case, implementing a hands-on simple task. In both courses, although the type (T2) of tasks was maintained in the successive implementations he proposed different tasks, and in C9 case its difficulty increased and became a group task in the second edition. Teacher considered it was a huge advantage to have access to an actual lab (VISIR) during these rather theoretical math courses. The lab served initially as a motivation for the methods, and later for verification of them in real circuits.

* Case C10: from the first to the second implementation, teacher increased VISIR usage in course contents from $15 \%$ to $50 \%$ and was more ambitious considering the level of competences he wanted their students to develop.

* Case C14: although the data for the first implementation is not complete, in the second course edition teacher increased the number of VISIR tasks from 1 to 3.

* Case C17: although lacking some pieces of information, from the first to the second course edition, teacher reduced the number of VISIR tasks and also abandoned the hands-on lab (performed in the first implementation). Although these modifications are somehow puzzling, they may be related to several strikes that happened about that time and severely affected this institution.

* Case C19: the VISIR usage in course contents increased from $6 \%$ in the first edition to $25 \%$ in the subsequent editions. This increase went along with a change in VISIR support along the semester: in the first edition teachers just uploaded a written doc in the course LMS page and in the subsequent ones they answered student doubts via email. The level of competence teachers pursued with this didactical implementation 
was also lowered to level L2, after the first course edition. This individual task also became mandatory to pass the course;

* Case C26: teacher maintained a T2 task, but increased its complexity and weigh in final grade from $5 \%$ to $10 \%$. In the last course edition, teacher split VISIR tasks in two parts delivered in different dates, forcing students to reflection in two distinct moments. This teacher also remarked the importance of monitoring VISIR system, including giving attention to students' "complains" about VISIR instability, during the task execution period, to make sure everything is working properly (Lima et al., 2019a). In fact, the suggestion of "always try ahead of time what students will be doing", referring to VISIR system, has already been suggested in literature (Marques et al., 2014).

The main modifications -in the 9 former described courses that have undergone several editions- perceived from this analysis are summarized in Table 23.

Table 23 - Course Implementation Editions: main Modifications

\begin{tabular}{|l|l|}
\hline \multicolumn{1}{|c|}{ Characteristics } & \multicolumn{1}{c|}{ Cases } \\
\hline Increase VISIR usage (\%) in course contents & $\mathrm{C} 5, \mathrm{C} 8, \mathrm{C} 9, \mathrm{C} 10, \mathrm{C} 19$ \\
\hline Implemented other experimental resources & $\mathrm{C} 3, \mathrm{C} 9$ \\
\hline Increase task weight in final grade & $\mathrm{C} 3, \mathrm{C} 26$ \\
\hline Change tasks regime (to mandatory and/or group) & $\mathrm{C} 3, \mathrm{C} 9, \mathrm{C} 19$ \\
\hline Increase number of tasks and/or its complexity & $\mathrm{C} 3, \mathrm{C} 9, \mathrm{C} 14, \mathrm{C} 26$ \\
\hline Adjust implementation competence goal level & $\mathrm{C} 10, \mathrm{C} 19$ \\
\hline
\end{tabular}

As teachers became more proficient with VISIR, they made some adjustments in the subsequent course editions and reinforced VISIR usage in several ways, taking the most of the tool. It is clear from the table they made a special effort when planning and implementing VISIR tasks, in subsequent course implementation editions. In fact, tasks design plays a crucial role in students' engagement and academic success. The proposed tasks should allow students to develop competences, by mobilizing the necessary knowledge, establishing the needed relations between concepts and procedures (Biggs \& Tang, 2007; Lopes, Cravino, et al., 2008; Viegas, 2017b). The implemented tasks should also be challenging, authentic and relevant, based as much as possible in real-life situations so that students appreciate them and feel interest and motivation to learn (Druzhinina et al., 2018; Lopes et al., 2014; Prince \& Felder, 2006; Roldão \& Almeida, 2018; Viegas, 2017b). Teachers' experience with VISIR and these incremental modifications and/or innovations in these successive course implementation editions facilitated the alignment 
the of the level of competence pursued with the selection of aligned and pertinent tasks. It also allowed, in some cases, the fomentation of cooperative work and it is also clear that there was made some effort in the assessment component as well (Viegas et al., 2009). In fact, it becomes clear teachers made an effort towards improving the curriculum design and its implementation in the classroom, but naturally these modifications imply not only teachers' involvement but also their effort, learning and maturation and do not produce immediate results.

Teacher reflection about his practises either individually or in some cases enhanced by sharing it with their peers (the other teachers involved in the same didactical implementation or in other) and for which students' feedback may have contributed, helped them into take more informed decisions about their practices and promote some modification in the subsequent course editions. From the results summarized in Table 23, it is clear most teachers increased "VISIR usage" in the course contents and some, taking into account the Project premises, added other "experimental resources" in the subsequent course editions. Still, the major modifications are related to the proposed tasks. From the first course edition to the subsequent ones, it is evident teachers made an effort to propose tasks more adequate to students' interests and/or contexts. They took into account tasks contribution to students' "final grade" (students' perception of their effort must have an immediate return or they commitment may be affected), the "tasks regime", the "number and type of tasks" (moving towards more contextualized, challenging and authentic tasks).

These former modifications took into account several domains in order to help students to develop not only knowledge, but also competences, behaviours and attitudes.

\subsubsection{Simultaneous Resources Analysis}

In the former 43 didactical implementations, teachers combined VISIR usage with other experimental resources (as presented in Table 4, page 80) along with calculus, accordingly to its availability and the target course contents, using VISIR to cover it, at some extent (or total: cases C13 and C14). Teachers combined the use of different experimental resources, in several ways, introducing VISIR using different activities and supporting students during the execution period task also in diverse forms (as explained in section 4.2). This experimental resources combination is presented in Figure 15 and from it, is clear that in three didactical implementations VISIR was the only experimental resource used, although in the majority teachers managed to use the three resources simultaneously. 


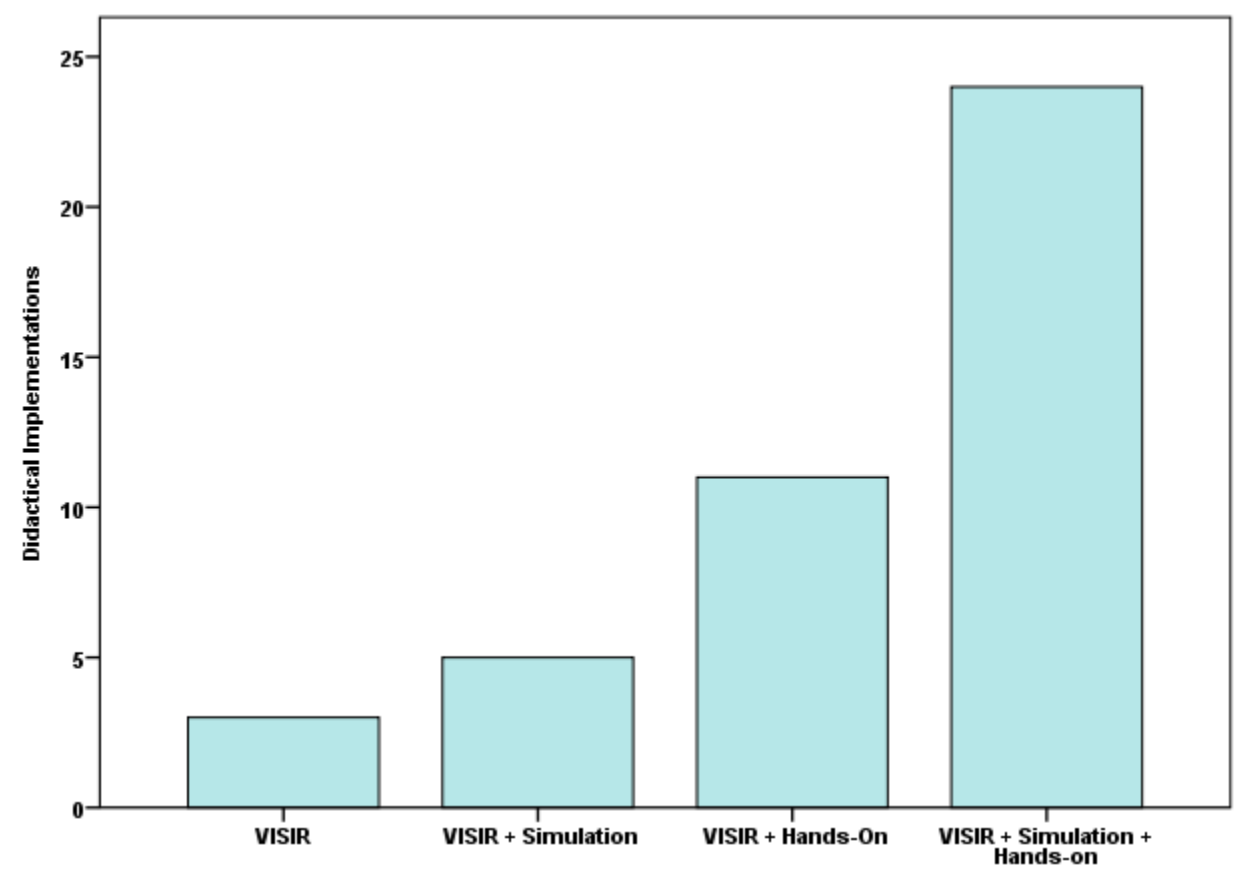

Figure 15 - Combination of Experimental Resources used in the Didactical Implementations

It was intended to figure out how these combinations of experimental resources usage "behaved" considering: the number of proposed hands-on tasks (when applicable) and VISIR tasks (it was not possible to have information about the number of simulation tasks), the percentage of VISIR usage in course contents, as well as the type of introductory activity to introduce VISIR and designed support to assist students. Some of these results are displayed in Table 24, which also enumerates the cases (some with more than one course implementation edition, so corresponding to more than one didactical implementation) or course implementation edition.

Table 24 - Experimental Resources Combination Details

\begin{tabular}{|c|c|c|c|c|c|}
\hline \multirow{2}{*}{\multicolumn{2}{|c|}{$\begin{array}{l}\text { Experimental Resources } \\
\text { Combination }\end{array}$}} & \multirow{2}{*}{ Cases } & \multicolumn{2}{|c|}{ Average \# of Tasks } & \multirow{2}{*}{$\begin{array}{c}\text { Average } \\
\text { VISIR } \\
\text { Contents (\%) } \\
\end{array}$} \\
\hline & & & Hands-on & VISIR & \\
\hline 1 & VISIR & $\mathrm{C} 3\left(1^{\mathrm{st}}\right), \mathrm{C} 20$ & & 2 & 16.7 \\
\hline 2 & VISIR + simulation & $\mathrm{C} 6, \mathrm{C} 8, \mathrm{C} 17\left(2^{\text {nd }}\right)$ & & 1.2 & 28 \\
\hline 3 & VISIR + hands-on & $\mathrm{C} 1, \mathrm{C} 2, \mathrm{C} 9, \mathrm{C} 16, \mathrm{C} 19\left(2^{\text {nd }}\right), \mathrm{C} 21, \mathrm{C} 26$ & 6.1 & 1.6 & 24.3 \\
\hline 4 & $\begin{array}{l}\text { VISIR + simulation + } \\
\text { hands-on }\end{array}$ & $\begin{array}{l}\mathrm{C} 3\left(2^{\text {nd }}\right), \mathrm{C} 4, \mathrm{C} 5, \mathrm{C} 7, \mathrm{C} 10, \mathrm{C} 11, \mathrm{C} 12, \mathrm{C} 13, \mathrm{C} 14, \mathrm{C} 15, \\
\mathrm{C} 17\left(\left(^{1 \mathrm{t}}\right), \mathrm{C} 18, \mathrm{C} 19\left(1^{\mathrm{st}}, 3^{\text {rd }}\right), \mathrm{C} 22, \mathrm{C} 23, \mathrm{C} 24, \mathrm{C} 25\right.\end{array}$ & 6.8 & 2.1 & 26 \\
\hline
\end{tabular}

The didactical implementation in which the three experimental resources were used are also the ones who proposed an average higher number of hands-on and VISIR tasks. Considering the didactical implementations for which there is data, in the resources combination 1 and 3, 
teachers privileged introducing VISIR in class allowing students doing some assembling and measurements while teachers were explaining (VISIR introduction level I3), while in combinations 2 and 4, student had a role of observers while teachers were explaining the basis of VISIR in class (I2). In combination 1 (only VISIR), the privileged support was presential, in the other combinations the privileged support was by uploading material in the LMS course page. Still, in the combinations 3 and 4, teachers also used a lot of both presential support and email support, having in several of them used a combination of two or even three types of support (as C26).

All these implementations were based upon VISIR and it was already plenty reported in literature VISIR increased students' confidence in hands-on lab (Fidalgo et al., 2012; García-Zubía, Gustavsson, et al., 2011; Marques et al., 2014; Salah et al., 2015; Tawfik, Sancristobal, Martín, et al., 2012; Tawfik, Sancristobal, Martín, Gil, Pesquera, Losada, et al., 2011). Additionally, when used prior to hands-on lab, in the subsequent hands-on lab classes, students were more at ease, performing less mistakes (the number of blown fuses decreased a lot) and assembling more circuits in a shorter time: VISIR being regarded as a "hands-on facilitator" (Alves et al., 2011; Lima et al., 2019c, 2019a, 2018; Marques et al., 2014). In the former didactical implementations, some teachers and students also made some comments about the added value they felt when VISIR was used prior to the hands-on labs, reinforcing what already has been stated in literature. Considering the experimental resources combination 3 and 4 (as defined in Table 24) the purpose is to understand how VISIR and hands-on lab were combined (in time and type of experiments) distinguishing between:

\footnotetext{
* Using VISIR prior the hands-on lab.

* Using VISIR after the hands-on lab.

* Using VISIR prior and after the hands-on lab.

* Using VISIR, not being clear from teachers' description if it was used before or after the hands-on lab.
}

And considering VISIR usage in mathematics course, it was added:

* VISIR for contextualization of theoretical mathematical concepts.

These results are detailed in Table 25 and for many didactical implementations it is not clear how this arrangement was performed. 
Table 25 - VISIR and Hands-on Usage Arrangement

\begin{tabular}{|c|l|c|}
\hline \multicolumn{2}{|c|}{ VISIR Usage } & Cases \\
\hline \multirow{2}{*}{ Prior the hands-on } & Similar experiments & $\mathrm{C} 7, \mathrm{C} 18, \mathrm{C} 21, \mathrm{C} 26\left(1^{\text {st }}, 2^{\text {nd }}\right)$ \\
\cline { 2 - 3 } & Different experiments & $\mathrm{C} 3\left(2^{\text {nd }}\right), \mathrm{C} 5, \mathrm{C} 10, \mathrm{C} 16, \mathrm{C} 25$ \\
\hline After the hands-on & $\mathrm{C} 19$ \\
\hline Prior and after & $\mathrm{C} 14, \mathrm{C} 24, \mathrm{C} 26\left(3^{\text {rd }}\right)$ \\
\hline Not clear & $\mathrm{C} 1, \mathrm{C} 2, \mathrm{C} 4, \mathrm{C} 11, \mathrm{C} 12, \mathrm{C} 13, \mathrm{C} 15, \mathrm{C} 17, \mathrm{C} 22, \mathrm{C} 23$ \\
\hline Contextualization & $\mathrm{C} 8, \mathrm{C} 9$ \\
\hline
\end{tabular}

Teachers intentions in students using VISIR prior to the hands-on goal included giving the students the opportunity to practice with electric components and equipment before going to the hands-on lab. This way students would be more confident to use the hands-on lab, being more at ease and autonomous. Still, teachers allowed students to keep on using VISIR, by their own will, until the end of the semester -including after the hands-on lab- at their homes (and repeat the experiences) as a way to complement the learning. Some teachers opted to develop similar experiments in the hands-on lab while others opted for a set of different experiments, increasing (this way) the number of different lab experiments students had the opportunity to develop. Just teachers from C19 (an EE major (scientific) advanced course) opted for using VISIR after the hands-on lab. VISIR was incorporated as a complement to the hands-on lab, after the last experimental activity, being the VISIR task regarded as an integrative mandatory and individual one. Teachers from case C14 introduced VISIR in the last one ( $1{ }^{\text {st }}$ course edition) $/$ three ( $2^{\text {nd }}$ course edition) experimental activities (out of 10) of the semester, considered the most demanding. VISIR was introduced as an extra step to be performed before the similar hands-on experiments, but after students had already a lot of practice in the hands-on lab. Teachers from C24 -a scientific introductory course- opted for using VISIR prior and after the hands-on lab allowing students the possibility of practising before and after the hands-on lab. That was the choice from the C26 case, in her third course edition: she wanted students to practice before the hands-on lab where they were supposed to perform a similar experiment; and afterwards, she wanted them to go back to VISIR to assemble a more complex circuit, taking advantage from what they have learned in the hands-on lab. For the majority of the cases it is not clear whether VISIR was used before and/or after the hands-on lab nor if the experiments developed were or not similar, except for $\mathrm{C} 13$ where it was clear the set of experiments was different. In fact, in C13 all the experimental activities are performed in a three setup: theoretical calculations + simulation + hands-on or VISIR. Mathematics courses do not have a lab component and VISIR was used with the main purpose of 
contextualizing theoretical concepts, providing the students an active learning environment where they could develop and use these mathematical competences in different and new contexts somehow related to their degrees' core.

Teachers have to work with the resources at their disposal that are relevant to the topic and learning objectives. From the previous analysis, it is evident that although in the majority of the cases teachers were able to use the three experimental resources simultaneously -following closely the Project premises- there were some cases in which they just were able to use two of them and in three didactical implementations VISIR was the only available experimental resource. Teachers implemented VISIR in their courses with different learning goals and used VISIR before, after or before and after the hands-on lab accordingly to what they perceived it was best for their cases.

Teachers used VISIR in some or all course contents, depending not only on the syllabus, but also on teachers' background, experience and beliefs and introduced VISIR in their classes and supported students work also in different ways.

\subsubsection{Level of Competence and Type of Task}

When teachers decided to use VISIR in their courses, they had to design a didactical implementation involving VISIR and other experimental resources along with calculus. To start they had to define the didactical implementation objectives, namely the goals they intended to achieve with the VISIR tasks, including the level/type of competence they pursued with it and try to design VISIR tasks accordingly to it. This sequence should be perfectly aligned to allow students to achieve the intended learning outcomes. Feisel \& Rosa (2005) recommend that "clear learning objectives are essential in designing an efficient learning system and also in applying an effective system of assessment". Still, accordingly to the same authors, many teachers have difficulties in writing them and some do not even write it. Or they state them in general terms and their accomplishment is not always evaluated. As already approached in section 2.2 student success and learning depends largely on how well the learning objectives (or ILO) are defined, its connection to the content and how well the assessment is designed.

As already described in section 5.1.1 and detailed in Table 9, in order to achieve the pursued learning objectives, teachers planed and designed VISIR tasks, that were categorized in three types: T1, T2, T3 task (as identified in this study, in section 4.2). The learning goals and the type of competences teachers expected their students to develop was stated by the teachers when they designed the didactical implementation and respective VISIR tasks. Using cross tabulation, it was 
analysed, by VISIR use level in course contents (B, I, A), if the type of task teachers proposed to students was in accordance with the level/type of competence (L1, L2, L3 and also described in section 4.2) teachers wanted their students to develop. These results are displayed in Figure 16 (for three didactical implementations it was not possible to have the data) and in some cases, there was a mismatch between the level of competence teachers wanted students to develop (teachers' intentions) and the type of task they implemented (actually achieved).

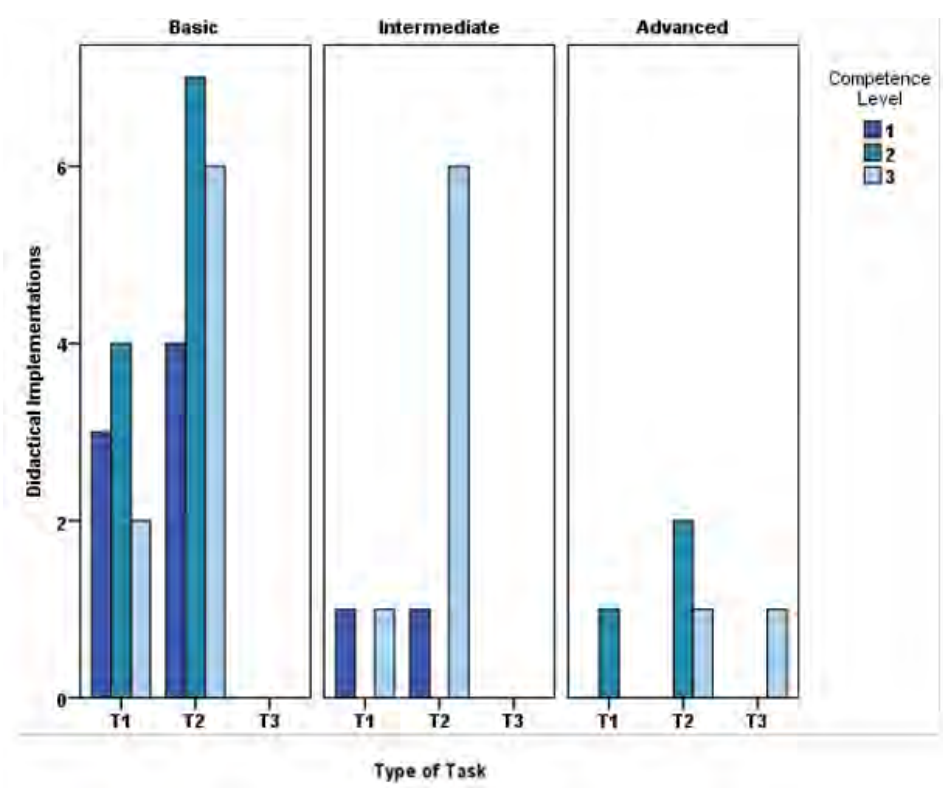

Figure 16 - Competence Level/ Type of Task

When developing the T1 task (assembling some circuits and measure some parameters) teachers were proposing to students level 1 competences achievements and eventually depending on the task details (developed in groups, deliver of a written report, present an oral communication) some soft skills (level 2). The T2 task (tasks in which students, after doing some circuits assembling and parameters measurements, were supposed to compare the VISIR results with the theoretical expected values and/or with the results obtained with other experimental resources) clearly may develop competences from level 1 and 2 and eventually level 3, depending upon the type of analysis required.

Still as we can observe in Figure 16, when proposing T1 tasks, teachers planned to develop not only level 1 competences but also level 2 and level 3 competences. Teachers, while proposing T2 tasks, also considered the development of level 3 competences. This mismatch between the competence level considering teachers' intentions and the actually achieved competences is more evident in the basic (B) VISIR use level, which includes all the secondary and technological didactical implementations. This makes perfect sense as teachers from these levels of education are not used to define learning outcomes particularly for experimental activities. Teachers from 
HE (which embrace all the didactical implementations in the intermediate (I) and advanced (A) level, although some are from the basic (B) level) are used to it, but some felt difficulties in aligning their intentions with VISIR didactical implementations with the tasks they designed and proposed to their students. There was a case (C16) that teachers' goal while implementing VISIR was basically developing experimental competences (L1) -by increasing the number of lab experiments and also allowing students more lab time to practice- but he proposed 4 VISIR tasks to students, in which they were supposed not only to do some circuits assembling and measurements, but also compare the obtained results with the theoretical expected value (T2 tasks). In this single case the mismatch was in the opposite direction.

The T2 tasks -tasks in which students, after circuits assembling and subsequent measurements, were supposed to compare the VISIR results with the theoretical expected values and/or with the results obtained with other experimental resources- considering its variability, will be further detailed. In some cases, teachers just opted for the comparison of the VISIR results with the theoretical calculation results, other decided for the comparison of the VISIR results with the results obtained with other experimental resources used (the same experiment was performed using several experimental resources) and still other wanted students to compare the VISIR results with both theory and the results obtained with the other experimental resources. The former results are summarized in Table $26((\mathrm{~S})$ - simulation; $(\mathrm{H})$ - hands-on lab).

Table 26 - Tasks Type 2 Detailed Characterization

\begin{tabular}{|l|l|}
\hline \multicolumn{1}{|c|}{ VISIR Results Comparison with } & \multicolumn{1}{c|}{ Cases } \\
\hline Theoretical calculations & $\mathrm{C} 1, \mathrm{C} 4, \mathrm{C} 7, \mathrm{C} 16, \mathrm{C} 19, \mathrm{C} 20, \mathrm{C} 21, \mathrm{C} 23, \mathrm{C} 24, \mathrm{C} 25, \mathrm{C} 26$, \\
\hline Other experimental resources & $\mathrm{C} 22(\mathrm{~S})$ \\
\hline $\begin{array}{l}\text { Theoretical calculations and other } \\
\text { experimental resources }\end{array}$ & $\mathrm{C} 8(\mathrm{~S}), \mathrm{C} 9(\mathrm{H}), \mathrm{C} 10(\mathrm{~S}), \mathrm{C} 14(\mathrm{SH})$ \\
\hline
\end{tabular}

The teachers from the lower levels of education that opted for T2 tasks, decided for the simplest ones. There was just one case (C14) in which the tasks involving VISIR were performed as a four setup experiment: theory/simulation/VISIR/hands-on. In cases C8 and C9, teacher also asked students to analyse the results obtained (using the several resources, including calculus) and in case C8 he asked students to also deliver the final report in the format of an IEEE Transactions paper, with the typical format of a research work (from the abstract to conclusion).

In the basic (B) VISIR use level, most teachers opted for group (not mandatory) DC (direct current) VISIR tasks, which contribution weight to final grade was, for the majority, also quantitative (from 5\% to 20\%). In the intermediate (I) VISIR use level, teachers' option was quite different: the majority opted for individual and mandatory AC (alternate current) VISIR 
tasks; considering its weight contribution to final grade: in $50 \%$ it was qualitative and the other $50 \%$ quantitative (from $5 \%$ to $27 \%$ ). In the advanced (A) VISIR use level all the proposed VISIR tasks were in $\mathrm{AC}$, to be developed individually and the majority was not mandatory. Its contribution to final grade was essentially qualitative.

The average number of proposed VISIR tasks is nearly similar for the three VISIR use levels, as detailed in Table 11 (page 102), but it was found a Spearman correlation between the number of tasks involving VISIR and respectively: (i) the type of task (T1, T2, T3): $\mathrm{r}_{\mathrm{SP}}=-0.363$ $(\mathrm{p}=0.021 ; \mathrm{N}=40)$ and (ii) the quantitative task weigh in final grade $(\%): \mathrm{r}_{\mathrm{SP}}=0.491(\mathrm{p}=0,017$; $\mathrm{N}=23$ ). These results denote that when the level of task complexity increases teachers tend to propose a lower number of tasks, as probably this type of tasks take more time and effort to design, implement and assess. Naturally, when the number of tasks increases their contribution to final grade also increases.

From the results of this section, it is perceived there was some mismatch between the "level/type of competence" teachers wanted to develop with VISIR remote lab and "the type of proposed/implemented tasks", being this mismatch higher at the VISIR use level basic. It is realized teachers must be extra careful while planning the activities with VISIR in order to overcome this discrepancy.

The correlations found in this section evidence that as the "number of VISIR tasks increase", their "weight into final grade" also increases although the task complexity (measured by the "type of task") decays.

\subsubsection{Teachers' Involvement}

Teachers' involvement is characterized by the number of teachers involved in each case, the teacher implementation edition, VISIR usage (teacher accesses in VISIR) as well as teachers implemented support (which was substantially different in the analysed courses).

As already detailed in section 5.1.2, the number of teachers involved by case varied from 1 to a maximum of 7 teachers. In half of the courses there was just one teacher involved in the didactical implementations and in the other half the didactical implementations were carried out by a team of teachers supervised by the head teacher. Teachers considered VISIR a valuable resource and several decided to keep on using it in subsequent course editions. Some even persuaded other teachers to use it in similar courses (giving them support) and also incorporated VISIR usage (with this methodology) in other courses (in which they were the head teachers). One of the most enthusiastic teachers was the mathematics teacher (cases C8 and C9) that was 
involved in 5 didactical implementations. He tried VISIR in one of his courses and considered it an advantage for theoretical mathematical concepts contextualization. Perceiving students' enthusiasm about it, he implemented it in another course. In fact, for two semesters he was involved as the only and head teacher in two simultaneous didactical implementations based upon VISIR. In C3 case, the three teachers involved in the second course edition (in three different degrees) were, as a team, involved in three simultaneous VISIR didactical implementations, but each of them was the head teacher of just one course. Cases C23, C24 and C25 -C23 and C25 had the same head teacher (different courses in different semesters)- although not having always the same head teacher, the implementations were carried out by a team of two teachers, being the assistant teacher (the second team element) the same for all. So, this assistant teacher was also involved in two simultaneous didactical implementations in the first semester of the 2017 academic year. All the other teachers involved in more than one didactical implementation, were involved in one at a time.

Teachers' VISIR usage was very different amongst cases (as detailed in Table 12, page 106): the number of VISIR accesses per task ranges from 3 to 85 accesses (being this minimum and maximum value obtained respectively in the first course edition and in the second course edition of case C20). This VISIR usage includes teacher usage during the task preparation phase, the activities developed to introduce VISIR and the support given during the task execution period. Indeed teachers' usage of VISIR is crucial: teachers need to spend some time getting familiarized with the resource, not only to assist students to overcome their eventual initial difficulties with the tool, but also to arouse students' perception of VISIR utility and their motivation to use it (Costa-Lobo et al., 2011; Lima et al., 2019a, 2019c; Marques et al., 2014; Viegas, Pavani, et al., 2018). This teacher implemented support (characterized in Table 14, page 108) is equally important during the task execution period, mainly by two reasons:

* Students may experience difficulties with the resource/proposed task, so teachers support is essential to avoid students' frustration and dropouts. Still, teachers should be aware not all the students have the same reaction to this type of resource: some immediately understand the tool while others take time to fully perceive it. Teachers ought to allow students to work at their own pace, tutoring them (and not pointing the solution) to overcome their difficulties.

* VISIR system sometimes has some instability; with a rapid teacher intervention this may be solved quickly enough to avoid the majority of students to feel it. During this period, teachers (or technicians) should keep on using VISIR- trying the circuits that were proposed to students -to make sure it is functioning well. In case, a student reports some problem it is advisable to examine its legitimacy and (being true) solve it 
as soon as possible (Evangelista et al., 2018, 2017; Lima et al., 2019a; Marques et al., 2014).

Analysing Table 14 (back in page 108), it is clear that the former two aspects identified in the table as: "heightened attention to students" and "heightened attention to VISIR system" became particular relevant in courses that have undergone several course editions (that are related to teacher implementation edition and thus experience with VISIR). In cases C19 and C26 the number of course implementation edition matches the teacher implementation edition. In case C3 (three similar courses in three different degrees), the second course implementation edition matches the head teacher implementation edition, for just one of the course implementations, but that teacher was part of the teachers' team of the other two courses, sharing with the other involved teachers his previous experience and providing them support. In cases C8 $\left(2^{\text {nd }}\right)$ and C9 (1st), it was respectively teachers second and third (simultaneous) implementation editions. The courses implementation editions identified in "heightened attention to VISIR system", were characterized by having a higher number of teachers' accesses per task (comparing to the other course editions), precisely because teachers payed extra attention to the VISIR system (and consequently used it more).

Considering the other aspects identified in the same table and with the exception of "head teacher had some resistance to the VISIR system", all cases have undergone several course editions/teacher implementation editions. In case C12, teacher implemented VISIR by his Institution suggestion, although he was not (still) feeling very confident with the tool. He made an effort to get familiarized with it and support his students -his number of teacher's VISIR accesses per task is 13.5- but as he just introduced it in his practices nearly the end of the semester, he developed a simple optional (AC) task.

In the cases identified in Table 14, half of them were carried out by just one teacher, the head teacher $(\mathrm{C} 8, \mathrm{C} 9, \mathrm{C} 12, \mathrm{C} 26)$ and the other half was carried out by a team of teachers $(\mathrm{C} 3, \mathrm{C} 5$, C29, C20).

In section 5.1.2 teacher VISIR involvement: number of teachers and number of VISIR accesses per task was also summarized, by education level, by implementation topic, by course level and VISIR use level in course contents (Table 13, page 107). It was there analysed the influence of C20 (first course edition) -which had 85.0 VISIR accesses per task- to the exhibited average number of VISIR accesses per task, in particular considering the VISIR use level and course level. It is really an outstanding value: C20 is an HE scientific course, in which the VISIR use level was intermediate and teacher proposed an AC task (type T2); VISIR was the only experimental resource available. The teacher did not report any constraints/problems about the implementation or VISIR itself, except a few times he had some problems connecting to the server. 
The teacher really needed time to get familiarized with the tool and design and implement an adequate task. The fact that VISIR was the only experimental resource probably may have contributed to this high value.

There is no correlation (Spearman or Pearson) between the three factors: "teacher implementation edition", "number of teachers involved" and "teacher accesses in VISIR". Considering the number of VISIR accesses per task in the implementations involving just one teacher and the ones in which there were several teachers involved (a team), the average number of VISIR accesses per task was respectively: 12.1 and 14.6. It was performed a statistical test -the nonparametric Mann-Whitney $U$ test for two independent samples- to determine whether there was a statistically significant difference in the mean values of the number of VISIR accesses per task of the two groups. It was concluded $(p>0.05)$ there was no statistically significant difference between the two groups, that is, an implementation being carried out by one teacher or a team of teachers does not affect the number of VISIR accesses per task.

Considering the courses in which there was more than one course implementation edition (C3, C5, C8, C9, C10, C14, C16, C17, C19, C20 and C26), intrinsically connected to the teacher implementation edition, the number of VISIR accesses per task tends to diminish or be similar, from one implementation to the next. In fact, as the implementations were carried out by the same teacher/team of teachers (except in C3 second course edition, where just one of the teachers of the first course edition was the same) the number of VISIR accesses per task would naturally decrease, as the teachers were already familiarized with VISIR. Eventually if, in the subsequent course editions, teachers decided to make significant adjustments (or felt some type of constraints accessing the VISR system) this number may increase a little. The exceptions are for case C5, C19 and C26 and partially C8. In case C5 the first two didactical implementations were performed using a VISIR system from one of the EU partners, as their own system was not yet installed. In the third implementation they used their own VISIR system, which implied some adjustments and mounting the experiments on the system. In case C8 there was a significant increase of the number of VISIR accesses per task from the first to the second course edition. In fact, this teacher was also using a VISIR system from an EU partner and that VISIR system had some problems during this period, including problems connecting to the system and some instability. In case C19, the slight increment on the number of VISIR accesses per task in the subsequent course editions is probably connected to the modifications (in the didactical implementations) teachers promoted, including paying more attention to students with a more individualized support. Case C26: from the first to the second course edition, the increase in the number of VISIR accesses per task is connected to the modifications implemented, namely the task complexity. From the second to the third course editions, the increment was due to system 
instability the system was quite instable with several operating/configuration issues and even problems connecting to the system itself. In fact, the teacher had to ask the support of the technical staff and the VISIR system had to be rebooted.

The studied factors do not appear determinant in modifying the teacher VISIR usage, but clearly there are several other factors that cannot be obtained or quantified by a statistical test that affect this usage. These factors -considering the 52 teachers involved in the 43 didactical implementations- may include: different academic backgrounds, different degrees of expertise in electric and electronic circuits area, previous different experience with VISIR and sensitivity to this type of resource, different levels of teaching experience and the technical support they had for the task implementation phase may also have varied. In fact, in some HEI there is technical staff that can implement the circuits in the VISIR system while in others is the teacher that has that responsibility. Plus, teachers opted for different types of activities to introduce VISIR, proposed different tasks (in number and level of complexity) to students -which also showed a wide range of backgrounds- and provided different types of support. Beyond that, the teacher's interview open answer assessment allowed the identification of two negative factors that may also have contributed to this variability: "instability" (including problems with the server) and "problems with Internet". The thorough analysis of it as well as teachers' answer to the question Q3: Did you have problems with the server? (includes in the interview) revealed that in the four didactical implementations where teachers reported server instability (C8 and C26 (3 ${ }^{\text {rd }}$ course edition)) that was, in fact, an increase in the numbers of teachers' VISIR accesses per task. Teachers who reported Internet problems and/or answered to Q3 in a positive way (yes or sometimes) also tend to reveal a higher number of VISIR accesses per task when comparable to similar courses where these issues were not reported. So, even though difficult to quantify, we may say these factors must have had some influence in teachers' VISIR usage.

Concluding, teachers implemented VISIR in their courses, either individually or supported by the other teachers involved in the course; this former aspect does not seem to affect teachers' VISIR usage. Some teachers had several "teacher implementation editions", some in more than one course and a few were involved in more than one didactical implementation simultaneously. Teachers' VISIR usage ("number of accesses per task") shows a wide variability amongst cases, although this number tends to diminish in subsequent course editions. Factors related to system instability and/or Internet connection problems seem to have some influence in teachers' VISIR usage. Although it was not found any correlation between the factors considered in this category, clearly teachers' experience with VISIR seems relevant in the "implemented support". 


\subsubsection{Teachers' Perception}

One of the factors that characterizes teachers' perception (of VISIR) is F2_T: Teachers' satisfaction with VISIR (the variable was detailed in section 4.4 .2 and the results are exhibited in Figure 11, page 110) and considering the former factor the scenario changes dramatically: this factor is almost constant for all cases, regardless the different contexts and characteristics, except for one of the second editions of case C3. In this particular didactical implementation, the teacher expressed he had problems to access the system, considered VISIR was not user friendly and not very adequate to his needs.

Students' level (Table 16, page 113) -teachers' perception of students' eventual difficulties or, on the other hand. their interest and adequate prior knowledge- does not seem to affect teachers' satisfaction with VISIR, either.

Teachers' perception about students' satisfaction with VISIR was already analysed and exhibited in Figure 10 (page 109), showing in the majority of the cases teachers perceived students were satisfied with the tool. In the courses in which there was more than one course implementation edition, teachers' perception of students' satisfaction with the tool was the same in the several course editions, except in cases C10 and C14. In case C10, it increased from level 2 (satisfied) to level 3 (completely satisfied). According to teacher's opinion, this might be linked to his experience with the tool and the number of students in the second course edition (14) being less than in the first one (31); in the second implementation, teacher not only had more experience with the tool but also had more time for each student. In case $\mathrm{C} 14$, in the first course edition teacher perceived VISIR had a positive impact on students but in the second course edition his perception was that students felt VISIR did not add any functionality that the hands-on lab did not have. Students did not fully appreciate VISIR (level 1). This may be linked to the increase in the number of VISIR tasks, with no extra contribution to their final grade. It was intended to figure out if there was any correlation between the former variables: teachers' satisfaction with VISIR and teachers' perception of students' satisfaction with VISIR. None of the variables follow up a normal distribution, so the Spearman correlation procedure was used, and no significant correlation was found between the two variables. Again, teachers' satisfaction with VISIR is not affected by (their perceived) students' satisfaction with the tool.

Considering the teacher's interview, teachers identified much more positive factors than negative factors when expressing their opinion about VISIR (Table 15). They considered VISIR was a valuable resource that allowed to increase students' practice- without out the cost and safety issues - as well as their motivation, giving teachers some autonomy in diversifying the teaching methods used in class. Although they have identified several constraints in VISIR -several 
configuration issues and instability, although some also referred that VISIR interface was "old fashionable"- these basically did not influence their satisfaction with the tool. The major advantages and constraints identified in VISIR are in accordance with former reported works in literature (Ferreira, Lacerda, Schlichting, \& Alves, 2014; Fidalgo et al., 2014; Lima et al., 2019c; Marques et al., 2014).

"Teachers' satisfaction with VISIR" is basically similar for all cases: in general, all expressed being very satisfied with the tool. Teachers' satisfaction with VISIR seems to be intrinsically connected to the added value teachers consider the remote lab has in their practice, not being correlated with none of the factors considered in this category (teachers' perception).

\subsubsection{Teacher Mediation}

The teacher mediation in the classroom, that is, the actions teacher promotes to stimulate students in their learning process, towards the development of knowledge and competences, plays a crucial role in students' engagement and learning (Lopes, 2004; Viegas, 2017b). Still, and as reported in the literature, the way teacher promotes the former implementation, depends upon several factors including his experience, personal beliefs, scientific competence and time and effort devoted to addressing the planned guidelines (Cunha et al., 2014; Lopes, Silva, et al., 2008; Viegas, 2017b). In fact, even a very well designed didactical implementation or for simplicity a task "can fail its purposes if teacher mediation is not adequate" (Viegas, 2017a).

In a team involving several teachers the best way to try to guarantee that the teacher mediation implemented in the classroom is following the designed curriculum (the designed tasks and the set of established mediation guidelines) is to promote several meetings -with all the teachers involved in the course- along the time, in order to agree on how to carry on the implementation and clarify any doubts. Still, as teachers are very different from each other, it is severe that all of them similarly address those guidelines. They end up, even with their best intentions, to make some adjustments according to several factors such as their own experience, background and beliefs (Lopes, 2004; Lopes, Cravino, et al., 2008).

In the scope of the VISIR+ Project, the involved LA teachers had the opportunity to attend at least a training action (TA) -some at their own institution, organized by each EU partner tutor, others in a nearby institution, organized by the LA partner, with the supervision of the EU partnerprior to the didactical implementation. The TA occurred at different times and its purpose was to present the Project goals and the general guidelines to the didactical implementations, addressing specific teachers' needs. The collection tools were also presented and some examples of previous 
successful VISIR implementations were shared and thorough detailed. Although for the TA it has been defined a joint base, they also had some differences (both in the contents, duration and presentation approach used), taking into account the very different contexts of both the LA and the EU partners involved and the tutoring relationships established (Viegas et al., 2017). Teachers were in general enthusiastic about the Project, but due to their personal characteristics, scientific expertise or "teaching style", not all of them fully understood its implications and made the necessary adjustments in their own didactical implementations. Some teachers were immediately moved by the Project, taking time to get acquainted with VISIR and this methodology (keeping the contact with the EU partners), while others were more "independent" and did things their own way. Naturally these informal contacts between some LA teachers were mainly established with their EU partner tutors although in some cases they were also kept with some members of the EU leader project partner.

In the former training actions (TA), it was not formally approached or established teacher mediation guidelines, although it is to believe that many teachers were aware of its importance and may have implemented the majority of the mediation traces approached in section 2.2.2, in their classes. Still, the majority of the data collection tools did not allow us to obtain that information. The majority of the cases for which we have some information, are the cases that some informal contacts were established (along with the didactical implementations) between the LA teachers and the research team of P.Porto/ISEP, where I was included as a PhD student. In several cases, there were some personal and skype meetings, as well as some email exchange, in which teachers reported us how they implemented VISIR in their classes.

From the former contacts and the information, it was possible to obtain in some of the instrumentation tools, the more relevant mediation characteristics identified in some cases, relevant to this study were acknowledged. They are summarized in Table 27, for the cases for which it was possible to obtain that data. In the next paragraphs they will be approached.

As it gets clear from the results expressed in the quoted table, there are several cases for which it was not possible to have data. For the ones it was possible to collect data, it is evident that in some cases teachers were more attentive (or we were able to get more data) than others, to implement in their classes the teacher mediation traces reckoned. 
Table 27 - Teacher Mediation Traces

\begin{tabular}{|c|c|c|}
\hline $\begin{array}{l}\text { Teacher Mediation } \\
\text { Characteristics }\end{array}$ & Teacher Mediation Traces & Cases \\
\hline \multirow{5}{*}{ (T1) Experienced teacher } & \multirow[t]{2}{*}{ (T1a) Previous VISIR Usage } & $\begin{array}{l}\text { Several course editions:C3, C5, C8, C9, C10, C14, C16, } \\
\mathrm{C} 17, \mathrm{C} 19, \mathrm{C} 20, \mathrm{C} 26\end{array}$ \\
\hline & & One course edition: $\mathrm{C} 13, \mathrm{C} 22, \mathrm{C} 25$ \\
\hline & $\begin{array}{l}\text { (T1b) Integrates a supported dynamic } \\
\text { team }\end{array}$ & $\mathrm{C} 3\left(2^{\text {nd }}\right), \mathrm{C} 6$ \\
\hline & (T1c) Frequently accesses VISIR & $\mathrm{C} 20\left(1^{\mathrm{st}}\right)$ \\
\hline & $\begin{array}{l}\text { (T1d) Understands VISIR potentiality } \\
\text { for learning }\end{array}$ & All cases, except partially $\mathrm{C} 3\left(2^{\text {nd }}, 3^{\text {rd }}\right), \mathrm{C} 11, \mathrm{C} 12, \mathrm{C} 14$ \\
\hline \multirow{2}{*}{$\begin{array}{l}\text { (T2) Teacher promotes a } \\
\text { good learning environment }\end{array}$} & $\begin{array}{l}\text { (T2a) Foments social learning and } \\
\text { collaboration in tasks }\end{array}$ & $\mathrm{C} 1, \mathrm{C} 3, \mathrm{C} 9, \mathrm{C} 22$ \\
\hline & $\begin{array}{l}\text { (T2b) Gives authority and } \\
\text { responsibility to students }\end{array}$ & $\mathrm{C} 3, \mathrm{C} 8, \mathrm{C} 13, \mathrm{C} 14, \mathrm{C} 26$ \\
\hline \multirow{2}{*}{$\begin{array}{l}\text { (T3) Teacher clarifies } \\
\text { objectives }\end{array}$} & $\begin{array}{l}\text { (T3a) Explains the pertinence of using } \\
\text { several experimental resources }\end{array}$ & $\mathrm{C} 3, \mathrm{C} 5, \mathrm{C} 8, \mathrm{C} 19, \mathrm{C} 22, \mathrm{C} 23, \mathrm{C} 24, \mathrm{C} 25, \mathrm{C} 26$ \\
\hline & $\begin{array}{l}\text { (T3b) Helps to mobilize prior } \\
\text { knowledge }\end{array}$ & $\mathrm{C} 5, \mathrm{C} 8, \mathrm{C} 9, \mathrm{C} 20$ \\
\hline \multirow{2}{*}{$\begin{array}{l}\text { (T4) Teacher keeps the task } \\
\text { authentic }\end{array}$} & $\begin{array}{l}\text { (T4a) Allows students to find a } \\
\text { solution }\end{array}$ & $\mathrm{C} 1, \mathrm{C} 8, \mathrm{C} 9, \mathrm{C} 13, \mathrm{C} 19, \mathrm{C} 22, \mathrm{C} 23$ \\
\hline & $\begin{array}{l}\text { (T4b) Gives support in crucial } \\
\text { moments }\end{array}$ & $\mathrm{C} 2, \mathrm{C} 5, \mathrm{C} 19\left(2^{\text {nd }}, 3^{\text {rd }}\right), \mathrm{C} 23, \mathrm{C} 26\left(2^{\text {nd }}, 3^{\text {rd }}\right)$ \\
\hline \multirow{2}{*}{$\begin{array}{l}\text { (T5) Teacher keeps up with } \\
\text { students work and gives } \\
\text { feedback }\end{array}$} & $\begin{array}{l}\text { (T5a) Gives timely and adequate } \\
\text { feedback }\end{array}$ & $\mathrm{C} 2, \mathrm{C} 5, \mathrm{C} 19\left(2^{\text {nd }}, 3^{\text {rd }}\right), \mathrm{C} 23, \mathrm{C} 26\left(2^{\text {nd }}, 3^{\text {rd }}\right)$ \\
\hline & $\begin{array}{l}\text { (T5b) Uses qualitative assessment to } \\
\text { allow students to progress }\end{array}$ & $\mathrm{C} 1, \mathrm{C} 20$ \\
\hline
\end{tabular}

(T1) Experienced teacher. The courses that have undergone several implementation editions -(T1a) previous VISIR usage- were already analysed in section.6.1.1.1 and the first implementation edition of each considered course overlapped exactly with the first teacher implementation edition, with the exception of case C9, as thorough detailed in that section. Naturally, in the former cases, except for case C9, that mediation trace (T1a) cannot be considered in the first-course implementation edition. Still, case C26 justifies some additional remarks: the head teacher of this course is the author of this thesis project, involved in Engineering Education research, including the use of remote labs in engineering courses, since 2014. She was also one of the researchers involved in the VISIR+ Project, in which there were plenty opportunities to discuss and share practice insights involving VISIR and naturally conscious of several aspects of these didactical implementations, even if she has never used it before in her practices. So, when she decided to implement VISIR in her course, the analysis of other researchers' practice and results, gave her insight inputs which played a crucial role in her first course implementation edition. Her didactical implementation based upon VISR along with hands-on lab and supported by calculus, took into account the aspects -mainly from literature- that caught her attention. In the subsequent course editions, she made some modifications shaped by her reflection upon literature review, her own practices and her research activity. These modification were detailed in section 6.1.1.1, but from her reflections -mainly from her practices- she concluded: (i) the support given to students (implemented support) has a crucial role in the didactical implementation and should be adequate to each student's needs; (ii) to compel students to truly 
explore and use more VISIR, the resource should be introduced as soon as possible in the semester; splitting tasks in several parts (with different deliver dates) or propose several tasks also induce students to use VISIR over a large period of time, accessing it more, forcing them to reflection in distinct moments; (iii) some students have difficulties understanding the difference between resources/type of results (Lima et al., 2019a).

From section 6.1.1.1, it became clear as teachers became more proficient with VISIR, they made some adjustments and reinforced VISIR usage in several ways, in the subsequent course editions, taking the most of the tool.

In the courses with only one implementation edition -except for cases C13, C22 and C25- it was teachers first experience with VISIR. All one edition course didactical implementations took place during the 2017 academic year, the majority in the second semester. Several teachers talked about their determination in keeping VISIR in the following academic year in these courses and even expand its usage to other courses. Still, as it was the last semester of the Project data collection, it was not possible to track the follow up. Some particular conditions considering the head teacher (T1a) teacher previous experience with VISIR led to some interesting features in the didactical implementations. In the next lines these will be further detailed:

* Case C13: teacher already had a previous experience with VISIR in a very similar course, during the 2013 academic year (previous to the project). He got to know VISIR from institutional contacts with an EU partner and about the same time a federal law in Brazil established HEI could offer courses in distance education methodology. As remote labs are efficient distance education resources and his own institution did not have any, he decided to propose a VISIR experiment (implementing two circuits) to his students- using a VISIR system from an EU partner- to have an idea of their perception about these technologies. This exploratory activity did not contribute to the final grade, but all the 15 students enrolled in the course adhered freely to it. This activity was proposed after students having already implemented similar circuits in the hands-on lab and the virtual lab. Students mentioned some inconveniences and constraints in VISIR usage and made some suggestions considering VISIR functioning. But overall they considered the remote lab as an excellent complementary resource to hands-on labs and expressed their desire of having it in their institution (Ferreira et al., 2014). When this teacher decided to implement VISIR and this methodology in his course in the second semester of 2017 academic year, he was already acquainted with VISIR and confident about its utility and constraints. This VISIR experience along his teaching experience, academic background and scientific competence gave him the necessary support for designing an "ambitious" didactical implementation for his course. In this 
scientific advanced course, he used the three experimental resources, used VISIR in $100 \%$ of the course contents and planned three T3 tasks (in AC) accordingly to the L3 level of competence he pursued. He was the only teacher to propose type T3 tasks, and they had a qualitative weight to students' final grade. All course experiments are organized in a 3 set up: 1) theoretical analysis, 2) simulation and 3) hands-on or VISIR (depending on the experiments): students expressed preference for a 3 set up with VISIR.

* Case C22 head teacher was involved in C3 first course edition (as one of the assistant teachers), during the second semester of the 2016 academic year. He got acquainted with VISIR and this methodology and in the first semester of 2017 academic year he implemented it in his own scientific basic course, using the three experimental resources simultaneously. He proposed two T2 tasks (DC) -which had a qualitative weight to the final grade- accordingly to the L2 level of competences he pursued.

* Case C25 head teacher, after using VISIR in one of his courses (C23) in the first semester of 2017 academic year, implemented it again in another of his courses, in the second semester, keeping up the same assistant teacher. From his experience from the first semester, in the second semester course he made an adjustment in the type of introductory activity (from I3 to I2) and attributed a qualitative weight contribution to the (mandatory) proposed VISIR tasks.

Concluding (T1a) teachers previous experience with VISIR had an important role supporting teachers in developing more "ambitious" and well aligned didactical implementations. This is corroborated by some PUC-Rio teachers' comments considering their didactical implementations: C14 and C16. C14 first course implementation edition took place in the first semester of 2016 academic year and was considered a pilot test to understand VISIR functioning and students' perception about the new tool. The faculty members considered the pilot test was very important because "it showed the importance of planning the experiments to be performed along the semester", as VISIR requires set up activities that must be prepared in advance (Viegas, Pavani, et al., 2018). This pilot test was considered an advantage for the subsequent didactical implementations that took place in the 2017 academic year.

(T1b) Integrates a supported dynamic team. The head teacher of the first course implementation edition of case $\mathrm{C} 3$, was one of the three members of the second course edition of the former course that occurred simultaneously in three degrees. This teacher perceiving VISIR advantages not only used it again but also convinced two teachers to use it and gave them assistance and support in a dynamic basis. Teacher from case C6 (although being the only teacher of his course) had a similar support and assistance from the case C5 head teacher. The former 
teacher had already a considerable experience with VISIR (his course has undergone three successive course editions) and not only stimulated case C6 teacher to use it, but also provided him support and assistance and even shared some of the lab guides he had prepared.

(T1c) Frequently accesses VISIR. Teachers' VISIR usage, that is, their number of VISIR accesses per task varied a lot, as already detailed section 6.1.2. In the former section it was already concluded that none of the factors (within the category teachers' involvement) affected this usage. There was still a didactical implementation where this VISIR usage achieved an outstanding value as recognised in Table 27 (case C20 (1st): 85).

(T1d) Understands VISIR potentiality for learning. In the majority of the cases teachers recognized VISIR potentiality for learning, except partially in the 4 cases reported in Table 27. In one of the second course editions of case C3, teacher considered VISIR was not very adequate to his needs. In cases C11 and C14(2 $\left.{ }^{\text {nd }}\right)$ teacher perception was that students disliked and/or had difficulties with VISIR and really did not appreciate the resource. In case C12, although teacher used VISIR and made an effort to integrate it in his course, he was not still very confident with the resource. He used it by his Institution recommendation, but expressing some resistance (to its usage): I realize that there is a need to have a time for the implementation of its use ...I estimate that it is still premature to present a diagnosis about the use of the laboratory, in his own words

Considering the analysis performed in sections 6.1.2 and 6.1.3, it is not clear which factors influence teachers' VISIR usage and teachers' satisfaction with VISIR which are respectively connected to (T1c) and (T1d). The first seems to be somewhat affected by Internet problems and/or server instability: teachers who reported those problems tend to have a higher number of VISIR accesses per task when compared to similar courses where these problems were not narrated. Teachers" satisfaction with VISIR (F2_T) seems to be "independent", not being affected for any of the considered factors or even by the constraints in VISIR system, identified by some teachers. In order to try to identify factors that might influence teachers' VISIR usage as well as teachers' satisfaction with the tool, it was decided to perform a nonparametric Mann-Whitney U test for two independent samples, as the former variables (test variables) do not follow a normal distribution. So, the data was split in two groups, accordingly to the factors we wanted to test:

* Additional used resources (combinations): VISIR + simulation: yes/no; VISIR + handson: yes/no; VISIR + simulation + hands-on: yes/no.

* VISIR designed support: uploading support material: yes/no; answering doubts by email: yes/no; clarifying doubts presential: yes/no.

* VISIR tasks attributes: DC/AC.

* VISIR task regime: mandatory: yes/no; group tasks: yes/no.

* VISIR tasks weight on final grade: qualitative/quantitative. 
* Course level: EE majors/non-EE (other majors).

* Number of teachers involved in the implementation: one/more than one (team).

* Students' background: VISIR contents worked before: yes/no.

The goal of the test was to determine whether there was any statistically significant difference in, for example: "teachers' satisfaction with VISIR" between the two groups: "the ones whose course was an EE major and the ones whose course was other majors". That was the underlying question for this test variable/factor. As there were two test variables and 13 factors, there were 26 questions that needed an answer.

At all cases $p>0.05$, that is, there was no statistically significant difference between the means of two groups. We concluded that none of the studied factors have a direct impact on the test variables: teachers' VISIR usage (measured by the number of VISIR accesses per task) and teachers' satisfaction with VISIR. Appendix G contains the Mann-Whitney U test results.

The two test variables are consistent, regardless the different context factors studied.

Continuing with the second mediation characteristic (T2) teacher promotes a good learning environment. It has been already explored in section 2.2.2 the importance of this feature based in an environment of communication and collaboration, as learning is a social process -(T2a) foments social learning and collaboration in tasks- to involve students in meaningful discussions that allow not only the promotion of social competences but also the development of higher-order competencies, such as critical thinking (Lopes, 2004; Lopes, Cravino, et al., 2008). As the teacher of case C3 commented the methodology proposed for the activities generated an exchange of ideas among the members of a group evidencing in the majority a very good teamwork. Some activities are proposed in the form of "competition", including an analysis and orally explanation of the results (together in the classroom), between the groups and this has a positive impact on student work. Students that first ended up the tasks were encouraged to help their colleagues from other groups Another important issue is (T2b) give authority and responsibility to students compels students towards a productive engagement in the classroom/tasks, fomenting their active participation in the activities (Artino, 2008; Lopes, 2004). A comment of the case C13 teacher: students practiced according to their needs and another aspect to draw attention is that when it was left for the student to choose between doing the practical activity on the bench or VISIR they chose to do in VISIR.

(T3) Teacher clarifies objectives. There were several cases in which teachers (T3a) explains the pertinence of using several experimental resources or in the own words of the case C25 head teacher that students interpret the difference between the measurements in handson lab, remote and simulation and theoretical calculations. In several cases (in the majority before introducing VISIR), teachers explained in class the difference between simulation and remote labs, 
emphasizing the type of results obtained with each resource. In fact, "understanding this difference is crucial, and only then students can get the most of working with simultaneous resources and develop critical thinking while analysing, comparing and discussing the different results, so the benefits of the simultaneous use of resources are more effective" (Lima, Viegas, Zannin, Marques, Alves, Felgueiras, Costa, et al., 2017). (T3b) Helps to mobilize prior knowledge. Indeed, in order to conform to with an insightful mediation, teachers should propose tasks according to students' prior knowledge, to help them in the development of scientific knowledge (Cunha et al., 2014; Viegas, 2017b). The case C20 head teacher commented develop a complete work guide, clear and consistent with the level of knowledge of the student... so that they could really reflect on the results obtained and could make the previous calculations to contrast with the measurements.

(T4) Teacher keeps the task authentic. In several cases teachers kept the tasks authentic, allowing students to work on their own pace until they find a solution (Lopes, Viegas, et al., 2010): (T4a) allows students to find a solution, as the case C9 teacher said The lecturer elected not to comment on the implications of resistor associations, as he expected students to "discover" for themselves. To avoid students from frustration or even giving up the tasks, teachers should "be always there", as tutors, giving them clues and tips (T4b) giving support in crucial moments. As in case C2 students who had difficulties were held extra class meetings (but teacher did not do students job).

(T5) Teacher keeps up with students work and gives feedback. It was already discussed the importance that regular feedback -teachers provide about students work- may have in students' engagements and a better control of their learning process (Hattie \& Timperley, 2007). (T5a) Gives time and adequate feedback allows students to adjust, if necessary, their behaviours and reorientation towards their learning goals (Viegas et al., 2009, 2010). The case C26 teacher commented students were also encouraged to come to the teacher office hours to clarify pertinent doubts (or send it, via email). That feedback allowed them to continue to autonomously develop their work. (T5b) Uses qualitative assessment to allow students to progress, the information provided in this type of assessment, depending on the type and the usefulness of the comments, may help students in their progress (Viegas, 2017a). In the first course implementation edition of case $\mathrm{C} 20$, the head teacher commented that, after the report of the VISIR is delivered, students were submitted to an oral test involving conceptual questions. That qualitative assessment was used by the teacher to construct a qualitative conceptual note of the student (shared with him). 
Although it is very difficult to isolate teacher mediation influence on students' results from the other categories considered in this study: VISIR's implementation, teachers' involvement and teachers' perception, it is widely reported in literature that an effective teacher mediation may stimulate the progression of students' knowledge and competences.

In this study, it was not established precise teacher mediation guidelines, and although we believe that many teachers may have implemented in their classes the majority of the mediation traces (acknowledged as relevant to this study), we have that information (and not always complete) for some cases. Still, some mediation traces were identified, supporting that teachers were able to implement in their classes in several cases, even though with different levels of extent, as summarized in Table 27. It is to believe that if the teachers implement several of these traces in their classes, it is likely that they may have contributed to enhance students' engagement and learning outcomes. This relation between teacher mediation and students' results will be explored in section 6.3.3.

\subsection{Students' Results}

The ultimate goal of any didactical implementation is to improve students' academic performance measured directly by their grades and/or by other important determinant factors in students' success, such as their accesses to the available resources and satisfaction.

Students' academic performance and perception of VISIR (F1 - Students' perceived learning; F2 - Students' satisfaction with VISIR and F3 - Students' satisfaction with support) were detaily characterized by didactical implementation in section 5.2. This data was also grouped and analysed by education level, implementation topic and VISIR use level. In this section these results will be deeper analysed to understand which factors impacted students' results and to establish the cross relations between students' characteristics, their academic performance and their perception of VISIR.

\subsubsection{Academic Performance}

Considering students' academic performance namely: the number of VISIR accesses per task and the grades obtained in each component as well as the final grade it was observed that all of them show a wide range of variability amongst cases (Table 17, page 115). In general -in the majority of the didactical implementations- students achieved good grades in the "VISIR component", the "other tasks" and the "laboratory", and worse results in the "exam" and "final" grade, as fully 
explored in section 5.2. However, in the case C11, the "VISIR average grade" reached a really low value ( $42.5 \%$ ); only $52.6 \%$ (of the enrolled students) passed the course.

Considering the global data (all students involved in the didactical implementations) the average grades obtained in the "VISIR tasks", "other tasks" and "laboratory" were all between 81 to $85 \%$ in opposition to the "average exam grade" and "final grade", also alike between them, but clearly lower (about 20\%). This analysis was also performed by education level, implementation topic and VISIR use level and some differences stood out as detailed in Table 18 (page 118) and analysed in that section.

Now, in order to identify factors that might influence students' results, the data available from the 43 didactical implementations will be first discussed together in order to try to identify some patterns -that may eventually be caught in this global analysis- independently of the courses' different characteristics in terms of VISIR's implementation, teachers' or students' VISIR usage and perception. In this global analysis, the goal is not to compare cases, which, in fact are not comparable considering the different characteristics and contexts. The goal is to identify some patterns that may allow to make global considerations. After this global analysis, the differences between different clusters of the same data (topic) will be explored and finally, a more detailed analysis by case will be carried out in order to more accurately understand each case and only then one can adventure reliable conclusions.

When carrying out this global analysis as well as the analysis by topic, the assumptions made in section 5.2.1 contemplating both the number of VISIR accesses per task and the VISIR grade will not be considered. In the former section it was considered the number of VISIR accesses per task was equal to all students, when the tasks were exclusively performed during class time (using all students the same user account) and in some cases teachers did not really graded the VISIR tasks and attributed $100 \%$ to the students who deliver the tasks and $50 \%$ if they delivered half of it. For this study (global and by topic), it was just used the number of VISIR accesses students had to the VISIR remote lab and registered by the system and the VISIR numeric (quantitative) grades provided by teachers.

In order to identify possible correlations between the number of VISIR accesses per task, and their actual grades (by component as well as final grade) it was used Pearson or Spearman correlation. As it can be observed in Table 28, several statistically significant correlations emerge between students' VISIR usage with their academic performance. While carrying out this analysis it was also considered possible correlations between VISIR grade and other tasks grade with the grades obtained in the other components as well as the final grade. 
Table 28 - Students' Grades Correlations with VISIR Usage (Global Analysis)

\begin{tabular}{|c|c|c|c|c|c|}
\hline & $\begin{array}{l}\text { VISIR } \\
\text { Grade }\end{array}$ & Other Tasks Grade & Lab Grade & Exam Grade & Final Grade \\
\hline $\begin{array}{c}\mathrm{N} \text { VISIR } \\
\text { Accesses/Task }\end{array}$ & n. s. & $\begin{array}{c}\mathrm{R}_{\mathrm{SP}}=-0.233^{* *} \\
(\mathrm{p}<0.001) \\
\mathrm{N}=666\end{array}$ & $\begin{array}{c}\mathrm{R}_{\mathrm{SP}}=-0.337 * * \\
(\mathrm{p}<0.001) \\
\mathrm{N}=623\end{array}$ & $\begin{array}{c}\mathrm{R}_{\mathrm{SP}}=-0.136^{* *} \\
(\mathrm{p}<0.001) \\
\mathrm{N}=758\end{array}$ & $\begin{array}{c}\mathrm{R}_{\mathrm{SP}}=0.236^{* *} \\
(\mathrm{p}<0.001) \\
\mathrm{N}=444\end{array}$ \\
\hline
\end{tabular}

There is no significant correlation between the number of VISIR accesses per task with the VISIR grade: their VISIR usage appears to have no significant direct impact in their VISIR performance. This global analysis involves a massive variety of factors (contexts, teachers, students, didactical implementation characteristics) that affects these data, that is, students may access more the VISIR for several reasons and not directly related to their academic performance. On the other hand, the number of VISIR accesses per task is statistically significantly positively (weak) correlated with their final grade and there is a negative correlation between this number and the other partial grades. One should be aware that in this global analysis and considering the enormous diversity in the characteristics of these implementations, these negative weak correlations may have no importance; other tasks refers to tasks, not directly related to VISIR and/or lab, which vary enormously in these implementations; although VISIR grade has typically an input to the lab grade and/or the final grade, its weight depends a lot on the implementation (from just a qualitative information to a meaningful weight). A more detailed and thorough analysis must be performed to try to understand this lack of correlation between the number of VISIR accesses per task and the VISIR grade -as this result seems to contradict previous results reported in literature (Corter et al., 2011; Lima, Zannin, et al., 2017; Marques et al., 2014; Viegas, Pavani, et al., 2018)- and further comprehend these factors. However, there are also some works, considering a single didactical implementation, that just found a correlation between the number of VISIR accesses per task with the grades obtained in specific components (like calculus) and or final grades, suggesting VISIR helped students broader in their learning (Alves, Viegas, et al., 2016; Lima, Alves, Viegas, et al., 2015).

Both VISIR and other tasks grades show statistically significant correlations with the grades obtained in the other components as well as the final grade. These correlations for VISIR grade and other tasks grade with the grades obtained in the other components are very similar between them, suggesting VISIR does not have an outstanding impact. For all cases, first is displayed the correlation between the considered grade with the VISIR grade and secondly the same considered grade with the other tasks grade, being naturally larger with the lab grade:

Lab grade: $\mathrm{r}_{\mathrm{SP}}=0.742(\mathrm{p}<0.001 ; \mathrm{N}=618) ; \mathrm{r}_{\mathrm{SP}}=0.793(\mathrm{p}<0.001 ; \mathrm{N}=550)$. 
Exam grade: $\mathrm{r}_{S P}=0.368(\mathrm{p}<0.001 ; \mathrm{N}=912) ; \mathrm{r}_{\mathrm{P}}=0.417(\mathrm{p}<0.001 ; \mathrm{N}=862)$.

Final grade: $r_{S P}=0.317(p<0.001 ; N=478) ; r_{P}=0.577(p<0.001 ; N=422)$.

In order to somehow narrow this variability of factors a similar analysis/procedure was carried out grouping the students by education level, by implementation topic and by VISIR use level and the possible correlations between the variables in study (as described for the global analysis) were searched. The results of this analysis will be described in the next paragraphs and the main results are summarized in Table 29 (in some cases there was not data to compute that variable or the topic did not consider that component (for instances: lab grade)). In the analysis by implementation topic, "Projects" was not considered as there is no data.

Table 29 - Students' Grades Correlations with VISIR Usage (by topic)

\begin{tabular}{|c|c|c|c|c|c|c|c|}
\hline & & & $\begin{array}{l}\text { VISIR } \\
\text { Grade }\end{array}$ & $\begin{array}{c}\text { Other Tasks } \\
\text { Grade }\end{array}$ & Lab Grade & Exam Grade & Final Grade \\
\hline \multirow{3}{*}{ 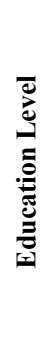 } & Secondary & \multirow{3}{*}{ 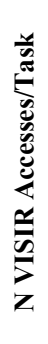 } & & & & & \\
\hline & Technological & & n. s. & n. s. & & $\begin{array}{c}\mathrm{R}_{\mathrm{SP}}=0.466^{* *} \\
(\mathrm{p}=0.006) \\
\mathrm{N}=33\end{array}$ & n. s. \\
\hline & $\begin{array}{l}\text { Higher } \\
\text { Education }\end{array}$ & & n. s. & $\begin{array}{c}\mathrm{R}_{\mathrm{SP}}=-0.253 * * \\
(\mathrm{p}<0.001) \\
\mathrm{N}=648\end{array}$ & $\begin{array}{c}\mathrm{R}_{\mathrm{P}}=-0.332^{* *} \\
(\mathrm{p}<0.001) \\
\mathrm{N}=623\end{array}$ & $\begin{array}{c}\mathrm{R}_{\mathrm{P}}=-0.169 * * \\
(\mathrm{p}<0.001) \\
\mathrm{N}=725\end{array}$ & $\begin{aligned} \mathrm{R}_{\mathrm{SP}} & =0.243^{* *} \\
(\mathrm{p} & <0.001) \\
\mathrm{N} & =408\end{aligned}$ \\
\hline \multirow{4}{*}{ 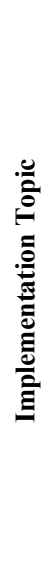 } & Electricity & \multirow{4}{*}{ 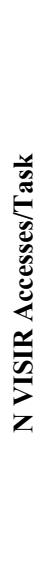 } & n. s. & n. s. & n. s. & n. s. & $\begin{array}{c}\mathrm{R}_{\mathrm{SP}}=0.287^{* *} \\
(\mathrm{p}=0.003) \\
\mathrm{N}=102\end{array}$ \\
\hline & Electronics & & $\begin{aligned} \mathrm{R}_{\mathrm{SP}} & =-0.482 * \\
(\mathrm{p} & =0.008) \\
\mathrm{N} & =29\end{aligned}$ & $\begin{array}{c}\mathrm{R}_{\mathrm{P}}=0.494^{*} \\
(\mathrm{p}=0.044) \\
\mathrm{N}=17\end{array}$ & n. s. & n. s. & $\begin{aligned} \mathrm{R}_{\mathrm{P}} & =0.391 * \\
(\mathrm{p} & =0.002) \\
\mathrm{N} & =59\end{aligned}$ \\
\hline & Mathematics & & $\begin{array}{c}\mathrm{R}_{\mathrm{P}}=0.170^{*} \\
(\mathrm{p}=0.047) \\
\mathrm{N}=137\end{array}$ & $\begin{array}{c}\mathrm{R}_{\mathrm{SP}}=0.241 * * \\
(\mathrm{p}=0.003) \\
\mathrm{N}=147\end{array}$ & & $\begin{array}{c}\mathrm{R}_{\mathrm{P}}=0.378^{* *} \\
(\mathrm{p}<0.001) \\
\mathrm{N}=143\end{array}$ & $\begin{aligned} \mathrm{R}_{\mathrm{SP}} & =0.387 * * \\
(\mathrm{p} & <0.001) \\
\mathrm{N} & =147\end{aligned}$ \\
\hline & Physics & & n. s. & n. s. & n. s. & n. s. & $\begin{array}{c}\mathrm{R}_{\mathrm{P}}=0.244 * * \\
(\mathrm{p}=0.008) \\
\mathrm{N}=119\end{array}$ \\
\hline \multirow{3}{*}{ 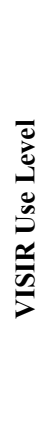 } & Basic & \multirow{3}{*}{ 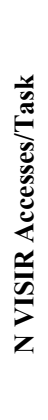 } & $\begin{array}{c}\mathrm{R}_{\mathrm{P}}=0.182 * * \\
(\mathrm{p}<0.001) \\
\mathrm{N}=425\end{array}$ & $\begin{array}{c}\mathrm{R}_{\mathrm{P}}=-0.271^{* *} \\
(\mathrm{p}<0.001) \\
\mathrm{N}=611\end{array}$ & $\begin{array}{c}\mathrm{R}_{\mathrm{P}}=-0.408^{* *} \\
(\mathrm{p}<0.001) \\
\mathrm{N}=538\end{array}$ & $\begin{array}{c}\mathrm{R}_{\mathrm{SP}}=-0.135^{* *} \\
(\mathrm{p}<0.001) \\
\mathrm{N}=701\end{array}$ & $\begin{aligned} \mathrm{R}_{\mathrm{SP}} & =0.180^{* *} \\
(\mathrm{p} & =0.002) \\
\mathrm{N} & =302\end{aligned}$ \\
\hline & Intermediate & & n. $s$ & $\begin{array}{c}\mathrm{R}_{\mathrm{SP}}=0.507^{* *} \\
(\mathrm{p}=0.001) \\
\mathrm{N}=25\end{array}$ & $\begin{array}{c}\mathrm{R}_{\mathrm{SP}}=0.533 * * \\
(\mathrm{p}=0.006) \\
\mathrm{N}=25\end{array}$ & n. $s$ & $\begin{aligned} \mathrm{R}_{\mathrm{SP}} & =0.336^{* *} \\
(\mathrm{p} & =0.022) \\
\mathrm{N} & =46\end{aligned}$ \\
\hline & Advanced & & n. $s$ & n. $s$ & n. $\mathrm{s}$ & n. $s$ & $\begin{aligned} \mathrm{R}_{\mathrm{SP}} & =0.390^{* *} \\
(\mathrm{p} & =0.002) \\
\mathrm{N} & =61\end{aligned}$ \\
\hline
\end{tabular}


The analysis by Education Level starts.

For the technological level, it emerges a statistically significant positive correlation between the number of VISIR accesses per task and the exam grade; however, at this education level we just have the number of VISIR accesses per task to case C5 $\left(2^{\text {nd }}, 3^{\text {rd }}\right)$, so the obtained results are the $\mathrm{C} 5$ results. In the higher education level, some negative very weak or weak correlations show up between the number of VISIR accesses per task and the grades (not directly related to VISIR) obtained in the partial grades in each component and a positive correlation with the final grade. In this level of education there is a great variability in course characteristics, implementation features, number of students enrolled, etc. which may somehow contribute to this intriguing result: students seem to benefit from VISIR, but only considering their final result in the course.

For all educational levels (for which there was data), both VISIR and other tasks grades show statistically significant correlations with the grades obtained in the other components and/or the final grade, except partially the technological level; in this level the VISIR grade does not have any correlation with the grades obtained in the exam grade and/or final grade; but once again the available data is basically the data for case C5 (where students achieved an excellent grade in the VISIR components and weak results particularly in the exam) and some data from the case C6. These correlations for VISIR grade and other tasks grade with the grades obtained in the other components are, in most cases, about the same type with each other (when it was possible to compute it). For all cases, first is displayed the correlation between the considered grade with the VISIR grade and secondly the same considered grade with the other tasks:

* Lab grade: higher education: $\mathrm{r}_{\mathrm{SP}}=0.742(\mathrm{p}<0.001 ; \mathrm{N}=618), \mathrm{r}_{\mathrm{SP}}=0.793(\mathrm{p}<0.001$; $\mathrm{N}=550)$.

* Exam grade: secondary: $\mathrm{r}_{\mathrm{SP}}=0.296(\mathrm{p}<0.001 ; \mathrm{N}=121), \mathrm{r}_{\mathrm{P}}=0.497(\mathrm{p}<0.001 ; \mathrm{N}=121)$; technological: $n$. s., $r_{P}=0.601(p=0.001 ; N=28)$; higher education: $r_{S P}=0.437$ $(\mathrm{p}<0.001 ; \mathrm{N}=786), \mathrm{r}_{\mathrm{P}}=0.468(\mathrm{p}<0.001 ; \mathrm{N}=685)$.

* Final grade: secondary: $r_{P}=0.472(p<0.001 ; N=121), r_{P}=0.785(p<0.001 ; N=121)$; technological: $n$. $s$., $r_{P}=0.538(p=0.003 ; N=29)$; higher education: $r_{S P}=0.471$ $(\mathrm{p}<0.001 ; \mathrm{N}=351), \mathrm{r}_{\mathrm{P}}=0672(\mathrm{p}<0.001 ; \mathrm{N}=272)$.

We will keep on the former type of analyses, but now by Implementation Topic.

When we move to implementation topic we somehow restrain to smaller cluster of the same data and for each topic the variability is not so vast; probably each topic deals with the same type of issues. For all the topics a statistically significant positive correlation shows up between the number of VISIR accesses per task and the final grade. Some other statistically significant positive correlations emerge between the number of VISIR accesses per task with the VISR grade and/or 
the other tasks grade and/or the exam grade. This supports that in general, the more students accessed VISIR, the better results they achieved, although these results may be related to the students' hardworking abilities. Nevertheless, it is interesting to notice that the correlation between the number of VISIR accesses per task and the final grade stood out in all topics and with a higher value than the values that emerged between the number of VISIR accesses per task and the other grades. This result may suggest that VISIR contributes to the development of more general competences that are useful in students' learning, development and success in the course. Considering the electronics topic (EE major), a negative moderate correlation shows up between the number of VISIR accesses per task and the VISIR grade. Although an intriguing result at first, we must bear in mind that these are proficient students, naturally interested in this topic; the ones with good knowledge probably do not feel the need to use VISIR so much; in this topic it seems VISIR is more used by the students who are still struggling with difficulties.

VISIR grades and other tasks grades show statistically significant correlations with the grades obtained in the other components and/or the final grade, for the majority of the topics. These correlations for VISIR grade and other tasks grade with the grades obtained in the other components are, in most cases, about the same type. For all cases, first is displayed the correlation between the considered grade with the VISIR grade and secondly the same considered grade with the other tasks:

* Lab grade: electricity: $\mathrm{r}_{\mathrm{SP}}=0.771(\mathrm{p}<0.001 ; \mathrm{N}=470), \mathrm{r}_{\mathrm{P}}=0.712(\mathrm{p}<0.001 ; \mathrm{N}=482)$; electronics: $r_{P}=0.864(p<0.001 ; N=14)$, n. s.; physics: $r_{S P}=0.442(p<0.001$; $\mathrm{N}=134), \mathrm{r}_{\mathrm{SP}}=0.422(\mathrm{p}<0.001 ; \mathrm{N}=51)$.

* Exam grade: electricity: $\mathrm{r}_{\mathrm{P}}=0.433(\mathrm{p}<0.001 ; \mathrm{N}=467), \mathrm{r}_{\mathrm{P}}=0.392(\mathrm{p}<0.001 ; \mathrm{N}=504)$; electronics: $n$. s., n. s.; mathematics: $r_{S P}=0.400(p<0.001 ; N=146), r_{P}=0.379$ ( $p<0.001 ; N=155)$; physics: $n$. $s, r_{P}=0.503(p<0.001 ; N=163)$.

* Final grade: electricity: $r_{S P}=0.743(p<0.001 ; N=18), r_{P}=0.586(p<0.001 ; N=43)$; electronics: $r_{P}=0.492(p=0.002 ; N=38)$, n. s.; mathematics: $r_{S P}=0.510(p<0.001$; $N=175), r_{P}=0.709(p<0.001 ; N=190)$; physics: $r_{S P}=0.167(p=0.008 ; N=247)$, $\mathrm{r}_{\mathrm{SP}}=0.741(\mathrm{p}<0.001 ; \mathrm{N}=163)$.

In the electronics implementation topic, the former results suggest VISIR had an outstanding impact on students' academic performance considering their lab component and final grade (at least when compared with the other tasks grade that does not seem to have any influence on students' academic performance).

Finally, analysing by VISIR Use Level. 
Analysing by VISIR use level, the scenario is very different from the basic level (with a vast number of students from diverse contexts, backgrounds and levels of prior knowledge) to the intermediate and advanced levels (with much less students and more "homogeneous"), although for all the topics a statistically significant positive correlation shows up between the number of VISIR accesses per task and the final grade. This supports VISIR has a positive effect on their learning. For the basic level the number of VISIR accesses per task shows a very weak positive correlation with the VISIR grade and negative correlations with the other partial grades. Again, in this level and considering the enormous diversity in the characteristics of these implementations, these negative weak correlations may have no relevance. In the intermediate level some statistically significant positive moderate correlations show up between the number of VISIR accesses per task with the grades obtained in the other tasks and the lab component. This supports that in general, the more students accessed VISIR, the better results they achieved, although these results may also be naturally related with the fact that these students are more proficient in these topics.

Both VISIR and other tasks grades show statistically significant correlations with the grades obtained in the other components and/or the final grade. For all cases, first is displayed the correlation between the considered grade with the VISIR grade and secondly the same considered grade with the other tasks:

* Lab grade: basic level: $\mathrm{r}_{\mathrm{SP}}=0.745(\mathrm{p}<0.001 ; \mathrm{N}=568), \mathrm{r}_{\mathrm{SP}}=0.754(\mathrm{p}<0.001 ; \mathrm{N}=491)$; intermediate level: $r_{P}=0.546(p=0.006 ; N=24), r_{P}=0.825(p<0.001 ; N=28)$; advanced level: $r_{P}=0.655(p<0.001 ; N=26), r_{P}=0.849(p<0.001 ; N=31)$.

* Exam grade: basic level: $r_{S P}=0.361(p<0.001 ; N=833), r_{P}=0.410(p<0.001$; $\mathrm{N}=795)$; intermediate level: $\mathrm{r}_{\mathrm{SP}}=0.489(\mathrm{p}<0.001 ; \mathrm{N}=42), \mathrm{r}_{\mathrm{SP}}=0.548(\mathrm{p}<0.001$; $N=25)$; advanced level: $r_{S P}=0.796(p=0.002 ; N=12), r_{S P}=0.799(p<0.001 ; N=14)$.

* Final grade: basic level: $r_{S P}=0.290(p<0.001 ; N=434), r_{S P}=0.584(p<0.001$; $N=393)$; intermediate level: $r_{S P}=0.489(p<0.001 ; N=42)$, not possible to compute; advanced level: $r_{S P}=0.852(p<0.001 ; N=26), r_{S P}=0.487(p<0.001 ; N=29)$.

For the didactical implementations, for which it was possible (data available, although not all the data for some of them) $-\mathrm{C} 3, \mathrm{C} 5, \mathrm{C} 8, \mathrm{C} 9, \mathrm{C} 10, \mathrm{C} 11, \mathrm{C} 12, \mathrm{C} 13, \mathrm{C} 14, \mathrm{C} 15, \mathrm{C} 16, \mathrm{C} 19, \mathrm{C} 20, \mathrm{C} 23$, C24, C26- the same type of analysis was carried out and the found correlation are summarized in Appendix H split by case. In case C3 the number of (students') VISIR accesses per task was constant (all students used the same account and the tasks were developed in class (or extra class), so each student had an equal number of accesses to the VISIR system. In the C5 (2nd) and the C19 (1st, $\left.3^{\text {rd }}\right)$ the VISIR grade was constant (all students achieved the same grade of $100 \%$ ). 
The cases summarized in Appendix $\mathbf{H}$ are the ones for which some significant correlations stood out. In some of them one or more components are missing, because either there was not data to compute that variable (as detailed in Table 17, page 115) or the variable had a constant value (as mentioned in the previous paragraph) or the teachers did not consider that component (for instance: the lab grade). For more details, check the Appendix F. In those correlation procedures, it was considered all the information available for each particular didactical implementation. In each case (summarized in Appendix $\mathbf{H}$ ) and when the course has undergone more than one implementation edition, the information is displayed for each edition and for the case (as a whole: "GL"). Looking in detail to that information, for several didactical implementations/cases, some correlations emerged between the number of VISIR accesses per task with the grade obtained in the VISIR components and/or the lab and/or the other partial grades (other tasks, exam) and/or the final grade. For simplicity, in this section it is just summarized the cases and/or course implementation editions for which the former correlations were found and if they were positive or negative. The correlation between the number of VISIR accesses per task with the grades are, respectively:

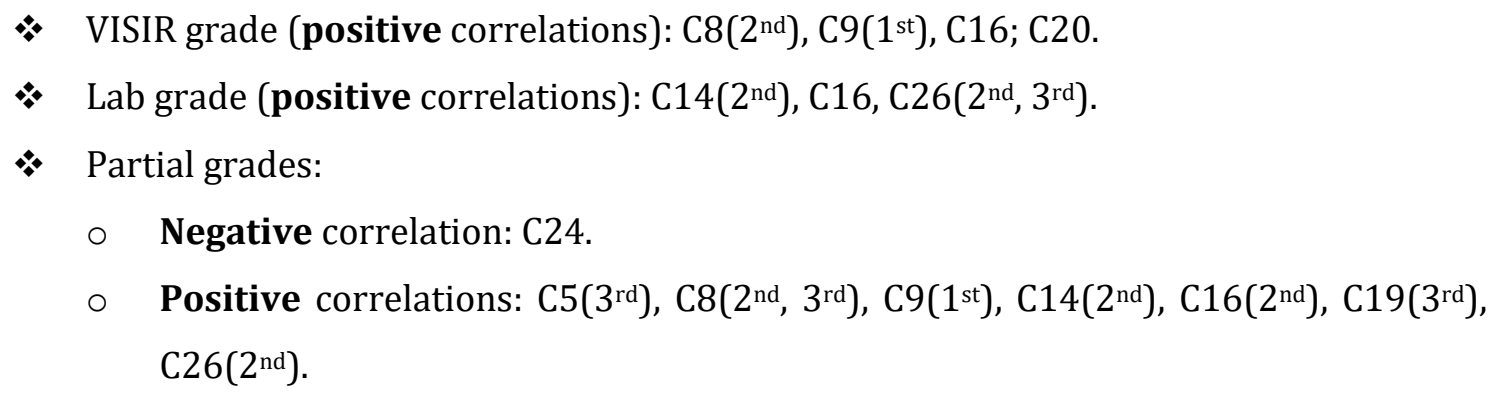

Looking to the previous results it is clear case C24 exhibited a different "behaviour" and so students' academic performance will be fully detailed. In case C24, a statistically significant negative correlation emerged between the number of VISIR accesses per task and the exam grade. VISIR grades do not show any significant correlation with the exam grade and/or the final grade (there is no lab grade nor other tasks grade). These results may reflect the reality if this course: 8 students enrolled ( 1 is NF, that is, did not show for the majority of classes and to any assessment moment); 6 students have accessed VISIR (the number of accesses per task varies from 0.5 to 4 ); the VISIR grade was $90 \%$ for 5 students and $100 \%$ to 2 students; the exam grade varied from $65 \%$ to $80 \%$ and the 7 students that were assessed passed the course and the teacher considered 6 of then developed HOS. Although these 7 students achieved good grades and a high level of success in this course, the results may suggest that the students that have more difficulties are the ones using more VISIR. 
Again, it was also considered possible correlations between the VISIR grade and the other tasks grade with the grades obtained in the other components as well as the final grade, trying to figure out if the VISIR component had a similar impact (as the other tasks) on students' academic performance or an outstanding impact.

In some didactical implementations/cases, similar type of correlations -as the ones that emerged in the global analysis and analysis by topic- stood out between the VISIR grade and the other tasks grade with the grades obtained in the other components and/or the final grade: C3(1 $\left.{ }^{\text {st }}\right), C 8\left(2^{\text {nd }}, 3^{\text {rd }}\right), C 11$ C16, C26(3rd $)$. In case C14 $\left(2^{\text {nd }}\right)$ the former correlations just emerged with respectively the final grade and the lab grade and it was lower for the VISIR grade (when compared with the other tasks grade). In case C9, the behaviour is not exactly the same in both course editions when we consider the correlations with the exam grade. In case C19 (2nd), a strong correlation emerged between the VISIR grade and the lab grade as well as the final grade (no similar correlation was found between the other tasks grade and the lab grade and/or the final grade), suggesting VISIR may have had an important impact on students' performance.

Considering the results discussed in the previous paragraphs it is clear that for the majority of the courses that have undergone several course editions, the revealed correlations between the studied variables are not always the same for all course editions. As explored in section 6.1.1.1, in some cases and for different reasons teachers made some modifications in the subsequent course editions which may have impact on the students' results.

For several cases -C10, C12, C13, C15, C23- there was not found any correlation between the studied variables. In fact, for the former cases, much of the important data (as the number of VISIR accesses per task, the grades in the various components and/or final grade) is missing and in some cases the number of students for which there is some data is really low. For the remaining cases, the found correlations were approached in the previous paragraphs and not all cases exhibited similar patterns, as already expected. In fact, the former analysis by course implementation edition somehow characterizes the results (students' academic performance) of each course strategy on implementing VISIR, considering the different characteristics and contexts. Still, one can conclude the use of VISIR and this methodology of several experimental resources has a positive influence on students' global learning achievements, for the majority of the cases.

To further understand if some factors, considering "students' background" and "students' success", impacted "students' grades" (VISIR grade and lab grade) and "students' accesses in VISIR", it was decided to perform some statistical tests (differences tests). These tests were performed considering the overall data (gathered in the 26 cases). From the prerequisite parametric conditions verification, it was concluded that the first two variables follow a normal 
distribution while the last one does not follow. Therefore, for the first two test variables it was performed an independent sample t-test while for the third it was chosen a nonparametric MannWhitney $\mathrm{U}$ test for two independent samples. So, the data was split in 2 groups, accordingly to the factors to be tested and then the average values obtained in the test variables for each factor were compared to determine if there were statistically significant differences between them. So, the underlying question for each factor/variable was, for instance: Is there a statistically significant difference between the students that have already used VISIR and the students that that are using it for the first time, considering the average VISIR tasks grade they reached? As there were 3 test variables and 3 factors, there were 9 questions that needed to be answered. The factors to be tested were:

* Students' background: VISIR contents worked before: yes/no (no, meaning it is the first time these contents are worked).

* Students' fist time to use VISIR: yes/no (no, meaning students have already experience with the tool).

* Students' "success": students developed HOS (yes/no).

Appendix I contains the results of both tests and Figure 17 illustrates the factors that influence each test variable. In the referred figure, the arrows go from the factor -out of the two considered hypothesis, accordingly to the way students were split in two groups (for instance, students developed HOS and students did not develop HOS)- that has a positive influence (on each of the test variables) to the test variable; if the arrow does not show up it means that factor has no influence on the test variable.

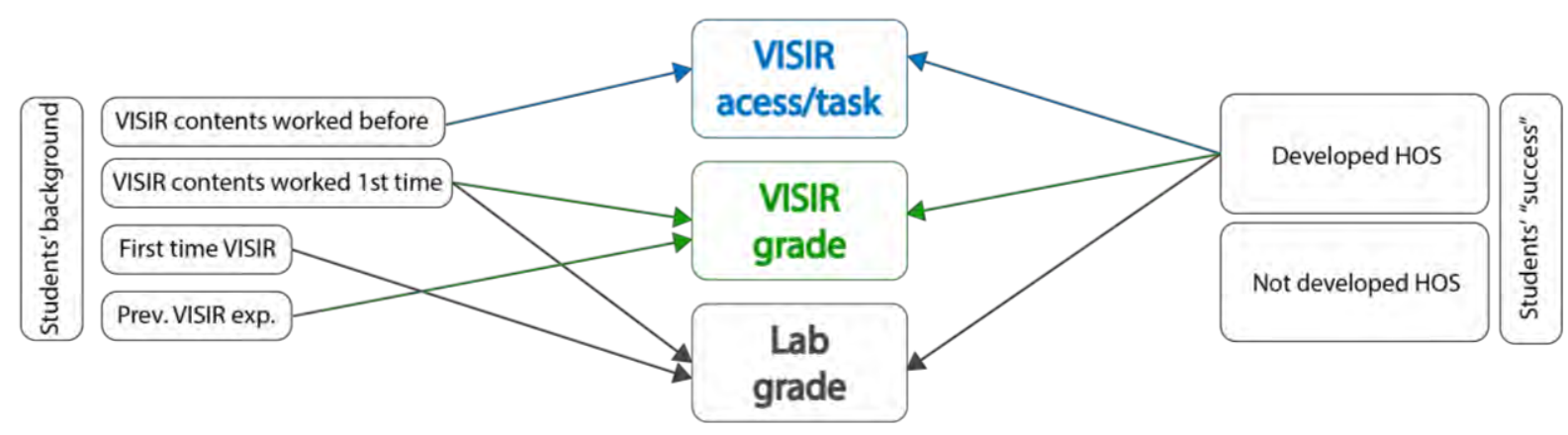

Figure 17 - Influence of Students' Background and Students' Success on Students' Grades and VISIR Usage

It is clear from Figure 17 that students' previous experience with VISIR does not affect their VISIR usage (number of VISIR accesses per task), although that previous experience has a positive impact in the VISIR grade: students achieve an higher average grade. On the other hand, students 
who are using VISIR for the first time achieve a higher average grade in the lab component. That may be related to the fact that the majority of students that have a previous experience with VISIR are students that are repeating the course, so probably students with some difficulties. Their previous experience with VISIR helped them in the VISIR component (a very specific task or set of tasks), but not in a broader way in the course. Students who teachers recognize as having developed HOS, naturally achieved average higher grades but also had an average higher number of VISIR accesses per task. These are the more hardworking students deeply involved in the learning activities and engaged in the course.

The global analysis carried out in this section, taking into account all students involved in these 43 didactical implementations namely their "grades", their "accesses in VISIR" as well as some features considering their "background" and "success", implies VISIR and this methodology may help students broader in their learning. This former statement was corroborated by the analysis performed by topic in which, for some topics it was also found a correlation between the number of VISIR accesses per task and the grades obtained directly in the VISIR component and/or some other partial grades, supporting the more students used VISIR the better results they achieved. Still as we are dealing, even in this narrower analyses, with such a variety of cases with different characteristics, the former result must be further explored as it may be related to some specific characteristics of the implementations and/or with some students' characteristics such as hardworking abilities. So, a similar analysis, by case, was carried on and although the correlations between the studied variables show some variability the results suggest that for the majority of the cases, for which it was possible to run the statistical procedures, VISIR has a positive impact on students' academic performance. We still need to explore the relevance of these cases characteristics differences on students' results.

\subsubsection{Students' Perception}

Considering students' perception of VISIR: F1 and F2 have the same value (3) for the majority of the didactical implementations, being F3 typically lower (Table 19, page 121). Still, there are two cases that stood out: case C7 and case C14 (second course edition). Case C7 stood out in a positive way (F1 = F2 = 4), but as the majority of the data is missing, it is not possible to perform a detailed analysis to understand what happened. In case C14 (second course edition) students did not appreciate at all the resource $(\mathrm{F} 2=1)$ and considered that its usefulness was questionable in their learning process $(\mathrm{F} 1=2)$. In the SSQ open answers they reported more negative factors than positive factors. Still, we must keep in mind that these students from PUC-Rio seem to be 
evaluating both VISIR and the Maxwell System. Nevertheless, considering the 8 students that answered Q22, the identified factors and their distribution were: "operating issues" (4), "poor interface/old fashionable/too simple" (4) and "nothing positive to highlight" (4). The former factors may have had a big influence in students' weak perception of VISIR. Students' VISIR average grade was $62.9 \%$ (the second lowest in all the considered didactical implementations), although very similar to their lab grade.

There are some other cases that had lower values of F1 and/or F2. In the next paragraphs we will try, using the SSQ answers, to get an insight of possible causes:

* Case C8: from the previous editions to the $3^{\text {rd }}$ course implementation edition, F2 and $F 3$ both decreased to F1 $=2.5$ and F2 $=2$. The number of students who answered the SSQ decreased expressively from the first two editions to the third one. The 10 students who answered Q22 reported, as negative comments, mainly "operating issues" (6), "external factors" (2), "insufficient material support" (2) and "being in English" (1). The first two factors were already reported in the previous editions. The other two were just reported in this edition and they may have contributed to these lower values of students' perception of VISIR (both F1 and F2).

* Case C11: F2 = 2; students did not really appreciate VISIR although they found it was a useful tool in their learning process $(F 3=3)$. In fact, in the SSQ open answers they reported more positive factors than negative ones. From the 9 students that answered Q22 the identified negative factors and their distribution were: "operating issues" (3), "errors not explained" (2), "poor interface/old fashionable/too simple" (2), "preference for traditional labs" (1), "circuits limitation" (2) and "external factors" (1). These factors may have had a big influence in the lower level of students' satisfaction with VISIR.

- Case C15: F2 = 2; from the 10 students who answered Q22, there were 6 answers in the factors "insufficient preparation from classes" (1) and "insufficient material support" (5). Students did not feel teachers adequate supported them in their experience with VISIR.

* Case C16: in the first course edition F2 just reached the value 2; 204 students answered Q22 and although 36 students answered they did not find any disadvantage in VISIR, they also reported several other factors. The most referred factors were "problems in understanding at the beginning"/"problems in understanding" (11/57), "insufficient preparation from classes"/"insufficient material support" (10/19), "poor interface/old fashionable/too simple" (21) and "external factor" (22). It seems students felt VISIR was old fashionable and they did not feel that they had teachers adequate support 
which caused them problems in understanding VISIR functioning aggravated by the Internet connection. Still these PUC-Rio students did not clearly understand Q22 and some of the constraints that appear connected to the VISIR system, may be related to the Maxwell system.

* Case C19: F1 and F2 decreased to 2, in the $3^{\text {rd }}$ course edition. From the 17 students who answered Q22, the most referred factors were: "operating issues" (8), "insufficient material support" (5) and "external factor" (2). The first factor has also been reported in the first two course editions, still the second and third factors just appeared in this edition. Some students did not feel they had the adequate support material to use VISIR and to make things worse they had some problems with Internet connection.

* Case C23: F1=F2=2. Only 3 students answered Q22 and they all reported "operating issues", which naturally contributed to the lower levels of satisfaction.

Considering the overall students' data, the scenario is: F1 and F2 have the same average value (3), being F3 lower. The analysis was also performed by education level, implementation topic and VISIR use level (Table 20, page 122) and the results kept basically the same.

In this section it will be followed exactly the same type of analysis described in the previous section (global to topic and final to case) when pursuing the correlation between F1 and F2. Table 30 summarizes the found correlations.

Either in the global analysis as in the several analyses by topic, there is always a (weak to strong) positive correlation between F1 and F2, suggesting that students' satisfaction with VISIR is related to the perception they have of the tool, considering its utility in their learning process. That correlation is weak for the students from the secondary level of education as well as for the physics' students (all the secondary students for which it was possible to have this data are from physics) and in opposition this correlation is strong for the intermediate VISIR use level. 


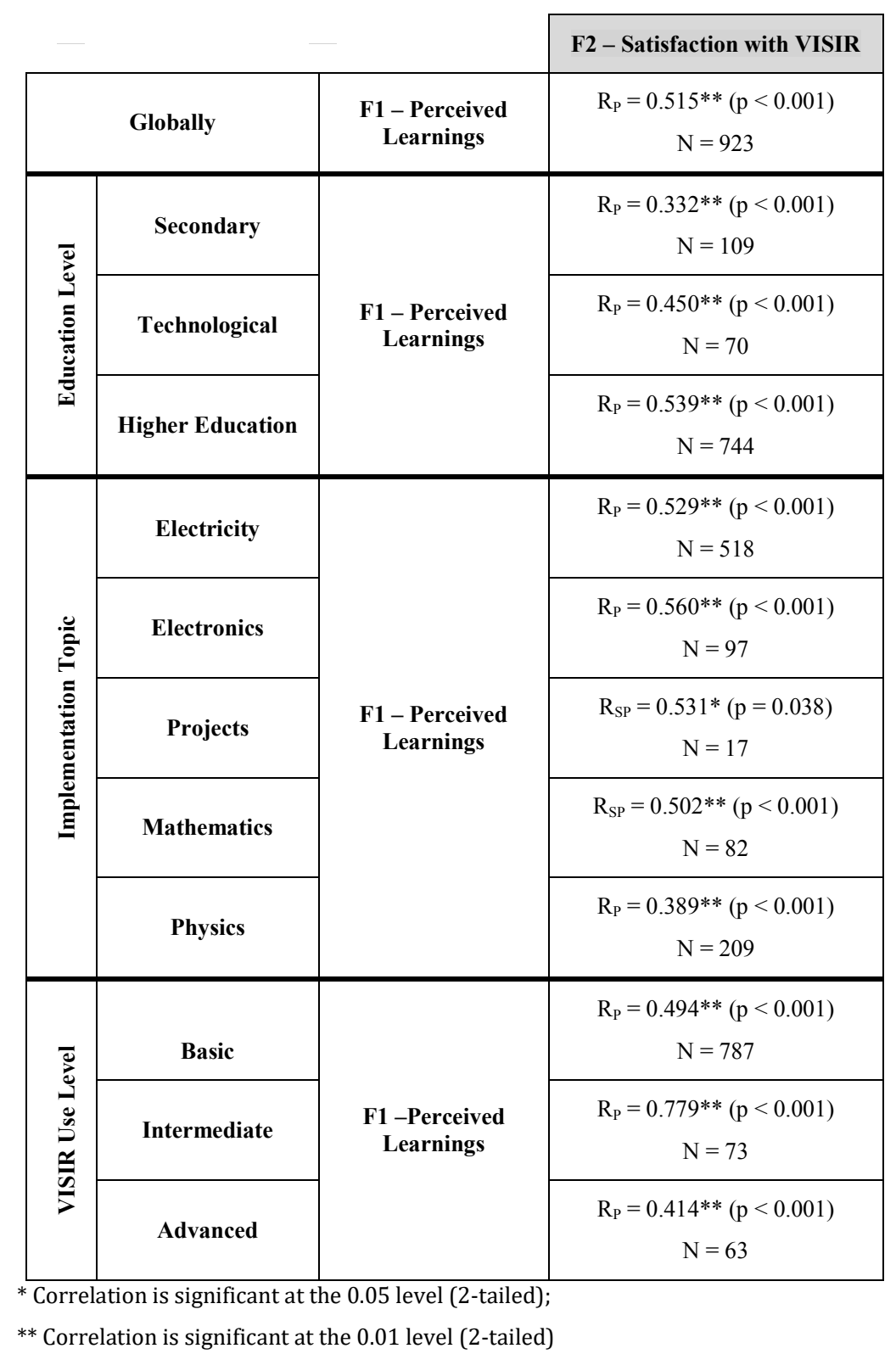

For the didactical implementations, for which it was possible, the same type of analysis was carried out. Although there was data for all cases/didactical implementations except: C1, C2, C17 $\left(2^{\text {nd }}\right), C 18$ and C25, one must also keep in mind that they should be reliable (Cronbach alpha $>0.5$ ) which is not the case for several cases/didactical implementations (as summarized in Table

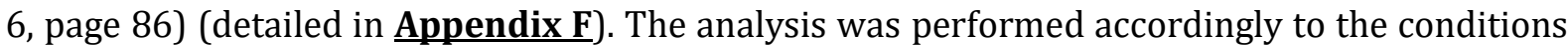
described in the previous section and Appendix $\mathbf{H}$ summarizes it (the correlations). In the majority it emerged a positive correlation between F1 and F2 (accordingly to the results obtained in the global analysis and the analysis by topic). There were still a few cases in which F1 is not correlated to F2. For simplicity, in this section, it will just be distinguished between the cases 
and/or course implementation edition in which a correlation emerged from the ones where there is no correlation (the correlation is not significative):

* Correlation between F1 and F2: C5(2nd, $\left.3^{\text {rd }}\right)$, C8(2nd $), C 9\left(1^{\text {st }}\right), C 10\left(1^{\text {st }}\right), C 14\left(2^{\text {nd }}\right), C 15$, C16, C20(2nd $), C 21, C 22, C 26\left(2^{\text {nd }}\right)$.

* No correlation between F1 and F2 (n. s.): C3(2 $\left.{ }^{\text {nd }}\right)$, C8(1 $\left.1^{\text {st }}\right)$, C11, C13, C19(3 $\left.{ }^{\text {rd }}\right)$, C24.

In both situations (correlation and no correlation between F1 and F2) the results do not seem dependent of students' perceived learnings (F1) or students' satisfaction with VISIR (F2). That is, correlations emerged for cases in which students had a good perception of VISIR (F1 and F2) and also for cases where this perception was not so good (for instances in case C14, which is the worst case, considering students' perception). The same is true for the cases in which no correlation was found (for instances cases C13 and C19).

The found results suggest that depending on the case(s) and its strategy on implementing VISIR, students' satisfaction with VISIR may be independent of their perception of the tool, considering its utility in their learning process. In the former cases, VISIR usage was directly stimulated by external factors, like its contribution weight to final grade or being mandatory to pass the course or by some specific teachers' and/or students' characteristics. Students' learning approach is highly influenced by their perception of the learning environment as well as their perception of themselves as learners and the learning process. These different perceptions may lead students to different learning approaches: a surface approach major determined by students' extrinsic motivation or a deep approach driven by students' intrinsic motivation to learn (Biggs \& Tang, 2007; Richardson, 2011).

The qualitative analysis performed to the open answers Q21 (What did you enjoy most about using VISIR remote lab?) and Q22 (What inconveniences did you find about using VISIR remote lab?), included in the SSQ, was already approached in section 5.2.2. The four most positive factors identified in this study, involving so many courses, students and different contexts were exactly the same of Viegas and colleagues (2018), although not exactly by the same order. Her study was focused in two different PUC -Rio courses and it is clear from her study and this one that the factor "access from anywhere/anytime" has a substantial importance. It is in accordance with previous works that already mentioned it (Corter et al., 2011; Ferreira et al., 2014) and supported by the location of some of the institutions considered in this work (including for some the lack of a good public transport network) and this accessibility/availability also allows students to practice at their own pace (Corter et al., 2007; Ma \& Nickerson, 2006; Tawfik, Sancristobal, Martín, et al., 2012). The accessibility factor is also related to the characteristics of these new generation of students -digital natives- being highly dependent and immersed on network and digital 
technologies (Prensky, 2001; Viegas et al., 2017). Some authors even suggest that the link to access VISIR (or another experimental online resource), should be included not only in the LMS course page but also in the social networks, such as Facebook and Twitter, allowing students to $\log$ in immediately without additional authentication (Lerro \& Marchisio, 2016). According to the same authors, students' login through the social networks tends to prevail to the LMS page as students are "always" connected to them for other purposes. The factors "the potential of the equipment", "better/more complete understanding" and "no fear of damaging" also clearly contributed to students' general perception that VISIR is an excellent resource. It supported them in their learning, allowed them to access it freely to fully apprehend the concepts and master the experimental techniques, without the fear of damaging the equipment

The three most negative factors are also in accordance with Viegas and colleagues (2018), although the order is not, again, the same. The factor "poor interface/old fashionable/too simple", although briefly referred in previous works (Ferreira et al., 2014), including by teachers (Lima et al., 2019c; Viegas, Pavani, et al., 2018) is now referred by many students and by some teachers; depending on students/courses/institutions context, it assumes a major importance. VISIR is now about 20 years old and although has suffered some changes and improvements along this time, most of them suggested by its users, its interface based upon real lab instruments (some of them not very recent) may be considered too simple and/or old fashionable for many students. In some of the former institutions, students had access to modern laboratories fully equipped with modern digital instruments: for those, VISIR really loses in the comparison. A factor that also emerged in some situations in this study "insufficient material support", suggests that some students did not consider the provided material was enough. The former factor (with the designation "lack of information") was also reported by Viegas (2018), but considering the diversity of resources their students had the opportunity to consult, she concluded students were not properly informed of its existence. In this study that factor assumed particular relevance in the cases C15, C16 and C20. Except for case C20, where that information is not explicit, for the other two cases teachers provided support material. Either students were not aware of it or considered it was not enough.

From this analysis it is clear that generally, students appreciated VISIR and their "satisfaction with the tool" is correlated to the perception they have of it, taking into account its utility in their "learning process". When the analysis was carried on by implementation topic the same results were achieved, although in some topics the correlation between F1 and F2 was more robust than in others.

The same type of analysis by case -considering its specifications and different contextsallowed to identify some cases in which students' satisfaction with VISIR was not correlated with 
their perception of the tool, considering its usefulness in their learning path. This type of result emerged in several cases regardless the level of satisfaction students achieved with the tool. The previous result suggests that in some cases students' motivation to use VISIR was driven by external factors (being mandatory to pass the course, VISIR contribution to final grade), extrinsic motivation, typically leading to a more surface learning.

In general students were very satisfied with VISIR and the potential of the equipment. They considered the resource helped them in their learning in the comprehension of the concepts and the development of the experimental techniques. Plus, they could use it whenever they needed it, from any place, even using their own smartphone, without the fear of damaging the equipment. They also identified some constraints in the resource, mainly related to its instability and considered VISIR could actually benefit from a renewal.

\subsubsection{Students' Characteristics}

The 1794 students involved in the 26 different courses -comprising 43 didactical implementations- come from various different contexts, including: education level, course level, students' background, students' level and type of VISIR tasks they were supposed to develop.

As it was already summarized in Table 5 (page 82), the majority of students (76\%) are from the HE level and the remaining $24 \%$ are nearly equally distributed from the secondary education level and the technological level. Considering the course level, $40 \%$ of the students were enrolled in EE major courses while the remaining $60 \%$ were inscribed in other majors (courses). So, most students core curricula are not on EE area and probably they take the course because it is mandatory, although the majority is probably not particularly interested in electricity and/or electronics nor is an expert on those topics.

Students' background is basically characterized by three items: the topic contents covered by VISIR were or not previously addressed, students were using VISIR for the first time or have already used it (either in another (previous) course or because they are repeating this specific course) and students were enrolled in the course for the first time (or not). The results for the first two items were briefly exhibited in Figure 12 (page 117) and for the third item they were summarized in Table 17(page 115). Now we will further explore it.

VISIR contents have been addressed before in 7 HE cases: C14, C17, C19, C20, C21, C23 and C24, comprising 12 didactical implementations, as several of these courses have undergone two or three course editions. In the former cases, involving 336 students, the VISIR use level was intermediate (I) or advanced (A) and in all it was proposed T2 tasks. For three courses -C4, C7 and C22- involving 91 students that information was not available and the remaining 1367 students 
were enrolled in courses -from the various education levels, developing tasks type 1, 2 and 3 (T1, T2, T3) and comprising all VISIR use levels (B, I, A)- in which these EE topics were being addressed for the first time. Considering students previous experience with VISIR, only 8\% have used VISIR before. From the former students: (i) 90 students were repeating the course -cases C5 (37), C8 (5), C10 (1), C16 (3), C19 (9) and C26 (35)- as they were attending the second or third course edition of the former cases; (ii) 52 students -enrolled in the courses C9 (30) and C20 (22)- have used VISIR in previous courses.

As already detailed in section 5.2.1, it was only possible to have information about students being enrolled in the course for the first time or not, for 1377 students and from these 1178 are freshman. Still the distribution of this item for the 26 cases is quite heterogeneous. In the secondary education level, all students are freshman. In the technological level of education, the situation is nearly the opposite: the number of students that is repeating the courses is really high, varying from $31 \%$ to $100 \%$ (case C6). In $\mathrm{HE}$, there is also a wide variation in this item: from a minimum of $43 \%$ of freshman to several cases in which all the enrolled students are freshman (cases C15, C21, C23, C24, C8 (2 $\left.{ }^{\text {nd }}\right)$, C9 (1 $\left.{ }^{\text {st }}\right)$ ).

Study skills, habits and attitudes have already been addressed in section 2.4, including its influence in students' learning (Crede \& Kuncel, 2008; Gettinger \& Seibert, 2002). Students holding appropriate studying techniques, establishing study routines -frequency of study sessions to address the material- and having a positive attitude (being interested) towards studying and developing the tasks have an important role in students' success.

Considering the previous paragraph contents, students' level was characterized in Table 16 (page 113), when possible, and based upon teachers' comments about students' level when starting the course. Teachers felt students had difficulties in three cases: C3, C5 and C11, one course from each education level, although in all the proposed tasks were type 1 (T1). Still in the first two courses teachers proposed DC tasks in which the VISR use level was basic in opposition to the third course (AC tasks, advanced VISIR use level). In case C3 (secondary course) teachers felt in general students did not have some soft skills such as: oral and written communication, as developed as teachers expected and some did not have adequate working habits, having difficulties in delivering the proposed tasks in due time. Somehow, teachers felt students were still a little immature, which is typical at this level/age. Case C5 is a technological course in which teacher felt students had severe difficulties: they did not have the adequate prior knowledge (including in mathematics) and also had many difficulties in reasoning and problem solving (a clearly lack of competences in these topics). Case C11 is a HE course -EE advanced major from the $4^{\text {th }}$ semester of a 5 years Electronics Engineering degree- in which the head teacher recognized students had difficulties in instrumentation (which they should already have acquired at this 
level) and they typically do not perform many exercise-solving activities, and this undermines learning a little, in teachers own words.

Teachers also identified several courses in which they felt students were good (had adequate prior knowledge) and/or were interested when starting that specific course. In fact, in three courses there was a superposition of both: teachers considered students were good and also interested. In all, teachers proposed tasks type 2 (T2), in DC or AC in which VISIR use level also varied (B, I, A) accordingly to the course syllabus. The teacher's perception of students' characteristics and their different approaches to learning are critical considering its implications in the way teachers should teach. The former perception may help teachers in "change students' experiences, perceptions, or conceptions of something" (Ramsden, 1992).

From Q7 and Q11 answers to SSQ, respectively I showed VISIR experiments to people outside University and I always shared experimental results with my peers, one can also infer some features about students: their global interest in learning, including the new tool introduced -VISIR (Q7)and get an idea if students, by themselves, interact with their peers, sharing results and hopefully reflecting about it (Q11). The results to these questions are illustrated, by course level, in Figure 18.

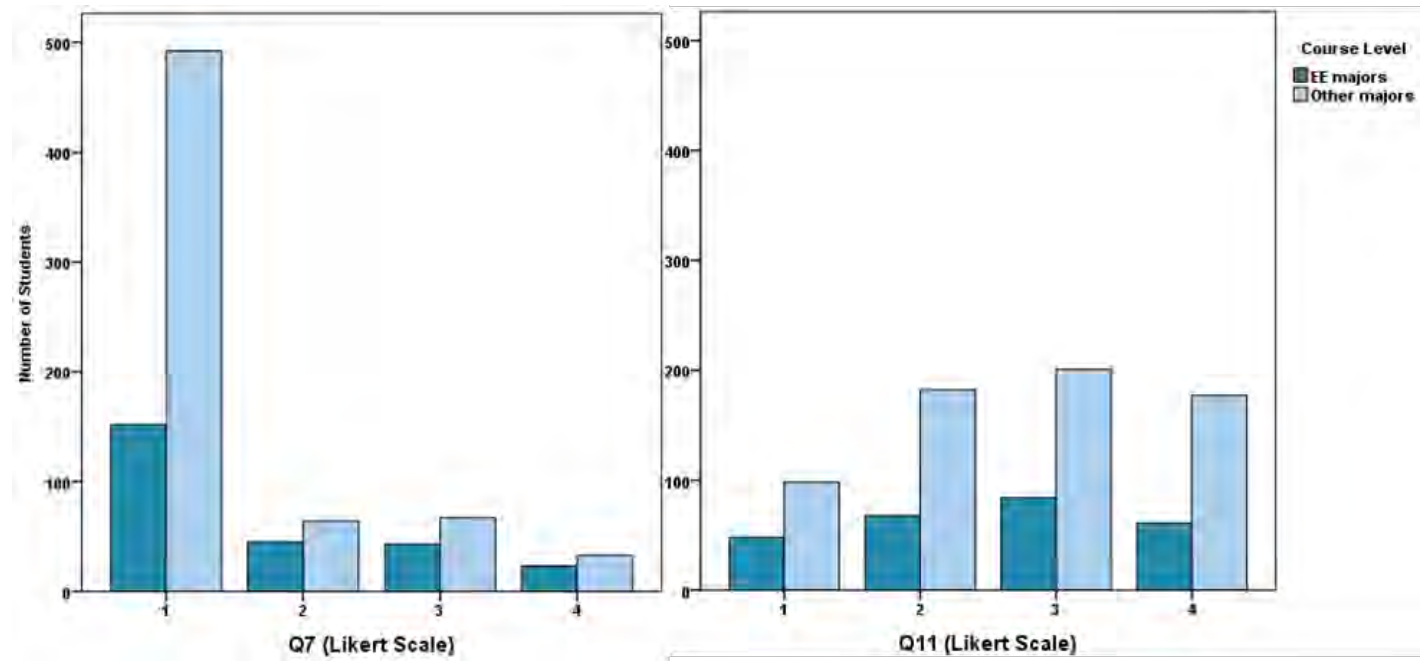

Figure 18 - Q7 and Q11 Students' Answers by Course Level

Just $18 \%$ of the students who answered Q7, manifested their agreement or fully agreement with it (the majority did not show VISIR to outsiders), while $57 \%$ answered 3 or 4 to the question Q11, supporting that students shared and discussed the experimental results with their peers. It was performed a chi-square independence test between the distribution of students' answers to the questions Q7 and Q11 with the education level and the course level. The chi-square test carried out on the former data just was significant for the Q7 distribution of students answers with course level $\left(p<0.001 ; \chi^{2}=26.448, \mathrm{df}=3\right)$, signifying that these variables are not independent, that is, 
there is a relationship between these variables: the percentage of students who answered 3 or 4 was $25 \%$ for EE majors and $15 \%$ for other majors (non-EE). Considering the results of the chisquare test for the remaining cases, in all cases $p>0.05$, so the variables in study are independent (the question Q7 with education level and the question Q11 with both education level and course level).

From this analysis, considering all students involved in the 43 didactical implementations, it becomes clear "students' background" is quite heterogeneous. Still considering it by "education level", some common features stood out: in all secondary and technological courses, VISIR contents were being addressed for the first time and except for some students in one technological course, it was also students first experience with VISIR. In the secondary courses all students were freshman while in the technological level the number of students who was repeating the courses was really high.

In some courses, teachers identified some students' characteristics ("students' level") mainly related to some students' study skills, habits and attitudes that may affect students' success. The analysis of the students answers to 2 questions included in the SSQ suggests students' interest in VISIR in not independent of their major (EE/non-EE).

\subsubsection{Academic Performance and Students' Perception}

In this section we will try to establish potential correlations between students' academic performance and students' perception of VISIR. It will be followed exactly the same type of analysis described in the sections 6.2.1 and 6.2.2 (from a global to an analysis by topic and finally an analysis by case/didactical implementation), taking in to account the same assumptions. It will be used Pearson or Spearman correlation to identify possible correlations between students' perceived learnings (F1) and their satisfaction with VISIR (F2) with respectively the number of VISIR accesses per task and their grades (by component as well as final grade).

Considering the (available) data of all students (global analysis) several statistically significant correlations emerged between students' perception of VISIR with their academic performance. Table 31 summarizes the correlations that stood out. 
Table 31 - Students' Academic Performance and Students' VISIR Perception Correlations (Global Analysis)

\begin{tabular}{|c|c|c|c|c|c|c|}
\hline & $\begin{array}{c}\text { N VISIR } \\
\text { Accesses/Task }\end{array}$ & VISIR Grade & $\begin{array}{l}\text { Other Tasks } \\
\text { Grade }\end{array}$ & Lab Grade & Exam Grade & Final Grade \\
\hline F1 & n. s. & $\begin{array}{c}\mathrm{R}_{\mathrm{SP}}=-0.099 * \\
(\mathrm{p}=0.009) \\
\mathrm{N}=704\end{array}$ & $\begin{array}{c}\mathrm{R}_{\mathrm{SP}}=-0.124 * * \\
(\mathrm{p}=0.001) \\
\mathrm{N}=679\end{array}$ & $\begin{array}{c}\mathrm{R}_{\mathrm{SP}}=-0.145^{* *} \\
(\mathrm{p}=0.001) \\
\mathrm{N}=537\end{array}$ & n. s. & n. s. \\
\hline F2 & n. s. & $\begin{array}{c}\mathrm{R}_{\mathrm{SP}}=-0.134 * * \\
(\mathrm{p}<0.001) \\
\mathrm{N}=704\end{array}$ & $\begin{array}{c}\mathrm{R}_{\mathrm{SP}}=-0.163 * * \\
(\mathrm{p}<0.001) \\
\mathrm{N}=679\end{array}$ & $\begin{array}{c}\mathrm{R}_{\mathrm{SP}}=-0.166^{* *} \\
(\mathrm{p}<0.001) \\
\mathrm{N}=537\end{array}$ & n. s. & n. s. \\
\hline
\end{tabular}

We must keep in mind the huge variety of factors (different contexts, teachers, students, didactical implementation characteristics) that may affect this data, which may take away the importance of the weak negative correlations that stood out. Still, these very weak negative correlations that emerged between both F1 and F2 with the grades obtained in the VISIR component, other tasks and the lab component, may suggest that the better academic results students achieve the more critical and rigorous they are considering their own learning as well as with the evaluation of the available learning tool. These results may point towards that VISIR may be "more helpful to students with some difficulties than for students with more developed knowledge... to VISIRs' target audience not being the most proficient students, but the ones who require more support in their learning" (Viegas, Pavani, et al., 2018).

There are no significant correlations between the number of VISIR accesses per task with their perceived learnings (F1) or their satisfaction with VISIR (F2) supporting the idea that their VISIR usage was not directly related with their perceived learnings and/or with their satisfaction with the system.

Accordingly, to what has been defined, a similar analysis/procedure was carried out grouping the students by education level, by implementation topic and by VISIR use level and the possible correlations between the variables in study (as described for the global analysis) were searched. The results of this analysis, which allowed to explore the differences between diverse clusters of the same data, will be described in the next paragraphs and the main results are summarized in Table 32. In some cases, there was not data to compute that variable or the topic did not consider that component (for instances: lab grade). In the analysis by implementation topic, "Projects" was not considered as there was not data. 
Table 32 - Students' Academic Performance and Students' VISIR Perception Correlations (by Topic)

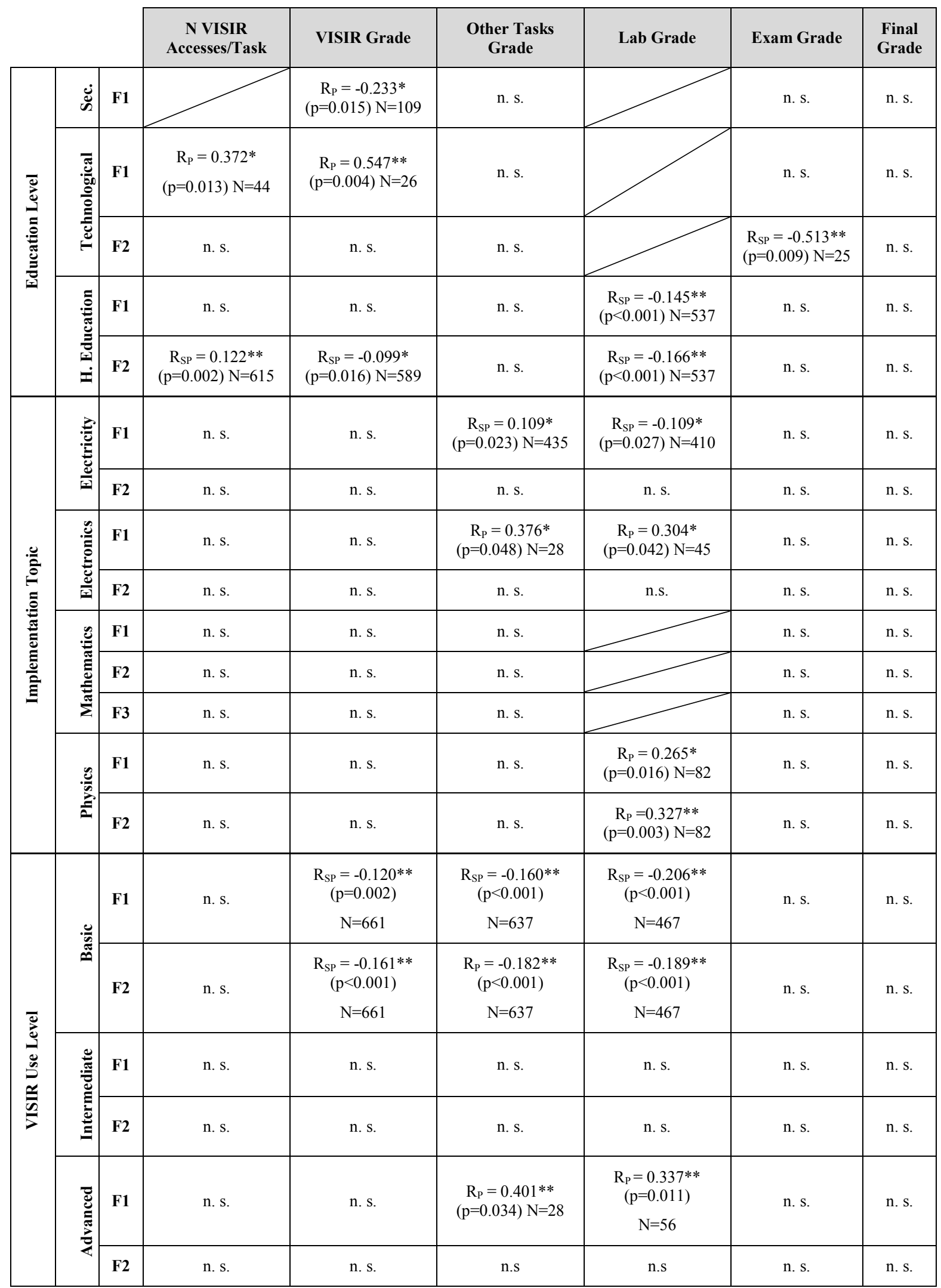




\section{Starting the analysis by the Education Level.}

The secondary level just includes students from the case C3 and the technological level includes students from the cases $\mathrm{C} 5$ and $\mathrm{C6}$, as for the remaining cases there was not data to compute the former correlation procedure. In the technological level, it emerged a positive moderate correlation between F1 and the grades obtained in the VISIR component, while at the secondary level this correlation is negative; for higher education students there is a negative very weak correlation between F1 and the grades obtained in the lab component and also a negative correlation between F2 and the grades obtained in the VISIR and the lab components. These negative/positive correlations may be related to the very different type of students in each level. In the studied technological cases, students achieved very poor academic results (the majority failed the course), with a high rate of NFs and dropouts opposite to the secondary and higher education students who had generally much better academic results. It may suggest that in secondary and higher education levels, the more demanding students are, the better academic results they achieved and the more critical and serious they are about their learning. Technological students, on the other hand, had (in general) a much better grade in the VISIR component (in comparison with their exam and final grade). However, they were in general students with lots of difficulties and less demanding about their learning perception, which appears intrinsically associated to the grades obtained. These technological students tend to use more VISIR when they understand the resource is really useful in their learning process while higher education students' VISIR usage is not really dependent on their perception of utility of the tool in their learning process although it seems slightly influenced by their satisfaction with it. Still, considering the diversity of cases included in the HE level, this weak correlation may have no meaning.

In fact, the former results seem to suggest VISIR can be more helpful to students with some difficulties than for more capable student (corroborated by the negative correlation between F2 and the exam grade -for the students from technological level- the students with worse grades are more satisfied with VISIR), as already been reported (Viegas, Pavani, et al., 2018).

\section{Analysing now by Implementation Topic.}

In the electronics topic, there is a positive weak correlation between F1 and the grades obtained in the other tasks and the lab. Electronics students are experts in this area and so it is logical that the best students (the ones who achieve better grades) are the ones who have a higher perception of their learning. For physics (just includes students from case C26, as the other cases did not have data to run the procedure), a positive weak correlation is also found between both F1 and F2 with the lab grade suggesting that students' perception about VISIR had an impact on their lab performance -the better impression they had about the tool the better results they got in 
lab- suggesting that VISIR may potentiate their lab performance. A very weak negative correlation is found between F1 and the grades obtained in the other tasks grade and the lab component for electricity students: the better academic results they achieved the more critical they are about their learnings. Still and again this topic comprises a huge variety of cases, so this weak correlation may lose its meaning.

For all the topics, there are no significant correlations between students' number of accesses per task with their perceived learnings (F1) and their satisfaction with VISIR (F2), that is, their usage is independent from students' perception of the tool.

Finally, analysing by VISIR Use Level.

Considering the correlation between F1 and F2 with the grades obtained in the various components, opposite scenarios emerge. In the basic level it appears a negative very weak correlations between F1 or F2 and the grades obtained in several components. Still as this level embraces many cases with very different characteristics these correlations may have no meaning. But if we consider it, the former results suggest the best students (the ones with better grades) are more severe and critical about their learning and also with the evaluation of the remote lab. At the advanced Level, it is exactly the other way around: the correlations between F1 and the grades obtained in other the tasks and lab component are positive moderate, suggesting that the more students perceive VISIR importance in their learning the better grades (although not directly in the VISIR component) they get; the best students are the ones who have a higher perception of their learning. At this this level, we are dealing with students that are experts in this topic and so with a very high perception of their real difficulties and possible ways to overcome it.

For all levels there are no significant correlations between the number of VISIR accesses per task and their perceived learnings (F1) as well as their satisfaction with VISIR (F2) - students' general contentment with VISIR is highly dependent of external factors and not directly connected to their greater or lesser usage.

Again, and considering the analysis performed in sections 6.2.1 and 6.2.2, the same procedure is adopted here, for the didactical implementations/cases, for which it was possible (data available, alpha de Cronbach > 0.5, etc.) and accordingly to the conditions described in those sections. Once more, in these analyses it was considered all the information available for each particular didactical implementation and it was possible to carry out the correlation procedure for all cases, except C1, C2; C4, C6, C12, C17, C18, C22 and C25. Appendix H summarizes the results found, split by case (for the cases in which some correlations stood out). Looking in detail to that information, for several didactical implementations/cases, some correlations emerged between their perceived learnings (F1) and/or their satisfaction with VISIR (F2) with the number 
of VISIR accesses per task and/or their actual grades (VISIR grade, lab grade, partial grades (other tasks, exam), final grade). The following lines summarize the found results:

* Correlation between F1 with the number of VISIR accesses per task (positive): C7.

* Correlation between F1 with the VISIR grade:

○ Positive: $\mathrm{C} 5\left(3^{\mathrm{rd}}\right)$.

$\circ \quad$ Negative: $\mathrm{C} 3\left(1^{\mathrm{st}}\right)$.

* Correlation between F1 with the lab grade (negative): C16 (1 $\left.{ }^{\text {st }}\right)$.

* Correlation between F1 with the partial grades:

○ Positive: C3(2nd;1), C10(2nd $), C 26\left(1^{\text {st }}\right)$.

$\circ \quad$ Negative: C3(1st), C3(2nd;2); C5(2nd $),$ C16(1st).

* Correlation between F1 with the final grade (positive): C26(1st).

* Correlation between F2 with the VISIR grade (positive): C26(3 $\left.3^{\text {rd }}\right)$.

* Correlation between F2 with the lab grade(positive): C26(2nd, $\left.3^{\text {rd }}\right)$.

* Correlation between F2 with the partial grades (negative): C5(3rd), C8(1 $\left.1^{\text {st }}\right), C 9\left(1^{\text {st }}\right)$, C14(2nd).

* Correlation between F2 with the final grade (negative):C8(1st), C9(1st).

* Correlation between F3 with the partial grades (positive): C9(1 $\left.{ }^{\text {st }}\right)$.

As it gets clear from the results exposed in the previous lines, for the majority of the cases/didactical implementations there are not any statistical significant correlations amongst the studied variables, suggesting for the majority of students their grades and/or VISIR usage are not directly correlated with their perception of the tool. In fact, just in one case (C7) emerged a strong positive correlation between the number of VISIR accesses per task with $F 1\left(\mathrm{r}_{\mathrm{SP}}=0.805\right.$ $(p=0.005 ; N=10)$ ), leading to the assumption these technological students perceiving the impact VISIR had in their learning process considering EE contents, reinforced its usage. The C7 students (as previously described) achieved also the highest level of satisfaction with VISIR (F1 = F2 = 4).

In the majority of the former cases, for which some correlations emerged, being these correlations between F1 and/or F2 with the corresponding grades negative, the results suggest the higher grades students achieved, the more demanding and critical they become not only with the used remote lab, but with their learning too. There are still some cases that exhibit a somehow different behaviour: C3(2nd), C10 and C26. In case C3, the second course implementation edition occurred simultaneously in three different courses and although they all had the same team of teachers, the head teacher was different in each of them, which naturally lead to some differences in the VISIR strategy implementation. Case $\mathrm{C} 10\left(2^{\text {nd }}\right)$ exhibits a moderate positive correlation between $\mathrm{F} 1$ and the exam grade $\left(r_{S P}=0.630(p=0.038 ; N=11)\right.$; in this course implementation 
edition, teachers consider $75 \%$ of the students developed HOS. It seems these students had a right perception of their learning, at least considering their exam grades. In case C26, in the various course implementation editions all the correlations that emerged between F1 and/or F2 with students' grades were positive. Although they were not the same (considering the studied variables) in all course editions, which makes sense, as there were some differences in each VISIR didactical implementation, the results suggest that, in this particular case, the best students (achieved better grades) tend to be the ones with a better impression of VISIR: either concerning their perceived learnings or satisfaction with the system.

Considering the global analysis conducted in this section, it can be concluded students' VISIR usage ("students' accesses in VISIR") is more dependent of "external factors" than students' direct perception of the tool. Factors like teachers' ability to promote student enthusiasm and/or the weight the VISIR task has in their final grade may have an important role. 'Students' satisfaction with VISIR" is highly related to the "perception they have of the tool", considering its utility in their learning process (as concluded in section 6.2.2), although in general, the "good" students tend to be more critical and demanding in their evaluation. These results were already reported in literature (Viegas, Pavani, et al., 2018).

When the former analysis is confined to topic, the same type of results is obtained for the majority of the considered topics. There are still some topics, in which the results do not follow the previous pattern, for different reasons. Students from the technological level -students that typically have some difficulties- tend to use more VISIR when they perceive the added value the resource may have in their learning while students from the advanced level seem to have an accurate perception of their difficulties.

Narrowing down the analysis by case, that is considering each teachers' strategy in implementing VISIR, the results for the majority of the cases for which it was possible to perform the procedure, do not differ a lot from the global analysis results. There were still a few cases that exhibited a different pattern, although not exactly the same in all the course implementation editions. Unsurprisingly, the modification made in the VISIR implementations, in the subsequent course editions had impact on students' results. The relation between both will be explored in the next section. 


\subsection{Didactical Implementation/Students' Results}

In this section, after exploring in the previous two sections, respectively the didactical implementation results and the students' results, it is intended to establish correlations between the didactical implementations characteristics and the students' results. Several statistical tests corroborated by qualitative analysis will be performed to identify factors that possible had influenced in students' perception, usage and performance using VISIR. In order to achieve it, the data from the 1794 students involved in these 43 implementations will be discussed together to try to find some patterns. Later a deeper analysis considering cases clustered by specific didactical implementation characteristics (factors) will be advanced. Finally, some cases will be individually considered, taking into account its specificities and consequent implications on students' results.

This section is split in four subsections and each of them will address the dimensions, categories and factors processed respectively in each $\mathbf{R Q}$, gathering the achieved results and discuss their overall interconnection for each one of them.

\subsubsection{Simultaneous Use of Resources and Students' Results}

In this section the aim was to realize in which way the use of simultaneous experimental resources -hands-on, simulation and remote lab VISIR- along with calculus affects students' results and contributes to promote their learning and engagement.

The first goal is to determine if there is any correlation between students' VISIR usage, students' grades (VISIR and lab) and students' perception of VISIR (F1 and F2) with some factors concerning simultaneous resources usage, namely:

\footnotetext{
* VISIR usage in course contents (\%).

* VISIR introduction (I1, I2, I3).

* Number of hands-on tasks.
}

Spearman or Pearson correlation analysis was used to determine whether there was a correlation, considering each former factor with the test variables: number of VISIR accesses per task, VISIR grade, lab grade, F1 (students' perceived learnings) and F2 (students' satisfaction with VISIR). The correlations found between each test variable and the considered factors, that somehow reflect the impact of simultaneous resources usage on the students' results, are displayed in Table 33. 


\begin{tabular}{|c|c|c|c|c|c|}
\hline & \multicolumn{5}{|c|}{ Students' Results } \\
\hline & $\begin{array}{c}\text { Number of } \\
\text { accesses/task }\end{array}$ & VISIR grade & Lab grade & $\mathrm{F} 1$ & $\mathrm{~F} 2$ \\
\hline $\begin{array}{l}\text { VISIR usage in course contents } \\
(\%)\end{array}$ & $\begin{array}{c}\mathrm{R}_{\mathrm{P}}=-0.110^{* *} \\
(\mathrm{p}=0.008) \\
\mathrm{N}=593\end{array}$ & $\begin{array}{c}\mathrm{R}_{\mathrm{P}}=-0.140^{* *} \\
(\mathrm{p}=0.002) \\
\mathrm{N}=511\end{array}$ & n. $s$ & $\begin{array}{c}\mathrm{R}_{\mathrm{P}}=-0.180^{* *} \\
(\mathrm{p}<0.001) \\
\mathrm{N}=527\end{array}$ & $\begin{array}{c}\mathrm{R}_{\mathrm{P}}=-0.243^{* *} \\
(\mathrm{p}<0.001) \\
\mathrm{N}=527\end{array}$ \\
\hline VISIR Introduction & $\begin{array}{c}\mathrm{R}_{\mathrm{SP}}=-0.170^{* *} \\
(\mathrm{p}=0.001) \\
\mathrm{N}=1032\end{array}$ & $\begin{array}{c}\mathrm{R}_{\mathrm{SP}}=0.188^{* *} \\
(\mathrm{p}<0.001) \\
\mathrm{N}=945\end{array}$ & $\begin{array}{c}\mathrm{R}_{\mathrm{SP}}=0.287^{* *} \\
(\mathrm{p}<0.001) \\
\mathrm{N}=706\end{array}$ & n. s. & $\begin{array}{c}\mathrm{R}_{\mathrm{SP}}=-0.112^{* *} \\
(\mathrm{p}<0.001) \\
\mathrm{N}=923\end{array}$ \\
\hline Number of hands-on tasks & $\begin{array}{c}\mathrm{R}_{\mathrm{SP}}=-0.109^{* *} \\
(\mathrm{p}=0.002) \\
\mathrm{N}=829\end{array}$ & $\begin{array}{c}\text { RsP }=0.202^{* *} \\
(p<0.001) \\
N=795\end{array}$ & $\begin{array}{c}\text { RsP }=0.412^{* *} \\
(\mathrm{p}<0.001) \\
\mathrm{N}=706\end{array}$ & $\begin{array}{c}\mathrm{R}_{\mathrm{SP}}=-0.164^{* *} \\
(\mathrm{p}<0.001) \\
\mathrm{N}=748\end{array}$ & $\begin{array}{c}\mathrm{R}_{\mathrm{SP}}=-0.243^{* *} \\
(\mathrm{p}<0.001) \\
\mathrm{N}=748\end{array}$ \\
\hline
\end{tabular}

In all didactical implementations VISIR was used along with calculus, and with the exception of three didactical implementations for which VISIR was the only experimental available resource, in all the others VISIR was combined with either simulation or hands-on labs or with the former two. Still we do not have data considering the number of simulation tasks students performed. The influence of VISIR support during the task execution period will also be analysed later in this section.

As already described in section 6.1, it was found a moderate positive correlation between the VISIR usage in course contents (\%) and the number of tasks involving VISIR, indicating that as more contents are addressed by VISIR in (\%) the higher the number of proposed tasks, to address all the topics.

When VISIR usage in course contents increases students tend to pay less attention to VISIR usage. Still, that does not seem to impair their academic performance although their grade in the VISIR component is negatively affected. We are dealing with more proficient students in these topics and after getting to know VISIR -which takes them some time and effort- they do not need so much effort to complete all the activities, as they already are familiarized with the tool. This may lead to their perceived learnings (F1) as well as their satisfaction with VISIR (F2) also decrease; they may get a little bit tired of using it, and after some time the advantages of the tool may somehow get blurred. Students' perception of their effort versus its benefits (measured by the grades they achieve) can strongly affect their commitment as already suggested in literature (Marques et al., 2014; Viegas et al., 2009; Viegas, Pavani, et al., 2018).

VISIR introduction, that was already seen as important in section 6.1.1.2 when the didactical implementations were analysed, also plays an important role in students' VISIR usage, academic performance and perception. In fact, as the activity teachers prepare to introduce VISIR becomes more complete/detailed, students feeling more supported in their first contact with this new tool, 
do not feel so much the need to use it and that support results in a better academic performance. However, their satisfaction with the tool decreases; it seems that when students are over supported and do not have the opportunity to explore the resource by themselves, their satisfaction drops. It is well known from literature that teachers support to a new tool like VISIR, not only in the introductory activity but also during the task execution period plays a crucial role in students' motivation and involvement (Alves et al., 2011; Claesson \& Håkansson, 2012; Marques et al., 2014; Viegas et al., 2014). Still, teachers need to be careful about the type of support provided: some may feel so anxious and eager about VISIR (especially when using it for the first time) that they may give too much support to students in order to easy their struggle. Even though with the best intentions, teachers may be depriving students from overcoming their natural difficulties, and in doing so, students are not really improving their ability for working with VISIR (Viegas, 2017b). Particularly in the introductory activity, it is important teachers give time to students to overcome their difficulties at their own pace with minimum guidance. That was the case of C26 teacher that considered in her first implementation she over supported some students -during the introductory activity- and in the subsequent editions she adjusted the support (Lima et al., 2019a), although maintaining the same type of introductory activity (I3). In some cases, that have undergone two or three course editions (C3, C5 and C8) or in the courses in which it was already, at least, the second teacher implementation edition (C9, C22 and C25) teachers opted for adjust the type of introductory activity to a less supportive one (I2).

The type of support (the right "amount") provided to students is indeed a key aspect that must be well thought out. It is really important teachers support students, but teachers must give them time to overcome their eventual difficulties and develop the necessary competences. They should keep their attention to students' work, as tutors, providing them guidance and clues so they can overcome their problems (Viegas, 2017b; Viegas et al., 2009) and go on performing the assigned tasks, with some effort, but not too much, as if they feel it is too difficult, they may quit (Ambrose et al., 2010; Tchoshanov, 2013). In some cases, as already described in section 5.2.2, some students reported they felt they were not adequate prepared in class to use VISIR and/or they did not have appropriate support material to explore VISIR functionalities and develop their work ("insufficient preparation from classes" and/or "insufficient material support"). Also, in this study, the (students) second most referred factor, considering the negative aspects about VISIR was the combination of "problems in understanding at the beginning" and "problems in understanding"; yet, some of the $23 \%$ of the students that referred the former factor were able to overcome it, with the appropriate support. Still, a noteworthy number of students appears to have had a hard time trying to understand and work with the system, which may lead to a loss of interest and dropouts. In fact, these resources should be introduced with some cautions in order 
to do not overload students with too much innovation to master at one time: students might be overwhelmed if teachers give them too many resources to freely explore (Viegas, Alves, \& Lima, 2015). Curiously, in the majority of the cases that have undergone several course editions the number of students reporting problem in working with the system or lacking support material tends to diminish, suggesting teachers made an effort to adjust their support.

As students make more use of the hands-on lab, they tend to use VISIR less, although the hands-on usage seems to also contribute to a better grade also in the VISIR tasks; the experimental competences they have developed in the hands-on lab may have helped students in VISIR usage as well. They had the opportunity to practice using different experimental resources -the higher the number of hands-on experiments, the more they practiced-contributing to increase their learning outcomes. Their perceived learnings (F1) and satisfaction with VISIR (F2) decrease with hands-on usage -they get more conscious of some VISIR constraints- and some students (although a minority) tend to prefer hands-on labs. Plus, hands-on labs allow students to acquire technical skills -practical skills that involve sensory feedback- that require interaction with physical objects and represents an important requisite for engineering students at some point (Brinson, 2015; Faulconer \& Gruss, 2018).

VISIR and hands-on lab were combined in different ways, accordingly to teachers learning goals (with VISIR didactical implementation), as detailed in Table 25 (page 141). A meticulous analysis was performed to the average students' usage, perception, grades (VISIR and lab) and the correlations attained between the former variables (detailed throughout section 6.2) to the cases reported in the former table. There is some variation in the average number of VISIR accesses per task and the average VISIR grade, when analysed accordingly to the type of resources arrangement (before and/or after, contextualization). In the combination "after the hands-on lab", there was just one case: an EE major (scientific) advanced course, in which VISIR task was proposed after the last experimental activity in the hands-on lab, being this mandatory and individual VISIR task regarded as an integrative one. In the former case, the average number of VISIR accesses per task (particularly in the third course implementation edition) as well as the average VISIR grade are really higher than the ones obtained in the other cases. Also, in this course edition it was found a positive correlation between students' VISIR usage and their grades (other tasks and final). Curiously both students' perceived learnings (F1) and students' satisfaction with VISIR (F2) had a lower value. This lower value seems to be connected to some Internet connection problems and students feeling (at least, some of them) that they did not have the adequate support material to develop their work with VISIR. Still this is a very particular case, and so, no conclusion can be drawn. In a few cases teachers opted to use VISIR "prior and after" (the hands-on lab). This way students could develop some experimental skills before going to the hands-on lab and later 
go back to VISIR, taking advantage from what they have learned in the hands-on lab. That was the case of C26( $\left.3^{\text {rd }}\right)$, and naturally, the number of VISIR accesses per task increased (when compared to the previous course editions where students just used VISIR before hands-on lab), but considering the cases included in this experimental resources arrangement, nothing stands out. In several other cases, teachers opted to introduce VISIR "prior the hands-on lab", so students could develop some experimental skills and be more at ease and autonomous when going to the hands-on lab (either to perform similar or different experiments). The former cases are all, except case C21, introductory courses, where VISIR DC contents were being addressed for the first time and where VISIR level was basic; so really, for the majority, it was students first contact with EE topics. Remote labs main advantages include: availability, accessibility and security, which were also recognized by students as being some of the most positive features about VISIR. Besides, online labs also have the advantage of allowing students to get deeper involved in their learning using it accordingly to their needs- contributing to promote their autonomy and responsibility (Bochicchio et al., 2015; Faulconer \& Gruss, 2018). So, teachers expected students to go on using VISIR after delivering the proposed VISIR tasks, accordingly to their own perceived learning needs. Actually, VISIR could help them broader in their learning, for instances for the exam preparation, but the majority of students after delivering the tasks, did not use it again. Students used VISIR during the task execution period, being their VISIR usage expressively higher nearly the due time of tasks deliver, so clearly driven by an extrinsic motivation to learning. Again, one can infer students' VISIR usage is more dependent of external factors (for instance, task weight, being mandatory) than student direct perception of the tool in their learning process. In some cases: C5, C7 and C10, teachers commented VISIR was a hands-on facilitator, in the sense, that after using it, students were really more confident at the hands-on lab, assembling circuits faster and doing less mistakes; so, teachers' goal was, in fact, achieved. Although there is some variability in students' VISIR usage and their grades, this cannot be attributed to the experimental resources combination, but rather to other didactical implementation characteristics and/or some students' characteristics like having some difficulties or, on the other hand, having the adequate prior knowledge and being motivated to learn.

The "contextualizing" was included in Table 25 to embrace the mathematics courses where VISIR was used to contextualize some theoretical and somehow abstract concepts. In this topic, the contents are rather theoretical and typically in this type of course teachers have at their disposal lecture and/or practice classes -to present the theoretical concepts and solve exercisesand they may also include some ICT tools, to create a more interesting learning environment and appeal students. Still, this teacher acknowledging the importance of lab work in engineering education, was able to introduce VISIR in his practices (complemented by simulation in case C8 
and a simple hands-on task in case (9), implementing challenging and contextualized tasks, contributing to the development of students' knowledge and competences (Biggs \& Tang, 2007; Lopes, 2004). In fact, teacher considered students were really committed, engaged and motivated and the correlations found between the number of VISIR accesses per task and their grades corroborates it. Actually, these were the only 2 cases (out of the 26) in which students' VISIR usage was correlated with all their partial grades (VISIR, other tasks, exam) as well as their final grade. The former result suggests students clearly benefit from the usage of several experimental resources, being more motivated and achieving better results. According to the teacher, the proposed VISIR tasks (which included the use of two experimental resources and the comparison and analysis of its results, both between them and with the theoretical model) also allowed the students to develop higher order skills, such as research skills and critical thinking. In fact, the diversification of tasks, including the assessment tasks, contributes not only to increase students' motivation, but also contributes to knowledge integration and the development of competences and attitudes (Lopes, 2004). Students access to a real lab, which allowed the contextualization of the theoretical concepts into real physical devices, helped them to understand its pertinence. This was an innovative approach that with some degree of imagination and good will, may be used for implementing some experimental work in several other mathematics engineering courses or applications. Some of the results of the first course implementation edition of case C8 were already reported in literature (Lima, Viegas, Zannin, Marques, Alves, Felgueiras, Fidalgo, et al., 2017; Lima, Zannin, et al., 2017) and its subsequent course implementation editions along with the case C9 didactical implementation strongly reinforce it.

From what had been exposed, the results suggest that the order/way by which VISIR is incorporated in a course (before and/or after the hands-on, performing similar or different experiments) should be decided by the teachers accordingly to the learning objectives they have defined and the type of course, students' background and prior knowledge. In general, students were satisfied with VISIR, considering VISIR supported them in their learning and in the majority of the cases, several students reported VISIR lead them to a "better/more complete understanding" of the concepts (the third most referred positive factor, in the global analysis). In fact, and as already been reported in literature, the sequence of TL and NTL component in the laboratory procedure, per se, seems to make little difference in students' learning outcomes (Brinson, 2015), in this case, measured by the grades they achieved in the VISIR component and in the laboratory. In this study it does not seem to affect also students' perception of VISIR (both F1 and F2). Students learn well from any type of laboratory and the combination and order of the resources (hands-on and VISIR) depends upon much of the learning goals beneath. 
A procedure similar to what was performed in section 6.2.1 is now performed to further understand if the different ways of combining the experimental resources as well as the type of (teachers) designed support to accompany students during the task execution period has influence on students' results. Likewise, it was performed some statistical tests to look for the differences, considering a particular factor (at a time), to the variables (test variables): F1 (students' perceived learnings with VISIR), F2 (students' satisfaction with VISIR), number of VISIR accesses per task, VISIR grade and lab grade. From the prerequisite parametric conditions verification, it was concluded that the first three variables do not follow a normal distribution while the last two follow. So, for the first three it was used the Mann-Whitney $U$ test for two independent samples and for the last two it was chosen an independent samples t-test. Thus, the data -the overall data gathered in the 26 cases- was split in 2 groups, accordingly to the factors to be tested and then the means obtained in the test variables for each factor were compared to determine if there were statistically significant differences between them. As there were 5 test variables and 6 factors, there were 30 questions that needed to be answered. The factors to be tested were:

* Additional used resources (combinations): VISIR + simulation: yes/no; VISIR + handson: yes/no; VISIR + simulation + hands-on: yes/no.

* VISIR designed support: uploading support material: yes/no; answering doubts by email: yes/no; clarifying doubts presential: yes/no.

Appendix I contains the results of both tests and Figure 19 and Figure 20 illustrate the factors that influence respectively, students' academic performance and students' perception. Again the arrows go from the factor -out of the two considered hypothesis, accordingly to the ways students were split in the two groups- that has a positive influence (on each of the test variables) to the test variable; if the arrow does not show up it means that factor has no influence on the test variable. 


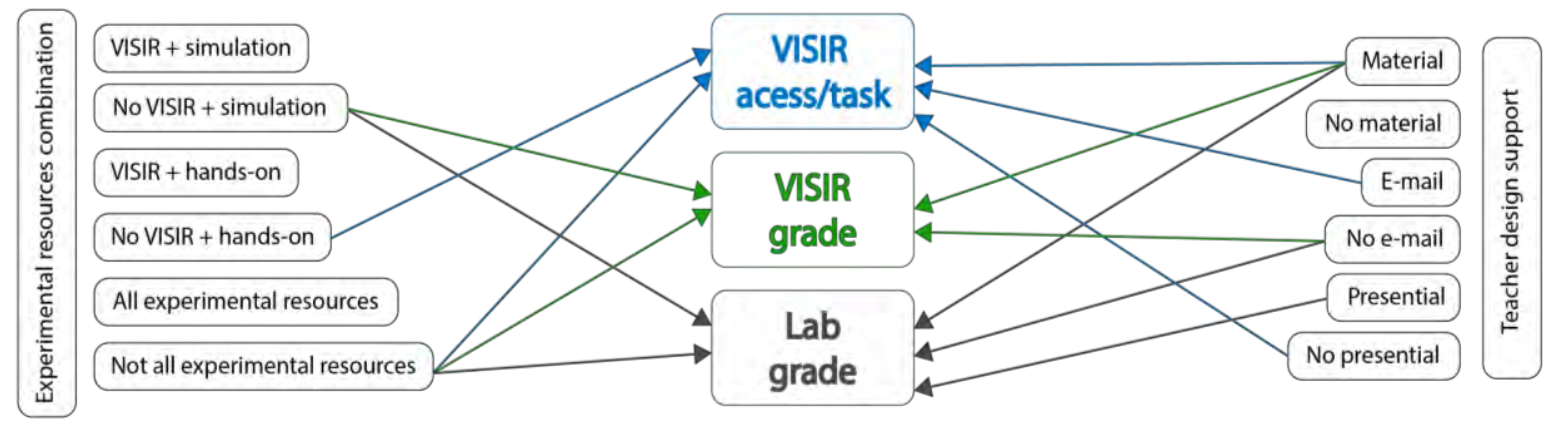

Figure 19 - Influence of Experimental Resources Combination and Teachers Designed Support on Students' Academic Performance

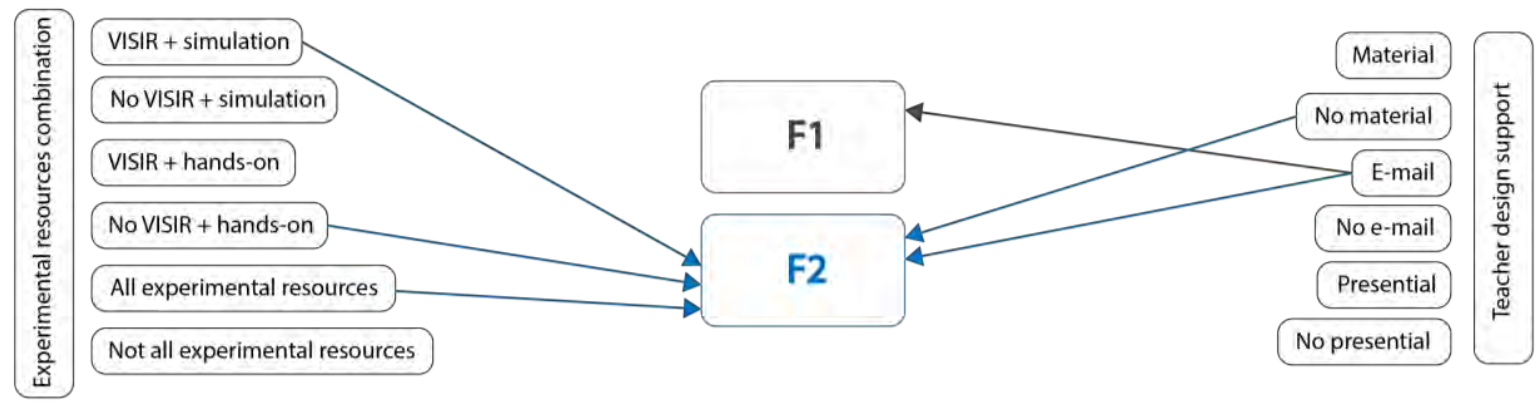

Figure 20 - Influence of Experimental Resources Combination and Teachers Designed Support in Students' VISIR Perception

Considering the (designed) support teachers provided to students during the task execution period, uploading support material and answering students doubt via email has a positive impact in students' VISIR usage; this suggests that students after clarifying their doubts by using the support material or by asking a specific doubt by email, try VISIR by themselves, making an effort to accomplish the task. This is corroborated by students having an average higher number of VISIR accesses per task when it is not provided presential support. On the other hand, VISIR grades and/or lab grades are better when there is support material -students have the opportunity to look into information whenever they need- and the support is presential (teacher without noticing, sometimes tends to over help students in their work). Students' perceived learnings (F1) is just affected (positively) by using email support; students having their specific doubts being clarified, helps them in going on in their learning process (by themselves) and that contributes to achieve a higher value of F1. Their satisfaction with VISIR (F2) is also higher when the support is via email and they do not have any material support. These results suggest that students need support, but this support has to be in the right proportion to keep the tasks authentic and challenging, compelling students to solve the problems by themselves, but with minimum guidance to avoid frustration that may lead to dropouts (Lopes, 2004; Viegas, 2017b; Viegas et al., 
2009). In the beginning of this section the same type of result was achieved, using a different analysis technique (triangulation).

In this study, it was found the different combinations of experimental resources (all or a combination of VISIR with simulation or VISIR with hands-on) either have a negative impact on students' grades or do not affect these grades (the combination of VISIR with hands-on). These experimental resources combination have exactly the same type of effect in VISIR usage, although this time the one that does not affect VISIR usage is the combination of VISIR with simulation. The former results suggest students have to split their effort and attention for several resources, and having the opportunity to practice with several resources, they do not feel the need (at least the majority) to use VISIR as much, as the other resources also allowed them to develop some experimental skills. In fact, in this study, the only case (C20) where VISIR was the single experimental resource, the average number of students' VISIR accesses per task is higher than other "similar" cases, where several experimental resources where used. Also, in the former case there is a positive correlation between the number of VISIR accesses per task with the grades students achieved in the VISIR component (in both course editions) and (in the first course edition) also with the final grade, suggesting the more students used VISIR, to develop the mandatory task, the best academic results they achieve. Indeed, when students do not have the opportunity to practice the hands-on component, they have an average higher number of VISIR accesses per task, suggesting students may feel VISIR somehow "replaces" that component. These different combinations of experimental resources usage have no impact in their perceived learnings with VISIR (F1), although the combination of VISIR with simulation and the three experimental resources usage has a positive impact in their satisfaction with VISIR (F2). Apparently, the hands-on usage somehow calls students attention to some VISIR constraints that simulation -providing results from computational models and depending on the type of simulator, with several restrictions- does not. This is corroborated by the negative correlations that emerged between the number of hands-on tasks with both F1 and F2 (Table 33).

From the previous paragraph one can conclude that in this study, and considering just the results of the former analysis involving an enormous variety of factors and contexts, the use of several experimental resources, by itself, does not seem to have a direct impact in students achieving better grades in the VISIR and/or the lab component. This result may somehow be biased from this diversity of factors and by the fact that students, when using several experimental resources, do not feel the need to dedicate as much attention to the VISIR system (and eventually to the other experimental resources) as these experimental resources complement each other (as suggested by the results exposed in Figure 19). As explored in section 6.2.1, in several cases (from the ones for which it was possible to run the procedure), some positive correlations emerged 
between students' VISIR usage and students' grades -although not necessarily in the VISIR component- suggesting the more students used VISIR the better learning performance they achieved. In the majority of the former cases, teachers just used two experimental resources (just in cases C5 and C19 teachers used the three experimental resources). Considering the cases in which it was found a correlation between VISIR usage and VISIR grade, we have left with the two mathematics courses (C8, C9), the case in which VISIR was the only experimental resource (C20) and case C16 (4 experimental activities with VISIR and other 8 in the hands-on lab; no simulation). Curiously, students from cases C16 and C20 had at their disposal some additionally resources, that could use freely in their learning process. In caseC16, students had access to the Maxwell system that includes several types of digital courseware, such as hypermedia learning objects, videos, simulators and interactive books. In case C20, students also have access, to complement their learning, to several other remote labs, and have already used a physics remote lab in a previous course.

The diversification of teaching approaches, including methods and used resources allows teachers to reach more students (Prince \& Felder, 2006; Richardson, 2011; Silverman \& Forum, 1988). Considering the experimental learning, it is widely reported in the literature the use of several experimental resources -a "blended" or "hybrid" approach- seems to be the most effective (Brinson, 2015, 2017; Corter et al., 2011, 2007; Nickerson et al., 2007; Restivo \& Alves, 2013). The combination of these experimental resources includes developing tasks in which students have the opportunity not only to obtain data with different experimental resources, but, most important, to analyse and compare data with the different resources, explaining its differences and/or compare it with the theoretical calculations. Actually, it is the former type of analysis that promotes deep understanding and higher performance, including the development of higher order skills, such as critical analysis, critical thinking or problem solving (Pinto et al., 2014; Sell \& Rüütmann, 2015; Veletsianos, 2016). In this study, although in some cases teachers proposed very simple VISIR tasks (T1 tasks) in which students just had to make some circuits assembling and some parameters measurement (so, not really profiting from the richness of using different experimental resources, except maybe getting to know it and develop some experimental competences), the majority proposed T2 tasks and in case C13 the teacher proposed a T3 task. The T2 task involves results comparison (some considering all resources, others just with the theoretical value and /or both) and at some extent explaining or analysing the differences.

It was important to determine if, in this study, there was also an association between the use of several experimental resources and the development of HOS. So, it was performed a chi-square independence test between the use of the three experimental resources (VISIR, simulation and hands-on) with the number of students who teachers considered have developed 
higher order skills (HOS). The chi-square test carried out on the data was significant $(p<0.001$; $\chi^{2}=12.240, \mathrm{df}=1$ ), so we conclude that there is a difference in the number of students who developed HOS across the ones who have used the three experimental resources and the ones who did not, that is, there is a statistical relationship between these variables (they are not independent). The number of students who have developed HOS is respectively 81 (out of 299) and 79 (out of 475). Concluding, this study supports the literature: the use of simultaneous experimental resources promotes the development of higher order skills.

\subsubsection{Synthesis of the Results Obtained in Simultaneous Use of Resources and Students' Results}

The purpose of this section was to give answer, in the most possible complete way, to the first research question (RQ1) "In which way the use of simultaneous resources (hands-on, simulation and remote labs along with calculus), contributes to promote students' learning and engagement?". The results of the 26 cases, comprising 43 didactical implementations and embracing 1794 students were globally analysed and then complemented by narrower analysis considering different clusters of the same data and by further analysis by case, when possible. The cases that have undergone several course implementation editions enrichened the former analyses, deserving our particular attention.

It was considered data collected from various sources and it were also applied diverse analysis techniques, converging in a process of triangulation to corroborate the same results, contributing to its validity and external acceptability. The first main illations learned from this study are that the use of several experimental resources (hands-on lab, simulation and remote lab), per se, does not seem to have a direct impact on students' grades. This simultaneous resource usage depends upon several factors, including the type of proposed task and level of competence addressed, students' background/characteristics and the way teachers implement this methodology in class, as it will be discussed in the next sections. Still there is clearly an association between its usage and the development of higher order skills and students' satisfaction.

Based upon empirical data, this study allowed to support the succeeding statements, related to the first research question:

$\checkmark \quad$ Teacher's support plays indeed a crucial role in students' engagement and performance. We must distinguish between the support to introduce the remote lab ("introductory activity") and the support provided during the task execution period ("designed support"). It is important teachers prepare an introductory activity, supplemented as 
possible by some type of support material, to introduce a new tool (like VISIR remote lab), giving students time to overcome their eventual initial difficulties and develop their ability to work with the new tool. This activity is also important to stimulate students' enthusiasm and their perception of this type of resources utility. During the task execution period this support is equally important: teachers must guide students with minimum supervision, providing the necessary clues to help them overcome their difficulties, while compelling them to solve, as autonomously as possible, the proposed tasks.

$\checkmark \quad$ The order by which VISIR is incorporated on a course, that is the sequence of hands-on labs and remote labs in the experimental learning procedure, per se, seems to have no effect in students' learning and engagement. This sequence should be determined by the teacher, taking into account the learning goals set up and naturally students' background.

$\checkmark \quad$ For introductory courses and if the teacher's goal is mainly to develop experimental competences and allow students to be more autonomous and at ease in the hands-on lab, introducing VISIR before hands-on, seems to be a good tactic as students' confidence in the lab may increase. The former strategy was found adequate to courses in which students have their first contact with EE topics where VISR use level is basic.

$\checkmark$ Students do not feel the need to use the remote lab much if several experimental resources are used simultaneously; this is particularly true when considering the handson labs. The use of several experimental resources complements each other, allowing students to develop experimental skills in different ways.

$\checkmark \quad$ Students' VISIR usage is more dependent on external factors than students' satisfaction with the tool and/or their perception of its utility in their learning process. This is so for the majority of the students, even though they acknowledge VISIR added value in their learning process. If teachers are comfortable with this type of methodology -which contributes to students' learning and engagement- they tend to find adequate strategies to compel students to use it more and for a longer period of time.

$\checkmark \quad$ This type of methodology seems perfectly adequate for courses that do not have an experimental component, nor its contents are directly related to the topics covered by the experimental resources (in this case, EE topics), such as mathematics courses. With some degree of imagination this type of methodology can be applied to several mathematics courses, with the purpose of contextualizing theoretical concepts that can be applied to real-life, day to day situations. This type of tasks enriches the setup of favourable learning environments, and if well aligned with the learning goals, 
contributes not only to motivate students but also to involve them as active participants in their own knowledge towards deep learning and contributes to their academic engineering profile development.

\subsubsection{Tasks Characteristics and Students' Results}

In this section it was made an attempt to establish if some VISIR tasks characteristics, including the level of competence addressed by them, affects students' results: both their learning and engagement.

The first goal is to determine if there is any correlation between students' VISIR usage, students' grades (VISIR and lab) and students' perception of VISIR (F1 and F2) with some factors concerning VISIR tasks characteristics, including the level of competence pursued, namely:

\footnotetext{
* VISIR competence goal level (L1, L2, L3).

* Number of tasks involving VISIR.

* Type of VISIR tasks (T1, T2, T3).

* Quantitative task weight in final grade (\%).

* VISIR use level (B, I, A).
}

Spearman or Pearson correlation analysis was used to determine whether there was a correlation, considering each former factor with the test variables that somehow reflect students' results: number of VISIR accesses per task, VISIR grade, lab grade, F1 (students' perceived learnings) and F2 (students' satisfaction with VISIR). The correlations found between each test variable and the considered factors are displayed in Table 34.

The tasks being in DC/AC as well as the tasks regime (individual/group; mandatory/not mandatory) will be approached later in this section, using a different statistical analysis technique.

As already described in section 6.1.1.3, it was found a negative weak correlation and a positive moderate correlation between the number of tasks involving VISIR with respectively the type of VISIR task and its quantitative task weight in final grade. The former result indicates that when the number of tasks increases the level of task complexity decreases but their contribution to final grade increases. 


\begin{tabular}{|c|c|c|c|c|c|}
\hline & \multicolumn{5}{|c|}{ Students' Results } \\
\hline & $\begin{array}{c}\text { Number of } \\
\text { accesses/task }\end{array}$ & VISIR grade & Lab grade & $\mathrm{F} 1$ & F2 \\
\hline VISIR competence goal level & $\begin{array}{c}\mathrm{R}_{\mathrm{SP}}=0.371^{* *} \\
(\mathrm{p}<0.001) \\
\mathrm{N}=1025\end{array}$ & $\begin{array}{c}\mathrm{R}_{\mathrm{SP}}=-0.226^{* *} \\
(\mathrm{p}<0.001) \\
\mathrm{N}=945\end{array}$ & $\begin{array}{c}\mathrm{R}_{\mathrm{SP}}=-0.743^{* *} \\
(\mathrm{p}<0.001) \\
\mathrm{N}=706\end{array}$ & $\begin{array}{c}\mathrm{R}_{\mathrm{SP}}=0.072^{* *} \\
(\mathrm{p}=0.029) \\
\mathrm{N}=916\end{array}$ & $\begin{array}{c}\mathrm{R}_{\mathrm{SP}}=0.169^{* *} \\
(\mathrm{p}<0.001) \\
\mathrm{N}=916\end{array}$ \\
\hline Number of tasks & $\begin{array}{c}\mathrm{R}_{\mathrm{SP}}=-0.504^{* *} \\
(\mathrm{p}<0.001) \\
\mathrm{N}=1032\end{array}$ & $\begin{array}{c}\mathrm{R}_{\mathrm{SP}}=0.185^{* *} \\
(\mathrm{p}<0.001) \\
\mathrm{N}=945\end{array}$ & $\begin{array}{c}\mathrm{R}_{\mathrm{SP}}=0.756^{* *} \\
(\mathrm{p}<0.001) \\
\mathrm{N}=706\end{array}$ & $\begin{array}{c}\mathrm{R}_{\mathrm{P}}=-0.100^{* *} \\
(\mathrm{p}=0.002) \\
\mathrm{N}=923\end{array}$ & $\begin{array}{c}\mathrm{R}_{\mathrm{SP}}=-0.221^{* *} \\
(\mathrm{p}<0.001) \\
\mathrm{N}=923\end{array}$ \\
\hline Type of tasks & $\begin{array}{c}\mathrm{R}_{\mathrm{SP}}=0.185^{* *} \\
(\mathrm{p}<0.001) \\
\mathrm{N}=1025\end{array}$ & $\begin{array}{c}\mathrm{R}_{\mathrm{SP}}=0.300^{* *} \\
(\mathrm{p}<0.001) \\
\mathrm{N}=945\end{array}$ & $\begin{array}{c}\mathrm{R}_{\mathrm{SP}}=140^{* *} \\
(\mathrm{p}<0.001) \\
\mathrm{N}=706\end{array}$ & n.s. & $\begin{array}{c}\mathrm{R}_{\mathrm{SP}}=-0.069^{* *} \\
(\mathrm{p}=0.036) \\
\mathrm{N}=916\end{array}$ \\
\hline $\begin{array}{l}\text { Quantitative task weight in final } \\
\text { grade }(\%)\end{array}$ & $\begin{array}{c}\mathrm{R}_{\mathrm{SP}}=-0.264^{* *} \\
(\mathrm{p}<0.001) \\
\mathrm{N}=819\end{array}$ & $\begin{array}{c}\mathrm{R}_{\mathrm{SP}}=0.280^{* *} \\
(\mathrm{p}<0.001) \\
\mathrm{N}=888\end{array}$ & $\begin{array}{c}\mathrm{R}_{\mathrm{SP}}=0.740^{* *} \\
(\mathrm{p}<0.001) \\
\mathrm{N}=660\end{array}$ & $\begin{array}{c}\mathrm{R}_{\mathrm{SP}}=-0.081^{* *} \\
(\mathrm{p}=0.025) \\
\mathrm{N}=762\end{array}$ & $\begin{array}{c}\mathrm{R}_{\mathrm{SP}}=-0.198^{* *} \\
(\mathrm{p}<0.001) \\
\mathrm{N}=762\end{array}$ \\
\hline VISIR use level & $\begin{array}{c}\mathrm{RSP}=0.325^{* *} \\
(\mathrm{p}<0.001) \\
\mathrm{N}=1032\end{array}$ & $\begin{array}{c}\mathrm{RP}_{\mathrm{P}}=-0.181^{* *} \\
(\mathrm{p}<0.001) \\
\mathrm{N}=945\end{array}$ & $\begin{array}{c}\mathrm{RSP}=-0.285^{* *} \\
(\mathrm{p}<0.001) \\
\mathrm{N}=706\end{array}$ & n.s. & n.s. \\
\hline
\end{tabular}

* Correlation is significant at the 0.05 level (2-tailed); ${ }^{* *}$ Correlation is significant at the 0.01 level (2-tailed)

When the number of VISIR tasks and consequently their quantitative task weight to final grade increases, students do not need apparently to use VISIR as much, to complete all the proposed tasks. Still that does not seem to impair their academic performance, particularly in the lab grade. In fact, as reviewed in the previous paragraph, when the number of tasks increases their level of complexity tend to decrease, so students naturally tend to achieve better grades. Students have to fulfil several tasks, still after getting acquainted with VISIR -which takes them some time and effort in the beginning, when VISIR was introduced and/or when they start to work with itthey do not need so much effort to complete the remaining activities, as they are already familiarized with the tool; they become "experts" in VISIR and easily complete the remaining tasks, particularly if they are not very different from each other (the same type of circuit, with similar components). Plus, they are compelled to use VISIR for a longer period of time, forcing them to reflect in different moments. In these cases, their perceived learnings (F1) as well as their satisfaction with VISIR (F2) also tend to decrease: they may get a little bit tired of using it and after some time the advantages of the tool may somehow fade away. If the tasks are not diversified, they may feel, after some time, they are not learning as much as they were with the first tasks and might sense they are, somehow, wasting their time. In fact, as already referred in section 2.2.1, the type and number of tasks should be carefully planned, considering its impact in students' performance. The number of proposed tasks should be in the right amount to promote a sustained development of learning knowledge, by involving students in continuous work (Felder et al., 2000). The proposed tasks should also be diversified, to promote the development of different 
type of competences. If the proposed tasks are about the same, students may lose some of their motivation, as the challenge they felt at the beginning may vanish away (Biggs \& Tang, 2007). In this study, it is clear that as students have the opportunity to perform more tasks with VISIR, their academic performance is better, although their perceived learning and satisfaction decreases. In fact, as already referred in the beginning of this section, as the number of proposed VISIR tasks increase their complexity tends to decrease and the proposed tasks are not really diversified (the tasks are quite repetitive, a student's comment in case $\mathrm{C} 16)$, which may have contributed to it. This is corroborated by the fact that there was not found any correlation between the number of tasks involving VISIR and the number of students that have developed HOS.

The more complex in exigency the tasks are, both considering the VISIR use level (more complex circuits are addressed) and the VISIR competence goal level (moving towards higher order competences), the more demanding it will be for students to accomplish it, therefore dedicating more attention to it (using more VISIR) and typically achieving worse grades. The former characteristics (considered in task exigency) hardly had any effect in both students' perceived learnings and satisfaction with VISIR, except when considering the VISIR competence goal: students tend to get more satisfied with VISIR when the VISIR competence level is higher. Apparently, they enjoyed the challenge. When the teacher's pursued competence goal is higher, the type of task should also accompany it: there should be a perfect adjustment between both with the view to the successful development of the pursued competences (Lopes, 2004). As already referred, it is really important students clearly understand the learning goals of the proposed tasks, as realizing the tasks pertinence in achieving those goals, more easily they get involved and engaged in them (Biggs \& Tang, 2007). Still, as already discussed in section 6.1.1.3, in some cases, a mismatch between the level of competence teachers wanted students to develop and the type of task they implemented was found, particularly for the lower levels of education. The type of correlation between the "type of task" and particularly the students' grades maybe partially explained by this mismatch. If there was not a mismatch the same type of correlation should emerge between the former factor (with students' grades) and the factor "VISIR competence goal level" (with students' grades).

The more demanding the tasks, the more challenging it will be for students, therefore using more VISIR (although the correlation is weaker than with the VISIR competence goal). This VISIR usage has a positive impact on students' academic performance (as opposition to what has happened with VISIR competence goal level). The task type does not have any effect in both students' perceived learnings and satisfaction with VISIR.

The positive correlations that emerged between the "type of task" and student's grades may also be partially explained by the tasks variability -categorized as T2 tasks- that were proposed to 
students (as detailed in Table 26, page 144). Clearly, in the majority of the cases, the former tasks allowed the development of level 1 and level 2 competences, but in some other cases (C8, C9 and C14) they also may have allowed the development of competences from level 3. Plus, there was only one didactical implementation (C13), in which the teacher proposed a task type T3: an advanced EE course with a low number of proficient students (4 students, as the other 6 enrolled in the course were NF).

In case C13, VISIR was used in all course contents, and students developed 3 AC tasks, perfectly aligned with the defined learning goals. Students preferred VISIR than the equivalent hands-on lab and considered VISIR main advantage was accessibility and availability although it was also referred "the potential of the equipment" and "no fear of damaging". They all also referred VISIR main disadvantage was "poor interface/old fashionable/too simple" related to the oscilloscope layout that could be more modern... more up to date... as in the bench. Still that did not seem to have affected their satisfaction, including perceived learnings $(F 1=3.5)$ with the tool. Students' final grade (the only for which we have data) follows a normal distribution (grades between 60 to $80 \%$ ) and all the 4 students accessed VISIR several times. The teacher also considered VISIR was adequate to his needs helping him in the diversification of the teachinglearning process and fostering students' autonomy. His perception was that students really liked it and felt very safe about using VISIR. The results obtained in the former case -VISIR adequacy to this advanced course- are corroborated by the positive correlations that emerged in case C19, another advanced course, between the students' number of VISIR accesses per task with their grades, suggesting VISIR helped students in their learning and performance. Again, the teacher's opinion about VISIR, for his course that has undergone three successive course implementation editions, was really good. The teacher implemented an integrative task -the last of the semester and after all the hands-on labs tasks- which included compare the VISIR results (basic amplifier circuit with transistors) with a mathematical solution and infer for possible differences. The teacher opted to propose it nearly the end of the semester as the former task was quite more demanding and required students to engage with higher-order cognitive processes (Tchoshanov, 2013). There is another case in the advanced VISIR use level (C11) where the didactical implementation did not work so well, but according to the teacher's perception, it was mainly related to students' background (inadequate prior knowledge and working habits), although he also referred the instruments used (in VISIR) have an old instrumentation appearance, and some students commented on it, thinking it was bad. In this didactical implementation, the 2 proposed tasks were not really aligned with the competences/learning goals teacher pursued and their contribution to students' final grade was just 5\%. Probably, the majority of these students felt the input effort to complete the tasks was not worthwhile considering its benefits. 
Although in the literature, it was reported both teachers and students find VISIR more appropriate/useful to introductory courses where the VISIR use level is basic (Alves et al., 2011; Fidalgo et al., 2012; Marques et al., 2014; Salah et al., 2015) the former results suggest VISIR (along with other experimental resources) is similarly appropriate to advanced courses. Indeed, and as can be observed in Table 34, the VISIR use level has no effect in students perceived learning with VISIR (F1), nor their satisfaction with the resource (F2). Plus, considering the results expressed in Table 29 (page 162), there is a positive correlation between students' VISIR usage and their grades, both in the VISIR use level intermediate and advanced. Eventually teachers need to do an extra effort in designing a didactical implementation more aligned with the pursued learning goals, including the preparation of support material and the development of adequate tasks (contributing to students' final grade). But as long as teachers have some experience with VISIR and the adequate academic background and scientific competence, this more advanced topics can be successful addressed using VISIR. In this level and although the first two most positive factors students identified in the SSQ are the same as those identified by students in the other VISIR use levels (and also in the global analysis) the third elected factor was "no fear of damaging". VISIR allows also these more proficient students the possibility of practicing freely without the risk of damaging expensive equipment and components, which can indeed contribute to their learning. VISIR has a positive impact in students' involvement and learning, even though their grades may not be as high as if the VISIR use level was basic. The advanced VISIR use level (and partially the intermediate VISIR use level) involves AC circuit analysis (and calculations), which are quite more demanding than DC (typically covered in introductory courses). In these more advanced courses, teachers' exigency also tends to be higher.

Considering the positive correlations emerged in some cases between the students' number of VISIR accesses per task with their grades (as detailed in section 6.2.1), the type of proposed task was T2, with the exception of case C5, where it was proposed a T1 task. Again, the type of analysis that this type of task (T2) endorses potentiates the development of competences, deep knowledge and higher performance (Pinto et al., 2014; Sell \& Rüütmann, 2015; Veletsianos, 2016). In case C5, the teacher's goal while using VISIR was the development of experimental skills. So, he proposed 2 simple tasks to his students (that start this course with lots of difficulties, including inadequate prior knowledge) and provided support (monitoring) through the task execution period. At the end, students had to deliver a simple report (which contributed $6 \%$ to their final grade) and afterwards they had to make an oral presentation of one of the experiments performed using VISIR (which had a contribution of $10 \%$ to the exam grade). In fact, for the former case the correlation that emerged was precisely between the number of VISIR accesses per task and their exam grade. As already referred and well established in the literature, assessment has a major 
impact in students' learning (Biggs \& Tang, 2007). Extrinsically motivated students tend to not fulfil the tasks if they not see immediate results of their efforts, that is, a contribution to their grades. Also, in this case, students' VISIR usage was motivated by external factors (like the monitoring support or the oral presentation and their contribution to the exam grade) and not by their perception of the tool (no correlation between the number of VISIR accesses per task with F1 or F2). However, students' satisfaction with VISIR was highly related to the perception they have of the tool, considering its utility in their learning process (correlation between F1 and F2).

The importance of the assessment is also reinforced by the positive correlations that emerged between the students' number of VISIR accesses per task with their grades. In all the cases in which these correlations appeared (section 6.2.1), the VISIR tasks weight contribution to students' final grade was expressive or the tasks were mandatory to pass the course. In none of the former cases were found correlations between students' VISIR usage and their perception of the tool (F1 and/or F2), suggesting again VISIR usage is motivated by external factors. In the cases in which the task contribution to the final grade was really low or when having a qualitative weight, it was not mandatory to pass the course, no correlations were found between students' VISIR usage and theirs grades (for the cases, for which it was possible to run the procedure). The former fact is also illustrated in some cases that have undergone several course implementation editions and the task weight and/or tasks regime have been modified. In case $\mathrm{C} 19$, the former correlations just emerged when the tasks become mandatory and in case C26 when the VISIR task weight in students' final grade increased to a more significant value (10\%). In case C14, although we do not have the majority of the data for the first course edition, teachers' perception was that students valued VISIR and found it an interesting resource. Still, in the second course edition, both the teachers' perception of students' satisfaction with VISIR as well as students' actual satisfaction with VISIR lowered (F1 = 2; F2 = 1) and this is related to the fact that the number of VISIR tasks increased from 1 to 3, without any measurable gain (to their final grade). Students complained about the extra load of work: VISIR, as they considered it, was an extra effort and not a resource that potentiated their learning opportunities.

Still considering the cases in which have emerged correlations between students' VISIR usage and their grades, in all except in case C20, the level of competences teachers pursued with the implemented VISIR tasks was aligned with the tasks they have proposed. If teachers clearly state the intended learning outcomes while designing an activity, students are aware of what to do to meet it and get deep engaged (Biggs \& Tang, 2007). In the cases where teachers were more ambitious -cases C8, C9, C14 and C20- wanting their students to also develop level 3 competences (L3), the first three cases they were successful. They implemented VISIR tasks that implied comparing and analysing the results obtained with VISIR and other experimental results with the 
theoretical expected values (calculus). In case C8, the teacher went a step forward as he asked students to deliver their final report in the format of an IEEE Transactions paper, so asking also for the development of research skills and critical thinking. In case C20, VISIR was the only available experimental resource and the teacher really worked hard to get familiarized with VISIR (the teacher who achieved the higher number of VISIR accesses per task) and accordingly to his own words the only disadvantage about VISIR is the high level of experience that must be acquired by teachers and spend considerable time in developing a complete work guide, clear and consistent with the level of knowledge of the student. The teacher proposed a mandatory task (type T2), to be developed in group, that clearly allowed the development of level 1 and level 2 competences (but hardly level 3).

Still in the former case, the assessment of the VISIR component included not only a final report but also an individual oral test, in which the teacher privileged conceptual evaluation. In this case, it emerged a moderate correlation between students' VISIR usage and their grades (in the VISIR component and their final grade, although the former just in the first-course edition) as well as their perceived learning (F1) with their satisfaction with the tool (F2). The teacher was clearly able to motivate students as well as stimulate their perception of VISIR utility in their learning process.

Considering the results detailed in Table 34, it is clear that the factors that have impact in VISIR grade also have the same type of effect, but typically stronger in the lab grade. Since the lab grade considers the VISIR component the connection is obvious. Also, students' satisfaction with VISIR seems to decrease with its usage (number of VISIR tasks): with the time some of the advantages VISIR has may get blurred and some of its constraints may become more obvious. Plus, after using it for a while, performing tasks that in general are not very different from each other, students may feel that the resource is no longer so useful in their learning.

Again, a procedure to what was implemented in the previous section (as well as section 6.2.1) is prosecuted to figure out if several factors related to the type of competence tackled by VISIR tasks affected students' results. Similarly, it was performed the same statistical tests to look for the differences, considering each factor, to exactly the same test variables defined in the previous section. Once more, the overall data was split in 2 groups, accordingly to the 4 factors to be tested (to give answer to a total of 20 questions):
* VISIR tasks attributes: DC/AC.
* VISIR tasks regime: group tasks: yes/no; mandatory: yes/no.
* VISIR tasks weight to final grade: qualitative/quantitative. 
Appendix I contains the results of both tests and Figure 21 and Figure 22 illustrate, respectively, the factors that affect students' academic performance and students' perception of the tool. Once again, the arrows go from the factor -out of the two considered hypothesis- that has a positive influence (on each of the test variable) to the test variable; if the arrow does not show up it means that factor has no influence on the test variable.

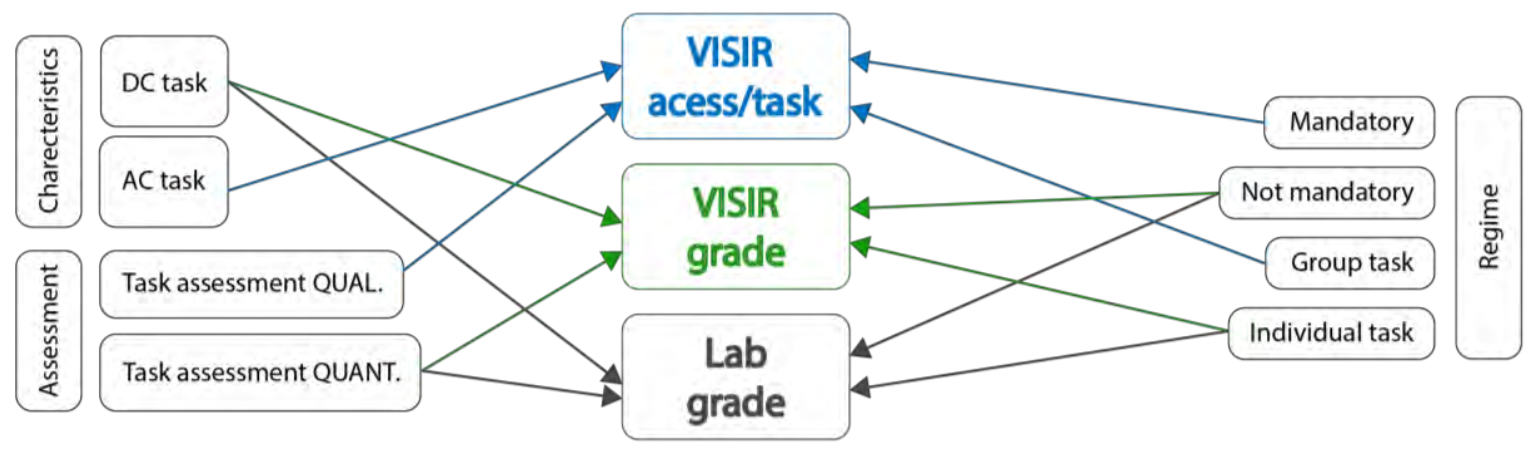

Figure 21 - Influence of Task Characteristics on Students' Academic Performance

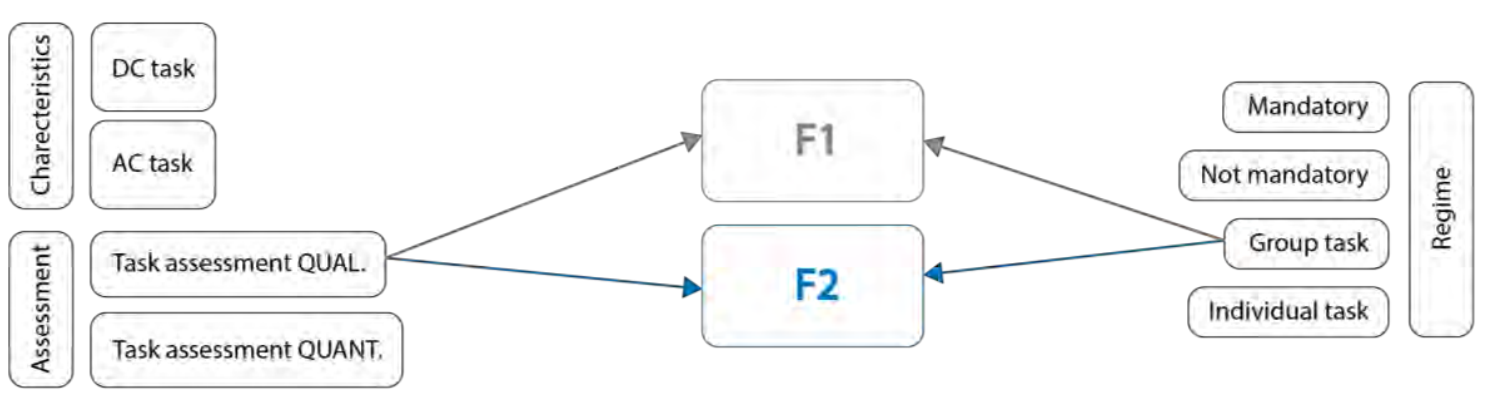

Figure 22 - Influence of Task Characteristics in Students' VISIR Perception

Students' grades and VISIR usage are affected in a way or another for all the studied factors (Figure 21). Students have a higher average number of VISIR accesses per task when the tasks are in $\mathrm{AC}$, but they reach better grades when the tasks are in $\mathrm{DC}$. AC tasks are quite more demanding, and even the more proficient students that deal with this type of task, have to make an extra effort to accomplish it. Naturally, as the DC tasks deal with simpler concepts and the underlying mathematics is really simple, the grades are better. When the tasks are mandatory, students have an average higher number of VISIR accesses per task as they really have to make an effort to accomplish it or they fail the course. So, they are compelled to use VISR to complete the tasks, but being the majority extrinsically motivated to learn, their performance is not affected by it. For this type of students, assessment may have a greater influence in their learning than the contents and curriculum, as basically they learn to pass the course. In these cases, the task contribution to final 
grade and/or being mandatory to pass the course somehow define students' effort (Biggs \& Tang, 2007; Tchoshanov, 2013). Mandatory tasks do not typically motivate students to learning. In fact, their grades are better when the tasks are not mandatory. In both cases (mandatory and not mandatory) the number and type of tasks, including task complexity, are diversified, but this diversification is about the same both for the mandatory and not mandatory tasks. So, in general we are dealing with about the same type of effort and complexity. Still when teachers propose mandatory tasks, that is, tasks in which students have to achieve a minimum level of performance and/or grade to pass the course is because they think they allow students to develop competences and knowledge, they believe are essential students attain at the end of the course. So probably, it is plausible teachers are more demanding in grading them.

The number of VISIR accesses per task is higher when the tasks are performed in groups. Still, this former result has to do with the way the number of VISIR accesses per task was accounted for when the tasks were performed in group: each group member number of accesses per task was considered as the sum of all group members number of accesses per task. In some groups, all group members accessed VISIR, but in several others, only one of the group members accessed the tool, suggesting students may not have had equal involvement with VISIR. In fact, in this study the students achieved higher average grades when the tasks were performed individually. To induce each student to be more involved, while fomenting group work which assumes special importance in the laboratory classes (Ma \& Nickerson, 2006), one can opt to an individual oral test (or some other individual assessment), after the delivery of the group report. That was the teacher option in case C20, where there was only one task involving VISIR. The type of assessment and feedback -explained in sections 2.2.1 and 2.2.2- has also a decisive role in students' learning. If this qualitative assessment provides students with useful information about their accomplishments and is provided on time (during the task in crucial moments or after each task) it can help students in their learning (Viegas, 2017a), strengthening students' responsibility and allowing them to adjust their efforts which may include VISIR usage. Students tend to prefer descriptive comments about their performance to numeric grades, as even a not very good comment is more stimulating to their learning than a negative grade (regarded as a failure associated to feelings of punishment and/or shame) (Butler \& Nisan, 1986). Still, they achieved better grades when the task weight was quantitative, but we must keep in mind the way, in several cases, VISIR tasks were graded when their contribution to final grade was qualitative, as detailed in section 5.2 .1 (100\% if they fully delivered the proposed activity and/or $50 \%$ if they delivered half of it). Nevertheless, the former results are corroborated by the correlations that emerged between the quantitative task weight in final grade (\%) with students' results, as presented in Table 34 
As exhibited in Figure 22, both students' perceived learnings (F1) and satisfaction with VISIR (F2) are not affected by the tasks being mandatory or not to pass the course nor by the proposed tasks attributes (AC/DC). The former result confirms that VISIR and this methodology is perfectly adequate for more advanced courses where the contents addressed are more demanding, involving AC circuits. Indeed, this result was already suggested by the results summarized in Table 34, where students' perceived learning (F1) and students' satisfaction with VISIR (F2) were found to be independent of the VISIR use level. So, clearly VISIR is as useful for introductory courses as for more advanced ones.

On the other hand, both F1 and F2 are positively affected -F1 and F2 achieve an average higher value- by the tasks being developed in group and the VISIR component having a qualitative weight to students' final grade. As already explored in section 2.3 , to make the most of these online environments teachers should promote collaborative social environments and support students in their work with timely feedback (Bright et al., 2008; Shea \& Bidjerano, 2013). Students' learning is affected by their interaction with the learning environment, including with other students (S-S interaction) (Lal et al., 2019). When the designed VISIR tasks are proposed as group tasks, this S$S$ interaction is enhanced and this collaborative work, interaction and communication with their colleagues contributes to enhance their perceived learnings (they believe they learn better when they work in groups and discuss the results with their colleagues than when their effort is individual) and their satisfaction with the tool. As explained in the previous paragraph this qualitative assessment may have provided students with valuable information about their accomplishments, contributing for their learning and students have exactly that perception.

It is clear from Figure 21 and Figure 22 that some factors that have a positive impact on the number of VISIR accesses per task and/or in F1 and F2 did not have the same type of impact on the grades students reached. In fact, it was the other way around. In some cases, an explanation was advanced, in the sense that some of the former results may have to do with the way some of those factors were accounted for (number of VISIR accesses per task when the tasks were developed in groups, the way VISIR tasks were graded when its contribution to final grade was qualitative). No doubt it is important students access VISIR and feel satisfied with the tool to be motivated and engaged in the tasks involving it. But, although VISIR was introduced in these courses with different goals, including the type of competences teachers pursued, ultimately teachers' intention was, in one way or another, to contribute to improve students' learning outcomes (which somehow should ultimately be measured by their grades and satisfaction). Therefore, teachers should really plan the didactical implementations taking into account all these repercussions. The proposed tasks have a tremendous impact in students' motivation and engagement and to try to meet all the students, it is important that those tasks are diversified, 
varying in content and complexity, some to be develop individually others to be performed in groups, some being optional others mandatory (Biggs \& Tang, 2007; Druzhinina et al., 2018; Tchoshanov, 2013).

\subsubsection{Synthesis of the Results Obtained in Tasks Characteristics and Students' Results}

In the former subsection the data collected from various sources was analysed using several statistical techniques. The data was first globally analysed, taking into account the results of the 26 cases considered in this study. The cases that have undergone several course implementation editions, including its modifications in the subsequent course editions somehow related to some VISIR tasks characteristics, were also considered. The former data analyses were complemented by qualitative analysis of the students' satisfaction questionnaires and the teachers' interviews, either considering different clusters of the same data or individual cases. Finally, a more detailed analysis by case was considered to corroborate the previous analysis towards reliable conclusions.

The data analyses described in the previous paragraph allowed to fulfil the main goal of the section: address, as completely as possible, the second research question (RQ2) "Are there VISIR tasks characteristics that affect students' learning and engagement?

From this study, it is clear that the course design characteristics intrinsically associated with the level of competence (addressed on VISIR tasks) -"VISIR competence goal level", "VISIR tasks attributes" (T1, T2, T3; DC/AC), "VISIR use level"- have basically no influence in students' perception of their learning with the tool (F1) and very little influence on their satisfaction with it (F2). All the former characteristics have a great influence on students' VISIR usage and their VISIR and lab performance. As the contents addressed were more complex, students increase their VISIR usage, although they tend to achieve lower grades.

This study allowed to support on empirical data several statements focusing the research question addressed in this section:

$\checkmark \quad$ The proposed VISIR tasks should be perfectly aligned with the intended learning outcomes (ILO) teachers defined (when designing the didactical implementation) and the type/level of competence they expected students to develop. Students' comprehension of the ILO, clearly potentiates their engagement and ultimately their learning.

The VISIR tasks should vary in content and be diversified, involving (if possible) the comparison and analysis of the data obtained with other experimental resources and/or the theoretical calculations, as these type of analysis and comparisons allows 
the enhancement of deep knowledge and higher-level competences development. As it gets clear from this study, it is the former type of tasks (tasks type 2 or type 3 ) that clearly affects positively students' results.

$\checkmark \quad$ The type of assessment -VISIR tasks contribution to final grade and/or the tasks being mandatory to pass the course- has a major influence in students' involvement and learning. In fact, most students tend to not fulfil the tasks if they do not see immediate results to their effort, as the majority have an extrinsic motivation to learn. The qualitative assessment -which, at least in some cases, included some pertinent comments about students' performance- had a positive effect in students' involvement as well as in their perceived learnings and their satisfaction with VISIR.

$\checkmark \quad$ Tasks that promote collaborative work -interaction and discussion with peers- are valued by students, contributing not only to the development of fundamental soft skills, but also enhance students' learning and satisfaction.

$\checkmark \quad$ VISIR and this methodology are as useful for introductory courses as for more advanced ones, as long as the didactical implementations are planned accordingly to the type of course and students' background. Both in introductory and more advanced courses VISIR has a positive impact in students' involvement and learning, even though their grades (VISIR and lab) tend to be lower when the addresses topics are more complex.

\subsubsection{Teacher Mediation and Students' Results}

Teachers' VISIR usage was significantly different amongst the 43 didactical implementations (as detailed in section 6.1.2). Even though each case could undoubtedly have unique dynamics which may influenced students differently, in this section it will be pursued an identification of teacher mediation traces (while using this methodology of several experimental resources usage) linked to better students' learning and engagement. The former pursued relation (implicit in RQ3) was the most difficult to address as the data collection tools (originally developed in the scope of VISIR+ Project) and used throughout this research work did not allow, in the majority of the cases, to collect data about mediation. However, some informal contacts -personal, skype, emailsmaintained between some teachers and the PhD student (included in the research team) allowed to gather data (about some of the mediation characteristics/traces) for some cases, as detailed in section 6.1.4. Considering the richness of the cases for which it was possible to gather some data, we decided to keep RQ3 as some interesting illations could be attained. Naturally, we cannot 
assume that the other teachers did not implement the former mediation characteristics in their classes. Probably they did, at least some of the mediation traces.

The first goal is to determine if there is any correlation between students' VISIR usage, students' grades (VISIR and lab) and students' perception of VISIR (F1 and F2) with some factors that can be related to so some teacher mediation traces, namely:

\footnotetext{
* Course implementation edition.

* Teacher implementation edition (number of editions of each teacher).

* Number of teachers involved.

* Teachers' accesses in VISIR (per task).
}

Pearson or Spearman correlation analysis was used to determine if there was a correlation between each former factor (characterizing mainly teachers' involvement) with the test variables (number of VISIR accesses per task, VISIR grade, lab grade, F1 (students' perceived learnings) and F2 (students' satisfaction with VISIR)). The correlations found are displayed in Table 35.

Table 35 - Correlation between Factors related to Teacher Mediation Traces with Students' Results

Students' results

\begin{tabular}{|c|c|c|c|c|c|}
\hline & $\begin{array}{c}\text { Number of } \\
\text { accesses/task }\end{array}$ & VISIR grade & Lab grade & F1 & F2 \\
\hline $\begin{array}{l}\text { Number of course } \\
\text { implementation edition }\end{array}$ & $\begin{array}{c}\mathrm{R}_{\mathrm{P}}=0.261^{* *} \\
(\mathrm{p}<0.001) \\
\mathrm{N}=1032\end{array}$ & $\begin{array}{c}\mathrm{R}_{\mathrm{SP}}=-0.106^{* *} \\
(\mathrm{p}=0.001) \\
\mathrm{N}=945\end{array}$ & $\begin{array}{c}\mathrm{R}_{\mathrm{P}}=-0.317^{* *} \\
(\mathrm{p}<0.001) \\
\mathrm{N}=706\end{array}$ & $\begin{array}{c}\mathrm{R}_{\mathrm{P}}=-0.068^{* *} \\
(\mathrm{p}=0.039) \\
\mathrm{N}=923\end{array}$ & n.s. \\
\hline $\begin{array}{l}\text { Number of editions of each } \\
\text { teacher }\end{array}$ & $\begin{array}{c}\mathrm{R}_{\mathrm{SP}}=0.181^{* *} \\
(\mathrm{p}<0.001) \\
\mathrm{N}=1032\end{array}$ & n. s. & $\begin{array}{c}\mathrm{R}_{\mathrm{P}}=-0.317^{* *} \\
(\mathrm{p}<0.001) \\
\mathrm{N}=706\end{array}$ & n. s. & n.s. \\
\hline Number of teachers involved & $\begin{array}{c}\mathrm{R}_{\mathrm{P}}=0.094^{* *} \\
(\mathrm{p}=0.003) \\
\mathrm{N}=1032\end{array}$ & $\begin{array}{c}\mathrm{R}_{\mathrm{SP}}=0.245^{* *} \\
(\mathrm{p}<0.001) \\
\mathrm{N}=945\end{array}$ & $\begin{array}{c}\mathrm{R}_{\mathrm{SP}}=0.710^{* *} \\
(\mathrm{p}<0.001) \\
\mathrm{N}=706\end{array}$ & $\begin{array}{c}\mathrm{R}_{\mathrm{SP}}=-0.087^{* *} \\
(\mathrm{p}=0.008) \\
\mathrm{N}=927\end{array}$ & $\begin{array}{c}\mathrm{R}_{\mathrm{SP}}=-0.192^{* *} \\
(\mathrm{p}<0.001) \\
\mathrm{N}=923\end{array}$ \\
\hline $\begin{array}{l}\text { Number of teachers' } \\
\text { accesses/task }\end{array}$ & $\begin{array}{c}\mathrm{R}_{\mathrm{SP}}=-0.302^{* *} \\
(\mathrm{p}<0.001) \\
\mathrm{N}=1025\end{array}$ & $\begin{array}{c}\mathrm{R}_{\mathrm{SP}}=0.253^{* *} \\
(\mathrm{p}<0.001) \\
\mathrm{N}=923\end{array}$ & $\begin{array}{c}\mathrm{R}_{\mathrm{SP}}=0.640^{* *} \\
(\mathrm{p}<0.001) \\
\mathrm{N}=706\end{array}$ & $\begin{array}{c}\mathrm{R}_{\mathrm{SP}}=-0.091^{* *} \\
(\mathrm{p}=0.007) \\
\mathrm{N}=873\end{array}$ & $\begin{array}{c}\mathrm{R}_{\mathrm{SP}}=-0.178^{* *} \\
(\mathrm{p}<0.001) \\
\mathrm{N}=873\end{array}$ \\
\hline
\end{tabular}

* Correlation is significant at the 0.05 level (2-tailed); ${ }^{* *}$ Correlation is significant at the 0.01 level (2-tailed)

Considering the mediation traces identified in Table 27 (page 153), the factors that appear in Table 35 are connected to (T1) experienced teacher. The first two factors somehow characterize (T1a) previous VISIR Usage. The third factor is related to (T1b) integrates a supported dynamic team and finally, the fourth factor is linked to (T1c) frequently accesses VISIR.

As the course undergoes subsequent editions (T1a), the students tend to use VISIR more. Even though the grades obtained in this component tend to decrease, it does not affect students' 
perception of the tool. In this study, these subsequent course editions were carried out by either the same teacher or at least one of the teachers was part of the team in all editions (typically the head teacher or a teacher involved in a previous course). The teachers familiarization with the tool is important to trigger students' perception of VISIR utility and their enthusiasm, motivating its usage and improving their satisfaction as reported in previous studies (Alves et al., 2011; Fidalgo et al., 2012; García-Zubía, Gustavsson, et al., 2011; Marques et al., 2014; Tawfik, Sancristobal, Martín, et al., 2012; Tawfik, Sancristobal, Martín, Gil, Pesquera, Losada, et al., 2011). This familiarisation with VISIR lead the teachers to reinforce its usage in the subsequent course editions, as explored in section 6.1.1.1 and summarized in Table 23 (page 137), trying to take the most of it which naturally lead to higher levels of exigency.

As already discussed in the previous paragraph (and reported in the literature), teachers' experience with the tool (T1a) seems to stimulate students' perception of VISIR utility, leading students to use it more, although their perception (both learning gains and satisfaction) of the tool is not affected. As teachers keep on using VISIR, implementing it in subsequent course editions or in other coursers, they got experienced and familiarized with the resource, making some adjustments and typically reinforcing VISIR usage. They got more demanding and although no correlation was found between teachers' experience (number of teacher implementation edition) and VISIR grade, a negative correlation was found with the lab grade, reflecting this exigency.

The number of teachers involved in the didactical implementation -being several teachers, working as a course team, and not just one- seems to have a positive effect in the students' academic performance (VISIR grade and lab grade), although their satisfaction with VISIR is reduced. In fact, as the number of teachers involved in the didactical implementation increases, the better grades students achieved. A team of teachers, in which the teachers can interact with each other, taking advantage of their different backgrounds and teaching experiences, can assure an interesting dynamic (in class and out of it), enhancing students' learning. The teachers' reflection about their practices can indeed be enhanced by their colleagues, which may potentiate the identification of some teaching or practical aspects that could be improved, that the teachers themselves may have difficulties in identifying (Biggs \& Tang, 2007; Schön, 1983). In fact, the former factor (a team of teachers) is related to (T1b), but except for the cases summarized in Table 27, and although we believe the majority of the teachers integrated a support dynamic team, we do not have data to allow us to check it. Students, depending on the cases, may also have the opportunity to interact with different teachers -can observe and learn with different interlocutors- enriching their learning experience, leading to better academic results. Still, it is tough to organize a team of different teachers and prepare them to use a new resource in similar ways. Not all the teachers have the same perception and/or take the time and effort to be properly 
familiarized with it, which somehow may compromise students' satisfaction with the tool. The average number of VISIR accesses per task may be the same, in different teams, but this does not mean that all the teachers have equally used the resource. A more detailed analysis would be necessary about this item (the number of VISIR accesses of each involved teacher), but in this study, we lack that data in the majority of the cases.

Teachers VISIR own usage (related to (T1c)) seems to have a direct influence on students' academic performance, not only in the VISIR component but also in the lab grade. This influence does not seem to be so direct in students' usage. In fact, it is the other way around: when teachers use VISIR a lot (maybe over supporting their students) students do not feel the need to use it so much. In fact, their satisfaction with VISIR varies in reverse way with teachers' VISIR usage; it may point to when students feel too much support they tend to be less satisfied, a result already found in this this work, using a different data source (section 6.3.1, from the results of Table 33 and Figure 19 and Figure 20). As pointed out in that section, this result suggests that students need support, but in the right proportion to keep them motivated and challenged. The negative correlation found between teachers' and students' VISIR usage may also point to the fact that when teachers do not use VISIR so much and probably do not support so much the students, the students feel the need to use it to overcome their difficulties. We must keep in mind this global analysis embraces 26 courses -from several institutions, education levels and socio-economical contexts- involving 52 teachers -with varied teacher experiences, professional background and scientific expertise- and 1794 students, with different backgrounds, interest and levels of expertise in these topics. Nevertheless, this result (the negative correlation between teachers' and students' VISIR usage) is not in accordance with previous works reported in literature (Alves et al., 2011; Marcelino, Silva, Fidalgo, Schaeffer, \& Alves, 2011; Marques et al., 2014). Marques and colleagues (2014), in a work involving 7 different courses (from various engineering degrees involving 1754 students from somehow different educational backgrounds), but all in the same Portuguese HE institution, the same education level and using the same VISIR system asseverated by the same technical team (so a much less variability in the contexts), found that "in all courses, student usage tracks that of the teacher".

The factor teacher accesses in VISIR related to (T1c) is in now deeply analysed considering its importance and the results obtained in this global analysis (negative correlation between teachers' and students' VISIR usage). In fact, teachers' usage of VISIR is vital in order to closely attend students and hastily and more efficiently recognize their difficulties and doubts, helping them to readily overcome them. As this factor has an ultimately tremendous impact in the didactical implementation success, this correlation between teachers' usage and students' usage will be further detailed in the next paragraphs. Equally a correlation procedure (Pearson 
or Spearman) was used to determine if the same type of correlation was kept considering: education level, implementation topic and VISIR use level (for the secondary level of education and projects there was not data to compute it). The results are summarized in Table 36.

Table 36 - Correlation between Teachers' VISIR Usage and Students' VISIR Usage

\begin{tabular}{|c|c|c|c|}
\hline & & & Number of students' accesses/task \\
\hline \multirow{3}{*}{$\begin{array}{l}\text { Education } \\
\text { Level }\end{array}$} & Secondary & \multirow{3}{*}{$\begin{array}{l}\text { Number of } \\
\text { teachers' } \\
\text { accesses/task }\end{array}$} & \\
\hline & Technological & & $\begin{array}{c}\mathrm{R}_{\mathrm{P}}=0.221 *(\mathrm{p}=0.037) \\
\mathrm{N}=90\end{array}$ \\
\hline & Higher Education & & $\begin{array}{c}\mathrm{R}_{\mathrm{SP}}=-0.394 * *(\mathrm{p}<0,001) \\
\mathrm{N}=935\end{array}$ \\
\hline \multirow{5}{*}{$\begin{array}{c}\text { Implementation } \\
\text { Topic }\end{array}$} & Electricity & \multirow{5}{*}{$\begin{array}{l}\text { Number of } \\
\text { teachers' } \\
\text { accesses/task }\end{array}$} & $\begin{array}{c}\mathrm{R}_{\mathrm{P}}=-0.085^{*}(\mathrm{p}=0.036) \\
\mathrm{N}=605\end{array}$ \\
\hline & Electronics & & $\begin{array}{c}\mathrm{R}_{\mathrm{SP}}=-0.216^{*}(\mathrm{p}=0.019) \\
\mathrm{N}=118\end{array}$ \\
\hline & Projects & & \\
\hline & Mathematics & & $\begin{array}{c}\mathrm{R}_{\mathrm{SP}}=-0.234^{* *}(\mathrm{p}=0.004) \\
\mathrm{N}=149\end{array}$ \\
\hline & Physics & & $\begin{array}{c}\mathrm{R}_{\mathrm{SP}}=0.744^{* *}(\mathrm{p}<0.001) \\
\mathrm{N}=136\end{array}$ \\
\hline \multirow{3}{*}{$\begin{array}{l}\text { VISIR Use } \\
\text { Level }\end{array}$} & Basic & \multirow{3}{*}{$\begin{array}{l}\text { Number of } \\
\text { teachers' } \\
\text { accesses/task }\end{array}$} & $\begin{array}{c}\mathrm{R}_{\mathrm{SP}}=-0.187^{* *}(\mathrm{p}<0.001) \\
\mathrm{N}=779\end{array}$ \\
\hline & Intermediate & & $\begin{array}{c}\mathrm{R}_{\mathrm{SP}}=-0.308^{* *}(\mathrm{p}<0.001) \\
\mathrm{N}=179\end{array}$ \\
\hline & Advanced & & $\begin{array}{c}\mathrm{R}_{\mathrm{SP}}=-0.312^{* *}(\mathrm{p}=0.010) \\
\mathrm{N}=67\end{array}$ \\
\hline
\end{tabular}

A negative weak statistically significant correlation also emerged between the teachers' number of VISIR accesses per task and the students' number of VISIR accesses per task, for the majority of the topics considered. That type of correlation appeared by education level (except for technological), by implementation topic (except for physics) and by VISIR use level. This negative correlations -corroborated the results found when considering all the students' and teachers' data together- suggests that either: (i) when teachers use VISIR a lot, they may have the temptation to over support their students and so students do not feel the need to use the resource so much or (ii) when students do not have so much teacher support as they eventually require to overcome their difficulties, they feel the need to use it more, on their own, to overcome their difficulties and practise in order to have success in the proposed tasks.

An already expected, in the physics topic and technological level a positive correlation appears between the teachers' number of VISIR accesses per task and the students' number of VISIR accesses per task. In fact, in the physics topic there was just data for three didactical implementations in a single physics course (C26) with one teacher the same in all implementations). Case C26 course was already fully detailed in sections 6.1.1.1 and 6.1.4: the teacher was very cautious in VISIR introduction -an activity developed during class with students using VISIR in their own computers and prepared some support material, that made available in Moodle, very directed to the proposed task- in the three editions the teachers' eagerness and 
familiarity stimulated students' enthusiasm and will to use VISIR. The teacher was also available to clarify students doubts via email and in her office time, but avoiding the temptation of answering all students' questions (doing students job), giving them clues and tips, as it was students first contact with EE topics. In the technological level as students tend to have lots of difficulties teachers payed extra care in VISIR introduction and support (for case C7, the way teachers supported students during the execution task period is not known). In case C4, the VISIR tasks were fully developed during class time. In case C5 the head teacher prepared monitors to provide support to students, during the task execution period, whenever they felt the need; case C6 is a very particular case, with only 8 students, all repeating the course; still, the teacher not only prepared material to support them, but also was available to answer their doubts by email. This is corroborated by students answers to Q22 open answer of the SSQ. In case C26, just 3 students out of the 52 that answered it, reported "insufficient preparation from class" (1) and "insufficient material support" (2). In the technological level, 69 students answered Q22 and just 2 reported "insufficient material support". So clearly in the former topics -students from specific contexts and specific needs- the "student usage tracks that of the teacher" (Marques et al., 2014) and teachers' VISIR usage seem determinant to motivate students and stimulate their awareness of VISIR utility. It seems the former teachers were able to support their students' needs in the right proportion.

Conducting an equivalent correlation procedure for the courses that have undergone several course implementation editions (besides case C26) a positive correlation was also found between teachers' and students' VISIR usage for cases C5 and C19, respectively: $\mathrm{r}_{\mathrm{Sp}}=0.358$ ( $\mathrm{p}=$ $0.007 ; \mathrm{N}=55)$ and $\mathrm{r}_{\mathrm{P}}=0.309(\mathrm{p}=0.037 ; \mathrm{N}=46)$. In fact, in the former cases, $(\mathrm{T} 4 \mathrm{~b})$ teachers gave support (to students) in crucial moments.

In section 6.1.4 it was already explored possible factors that may have impact both in teachers' VISIR usage and teachers' satisfaction with VISIR (F2_T) and it was found the number of teachers' VISIR accesses per task (T1c) and teachers' satisfaction with VISIR (somehow connected to the mediation trace (T1d)) were independent of all the factors considered in that section. Still, in this section it was already established that teachers' VISIR usage was correlated with students' VISIR usage as well as their grades and at a lower extent with their perception of VISIR (F2). Plus, in the former section, it was already established that in all cases teachers (T1d) understand VISIR potentiality for learning, except partially in 4 cases. In order to further understand these two variables -teachers' VISIR usage and teachers' satisfaction with VISIR (F2_T) -a correlation procedure was carried out between the former variables and all the factors considered in the correlation procedures carried out in sections 6.3.1, 6.3.2 (Table 33, page 186 and Table 34, page 198) and also the factors considered in this section (Table 35) as well as the education level and 
the course level. The only correlation found, for both variables -number of teachers' VISIR accesses per task and teachers' satisfaction with VISIR (F2_T)- was with the education level, respectively: (i) $r_{\mathrm{Sp}}=0.448(\mathrm{p}=0,010 ; \mathrm{N}=32)$ and (ii) $\mathrm{r}_{\mathrm{P}}=0.404(\mathrm{p}=0.011 ; \mathrm{N}=39)$. The previous results remark that: (i) as the level of education increases, the proposed VISIR tasks are more teacher-demanding, requiring more time to implement them and support their students during the task execution period and (ii) VISIR is better accepted by the HE teachers than the teachers from lower levels of education. Although, there were 52 teachers involved in these 43 didactical implementations, with very different profiles, within an education level that variability certainly is not so vast; in fact, teachers from the same education level feel, in average, the same type of needs and deal with the same type of issues and students (including age and previous background). The result - teachers' satisfaction with VISIR is higher for higher levels of educationis in agreement with a previous work (Lima et al., 2019c).

It was decided to further explore the factor teachers' satisfaction with VISIR (F2_T) and find out if this variable was affected by teachers' perception of students' satisfaction with VISIR (illustrated in Figure 10, page 109) as well as the students' (actual) satisfaction with VISIR (F2). It was used, once again, Pearson and Spearman correlation procedure to determine the association, if any, between these variables. In Table 37, the found correlations are registered.

Table 37 - Correlation between Teachers' Satisfaction and Students' Satisfaction (with VISIR)

\begin{tabular}{|l|c|}
\cline { 2 - 2 } \multicolumn{1}{c|}{} & Students' Satisfaction with VISIR (F2) \\
\hline $\begin{array}{l}\text { Teachers' Perception of Students' Satisfaction with } \\
\text { VISIR }\end{array}$ & $\mathrm{R}_{\mathrm{P}}=0.169^{* *}(\mathrm{p}<0.001)$ \\
$\mathrm{N}=916$
\end{tabular}

This positive correlation between teacher's perception of students' satisfaction with VISIR and the actual students' satisfaction with VISIR (F2) (Table 37) suggests teachers evaluated correctly students' satisfaction with the tool, that is, teachers sensed students' satisfaction correctly. However, students' actual satisfaction with VISIR is not significantly influenced by teachers' own satisfaction.

Considering the consistency of this study variable - teachers' satisfaction with VISIR (F2_T) related to (T1d)- it was decided to explore if it was affected by students' VISIR usage (number of VISIR accesses per task), students' perceived learnings with VISIR (F1) and students' academic performance (grades by component and final grade). No correlation was found between F2_T and the studied variables except a very weak negative correlation with the exam grade and final grade, respectively $r_{P}=-0.112(p<0.001 ; N=1005)$ and $r_{P}=-0.130(p<0.001 ; N=752)$. Teachers' 
satisfaction with VISIR is not correlated with students' usage and actual perception of the tool nor with students' academic performance in the VISIR/lab component. The teachers seem to use VISIR because they consider it an interesting and worthwhile resource to explore. Teachers are probably more interested in VISIR effects in students' global development of experimental competences and its influence in the course than the direct use of the tool. The negative correlations found may suggest VISIR seems to be more useful for the students with difficulties than for the proficient students, accordingly to the teachers' discernment, corroborating the results obtained considering the students' results and the literature "this might point to VISIRs' target audience not being the most proficient students, but the ones who require more support in their learning" (Viegas, Pavani, et al., 2018).

Considering the cases, summarized in Table 27 (page 153), for which the mediation trace (T1d) understand VISIR potentiality for learning was not identified $-\mathrm{C} 3$ (2 $\left.2^{\text {nd }}, 3\right), \mathrm{C} 11, \mathrm{C} 12$ and C14- some comments will be done about cases C11 and C12 (in the other two cases, it were identified some mediation traces, so they will be explored later in this section):

* Case C11: as already reported, it is an EE major advanced course, in which teachers recognize students have not the adequate prior knowledge in instrumentation and also the majority does not have adequate work habits. Teacher's perception of students' satisfaction with VISIR was really low (1) and the students' actual satisfaction with VISIR was also low (F1 = 2), partially associated to several constraints such as instability, operating issues and some also considered the interface was obsolete. This last factor -"poor interface/old fashionable/too simple"- was also shared by the teacher, which someway may affect students' motivation and perception of VISIR utility. The majority of students used VISIR (average number of VISIR accesses per task = 3.1)), but they ended with a really low average grade in the VISIR component (42.5\%). The former grade was much lower than the average grades they achieved in the other components, still its contribution ( 2 tasks) to their final grade was just $5 \%$, which probably contributed to a lower level of engagement and motivation. In fact, one student commented I ended up not using VISIR for experiments, I only tested it once.

* Case C12: the head teacher had "some resistance to the VISIR system" (Table 14, page 108), although he made an effort to incorporate it in his practices (an optional task), due to his Institution suggestion. Students had an average number of VISIR accesses per task (1.7) lower than similar courses although they expressed their satisfaction with VISIR (F1 = F2 = 3). From the 7 anonymous opinions expressed in Q22 (it was supposed to have the students' identification in the SSQ, but this teacher did not agree with it), just one is related to the didactical implementation: "problems in 
understanding". The majority of the students reported "circuits limitation", suggesting they were expecting to have more circuits available to practice with VISIR. As part of their assessment, at the end of the semester they had to present and defend an experiment they have performed during the semester, still they could choose between a hands-on experiment or a VISIR experiment. The majority opted for a hands-on experiment.

The former cases suggest that teachers' resistance or lack of enthusiasm affect students' results in a way or another.

Considering the teacher mediation traces relevant to this study (Table 27), an effort of identification per case was made to make a brief summary of the results of the mediation (through the mediation traces implemented). Their association with students' academic performance: number of students' accesses in VISIR, students' grades and students' perception of their learning and satisfaction with the tool is presented in Table 38, which summarizes the comparison between both results (teacher mediation and students' academic performance). The case C3, in its second course implementation edition, was implemented simultaneously in three different degrees.

Let us start by considering the other two cases where the teacher mediation trace (T1d) understand VISIR potentiality for learning was not identified: C3 (2nd 3$)$, and C14. In the first case, the teacher had the privilege to (T1b) integrate a supported dynamic team, with which all the students interacted, so although students average number of VISIR accesses per task was slightly lower than for the same course in the other two degrees, students did not seem to really be affected by this particular teacher's (one out of three) perception. On case C14, students had a really low perception of VISIR (which was in accordance with teachers' perception of it), although their VISIR usage was comparable to other cases. The head teacher of this case also felt perhaps the interface is a bit too simple and does not rouse the enthusiasm of the young students, which naturally is sensed by students. Plus, these students have at their disposal modern and wellequipped labs (whenever they want, during expedient hours) with technical staff to support them. Indeed, one student commented I did not like VISIR. I prefer the hands-on labs when I can ask teachers or monitors help, whenever I need. 
Table 38 - Teacher Mediation Traces and Students' Academic Results

\begin{tabular}{|c|c|c|c|c|c|c|c|c|c|c|c|c|}
\hline \multirow{3}{*}{$\begin{array}{l}\# \\
\# \\
\mathscr{E} \\
\tilde{z}\end{array}$} & \multirow{3}{*}{ 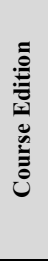 } & \multirow{2}{*}{\multicolumn{5}{|c|}{ Mediation Traces (promoted by teacher) }} & \multicolumn{6}{|c|}{ Students' Academic Performance } \\
\hline & & & & & & & \multirow[b]{2}{*}{ 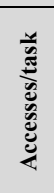 } & \multicolumn{3}{|c|}{ Grades } & \multicolumn{2}{|c|}{ Satisfaction } \\
\hline & & $\begin{array}{c}\text { (T1) } \\
\text { Experienced } \\
\text { Teacher }\end{array}$ & $\begin{array}{c}\text { (T2) } \\
\text { Good learning } \\
\text { environment }\end{array}$ & $\begin{array}{c}\text { (T3) } \\
\text { Clarifies } \\
\text { objectives }\end{array}$ & $\begin{array}{c}\text { (T4) } \\
\text { Keeps the } \\
\text { task } \\
\text { authentic }\end{array}$ & $\begin{array}{c}\text { (T5) } \\
\text { Keeps up with } \\
\text { students work } \\
\text { and gives } \\
\text { feedback }\end{array}$ & & VISIR & Lab & Final & F1 & F2 \\
\hline \multirow{4}{*}{$\mathbf{C 3}$} & 1 & T1d & \multirow{4}{*}{$\mathrm{T} 2 \mathrm{a} ; \mathrm{T} 2 \mathrm{~b}$} & \multirow{4}{*}{ T3a } & & & 1.0 & 68.2 & \multirow{4}{*}{ No } & 76 & \multirow{4}{*}{3} & \multirow{4}{*}{3} \\
\hline & 2 & $\begin{array}{l}\text { T1a; T1b; } \\
\text { T1d }\end{array}$ & & & & & 2.1 & 61.2 & & 69.9 & & \\
\hline & 2 & T1b; T1d & & & & & 3.9 & 76.6 & & 76.8 & & \\
\hline & 2 & $\mathrm{~T} 1 \mathrm{~b}$ & & & & & 1.8 & 78.7 & & 76.4 & & \\
\hline \multirow{3}{*}{ C5 } & 1 & T1d & & \multirow{3}{*}{ T3a } & \multirow{3}{*}{$\mathrm{T} 4 \mathrm{~b}$} & \multirow{3}{*}{ T5a } & & - & \multirow{3}{*}{ No } & 57.1 & \multirow{3}{*}{3} & \multirow{3}{*}{3} \\
\hline & 2 & \multirow{2}{*}{ T1a; T1d } & & & & & 1.0 & 100 & & 64.3 & & \\
\hline & 3 & & & & & & 1.8 & 73.5 & & 60.4 & & \\
\hline C6 & 1 & T1b; T1d & & & & & & 90 & No & 78.3 & 3 & 3 \\
\hline \multirow{3}{*}{ C8 } & 1 & T1d & \multirow{3}{*}{$\mathrm{T} 2 \mathrm{~b}$} & \multirow{3}{*}{$\mathrm{T} 3 \mathrm{a} ; \mathrm{T} 3 \mathrm{~b}$} & & & & 90.6 & & 63.7 & 3 & 3 \\
\hline & 2 & $T 12 \cdot T 1 d$ & & & $\mathrm{~T} 4 \mathrm{a}$ & & 3.6 & 82.2 & No & 54.7 & 3 & 3 \\
\hline & 3 & $11 a, 11 d$ & & & & & 6.3 & 86.4 & & 60.3 & 2.5 & 2 \\
\hline & 1 & & & & & & 3.4 & 94.1 & & 70.4 & 3 & \\
\hline C9 & 2 & Tla; Tld & T2a & T3b & T4a & & 2.8 & 83.1 & No & 57.9 & 3 & 3 \\
\hline C10 & 1 & T1d & & & & & & & & 70.6 & 3 & 3 \\
\hline C10 & 2 & T1a; T1d & & & & & & 86.7 & No & 68.6 & 3 & 3 \\
\hline C13 & 1 & T1a; T1d & $\mathrm{T} 2 \mathrm{~b}$ & & & & 5.8 & & & 70.0 & 3.5 & 3 \\
\hline $\mathrm{C} 14$ & 1 & & & & & & & & & & & 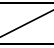 \\
\hline C14 & 2 & T1a & $\mathrm{T} 2 \mathrm{~b}$ & & & & 3.0 & 62.9 & 64.8 & & 2 & 1 \\
\hline C16 & 1 & T1d & & & & & 2.3 & 85.7 & 95.5 & & 2 & 2 \\
\hline C16 & 2 & T1a; T1d & & & & & 1.6 & 86.4 & 72.1 & & 3 & 2.5 \\
\hline $\mathrm{C17}$ & 1 & T1d & & & & & 3.4 & & & & 3 & 4 \\
\hline C17 & 2 & T1a; T1d & & & & & 1 & & & & & \\
\hline & 1 & T1d & & & $\mathrm{T} 4 \mathrm{a}$ & & 7.4 & 100 & 75.9 & 81.8 & 3 & 2 \\
\hline C19 & 2 & & & T3a & & & 6.9 & 86.4 & 79.3 & 82.9 & 3 & 3 \\
\hline & 3 & Tla; Tld & & & T4a; T4b & T5a & 15.5 & 100 & 71.5 & 82.7 & 2 & 2 \\
\hline$C 20$ & 1 & T1c; T1d & & & & & 6.3 & 78.6 & & 70 & & \\
\hline $\mathrm{C20}$ & 2 & T1a; T1d & & T3b & & T5b & 13.3 & 90.8 & & 72.8 & 3 & 3 \\
\hline $\mathrm{C22}$ & 1 & T1a; T1d & $\mathrm{T} 2 \mathrm{a}$ & T3a & $\mathrm{T} 4 \mathrm{a}$ & & 7 & 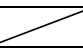 & 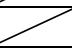 & 1 & 3 & 3 \\
\hline $\mathrm{C23}$ & 1 & T1d & & T3a & $\mathrm{T} 4 \mathrm{a}$ & T5a & 3.1 & 81.8 & No & 73.8 & 2 & 2 \\
\hline $\mathrm{C24}$ & 1 & T1d & & T3a & & & 1,6 & 92.9 & No & 72.9 & 3 & 3 \\
\hline $\mathrm{C25}$ & 1 & T1a;T1d & & T3a & & & 7 & 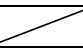 & 7 & 7 & 3 & 3 \\
\hline & 1 & & & & & & 2.4 & 78.3 & 65.8 & 53.7 & & \\
\hline $\mathrm{C} 26$ & 2 & T1a; T1d & $\mathrm{T} 2 \mathrm{~b}$ & T3a & $T \Delta b$ & & 7.4 & 80 & 57.6 & 54.1 & 3 & 3 \\
\hline & 3 & & & & $14 b$ & T5a & 12.8 & 72.0 & 58.2 & 57.0 & & \\
\hline
\end{tabular}

In some cases, several global teacher mediation characteristics were simultaneously identified ((T1), (T2), (T3), (T4), (T5)). In case C26, all of them were identified, although not all the components in each of them. Looking in detail to the two types of data (teacher mediation traces and students' results) it gets clear that "when teacher mediation was able to address all dimensions (characteristics) simultaneously harmoniously, i.e., without discarding any, better results could be achieved" (Viegas, 2017b). In this study -and considering the cases for which we have data- it is clear that for the cases where teachers were able to integrate more mediation traces in their classes -e.g. cases C5, C8, C9- the more they were able to help their students in 
developing quality and integrated knowledge (Viegas et al., 2009). In fact, in the former cases students' academic performance was better (comparing to similar courses where less (or none) mediation traces were, according to our knowledge, implemented) particularly considering students' usage of the resources, that clearly increased. In some cases -from one course edition to the subsequent ones- their VISIR grade decreased a little, probably because teachers implemented more complex tasks (Table 23, page 137), although the students kept achieving really good grades. There were still two cases -cases C8 and C19- in which teachers implemented several mediation traces (and from the first to the subsequent course editions they were even more careful in the implemented mediation) and in both the students' satisfaction with VISIR (both F1 and F2) decreased. The former two cases will be detailed in section 6.3.4, but apparently the decrease was associated with "insufficient material support" and some instability problems with VISIR system.

Although all of the mediation traces, included in Table 38, have already been reported in the literature as having an important influence in student's engagement, learning and development of competences, not all of them have the same impact in students' results and their combination (particularly of some of them) that potentiates students' academic performance. It is clear, from the former table, that there are some traces that appear more often than others and probably some of them are more determinant than others in students' success. Clearly and taking into account the data we were able to gather (which was incomplete), teachers implemented more mediation traces in the characteristic (T1) experienced teacher than in the others, particularly the (T5) keeps up with students work and give feedback. The three teacher mediation traces that appeared more often were (by order): (T1d) understands VISIR potentiality for learning, (T1a) previous VISIR usage and (T3a) explains the pertinence of using several experimental resources.

It was explored in this section that when teachers do not fully appreciate VISIR (linked to the inexistence of (T1d)), they somehow pass that feeling to their students: they have difficulties in motivating them to use it as probably they do not give students an appropriate justification of VISIR's utility (García-Zubía, Gustavsson, et al., 2011; Tawfik, Sancristobal, Martín, Gil, Pesquera, Ros, et al., 2011), as probably has occurred in case C14 at some level.

In the beginning of this section and considering the results included in Table 35, it was found a positive correlation between (T1a) (the number of course implementation edition and the number of teacher implementation edition) with students' VISIR usage. As already reported in the literature (directly related to VISIR) teacher's familiarization with VISIR is important not only to motivate students, but to make them understand VISIR utility as well as quickly adapt and ascertain students' difficulties (Fidalgo et al., 2012; Lima et al., 2019a). In the same table a negative weak correlation appeared between the number of course implementation edition and the VISIR 
grade, probably because as teachers became more experienced with VISIR, in some cases, they implemented more complex and demanding tasks. Still, that experience also allowed teacher to implement some other mediation traces like for instances (T2b) gives authority and responsibility to students (cases C3, C8, C13, C14 and C26) which compels students to a more autonomous effort to accomplish the tasks. In fact, "teachers' experience with the didactical implementations are also very important in reaching better academic results and getting students involved" (Viegas, 2017b). Indeed, teachers' experience (teacher/course implementation editions) in the didactical implementations described in this study (using several experimental resources, based upon VISIR) can be really important and more pertinent than years of teachers' experience, by itself.

In several cases, teachers take a special effort in (T3a) explains the pertinence of using several experimental resources. Each experimental resource allows the development of different competences, so it is important students understand the major differences in the type of data obtained with these experimental resources besides having the opportunity of practicing with each of them (Brinson, 2015; Nickerson et al., 2007). Taking into account the results to the questions from the SSQ: Q13 (I could see the differences between results obtained by simulations and remote labs) and $\mathbf{Q 1 8}$ (I could see similarities between experimenting with remote and handson labs), illustrated in Figure 14 (page 124), the majority of the students considers they understood it. Still, from their answers to the SSQ Q21 and Q22 one gets the impression that some of them did not really assimilate the difference between simulation and remote labs (and the different type of data obtained with each resource) and some of them seem to not even acknowledge that they did not understand it (Lima et al., 2019a; Lima, Viegas, Zannin, Marques, Alves, Felgueiras, Costa, et al., 2017). Some examples from the students' answers (referring to VISIR remote lab), from different cases, that illustrate it: I downloaded another software to simulate the circuit; sometimes it takes too long to run the simulation; not being able to save the assembled to use afterwards; I stayed several hours trying to simulate an experiment; I tried to find a solution in the Internet, but I did not; the program is not very flexible. So clearly, teachers' effort and explanations did not reach all students. (T3b) was clearly less implemented but one student from case C5 completely understood its pertinence test in practice all analysis and theoretical study that I learned in a traditional classroom. I am seeing in practice the result of several hours of study taking shape.

(T1b) Integrates a supported dynamic team it was a privilege particularly for the second course edition of case C3. The experience, enthusiasm and dynamism of the head teacher of the first course implementation edition allowed these unexperienced teachers with VISIR and this methodology to implement a well-designed didactical implementation and being attentive to 
several mediation traces. The head teacher of case C6, although was working alone in his course also had the support of an experienced teacher with this methodology, although the results in terms of mediation traces were not quite the same, even if students' results were really good. In fact, half of the didactical implementations was carried out by teams of teachers (with a varied number of elements), but we do not have information how these teams have worked. Still the results from Table 35, advocate students' results (number of VISIR accesses per task and grades), are better when they are taught by a team of teachers, suggesting that the majority of the teams worked in a dynamic supportive way.

(T2) Teacher promotes a good learning environment was not possible to be identified in several of the reported cases. Considering both (T2a) and (T2b), the first was even less explicitly considered as simply developing the tasks in group was not accounted in this trace. For the majority of the cases, we do not know if in those group tasks teachers really promoted interaction between group members and/or between groups or if they just planned group tasks for being simpler (or any other reason) and let the groups to interact (or not) as they wished. Still, the results from Figure 22 (page 204) suggest that when teachers developed groups tasks, both students' perceived learning with VISIR (F1) and their satisfaction with VISIR (F2) increased.

It has already been fully explored the importance of teachers' VISIR usage (related to (T1c)) and its influence in students own usage and their grades and satisfaction with VISIR (results from Table 35). It was concluded teachers should give support to students, but in the right proportion: not too much (having the temptation of doing students job) nor too little (leading to eventual frustration and dropouts). Indeed, it is important "the teachers help occurring after the students have reached those doubts, so the explanations make sense to them" (Viegas, 2017b), that represents (T4b) gives support in crucial moments (like in cases C5, C19 and C26, where a positive correlation was found between teachers' and students' VISIR usage), in which this trace is present in teachers' didactical implementations.

One of the teacher mediation traces that contributes to students' engagement and better competence development (Viegas, 2017b), as discusses in section 2.2.2, is proposing tasks (to the students) and (T4) teacher keeps the task authentic, until they find a solution, providing students with authentic learning experiences (Viegas et al., 2009). One of the answers to a question of the SSQ -I think I can work out electricity problems from real-life (Q16) -somehow gives an insight if this purpose (connection to the real world) was achieved. The students' answers to this question (in a Likert scale from 1 (minimum) to 4 (maximum)) are exhibited in Figure 23. 


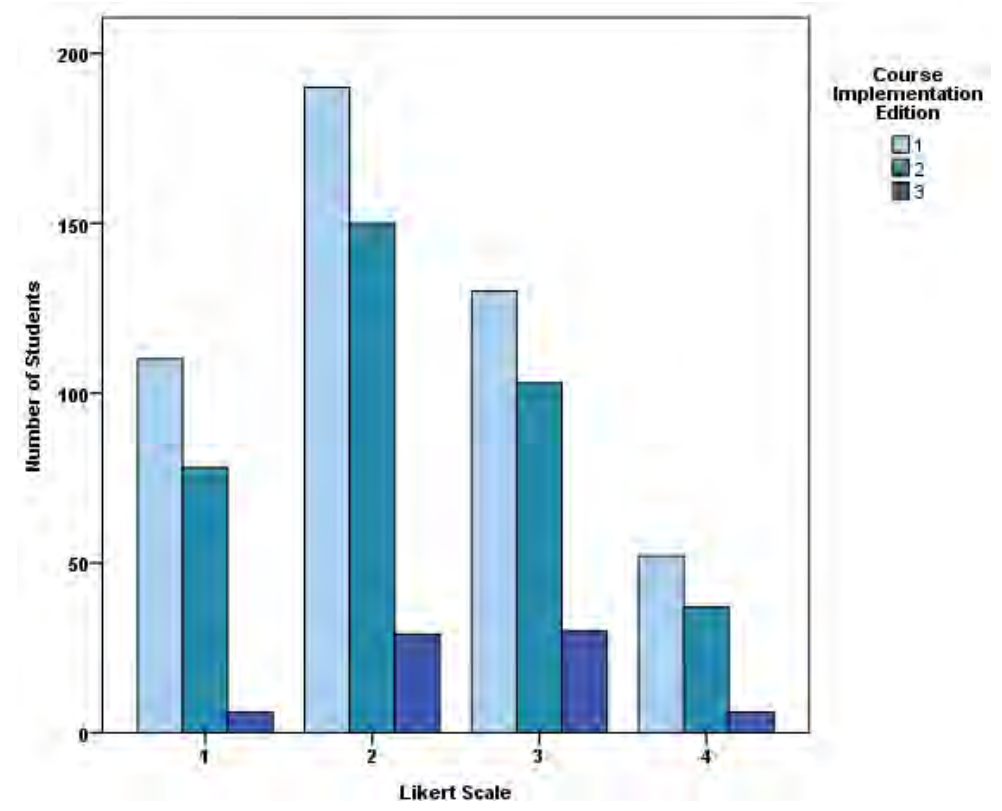

Figure 23 - Students' Answers to Q16, by Number of Course Implementation Edition

As it can be observed in Figure 23, the majority of the students do not agree or just partially agree with this statement. In fact, just $39 \%$ of the students who answered this question considered (agreement or fully agreement) they could workout electricity problems from real-life. It was performed a chi-square independence test between the distribution of students answers to Q16 with both the number of course implementation edition and the teacher implementation edition. In both cases $p>0.05$ (respectively $p=0.07$ and $p=0.122$ ), so the conclusion is that the variables in study are independent, that is, there is no relationship between the distribution of students answers to Q16 with either the number of course implementation editions or the teacher implementation edition related to (T1a). Their perception is not affected by teachers' experience with VISIR (gained in subsequent course editions).

To understand if there were any association between the former variable (the students' answers to Q16) with the number of students who developed HOS as well as students' VISIR usage and their perception of the tool (F1 and F2), the correlations between those variables were analysed (Table 39).

Table 39 - Correlation between Q16 Answers Distribution and Students' Results

\begin{tabular}{|c|c|c|c|c|}
\cline { 2 - 5 } \multicolumn{1}{c|}{} & $\begin{array}{c}\text { Number of } \\
\text { students HOS }\end{array}$ & $\begin{array}{c}\text { Number of } \\
\text { accesses/task }\end{array}$ & F1 & F2 \\
\hline $\begin{array}{c}\text { Q16 students' answers } \\
\text { distribution }\end{array}$ & n. s. & $\begin{array}{c}\mathrm{R}_{\mathrm{SP}}=0.191^{* *} \\
(\mathrm{p}=0.001) \\
\mathrm{N}=658\end{array}$ & $\begin{array}{c}\mathrm{R}_{\mathrm{P}}=0.481^{* *} \\
(\mathrm{p}<0.001) \\
\mathrm{N}=921\end{array}$ & $\begin{array}{c}\mathrm{R}_{\mathrm{P}}=0,322^{* *} \\
(\mathrm{p}<0.001) \\
\mathrm{N}=921\end{array}$ \\
\hline
\end{tabular}


Accordingly to the results illustrated in Table 39, the more students feel they can work out electricity problems from real-life, which suggest they felt the proposed tasks they had to develop were authentic (T4), the more they used VISIR and the higher is their perception with the tool, specially their perceived learnings (F1). ). So, students' perception that the task is authentic, that is productive for them, really contributes to increasing students' engagement and satisfaction of the tool.

(T5) Teacher keeps up with students work and gives feedback was the least mediation characteristic contemplated on this study, probably because we did not have data to gather information about it and/or eventually was the most difficult to teachers to implement. Still, the mediation trace (T5b) in which the head teacher of case C20 referred he provided a conceptual (qualitative) evaluation to students. The results from Figure 21 and Figure 22 (both in page 204) suggest students clearly benefit from a qualitative assessment (the type of provided comments seems to be pertinent) both in their VISIR usage as in their satisfaction (both F1 and F2) with the tool.

As already discussed in section 6.1.2, in several cases, teachers made a special effort to accompany their students in their work with VISIR. This "implemented support" was summarized in Table 14 (page 108) and now we will try to establish if that effort had impact in students' results. Naturally, it is possible that other teachers also made a special effort to support their students' work, but they did not mention it in their interviews and/or informal comments. Analysing by type of "implemented support":

* High level of experience/time: considering the students' answer (both case C20 and C26) to Q22 from the SSQ, there were just 3 students (out of 78 who answered the Q22, expressing 82 opinions) that reported "insufficient material support" and one that elected "insufficient preparation from classes". So, although these teachers felt this new tool required experience and was time consuming, they managed to overcome it and prepare the support material for their students. In fact, considering the negative factors related to F1 (perceived learnings) the students from C20 and C26 just had 3 answers in the factor "problems in understanding at the beginning", suggesting they overcome their difficulties with teachers' support and two answers in the factor "problems in understanding". So, it seems teachers' effort was worthwhile: they were able to implement several mediation traces in their courses/classes (Table 38) which seems to have had a positive impact in students' VISIR usage, their grades and their satisfaction with VISIR.

* Head teacher trained monitors to assist students: from the 47 answers to Q22 expressing 49 opinions, just one reported "insufficient material support"; still 9 
students reported "problems in understanding at the beginning"/"problems in understanding", that overcome with the monitors support. The teacher considered that although these students start this course with lots of difficulties, VISIR and this methodology motivated students and this attentive teacher was able to implement several mediation traces in his classes that helped students to overcome their initial difficulties.

* Heightened attention to the VISIR system: teachers' goal was to make sure VISIR experiments were working well, to avoid students' frustration by dealing with operating or server issues. They managed to avoid problems with server connection, but 21 students, out of the 57 who answered Q22, reported "operating issues" and 8 reported problems with Internet connection, which although not related directly to VISIR may affect students' engagement. Still, teachers' familiarization with VISIR allowed them to implement several mediation traces that seemed to have a positive influence on students' academic performance.

* Heightened attention to students: teachers' goal was not only to pay attention to the students' comments about VISIR system -and intervene when necessary to rectify some detected problem (instability, operating issues)- but also to make a special effort to tutoring students, by monitoring their difficulties, in a general way, to prevent frustration. In case C16 and case C19 (3rd), the teacher did not really have success, considering students' satisfaction with VISIR (F1 and F2). In case C16, teachers had difficulties in implementing a successful mediation (that embraced several characteristics/traces, including (T4b) give support in crucial moments) and students had lots of complains: the lack of classes explaining how to use the program better; information and explanation are lacking; absence of support from a monitor when there was a problem in the experiment and the tasks were very repetitive; ... there is no way to clarify doubts; lack of an instructor for real-time attendance. This is a course with a total of 442 students (in both editions) and even with their best effort it was difficult for the 4 teachers to give the support students expected. In case C19 (3 ${ }^{\text {rd }}$ ), it seems teachers did not really have success, considering students' satisfaction with VISIR that decreased (although their VISIR usage has increases and their grades were really good). Teachers were able to implement several mediation traces -that increased in the second and third course implementation editions- including (T4b). Students, in the third course implementation edition, complained about "insufficient material support" and were probably referring they were feeling less support that in previous editions, which they disliked. 
Considering the results expressed in Table 38, corroborated by the results summarized in Table 14 (and the correlations stated in Table 35, Table 36 and Table 37), it is clear that some teachers had facility in implementing several mediation characteristics while others appear to have more difficulties. Still, it is better to implement one or two mediation traces, and with experience in this type of methodology being able to implement more and, if possible, from all the important mediation characteristics identified in this study, than none. From the former results it seems that as more traces the teacher is able to implement the best academic performance students have the possibility to achieve. Still, there are some traces that appear to have more impact -dominant- than others in this study. The most successful implemented traces, that is, the ones with the teachers seem to be more comfortable, are (T1a), (T1d) and the "relation" (T1c)/(T4b). Most teachers seem to be less comfortable in addressing the mediation traces (T3b), (T5a) and (T5b).

\subsubsection{Synthesis of the Results Obtained in Teacher Mediation and Students' Results}

In this section our aim was focus on the third research question (RQ3) "Are there teacher mediation traces that can be linked to better students' learning and engagement?". Supported in empirical data, collected from various sources -analysed using several quantitative and qualitative statistical techniques- teachers' didactical practices (mainly experimental) were cross analysed with students' results (grades, accesses in VISIR and perception of the tool) to try to identify the teacher mediation traces connected to better students' results. In this study, we have identified 5 teacher mediation characteristics, supported by the literature: (T1) experienced teacher; (T2) teacher promotes a good learning environment; (T3) teacher clarifies objectives; (T4) teacher keeps the task authentic; (T5) teacher keeps up with students work and gives

feedback. We started by facing immediately a major problem: although the teachers involved in the 43 didactical implementations addressed in this study had the opportunity to attend, at least, a training action (TA) to get familiarized with VISIR and this methodology in the former sessions, the teacher mediation guidelines were not established. Plus, the data collection tools that were originally developed to serve the VISIR+ Project and used throughout this work did not allow, in the majority of the cases, to collect data about mediation. So, the gathering of that data (concerning some of the mediation traces) presented in section 6.1.4, was mostly the personal and skype meetings that were kept between some teachers and mainly the research team, in which this $\mathrm{PhD}$ student is included, as well as some teachers' and students' informal contacts. So, Table 27 (page 153), identifies the mediation characteristics/traces in the cases where some information was available 
So considering the third research question addressed in this work, the first main illation versed from this study is teachers who have more experience with VISIR and this methodology (several course/teacher implementation editions) were more sensitive to the identified (teacher) mediation characteristics/traces, making an effort, in some cases, to be even more alert in subsequent course implementation editions. Naturally, not all the teachers are equally sensitive to these aspects, but with time, experience and support by other teachers ((T1b) integrated in a support dynamic team) they can gain knowledge and improve their sensitivity to theses aspects as some did. Secondly, when teacher mediation was able to address all mediation characteristics (incorporating the majority of the mediation traces), students tend to achieve better academic results (both better grades, greater VISIR usage and better perception of the remote lab). Third, there are some mediation traces that seem more dominant than others in terms of affecting students' results: (T1a) previous VISIR usage, the duo (T1c) frequently accesses VISIR / (T4b) gives support in crucial moments and (T1d) understands VISIR potentiality for learning (Figure 24).

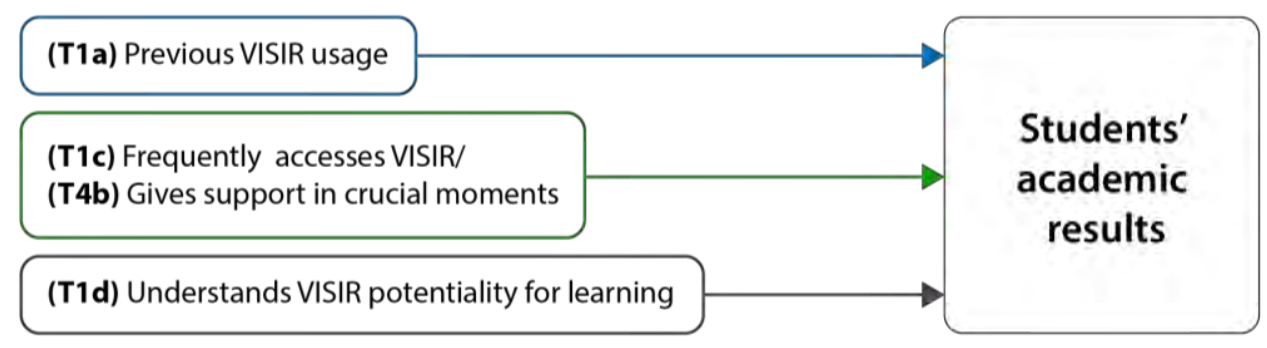

Figure 24 - Dominant Mediation Traces on Students' Results

This work allowed to support on the former empirical data several statements regarding the third research question:

$\checkmark \quad$ Teachers' experience/familiarization with VISIR (T1a) clearly influences students' VISIR usage. The former teacher familiarization with the tool seems to call students attention for the resource usage utility in their learning process. Still, it affects neither their learning perception with VISIR nor their satisfaction with the tool.

$\checkmark \quad$ Teachers' VISIR own usage (related to (T1c))clearly affects students' own usage in several ways: (i) when teachers use VISIR a lot, probably over supporting students, the students do not feel the need to use it so much; (ii) when teachers do not use VISIR so much and probably do not support students as they "need", the students necessitate to use it more to overcome their difficulties; (iii) if teachers only give support to students in crucial moments (T4b) "the students usage tracks that of the teacher", that is the right amount of support is achieved. 
$\checkmark \quad$ Students being enrolled in a course in which they have the opportunity to interact with different teachers (T1b) has a positive impact in their learning (higher grades both in VISIR tasks and the lab component), however their satisfaction with VISIR may be sometimes compromised.

$\checkmark \quad$ Teachers, in general, valued the remote lab, (T1d) understanding VISIR potentiality for learning. Teachers' satisfaction with VISIR is not dependent of any of the studied context factors, except the education level: their satisfaction with the tool is higher for higher levels of education. Still, when teachers were not so enthusiastic with the resource (by some reason), that feeling somehow was sensed by the students, affecting, in a way or another, students' learning and/or engagement.

$\checkmark \quad$ Teachers' perception (from their experience with VISIR) is that this remote lab seems to be more useful for the students still struggling with difficulties than the more proficient students. The students' results corroborate that fact: VISIR target public seems to be the students that require more support in their learning.

\subsubsection{Students' Characteristics and Students' Results}

This study involved 1794 students from very different contexts, including: country, socio-culturaleconomic factors, background, education level, etc., which means in these 43 didactical implementations, there were enrolled students with very different characteristics. In this section the aim was to find out if there are any students' characteristics, while involved in didactical implementations supported by VISIR, that can be associated to t students' learning outcomes and engagement.

The first goal is to determine if there is any correlation between students' VISIR usage, students' grades (VISIR and lab) and students' perception of VISIR (F1 and F2) with two factors that are somehow related to students' characteristics, namely:

* Education level.

* Number of students enrolled in the course.

A correlation procedure was used to determine if there was a correlation between each former factor with the test variables (number of VISIR accesses per task, VISIR grade, lab grade, F1 (students' perceived learnings) and F2 (students' satisfaction with VISIR)). The correlations found are displayed in Table 40. 


\begin{tabular}{|c|c|c|c|c|c|}
\hline & \multicolumn{5}{|c|}{ Students' results } \\
\hline & $\begin{array}{c}\text { Number of } \\
\text { accesses/task }\end{array}$ & VISIR grade & Lab grade & $\mathrm{F} 1$ & F2 \\
\hline Education level & $\begin{array}{c}\mathrm{R}_{\mathrm{SP}}=0.262^{* *} \\
(\mathrm{p}<0.001) \\
\mathrm{N}=1032\end{array}$ & $\begin{array}{c}\mathrm{R}_{\mathrm{SP}}=0.259^{* *} \\
(\mathrm{p}<0.001) \\
\mathrm{N}=945\end{array}$ & & $\begin{array}{c}\mathrm{R}_{\mathrm{p}}=-0.069^{* *} \\
(\mathrm{p}=0.035) \\
\mathrm{N}=1032\end{array}$ & $\begin{array}{c}\mathrm{R}_{\mathrm{SP}}=-0.135^{* *} \\
(\mathrm{p}<0.001) \\
\mathrm{N}=923\end{array}$ \\
\hline $\begin{array}{l}\text { Number of students enrolled in } \\
\text { the course }\end{array}$ & $\begin{array}{c}\mathrm{R}_{\mathrm{P}}=-0.306^{* *} \\
(\mathrm{p}<0.001) \\
\mathrm{N}=1032\end{array}$ & $\begin{array}{c}\mathrm{R}_{\mathrm{SP}}=0.278^{* *} \\
(\mathrm{p}<0.001) \\
\mathrm{N}=945\end{array}$ & $\begin{array}{c}\mathrm{R}_{\mathrm{P}}=0.643^{* *} \\
(\mathrm{p}<0.001) \\
\mathrm{N}=796\end{array}$ & $\begin{array}{c}\mathrm{R}_{\mathrm{P}}=-0.104^{* *} \\
(\mathrm{p}=0.002) \\
\mathrm{N}=923\end{array}$ & $\begin{array}{c}\mathrm{R}_{\mathrm{P}}=-0.208^{* *} \\
(\mathrm{p}<0.001) \\
\mathrm{N}=923\end{array}$ \\
\hline
\end{tabular}

** Correlation is significant at the 0.01 level (2-tailed)

Several other students' characteristics -some perceived by teachers' while getting to know their students at the beginning of the course and others collected by some tool during this study- will be approached later in this section.

Throughout this analysis and considering these 43 didactical implementations, it can be inferred the education level significantly affects students' VISIR usage and performance and at a lower extent and in the opposite direction students' perceived satisfaction with the tool. In fact, as one goes up in the education level, students use more VISIR and also achieve better grades although their satisfaction with the tool diminishes. At higher levels of education VISIR tasks tend to be more demanding, so students have to access it more to accomplish it. As they are using it more and typically are more proficiently in these topics, their grades are better. However, students from the lower levels of education, not so used to this type of resources are more satisfied with VISIR. Plus, at this lower levels of education VISIR usage is somehow more punctual as well as more supported (by the teachers) and so some students do not even realize some VISIR constraints that students from the higher levels of education do. The former results are in agreement with a previous work (Lima et al., 2019c), in which accordingly to teachers' perception, students from the lower levels of education achieved a higher level of satisfaction with VISIR. That result was exclusively based on teachers' perception and not the direct opinion of the students. This study, considering the students' results corroborates that students' satisfaction with VISIR is indeed superior at lower levels of education. Still and accordingly to the results obtained in the previous section, teachers' satisfaction with VISIR is higher for higher levels of education, mainly because it is more challenging to implement VISIR and truly explore its potentialities at these levels of education. That is, teachers were more satisfied when VISIR was used in higher levels of education, but students from the lowers level of education are more satisfied with VISIR. It was also already concluded in this work (section 6.3.2) that VISIR and this methodology are appropriate both for introductory courses and more advanced ones. 
Most secondary schools do not have at their disposal well-equipped hands-on labs and even when they have, they do no usually have the necessary human resources to allow its use in a regular basis. Plus, for these younger students the hands-on lab usage usually implies either splitting the class or arrange for technical staff for helping in the hands-on experiments. Remote labs allowed these younger students to explore the lab apparatus, assembling circuits and doing some measurements, in a more autonomous way and without the security issues. Besides, the use of ICT in class tends to appeal this generation of digital natives, being for the majority their first contact with a remote lab. In fact, in all the secondary and technological level cases (for which we have data) both students' perceived learnings with VISIR as well as their satisfaction with it, were good $(F 1=F 2=3)$ or very good for the case C7 $(F 1=F 2=4)$. Considering (for the former levels of education) the students' answers to one of the SSQ questions, t Q17: I wish I had remote labs in other subjects, one can infer that students' answers from the lower levels of education was quite enthusiastic: the majority (at least 70\%) to all of them (100\%), depending on the cases, expressed their will (agreement/fully agreement) of using remote labs in other courses, establishing the added value they considered VISIR had. Considering their comments in Q22 open answer, although we do not have that data for the secondary level of education, none of the technological students expressed preference for traditional labs and the third most negative factor they reported was (in ex aequo with other two) "circuits limitation", suggesting their will to further practice with VISIR which somehow may indicate their satisfaction with VISIR. In all cases, teachers' comments about students' engagement and satisfaction with VISIR were quite praiseworthy: they demonstrated curiosity and interest, sometimes extrapolating the requisite in the experimental script, students accepted VISIR very well and were quite enthusiastic about it, students felt motivated and challenged, ...students enjoyed working in the VISIR environment. Although there are many reported cases in the literature considering VISIR usage, including students' satisfaction with the resource, the majority is about VISIR usage in HE courses. There are some works in which VISIR was used in a secondary school in Sweden and its conclusions were also that the students were very satisfied, showing great interest and being engaged in VISIR tasks. Furthermore, at this age, these authors describe that not all students have developed an interest in electric and electronic circuits and VISIR was indeed very useful for those students, even though not all of them fully understood VISIR was real experimental work (Claesson \& Håkansson, 2012; Claesson et al., 2013; Claesson, Nilsson, Zackrisson, Gustavsson, \& Håkansson, 2010). A more recent work, involving several elementary and secondary schools in Brazil, describes a program (InTecEdu), which aim was the integration of digital technologies in education -including virtual and remote labs- and also concluded the students highly valued remote labs. The students expressed satisfaction with it, considering not only its functionality and 
availability, but also its impact in their learning process; it was also concluded remote labs utility was associated with motivation for learning as well as its possible impact in "increasing the attractiveness of STEM careers for students" (Silva, Nardi Silva, \& Biléssimo, 2020).

The number of students enrolled in the course also affects students' VISIR usage as well as their academic performance and perception. As the number of the students enrolled in the course increases their academic performance is better although their VISIR usage and perception is lower. Having the opportunity to discuss with peers (for instance, clarifying doubts) seems to contribute to better academic results. In fact and as already discussed in section 2.4, one important factor to have in account when using these on line resources is the type and level of interaction promoted, as students' performance as well as their satisfaction and engagement are deeply affected by it. It is up to the teacher to foment collaboration and interaction, not only between the students themselves, but also with the teachers and the lab equipment. In fact, students can learn from all the former type of interactions and also by interactions in which they are not direct participants -indirect-interaction (I-I)- considering students' learning by listening and observing other students' interactions between themselves or with the teacher (Lal et al., 2019, 2018; Lowe et al., 2009; Wei et al., 2019). This cooperation and interaction, particularly the S-S and the I-I interactions, may have implications in VISIR usage- they learn from each other and from what they observe in other students' interactions and do not fell so much the need to use itand also in their VISIR perception. Actually, comparing directly similar cases (same level of education, same VISIR use level, etc.) it is clear (Table 17, page 115) that the average number of VISIR accesses per task is lower in cases where the number of enrolled students is higher. VISIR has some constraints, already identified by students in their SSQ open answers -being many students they have the opportunity to share their opinions, and what is a minor issue may be somehow inflated- which may have a negative effect in their perception. On the other hand, and even more important, when the number of students involved is really high (like in case C16: $1^{\text {st }}$ course edition (260); $2^{\text {nd }}$ course edition (182)) and even with a team of four teachers it is really difficult to provide personalized support to all the students enrolled in the course. If the students from this or other cases (involving a high number of students) felt difficulties in working with VISIR, teachers really had a hard time to support all of them and even with their best effort and good will, they may not be able to be successful. In fact, teacher from case C10 commented that in the second course edition, due to his previous experience with VISIR, but also from the lower number of students enrolled in this (second) course edition, he was able to provide a more individual support to students, accordingly to their needs and respecting their own pace. His perception was that students were actually more satisfied in this second course edition, although 
students' actual perception of the resource and this methodology was the same in both course editions.

The number of students in each case presents a wide variability from 8 to 442 students. Additionally, in courses with lower number of students, the majority is repeating the course, and this may, somehow, mislead the results. Nevertheless, the result may point out that a minimum number of students is preferred to assure an interesting dynamic in class and collaborative work between peers (Wood \& O’Malley, 1996).

To further understand if some factors, considering course level and students' background, somehow related to the students' characteristics, had impact on students' results, the statistical tests performed in section 6.2.1, were completed taking into account these factors. In that section, the tests were performed to figure out the impact of students' background in 3 test variables: students' grades (VISIR grade and lab grade) and the number of students' accesses per task (in VISIR). Now, it will be tested the impact of students' background in 2 other test variables: students' perceived learning with VISIR (F1) and students' satisfaction with VISIR. For the factor course level, it will be tested its impact in the 5 test variables. As there are 5 test variables for the first factor and 2 test variables for the second one, there were 9 questions that needed to be answered. The factors to be tested were:

* Course level: EE majors/non-EE (other majors).

* Students' background: VISIR contents worked before: yes/no; students first time to use VISIR: yes/no.

Appendix I contains the results of the tests.

The course level, being an EE major or other major, has no impact on students' perceived learnings (F1) and satisfaction with VISIR (F2) neither with their VISIR grade. Still, it influences students' usage of VISIR: students from EE majors use more VISIR, probably because they are more motivated to the EE topics. The former result -considering the 1794 students enrolled in 26 courses comprising a complexity and variety in contexts, implementation characteristics, students' backgrounds and teachers' profiles- is corroborated by the chi-square test of Q7 distribution of the students' answers with course level (carried out in section 6.2.3). This result allowed to conclude the students' interest in VISIR (measured by showing it to people outside the university) was also not independent of their major: students from EE majors seem to be more interested in VISIR.

Students' background does not have any impact in students' perceived learnings or satisfaction with VISIR. Complementing with Figure 17 results, it is clear students' previous experience with VISIR has a positive impact in their grade in that specific component. 
In some cases, it was possible to have teachers' perception of "students' level", when starting the course, as characterized in Table 16 (page 113). In cases C3, C5 and C11 teachers felt students had some type of difficulty while in cases C8, C9, C14, C16, C19 and C26 teachers' perception was that those students were interested and/or good (adequate prior knowledge and competences). The purpose, now, is to understand if that "level" (difficulties/interest/good) had any impact in students' results (number of VISIR accesses per task, grades, perceived learnings, satisfaction, motivation). For this analysis the data obtained from multiple sources, including the students' satisfaction questionnaires (considering also Q21 and Q22 open answers), the teachers' interviews and also some students' and teachers' informal comments will be used. Considering the cases in which teachers recognized some type of difficulty, the analysis will be carried out by case:

* Case C3: students achieved good results; their average VISIR grade was good (similar to the grades they obtained in the other components), their VISIR usage increased from the first to the second course edition (three simultaneous course editions in three different degrees) and they were satisfied with VISIR (F1 = F2 = 3). Their difficulties were mainly some lack of soft skills and inadequate working habits, that teachers tried to promote proposing (VISIR) group tasks, in which students were supposed to work in pairs and deliver simples reports of each proposed task. As students were finishing the tasks, they were encouraged to help their colleagues from other groups that were still developing their work. All groups included their results in a shared spreadsheet in Google Drive and finally (when all have finished the tasks) the results were then analysed together and discussed in the classroom, within the participation of all students/groups. All groups were able to resolve the tasks (with teacher support to a greater or lesser extent). Accordingly, to the teacher own words the students who regularly participate in classes throughout of the year are the most enthusiastic and those who have the most initiative to work with VISIR and activities. The main difficulty evidenced by the students was the fulfilment in time and form of the reports and the correct elaboration of the reports (shallow depth, difficulties to express their ideas, etc.). Students were enthusiastic about learning in a setting different from the traditional classroom, that generated an exchange of ideas amongst students and were able to achieve good results.

- Case C5: this is a course characterized by a lot of failures and dropouts mainly due to students lack of prior knowledge (mathematics, reasoning organization, problem solving difficulties as well as soft skills). Students achieved good results; their average VISIR grade was really good (much higher than the grades they obtained in the other 
components, probably by the way the teacher graded these tasks; they had $100 \%$ if they delivered the two tasks and 50\% if they just delivered one), their VISIR usage increased from the second to the third course edition (we do not have that data for the first course edition) and they were also satisfied with VISIR (F1 = F2 = 3). Still, several students, considering VISIR system, reported they had "problems in understanding in the beginning"/"problems in understanding". Some of them were able to overcome their difficulties, with the support of monitors that were available to help students during the task execution period. Others did not overcome their difficulties so easily, but looking in detail to their answers, it is clear that their difficulties are mainly in understanding if the circuit is properly assembled (I am not sure if the circuit is well assembled) and difficulties in using the multimeter (in the measurement part, using he multimeter) and probably those difficulties are not really associated with the VISIR system itself, but with circuits topics knowledge. The head teacher considered students accepted very well VISIR and were quite enthusiastic about it. It helped in the insight of measuring electric parameters and after using it, they were more at ease at the hands-on lab, doing less mistakes. According to the head teacher's perception there is a correlation between doing the experiments (including VISIR tasks)/lists with the final mark/approval. The big problem in this discipline is that many students give up, so do not do the experiments nor give the lists. The students who used VISIR were the ones who achieved a higher success. Still, the level of success in the course in quite low.

* Case C11: students start the course with inadequate prior knowledge in instrumentation and teacher considers that some students do not work as hard as they should. Students achieved poor results in the VISIR component; their average VISIR grade was really low $(42,5 \%)$, much lower than the grades they obtained in the other components, their VISIR usage was comparable to other similar courses, but their satisfaction with VISIR was also low (F2 = 2). Although they considered VISIR has some advantages, namely the "potential of the equipment" and "access from anywhere/anytime", this lower value of F2 seems to be associated with several constraints they identified in the VISIR system, as instability and operating issues. Plus, they considered VISIR had a "poor interface/old fashionable/too simple": the instruments used have an old instrumentation appearance... which is bad. Teacher reported the experiments were performed by the students at off-course times, several students procrastinated and ended up not completing the activities in the planned time. The fact the 2 proposed VISIR tasks (in AC), just had 5\% weight to final grade clearly affected students' commitment. Probably, students felt the effort they had to do to 
complete the tasks were not worthwhile considering its benefits, denoting an extrinsic motivation to learning.

In the former cases, teachers proposed simple VISIR tasks to their students (tasks type 1: in DC for the first two cases and in AC in the third one, accordingly to the courses syllabus) that seem to offer interest and motivation to learn and attainable (adequate to their knowledge) to these students that had some difficulties (Biggs \& Tang, 2007; Lopes, Cunha, et al., 2012; Viegas, 2017b; Viegas et al., 2009). The proposed tasks appear also to have provided an appropriate level of cognitive challenge which is important to "reinforce students' learning motivation and confidence" (Chang \& Bell, 2002). In case C3, teachers were able to promote a learning environment that fomented communication and collaboration, giving students more autonomy and responsibility, contributing to the development of soft skills and social competences (Biggs \& Tang, 2007; Felder et al., 2000; Tchoshanov, 2013), which may helped them in their study attitudes (Crede \& Kuncel, 2008). In case C5, the support provided by the monitors, giving students tips in crucial moments, including effective and timely feedback (Hattie \& Timperley, 2007; Viegas et al., 2010) helped them to gain confidence and successfully complete the proposed tasks. In case C11, students' engagement in the VISIR was somehow compromised by its contribution to students' final grade. In the former cases (except in case C11 where no correlations emerged, that is, they were not significative) some negative correlations emerged between F1 and/or F2 with students' grades, suggesting VISIR may be more useful for students with difficulties, which is in accordance with a previous work (Viegas, Pavani, et al., 2018).

Exploring the cases in which teachers recognized students were interested and/or had the adequate prior knowledge when starting the course, and grouping the cases with the same type of students' results:

* Case C14: this is a mandatory $5^{\text {th }}$ semester curricula course representing students first contact with the electronics lab, being characterized by students' frequent failures. Students average VISIR grade was reasonable (similar to their average lab grade), their VISIR usage was higher than other similar courses, but their perception about VISIR was really low $(\mathrm{F} 1=2 ; \mathrm{F} 2=1)$. In this course, students have 10 experimental activities: 7 were developed as a three setup: theory/simulation/hands-on and the last three of the syllabus were performed as a four setup: theory/simulation/VISIR/hands-on. Still, all 10 experiments had an equal contribution to the lab course final grade. Students complained about the extra load of work they had on the last 3 experiments without any measurable gain: their effort did not have an immediate compensation, so they did not feel it, as a learning opportunity. Students identified several constraints in the VISIR 
system (as already referred) related to some instability and also considered its interface was old fashionable, although they seem to be evaluating both the Maxwell and the VISIR system. Teacher commented students felt VISIR did not add any functionality that the hands-on lab did not have. In fact, these students could go to the hands-on lab whenever they need, as the lab is open during all day and with technical staff to support students' in their work.

* Case C16: this course has the highest number of enrolled students (in both course editions). Students' average VISIR grade was good (although a little lower than the lab grade), their VISIR usage decreased a little in the second course edition, their perceived learnings with VISIR are good (F1 = 3), although their satisfaction with the tool is not so good (F2 = 2 ( $1^{\text {st }}$ course edition) $; F 2=2.5$ ( $2^{\text {nd }}$ course edition $)$ ). In fact, analysing Q22 open answer from the SSQ, the two mots referred factors reported by students were "problems in understanding at the beginning"/"problems in understanding" and "insufficient preparation from classes"/ "insufficient material support". Again, students seem to consider not only the VISIR system, but also the Maxwell system (VISIR and all its resources, including support material and guides, were integrated in the Maxwell system). Still, from the first to the second course edition, there were less students reporting the former factors and indeed their satisfaction with the tool increased. Although these students also have easy access to hands-on labs, the experiences they performed with VISIR were not available in the hands-on lab and the head teacher considered students' immediate perception was that VISIR was an advantage as allowed students to practice in a different and simple way.

* Cases C9 and C26: students achieved good results; their average VISIR grade was really good in case C9 and good in case C26 (in both cases, higher than the grades they obtained in the other components), their VISIR usage increased from the first to the subsequent course editions in case C26 (mainly as a result of the modifications the teacher made in the subsequent course editions) and students were satisfied with VISIR (F1 = F2 =3). In case C9, students' negative comments about VISIR are exclusively related to "operating issues" and in case C26 the most referred factors are also related to VISIR instability. In both cases teachers' comments are highly positive: the students were highly committed and motivated (with VISIR) (case C9) and the students realized VISIR was an advantage allowing them to increase their practice although some did not really understand VISIR is a remote lab (case C26).

* Cases C8 and C19: these very different courses have undergone three course editions. In both cases (and in all three editions) students achieved good results; their average 
VISIR grade was really good (in both cases, higher than the grades they obtained in the other components, although students from case C19 achieved really high final grades); their VISIR usage increased from the first to the subsequent course editions and although students were satisfied with VISIR (F1 = F2 = 3) in the first two course editions, their satisfaction lowered in the third course edition, for both cases (F1 = 2.5; F2 = 2 (C8); F1 = F2 = 2 (C19)). In both cases and in all course editions some students reported "operating issues". Curiously and also for both cases in the first two course editions, the most referred negative factors were "problems in understanding at the beginning"/"problems in understanding", but with some support they managed to overcome it. In the third course edition of case C8, these factors were not reported at all and the 10 students who answered Q22 (a big decrease from the first two editions, in which respectively 19 and 34 students answered it) reported "insufficient material support". In case C19, something similar happened: the number of students who reported "problems in understanding at the beginning" /"problems in understanding" decreased a lot (to the $3^{\text {rd }}$ course implementation edition), but some students also reported "insufficient material support" and at a significative minor extent problems connecting to the Internet. In the third course edition of both cases, several students considered they did not have the appropriate support to develop their work with VISIR. They managed to get through it -their number of VISIR accesses per task (to equivalent tasks) increased- but probably the really demanded work asked to the students (Lopes, Cravino, et al., 2008; Lopes, Viegas, et al., 2010) was different from the first two course editions. The former results may also suggest that, in these cases, teachers may have lost some of its initial enthusiasm (with VISIR); in fact, these type of activities are time consuming, especially in the first course edition, but also in the subsequent ones, to provide adequate and individualized support to students. Besides, in case C8 teacher reported (in the three course editions) the performance of the remote lab was unstable at times, which after some time may compromise teacher's motivation (on using VISIR) that typically has a reflection in students.

The overall results of the former cases are summarized in Table 41, in which grades in other components include the lab grade and/or the grades obtained in the other tasks. 
Table 41 - "Students' Level" (According to Teachers' Perception) and Students' Academic Performance

\begin{tabular}{|c|c|c|c|}
\hline \multirow{2}{*}{\multicolumn{2}{|c|}{ Students' Results }} & \multicolumn{2}{|r|}{ Cases ("Students' Level") } \\
\hline & & \multirow{2}{*}{$\begin{array}{l}\text { Difficulties } \\
\mathrm{C} 11\end{array}$} & \multirow{2}{*}{$\begin{array}{l}\text { Interested and/or Good } \\
\mathrm{C} 9, \mathrm{C} 14, \mathrm{C} 16\end{array}$} \\
\hline Number of VISIR & Adequate & & \\
\hline accesses $/$ task & Increased & $\mathrm{C} 3, \mathrm{C} 5$ & $\mathrm{C} 8, \mathrm{C} 19, \mathrm{C} 26$ \\
\hline \multirow{3}{*}{ VISIR grade } & $<$ grades other components & $\mathrm{C} 11$ & $\mathrm{C} 14, \mathrm{C} 16$ \\
\hline & $\approx$ grades other components & $\mathrm{C} 3$ & \\
\hline & $>$ grades other components & $\mathrm{C} 5$ & $\mathrm{C} 8, \mathrm{C} 9, \mathrm{C} 19, \mathrm{C} 26$ \\
\hline \multirow{2}{*}{$\begin{array}{l}\text { Perceived } \\
\text { Learnings (F1) }\end{array}$} & $\mathrm{F} 1=3$ & $\mathrm{C} 3, \mathrm{C} 5, \mathrm{C} 11$ & $\mathrm{C} 8\left(1^{\text {st }}, 2^{\text {nd }}\right), \mathrm{C} 9, \mathrm{C} 16, \mathrm{C} 19\left(1^{\text {st }}, 2^{\text {nd }}\right), \mathrm{C} 26$ \\
\hline & $\mathrm{F} 1<3$ & & $\mathrm{C} 8\left(3^{\mathrm{rd}}\right), \mathrm{C} 14, \mathrm{C} 19\left(3^{\mathrm{rd}}\right)$ \\
\hline \multirow{2}{*}{$\begin{array}{l}\text { Satisfaction with } \\
\text { VISIR (F2) }\end{array}$} & $\mathrm{F} 2=3$ & $\mathrm{C} 3, \mathrm{C} 5$ & $\mathrm{C} 8\left(1^{\text {st }}, 2^{\text {nd }}\right), C 9, C 19\left(1^{\text {st }}, 2^{\text {nd }}\right), C 26$ \\
\hline & $\mathrm{F} 2<3$ & $\mathrm{C} 11$ & $\mathrm{C} 8\left(3^{\mathrm{rd}}\right), \mathrm{C} 14, \mathrm{C} 16, \mathrm{C} 19\left(3^{\mathrm{rd}}\right)$ \\
\hline
\end{tabular}

It is clear, from the results expressed in Table 41, that the "students' level" when starting the course does not define, per se, students' academic path nor their academic performance.

Considering the correlations that have emerged, for the former cases, referred in section 6.2 (and detailed in Appendix $\mathbf{H}$ ), for all the cases (except case C3) for which it was possible to run the procedure it stood out some correlations between students' VISIR usage and their grades, except in case C11. Still, nor students' usage nor their VISIR grade were correlated with students' perceived learnings (F1) and/or students' satisfaction with VISIR (F2) (considering the correlation between VISIR grade with F1 and F2, there were some minor exceptions). Still, the former results suggest that students' general contentment with VISIR is not dependent of the time and effort devoted to the tool (for instances, in the $3^{\text {rd }}$ course edition of cases C8 and C19, the number of students' VISIR accesses per task increased and their satisfaction decreased), that can be different depending on "students' level", but as already pointed out in this work, it seems highly dependent on external factors, namely teachers' ability to promote students' motivation, the tasks weight contribution to students' final grade and/or being mandatory to pass the course.

In the section 6.2.3, it was analysed the distribution of the answers to the questions $\mathbf{Q 7}$ and Q11 (from the SSQ), respectively I showed VISIR experiments to people outside University and I always shared experimental results with my peers as they somehow are associated with students' characteristics. Now, the goal is to figure out if there is any association between the former variables (students answers to Q7 and Q11) with the number of students who developed HOS as well as students' VISIR usage and their perception of the tool (F1 and F2). The correlations between the variables are summarized in Table 42 . 
Table 42 - Correlation between Q7 and Q11 Answers Distribution with Students' Results

\begin{tabular}{|c|c|c|c|c|}
\cline { 2 - 5 } \multicolumn{1}{c|}{} & $\begin{array}{c}\text { Number of } \\
\text { students HOS }\end{array}$ & $\begin{array}{c}\text { Number of } \\
\text { accesses/task }\end{array}$ & $\mathrm{F} 1$ & $\mathrm{~F} 2$ \\
\hline $\begin{array}{c}\text { Q7 students answers } \\
\text { distribution }\end{array}$ & n. s. & $\begin{array}{c}\mathrm{R}_{\mathrm{SP}}=0.179^{* *} \\
(\mathrm{p}=0.001) \\
\mathrm{N}=659\end{array}$ & $\begin{array}{c}\mathrm{R}_{\mathrm{P}}=0.145^{* *} \\
(\mathrm{p}<0.001) \\
\mathrm{N}=919\end{array}$ & $\begin{array}{c}\mathrm{R}_{\mathrm{P}}=0,265^{* *} \\
(\mathrm{p}<0.001) \\
\mathrm{N}=919\end{array}$ \\
\hline $\begin{array}{c}\text { Q11 students answers } \\
\text { distribution }\end{array}$ & n. s. & $\begin{array}{c}\mathrm{R}_{\mathrm{SP}}=0.126^{* *} \\
(\mathrm{p}=0.001) \\
\mathrm{N}=656\end{array}$ & $\begin{array}{c}\mathrm{R}_{\mathrm{P}}=0.160^{* *} \\
(\mathrm{p}<0.001) \\
\mathrm{N}=919\end{array}$ & $\begin{array}{c}\mathrm{R}_{\mathrm{P}}=0,139^{* *} \\
(\mathrm{p}<0.001) \\
\mathrm{N}=919\end{array}$ \\
\hline
\end{tabular}

Accordingly to the results illustrated in Table 42, the more students feel enthusiastic with VISIR as well as the more they shared the experimental results with their peers, fomenting discussion and reflection (Artino, 2008; Biggs \& Tang, 2007), the more they use VISIR and the higher is their perception about their perceived learnings (F1) as well as their satisfaction with VISIR (F2). The students who answered 3 or 4 to the previous questions are the students that feel pleasure in learning and usually get easily engaged in the proposed tasks (Biggs \& Tang, 2007). It is perceptible in the previous results that the correlations involving Q7 reached a higher value with F2, denoting precisely students' enthusiasm and satisfaction with VISIR; the correlations involving Q11 reached a higher value with F1, suggesting that peer collaboration really enhances students' (perceived) learning. So, students' interest in VISIR and will to work with their peers contributes to increase students' engagement.

\subsubsection{Synthesis of the Results Obtained in Students' Characteristics and Students' Results}

In this section we focused on the fourth research question (RQ4) "Are there students' characteristics that can be associated to students' learning and engagement?". Still, learning is a continuous and complex social process and teacher has a crucial role in this process and it is up to him create learning environments -based on a positive culture of success- that encourage students to be productive engaged in the courses and perform the proposed tasks (Biggs \& Tang, 2007). A constructive aligned teaching and learning environment system, in which the teachers can assist students "learn how to learn" (Novak, 2002), can help students to overcome their difficulties, contributing to increase students' responsibility and autonomy and the development of scientific and social competences (Biggs \& Tang, 2007).

In this section, it was clarified how some students' characteristics associated with these 1794 students' different contexts, giving a special emphasis to "students' level" -a set of general 
characteristics, accordingly to teachers' perception, students possessed when starting that particular course- impacted in their learning and engagement. For that, the collected data from various sources was analysed using several statistical techniques, not only quantitative but also qualitative analysis techniques. The qualitative analysis techniques were mainly used in the students' satisfaction questionnaires opens answers, the teachers' interviews as well as some teachers' and students' informal comments. This process of triangulation allowed us to move towards reliable conclusions.

Hence, considering the fourth research question addressed in this work, we can state that "students' level" (adequate prior knowledge or some type of difficulty) when starting the course, per se, does not determine students' learning outcomes and engagement. Still, teachers must take into account the "students' level" characterization while planning a didactical implementation to those courses, if they want to be successful. Some aspects, including: propose (to students) tasks that provide interest and motivation and have a contribution to their final grade while supporting students work in crucial moments, giving them more responsibility and autonomy and providing effective and timely feedback, should be considered, as they may promote students' success and engagement

This work allowed to support on empirical data several statements considering the fourth research question, tackled in this section:

Students' perceived learnings with VISIR do not depend on their "education level". On the other hand, their satisfaction with VISIR is. The students from the lower levels of education, the majority not used to this type of resources, are clearly more satisfied with VISIR and its potentialities (and even not noticing so much some of the VISIR constraints).

$\checkmark \quad$ The "number of students" enrolled in the course and the interaction and cooperation established amongst them has a positive impact in their academic performance. Still, that social learning environment associated with the lower level of individualized support teachers can provide when the number of students achieves high values seems to lower students' perception of the tool.

$\checkmark \quad$ The "course level" (EE majors/ non-EE (other majors)) has no influence on students' perception of VISIR -both F1 and F2- nor in their grades in the VISIR component. Still, it has a significant influence on students' VISIR usage. These more interested and proficient students in these topics tend to use more VISIR.

$\checkmark \quad$ "Students' background" (previously addressed topics, first time with VISIR) does not have any influence in students' perceived learnings or satisfaction with VISIR. Still, the 
students' previous experience with VISIR has a positive impact in their performance in that particular component.

$\checkmark \quad$ The more enthusiastic and reflective students are (sharing results with their peer and fomenting discussion) the more they tend to use VISIR, achieving a higher perception of their learning with the tool and being more satisfied with it.

Students' VISIR usage and satisfaction with the tool is still highly dependent of external factors, with a special focus on teachers' ability to promote students' motivation and enthusiasm, which naturally contributes to higher levels of engagement. 



\section{Overview OF The STUDy, Conclusions, Limitations AND FUTURE DiRECTIONS}

The previous chapters have in-depth described the trials that have been used to ascertain the
problematic tackled in this PhD project: better understand how the use of simultaneous experimental didactical resources can foster student' learning outcomes. This methodology aimed to identify factors that affect students' learning in the electric and electronic circuits topic. This closure chapter draws upon these trials to answer, in the most possible complete way, to the four pursued research questions (RQs) addressed in this thesis. The existing gap in the literature, considering this thematic, was the driving force beneath this research project which aim was to contribute to the knowledge development in this area. This chapter starts by an overview of the study and its main outcomes, that is, the answers to the four presented research questions. Although considering this work shed light on research about the influence simultaneous use of experimental resources have on students' (academic) results, it also presents some limitations and problems which will be detailed. Finally, the future directions for research in this area, considering the former limitations in this study and some recommendations based on the results, are presented

\subsection{Overview of the Study}

The aim of this doctoral thesis was to contribute to fill a gap in the literature considering the impact that a simultaneous experimental resources usage -in experimental learning- has on students' academic results. Based upon a specific remote lab in the electric and electronic circuits topic, VISIR, the goal was to identify contributing factors to students' improvements on learning and engagement. Taking into account the importance of the overall learning context, it was intended to identify common traces in "experimental resources combination", "VISIR tasks characteristics", "teacher mediation traces", considering the eventual effect of some "students' characteristics", that produced (or not) better students' results. Each of the former features (having the use of VISIR as a common ground) and its relation to students' learning and engagement was addressed by a set of four complementary research questions (RQs):

\footnotetext{
* RQ1: In which way the use of simultaneous resources (hands-on, simulation and remote labs along with calculus), contributes to promote students' learning and engagement?
} 


\section{* RQ2: Are there VISIR tasks characteristics that affect students' learning and engagement?}

\section{* RQ3: Are there teacher mediation traces that can be linked to better students' learning and engagement?}
* RQ4: Are there students' characteristics that can be associated to students' learning and engagement?

To address these RQs, a large-scale thoroughly analysis was conducted, involving 43 didactical implementations that took place in 26 different courses, in 14 institutions from several education levels (secondary, technological and higher education) involving 52 different teachers and 1794 students. Several data sources and analyses techniques were used converging in a process of triangulation -contributing to the results validity and acceptability- to achieve to reliable conclusions.

The answers to the former research questions and the main conclusions derived from it will be detailed in the next section.

In the following paragraphs some remarks will be made, considering two aspects that were important in this study: the $\mathrm{PhD}$ student dual role as a Teacher-Researcher (TR) and the importance of the teachers' reflection upon the modifications made in the subsequent course implementation editions.

The dual role of the PhD student -researcher and one of the teachers (TR) involved in one of the didactical implementations (case C26, with 3 editions)- was not planned in the beginning of this project, but became an asset value. One of her courses, since 2016/17, started to include in its syllabus an electricity and circuits module and she immediately took advantage of it and planned a didactical implementation, following the VISIR+ Project premises, using VISIR and hands-on labs. The TR was responsible for all types of classes, being the only teacher in the "Applied Physics" course, which simplified the process of rapidly moving to this methodology (Lima et al., 2019a). Being involved in the didactical implementations, not only as a member of the Project research team, but also as a teacher using the prosed methodology, was a great advantage: she sensed the problems and constraints that, in a general way, the other teachers felt and was able to interact with some of them at a different level, sometimes even giving hints and clues from her own experience. She was more alert and able to help which was also important in the data collection phase and the informal contacts established.

The importance of the teachers' reflection upon their practices and progress is widely reported in the literature, being considered as a key aspect in teachers' professional development. The former process can have a big impact in the teaching process itself and also in students' learning (Núñez Pardo et al., 2006; Ramsden, 1987). In fact, in this study -in the courses that have 
undergone several course implementation editions- it is clear that the teachers' reflection upon their practice and experience with VISIR helped each one into more well planned VISIR tasks and better aligned with the level of competence they pursued. It also helped them in making some other minor adjustments, considering several aspects such as: the other experimental resources used, the assessment strategy and also in the increment of VISIR usage in course contents. Indeed, one of the determinant teacher mediation traces identified (RQ3) as potentiating students' VISIR usage was teachers' experience with VISIR (T1a).

\subsection{General Conclusions}

The first RQ goal was to perceive in which way the use of this methodology -simultaneous experimental resources along with calculus- affected students' learning and engagement. Several factors were studied, including the way VISIR was introduced to the students, teachers support provided during the semester (presential, email and/or by uploading support material), the different combinations of experimental resources (VISIR + simulation; VISIR + hands-on; VISIR + simulation + hands-on) along with calculus, including the number of hands-on tasks, a particular focus on how VISIR and hands-on labs were combined (VISIR used before and/or after hands-on labs, with a set of similar or different experimental activities) and study its repercussion on students' results. The first main lesson learned from the former study is that the use of several experimental resources (along with calculus), per se, does not seem to have a direct impact on students' grades. Still there is clearly an association between its usage and the development of higher order skills and students' satisfaction.

Based upon empirical data, this study allowed to support the succeeding knowledge statements that are considered answers to RQ1: "In which way the use of simultaneous resources (hands-on, simulation and remote labs along with calculus), contributes to promote students' learning and engagement?"

$\checkmark \quad$ Teacher's support plays a crucial role in students' engagement and performance. It is important the teachers prepare an introductory activity, supplemented as possible by some type of support material, to introduce VISIR remote lab, giving students time to overcome their eventual initial difficulties and develop their ability to work with the new tool. This activity is also important to stimulate students' enthusiasm and their perception of this type of resources utility. During the task execution period this support is equally important: teachers must guide students with minimum supervision, providing the necessary clues to help them overcome their difficulties (e.g. use email to 
answer students doubts), while compelling them to solve, as autonomously as possible, the proposed tasks.

$\checkmark \quad$ The order in which VISIR is incorporated on a course, that is the sequence of hands-on labs and remote labs in the experimental learning procedure, per se, seems to have no effect in students' learning and engagement, that is there is no right way of doing it. This sequence should be determined by the teacher, taking into account the set-up learning goals and their students' background. However, for introductory courses, if the teacher goal is mainly to develop experimental competences and allow students to be more autonomous and at ease in the hands-on lab, introducing VISIR first, seems to be a good tactic as students' confidence in lab may really increase. The former strategy was found adequate to courses in which students have their first contact with EE topics where VISR use level is basic.

$\checkmark$ Regarding the number of different experimental resources teachers should use simultaneously, there should be an evenly distributed balance, as they complement each other, allowing students to develop experimental skills in different ways. When available students prefer to use hands-on lab than other alternatives, tending to use less VISIR in that circumstances.

$\checkmark \quad$ Students' VISIR usage is more dependent on external factors than students' satisfaction with the tool and/or their perception of its utility in their learning process. This is so for the majority of the students, regardless their acknowledgement of VISIR added value in their learning process. If teachers are comfortable with this type of methodology -which contributes to students' learning and engagement- they tend to find adequate strategies to compel students to use it more and for a longer period of time.

$\checkmark \quad$ In terms of context of usage, this type of methodology was also found perfectly adequate for courses that do not have an experimental component, or for courses which contents are not directly related to the topics covered by the experimental resources (in this case, EE topics), such as mathematics courses. With some degree of imagination this type of methodology can be applied to several mathematics courses, with the purpose of contextualizing theoretical concepts that can be applied to real-life, day to day situations. This type of tasks enriches the setup of favourable learning environments, and if well aligned with the learning goals, not only contributes to motivate students but also to involve them as active participants in their own knowledge towards deep learning and contributes to their academic engineering profile development. 
The second RQ addressed the didactical implementations characteristics intrinsically associated with the proposed VISIR tasks characteristics, including competence goal level, VISIR tasks attributes (type of tasks, DC/AC), number of VISIR tasks, VISIR use level and VISIR contribution (quantitative (\%) or qualitative) to students' final grade and the influence of the former factors on students' learning and engagement. It was also considered the influence of the tasks regime (individual/group; mandatory/not mandatory) on students' results. From this study, it is clear that the course design characteristics intrinsically associated with the level of competence (addressed on VISIR tasks) -VISIR competence goal level, VISIR tasks attributes (T1, T2, T3; DC/AC), VISIR use level- have basically no influence in students' perception of their learning with the tool (F1) and very little influence on their satisfaction with it (F2), but have a great influence on students' VISIR usage and their VISIR and lab performance. As the contents addressed are more complex, students increase their VISIR usage, although they tend to achieve lower grades. On the other hand, the tasks being developed in groups and the VISIR component having a qualitative weight to students' final grade have a positive influence both in F1 (students' perceived learnings) and F2 (students' satisfaction with VISIR).

This study allowed to support on empirical data several knowledge statements that are considered answers to the former research question (RQ2): "Are there VISIR tasks characteristics that affect students' learning and engagement?"

$\checkmark \quad$ The proposed VISIR tasks should be perfectly aligned with the intended learning outcomes (ILO) teachers defined (when designing the didactical implementation) and the type/level of competence they expected students to develop. Students' comprehension of the ILO clearly potentiates their engagement and ultimately their learning.

$\checkmark \quad$ The VISIR tasks should vary in content and be diversified, involving (if possible) the comparison and analysis of the data obtained with other experimental resources and/or the theoretical calculations, as these type of analysis and comparisons allows the enhancement of deep knowledge and higher-level competences development.

$\checkmark \quad$ The type of assessment -VISIR tasks contribution to final grade and/or the tasks being mandatory to pass the course- has a major influence in the students' involvement and learning. In fact, most students tend to not fulfil the tasks if they do not see immediate results to their effort, as the majority have an extrinsic motivation to learn. The qualitative assessment -which, at least in some cases, included some pertinent comments about students' performance- had a positive effect in students' involvement as well as in their perceived learnings and their satisfaction with VISIR. 
$\checkmark$ Tasks that promote collaborative work -interaction and discussion with peers- are valued by students, contributing not only to the development of fundamental soft skills, but also enhance students' learning and satisfaction.

$\checkmark \quad$ VISIR and this methodology are as useful for introductory courses as for more advanced ones, as long as the didactical implementations are planned accordingly to the type of course and students' background. Both in introductory and more advanced courses VISIR has a positive impact in students' involvement and learning, even though their grades (VISIR and lab) tend to be lower when the addressed topics are more complex.

RQ3 studied the relationship between several teacher mediation traces (identified in Table 27, page 153) and possible consequences in students' learning, involvement and satisfaction. It also tried to apprehend if all the former identified mediation traces had the same impact on students' results or if some were more determinant than others. As previously described, it was not possible to obtain information for about $40 \%$ of the cases and even some of the remaining $60 \%$ the data is incomplete. Although we believe that in the other cases, teachers implemented, at least, some of the mediation traces, this constrain does not allow an answer to this question as complete as we expected (at the beginning of this study). Still, although it became clear from the former study that not all the teachers are equally sensitive to mediation, it was also perceived that with time, experience and support by other teachers, they can gain knowledge about it. In fact, this study also supported that the teachers who have more experience with VISIR and this methodology were more sensitive to the identified (teacher) mediation characteristics/traces, in some cases making an effort to be even more alert in subsequent course implementation editions. Furthermore, when the teacher mediation was able to address all the identified characteristics (incorporating the majority of the mediation traces), the students tend to achieve better academic results (both better grades, greater VISIR usage and better perception of the remote lab). Finally, there are some mediation traces that seem more dominant than others in terms of affecting students' results as identified in Figure 24 (page 225).

This study allowed to identify some teacher mediation patterns that could be linked to better students' results, supporting on empirical data an answer to RQ3: "Are there teacher mediation traces that can be linked to better students' learning and engagement?"

$\checkmark \quad$ Teachers' experience/familiarization with VISIR (T1a) clearly influences students' VISIR usage. The teacher's familiarization with the tool seems to call students attention for the resource usage utility in their learning process. Still, it affects neither their learning perception with VISIR nor their satisfaction with the tool. 
$\checkmark$ Teachers' VISIR own usage (related to (T1c)) clearly affects students' own usage in several ways: (i) when teachers use VISIR a lot, probably over supporting students, the students do not feel the need to use it so much; (ii) when teachers do not use VISIR so much and probably do not support students as they "need", the students are compelled to use it more to overcome their difficulties; (iii) if teachers only give support to students in crucial moments (T4b) students' VISIR usage is accordingly their perceived learning needs, to develop the task.

$\checkmark \quad$ Students being enrolled in a course in which they have the opportunity to interact with different teachers (T1b) has a positive impact in their learning (higher grades both in VISIR tasks and the lab component), however their satisfaction with VISIR may sometimes be compromised.

$\checkmark$ Teachers, in general, valued the remote lab, (T1d) understanding VISIR potentiality for learning. Teachers' satisfaction with VISIR is not dependent of any of the studied context factors, except the education level: their satisfaction with the tool is higher for higher levels of education. Still, when the teachers were not so enthusiastic with the resource (by some reason), that feeling somehow was sensed by the students, affecting students' learning and/or engagement.

$\checkmark$ Teacher's perception (from their experience with VISIR) is that this remote lab seems to be more useful for the students still struggling with difficulties than the more proficient students. Students' results corroborate that fact: the VISIR target public seems to be the students that require more support in their learning.

The last RQ tried to figure out the eventual impact of several students' characteristics -while using this methodology of several experimental resources- on students' academic performance and engagement. We tried to realize which students' characteristics (including education level, type of course (EE majors/ non-EE (other majors)), students' background and some others that could be apprehended by some students answers to some questions included in the SSQ) promoted their learning and/or engagement. We also considered how teachers should take into account "students' level" -teachers' perception of some students' characteristics when initiating a specific course- if they wanted students to have success (naturally without diminishing the rigor and/or doing students job). From the previous study, we can start by state that the "students' level" (adequate prior knowledge or some type of difficulty) when starting the course, per se, does not determine students' learning outcomes and engagement, as long as teachers plan a didactical implementation that takes into account the "students' level" characterization. 
So, answering the last research question "Are there students' characteristics that can be associated to students' learning and engagement?", we can state that:

$\checkmark \quad$ Students' perceived learnings with VISIR does not depend on their education level. On the other hand, their satisfaction with VISIR is. The students from the lower levels of education, the majority not used to this type of resources, are clearly more satisfied with VISIR and its potentialities (and even not noticing so much some of the VISIR constraints).

$\checkmark \quad$ The number of the students enrolled in the course and the interaction and cooperation established amongst them have a positive impact in their academic performance. Still, that social learning environment associated with the lower level of individualized support teachers can provide when the number of the students achieves high values seems to lower students' perception of the tool.

$\checkmark \quad$ The course level (EE majors/ non-EE (other majors)) does not have influence in students' perception of VISIR -both F1 and F2- nor in their grades in the VISIR component. Still, it has a significant influence on students' VISIR usage. These more interested and proficient students in these topics tend to use VISIR more.

$\checkmark \quad$ Students' background (previously addressed topics, first time with VISIR) does not have any influence in students' perceived learnings or satisfaction with VISIR. Still, students' previous experience with VISIR has a positive impact in their performance in that particular component.

$\checkmark \quad$ The more enthusiastic and reflective the students are (sharing results with their peer and fomenting discussion) the more they tend to use VISIR, achieving a higher perception of their learning with the tool and being more satisfied with it.

$\checkmark$ Students' VISIR usage and satisfaction with the tool are still highly dependent of external factors, with a particular focus on teachers' ability to promote students' motivation and enthusiasm, which naturally contributes to higher levels of engagement.

The majority of the statements that constitute answers to our four research questions are in accordance with previous studies, although this work has also several original contributions, conducing to the advancement of knowledge, which lead us to formulate new knowledge statements. The former statements were included in the RQs' answers and are now summarized in Figure 25. 


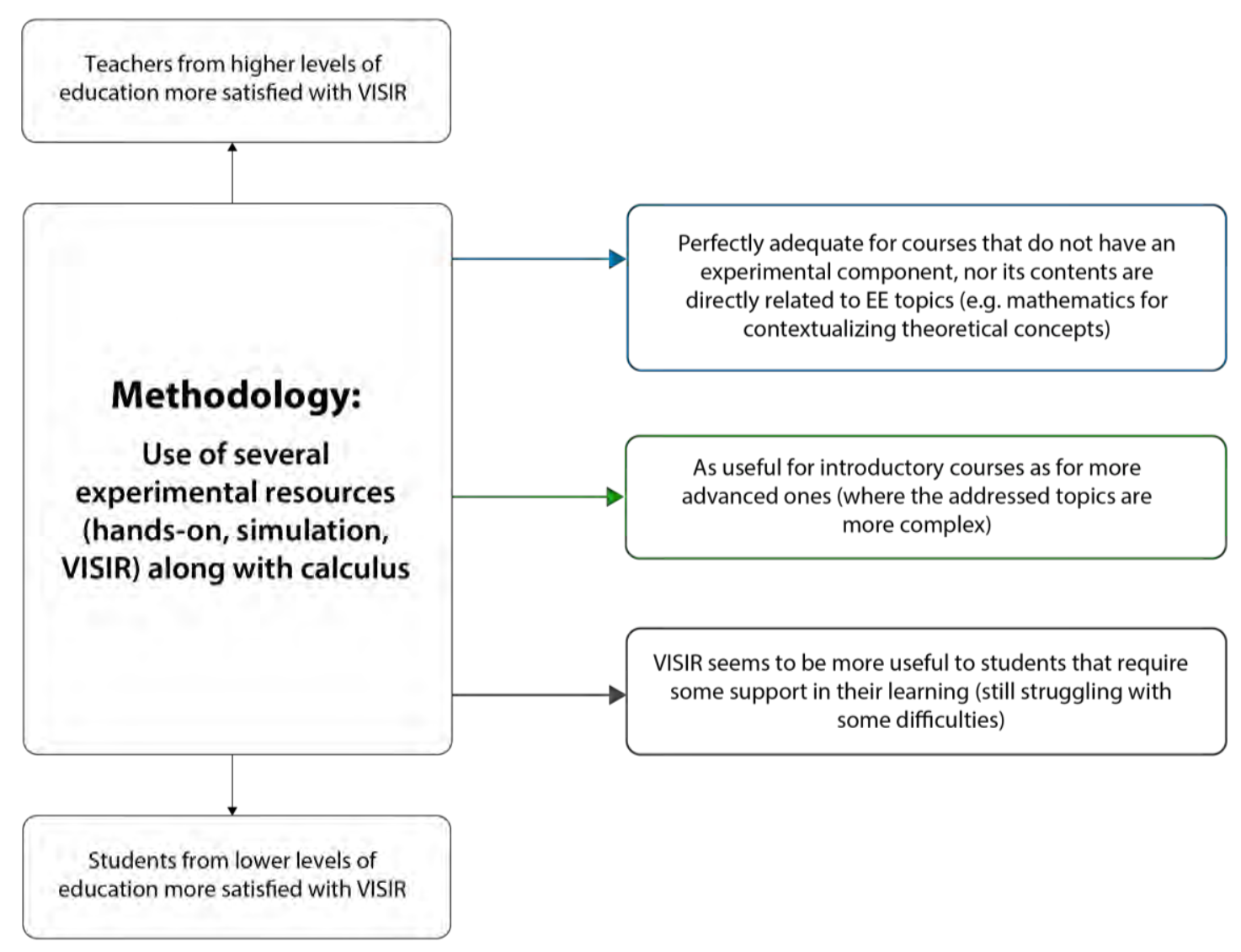

Figure 25 - Contributions to the Advancement of Knowledge

Each of the former RQ allowed to identify some factors that affect students' learning and engagement. But considering the answers to each RQ, on its own, is impoverishing. To promote (the most) students' success and engagement, we have to think in each of the field of inquiry addressed by each RQ and consider it all together when designing and planning a didactical implementation based upon this methodology, contributing to a system of best experimental practices. Taking into account the former results, and as a final conclusion, a set of suggestions/advices -as possible best course of action- to take the most of a didactical implementation (supported by VISIR and based upon this methodology), to promote students' academic results and engagement, is detailed in Figure 26. The last box in the bottom of the referred figure summarizes a set of students' characteristics, identified in this work, as affecting students' results, considering this methodology. 


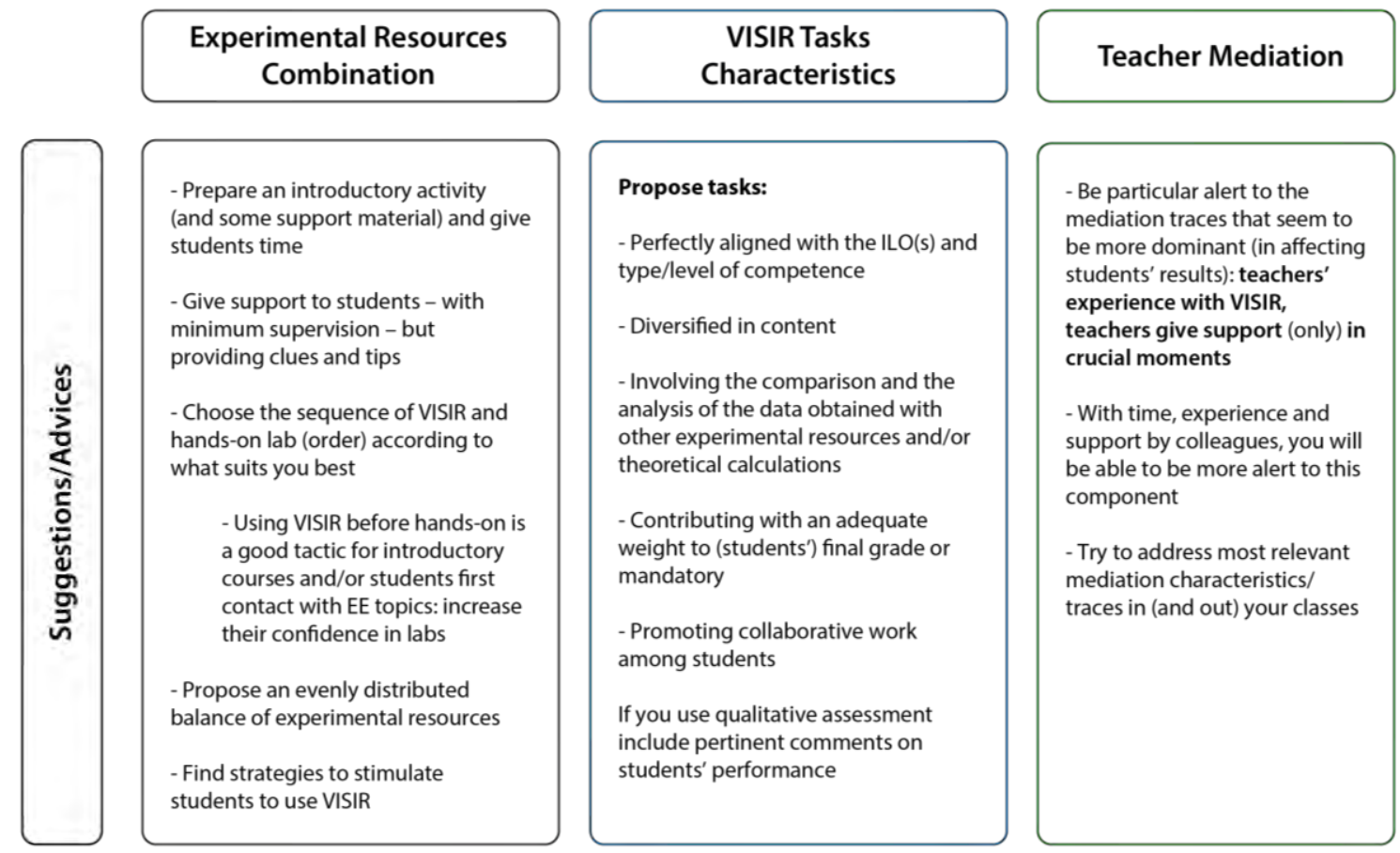

Students' Characteristics: Education level, course level, students background (partially), some psychological characteristics (enthusiasm, reflection)

Figure 26 - Recommendations for a System of Best Experimental Practices

Furthermore, there are two more important recommendations for teachers that intend and/or plan to use VISIR in their courses: (i) teachers may consider to start (as the first action) with a simple activity, involving the three experimental resources as a way to students better understand these differences/resemblances. This type of activity would be particularly pertinent for students working with these topics and/or resources for the first time, allowing them the possibility of exploring by themselves -with teachers' support- the varied type of data/results and their signification. Understanding this difference is crucial, so the students get the most benefits of working with simultaneous experimental resources; (ii) at least, during the period students are using VISIR to perform the assigned tasks, teachers (or technicians) should frequently try the circuits students are supposed to assemble, to guarantee everything is working correctly. Similarly, they should be alert to the students' comments about eventual problems with the system and solve them the fastest possible to prevent other students of experiencing it and prevent students' frustration and dropouts. 


\subsection{Problems and Limitations of the Work}

As every PhD work, this study has several limitations that should be considered in future research works about this thematic. The former constraints will be outlined in the next paragraphs, for amendment in future works.

The first, relates to the three factors of analysis considered: F1 (Students' perceived learnings), F2 (Students' satisfaction with VISIR) and F3 (Students' satisfaction with support). Considering the 26 cases comprising this study, the majority of the cases showed internal consistency in F1 and F2, but, also for the majority, F3 was not reliable (Cronbach alpha < 0.5). For this reason, for most cases, F1 and F2 could be considered and F3 was only qualitatively analysed. This type of result (unacceptable reliability for F3) was also obtained when the overall students' results were considered and also when the results were clustered by several topics (except in the mathematics implementation topic). Naturally, this has influenced -and in some cases not allowed- several subsequent analyses. So, in future research the factor F3 should be rethought and eventually add additional items to it -as this factor was measured considering only 4 student's satisfaction questionnaire (SSQ) questions- to improve its internal consistency.

Secondly, our sample was really large -43 didactical implementations (in 26 different courses) in 14 different educational institutions in three countries, involving 52 teachers and 1794 students- and the amount of data teachers had to collect, and deliver was massive. This choice was justified by its strength to deal with several data sources (triangulation) contributing to the results validity and acceptability. Even though this allowed for a very rich set of data, including data from students from diverse contexts, backgrounds and levels of prior knowledge as well as teachers with different years of teaching experience, professional background, scientific expertise and personal beliefs, it was really difficult to involve all the teachers in the same way. As result, it was not possible to collect all the required data for all implementations -despite our efforts and repeated contacts- being those missing data issues different from one implementation to the next, which compromised several posterior analyses. Besides, the type of data collected was conditioned by the Project premises and goals, which were clearly different from the goals of this study. Although it was made an effort to overcome some issues, this was not fully achieved. We really could not find a solution for the former problem.

Thirdly, although it was considered students from three different education levels (secondary, technological and higher education), the samples from each level were quite heterogeneous, respectively 211, 222 and 1361 students. If the samples were more homogeneous, expressly considering the lack of data there is in some cases, maybe we could go a step further in some analyses. 
Fourth, although in the scope of the VISIR+ Project, it was developed a set of tools for collecting data and it was also used other instruments including documents as well as students and teachers informal contacts and observations, none of the former instruments was designed to gather evidence about teacher implemented mediation in class. So, that undermined obtaining a complete set of data about the implemented teacher mediation in each course, and we could just get (partial) data for about $60 \%$ of the cases. These kind of data from the inside of class is really difficult to obtain, since it can only be shared by the teacher himself or by an observer of the class. Obviously, that conditioned the total scope RQ3 could have addressed. But even with this limitation, our goal to establish relationships between teacher mediation traces and possible consequences for students' learning, their involvement and satisfaction, was assumed still interesting to pursue.

\subsection{Future Directions}

Considering the limitations described in the previous section four aspects to incorporate in future research arise immediately.

It would be interesting to also add students from lower levels of education to the sample, (the basic level, which for the majority of the school systems, these topics are first approached) using more homogenous (numerical) samples from the four levels of education. In fact, these younger students high value ICT, like remote labs and possibly this may have any impact in increasing the students' interest for STEM courses.

As VISIR is, by now, installed and widely used in 11 countries, it would be interesting to extend the former methodology and data analysis to students from the other 8 countries. This way, the results of this thesis work could be generalized in terms of demographics.

There were two courses (in this study) in which some students have already used VISIR before, in a previous course. Still, the number of students in those conditions was low, and for the majority, there was some missing data in some different issues from one student to another. However, it would be fascinating to conduct a longitudinal study in these cases to try to understand if the former VISIR usage had any impact in the subsequent course, where VISIR was going to be used again. Naturally, this longitudinal study could be extended to the other students (that used VISIR in a single course) and try to figure out if this methodology of using several experimental resources had any repercussions in terms of developed competences or other skills that were perceptible in subsequent courses. It would be somehow a follow up to assess if this methodology based upon VISIR has impact in a long term. 
Teacher mediation was the "Achilles' heel" of this project. Still, the former vector has a major impact in students' learning development, so it would be interesting to further explore it in future research in this topic of using several experimental resources. To achieve it the designed curriculum may include some teacher mediation guidelines -that is ideating ways of putting teaching planning into action, using the experimental resources- and the research team could clarify those guidelines to all involved teachers and develop some tools to gather information about it (such as audio records, interviews and diaries). This would allow to make a more thorough crossing between teacher mediation traces and students' results and further explore this item of research.

It would be difficult to finish this work without leaving one last recommendation to the VISIR design team of professor Ingvar Gustavsson, in BTH. The VISIR interface could clearly benefit from a renewal to turn it more attractive to these generation of digital natives, especially the ones who have the opportunity to access modern and well-equipped hands-on labs. Some improvements could be made to the interface of the devices front (instrument) panels (including the animated controls and displays) to more up to date ones.

\subsection{Results Dissemination}

Throughout the development of this thesis project, some of its results and analyses carried out within this context (obtained in different phases) have been disseminated. The former dissemination had the advantage of also allowing to obtain feedback from experts in this research area. In the following paragraphs they will be detailed. It will be distinguished between publications made in international conferences, indexed international journals and book chapters, between the end of 2015 and 2019. As some papers received an award, in those, it will be mentioned.

\section{* International Conferences Proceedings}

○ Lima, N., Alves, G. R., Viegas, C., \& Gustavsson, I. (2015). Combined efforts to develop students experimental competences. In M. Teresa Restivo \& A. Cardoso (Eds.), Proceedings of the 3rd Experiment@ International Conference (exp.at'15) (Ponta Delgada, Azores; Portugal, 2-4 June, 2015) (pp 243-248). IEEE. doi: 10.1109/EXPAT.2015.7463273 (Lima, Alves, Viegas, et al., 2015).

○ Viegas, C., Alves, G. R., \& Lima, N. (2015). Formative assessment diversity to foster students engagement. Proceedings of the 18th International Conference on Interactive Collaborative Learning - ICL 2015 (Florence, Italy, 20-24 September, 2015) (pp 929- 
935). IEEE. doi:10.1109/ICL.2015.7318152 (Viegas et al., 2015).

- Lima, N., Alves, J., \& Alves, G. R. (2015). Higher education competences versus companies professional needs in engineering. In G. R. Alves \& M. C. Felgueiras (Eds.), Proceedings of the Third International Conference on Technological Ecosystem for Enhancing Multiculturality (TEEM'15) (Porto, Portugal, October, 7-9, 2015) (pp 585589). New York, USA: ACM. doi:10.1145/2808580.2808670 (Lima, Alves, \& Alves, 2015).

- Alves, G. R., Fidalgo, A., Marques, M. A., Viegas, C., Felgueiras, M. C., Costa, R., Lima, N., García-Zubía, J., Hernándes, U., Castro, M., Días-Orueta, G., Pester, A., Zutin, D., Kuleska, W., Gustavsson, I., Schlichting, L.C., Ferreira, G., Bona, D., Silva, J. B., Alves, J. B., Biléssimo, S., Pavani, A., Lima, D., Temporão, G., Marchisio, S., Concari, S., Lerro, F., Férnandez, R., Paz, H., Soria, F., Almeida, N., Oliveira, V., Pozzo, M. I., \& Dobboletta, E. (2016). Spreading remote lab usage A system - A community - A Federation. In M. Nascimento \& G. R. Alves (Eds.), Proceedings of the 2nd International Conference of the Portuguese Society for Engineering Education - CISPEE 2016 (Vila Real, Portugal, 20-21 October, 2016) (pp 31-37). IEEE. doi:10.1109/CISPEE.2016.7777722 (Alves, Fidalgo, et al., 2016). Best Paper Award

- Lima, N., Viegas, C., Alves, G. R., \& García-Peñalvo, F. J. (2016). VISIR's Usage as a Learning Resource: a Review of the Empirical Research. In F. J. García-Peñalvo (Ed.), Proceedings of the Fourth International Conference on Technological Ecosystems for Enhancing Multiculturality (TEEM'16) (Salamanca, Spain, November, 2-4, 2016) (pp.293-301). New York, USA: ACM. doi:10.1145/3012430.3012623 (Lima et al., 2016b). Best Paper Award in the category "Engineering Education".

- Lima, N., Zannin, M., Viegas, C., Marques, M. A., Alves, G. R., Felgueiras, M. C., Costa, R., Fidalgo, A., Silva, J. B., Pozzo, M. I., Dobboletta, E., Gustavsson, I., \& GarcíaPeñalvo, F. J. (2017). The VISIR+ Project - Helping Contextualize Math in an Engineering Course. In M. T. Restivo \& A. Cardoso (Eds.), Proceedings of the 4th Experiment@International Conference (exp.at'17) (Faro, Portugal, 6-8 June, 2017) (pp 7-12). IEEE. doi:10.1109/EXPAT.2017.7984369 (Lima, Zannin, et al., 2017).

- Pozzo, M. I., Dobboletta, E., Viegas, C., Marques, M. A., Lima, N., Evangelista, I., \& Alves, G. R. (2017). Diseño de instrumentos para la investigación sobre la implementación educativa del laboratorio remoto VISIR en Latinoamérica. 1er Congresso Latinoamericano de Ingeniería (CLADI) (Paraná, Entre Ríos, Argentina, 1315 September 2017) (Pozzo, Dobboletta, Viegas, et al., 2017).

- Lima, N., Viegas, C., Zannin, M., Marques, M. A., Alves, G. R., Felgueiras, M. C., Costa, R., Fidalgo, A., Silva, J. B., Pozzo, M. I., Dobboletta, E., Gustavsson, I. \& García- 
Peñalvo; F. J. (2017). Projeto VISIR+ Contextualização da Matemática em Engenharia. ler Congresso Latinoamericano de Ingeniería (CLADI) (Paraná, Entre Ríos, Argentina, 13-15 September 2017) (Lima, Viegas, Zannin, Marques, Alves, Felgueiras, Fidalgo, et al., 2017).

- Lima, N., Viegas, C., Zannin, M., Marques, M. A., Alves, G. R., Felgueiras, M. C., Costa, R., Fidalgo, A., Marchisio, S., Lerro, F., Claudio, M., Silva, J. B., Pozzo, M. I., Dobboletta, E., Gustavsson, I., Nilsson, K. \& García-Peñalvo, F. J (2017). Do Students Really Understand the Difference Between Simulation and Remote Labs? In J. M. Dodero, M. S. I. Sáiz, \& I. R. Rube (Eds.), Proceedings of the Fifth International Conference on Technological Ecosystems for Enhancing Multiculturality (TEEM'17) (Cadiz, Spain, October, 20-20, 2017) (pp 1-10). New York, USA: ACM. doi:10.1145/3144826.3145362 (Lima, Viegas, Zannin, Marques, Alves, Felgueiras, Costa, et al., 2017).

- Alves, G. R., Fidalgo, A., Marques, M. A., Viegas, C., Felgueiras, M. C., Costa, R., Lima, N., Kuleska, W., García-Zubía, J., Castro, M., Pester, A., Pavani, A., Silva, J. B., Schlichting, L. C., Marchisio, S., Fernández, R., Oliveira, V., \& Pozzo, M. I. (2018). Using a 3-Tier Training Model for Effective Exchange of Good Practices in an Erasmus+ Project. Proceedings of the 12th International Technology, Education and Development Conference - INTED 2018 (Valencia, Spain, 5-7 March, 2018) (pp 6392-6400). IATED. doi:10.21125/inted.2018.1505 (Alves, Fidalgo, Marques, Viegas, Felgueiras, Costa, Lima, Kulesza, et al., 2018).

- Lima, N., Viegas, C., Marques, M. A., Alves, G. R., \& García-Peñalvo, F. J. (2018). Macro Analysis on how to Potentiate Experimental Competences Using VISIR. In F. J. García-Peñalvo (Ed.), Proceedings of the Sixth International Conference on Technological Ecosystems for Enhancing Multiculturality (TEEM'18) (Salamanca, Spain, October, 24-26, 2018) (pp 624-632). New York, USA: ACM. doi:10.1145/3284179.328428 (Lima et al., 2018).

- Alves, G. R., Felgueiras, M. C., Viegas, C., Fidalgo, A., Marques, M. A., Costa, R., Lima, N., Castro, M., García-Zubía, J., Andreas, P., Kulesza, W., Silva, J. B., Pavani, A., Pozzo, M. I., Marchisio, S., Fernández, R., Oliveira, V., \& Schlichting, L. C. (2018). A sustainable approach to let students do more real experiments with electrical and electronic circuits. In F. J. García-Peñalvo (Ed.), Proceedings of the Sixth International Conference on Technological Ecosystems for Enhancing Multiculturality (TEEM'18) (Salamanca, Spain, October, 24-26, 2018) (pp 508-514). New York, USA: ACM. doi:10.1145/3284179.3284265 (Alves, Felgueiras, et al., 2018). Best Paper Award in the category “Advances on Sustainable Development in Higher Education”. 
- Lima, N., Viegas, C., \& García-Peñalvo, F. J. (2019). Didactical use of a remote lab : a qualitative reflection of a teacher. In M. Á. Conde-González, F. J. Rodríguez-Sedano, C. Fernández-Llamas, \& F. J. García-Peñalvo (Eds.), Proceedings of the Seventh International Conference on Technological Ecosystems for Enhancing Multiculturality (TEEM'19) (Léon, Spain, October, 16-18, 2019) (pp 99-108).New York, USA: ACM. doi:10.1145/3362789.3362891 (Lima et al., 2019a). Best Paper Award in the category "Engineering Education adressing Professional Challenges".

○ Felgueiras, M. C., Costa, R., Alves, G. R., Viegas, C., Fidalgo, A., Marques, M. A., Marques, M. A., Lima, N., Castro, M., García-Zubía, J., Pester, A., Kulesza, W., Silva, J. B., Pavani, A., Pozzo, M. I., Marchisio, S., Fernández, R., Oliveira, V. \& Schlichting, L. C. (2019). A sustainable approach to laboratory experimentation. In M. Á. CondeGonzález, F. J. Rodríguez-Sedano, C. Fernández-Llamas, \& F. J. García-Peñalvo (Eds.), Proceeding of the Seventh International Conference on Technological Ecosystems for Enhancing Multiculturality (TEEM’19) (León, Spain, October, 16-18, 2019) (pp 500507). New York, USA: ACM. doi: 10.1145/3362789.3362952 (Felgueiras et al., 2019).

\section{* Journals indexed in JCR (+Scopus)}

- Viegas, C., Pavani, A., Lima, N., Marques, M. A., Pozzo, M. I., Dobboletta, E., Vanessa, A., Barreto, D., Calliari, F., Fidalgo, A., Lima, D., Temporão, \& Alves, G. R. (2018). Impact of a remote lab on teaching practices and student learning. Computers \& Education, 126, 201-216. doi: 10.1016/j.compedu.2018.07.012 (Viegas, Pavani, et al., 2018).

\section{* Journals indexed in Scopus}

○ Alves, G. R., Viegas, C., Lima, N., \& Gustavsson, I. (2016). Simultaneous Usage of Methods for the Development of Experimental Competences. International Journal of Human Capital and Information Technology Professionals (IJHCITP), 7(1), 54-73. doi: 10.4018/IJHCITP.2016010104 (Alves, Viegas, et al., 2016).

- Alves, J., Lima, N., Alves, G. R., \& García-Peñalvo, F. J. (2017). Adjusting Higher Education Competences to Companies Professional Needs. International Journal of Human Capital and Information Technology Professionals, 8(1), 66-78. doi:10.4018/ijhcitp.2017010105 (J. Alves, Lima, Alves, \& García-Peñalvo, 2017).

○ Lima, N., Viegas, C., \& García-Peñalvo, F. J. (2019). Different Didactical Approaches Using a Remote Lab: Identification of Impact Factors. IEEE Revista Iberoamericana de Tecnologias del Aprendizaje (IEEE RITA), 14(3), 76-86. doi: 10.1109/RITA.2019.2942256 (Lima et al., 2019c). 


\section{* Journals indexed in ESCI}

- Lima, N., Viegas, C., \& García-Peñalvo, F. J. (2017). Learning from Complementary Ways of Developing Experimental Competences. Education in the Knowledge Society (EKS), 18(1), 63-74. doi:10.14201/eks20171816374 (Lima, Viegas, \& García-Peñalvo, 2017).

\section{Other Journals}

- Lima, N., Viegas, C., \& García-Peñalvo, F. J. (2019). Diferentes Abordagens Didáticas Usando um Laboratório Remoto: Identificação de Fatores de Impacto. IEEE VAEP-RITA (Versão Aberta Espanhol-Português), 7(3), 69-78 (Lima et al., 2019b).

\section{* Book chapters}

○ Lima, N., Viegas, C., Alves, G. R., \& García-Peñalvo, F. J. (2016). A utilização do VISIR como um recurso educativo: uma revisão da literatura. In A. Lago Ferreira \& G. G. Manuel (Eds.), TICAI (2016) TICs para el Aprendizaje de la Ingeniería (pp. 105-114). CIEEE, Sociedad de Educación: Capítulos Español y Portugués (Lima et al., 2016a).

- Viegas, C., Alves, G. R., Marques, M. A., Lima, N., Felgueiras, M. C., Costa, R., Fidalgo, A., Pozzo, M. I., Dobboletta, E., García-Zubía, J., Hernandez, U., Castro, M., GarcíaLoro, F., Zutin, \& D. Kreiter, C. (2018). The VISIR+ Project - Preliminary results of the training actions. In M. Auer \& D. Zutin (Eds.), Online Engineering \& Internet of Things. Lecture Notes in Networks and Systems (Vol. 22, pp. 375-391). Springer Cham. doi:10.1007/978-3-319-64352-6_36 (Viegas, Alves, et al., 2018). 



\section{REFERENCES}

11 of The Oldest Engineering Schools In The World That Shaped The Field. (n.d.). Retrieved February 2, 2020, from https://interestingengineering.com/11-of-the-oldest-engineeringschools-in-the-world-that-shaped-the-field

ABET. (n.d.). Retrieved February 2, 2020, from https://www.abet.org/

Al-Bahi, A. M., Taha, M. A., \& Turkmen, N. (2013). Teaching and Assessing Engineering Professional Skills. International Journal of Engineering Pedagogy (IJEP), 3(S3), 13-20. https://doi.org/10.3991/ijep.v3iS3.2728

Alves, G. R., Felgueiras, M. C., Viegas, C., Fidalgo, A., Marques, M. A., Costa, R., ... Schlichting, L. C. (2018). A sustainable approach to let students do more real experiments with electrical and electronic circuits. In F. J. García-Peñalvo (Ed.), Proceedings of the Sixth International Conference on Technological Ecosystems for Enhancing Multiculturality (TEEM'18) (pp. 508514). New York, USA: ACM. https://doi.org/10.1145/3284179.3284265

Alves, G. R., Fidalgo, A., Marques, M. A., Viegas, C., Felgueiras, M. C., Costa, R., ... Bertramo, B. (2018). International Cooperation for Remote Laboratory Use. In M. M. Nascimento, G. R. Alves, \& E. V. A. Morais (Eds.), Contributions to Higher Engineering Education (1st ed., pp. 1-31). Springer Singapore. https://doi.org/10.1007/978-981-10-8917-6

Alves, G. R., Fidalgo, A., Marques, M. A., Viegas, C., Felgueiras, M. C., Costa, R., ... Dobboletta, E. (2016). Spreading remote lab usage A system - A community - A Federation. In M. Nascimento \& G. R. Alves (Eds.), Proceedings of the 2nd International Conference of the Portuguese Society for Engineering Education - CISPEE 2016 (pp. 31-37). IEEE. https://doi.org/10.1109/CISPEE.2016.7777722

Alves, G. R., Fidalgo, A., Marques, M. A., Viegas, C., Felgueiras, M. C., Costa, R., ... Pozzo, M. I. (2018). Using a 3-Tier Training Model for Effective Exchange of Good Practices in an Erasmus+ Project. Proceedings of the 12th International Technology, Education and Development Conference - INTED 2018, 6392-6400. IATED. https://doi.org/10.21125/inted.2018.1505

Alves, G. R., Marques, M. A., Viegas, C., Costa Lobo, M. C., Barral, R. G., Couto, R. J., ... Gustavsson, I. (2011). Using VISIR in a large undergraduate course: Preliminary assessment results. Proceedings of the IEEE Global Engineering Education Conference - EDUCON 2011, 1125-1132. IEEE. https://doi.org/10.1109/EDUCON.2011.5773288

Alves, G. R., Viegas, C., Lima, N., \& Gustavsson, I. (2016). Simultaneous Usage of Methods for the Development of Experimental Competences. International Journal of Human Capital and Information Technology Professionals (IJHCITP), $7(1), \quad 54-73$. https://doi.org/10.4018/IJHCITP.2016010104

Alves, J., Lima, N., Alves, G. R., \& García-Peñalvo, F. J. (2017). Adjusting Higher Education Competences to Companies Professional Needs. International Journal of Human Capital and Information Technology Professionals, 8(1), 66-78. https://doi.org/10.4018/ijhcitp.2017010105

Ambrose, S. A., Bridges, M. W., DiPietro, M. W., Lovett, M. C., \& Norman, M. K. (2010). How learning works: Seven reseach-based principles for smart teaching. San Francisco: CA:Jossey-Bass. 
Arguedas-Matarrita, C., Concari, S., García-Zubía, J., Marchisio, S., Hernández-Jayo, U., Alves, G. R., ... Elizondo, F. U. (2017). A teacher training workshop to promote the use of the VISIR remote laboratory for electrical circuits teaching. In M. T. Restivo \& A. Cardoso (Eds.), Proceedings of the 4th Experiment@ International Conference (exp.at' 17) (pp. 1-6). IEEE. https://doi.org/10.1109/EXPAT.2017.7984351

Artino, A. R. (2008). Promoting academic motivation and self-regulation: Practical guidelines for online instructors. TechTrends, 52(3), 37-45. https://doi.org/10.1007/s11528-008-0153-x

Atzori, L., Iera, A., \& Morabito, G. (2010). The Internet of Things: A survey. Computer Networks, 54(15), 2787-2805. https://doi.org/10.1016/j.comnet.2010.05.010

Ausubel, D. P. (2000). The Acquisition and Retention of Knowledge: A Cognitive View. Springer Netherlands.

Baldwin, C. Y., \& Clark, K. B. (2000). Design Rules: The Power of Modularity (Volume 1). MIT Press.

Biggs, J. (1999). Teaching for quality Learninng at Univeristy. Buckingham, UK: Open Univeristy Press.

Biggs, J., \& Tang, C. (2007). Teaching for Quality Learning at University: What the Student Does (3rd ed.). Mc Graw-Hill: Society for Research into Higher Education \& Open University Press.

Billett, S. (2014). Learning in the circumstances of practice. International Journal of Lifelong Education, 33(5), 674-693. https://doi.org/10.1080/02601370.2014.908425

Black, P., \& Wiliam, D. (1998). Assessment and classroom learning. Assessment in Education: Principles, Policy \& Practice, 5(1), 7-74. https://doi.org/10.1080/0969595980050102

Board on Engineering Education, N. R. C. (1995). Engineeering Education: Designing an Adaptive System. Retrieved from http://www.nap.edu/catalog/4907.html

Bochicchio, M. A., Longo, A., Vaira, L., \& Zappatore, M. (2015). Fostering online scientific experimentations in universities and high schools: The EDOC project. In M. T. Restivo \& A. Cardoso (Eds.), Proceedings of the 3rd Experiment@ International Conference 2015: Online Experimentation (exp.at'15) (pp. IEEE. https://doi.org/10.1109/EXPAT.2015.7463291

Bourgeois-Bougrine, S., Buisine, S., Vandendriessche, C., Glaveanu, V., \& Lubart, T. (2017). Engineering students' use of creativity and development tools in conceptual product design: What, when and how? Thinking Skills and Creativity, 24, 104-117. https://doi.org/10.1016/j.tsc.2017.02.016

Branco, M. V., Coelho, L. A., \& Alves, G. R. (2017). Estudo Comparativo entre Laboratórios Remotos e Simuladores. In A. L. Ferreira, A. Fidalgo, \& O. da Silva (Eds.), TICAI (2017) TICs para el Aprendizaje de la Ingeniería (CIEEE, Soc, pp. 117-123).

Brandmo, C., \& Berger, J. (2013). Fostering Self-Regulated Learning: An Introduction. Journal of Cognitive Education and Psychology, 12(2), 127-137. https://doi.org/10.1891/19458959.12.2.127

Bright, C., Lindsay, E. D., Lowe, D., Murray, S., \& Liu, D. (2008). Factors that impact learning outcomes in both simulation and remote laboratories. In J. Luca \& E. Weippl (Eds.), 
Proceedings of the World Conference on Educational Multimedia, Hypermedia and Telecommunications - EdMedia 2008 (pp. 6251-6258). Vienna, Austria: Association for the Advancement of Computing in Education (AACE).

Brinson, J. R. (2015). Learning outcome achievement in non-traditional (virtual and remote) versus traditional (hands-on) laboratories: A review of the empirical research. Computers and Education, 87, 218-237. https://doi.org/10.1016/j.compedu.2015.07.003

Brinson, J. R. (2017). A Further Characterization of Empirical Research Related to Learning Outcome Achievement in Remote and Virtual Science Labs. Journal of Science Education and Technology, 26, 546-560. https://doi.org/10.1007/s10956-017-9699-8

Butler, R., \& Nisan, M. (1986). Effects of no feedback, task-related comments, and grades on intrinsic motivation and performance. Journal of Education Psycology, 3, 210-216.

Cachapuz, A. (1994). Da investigação sobre e para professores à investigação com e pelos professores de ciências. Proceedings of the I Jornada de La Formación Del Profesorado de Ciencias y Matemáticas En España y Portugal., 243-254. Badajoz, Spain.

Cachapuz, A., Praia, J., Gil-Pérez, D., Carrascosa, J., \& Martinez Terrades, I. (2001). A emergência da didáctica das ciências como campo específico de conhecimento. Revista Portuguesa de Educação, 14(1), 155-195. Retrieved from http://www.redalyc.org/articulo.oa?id=3741408

Çardak, C.. S., \& Selvi, K. (2016). The Construct Validity of Felder-Soloman Index of Learning Styles (ILS) for the Prospective Teachers. Gaziantep University Journal of Social Sciences, 15(2), 675-693. https://doi.org/10.21547/jss.256723

Cardellino, P., Araneda, C., \& García Alvarado, R. (2018). Interventions in the classroom - the influence of spatial organisation on educational interaction in Uruguay. Architectural Engineering and Design Management, 14(6), 413-426.

Casillas Martín, S., Cabezas González, M., \& García-Peñalvo, F. J. (2020). Digital competence of early childhood education teachers: attitude, knowledge and use of ICT. European Journal of Teacher Education, 43(2), 210-223. https://doi.org/10.1080/02619768.2019.1681393

Chang, W., \& Bell, B. (2002). Making content easier or adding more challenge in year one university physics? Research in Science Education, 32(1), 81-96. https://doi.org/10.1023/A:1015054804515

Chidambaram, K., Mugundhan, D., \& Rao, M. P. (2020). A glimpse of a stratagem for endorsing communication skills in the line of engineering for career excellence. Research Journal in Advanced Social Sciences, $1 . \quad$ Retrieved from https://royalliteglobal.com/rjass/article/view/260

CIETI Research Group. (n.d.). Retrieved November 25, 2019, from http:/http://www.cieti.isep.ipp.pt/index.php?page=home-2

CISCO. (2013). The Internet of Learning Things.

Claesson, L., \& Håkansson, L. (2012). Using an Online Remote Laboratory for Electrical Experiments in Upper Secondary Education. International Journal of Online Engineering (IJOE), 8(2), 24-30. https://doi.org/10.3991/ijoe.v8is2.1941 
Claesson, L., Khan, I., Zackrisson, J., Nilsson, K., Gustavsson, I., \& Håkansson, L. (2013). Using a VISIR laboratory to supplement teaching and learning processes in physics courses in a Swedish Upper Secondary School. In O. Dziabenko \& J. Garcia-Zubia (Eds.), IT Innovative Practices in Secondary Schools: Remote Experiments (pp. 141-176). Bilbao, Spain: Deusto Univeristy Press.

Claesson, L., Nilsson, K., Zackrisson, J., Gustavsson, I., \& Håkansson, L. (2010). Remote laboratory experiments at the Upper Secondary School Katedralsjolan in LUND. Proceedings of the Seventh International Conference on Remote Engineering \& Virtual Instrumentation REV2010. Stockholm, Sweden.

Clariana, R. B., Waguer, D., \& Roher Murphy, L. C. (2000). Applying a connectionist description of feedback timing. Educational Technology Research and Development, 48(3), 5-21.

Cohen, L., Manion, L., \& Morrison, K. (2007). Research Methods in Education (6th ed.). London and New York: Routledge Falmer.

Conceição, C., \& de Sousa, Ó. (2012). Ser professor hoje. O que pensam os professores das suas competências. Revista Lusófona de Educação, 20, 81-98.

Conde-González, M. Á., Colomo-Palacios, R., García-Peñalvo, F. J., \& Larrueca, X. (2018). Teamwork assessment in the educational web of data: A learning analytics approach towards ISO 10018. Telematics and Informatics, 35(3), 551-563. https://doi.org/10.1016/j.tele.2017.02.001

Conde, M. Á., Fernández-Llamas, C., Ribeiro Alves, J. F., Ramos, M. J., Celis Tena, S., Gonçalves, J., ... García-Peñalvo, F. J. (2019). RoboSTEAM - A Challenge Based Learning Approach for integrating STEAM and develop Computational Thinking. In M. Á. Conde-González, F. J. Rodríguez-Sedano, C. Fernández-Llamas, \& F. J. García-Peñalvo (Eds.), Proceedings of the Seventh International Conference on Technological Ecosystems for Enhancing Multiculturality (TEEM'19) (pp. 24-30). New York, USA: ACM. https://doi.org/10.1145/3362789.3362893

Conover, W. J. (1999). Practical nonparametric statistics. New York: John Wiley.

Cooper, M. (2000). The challenge of practical work in an e-University - real, virtual and remote experiments. Proceedings of the Information Society Technologies Conference: The Information Society for All. Nice, France.

Cordasco, F. (1976). A Brief History of Education: A Handbook of Information on Greek, Roman, Medieval, Renaissance, and Modern Education Practice (3rd ed.). Totowa, New Jersey: LITTLEFIELD. ADAMS \& Co.

Corter, J. E., Esche, S. K., Chassapis, C., Ma, J., \& Nickerson, J. V. (2011). Process and learning outcomes from remotely-operated, simulated, and hands-on student laboratories. Computers and Education, 57(3), 2054-2067. https://doi.org/10.1016/j.compedu.2011.04.009

Corter, J. E., Nickerson, J. V., Esche, S. K., Chassapis, C., \& Ma, J. (2007). Constructing Reality: A Study of Remote, Hands-On, and Simulated Laboratories. ACM Transactions on Computer-Human Interaction, 14(2). https://doi.org/10.1016/0140-1750(85)90002-8

Costa-Lobo, M. C., Alves, G. R., Marques, M. A., Viegas, C., Barral, R. G., Couto, R. J., ... Gustavsson, I. (2011). Using remote experimentation in a large undergraduate course: Initial findings. 
Proceedings - Frontiers in Education Conference, FIE, 1-7. IEEE. https://doi.org/10.1109/FIE.2011.6142913

Crede, M., \& Kuncel, N. R. (2008). Study Habits, Skills , and Attitudes. Perspectives on Psychological Science, 3(6), 425-453. https://doi.org/10.1111/j.1745-6924.2008.00089.x

Creswell, J. W. (2013). Research Design: Qualitative, quantitative, and mixed methods approaches (4th ed.). https://doi.org/10.1063/1.1150549

Crisol-Moya, E., Herrera-Nieves, L., \& Montes-Soldado, R. (2020). Educación virtual para todos: una revisión sistemática. Education in the Knowledge Society (EKS), 21, 15-1-15-13. https://doi.org/10.14201/eks.20327

Crosier, D., \& Parveva, T. (2013). Fundamentals of Educational Planning The Bologna process: its impact on higher education development in Europe and beyond. Paris, France: UNESCO.

Cunha, A. E., Lopes, J. B., Cravino, J. P., \& Santos, C. (2012). Envolver os alunos na realização de trabalho experimental de forma produtiva: o caso de um professor experiente em busca de boas práticas. REEC: Revista Electrónica de Enseñanza de Las Ciencias, 11(3), 635-659.

Cunha, A. E., Saraiva, E., Santos, C. A., Dinis, F., \& Lopes, J. B. (2014). Teacher Mediation Actions and Students' Productive Engagement During the Use of Computer Simulations in Physical Science Classrooms. Procedia Technology, 13, 76-85. https://doi.org/10.1016/j.protcy.2014.02.011

D'Angelo, G. (2007a). E-authoring - Didactic Methodologies and Models of E-learning Content Development. Retrieved from http://www.leonardolets.net/ict/common/download/GiuseppeDAngelo.pdf

D’Angelo, G. (2007b). From Didactics to e-Didactics: e-Learning Paradigms, Models and Techniques. Napoli:Ligori.

Dewhurst, D. G., MacLeod, H. A., \& Norris, T. A. M. (2000). Independent student learning aided by computers: An acceptable alternative to lectures? Computers \& Education, 35(3), 223-241. https://doi.org/10.1016/S0360-1315(00)00033-6

Dias, I. S. (2010). Competências em educação: conceito e significado pedagógico. Revista Semestral Da Associação Brasileira de Psicologia Escolar e Educacional, SP, 14(1), 73-78. https://doi.org/10.1590/s1413-85572010000100008

DiBiase, D. (2000). Is distance teaching more work or less work? International Journal of Phytoremediation, 21(1), 6-20. https://doi.org/10.1080/08923640009527061

Druzhinina, M., Belkova, N., Donchenko, E., Liu, F., \& Morozova, O. (2018). Curriculum Design in Professional Education: Theory and Practice. In S. Cindori, O. Larouk, L. N. Malushko, L. N. Rebrina, \& N. L. Shamne (Eds.), Proceedings of the International Scientific and Practical Conference "Current Issues of Linguistics and Didactics: The Interdisciplinary Approach in Humanities and Social Sciences" (CILDIAH-2018). https://doi.org/10.1051/shsconf/20185001046

Dufresne, R. J., \& Gerace, W. J. (2004). Assessing-To-Learn: Formative Assessment in Physics Instruction. The Physics Teacher, 42(7), 428-433. https://doi.org/10.1119/1.1804662 
Dufresne, R. J., Gerace, W. J., Leonard, W. J., Mestre, J. P., \& Wenk, L. (1996). Classtalk: A classroom communication system for active learning. Journal of Computing in Higher Education, 7(2), 3-47. https://doi.org/10.1007/BF02948592

Earl, L. (2006). Assessment - A Powerful Lever for Learning. Brock Education Journal, 16(1). https://doi.org/10.26522/brocked.v16i1.29

Elton, L. (1987). Teaching in Higher Education: Appraisal and Training. London: Kogan.

Engle, R. A., \& Conant, F. R. (2002). Guiding principles for fostering productive disciplinary engagement: Explaining an emergent argument in a community of learners classroom. Cognition and Instruction, 20(4), 399-483. https://doi.org/10.1207/S1532690XCI2004_1

Estella, A. M., \& Vera, C. S. (2008). La ensenãnza en competências en el marco de la educación a lo largo de la vida y la sociedad del conocimiento. Revista IberoAmericana de Educación, 47, 159-183.

Evangelista, I., Cadierno, M., Farina, J. A., Roldan, G., Pozzo, M. I., Dobboletta, E., ... Nilsson, K. (2018). Active learning of DC circuits: Spreading the use of the VISIR remote lab in Argentina. Proceedings of the 2nd IEEE World Engineering Education Conference - EDUNINE 2018. IEEE. https://doi.org/10.1109/EDUNINE.2018.8450966

Evangelista, I., Farina, J. A., Pozzo, M. I., Dobboletta, E., Alves, G. R., García-Zubía, J., ... Gustavsson, I. (2017). Science education at high school: A VISIR remote lab implementation. In M. T. Restivo \& A. Cardoso (Eds.), Proceedings of the 4th Experiment@ International Conference (exp.at'2017) (pp. 13-17). IEEE. https://doi.org/10.1109/EXPAT.2017.7984378

Fagundes, T. B. (2016). Os conceitos de professor pesquisador e professor reflexivo: perspectivas do trabalho docente. Revista Brasileira de Educação, 21(65), 281-298. https://doi.org/10.1590/s1413-24782016216516

Fantin, M. (2015). Novos Paradigmas da Didática e a Proposta Metodológica dos Episódios de Aprendizagem Situada, EAS. Educação \& Realidade, 40(2), 443-464. https://doi.org/10.1590/2175-623646056

Faulconer, E. K., \& Gruss, A. B. (2018). A review to weigh the pros and cons of online, remote, and distance science laboratory experiences. International Review of Research in Open and Distance Learning, 19(2), 155-168. https://doi.org/10.19173/irrodl.v19i2.3386

Feisel, L. D., \& Peterson, G. D. (2002a). A Colloquy on Learning Objectives for Engineering Education Laboratories. Proceedings of the 2002 American Society for Engineering Education Annual Conference \& Exposition, 7.20.1-7.20.12. (C) 2002, American Society for Engineering Education.

Feisel, L. D., \& Peterson, G. D. (2002b). The Challenge of the Laboratory in Engineering Education. Journal of Engineering Education, 91(4), 367-368.

Feisel, L. D., \& Rosa, A. J. (2005). The role of the laboratory in Undergraduate Engineering Education. Journal of Engineering Education, 121-130. Retrieved from http://www.ncbi.nlm.nih.gov/pubmed/14908345

Felder, R. M., Woods, D. R., Stice, J. E., \& Rugarcia, A. (2000). The future of engineering education II. Teaching methods that work. Chemical Engineering Education, 34(1), 26-39. 
Felgueiras, M. C., Costa, R., Alves, G. R., Viegas, C., Fidalgo, A., Marques, M. A., ... Schlichting, L. C. (2019). A sustainable approach to laboratory experimentation. In M. Á. Conde-González, F. J. Rodríguez-Sedano, C. Fernández-Llamas, \& F. J. García-Peñalvo (Eds.), Proceeding of the Seventh International Conference on Technological Ecosystems for Enhancing Multiculturality (TEEM'19) (pp. 500-507). New York, USA: ACM. https://doi.org/10.1145/3362789.3362952

Ferreira, G., Lacerda, J., Schlichting, L. C., \& Alves, G. R. (2014). Enriched scenarios for teaching and learning electronics. Proceedings of the XI Tecnologias Aplicadas a La Ensenanza de La Electronica (Technologies Applied to Electronics Teaching) - TAEE 2014. IEEE. https://doi.org/10.1109/TAEE.2014.6900132

Ferreras-Fernández, T. (2018). Los repositorios institucionales: Evolución y situación actual en España. In J. A. M. Vega (Ed.), Ecosistemas del Conocimiento Abierto (pp. 39-84). Ediciones Universidad de Salamanca.

Fidalgo, A., Alves, G. R., Marques, M. A., Viegas, C., Costa-Lobo, M. C., Henandez-Jayo, U., ... Gustavsson, I. (2014). Adapting remote labs to learning scenarios: Case studies using VISIR and remotElectLab. IEEE Revista Iberoamericana de Tecnologias Del Aprendizaje (IEEE RITA), 9(1), 33-39. https://doi.org/10.1109/RITA.2014.2302071

Fidalgo, A., Alves, G. R., Marques, M. A., Viegas, C., Costa-Lobo, M. C., Hernandez, U., ... Gustavsson, I. (2012). Using remote labs to serve different teacher's needs - A case study with VISIR and remotelectlab. International Journal of Online Engineering, 8(Special Issue 3), 36-41. https://doi.org/10.3991/ijoe.v8iS3.2259

Frerich, S., Kruse, D., Petermann, M., \& Kilzer, A. (2014). Virtual Labs and Remote Labs: Practical experience for everyone. Proceedings of the 2014 IEEE Global Engineering Education Conference - EDUCON 2014, 312-314. https://doi.org/10.1109/EDUCON.2014.6826109

Froyd, J. E., Wankat, P. C., \& Smith, K. A. (2012). Five major shifts in 100 years of engineering education. Proceedings of the IEEE, 100(Special Centennial Issue), 1344-1360. https://doi.org/10.1109/JPROC.2012.2190167

García-Loro, F., Sancristobal, E., Diaz, G., Castro, M., Orduña, P., Kulesza, W., ... Lehtikangas, E. (2019). PILAR: Sharing VISIR remote labs through a federation. In A. K. Ashawy \& S. Schreiter (Eds.), Proceedings of the IEEE Global Engineering Education Conference - EDUCON 2019 (pp. 102-106). IEEE. https://doi.org/10.1109/EDUCON.2019.8725093

García-Peñalvo, F. J. (2013). Education in knowledge society: A new PhD programme approach. In F. J. García-Peñalvo (Ed.), Proceedings of the First International Conference on Technological Ecosystems for Enhancing Multiculturality (TEEM'13) (pp. 575-577). New York, USA:ACM. https://doi.org/10.1145/2536536.2536624

García-Peñalvo, F. J. (2014). Formación en la sociedad del conocimiento, un programa de doctorado con una perspectiva interdisciplinar. Education in the Knowledge Society (EKS), 15(1), 4-9. https://doi.org/10.14201/eks.11641

García-Peñalvo, F. J. (2015a). Cómo entender el concepto de presencialidad en los procesos educativos en el siglo XXI. Education in the Knowledge Society (EKS), 16(2), 6-12. https://doi.org/10.14201/eks2015162612

García-Peñalvo, F. J. (2015b). Engineering contributions to a Knowledge Society multicultural 
perspective. IEEE Revista Iberoamericana de Tecnologías Del Aprendizaje (IEEE RITA), 10(1), 17-18. https://doi.org/10.1109/RITA.2015.2391371

García-Peñalvo, F. J. (2020). El sistema universitario ante la COVID-19: Corto, medio y largo plazo. Retrieved July 28, 2020, from Universídad website: https://bit.ly/2YPUeXU

García-Peñalvo, F. J., Alarcón, H., \& Domínguez, Á. (2019). Active learning experiences in Engineering Education. International Journal of Engineering Education, 35(1 (B)), 305-309.

García-Peñalvo, F. J., Corell, A., Abella-García, V., \& Grande, M. (2020). La evaluación online en la educación superior en tiempos de la COVID-19. Education in the Knowledge Society (EKS), 21, 12-1-12-26. https://doi.org/10.14201/eks.23013

García-Peñalvo, F. J., Fernández-Hermo, V., Fidalgo-Blanco, Á., \& Sein-Echaluce, M. L. (2014). Applied educational innovation MOOC: : Learners' experience and valorization of strengths and weaknesses. In F. J. García-Peñalvo (Ed.), Proceedings of the Second International Conference on Technological Ecosystems for Enhancing Multiculturality (TEEM '14) (pp. 139145). New York, USA:ACM. https://doi.org/10.1145/2669711.2669892

García-Peñalvo, F. J., Fidalgo-Blanco, Á., \& Sein-Echaluce, M. L. (2017). Los MOOC: Un análisis desde una perspectiva de la innovación institucional universitaria. La Cuestión Universitaria, $9,117-135$.

García-Peñalvo, F. J., Fidalgo-Blanco, Á., \& Sein-Echaluce, M. L. (2018). An adaptive hybrid MOOC model: Disrupting the MOOC concept in higher education. Telematics and Informatics, 10181030. https://doi.org/10.1016/j.tele.2017.09.012

García-Peñalvo, F. J., Moreno López, L., \& Sánchez-Gómez, M. C. (2018). Empirical evaluation of educational interactive systems. Quality \& Quantity, 52(6), 2427-2434. https://doi.org/10.1007/s11135-018-0808-4

García-Peñalvo, F. J., \& Seoane-Pardo, A. M. (2015). An updated review of the concept of eLearning. Tenth anniversary. Education in the Knowledge Society (EKS), 16(1), 119-144. https://doi.org/10.14201/eks2015161119144

García-Zubía, J., Cuadros, J., Hernandez-Jayo, U., Romero, S., Serrano, V., Angulo, I., ... RodriguezGil, L. (2020). Using VISIR Remote Lab in the Classroom : Case of Study of the University of Deusto 2009-2019 (M. Auer \& D. May, Eds.). Cross Reality and Data Science in Engineering. REV 2020. Advances in Intelligent Systems and Computing, Vol. 1231, pp. 82-102.Springer, Cham. https://doi.org/10.1007/978-3-030-52575-0_7

García-Zubía, J., Cuadros, J., Romero, S., Hernandez-jayo, U., Orduña, P., Guenaga, M., ... Gustavsson, I. (2017). Empirical Analysis of the Use of the VISIR Remote Lab in Teaching Analog Electronics. IEEE Transactions on Education, 60(2), 149-156. https://doi.org/10.1109/TE.2016.2608790

García-Zubía, J., Gustavsson, I., Hernandez-Jayo, U., Orduña, P., Angulo, I., Dziabenko, O., ... LopezIpiña, D. (2011). Using VISIR experiments, subjects and students. International Journal of Online Engineering, 7(Specialissue2), 11-14. https://doi.org/10.3991/ijoe.v7iS2.1769

García-Zubía, J., Hernández, U., Gustavsson, I., \& Alves, G. R. (2011). Academic effectiveness of VISIR remote lab in analog electronics. In M. T. Restivo \& A. Cardoso (Eds.), Proceedings of the 1st Experiment@ Internacional Conference: Online Experimentation (exp.at'11). Lisbon, 
Portugal.

Gettinger, M., \& Seibert, J. K. (2002). Contribution of Study Skills To Academic Competence. School Psycological Review, 31(3), 350-365.

Gillet, D., Jon, T. de, Sotiriou, S., \& Salzmann, C. (2013). Personalised learning spaces and federated online labs for STEM education at school: Supporting Teacher Communities and Inquiry Learning. Proceedings of the 4th IEEE Global Engineering Education Conference - EDUCON 2013, 769-773. Berlin, Germany.

Glaser, B., \& Strauss, A. (2012). The Discovery of Grounded Theory: Studies for Qualitative Research. New York: Adline.

Gomes, L., \& Bogosyan, S. (2009). Current trends in remote laboratories. IEEE Transactions on Industrial Electronics, 56(12), 4744-4756. https://doi.org/10.1109/TIE.2009.2033293

González-Pérez, L. I., Glasserman Morales, L. D., Ramírez-Montoya, M. S., \& García-Peñalvo, F. J. (2017). Repositorios como soportes para diseminar experiencias de innovación educativa. In M. S. Ramírez-Montoya \& J. R. V. González (Eds.), Innovación Educativa. Investigación, formación, vinculación y visibilidad (pp. 259-272). Síntesis.

Gorham, J., \& Zakahi, W. R. (1990). A comparison of teacher and student perceptions of immediacy and learning: Monitoring process and product. Communication Education, 39(4), 354-368. https://doi.org/https://doi.org/10.1080/03634529009378815

Gray, J., \& Campbell-Evans, G. (2002). Beginning Teachers as Teacher-Researchers. Australian Journal of Teacher Education, 27(1). https://doi.org/10.14221/ajte.2002v27n1.4

Greenberg, L. (2002). LMS and LCMS: What's the difference? Learning Circuits-ASTD's Online Magazine All about e-Learning, 31(2).

Griffiths, D., \& García-Peñalvo, F. J. (2016). Informal learning recognition and management. Computers in Human Behavior, 55(A), 501-503. https://doi.org/10.1016/j.chb.2015.10.019

Gros, B., \& García-Peñalvo, F. J. (2016). Future trends in the design strategies and technological affordances of e-learning. In B. B. L. M. Spector \& M. D. Childress (Eds.), Learning, Design, and Technology. An International Compendium of Theory, Research, Practice, and Policy (pp. 123). https://doi.org/10.1007/978-3-319-17727-4_67-1

Gustavsson, I. (2011). On Remote Electronics Experiments. In J. García-Zubía \& G. R. Alves (Eds.), Using Remote Labs in Education, Two Little Ducks in Remote Experimentation (pp. 157-176). Bilbao: Deusto Univeristy Press.

Gustavsson, I., Alves, G. R., Nilsson, K., Zackrisson, J., Hernandez-Jayo, U., \& García-Zubía, J. (2011). The VISIR Open Lab Platform 5.0 - an architecture for a federation of remote laboratories. Proceedings of the 8th International Conference on Remote Engineering \& Virtual Instrumenntation - REV2011, 284-288. Brasov, Romania.

Gustavsson, I., Nilsson, K., Zackrisson, J., García-Zubía, J., Hernandez-Jayo, U., Nafalski, A., ... Håkansson, L. (2009). On objectives of instructional laboratories, individual assessment, and use of collaborative remote laboratories. IEEE Transactions on Learning Technologies, 2(4), 263-274. https://doi.org/10.1109/TLT.2009.42 
Gustavsson, I., Zackrisson, J., Bartunek, J. S., Nilsson, K., Håkansson, L., Claesson, I., \& Lagö, T. (2008). Telemanipulator for Remote Wiring of Electrical Circuits. Proceedings of the 5th International Conference on Remote Engineering \& Virtual Instrumentation - REV2008. Dusseldorf, Germany.

Gustavsson, I., Zackrisson, J., Håkansson, L., Claesson, I., \& Lagö, T. (2007). The VISIR project - an Open Source Software Initiative for Distributed Online Laboratories. Proceedings of the 4th International Conference in Remote Engineering \& Virtual Instrumentation - REV2007. Porto, Portugal.

Gustavsson, I., Zackrisson, J., \& Lundberg, J. (2014). VISIR work in progress. Proceedings of the 5th IEEE Global Engineering Education Conference - EDUCON 2014, 1139-1148. Istambul, Turkey.

Gustavsson, I., Zackrisson, J., Nilsson, K., Håkansson, L., Claesson, I., \& Lagö, T. (2008). A Flexible Electronics Laboratory with Local and Remote Workbenches in a Grid. Proceedings of the 5th International Conference on Remote Engineering \& Virtual Instrumentation - REV2008, 12-16. Dusseldorf, Germanany.

Gustavsson, I., Zackrisson, J., \& Olsson, T. (2004). Traditional Lab Sessions in a Remote Laboratory for Circuit Analysis. Proceedings of the 15th Annual Conference on Innovation in Education for Electrical and Information Engineering - EAEEIE 2004, 1-6. Sofia, Bulgaria.

Hattie, J., \& Timperley, H. (2007). The power of feedback. Review of Educational Research, 77(1), 81-112. https://doi.org/10.3102/003465430298487

Heradio, R., de la Torre, L., \& Dormido, S. (2016). Virtual and remote labs in control education: A survey. Annual Reviews in Control. https://doi.org/10.1016/j.arcontrol.2016.08.001

Heradio, R., de La Torre, L., Galan, D., Cabrerizo, F. J., Herrera-Viedma, E., \& Dormido, S. (2016). Virtual and remote labs in education: A bibliometric analysis. Computers \& Education, 98, 1438. https://doi.org/10.1016/j.compedu.2016.03.010

Hernandez-March, J., Martin Del Peso, M., \& Leguey, S. (2009). Graduates' skills and higher education: The employers' perspective. Tertiary Education and Management, 15(1), 1-16. https://doi.org/10.1080/13583880802699978

Hernández-Sampieri, R., \& Mendoza, C. P. (2008). El matrimonio cuantitativo-cualitativo: El paradigma mixto. 6to. Congreso de Investigación En Sexología. Villahermosa, Tabasco, México.

Humanante-Ramos, P. R., García-Peñalvo, F. J., \& Conde-González, M. Á. (2015). Personal Learning Environments and online classrooms: An experience with university students. IEEE Revista Iberoamericana de Tecnologías Del Aprendizaje (IEEE RITA), 10(1), 26-32. https://doi.org/10.1109/RITA.2015.2391411

IAOE: Winners for the GOLC Online Laboratory Award, 11 February 2015. (n.d.).

Issac, J. C. (2010). Methods and Stategies of Teaching: an overview. Pondicherry Univeristy Press.

Jara, C. A., Candelas, F. A., Puente, S. T., \& Torres, F. (2011). Hands-on experiences of undergraduate students in Automatics and Robotics using a virtual and remote laboratory. $\begin{array}{llll}\text { Computers \& Education, 2451-2461. } & \text { 57(4), }\end{array}$ https://doi.org/10.1016/j.compedu.2011.07.003 
Jurado, E., Fonseca, D., Coderch, J., \& Canaleta, X. (2020). Social STEAM Learning at an Early Age with Robotic Platforms: A Case Study in Four Schools in Spain. Sensors, 20(13). https://doi.org/10.3390/s20133698

Kang, B., Kim, D., \& Choo, H. (2017). Internet of Everything: A Large-Scale Autonomic IoT Gateway. IEEE Transactions on Multi-Scale Computing Systems, 3(3), 206-214. https://doi.org/10.1109/TMSCS.2017.2705683

Kehm, B. M., \& Teichler, U. (1995). Higher Education and Emplyment. European Journal of Education, 30(4), 407-422.

Kirschner, P. A., \& Van Merriënboer, J. J. G. (2013). Do Learners Really Know Best? Urban Legends in Education. Educational Psychologist, 48(3), 169-183. https://doi.org/10.1080/00461520.2013.804395

Kitchenham, B., \& Charters, S. (2007). Guidelines for performing Systematic Literature Reviews in Software Engineering. Version 2.3. Retrieved from https://goo.gl/L1VHcw [Technical Report](EBSE-2007-01)

Kutnjak, A., Pihiri, I., \& Furjan, M. T. (2019). Digital Transformation Case Studies Across Industries - Literature Review. In 10.23919/MIPR0.2019.8756911 (Ed.), Proceedings of the 2019 42nd International Convention on Information and Communication Technology, Electronics and Microelectronics (MIPRO). Opatija, Croatia, 20-24 May.

Lal, S., Lucey, A. D., Lindsay, E. D., Treagust, D. F., Mocerino, M., \& Zadnik, M. G. (2019). A study of the relative importance of student interactions for the attainment of laboratory-learning outcomes. 30th Annual Conference for the Australasian Association for Engineering Education (AAEE 2019): Educators Becoming Agents of Change: Innovate, Integrate, Motivate, 372-380. Brisbane, Queensland.

Lal, S., Lucey, A. D., Treagust, D. F., \& Mocerino, M. (2018). The Effects of Remote Laboratory Implementation on Freshman Engineering Students' Experience. ASEE Annual Conference and Exposition, Conference Proceedings (ASEE Annual Conference and Exposition, Conference Proceedings), 1-14. Salt Lake City, USA.

Lapek, J. (2017). 21st century skills: the tools students need. Children's Technology \& Engineering, 21(3), 24-26.

Larkin-Hein, T., \& Budny, D. D. (2001). Research on learning style: Applications in the physics and engineering classrooms. IEEE Transactions on Education, 44(3), 276-281. https://doi.org/10.1109/13.941000

Laurillard, D. (2013). Rethinking university teaching, a conversational framework for the effective use of learning technologies (2nd ed.). London: Routledge Falmer: Taylor and Francis Group.

León, 0., Hernández-Serrano, J., \& Soriano, M. (2010). Securing cognitive radio networks. International Journal of Communication Systems, 23(5), 633-652. https://doi.org/10.1002/dac

Lerro, F., \& Marchisio, S. (2016). Preferences and uses of a remote lab from the students' viewpoint. International Journal of Online Engineering, 12(3), 53-57. https://doi.org/10.3991/ijoe.v12i03.5468 
Lerro, F., \& Protano, M. D. (2007). Web-based Remote Semiconductors Devices Testing Laboratory. International Journal of Online Engineering (IJOE), 3(3), 1-4.

Lima, N., Alves, G. R., Viegas, C., \& Gustavsson, I. (2015). Combined efforts to develop students experimental competences. In M. Teresa Restivo \& A. Cardoso (Eds.), Proceedings of the 3rd Experiment@ International Conference: Online Experimentation (exp.at'15) (pp. 243-248). IEEE. https://doi.org/10.1109/EXPAT.2015.7463273

Lima, N., Alves, J., \& Alves, G. R. (2015). Higher education competences versus companies professional needs in engineering. In G. R. Alves \& M. C. Felgueiras (Eds.), Proceedings of the Third International Conference on Technological Ecosystem for Enhancing Multiculturality (TEEM'15) (pp. 585-589). New York, USA: ACM. https://doi.org/10.1145/2808580.2808670

Lima, N., Viegas, C., Alves, G. R., \& García-Peñalvo, F. J. (2016a). A utilização do VISIR como um recurso educativo: uma revisão da literatura. In A. Lago Ferreira \& G. G. Manuel (Eds.), TICAI (2016) TICs para el Aprendizaje de la Ingeniería (pp. 105-114). CIEEE, Sociedad de Educación: Capítulos Español y Portugués.

Lima, N., Viegas, C., Alves, G. R., \& García-Peñalvo, F. J. (2016b). VISIR's Usage as a Learning Resource: a Review of the Empirical Research. In F. J. García-Peñalvo (Ed.), Proceedings of the Fourth International Conference on Technological Ecosystems for Enhancing Multiculturality (TEEM'16) (pp. 293-301). New York, USA: ACM. https://doi.org/10.1145/3012430.3012623

Lima, N., Viegas, C., \& García-Peñalvo, F. J. (2017). Learning from Complementary Ways of Experimental Competences Developing. Education in the Knowledge Society (EKS), 18, 63-74. https://doi.org/10.14201/eks20171816374

Lima, N., Viegas, C., \& García-Peñalvo, F. J. (2019a). Didactical use of a remote lab : a qualitative reflection of a teacher. In M. Á. Conde-González, F. J. Rodríguez-Sedano, C. Fernández-Llamas, \& F. J. García-Peñalvo (Eds.), Proceedings of the Seventh International Conference on Technological Ecosystems for Enhancing Multiculturality (TEEM'19) (pp. 99-108). New York, USA: ACM. https://doi.org/10.1145/3362789.3362891

Lima, N., Viegas, C., \& García-Peñalvo, F. J. (2019b). Diferentes Abordagens Didáticas Usando um Laboratório Remoto: Identificação de Fatores de Impacto. IEEE VAEP-RITA (Versão Aberta Espanhol-Português), 7(3), 69-78.

Lima, N., Viegas, C., \& García-Peñalvo, F. J. (2019c). Different Didactical Approaches Using a Remote Lab: Identification of Impact Factors. IEEE Revista Iberoamericana de Tecnologias Del Aprendizaje (IEEE-RITA), 14(3), 76-86. https://doi.org/10.1109/RITA.2019.2942256

Lima, N., Viegas, C., Marques, A., Alves, G. R., \& García-Peñalvo, F. J. (2018). Macro Analysis on how to Potentiate Experimental Competences Using VISIR. In F. J. García-Peñalvo (Ed.), Proceedings of the Sixth International Conference on Technological Ecosystems for Enhancing Multiculturality (TEEM'18) (pp. 624-632). New York, USA: ACM. https://doi.org/10.1145/3284179.3284282

Lima, N., Viegas, C., Zannin, M., Marques, M. A., Alves, G. R., Felgueiras, M. C., ... Gustavsson, I. (2017). Projeto VISIR+ Contextualização da Matemática em Engenharia. 1er Congresso Latinoamericano de Ingeniería - CLADI. Paraná, Entre Ríos,Argentina, 13-15 September 2017.

Lima, N., Viegas, C., Zannin, M., Marques, M. A., Alves, G. R., Felgueiras, M. C., ... Marchisio, S. (2017). Do Students Really Understand the Difference Between Simulation and Remote Labs? In J. M. 
Dodero, M. S. I. Sáiz, \& I. R. Rube (Eds.), Proceedings of the Fifth International Conference on Technological Ecosystems for Enhancing Multiculturality (TEEM'17) (pp. 1-10). New York, USA: ACM. https://doi.org/10.1145/3144826.3145362

Lima, N., Zannin, M., Viegas, C., Marques, M. A., Alves, G. R., Felgueiras, M. C., ... García-Peñalvo, F. J. (2017). The VISIR+ Project - Helping Contextualize Math in an Engineering Course. In M. T. Restivo \& A. Cardoso (Eds.), Proceedings of the 4th Experiment@ International Conference (exp.at' 17) (pp. 7-12). IEEE. https://doi.org/10.1109/EXPAT.2017.7984369

Lindsay, E. D., \& Good, M. C. (2005). Effects of laboratory access modes upon learning outcomes. IEEE Transactions on Education, 48(4), 619-631. https://doi.org/10.1109/TE.2005.852591

Lopes, J. B. (2004). Aprender e Ensinar Física [Learning and Teaching Physics ]. Lisboa: Fundação Calouste Gulbenkian.

Lopes, J. B., Cravino, J. P., Branco, M. J., Saraiva, E., \& Silva, A. A. (2008). Mediation of student learning: dimensions and evidences in science teaching. Problems of Education in the 21st Century, 9, 42-52. Retrieved from http://scholar.google.com/scholar?hl=en\&btnG=Search\&q=intitle:Mediation+of+student+l earning:+dimensions+and+evidences+in+science+teaching\#0

Lopes, J. B., Cunha, A. E., Santos, C. A., Saraiva, E., Cravino, J. P., \& Dinis, F. (2012). Envolver produtivamente os alunos em aulas de Física e Química durante o uso de simulações computacionais: dois professores com mediações distintas e uso distinto. Sensos, 2(2), 121137.

Lopes, J. B., Silva, A. A., Cravino, J. P., Costa, N., Marques, L., \& Campos, C. (2008). Transversal traits in science education research relevant for teaching and research: A meta-interpretative study. Journal of Research in Science Teaching, 45(5), 574-599. https://doi.org/10.1002/tea.20225

Lopes, J. B., Silva, A. A., Cravino, J. P., Santos, C. A., Cunha, A. E., Pinto, A., ... Branco, M. J. (2014). Constructing and Using Multimodal Narratives to Research in Science Education: Contributions Based on Practical Classroom. Research in Science Education, 44(3), 415-438. https://doi.org/10.1007/s11165-013-9381-y

Lopes, J. B., Silva, A. A., Cravino, J. P., Viegas, C., Cunha, A. E., Saraiva, E., ... Santos, A., C. (2012). Instrumentos de ajuda à mediação do professor para promover a aprendizagem dos alunos e o desenvolvimento profissional dos professores. Sensos, 2(1), 125-171. Retrieved from http://recipp.ipp.pt/bitstream/10400.22/6298/1/Sensos 3

Lopes, J. B., Silva, A. A., Cravino, J. P., Viegas, C., Cunha, A. E., Saraiva, E., ... Santos, C. A. (2010). Investigação sobre a Mediação de professores de Ciências Físicas em sala de aula. Vila Real, Poruigal: (C) Universidade de Trás-os Montes e Alto Douro.

Lopes, J. B., Viegas, C., \& Cravino, J. P. (2010). Improving the Learning of Physics and Development of Competences in Engineering Students. International Journal of Engineering Education, $26(3), 612-627$.

Lowe, D., Member, S., Murray, S., Lindsay, E. D., \& Liu, D. (2009). Evolving Remote Laboratory Architectures to Leverage Emerging Internet Technologies. IEEE Transactions on Learning Technologies, 2(4), 289-294. https://doi.org/10.1109/TLT.2009.33 
Lustigova, Z., \& Novotna, V. (2012). The role of virtual and remote labs in promoting conceptual understanding of students. Proceedings of the International Conference on Interactive Mobile and Computer Aided Learning - IMCL 2012, 42-47. IEEE. https://doi.org/10.1109/IMCL.2012.6396448

Ma, J., \& Nickerson, J. V. (2006). Hands-on, simulated, and remote laboratories: a comparative literature review. ACM Computing Surveys, 38(3), 1-24. https://doi.org/10.1145/1132960.1132961

Magin, D., \& Kanapathipillai, S. (2000). Engineering students' understanding of the role of experimentation. International Journal of Phytoremediation, 25(4), 351-358. https://doi.org/10.1080/03043790050200395

Marcelino, R., Silva, J. B., Fidalgo, A., Schaeffer, L., \& Alves, J. (2011). Virtual 3D worlds and remote experimentation: A methodological proposal apllied to engineering students. In Javier García Zubía \& Gustavo R. Alves (Eds.), Using Remote Labs in Education: Two Little Ducks in Remote Engineering (1st ed., pp. 348-374). Bilbao, Spain: Deusto Univeristy Press.

Marchisio, S., Crepaldo, D., Del Colle, F., \& Lerro, F. (2018). Incorporación de VISIR en Ingeniería Electrónica: Una experiencia institucional en Argentina. Proceedings of XIII Tecnologias Aplicadas a La Ensananza de La Electronica (Technologies Applied to Electronics Teaching) Conference - TAEE 2018.

Margolinas, C., \& Drijvers, P. (2015). Didactical engineering in France; an insider's and an outsider's view on its foundations, its practice and its impact. ZDM - Mathematics Education, 47(6), 893-903. https://doi.org/10.1007/s11858-015-0698-z

Marôco, J. (2018). Análise Estatística com o SPSS Statistics (7a Edição). ReportNumber, Lda.

Marques, M. A., Viegas, C., Costa-Lobo, M. C., Fidalgo, A., Alves, G. R., Rocha, J. S., \& Gustavsson, I. (2014). How remote labs impact on course outcomes: Various practices using VISIR. IEEE Transactions on Education, 57(3), 151-159. https://doi.org/10.1109/TE.2013.2284156

Martín Del Peso, M., Rabadán Gómez, A. B., \& Hernández March, J. (2013). Mismatches between higher education and the labour market in engineering sciences: The employers' point of view in the region of Madrid. Revista de Educacion, (360), 244-267. https://doi.org/10.4438/1988-592X-RE-2011-360-110

Mazur, E. (1997). Peer Instruction, a user's manual. New Jersey: Person Prentice Hall.

McDonough, J., \& McDonough, S. (1997). Research Methods for English Language Teachers. London: Arnold.

Murteira, B., Ribeiro, C. S., Andrade e Silva, J., \& Pimenta, C. (2002). Introdução à Estatística. Lisboa: McGraw-Hill.

Myneni, L. S., Narayanan, N. H., Rebello, S., Rouinfar, A., \& Pumtambekar, S. (2013). An Interactive and Intelligent Learning System for Physics Education. IEEE Transactions on Learning Technologies, 6(3), 228-239. https://doi.org/10.1109/TLT.2013.26

Negreiro, M., \& Madiega, T. (2019). Digital transformation. Retrieved from https://bit.ly/2QXICPd [Briefing] European Union 
Nemoto, T., \& Beglar, D. (2013). Developing Likert Scale Questionnaires. In N. Sonda \& A. Krause (Eds.), JALT2013 Conference Proceedings. Tokyo, Japan:JALT.

Nickerson, J. V., Corter, J. E., Esche, S. K., \& Chassapis, C. (2007). A model for evaluating the effectiveness of remote engineering laboratories and simulations in education. Computers \& Education, 49(3), 708-725. https://doi.org/10.1016/j.compedu.2005.11.019

Nicol, D. (2008). Transforming Assessment and Feedback: Enhancing Integration and Empowerment in the First Year. Quality Assurance Agency, Scotland.

Novak, J. D. (2002). Meaningful Learning: The Essential Factor for Conceptual Change in Limited or Inappropriate Propositional Hierarchies Leading to Empowerment of Learners. Science Education, 86(4), 548-571. https://doi.org/10.1002/sce.10032

Núñez Pardo, A., Ramos, B., \& Téllez, M. F. (2006). Reflexión en el contexto educativo havia la toma de decisiones en el aula. Apuntes Contables, 11, 111-115.

Núñez Pardo, A., \& Téllez, M. F. (2015). Reflection on Teachers' Personal and Professional Growth Through a Materials Development Seminar. HOW, 22(2), 54-74. https://doi.org/10.19183/how.22.2.151

O' Keeffe, M. (2017). How can Communities of Practice and UMI technologies support and enhance STEM learning. ECSCW Doctoral Colloquium. https://doi.org/10.18420/ecscw2017-to-beadded

Odeh, S., Alves, J., Alves, G. R., Gustavsson, I., Anabtawi, M., Arafeh, L., ... Arekat, M. R. (2015). A Two-Stage Assessment of the Remote Engineering Lab VISIR at Al-Quds University in Palestine. IEEE Revista Iberoamericana de Tecnologías Del Aprendizage (IEEE RITA), 10(3), 175-185. https://doi.org/10.1109/RITA.2015.2452752

Orduña, P., Rodriguez-Gil, L., Angulo, I., Dziabenko, O., López-de-Ipiña, D., \& García-Zubía, J. (2012). Exploring students collaboration in remote laboratory infrastructures. Proceedings of the 9 th International Conference on Remote Engineering \& Virtual Instrumentation - REV2012, 1-5. https://doi.org/10.1109/REV.2012.6293159

Papachroni, A., \& Lochrie, S. (2017). Case Studies and Data. Research Methods for Business and Management, 75-78. https://doi.org/10.23912/978-1-910158-51-7-2778

Pavani, A., Barbosa, W. S., Calliari, F. P. D., Lima, V. A., \& Cardoso, G. P. (2018). Integration of an LMS, a IR and a remote lab. In Michael Auer \& D. Zutin (Eds.), Online Engineering \& Internet of Things. Lecture Notes in Networks and Systems (Vol. 22, pp. 427-442). Springer Cham. https://doi.org/10.1007/978-3-319-64352-6_90

Pavani, A., Lima, D., Temporão, G., \& Alves, G. R. (2017). Different uses for remote labs in electrical engineering education: Initial conclusions of an ongoing experience. In M. E. Auer \& T. Tsiatsos (Eds.), Proceedings of the International Conference on Interactive Mobile Communication, Technologies and Learning - IMCL 2017 (pp. 553-564). https://doi.org/10.1007/978-3-319-75175-7_86

Pea, R. D. (2004). The Social and Technological Dimensions of Scaffolding and Related Theoretical Concepts for Learning, Education and Human Activity. The Journal of Learning Sciences, $12(3), 423-451$. 
Pease, R., Vuke, M., June Maker, C., \& Muammar, O. M. (2020). A Practical Guide for Implementing the STEM Assessment Results in Classrooms: Using Strength-Based Reports and Real Engagement in Active Problem Solving. Journal of Advanced Academics, 31(3), 367-406. https://doi.org/10.1177/1932202X20911643

Pereira, J., Nardi Silva, I., Simão, J. P. S., Mellos Carlos, L., Bento Silva, J., Biléssimo, S., \& Alves, J. B. (2017). Modelo de Repositório de Práticas Didáticas de Circuitos Elétricos e Eletrônicos Utilizando o Laboratório Remoto VISIR. XLV Congresso Da Associação Brasileira de Ensino de Engenharia (COBENGE2017). Joinville, SC.

Pestana, M. H., \& Gageiro, J. N. (2014). Análise de Dados para Ciências Sociais A Complementaridade do SPSS (6a; M. Robalo, Ed.). Lisboa: Edícões Sílabo.

Peterson, G. D., \& Feisel, L. D. (2002). e-Learning: The Challenge for Engineering Education. Proceedings of the E-Technologies in Engineering Education Conference - ETEE 2002, 164169. Davos, Switzerland.

Philipsen, B., Tondeur, J., McKenney, S., \& Zhu, C. (2019). Supporting teacher reflection during online professional development: a logic modelling approach. Technology, Pedagogy and Education, 28(2), 237-253. https://doi.org/10.1080/1475939X.2019.1602077

Piaget, J. (1972). The Psychology of the Children. New York: Basic Books.

Pinto, A., Barbot, A., Viegas, C., Silva, A. A., Santos, C. A., \& Lopes, J. B. (2014). Teaching Science with Experimental Work and Computer Simulations in a Primary Teacher Education Course: What Challenges to Promote Epistemic Practices? Procedia Technology, 13, 86-96. https://doi.org/10.1016/j.protcy.2014.02.012

Post, L. S., Guo, P., Saab, N., \& Admiraal, W. (2019). Effects of remote labs on cognitive, behavioral, and affective learning outcomes in higher education. Computers \& Education, 140, 1-9. https://doi.org/10.1016/j.compedu.2019.103596

Pozzo, M. I., Borgobello, A., \& Pierella, M. P. (2019). Using questionnaires in research on universities: analysis of experiences from a situated perspective. REIRE Revista d'Innovació $i$ Recerca En Educació, 12(2), 1-16. https://doi.org/10.1344/reire2019.12.227010

Pozzo, M. I., Dobboletta, E., García-Loro, F., Sancristobal, E., Diaz, G., Castro, M., ... Alves, G. R. (2017). Sharing educational experiences from in-person classroom to collaborative lab environments. Proceedings of the IEEE Global Engineering Education Conference - EDUCON 2017, 1506-1512. IEEE. https://doi.org/10.1109/EDUCON.2017.7943049

Pozzo, M. I., Dobboletta, E., Viegas, C., Marques, M. A., Lima, N., Evangelista, I., \& Alves, G. R. (2017). Diseño de instrumentos para la investigación sobre la implementación educativa del laboratorio remoto VISIR en Latinoamérica. 1er Congresso Latinoamericano de Ingeniería CLADI. Paraná, Entre Ríos,Argentina, 13-15 September 2017.

Prasad, J., Goswami, A., Kumbhani, B., Mishra, C., Tyagi, H., Jun, J. H., ... Das, S. K. (2018). Engineering curriculum development based on education theories. Current Science, 114(9), 1829-1834. https://doi.org/10.18520/cs/v114/i09/1829-1834

Prasanna, S. (2017). Expanding the learning environment by using Internet of Things for eLearning. Proceedingss of 2017 International Conference on Intelligent Sustainable Systems (ICISS), 361-364. IEEE. https://doi.org/10.1109/ISS1.2017.8389430 
Prensky, M. (2001). Digital Natives, Digital Immigrants. On the Horizon (MCB University Press), 9(5). https://doi.org/10.1108/10748120110424816

Prince, M. J., \& Felder, R. M. (2006). Inductive Teaching and Learning Methods: Definitions, Comparisions, and Research Bases. Journal of Engineering Education, 95, 123-138. https://doi.org/10.1002/j.2168-9830.2006.tb00884.x

Prosser, M., Ramsden, P., Trigwell, K., \& Martin, E. (2003). Dissonance in experience of teaching and its relation to the quality of student learning. Studies in Higher Education, 28(1), 37-48. https://doi.org/10.1080/03075070309299

Ramírez-Montoya, M. S. (2015). Acceso abierto y su repercusión en la Sociedad del Conocimiento: Reflexiones de casos prácticos en Latinoamérica. Education and Information Technologies, 16(1), 103-118. https://doi.org/10.14201/eks2015161103118

Ramírez-Montoya, M. S. (Ed.). (2017). Handbook of Research on Driving STEM Learning With Educational Technologies. IGI Global.

Ramsden, P. (1987). Improving Teaching and Learning in Higher Education: The case for a relational perspective. Studies in Higher Education, 12(3), 275-286. https://doi.org/10.1080/03075078712331378062

Ramsden, P. (1992). Learning to Teach in Higher Education. London: Routledge Falmer.

Redaelli, J. C., \& Lima Jr, O. F. (2013). Self-Regulated Learning Strategies Applied to Undergraduate, Graduate and Specialization Students from Civil Engineering. International Journal of Engineering Pedagogy (IJEP), 3(2), 23-26. https://doi.org/10.3991/ijep.v3is2.2421

Redish, E. F. (2003). Teaching Physisc in a Physics Suite. USA: John Wiley \& Sons, Inc.

Restivo, M. T., \& Alves, G. R. (2013). Acquisition of higher-order experimental skills through remote and virtual laboratories. In Olga Dziabenko \& J. García-Zubía (Eds.), IT Innovative Practices in Secondary Schools: Remote experiments (pp. 321-347). Bilbao, Spain: Deusto Univeristy Press.

Richardson, J. T. E. (2011). Approaches to studying, conceptions of learning and learning styles in higher education. Learning and Individual Differences, 21(3), 288-293. https://doi.org/10.1016/j.lindif.2010.11.015

Rivera, L. F. Z., \& Petrie, M. M. L. (2016). Models of collaborative remote laboratories and integration with learning environments. International Journal of Online Engineering, 12(9), 14-21. https://doi.org/10.3991/ijoe.v12i09.6129

Rocha Roque, G., Izidoro, C. L., Nardia Silva, K., Simão, J. P. S., Alves, G. R., Bilessimo, S., \& Bento Silva, J. (2017). Utilização do Laboratório Remoto VISIR como Recurso Educacional num Curso de Engenharia Mecatrônica. XLV Congresso Da Associação Brasileira de Ensino de Engenharia (COBENGE2017). Retrieved from http://recipp.ipp.pt/handle/10400.22/10800

Rodriguez-Gil, L., García-Zubía, J., Orduña, P., \& Lopez-Ipiña, D. (2017). Towards New Multiplatform Hybrid Online Laboratory Models. IEEE Transactions on Learning Technologies, 10(3), 318-330. https://doi.org/10.1109/TLT.2016.2591953

Rodriguez-Gil, L., Orduña, P., García-Zubía, J., \& López-de-Ipiña, D. (2012). Advanced integration 
of OpenLabs VISIR (Virtual Instrument Systems in Reality) with Weblab-Deusto. Proceedings of the 9th International Conference on Remote Engineering \& Virtual Instrumentation - REV 2012, 1-7. https://doi.org/10.1109/REV.2012.6293150

Roldão, M. do C. (2003). Gestão do Currículo e Avaliação de Competências. Lisboa: Editorial Presença.

Roldão, M. do C., \& Almeida, S. (2018). Gestão Curricular para a a autonomia das escolas e professores (J. V. Pedroso, Ed.). Portugal: Direção-Geral da Educação (DGE).

Romero, S., Guenaga, M., García-Zubía, J., \& Orduña, P. (2014). New challenges in the Bologna Process using Remote Laboratories and Learning Analytics to support teachers in continuous assessment. Proceedings of the XVI International Symposium on Computers in Education - SIIE 2014, 227-230. https://doi.org/10.1109/SIIE.2014.7017735

Rosa, C. W., \& Rosa, Á. B. (2007). Ensino da Física: tendências e desafios na prática docente. Revista Iberoamericana de Educación, 42(7), 1-12. Retrieved from http://www.rieoei.org/deloslectores/1770Rosa.pdf

Rose, K., Eldrdge, S., \& Chapin, L. (2015). The Internet of Things: an Overview Understanding the Issued and Challenges of a More Connected World (Carolyn Marsan, Ed.). (C) 2015 The Internet Society (ISOC).

Salah, R. M., Alves, G. R., Abdulazeez, D. H., Guerreiro, P., \& Gustavsson, I. (2015). Why VISIR? Proliferative Activities and Collaborative Work of VISIRSystem. Proceedings of the 7Th International Conference on Education and New Learning Technologies - Edulearn15, 38243835. Barcelona, Spain: IATED.

Samavedham, L., \& Ragupathi, K. (2015). Facilitating 21st century skills in engineering students. The Journal of Engineering Education, XXVI(1).

Sancristobal, E., Martín, S., Gil, R., Orduña, P., Tawfik, M., Pesquera, A., ... Castro, M. (2012). State of art, initiatives and new challenges for virtual and remote labs. Proceedings of the 12th IEEE International Conference on Advanced Learning Technologies and Technology-Enhanced Learning, ICALT 2012, 714-715. https://doi.org/10.1109/ICALT.2012.232

Sarabando, C., Cravino, J. P., \& Soares, A. A. (2016). Improving student understanding of the concepts of weight and mass with a computer simulation. Journal of Baltic Science Education, 15(1), 109-126.

Schön, D. (1983). The reflective practioner: How professionals think in action. New York: Basic Books.

Schunk, D. H., \& Zimmerman, B. (Eds.). (1998). Self-regulated learning: From teaching to selfreflective practicele. Guilford Publications.

Scott, P. H., Mortimer, E. F., \& Aguiar, O. G. (2006). The tension between authoritative and dialogic discourse: A fundamental characteristic of meaning making interactions in high school. Science Education, 90(4), 605-631. https://doi.org/10.1002/sce.20131

Sell, R., \& Rüütmann, T. (2015). The International Cooperation on Remote Laboratories in the Framework of Engineering Didactics. International Journal of Engineering Pedagogy (IJEP), 5(1), 8-11. https://doi.org/10.3991/ijep.v5i1.3917 
Seoane-Pardo, A. M., \& García-Peñalvo, F. J. (2008). Online Tutoring and Mentoring. In G. D. Putnik \& M. M. Cunha (Eds.), Encyclopedia of Networked and Virtual Organizations (Vol II) (pp. 11201127). Information Science Reference.

Serdyukov, P., \& Serdyukova, N. (2011). Online Instructor's Efficiency : Why Can't We Do Better? E-Leader Croatia.

Shanta, S., \& Wells, J. G. (2020). T/E design based learning: assessing student critical thinking and problem solving abilities. International Journal of Technology and Design Education(In Press). https://doi.org/10.1007/s10798-020-09608-8

Shea, P., \& Bidjerano, T. (2013). Understanding distinctions in learning in hybrid, and online environments: An empirical investigation of the community of inquiry framework. Interactive Learning Environments, 21(4), 355-370. https://doi.org/10.1080/10494820.2011.584320

Sicker, D. C., Lookabaugh, T., Santos, J., \& Barnes, F. (2005). Assessing the Effectiveness of Remote Networking Laboratories. Proceedings Frontiers in Education 35th Annual Conference, S3F-7S3F-12. https://doi.org/10.1109/fie.2005.1612279

Silva, J. B., Nardi Silva, I., \& Biléssimo, S. (2020). Technological structure for technology integration in the classroom, inspired by the maker culture. Journal of Information Technology Education: Research, 19, 167-204. https://doi.org/htttps://doi.org/10.28945/4532

Silverman, W. L., \& Forum, L. (1988). Learning and Teaching Styles in Engineering Education. Engineering Education, 78(7), 674-681.

Soini, T., Pietarinen, J., \& Pyhältö, K. (2016). What if teachers learn in the classroom? Teacher Development, 20(3), 380-397. https://doi.org/10.1080/13664530.2016.1149511

Soria, M. F., Fernandez, R., Fernández, R., Gómez, M., Paz, H., Pozzo, M. I., ... Diaz, G. (2017). Perspectivas de los Laboratorios Remotos en la Educación Media y Superior de Santiago del Estero. 1er Congresso Latinoamericano de Ingeniería - CLADI. Paraná, Entre Ríos,Argentina, 13-15 September 2017.

Stiwne, E. E., \& Jungert, T. (2010). Engineering students' experiences of transition from study to work. Journal of Education and Work, 23(5), 417-437. https://doi.org/10.1080/13639080.2010.515967

Tawfik, M., Monteso, S., García-Loro, F., Losada, P., Antonio-Barba, J., Ruiz, E., ... Castro, M. (2015). Online Experiments with DC/DC Converters Using the VISIR Remote Laboratory. IEEE Revista Iberoamericana de Tecnologias Del Aprendizaje (IEEE RITA), 10(4), 310-318. https://doi.org/10.1109/RITA.2015.2486459

Tawfik, M., Monteso, S., Garcia-Loro, F., Sancristobal, E., Ruiz, E., Díaz, G., ... Castro, M. (2014). Novel design and development of advanced remote electronics experiments. Computer Applications in Engineering Education, n/a-n/a. https://doi.org/10.1002/cae.21602

Tawfik, M., Monteso, S., García-Loro, F., Sancristobal, E., Ruiz, E., Díaz, G., ... Castro, M. (2015). Novel design and development of advanced remote electronics experiments. Computer Applications in Engineering Education, 23(3), 327-336. https://doi.org/10.1002/cae.21602

Tawfik, M., Sancristobal, E., Martin, S., Diaz, G., \& Castro, M. (2012). State-of-the-art remote 
laboratories for industrial electronics applications. Proceedings of the 2012 Technologies Applied to Electronics Teaching (TAEE), 359-364. https://doi.org/10.1109/TAEE.2012.6235465

Tawfik, M., Sancristobal, E., Martín, S., Gil, C., Pesquera, A., Losada, P., ... Alves, G. R. (2011). VISIR deployment in undergraduate engineering practices. Proceedings of the 2011 Frontiers in Education Conference (FIE), T1A-1-T1A-7. https://doi.org/10.1109/FIE.2011.6143133

Tawfik, M., Sancristobal, E., Martín, S., Gil, C., Pesquera, A., Losada, P., ... Alves, G. R. (2012). VISIR: Experiences and challenges. International Journal of Online Engineering, 8(1), 25-32. https://doi.org/10.3991/ijoe.v8i1.1879

Tawfik, M., Sancristobal, E., Martín, S., Gil, C., Pesquera, A., Ros, S., ... Castro, M. (2011). Towards a Better Deplyment of of Remote Laboratories in Undergraduate Enginereeing Education. In J. García Zubía \& G. R. Alves (Eds.), Using Remote Labs in Education: Two Little Ducks in Remote Engineerring (1st ed., pp. 387-402). Bilbao, Spain: Deusto Univeristy Press.

Tawfik, M., Sancristobal, E., Martín, S., Gil, R., Diaz, G., Colmenar, A., ... Gustavsson, I. (2013). Virtual instrument systems in reality (VISIR) for remote wiring and measurement of electronic circuits on breadboard. IEEE Transactions on Learning Technologies, 6(1), 60-72. https://doi.org/10.1109/TLT.2012.20

Tchoshanov, M. (2013). Engineering of Learning: Conceptualizing e-Didactics (Svetlana Knyazeva, Ed.). Retrieved from www.iite.unesco.org

The Glossary of Education Reform. (2015). Retrieved from https://www.edglossary.org/assessment/

Tibilova, G. S., Ovcharenko, A. V., \& Potapova, A. V. (2020). Proactivity and Subsidiarity as the Basic Principles of Digital Transformation of State Interaction with Citizens and Businesses. In D. G. Arseniev, L. Overmeyer, H. Kälviäinen, \& B. Katalinić (Eds.), International Conference Cyber-Physical Systems and Control (CPS\&C'2019) (pp. 544-553). https://doi.org/10.1007/978-3-030-34983-7_53

Tinoco-Giraldo, H., Torrecilla Sánchez, E. M., \& García-Peñalvo, F. J. (2020). E-Mentoring in Higher Education: A Structured Literature Review and Implications for Future Research. Sustainability, 12(11). https://doi.org/10.3390/su12114344

Valcke, M., Sang, G., Rots, I., \& Hermans, R. (2010). Taking prospective teachers' beliefs into account in teacher education. International Encyclopedia of Education, 7, 622-628. https://doi.org/10.1016/B978-0-08-044894-7.00668-0

Varela, B. (2013). Evolução dos paradigmas educacionais e "novas" tendências nas abordagens pedagógico-didáticas. Seminário de Formação de Professores Do ISPTEC Em Currículo e Didática Do Ensino Superior, 1-37. https://doi.org/10.13140/2.1.2343.0726

Veletsianos, G. (2016). Digital Learning Environments. In R. Nick \& D. W. Surry (Eds.), The Wiley Handbook of Learning Technology (1st ed., pp. 242-260. (C) 2016 John Wiley \& Sons, Inc.). https://doi.org/10.1002/9781118736494.ch14

Viegas, C. (2017a). Students' Assessment in Teaching Science and Technology. In J. B. Lopes, J. Cravino, E. Cruz, \& A. Barbot (Eds.), Teaching Science (pp. 283-301). (C) 2017 Nova Science Publishers, Inc. 
Viegas, C. (2017b). The development of comptences in Engineering Students. In J. B. Lopes, J. Cravino, E. Cruz, \& A. Barbot (Eds.), Teaching Science (pp. 189-207). (C) 2017 Nova Science Publishers, Inc.

Viegas, C., Alves, G. R., \& Lima, N. (2015). Formative assessment diversity to foster students engagement. Proceedings of the 18th International Conference on Interactive Collaborative Learning - ICL 2015, 929-935. IEEE. https://doi.org/10.1109/ICL.2015.7318152

Viegas, C., Alves, G. R., Marques, M. A., Lima, N., Felgueiras, M. C., Costa, R., ... Kreiter, C. (2017). The VISIR+ Project - Preliminary results of the training actions. Proceedings of the 14th International Conference on Remote Engineering \& Virtual Instrumentation - REV2017. New York, USA.

Viegas, C., Alves, G. R., Marques, M. A., Lima, N., Felgueiras, M. C., Costa, R., ... Kreiter, C. (2018). The VISIR+ Project - Preliminary results of the training actions. In Michael Auer \& D. Zutin (Eds.), Online Engineering \& Internet of Things. Lecture Notes in Networks and Systems (Vol. 22, pp. 375-391). Springer Cham. https://doi.org/10.1007/978-3-319-64352-6_36

Viegas, C., Lima, N., Alves, G. R., \& Gustavsson, I. (2014). Improving students experimental competences using simultaneous methods in class and in assessments. In F. J. García-Peñalvo (Ed.), Proceedings of the Second International Conference on Technological Ecosystems for Enhancing Multiculturality (TEEM'14) (pp. 125-132). New York, USA:ACM. https://doi.org/10.1145/2669711.2669890

Viegas, C., Lopes, J. B., \& Cravino, J. P. (2009). Incremental Innovations in a Physics Curriculum for Engineering Undergraduates. In W. Aung, K. Kim, J. Mecsi, J. Moscinnski, \& I. Rouse (Eds.), Innovations 2009: World Innovations in Engineering Education and Research (pp. 175-186). Arlington, VA, USA:iNEER.

Viegas, C., Lopes, J. B., \& Cravino, J. P. (2010). Learning through Assessment and Feedback in and out of Class. In W. Aung, K. Kim, J. Mecsi, J. Moscinnski, \& I. Rouse (Eds.), Innovations 2010 World Innovations in Engineering Education and Research (pp. 33-46). Arlington, VA, USA:iNEER.

Viegas, C., Pavani, A., Lima, N., Marques, M. A., Pozzo, M. I., Dobboletta, E., ... Alves, G. R. (2018). Impact of a remote lab on teaching practices and student learning. Computers \& Education, 126, 201-216. https://doi.org/10.1016/j.compedu.2018.07.012

Vygotsky, L. S. (1978). Mind in Society: The development of higher psychological processes. Cambridge, Massachusettes: Harvard Univeristy Press.

Wei, J., Treagust, D. F., Mocerino, M., Lucey, A. D., Zadnik, M. G., \& Lindsay, E. D. (2019). Understanding interactions in face-to-face and remote undergraduate science laboratories : a literature review. Disciplinary and Interdisciplinary Science Education Research, 1(14), 116.

Wendell, K. B., Wright, C. G., \& Paugh, P. (2017). Reflective Decision-Making in Elementary Students' Engineering Design. Journal of Engineering Education, 106(3), 356-397. https://doi.org/doi.org/10.1002/jee.20173

Wenger, E., Mcdermott, R. A., \& Snyder, W. (2002). Cultivating communities of practice: a guide to managing Knowledge. Harvard Business Press. 
William, D. (2011). What is assessment for learning? Studies in Education Evaluation, 37, 3-14.

Williams, B., \& Neto, P. (2012). Tracking Engineering Education Research and Development. International Journal of Engineering Pedagogy (IJEP), 2(2), 37. https://doi.org/10.3991/ijep.v2i2.2087

Williams, C. (2007). Research Methods. Journal of Business \& Economic Research, 5(3), 65-72.

Wilson, S., Liber, O., Johnson, M., Beauvoir, P., Sharples, P., \& Milligan, C. (2007). Personal Learning Environments: Challenging the dominant design of educational systems. Journal of $E$ Learning and Knowledge Society, 3(3), 27-38.

Wood, D., \& O’Malley, C. (1996). Collaborative Learning between Peers. Educational Psycology in Practice, 11(4), 4-9.

Yin, R. K. (2014). Case Study Research Design and Methods (5th ed.). Thousand Oaks, CA: Sage.

Zahonero Rovira, A., \& Martín Bris, M. (2012). Formación integral del profesorado : hacia el desarrollo de competencias personales y de valores en los docentes. Tendencias Pedagógicas, 20(0), 51-70.

Zainal, Z. (2007). Case Study as a Research Method. Journal Kemanusiaan, 9(1), 1-6. https://doi.org/10.1515/klio-2015-0004

Zimmerman, B. (2000). Attaining self-regulation: a social cognitive perspective. In M. Boekaerts, P. Pintrich, \& M. Zeidner (Eds.), Handbook of Self-Regulation. New York: Academic Press.

Zutin, D. G., Auer, M. E., Maier, C., \& Niederstätter, M. (2010). Lab2go - A repository to locate educational online laboratories. Proceedings of the 1st IEEE Global Engineering Education Conference - EDUCON 2010, 1741-1746. https://doi.org/10.1109/EDUCON.2010.5492412 


\section{APPENDiX A - STUDENT'S SATISFACTION QUESTIONNAIRE}

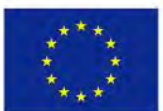

Co-funded by the

Erasmus+ Programme

of the European Union

Educational Modules for Electric and Electronic Circuits Theory and Practice following an Enquiry-based Teaching and Learning Methodology supported by VISIR

LATIN AMERICAN PARTNER: (name of HEI)

Institution: (name of HEI)

Degree: (name of Degree)

Course: (name of Course)

Head Teacher: (name of Teacher)

\section{STUDENT'S SATISFACTION QUESTIONNAIRE}

Student ID Number:

1: I don't agree

2: I partially agree

3: I agree

4: I fully agree

Please read the sentences and write a X with your opinion:

\begin{tabular}{|c|c|c|c|c|}
\hline & 1 & 2 & 3 & 4 \\
\hline 1. I could use VISIR $24 / 7$, so I frequently performed experiments & & & & \\
\hline 2. VISIR helped me understand the subject better & & & & \\
\hline 3. I prefer hands-on experiments to remote labs & & & & \\
\hline 4. I found support in the institutional LMS (hyperlinks, manuals, forum) & & & & \\
\hline 5. I tried the experiments many times if I thought measures were odd & & & & \\
\hline 6. I found the measurement devices easy to use & & & & \\
\hline 7. I showed VISIR experiments to people outside university & & & & \\
\hline 8. Even away from VISIR I felt I controlled the all the time & & & & \\
\hline 9. I read VISIR students' manual to learn more about the system & & & & \\
\hline 10. Instructions for experiments were always clear & & & & \\
\hline 11. I always shared experiment results with my peers & & & & \\
\hline 12. I was less afraid of damaging the remote lab system than during hands & & & & \\
\hline 13. I could see the differences between results obtained by simulations and & & & & \\
\hline 14. I think I can manage the remote lab very well & & & & \\
\hline 15. I usually had problems with the server & & & & \\
\hline 16. I think I can work out electricity problems from real-life & & & & \\
\hline 17. I wish I had remote labs in other subjects & & & & \\
\hline 18. I could see similarities between experimenting with remote and hands- & & & & \\
\hline 19. It was hard to find time to perform the assigned experiments & & & & \\
\hline 20. I could use scientific concepts to explain the results of the experiments & & & & \\
\hline
\end{tabular}


21. What did you enjoy most about using VISIR remote lab?

22. What inconveniences did you find about using VISIR remote lab?

Work Package 3:

IRICE- CONICET: María Isabel Pozzo - Elsa Dobboletta

IPP/ISEP: Clara Viegas - Arcelina Marques - Natércia Lima 


\section{APPENDIX B - TEACHER'S INTERVIEW SCRIPT}

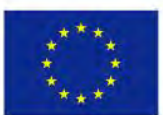

Co-funded by the

Erasmus+ Programme

of the European Union

Educational Modules for Electric and Electronic Circuits Theory and Practice following an Enquiry-based Teaching and Learning Methodology supported by VISIR

LATIN AMERICAN PARTNER: (name of HEI)

Institution: (name of HEI)

Degree: (name of Degree)

Course: (name of Course)

Head Teacher: (name of Teacher)

\section{TEACHER'S INTERVIEW}

Please answer the following questions

\begin{tabular}{|c|c|c|c|}
\hline & YES & Sometimes & NO \\
\hline 1. Did you find the use of VISIR remote lab easy? & & & \\
\hline 2. Did you assign more experiments practice than you us & & & \\
\hline 3. Did you have problems with the server? & & & \\
\hline 4. Did you find the components suitable for your teachin & & & \\
\hline 5. Were the log-in procedures difficult to carry out? & & & \\
\hline 6. Did students have more practice with calculation exerc & & & \\
\hline 7. Did you use open experiments? & & & \\
\hline 8. Was the user interface user friendly? & & & \\
\hline 9. Did you use VISIR teacher, student and user manuals? & & & \\
\hline
\end{tabular}

1. What advantages and disadvantages do you find in the use of remote labs?

Work Package 3:

IRICE- CONICET: María Isabel Pozzo - Elsa Dobboletta

IPP/ISEP: Clara Viegas - Arcelina Marques - Natércia Lima
VISIR+ Teacher's Interview 


\section{APPENDix C - EduCATIONAL MOdULES}

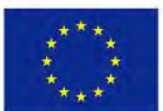

Co-funded by the

Erasmus+ Programme

of the European Union

Educational Modules for Electric and Electronic Circuits Theory and Practice following an Enquiry-based Teaching and Learning Methodology supported by VISIR

LATIN AMERICAN PARTNER: (name of HEI)

RESPONSIBLE MEMEBER: (name of HEl contact member)

\section{VISIR+ EDUCATIONAL DESCRIPTIONS}

Course:

Teaching staff:

MODULE Title:

Topic:

\section{Teaching \& Learning Methodology}

- Did you use an Inquiry-based learning methodology? Yes / No

If yes, in which average percentage did you use it along the course? $\%$

(Inquiry-based learning is an inductive process in which students pose a question from real or hypothetical scenarios, develop experiments, collect and analyse data, answer initial question and present the results)

AIM

- In which \% did you use VISIR along the semester?

$$
\text { (in weeks/ semester) }
$$
$\%$

(in course curricula content) $\%$

- What were your educational goals while using VISIR?

(examples of answers: motivate students; allow students to practice outside lab (before, after...); complementary to students' usual developments...)

- Which were the expected competences to be developed? 
(examples of answers: to be able to measure electric currents in circuits; help students understand the difference between measures in hands-on labs, remote labs, simulations and calculus; be able to work in different resources, developing critical thinking, autonomy...)

\section{RESOURCES}

- Did you use other resources in simultaneous (besides VISIR)? With what periodicity?

Calculus problems

Hand-on lab

Simulations

Other:

Other: (never / seldom / frequently)

(never / seldom / frequently)

(never / seldom / frequently)

(never / seldom / frequently)

(never / seldom / frequently)

- What kind of tasks (and in which number) did you developed using VISIR?

(examples of answers: $x$ lab guides; y VISIR “learn to use it” tasks; ...)

\section{IMPLEMENTATION}

- How was VISIRs' first approached with students?

(examples of answers: there was a previous presentation; it was also developed in class; there was support to students' doubts (in LMS platform)...)

- How will students' learning with VISIR be assessed?

(examples of answers: $\mathrm{x} \%$ in the final assessment; final exams used VISIR in $\mathrm{x} \%$; it was not accounted in the final grade...)

Work Package 3:

VISIR+ Educational Modules

IRICE- CONICET: María Isabel Pozzo - Elsa Dobboletta

IPP/ISEP: Clara Viegas - Arcelina Marques - Natércia Lima 


\section{APPENDIX D - TARgET COURSE FACT FILE}

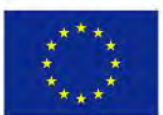

Co-funded by the

Erasmus+ Programme

of the European Union

Educational Modules for Electric and Electronic Circuits Theory and Practice following an Enquiry-based Teaching and Learning Methodology supported by VISIR

- $\quad$ This document must be filled by each EU Partner in associating with his LA Partner HEI.

- $\quad$ One fact file per implementation

\section{VISIR+ EDUCATIONAL DESCRIPTIONS}

LATIN AMERICAN PARTNER: (name of HEI)

RESPONSIBLE MEMEBER: (name of the person who filled this fact file)

VISIR+ IMPLEMENTATION: From: to

Please fill in the form below with information about the course you have selected to carry out the implementation

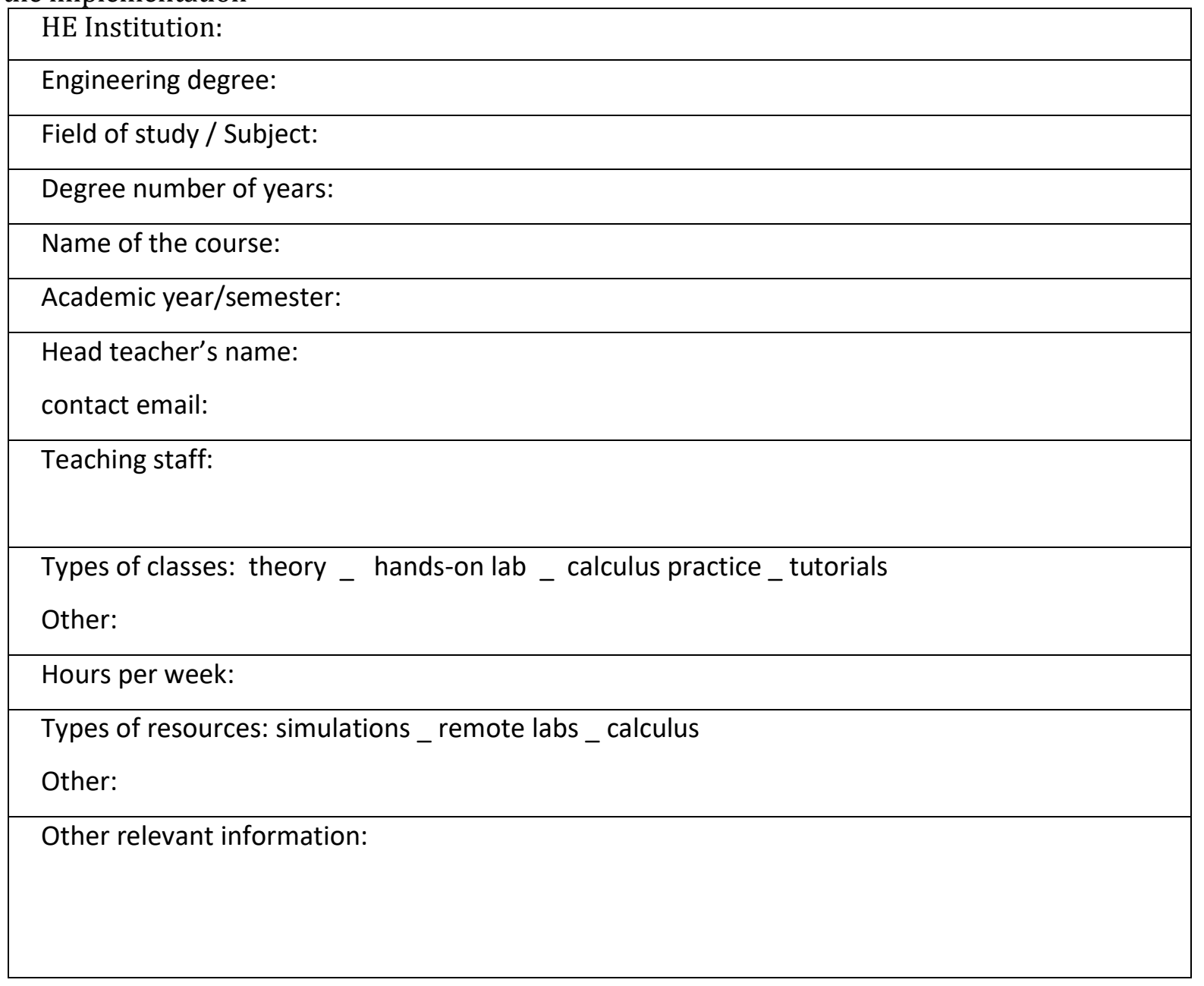




\section{STUDENTS' PERFORMANCE RECORDS}

Please fill in the form table about the course before and after the implementation where applicable

\begin{tabular}{|c|c|c|}
\hline & $\begin{array}{l}\text { Before } \\
\text { implementation }\end{array}$ & $\begin{array}{l}\text { After } \\
\text { implementation }\end{array}$ \\
\hline \multicolumn{3}{|l|}{ Number of students in target course } \\
\hline \multicolumn{3}{|l|}{ Percentage of freshman } \\
\hline \multicolumn{3}{|l|}{ Average of students' general grades } \\
\hline \multicolumn{3}{|l|}{ Average of students' grades on hands-on lab } \\
\hline \multicolumn{3}{|l|}{ Average of students' grades using VISIR } \\
\hline \multicolumn{3}{|l|}{ Average of student's grades using simulation } \\
\hline \multicolumn{3}{|l|}{ Average of students' grades in calculus problems } \\
\hline \multicolumn{3}{|l|}{$\begin{array}{l}\text { Number of students who didn't fulfil any kind of } \\
\text { assessment }\end{array}$} \\
\hline \multicolumn{3}{|l|}{$\begin{array}{l}\text { Students that teachers consider having developed } \\
\text { high skills }\end{array}$} \\
\hline \multicolumn{3}{|l|}{$\begin{array}{l}\text { Did you find any difference in students' motivation } \\
\text { when using hand-on, simulators or remote labs? }\end{array}$} \\
\hline \multicolumn{3}{|c|}{$\begin{array}{l}\text { Were students asked to reflect on their learning experiences while carrying out VISIR } \\
\text { implementation? }\end{array}$} \\
\hline \multicolumn{3}{|l|}{ Comments on student's general performance } \\
\hline
\end{tabular}




\section{APPEndiX E - Methodology Details}

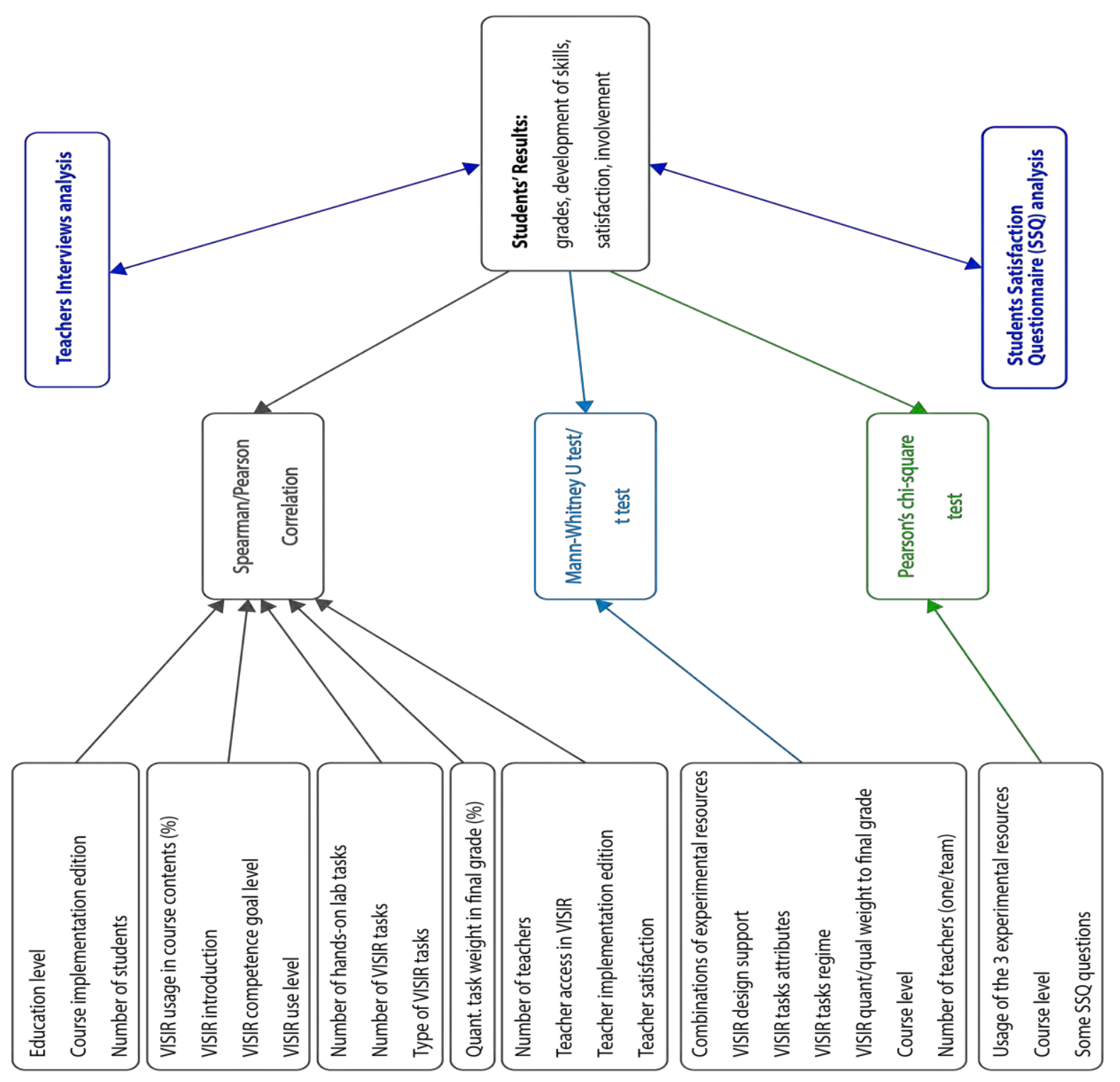

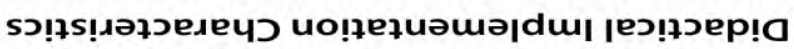




\section{APPEndix F - Summary OF THE ANAlyses Involving EACH CASE}

\begin{tabular}{|c|c|c|c|c|c|c|}
\hline \multirow{2}{*}{ 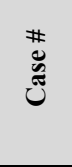 } & \multicolumn{4}{|c|}{ Correlations } & \multirow{2}{*}{ SSQ } & \multirow{2}{*}{$\begin{array}{l}\text { Teacher's } \\
\text { Interview }\end{array}$} \\
\hline & $\begin{array}{l}N . \text { VISIR } \\
\text { accesses/task } \\
\text { with grades. }\end{array}$ & $\begin{array}{l}\text { VISIR grade and other task } \\
\text { grade with other components } \\
\text { and final grade }\end{array}$ & $\begin{array}{l}F 1 \text { and } F 2 \text { with } N \text {. VISIR } \\
\text { accesses/task and grades. }\end{array}$ & F1 with F2 & & \\
\hline $\mathrm{C} 1$ & $\mathrm{X}$ & $\mathrm{X}$ & $\mathrm{X}$ & $\mathrm{X}$ & $\mathrm{X}$ & $\mathrm{X}$ \\
\hline $\mathrm{C} 2$ & $\mathrm{X}$ & $\mathrm{X}$ & $\mathrm{X}$ & $\mathrm{X}$ & $\mathrm{X}$ & $\checkmark$ \\
\hline C3 & $\mathrm{X}$ & $J$ & $J$ & $J$ & $J$ & $\checkmark$ \\
\hline C4 & $\mathrm{X}$ & $\mathrm{X}$ & $\mathrm{X}$ & $\mathrm{X}$ & J & $\checkmark$ \\
\hline C5 & $J$ & $J$ & $J$ & $J$ & $J$ & $J$ \\
\hline C6 & $\mathrm{X}$ & $\mathrm{X}$ & $\mathrm{X}$ & $\mathrm{X}$ & $J$ & $J$ \\
\hline C7 & X & X & $J$ & $J$ & $J$ & $J$ \\
\hline C8 & $J$ & $J$ & $J$ & $J$ & $J$ & $J$ \\
\hline C9 & $J$ & $J$ & $J$ & $J$ & $J$ & $J$ \\
\hline $\mathrm{C} 10$ & $\mathrm{X}$ & $J$ & $J$ & $J$ & $J$ & $J$ \\
\hline C11 & $J$ & $J$ & $J$ & $J$ & $J$ & $J$ \\
\hline $\mathrm{C12}$ & $J$ & $\mathrm{X}$ & $\mathrm{X}$ & $\mathrm{X}$ & $J$ & $J$ \\
\hline $\mathrm{C} 13$ & $\checkmark$ & $\mathrm{X}$ & $\checkmark$ & $J$ & $J$ & $J$ \\
\hline C14 & $J$ & $J$ & $\checkmark$ & $J$ & $J$ & $J$ \\
\hline $\mathrm{C} 15$ & $J$ & $\mathrm{X}$ & $J$ & $J$ & $J$ & $J$ \\
\hline C16 & $\checkmark$ & $J$ & $J$ & $J$ & $J$ & $J$ \\
\hline C17 & $\mathrm{X}$ & $\mathrm{X}$ & $\mathrm{X}$ & $\mathrm{X}$ & $\checkmark$ & $\mathrm{X}$ \\
\hline C18 & $\mathrm{X}$ & $\mathrm{X}$ & $\mathrm{X}$ & $\mathrm{X}$ & $\mathrm{X}$ & $J$ \\
\hline C19 & $\sqrt{ }$ & $J$ & $\sqrt{ }$ & $J$ & $\sqrt{ }$ & $J$ \\
\hline $\mathrm{C20}$ & $\sqrt{ }$ & $J$ & $\sqrt{ }$ & $J$ & $J$ & $J$ \\
\hline C21 & $\mathrm{X}$ & $\mathrm{X}$ & $\checkmark$ & $J$ & $\sqrt{ }$ & $\checkmark$ \\
\hline $\mathrm{C22}$ & $\mathrm{X}$ & $\mathrm{X}$ & $\mathrm{X}$ & $J$ & $J$ & $J$ \\
\hline $\mathrm{C} 23$ & $J$ & $J$ & $J$ & $J$ & $J$ & $J$ \\
\hline $\mathrm{C24}$ & $\mathrm{X}$ & $J$ & $J$ & $J$ & $J$ & $J$ \\
\hline $\mathrm{C25}$ & $\checkmark$ & $\mathrm{X}$ & $\mathrm{X}$ & $\mathrm{X}$ & $J$ & $J$ \\
\hline C26 & $J$ & $\checkmark$ & $\checkmark$ & $J$ & $\checkmark$ & $J$ \\
\hline
\end{tabular}

Legend: $\boldsymbol{J}$ - possible to run the analysis or procedure (at least partially); X - not possible to run the analysis/procedure 


\section{APPENDIX G - MANN-Whitney TeSt RESUlts for TeACHERS}

\begin{tabular}{|c|c|c|c|c|c|c|c|}
\hline Factor & Group & $\mathbf{N}$ & $\begin{array}{l}\text { Mean } \\
\text { Rank }\end{array}$ & $\begin{array}{l}\text { Sum of } \\
\text { Ranks }\end{array}$ & Test Variable & $\begin{array}{c}\text { Mann- } \\
\text { Whitney U }\end{array}$ & $\begin{array}{c}\text { Asymp. Sig. } \\
\text { (2-tailed.) } \\
\text { (p value) }\end{array}$ \\
\hline \multirow{4}{*}{ Used Simulation? } & No & 12 & 20.50 & 246.00 & \multirow{2}{*}{$\begin{array}{c}\text { Teachers' Satisfaction with } \\
\text { VISIR }\end{array}$} & \multirow{2}{*}{156.000} & \multirow{2}{*}{0.505} \\
\hline & Yes & 27 & 19.78 & 534.00 & & & \\
\hline & No & 12 & 17.58 & 211.00 & Number of Teachers' & 107000 & 0.613 \\
\hline & Yes & 20 & 15.85 & 317.00 & Accesses/Task & $10 \% .000$ & 0.613 \\
\hline \multirow{4}{*}{ Used Hands-on? } & No & 7 & 20.50 & 143.50 & \multirow{2}{*}{$\begin{array}{c}\text { Teachers' Satisfaction with } \\
\text { VISIR }\end{array}$} & \multirow{2}{*}{108.500} & \multirow{2}{*}{0.640} \\
\hline & Yes & 32 & 19.89 & 636.50 & & & \\
\hline & No & 6 & 16.47 & 100.00 & \multirow{2}{*}{$\begin{array}{c}\text { Number of Teachers' } \\
\text { Accesses/Task }\end{array}$} & \multirow{2}{*}{77.000} & \multirow{2}{*}{0.961} \\
\hline & Yes & 26 & 16.46 & 428.00 & & & \\
\hline \multirow{4}{*}{$\begin{array}{l}\text { Number of } \\
\text { Teachers } \\
\text { involved? }\end{array}$} & 1 & 18 & 20.50 & 369.00 & \multirow{2}{*}{$\begin{array}{c}\text { Teachers' Satisfaction with } \\
\text { VISIR }\end{array}$} & \multirow{2}{*}{180.000} & \multirow{2}{*}{0.355} \\
\hline & $>1$ & 21 & 19.57 & 411.00 & & & \\
\hline & 1 & 13 & 18.31 & 238.00 & Number of Teachers' & 100000 & 0367 \\
\hline & $>1$ & 19 & 15.26 & 290.00 & Accesses/Task & 100.000 & $0.36 /$ \\
\hline \multirow{4}{*}{ Task Mandatory? } & No & 26 & 19.50 & 507.00 & \multirow{2}{*}{$\begin{array}{c}\text { Teachers' Satisfaction with } \\
\text { VISIR }\end{array}$} & \multirow{2}{*}{130.000} & \multirow{2}{*}{0.124} \\
\hline & Yes & 11 & 17.82 & 196.00 & & & \\
\hline & No & 21 & 17.95 & 377.00 & Number of Teachers' & 85000 & 0226 \\
\hline & Yes & 11 & 13.73 & 151.00 & Accesses/Task & 0.000 & 0.220 \\
\hline & No & 16 & 16.50 & 264.00 & Teachers' Satisfaction with & & \\
\hline & Yes & 15 & 15.47 & 232.00 & VISIR & 112.000 & 0.302 \\
\hline I ask in Groups? & No & 14 & 17.00 & 238.00 & Number of Teachers' & 63000 & 0108 \\
\hline & Yes & 14 & 12.00 & 168.00 & Accesses/Task & 63.000 & 0.108 \\
\hline & Qual & 13 & 19.50 & 273.00 & Teachers' Satisfaction with & 154.000 & 0.435 \\
\hline Tack A scescment? & Quant & 23 & 18.70 & 430.00 & VISIR & 154.000 & 0.455 \\
\hline I ask Assessment? & Qual & 11 & 14.00 & 154.00 & Number of Teachers' & & \\
\hline & Quant & 21 & 17.81 & 374.00 & Accesses/Task & 88.000 & $0.2 / 5$ \\
\hline & No & 16 & 20.50 & 328.00 & Teachers' Satisfaction with & & \\
\hline Used the 3 & Yes & 23 & 19.65 & 452.00 & VISIR & 176.000 & 0.404 \\
\hline resources? & No & 15 & 18.27 & 274.00 & Number of Teachers' & 101000 & 0317 \\
\hline & Yes & 17 & 14.94 & 254.00 & Accesses/Task & 101.000 & 0.317 \\
\hline & No & 10 & 15.00 & 150.00 & Teachers' Satisfaction with & & \\
\hline VISIR Support & Yes & 19 & 15.00 & 285.00 & VISIR & 95.000 & 1.000 \\
\hline $\begin{array}{l}\text { Uploading } \\
\text { Sunnort Material? }\end{array}$ & No & 9 & 11.36 & 92.50 & Number of Teachers' & 565000 & 0503 \\
\hline & Yes & 17 & 13.68 & 232.50 & Accesses/Task & 50.5000 & 0.503 \\
\hline & No & 20 & 15.00 & 300.00 & Teachers' Satisfaction with & & \\
\hline VISIR Support & Yes & 9 & 15.00 & 135.00 & VISIR & 90.000 & 1.000 \\
\hline by email? & No & 17 & 11.97 & 203.50 & Number of Teachers' & 50.500 & 0308 \\
\hline & Yes & 8 & 15.19 & 121.50 & Accesses/Task & 50.500 & 0.308 \\
\hline & No & 17 & 15.00 & 255.00 & Teachers' Satisfaction with & 102000 & 1000 \\
\hline VISIR Support & Yes & 12 & 15.00 & 180.00 & VISIR & 000 & 1.000 \\
\hline presential? & No & 15 & 13.13 & 197.00 & Number of Teachers' & & \\
\hline & Yes & 10 & 12.80 & 128.00 & Accesses/Task & 13.000 & 0.912 \\
\hline & $\mathrm{DC}$ & 24 & 19.21 & 461.00 & Teachers' Satisfaction with & 161000 & 0445 \\
\hline Task DC or AC? & $\mathrm{AC}$ & 14 & 20.00 & 280.00 & VISIR & 101.000 & 0.443 \\
\hline Iask DC or AC? & $\mathrm{DC}$ & 19 & 16.18 & 307.50 & Number of Teachers' & 500 & 0818 \\
\hline & $\mathrm{AC}$ & 13 & 16.96 & 220.50 & Accesses/Task & 00 & 0.818 \\
\hline & No & 26 & 18.31 & 476.00 & Teachers' Satisfaction with & & \\
\hline VISIR contents & Yes & 10 & 19.00 & 190.00 & VISIR & 125.000 & 0.535 \\
\hline worked before? & No & 22 & 16.34 & 359.50 & Number of Teachers' & & \\
\hline & Yes & 9 & 15.17 & 136.50 & Accesses/Task & 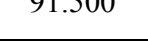 & \\
\hline & $\mathrm{EE}$ & 22 & 20.00 & 440.00 & & & \\
\hline EE majors other & Other EE & 16 & 18.81 & 301.00 & VISIR & 165.000 & 0.241 \\
\hline EE majors? & $\mathrm{EE}$ & 17 & 17.32 & 294.50 & Number of Teachers' & & \\
\hline & Other EE & 15 & 15.37 & 233.50 & Accesses/Task & 113.500 & 0.597 \\
\hline
\end{tabular}




\section{APPENDIX H - CORRELATIONS BY DIDACTICAL IMPLEMENTATION}

The correlations procedures that were carried out, by case -and in the cases that have undergone than more one course implementation edition by course edition and also globally (all students enrolled in that course in all course editions (GL))- are displayed by case.

As previous explained, it was not possible to run the procedures for all cases/course editions, for the reasons already enumerated in the thesis "body". So, the cases listed in this appendix are the ones for which it was possible to run, at least, some of the procedures and also the ones for which some significant correlations have emerged.

The tables contain the found correlations between the number of VISIR accesses/task and the grades obtained in each component and final grade, as well as the correlations that stood out between both F1 and F2 (and in the mathematics cases also F3) with the former grades. In bullets (and after the tables) it appears:

* The correlations found between VISIR grade as well as other tasks grade with the grades achieved in the other components, including the final grade. For all cases, first is displayed the correlation between the considered grade with VISIR grade and secondly the same considered grade with the other tasks grade.

* The correlations found between F1 and F2 (in the cases alpha de Cronbach > 0.5).

* The correlations found between the number of VISIR accesses/task with F1 and/or F2.

If the former table or bullets do not appear (or if some components are missing, for instances the lab grade), it means there were no significant correlations between the studied variables.

\section{Case C3}

\begin{tabular}{|c|c|c|c|c|c|}
\hline \multicolumn{2}{|c|}{ C3 } & VISIR Grade & Other Tasks Grade & Exam Grade & Final Grade \\
\hline $\begin{array}{l}\text { N VISIR } \\
\text { accesses/ } \\
\text { task }\end{array}$ & $\begin{array}{l}1^{\mathrm{st} /} \mathbf{2}^{\text {nd }} \\
(1,2,3)\end{array}$ & & & & \\
\hline \multirow{3}{*}{ F1 } & $1^{\text {st }}$ & $\begin{array}{c}\mathrm{R}_{\mathrm{P}}=-0.506^{* *}(\mathrm{p}=0.002) \\
\mathrm{N}=35\end{array}$ & $\begin{array}{c}\mathrm{R}_{\mathrm{P}}=-0.352 * *(\mathrm{p}=0.038) \\
\mathrm{N}=35\end{array}$ & n.s. & n.s. \\
\hline & $2^{\text {nd }}(1)$ & n.s. & $\begin{array}{c}\mathrm{R}_{\mathrm{SP}}=0.441^{*}(\mathrm{p}=0.035) \\
\mathrm{N}=23\end{array}$ & n.s. & n.s. \\
\hline & $2^{\text {nd }}(2)$ & n.s. & $\begin{array}{c}\mathrm{R}_{\mathrm{SP}}=-0.411^{* *}(\mathrm{p}=0.041) \\
\mathrm{N}=25\end{array}$ & n.s. & n.s. \\
\hline
\end{tabular}




\begin{tabular}{|c|c|c|c|c|c|}
\hline & $2^{\text {nd }}(3)$ & n.s. & n.s. & n.s. & n.s. \\
\hline & GL & $\begin{array}{c}\mathrm{R}_{\mathrm{P}}=-0.233 *(\mathrm{p}=0.015) \\
\mathrm{N}=109\end{array}$ & n.s. & n.s. & n.s. \\
\hline \multirow[t]{2}{*}{ F2 } & $\begin{array}{c}2^{\text {nd }} \\
(1,2,3)\end{array}$ & n.s. & n.s. & n.s. & n.s. \\
\hline & GL & n.s. & n.s. & n.s. & n.s. \\
\hline
\end{tabular}

* Correlations found between VISIR grade as well as other tasks grade with the grades achieved in the other components:

- Exam grade - $1^{\text {st }}$ implementation: $\mathrm{r}_{\mathrm{P}}=0.416(\mathrm{p}=0.010 ; \mathrm{N}=37) ; \mathrm{r}_{\mathrm{P}}=0.592(\mathrm{p}<0.001 ; \mathrm{N}=37)$; $2^{\text {nd }}$ (1) implementation: n.s; n.s.; $2^{\text {nd }}(2)$ implementation: n.s.; $\mathrm{r}_{\mathrm{P}}=0.643(\mathrm{p}<0.001 ; \mathrm{N}=28)$; $2^{\text {nd }}$ (3) implementation: n.s; n.s..

- Final grade: $1^{\text {st }}$ implementation: $\mathrm{r}_{\mathrm{P}}=0.661(\mathrm{p}<0.001 ; \mathrm{N}=37) ; \mathrm{r}_{\mathrm{P}}=0.864(\mathrm{p}<0.001 ; \mathrm{N}=37)$; $2^{\text {nd }}(1)$ implementation $\mathrm{r}_{\mathrm{P}}=0.481(\mathrm{p}=0.02 ; \mathrm{N}=23) ; \mathrm{r}_{\mathrm{P}}=0.808(\mathrm{p}<0.001 ; \mathrm{N}=23) ; 2^{\text {nd }}(2)$ implementation: $n . s . ; r_{S P}=0.857(p<0.001 ; N=28) ; 2^{\text {nd }}(3)$ implementation: $n . s ; r_{S P}=0.880$ $(\mathrm{p}<0.001 ; \mathrm{N}=33)$.

\section{Case C5}

\begin{tabular}{|c|c|c|c|c|c|}
\hline \multicolumn{2}{|c|}{$\mathbf{C 5}$} & VISIR Grade & Other Tasks Grade & Exam Grade & Final Grade \\
\hline \multirow{3}{*}{$\begin{array}{l}\text { N VISIR } \\
\text { accesses/ } \\
\text { task }\end{array}$} & $2^{\text {nd }}$ & & & n.s. & n.s. \\
\hline & $3^{\text {rd }}$ & n.s. & n.s. & $\begin{array}{c}\mathrm{R}_{\mathrm{P}}=0.564 * *(\mathrm{p}=0.003) \\
\mathrm{N}=25\end{array}$ & n.s. \\
\hline & GL & n.s. & n.s. & $\begin{array}{c}\mathrm{R}_{\mathrm{P}}=0.466^{* *}(\mathrm{p}=0.006) \\
\mathrm{N}=33\end{array}$ & n.s. \\
\hline \multirow{3}{*}{ F1 } & $2^{\text {nd }}$ & & & $\begin{array}{c}\mathrm{R}_{\mathrm{SP}}=-0.828^{*}(\mathrm{p}=0.042) \\
\mathrm{N}=6\end{array}$ & n.s. \\
\hline & $3^{\text {rd }}$ & $\begin{array}{c}\mathrm{R}_{\mathrm{SP}}=0.768^{* *}(\mathrm{p}=0.001) \\
\mathrm{N}=15\end{array}$ & n.s. & n.s. & n.s. \\
\hline & GL & $\begin{array}{c}\mathrm{R}_{\mathrm{SP}}=0.568^{* *}(\mathrm{p}=0.009) \\
\mathrm{N}=20\end{array}$ & n.s. & n.s. & n.s. \\
\hline \multirow{3}{*}{ F2 } & $2^{\text {nd }}$ & & & n.s. & n.s. \\
\hline & $\mathbf{3}^{\mathrm{rd}}$ & n.s. & n.s. & $\begin{array}{c}\mathrm{R}_{\mathrm{SP}}=-0.465^{*}(\mathrm{p}=0.045) \\
\mathrm{N}=19\end{array}$ & n.s. \\
\hline & GL & n.s. & n.s. & $\begin{array}{c}\mathrm{R}_{\mathrm{SP}}=-0.513^{*}(\mathrm{p}=0.009) \\
\mathrm{N}=25\end{array}$ & n.s. \\
\hline
\end{tabular}

There are not any significant correlations between the VISIR grade and the exam grade and/or final grade, considering both implementations. For the third implementation, 
other tasks grades show statistically significant correlations with the exam grade and the final grade.

- Exam grade - $3^{\text {rd }}$ implementation: $\mathrm{r}_{\mathrm{P}}=0.601(\mathrm{p}=0.001 ; \mathrm{N}=28)$;

- Final grade $-3^{\text {rd }}$ implementation: $\mathrm{r}_{\mathrm{P}}=0.595(\mathrm{p}=0.003 ; \mathrm{N}=23)$;

There is a correlation between F1 and F2, for both implementations, correspondingly: $r_{S P}=0.475(p=0.014 ; N=26) ; r_{P}=0.472(p=0.041 ; N=19)$.

\section{Case C7}

* There is a correlation between the number of VISIR accesses/task and F1: $\mathrm{r}_{\mathrm{SP}}=0.805(\mathrm{p}=0.005 ; \mathrm{N}=10)$.

\section{Case C8}

\begin{tabular}{|c|c|c|c|c|c|}
\hline \multicolumn{2}{|c|}{$\mathrm{C8}$} & VISIR Grade & Other Tasks Grade & Exam Grade & Final Grade \\
\hline \multirow{3}{*}{$\begin{array}{l}\text { N VISIR } \\
\text { accesses/ } \\
\text { task }\end{array}$} & $2^{\text {nd }}$ & $\begin{array}{c}\mathrm{R}_{\mathrm{SP}}=0.659^{* *}(\mathrm{p}<0.001) \\
\mathrm{N}=30\end{array}$ & $\begin{array}{c}\mathrm{R}_{\mathrm{SP}}=0.589^{* *}(\mathrm{p}<0.001) \\
\mathrm{N}=33\end{array}$ & $\begin{array}{c}\mathrm{R}_{\mathrm{P}}=0.635^{* *}(\mathrm{p}<0.001) \\
\mathrm{N}=34\end{array}$ & $\begin{array}{c}\mathrm{R}_{\mathrm{SP}}=0.659^{* *}(\mathrm{p}<0.001) \\
\mathrm{N}=35\end{array}$ \\
\hline & $3^{\text {rd }}$ & n.s. & $\begin{array}{c}\mathrm{R}_{\mathrm{SP}}=0.331^{*}(\mathrm{p}=0.026) \\
\mathrm{N}=45\end{array}$ & $\begin{array}{c}\mathrm{R}_{\mathrm{SP}}=0.417^{* *}(\mathrm{p}=0.005) \\
\mathrm{N}=43\end{array}$ & $\begin{array}{c}\mathrm{R}_{\mathrm{SP}}=0.401^{* *}(\mathrm{p}=0.007) \\
\mathrm{N}=44\end{array}$ \\
\hline & GL & $\begin{array}{c}\mathrm{R}_{\mathrm{SP}}=0.289 *(\mathrm{p}=0.013) \\
\mathrm{N}=74\end{array}$ & $\begin{array}{c}\mathrm{R}_{\mathrm{SP}}=0.384 * *(\mathrm{p}=0.001) \\
\mathrm{N}=78\end{array}$ & $\begin{array}{c}\mathrm{R}_{\mathrm{P}}=0.513^{* *}(\mathrm{p}<0.001) \\
\mathrm{N}=77\end{array}$ & $\begin{array}{c}\mathrm{R}_{\mathrm{SP}}=0.536^{* *}(\mathrm{p}<0.001) \\
\mathrm{N}=79\end{array}$ \\
\hline \multirow{4}{*}{ F1 } & $1^{\text {st }}$ & n.s. & n.s. & n.s. & n.s. \\
\hline & $2^{\text {nd }}$ & n.s. & n.s. & n.s. & n.s. \\
\hline & $3^{\text {rd }}$ & n.s. & n.s. & n.s. & n.s. \\
\hline & GL & n.s. & n.s. & n.s. & n.s. \\
\hline \multirow{3}{*}{ F2 } & $1^{\text {st }}$ & n.s. & n.s. & $\begin{array}{c}\mathrm{R}_{\mathrm{P}}=-0.467 *(\mathrm{p}=0.044) \\
\mathrm{N}=19\end{array}$ & $\begin{array}{c}\mathrm{R}_{\mathrm{P}}=-0.458^{*}(\mathrm{p}=0.042) \\
\mathrm{N}=20\end{array}$ \\
\hline & $2^{\text {nd }}$ & n.s. & n.s. & n.s. & n.s. \\
\hline & GL & n.s. & n.s. & n.s. & n.s. \\
\hline \multirow[t]{2}{*}{ F3 } & $2^{\text {nd }}$ & n.s. & n.s. & n.s. & n.s. \\
\hline & GL & n.s. & n.s. & n.s. & n.s. \\
\hline
\end{tabular}

Correlations found between VISIR grade as well as other tasks grade with the grades achieved in the other components:

- Exam grade - $1^{\text {st }}$ implementation: n.s.; n.s.; $2^{\text {nd }}$ implementation: $\mathrm{r}_{\mathrm{SP}}=0.454(\mathrm{p}=0.014$; $\mathrm{N}=38) ; \mathrm{r}_{\mathrm{P}}=0.540(\mathrm{p}<0.001 ; \mathrm{N}=40) ; 3^{\text {rd }}$ implementation: $\mathrm{r}_{\mathrm{SP}}=0.608(\mathrm{p}=0.001 ; \mathrm{N}=43)$; $\mathrm{r}_{\mathrm{P}}=0.704(\mathrm{p}<0.001 ; \mathrm{N}=43)$; 
- Final grade: $1^{\text {st }}$ implementation: n.s.; $r_{P}=0,496(p=0.006 ; N=29) \cdot ; 2^{\text {nd }}$ implementation: $\mathrm{r}_{\mathrm{P}}=0.517(\mathrm{p}=0.001 ; \mathrm{N}=33) ; \mathrm{r}_{\mathrm{P}}=0.788(\mathrm{p}<0.001 ; \mathrm{N}=41) ; 3^{\text {rd }}$ implementation: $\mathrm{r}_{\mathrm{SP}}=0.630$ $(\mathrm{p}=0.001 ; \mathrm{N}=43) ; \mathrm{r}_{\mathrm{P}}=0.881(\mathrm{p}<0.001 ; \mathrm{N}=44)$;

* There is a correlation between F1 and F2, $r_{S P}=0.486(p=0.004 ; N=34)$, just for the second implementation.

\section{Case C9}

\begin{tabular}{|c|c|c|c|c|c|}
\hline \multicolumn{2}{|c|}{ C9 } & VISIR Grade & Other Tasks Grade & Exam Grade & Final Grade \\
\hline \multirow{3}{*}{$\begin{array}{l}\text { N VISIR } \\
\text { accesses/ } \\
\text { task }\end{array}$} & 1st & $\begin{array}{c}\mathrm{R}_{\mathrm{SP}}=0.409^{*}(\mathrm{p}=0.031) \\
\mathrm{N}=28\end{array}$ & n.s. & $\begin{array}{c}\left.\mathrm{R}_{\mathrm{SP}}=0.580^{*}(\mathrm{p}<0.001)\right) \\
\mathrm{N}=32\end{array}$ & $\begin{array}{c}\mathrm{R}_{\mathrm{SP}}=0.597^{* *}(\mathrm{p}<0.001) \\
\mathrm{N}=32\end{array}$ \\
\hline & 2nd & n.s. & n.s. & n.s. & n.s. \\
\hline & GL & $\begin{array}{c}\mathrm{R}_{\mathrm{SP}}=0.343 * *(\mathrm{p}=0.006) \\
\mathrm{N}=63\end{array}$ & n.s. & $\begin{array}{c}\mathrm{R}_{\mathrm{P}}=0.443 *(\mathrm{p}<0.001) \\
\mathrm{N}=66\end{array}$ & $\begin{array}{c}\mathrm{R}_{\mathrm{SP}}=0.355^{* *}(\mathrm{p}=0.003) \\
\mathrm{N}=68\end{array}$ \\
\hline \multirow{3}{*}{ F1 } & 1 st & n.s. & n.s. & n.s. & n.s. \\
\hline & 2nd & n.s. & n.s. & n.s. & n.s. \\
\hline & GL & n.s. & n.s. & n.s. & n.s. \\
\hline \multirow{3}{*}{ F2 } & 1st & n.s. & n.s. & $\begin{array}{c}\mathrm{R}_{\mathrm{SP}}=-0.817 * *(\mathrm{p}=0.007) \\
\mathrm{N}=9\end{array}$ & $\begin{array}{c}\mathrm{R}_{\mathrm{SP}}=-0.811^{* *}(\mathrm{p}=0.008) \\
\mathrm{N}=9\end{array}$ \\
\hline & 2nd & n.s. & n.s. & n.s. & n.s. \\
\hline & GL & n.s. & n.s. & n.s. & $\begin{array}{c}\mathrm{R}_{\mathrm{P}}=-0.483^{*}(\mathrm{p}=0.042) \\
\mathrm{N}=18\end{array}$ \\
\hline \multirow{2}{*}{ F3 } & 1st & n.s. & n.s. & $\begin{array}{c}\mathrm{R}_{\mathrm{P}}=0.679 * *(\mathrm{p}=0.044) \\
\mathrm{N}=9\end{array}$ & n.s. \\
\hline & GL & n.s. & n.s. & $\begin{array}{c}\mathrm{R}_{\mathrm{SP}}=0.766 * *(\mathrm{p}=0.006) \\
\mathrm{N}=11\end{array}$ & n.s. \\
\hline
\end{tabular}

* Correlations found between VISIR grade as well as other tasks grade with the grades achieved in the other components:

- Exam grade - $1^{\text {st }}$ implementation: n.s.; $r_{\mathrm{P}}=0.321(\mathrm{p}=0.050 ; \mathrm{N}=38) ; 2^{\text {nd }}$ implementation: $\mathrm{r}_{\mathrm{P}}=0.433(\mathrm{p}=0.012 ; \mathrm{N}=33) ; \mathrm{n} . \mathrm{s}$;

- Final grade: $1^{\text {st }}$ implementation: $\mathrm{r}_{\mathrm{SP}}=0.383(\mathrm{p}=0.025 ; \mathrm{N}=34) ; \mathrm{r}_{\mathrm{P}}=0.576(\mathrm{p}<0.001 ; \mathrm{N}=38)$; $2^{\text {nd }}$ implementation: $\mathrm{r}_{\mathrm{S}}=0.494(\mathrm{p}=0.003 ; \mathrm{N}=35) ; \mathrm{r}_{\mathrm{P}}=0.708(\mathrm{p}<0.001 ; \mathrm{N}=38)$;

There is a correlation between $\mathbf{F 1}$ and F2, $\mathrm{r}_{\mathrm{P}}=0.728(\mathrm{p}=0.026 ; \mathrm{N}=9)$, just for the first implementation.

\section{Case C10}




\begin{tabular}{|c|c|c|c|c|c|}
\hline \multicolumn{2}{|c|}{$\mathrm{C} 10$} & VISIR Grade & Other Tasks Grade & Exam Grade & Final Grade \\
\hline \multirow{3}{*}{$\mathrm{F} 1$} & $1 \mathrm{st}$ & & & & n.s. \\
\hline & 2 nd & n.s. & n.s. & $\begin{array}{c}\mathrm{R}_{\mathrm{P}}=0.630 *(\mathrm{p}=0.038) \\
\mathrm{N}=11\end{array}$ & n.s. \\
\hline & GL & n.s. & n.s. & $\begin{array}{c}\mathrm{R}_{\mathrm{P}}=0.630 *(\mathrm{p}=0.038) \\
\mathrm{N}=11\end{array}$ & n.s. \\
\hline \multirow{3}{*}{$\mathrm{F} 2$} & $1 \mathrm{st}$ & & & & n.s. \\
\hline & 2nd & n.s. & n.s. & n.s. & n.s. \\
\hline & GL & n.s. & n.s. & n.s. & n.s. \\
\hline
\end{tabular}

There is a correlation between F1 and F2, $\mathrm{r}_{\mathrm{P}}=0.625(\mathrm{p}<0.001 ; \mathrm{N}=29)$, just for the first implementation.

\section{Case C11}

* Correlations found between VISIR grade as well as other tasks grade with the grades achieved in the other components:

- Lab grade: $\mathrm{r}_{\mathrm{SP}}=0.711(\mathrm{p}=0.010 ; \mathrm{N}=12) ; \mathrm{r}_{\mathrm{SP}}=0.889(\mathrm{p}=0.001 ; \mathrm{N}=14)$;

- Exam grade: $\mathrm{r}_{\mathrm{SP}}=0.796(\mathrm{p}=0.002 ; \mathrm{N}=12) ; \mathrm{r}_{\mathrm{SP}}=0.799(\mathrm{p}=0.001 ; \mathrm{N}=14)$;

- Final grade: $\mathrm{r}_{\mathrm{SP}}=0.806(\mathrm{p}=0.002 ; \mathrm{N}=12) ; \mathrm{r}_{\mathrm{SP}}=0.806(\mathrm{p}<0.001 ; \mathrm{N}=14)$.

\section{Case C14}

\begin{tabular}{|c|c|c|c|c|c|}
\hline \multicolumn{2}{|c|}{ C14 } & VISIR Grade & Other Tasks Grade & Lab Grade & Exam Grade \\
\hline $\begin{array}{c}\text { N VISIR } \\
\text { accesses/ } \\
\text { task }\end{array}$ & 2nd & n.s. & $\mathrm{R}_{\mathrm{SP}}=0.507^{* *}(\mathrm{p}=0.010)$ & $\mathrm{R}_{\mathrm{SP}}=0.533^{*}(\mathrm{p}=0.006)$ \\
$\mathrm{N}=25$ & n.s. \\
\hline F1 & 2nd & n.s. & n.s. & n.s. & n.s. \\
\hline F2 & 2nd & n.s. & $\begin{array}{c}\mathrm{R}_{\mathrm{P}}=-0.558^{*}(\mathrm{p}=0.038) \\
\mathrm{N}=14\end{array}$ & n.s. & n.s. \\
\hline
\end{tabular}

Correlations found between VISIR grade as well as other tasks grade with the grades achieved in the other components:

- Lab grade: $\mathrm{r}_{\mathrm{P}}=0.546(\mathrm{p}=0.006 ; \mathrm{N}=24) ; \mathrm{r}_{\mathrm{P}}=0.825(\mathrm{p}<0.001 ; \mathrm{N}=28)$;

- Exam grade: $n . s . ; r_{\mathrm{P}}=0.548(\mathrm{p}=0.005 ; \mathrm{N}=25)$.

There is a correlation between F1 and F2: $\mathrm{r}_{\mathrm{SP}}=0.642(\mathrm{p}=0.013 ; \mathrm{N}=14)$.

\section{Case C15}


There is a correlation between F1 and F2: $\mathrm{r}_{\mathrm{P}}=0.531(\mathrm{p}=0.028 ; \mathrm{N}=17)$.

\section{Case C16}

\begin{tabular}{|c|c|c|c|c|c|}
\hline \multicolumn{2}{|c|}{ C16 } & VISIR Grade & Other Tasks Grade & Lab Grade & Exam Grade \\
\hline \multirow{3}{*}{$\begin{array}{l}\text { N VISIR } \\
\text { accesses/ } \\
\text { task }\end{array}$} & $1 \mathrm{st}$ & $\begin{array}{c}\mathrm{R}_{\mathrm{P}}=0.189 * *(\mathrm{p}=0.004) \\
\mathrm{N}=235\end{array}$ & n.s & $\begin{array}{c}\mathrm{R}_{\mathrm{P}}=0.151 *(\mathrm{p}=0.020) \\
\mathrm{N}=235\end{array}$ & n.s. \\
\hline & 2nd & $\begin{array}{c}\mathrm{R}_{\mathrm{SP}}=0.194^{*}(\mathrm{p}=0.012) \\
\mathrm{N}=167\end{array}$ & n.s. & $\begin{array}{c}\mathrm{R}_{\mathrm{P}}=0.235^{* *}(\mathrm{p}=0.002) \\
\mathrm{N}=168\end{array}$ & $\begin{array}{c}\mathrm{R}_{\mathrm{P}}=0.238^{* *}(\mathrm{p}=0.002) \\
\mathrm{N}=168\end{array}$ \\
\hline & GL & $\begin{array}{c}\mathrm{R}_{\mathrm{P}}=0.162 * *(\mathrm{p}=0.001) \\
\mathrm{N}=397\end{array}$ & n.s. & $\begin{array}{c}\mathrm{R}_{\mathrm{P}}=0.173 * *(\mathrm{p}<0.001) \\
\mathrm{N}=403\end{array}$ & n.s. \\
\hline \multirow{3}{*}{ F1 } & 1st & n.s & $\begin{array}{c}\mathrm{R}_{\mathrm{SP}}=-0.143^{*}(\mathrm{p}=0.023) \\
\mathrm{N}=253\end{array}$ & $\begin{array}{c}\mathrm{R}_{\mathrm{SP}}=-0.162^{*}(\mathrm{p}=0.010) \\
\mathrm{N}=253\end{array}$ & n.s \\
\hline & 2nd & n.s. & n.s. & n.s. & n.s. \\
\hline & GL & n.s. & $\begin{array}{c}\mathrm{R}_{\mathrm{SP}}=-0.141^{*}(\mathrm{p}=0.005) \\
\mathrm{N}=385\end{array}$ & $\begin{array}{c}\mathrm{R}_{\mathrm{SP}}=-0.162 *(\mathrm{p}=0.001) \\
\mathrm{N}=385\end{array}$ & n.s. \\
\hline \multirow{3}{*}{ F2 } & 1st & n.s. & n.s. & n.s. & n.s. \\
\hline & 2nd & n.s. & n.s. & n.s. & n.s. \\
\hline & GL & $\begin{array}{c}\mathrm{R}_{\mathrm{SP}}=-0.108 *(\mathrm{p}=0.035) \\
\mathrm{N}=380\end{array}$ & n.s. & n.s. & n.s. \\
\hline
\end{tabular}

Correlations found between VISIR grade as well as other tasks grade with the grades achieved in the other components:

- Lab grade - $1^{\text {st }}$ implementation: $\mathrm{r}_{\mathrm{SP}}=0.748(\mathrm{p}<0.001 ; \mathrm{N}=254) ; \mathrm{r}_{\mathrm{P}}=0.889(\mathrm{p}<0.001)$; $\mathrm{N}=259)$.; $2^{\text {nd }}$ implementation: $\mathrm{r}_{\mathrm{SP}}=0.753(\mathrm{p}<0.001 ; \mathrm{N}=180) ; \mathrm{r}_{\mathrm{SP}}=0.653(\mathrm{p}<0.001 ; \mathrm{N}=181)$;

- Exam grade: $1^{\text {st }}$ implementation: $\mathrm{r}_{\mathrm{P}}=0.280(\mathrm{p}<0.001 ; \mathrm{N}=251) ; \mathrm{r}_{\mathrm{P}}=0.298(\mathrm{p}<0.001)$; $\mathrm{N}=256)$; $2^{\text {nd }}$ implementation: $\mathrm{r}_{\mathrm{P}}=0.446(\mathrm{p}<0.001 ; \mathrm{N}=180) ; \mathrm{r}_{\mathrm{P}}=0.157(\mathrm{p}=0.035 ; \mathrm{N}=181)$.

* There is a correlation between F1 and F2, for both implementations, correspondingly: $\mathrm{r}_{\mathrm{SP}}=0.593(\mathrm{p}<0.001 ; \mathrm{N}=254) ; \mathrm{r}_{\mathrm{P}}=0.361(\mathrm{p}<0.001 ; \mathrm{N}=132)$

\section{Case C19}

\begin{tabular}{|c|c|c|c|c|c|}
\hline \multicolumn{2}{|c|}{ C19 } & VISIR Grade & Other Tasks Grade & Lab Grade & Final Grade \\
\hline \multirow{4}{*}{$\begin{array}{c}\text { N VISIR } \\
\text { accesses/ } \\
\text { task }\end{array}$} & $1 \mathrm{st}$ & & & n.s. & n.s \\
\hline & 2nd & n.s. & & n.s. & n.s \\
\hline & 3rd & & $\begin{array}{c}\mathrm{R}_{\mathrm{P}}=0.494^{*} \\
(\mathrm{p}=0.044) \mathrm{N}=17\end{array}$ & n.s. & $\begin{array}{c}\mathrm{R}_{\mathrm{P}}=0.685^{* *} \\
(\mathrm{p}=0.005) \mathrm{N}=15\end{array}$ \\
\hline & GL & n.s. & $\mathrm{R}_{\mathrm{P}}=0.494 *$ & n.s. & n.s. \\
\hline
\end{tabular}




\begin{tabular}{|c|c|c|c|c|c|}
\hline & & & $(\mathrm{p}=0.044) \mathrm{N}=17$ & & \\
\hline \multirow[b]{2}{*}{ F1 } & 2nd & n.s. & & n.s. & n.s. \\
\hline & GL & $\begin{array}{c}\mathrm{R}_{\mathrm{SP}}=-0.327^{*} \\
(\mathrm{p}=0.029) \mathrm{N}=45\end{array}$ & n.s. & $\begin{array}{c}\mathrm{R}_{\mathrm{P}}=0.304 * \\
(\mathrm{p}=0.042) \mathrm{N}=45\end{array}$ & n.s. \\
\hline \multirow{2}{*}{ F2 } & 3rd & & n.s. & n.s. & n.s \\
\hline & GL & n.s. & n.s. & n.s. & n.s \\
\hline \multirow{2}{*}{ F3 } & 3rd & & n.s. & n.s. & n.s. \\
\hline & GL & n.s. & n.s. & n.s. & n.s. \\
\hline
\end{tabular}

* For the second implementation VISIR grades show significant positive strong correlation with the lab grade and the final grade, correspondingly $\mathrm{r}_{\mathrm{P}}=0.864$ $(p<0.001 ; N=14)$ and $r_{S P}=0.902(p<0.001 ; N=14)$. In the third implementation other tasks grade is correlated with the final grade, $\mathrm{r}_{\mathrm{P}}=0.738(\mathrm{p}=0.002 ; \mathrm{N}=15)$.

\section{Case C20}

\begin{tabular}{|c|c|c|c|}
\hline \multicolumn{2}{|c|}{$\mathrm{C2O}$} & VISIR Grade & Final Grade \\
\hline \multirow{3}{*}{$\begin{array}{l}\text { N VISIR } \\
\text { accesses/ } \\
\text { task }\end{array}$} & 1st & $\begin{array}{c}\mathrm{R}_{\mathrm{P}}=0.523^{* * *}(\mathrm{p}=0.046) \\
\mathrm{N}=15\end{array}$ & $\begin{array}{c}\mathrm{R}_{\mathrm{SP}}=0.845^{* *}(\mathrm{p}=0.034) \\
\mathrm{N}=6\end{array}$ \\
\hline & 2nd & $\begin{array}{c}\mathrm{R}_{\mathrm{SP}}=0.446^{* *}(\mathrm{p}=0.005) \\
\mathrm{N}=38\end{array}$ & n.s \\
\hline & GL & $\begin{array}{c}\mathrm{R}_{\mathrm{SP}}=0.550^{* *}(\mathrm{p}<0.001) \\
\mathrm{N}=53\end{array}$ & n.s \\
\hline \multirow{2}{*}{ F1 } & 2nd & n.s. & n.s. \\
\hline & GL & n.s. & n.s. \\
\hline \multirow{3}{*}{ F2 } & 1st & n.s. & n.s. \\
\hline & 2nd & n.s. & n.s. \\
\hline & GL & n.s. & n.s. \\
\hline
\end{tabular}

There is a correlation between $\mathbf{F} 1$ and F2, for the second implementation, $\mathrm{r}_{\mathrm{P}}=0.853$ $(\mathrm{p}<0.001 ; \mathrm{N}=18)$.

\section{Case C21}

There is a correlation between F1 and F2: $\mathrm{r}_{\mathrm{SP}}=0.640(\mathrm{p}=0.025 ; \mathrm{N}=12)$. 


\section{Case C22}

* There is a correlation between F1 and F2: $\mathrm{r}_{\mathrm{P}}=0.640(\mathrm{p}=0.006 ; \mathrm{N}=17)$.

\section{Case C24}

\begin{tabular}{|c|c|c|c|}
\hline C24 & VISIR Grade & Exam Grade & Final Grade \\
\hline $\begin{array}{c}\text { N VISIR } \\
\text { accesses/ } \\
\text { task }\end{array}$ & n.s. & $\mathrm{R}_{\mathrm{SP}}=-0.844^{*}(\mathrm{p}=0.035)$ & n.s. \\
\hline F1 & n.s. & $\mathrm{N}=6$ & n.s. \\
\hline F2 & n.s. & n.s. & n.s. \\
\hline
\end{tabular}

\section{Case C26}

\begin{tabular}{|c|c|c|c|c|c|c|}
\hline \multicolumn{2}{|c|}{$\mathrm{C} 26$} & VISIR Grade & Other Tasks & Lab Grade & Exam Grade & Final Grade \\
\hline \multirow{7}{*}{$\begin{array}{l}\text { N VISIR } \\
\text { accesses/ } \\
\text { task }\end{array}$} & $1 \mathrm{st}$ & n.s. & & n.s. & n.s & n.s \\
\hline & 2nd & n.s. & & $\mathrm{R}_{\mathrm{SP}}=0.378^{* *}$ & $\begin{aligned} \mathrm{R}_{\mathrm{P}} & =0.425^{* *} \\
(\mathrm{p} & =0.003)\end{aligned}$ & $\mathrm{R}_{\mathrm{P}}=0.546^{* *}$ \\
\hline & & & & $\mathrm{N}=46$ & $\mathrm{~N}=46$ & $\mathrm{~N}=41$ \\
\hline & 3rd & n.s. & n.s. & $\begin{array}{c}\mathrm{R}_{\mathrm{P}}=0.302^{*} \\
(\mathrm{p}=0.044)\end{array}$ & n.s. & n.s. \\
\hline & & & & $\mathrm{N}=45$ & & \\
\hline & GL & n.s. & n.s. & n.s. & n.s. & $\begin{array}{c}\mathrm{R}_{\mathrm{P}}=0.244 * * \\
(\mathrm{p}=0.008)\end{array}$ \\
\hline & & & & & & $\mathrm{N}=119$ \\
\hline \multirow{5}{*}{ F1 } & $1 \mathrm{st}$ & n.s. & & n.s. & $\begin{array}{c}\mathrm{R}_{\mathrm{P}}=0.513^{*} \\
(\mathrm{p}=0.025)\end{array}$ & $\begin{aligned} \mathrm{R}_{\mathrm{P}} & =0.479^{*} \\
(\mathrm{p} & =0.038)\end{aligned}$ \\
\hline & & & & & $\mathrm{N}=19$ & $\mathrm{~N}=19$ \\
\hline & 2nd & n.s. & & n.s. & n.s. & n.s. \\
\hline & GL & $\begin{array}{c}\mathrm{R}_{\mathrm{SP}}=0.229^{*} \\
(\mathrm{p}=0.042)\end{array}$ & n.s. & $\begin{array}{c}\mathrm{R}_{\mathrm{P}}=0.265^{*} \\
(\mathrm{p}=0.016)\end{array}$ & n.s. & n.s. \\
\hline & & $\mathrm{N}=79$ & & $\mathrm{~N}=82$ & & \\
\hline \multirow{5}{*}{ F2 } & 1st & n.s. & & n.s. & n.s & n.s \\
\hline & 2nd & n.s. & & $\begin{array}{c}\mathrm{R}_{\mathrm{P}}=0.358^{*} \\
(\mathrm{p}=0.028)\end{array}$ & n.s. & n.s. \\
\hline & & & & $\mathrm{N}=38$ & & \\
\hline & 3rd & $\begin{array}{c}\mathrm{R}_{\mathrm{SP}}=0.419 *(\mathrm{p}=0.037) \\
\mathrm{N}=25\end{array}$ & n.s. & $\begin{array}{c}\mathrm{R}_{\mathrm{P}}=0.484 * \\
(\mathrm{p}=0.014)\end{array}$ & n.s. & n.s. \\
\hline & & & & $\mathrm{N}=25$ & & \\
\hline
\end{tabular}




\begin{tabular}{|l|c|c|c|c|c|c|}
\hline GL & $\begin{array}{c}\mathrm{R}_{\mathrm{SP}}=0.275^{*}(\mathrm{p}=0.014) \\
\mathrm{N}=79\end{array}$ & n.s. & $\begin{array}{c}\mathrm{R}_{\mathrm{P}}=0.327^{*} \\
(\mathrm{p}=0.003) \\
\mathrm{N}=82\end{array}$ & n.s. & n.s. \\
\hline
\end{tabular}

Correlations found between VISIR grade as well as other tasks grade with the grades achieved in the other components:

- Lab grade $-1^{\text {st }}$ implementation: $\mathrm{r}_{\mathrm{P}}=0.438(\mathrm{p}=0.002 ; \mathrm{N}=48) ; 2^{\text {nd }}$ implementation: n.s.; $3^{\text {rd }}$ implementation: $\mathrm{r}_{\mathrm{P}}=0.620(\mathrm{p}<0.001 ; \mathrm{N}=39) ; \mathrm{r}_{\mathrm{SP}}=0.422(\mathrm{p}=0.002 ; \mathrm{N}=51)$;

- Exam grade - $1^{\text {st }}$ implementation: n.s.; $2^{\text {nd }}$ implementation: n.s.; $3^{\text {rd }}$ implementation: $r_{S P}=0.398(p=0.016 ; N=36) ; r_{P}=0.477(p=0.001 ; N=42)$;

- Final grade: $1^{\text {st }}$ implementation: n.s.; $2^{\text {nd }}$ implementation: n.s.; $3^{\text {rd }}$ implementation: $\mathrm{r}_{\mathrm{P}}=0.407(\mathrm{p}=0.014 ; \mathrm{N}=36) ; \mathrm{r}_{\mathrm{P}}=0.713(\mathrm{p}<0.001 ; \mathrm{N}=42)$.

- There is correlation between $\mathbf{F 1}$ and F2, for the second implementation, $\mathrm{r}_{\mathrm{SP}}=0.644$ $(\mathrm{p}<0.001 ; \mathrm{N}=38)$. 


\section{APPENDIX I - MANN-WHITNEY AND STUDENT'S T-TEST RESULTS}

\section{FOR STUDENTS}

\section{MANN-Whitney Test}

\begin{tabular}{|c|c|c|c|c|c|c|c|}
\hline Factor & Group & $\mathbf{N}$ & $\begin{array}{l}\text { Mean } \\
\text { Rank }\end{array}$ & $\begin{array}{l}\text { Sum of } \\
\text { Ranks }\end{array}$ & Test Variable & $\begin{array}{c}\text { Mann- } \\
\text { Whitney U }\end{array}$ & $\begin{array}{c}\text { Asymp. Sig. } \\
\text { (2-tailed.) } \\
\text { (p value) }\end{array}$ \\
\hline \multirow{6}{*}{ Used Simulation? } & No & 553 & 456.35 & 252362.50 & \multirow{2}{*}{$\begin{array}{l}\text { F1(St Perceived } \\
\text { Learnings) }\end{array}$} & \multirow{2}{*}{99181.500} & \multirow{2}{*}{0.387} \\
\hline & Yes & 370 & 470.44 & 174063.50 & & & \\
\hline & No & 553 & 437.06 & 241695.50 & \multirow{2}{*}{$\begin{array}{c}\text { F2 (St Satisfaction with } \\
\text { VISIR }\end{array}$} & \multirow{2}{*}{88514.500} & \multirow{2}{*}{0.000} \\
\hline & Yes & 370 & 499.27 & 184730.50 & & & \\
\hline & No & 721 & 516.11 & 372117.00 & \multirow{2}{*}{$\begin{array}{c}\text { Number of Sudents' } \\
\text { Accesses/Task }\end{array}$} & \multirow{2}{*}{111835.000} & \multirow{2}{*}{0.949} \\
\hline & Yes & 311 & 517.40 & 160912.00 & & & \\
\hline \multirow{6}{*}{ Used Hands-on? } & No & 132 & 487.53 & 64353.50 & \multirow{2}{*}{$\begin{array}{l}\text { F1(St Perceived } \\
\text { Learnings) }\end{array}$} & \multirow{2}{*}{48836.500} & \multirow{2}{*}{0.192} \\
\hline & Yes & 791 & 457.74 & 362071.50 & & & \\
\hline & No & 132 & 503.46 & 66457.00 & \multirow{2}{*}{$\begin{array}{c}\text { F2 (St Satisfaction with } \\
\text { VISIR }\end{array}$} & \multirow{2}{*}{46733.000} & \multirow{2}{*}{0.037} \\
\hline & Yes & 791 & 455.08 & 359969.00 & & & \\
\hline & No & 134 & 702.00 & 94968.50 & \multirow{2}{*}{$\begin{array}{c}\text { Number of Sudents' } \\
\text { Accesses/Task }\end{array}$} & \multirow{2}{*}{35308.500} & \\
\hline & Yes & 898 & 488.82 & 438959.50 & & & 0.000 \\
\hline & 1 & 247 & 498.25 & 123068.50 & F1(St Perceived & & \\
\hline & $>1$ & 676 & 448.75 & 303357.50 & Learnings) & 74531.500 & 0.006 \\
\hline Number of & 1 & 247 & 524.49 & 129548.50 & F2 (St Satisfaction with & 68051500 & 0000 \\
\hline 1eacners & $>1$ & 676 & 439.17 & 296877.50 & VISIR & 08001.500 & 0.000 \\
\hline & 1 & 356 & 592.31 & 210863.50 & Number of Sudents' & 93338500 & 0.000 \\
\hline & $>1$ & 676 & 476.57 & 322164.50 & Accesses/Task & 93338.500 & 0.000 \\
\hline & No & 759 & 456.03 & 346124.00 & F1(St Perceived & 57704000 & 0405 \\
\hline & Yes & 157 & 470.46 & 73862.000 & Learnings) & $5 / 704.000$ & 0.495 \\
\hline & No & 759 & 452.67 & 343579.000 & F2 (St Satisfaction with & & 0113 \\
\hline I ask Mandatory? & Yes & 157 & 486.67 & 76407.000 & VISIR & 50159.000 & 0.113 \\
\hline & No & 907 & 488.74 & 443283.50 & Number of Sudents' & 31505500 & 0000 \\
\hline & Yes & 118 & 699.50 & 82541.50 & Accesses/Task & 31500.500 & 0.000 \\
\hline & No & 522 & 403.18 & 210457.50 & F1(St Perceived & 73954500 & 0000 \\
\hline & Yes & 331 & 464.57 & 153773.50 & Learnings) & 13954.500 & 0.000 \\
\hline Task in Grouns? & No & 522 & 380.87 & 198813.50 & F2 (St Satisfaction with & 62310.500 & 0.000 \\
\hline I ask in Groups? & Yes & 331 & 499.75 & 165417.50 & VISIR & 02310.500 & 0.000 \\
\hline & No & 648 & 406.43 & 263366.50 & Number of Sudents' & 53090500 & 0000 \\
\hline & Yes & 306 & 628.00 & 192168.50 & Accesses/Task & 55090.500 & 0.000 \\
\hline & Qual & 154 & 515.84 & 79439.00 & F1(St Perceived & & \\
\hline & Quant & 762 & 446.91 & 340547.00 & Learnings) & .000 & 0.001 \\
\hline Task Assessment? & Qual & 154 & 535.20 & 82421.50 & F2 (St Satisfaction with & & \\
\hline Iask Assessment? & Quant & 762 & 443.00 & 337564.50 & VISIR & 46861.500 & 0.000 \\
\hline & Qual & 206 & 671.14 & 138255.50 & Number of Sudents' & 500 & 0000 \\
\hline & Quant & 819 & 473.22 & 387569.50 & Accesses/Task & 500 & 0.000 \\
\hline & No & 631 & 460.00 & 200262.50 & & & \\
\hline & Yes & 292 & 466.31 & 136163.50 & Learnings) & 90866.5000 & 0.713 \\
\hline Used the 3 & No & 631 & 444.98 & 280779.50 & F2 (St Satisfaction with & 81383500 & 0002 \\
\hline resources? & Yes & 292 & 498.79 & 145646.50 & VISIR & 81383.500 & 0.002 \\
\hline & No & 809 & 534.55 & 432452.50 & Number of Sudents' & 500 & 0000 \\
\hline & Yes & 223 & 451.01 & 100575.50 & Accesses/Task & 500 & 0.000 \\
\hline & No & 150 & 402.38 & 60507.50 & F1(St Perceived & & 0.903 \\
\hline & Yes & 652 & 401.07 & 261495.50 & Learnings) & $4861 / .500$ & 0.903 \\
\hline Uploading & No & 150 & 436.22 & 65433.50 & F2 (St Satisfaction with & 500 & 0028 \\
\hline Support Material? & Yes & 652 & 393.51 & 256569.50 & VISIR & .000 & $0.0<0$ \\
\hline & No & 102 & 413.25 & 42152.00 & Number of Sudents' & 000 & 0.040 \\
\hline & Yes & 826 & 470.83 & 388904.00 & Accesses/Task & 30899.000 & 0.040 \\
\hline & No & 662 & 394.31 & 261035.00 & F1(St Perceived & 41582000 & 0036 \\
\hline $\begin{array}{l}\text { ISIR Support } \\
\text { by email? }\end{array}$ & Yes & 140 & 435.49 & 60969.00 & Learnings) & 41582.000 & 0.056 \\
\hline & No & 662 & 393.95 & 260396.50 & & 40943.500 & 0.020 \\
\hline
\end{tabular}




\begin{tabular}{|c|c|c|c|c|c|c|c|}
\hline & Yes & 140 & 440.05 & 61606.50 & $\begin{array}{c}\text { F2 (St Satisfaction with } \\
\text { VISIR }\end{array}$ & & \\
\hline & No & 728 & 420.01 & 305770.50 & Number of Sudents' & & \\
\hline & Yes & 200 & 626.43 & 125285.50 & Accesses/Task & 40414.500 & 0.000 \\
\hline \multirow{6}{*}{$\begin{array}{l}\text { VISIR Support } \\
\text { presential? }\end{array}$} & No & 196 & 402.56 & 78901.50 & \multirow{2}{*}{$\begin{array}{l}\text { F1(St Perceived } \\
\text { Learnings) }\end{array}$} & & \multirow[b]{2}{*}{0.905} \\
\hline & Yes & 605 & 400.50 & 242299.50 & & & \\
\hline & No & 196 & 411.09 & 80573.50 & \multirow{2}{*}{$\begin{array}{c}\text { F2 (St Satisfaction with } \\
\text { VISIR }\end{array}$} & \multirow{2}{*}{57312.500} & \multirow{2}{*}{0.450} \\
\hline & Yes & 605 & 397.73 & 240627.50 & & & \\
\hline & No & 332 & 587.22 & 194958.00 & \multirow{2}{*}{$\begin{array}{c}\text { Number of Sudents' } \\
\text { Accesses/Task }\end{array}$} & \multirow{2}{*}{57860.000} & \multirow{2}{*}{0.000} \\
\hline & Yes & 595 & 395.24 & 235170.00 & & & \\
\hline \multirow{6}{*}{ Developed HOS? } & No & 294 & 306.66 & 60759.00 & \multirow{2}{*}{$\begin{array}{l}\text { F1(St Perceived } \\
\text { Learnings) }\end{array}$} & \multirow{2}{*}{17394.000} & \multirow{2}{*}{0.406} \\
\hline & Yes & 124 & 216.23 & 26812.00 & & & \\
\hline & No & 294 & 212.75 & 62549.00 & \multirow{2}{*}{$\begin{array}{c}\text { F2 (St Satisfaction with } \\
\text { VISIR }\end{array}$} & \multirow{2}{*}{17272.000} & \multirow{2}{*}{0.334} \\
\hline & Yes & 124 & 201.79 & 25022.00 & & & \\
\hline & No & 309 & 192.67 & 59535.50 & \multirow{2}{*}{$\begin{array}{c}\text { Number of Sudents' } \\
\text { Accesses/Task }\end{array}$} & \multirow{2}{*}{11640.500} & \multirow{2}{*}{0.005} \\
\hline & Yes & 93 & 280.83 & 21467.50 & & & \\
\hline \multirow{6}{*}{ Task DC or AC? } & $\mathrm{DC}$ & 731 & 461.28 & 337197.00 & \multirow{2}{*}{$\begin{array}{l}\text { F1(St Perceived } \\
\text { Learnings) }\end{array}$} & \multirow{2}{*}{65584.000} & \multirow{2}{*}{0.487} \\
\hline & $\mathrm{AC}$ & 185 & 447.51 & 82789.00 & & & \\
\hline & $\mathrm{DC}$ & 731 & 460.83 & 336868.00 & \multirow{2}{*}{$\begin{array}{c}\text { F2 (St Satisfaction with } \\
\text { VISIR } \\
\end{array}$} & \multirow{2}{*}{65913.000} & 0566 \\
\hline & $\mathrm{AC}$ & 185 & 449.29 & 83118.00 & & & 0.566 \\
\hline & $\mathrm{DC}$ & 767 & 465.50 & 357039.50 & Number of Sudents' & & \\
\hline & $\mathrm{AC}$ & 258 & 654.21 & 168785.50 & Accesses/Task & 62511.500 & 0.000 \\
\hline & No & 785 & 444.98 & 349306.00 & F1(St Perceived & & \\
\hline & Yes & 102 & 436.49 & 44522.00 & Learnings) & 39269.000 & 0.129 \\
\hline VISIR contents & No & 785 & 443.68 & 348292.50 & F2 (St Satisfaction with & & \\
\hline worked before? & Yes & 102 & 446.43 & 45535.50 & VISIR & 39787.500 & 0.912 \\
\hline & No & 796 & 446.32 & 355269.50 & Number of Sudents' & 38063500 & 0000 \\
\hline & Yes & 201 & 707.63 & 142233.50 & Accesses/Task & 38063.500 & 0.000 \\
\hline & No & 35 & 443.74 & 15531.00 & F1(St Perceived & 000 & 0.659 \\
\hline & Yes & 887 & 462.20 & 409972.00 & Learnings) & 000 & 0.039 \\
\hline Students first time & No & 35 & 524.54 & 18359.00 & & & \\
\hline to use VISIR? & Yes & 887 & 459.01 & 407144.00 & VISIR & 13316.000 & 0.123 \\
\hline & No & 72 & 561.63 & 40437.50 & Number of Sudents' & 30734500 & 0.143 \\
\hline & Yes & 952 & 508.78 & 484362.50 & Accesses/Task & $30 / 34.500$ & 0.143 \\
\hline & $\mathrm{EE}$ & 264 & 476.06 & 125680.00 & F1(St Perceived & & \\
\hline & Other EE & 659 & 456.37 & 300746.000 & Learnings) & $832 / 6.000$ & 0.265 \\
\hline & $\mathrm{EE}$ & 264 & 487.81 & 128782.50 & & & \\
\hline major? & Other EE & 659 & 451.66 & 297643.50 & VISIR & 80173.500 & 0.044 \\
\hline & $\mathrm{EE}$ & 343 & 574.65 & 197104.50 & Number of Sudents' & & \\
\hline & Other EE & 689 & 487.55 & 335923.50 & Accesses/Task & 98218.500 & 0.000 \\
\hline
\end{tabular}

STUDENT'S T-TEST

\begin{tabular}{|c|c|c|c|c|c|c|c|}
\hline Factor & Group & $\mathbf{N}$ & Mean & $\begin{array}{l}\text { Standard } \\
\text { Deviation }\end{array}$ & $\begin{array}{l}\text { Test } \\
\text { Variable }\end{array}$ & $\begin{array}{l}\text { Levene's test for } \\
\text { Equality of Variances } \\
\text { (Sig) }\end{array}$ & $\begin{array}{l}\text { Student's T- Test } \\
\text { (Sig. 2-tailed.) }\end{array}$ \\
\hline \multirow{4}{*}{ Used Simulation? } & No & 681 & 83.60 & 18.654 & \multirow{2}{*}{$\begin{array}{l}\text { VISIR } \\
\text { Grade }\end{array}$} & \multirow{2}{*}{0.004} & \multirow{2}{*}{0.000} \\
\hline & Yes & 264 & 77.78 & 17.544 & & & \\
\hline & No & 616 & 83.28 & 19.411 & \multirow{2}{*}{ LAB Grade } & \multirow{2}{*}{0.021} & \multirow{2}{*}{0.001} \\
\hline & Yes & 90 & 69.80 & 17.533 & & & \\
\hline \multirow{4}{*}{ Used Hands-on? } & No & 150 & 81.71 & 14.819 & \multirow{2}{*}{$\begin{array}{l}\text { VISIR } \\
\text { Grade }\end{array}$} & \multirow{2}{*}{0.000} & \multirow{2}{*}{0.823} \\
\hline & Yes & 795 & 82.02 & 19.154 & & & \\
\hline & No & & & & \multirow{2}{*}{ LAB Grade } & & \\
\hline & Yes & 706 & 81.56 & 19.691 & & & \\
\hline \multirow{4}{*}{$\begin{array}{l}\text { Number of } \\
\text { Teachers } \\
\text { involved? }\end{array}$} & 1 & 334 & 81.43 & 15.630 & \multirow{2}{*}{$\begin{array}{l}\text { VISIR } \\
\text { Grade }\end{array}$} & \multirow{2}{*}{0.000} & \multirow[t]{2}{*}{0.475} \\
\hline & $>1$ & 611 & 82.27 & 19.940 & & & \\
\hline & 1 & 191 & 60.80 & 19.864 & \multirow{2}{*}{ LAB Grade } & \multirow{2}{*}{0.000} & \multirow[t]{2}{*}{0.000} \\
\hline & $>1$ & 515 & 89.26 & 12.897 & & & \\
\hline \multirow{2}{*}{ Task Mandatory? } & No & 829 & 82.70 & 19.055 & \multirow{2}{*}{$\begin{array}{l}\text { VISIR } \\
\text { Grade }\end{array}$} & \multirow{2}{*}{0.000} & \multirow[t]{2}{*}{0.000} \\
\hline & Yes & 116 & 76.82 & 13.143 & & & \\
\hline
\end{tabular}




\begin{tabular}{|c|c|c|c|c|c|c|c|}
\hline & No & 675 & 81.86 & 20.008 & \multirow{2}{*}{ LAB Grade } & \multirow{2}{*}{0.000} & \multirow{2}{*}{0.000} \\
\hline & Yes & 31 & 75.00 & 8.466 & & & \\
\hline \multirow{4}{*}{ Task in Groups? } & No & 536 & 85.52 & 20.971 & \multirow{2}{*}{$\begin{array}{l}\text { VISIR } \\
\text { Grade }\end{array}$} & \multirow{2}{*}{0.000} & \multirow{2}{*}{0.000} \\
\hline & Yes & 403 & 78.47 & 14.103 & & & \\
\hline & No & 530 & 88.52 & 14.107 & \multirow[b]{2}{*}{ LAB Grade } & \multirow{2}{*}{0.003} & \multirow{2}{*}{0.000} \\
\hline & Yes & 176 & 60.62 & 19.313 & & & \\
\hline \multirow{4}{*}{ Task Assessment? } & Qual & 57 & 75.00 & 16.529 & \multirow{2}{*}{$\begin{array}{l}\text { VISIR } \\
\text { Grade }\end{array}$} & \multirow{2}{*}{0.265} & \multirow{2}{*}{0.003} \\
\hline & Quant & 888 & 82.42 & 18.567 & & & \\
\hline & Qual & 46 & 75.22 & 8.094 & \multirow{2}{*}{ LAB Grade } & \multirow{2}{*}{0.000} & \multirow{2}{*}{0.000} \\
\hline & Quant & 660 & 82.01 & 20.182 & & & \\
\hline \multirow{4}{*}{$\begin{array}{l}\text { Used the } 3 \\
\text { resources? }\end{array}$} & No & 801 & 83.93 & 17.757 & \multirow{2}{*}{$\begin{array}{l}\text { VISIR } \\
\text { Grade }\end{array}$} & \multirow{2}{*}{0.944} & \multirow{2}{*}{0.000} \\
\hline & Yes & 144 & 71.12 & 19.025 & & & \\
\hline & No & 630 & 83.19 & 19.235 & \multirow{2}{*}{ LAB Grade } & & \\
\hline & Yes & 76 & 68.05 & 18.285 & & 0.157 & 0.000 \\
\hline & No & 92 & 72.15 & 16.536 & VISIR & & \\
\hline VISIR Support & Yes & 814 & 83.12 & 18.803 & Grade & 0.073 & 0.000 \\
\hline Supnort Material? & No & 31 & 75.00 & 8.466 & I A P Crodo & 0000 & 0000 \\
\hline & Yes & 675 & 81.86 & 20.008 & LAB Grade & 0.000 & 0.000 \\
\hline & No & 722 & 83.40 & 19.363 & VISIR & 0.000 & 0.000 \\
\hline VISIR Support & Yes & 184 & 76.83 & 15.505 & Grade & 0.000 & 0.000 \\
\hline by email? & No & 484 & 90.18 & 12.596 & I P Crodo & $0 \Omega 00$ & 0000 \\
\hline & Yes & 222 & 62.78 & 19.321 & LAB Grade & 0.000 & 0.000 \\
\hline & No & 249 & 82.52 & 18.378 & VISIR & 0002 & 0655 \\
\hline VISIR Support & Yes & 656 & 81.90 & 19.013 & Grade & 0.002 & 0.655 \\
\hline presential? & No & 90 & 69.80 & 17.533 & LAB Grade & 0.021 & 0,000 \\
\hline & Yes & 616 & 83.28 & 19.411 & LAB Grade & 0.021 & 0.000 \\
\hline & No & 360 & 77.44 & 14.222 & VISIR & 0000 & 0.000 \\
\hline Develoned HOS? & Yes & 115 & 89.09 & 9.901 & Grade & 0.000 & 0.000 \\
\hline Developed HUS? & No & 185 & 61.25 & 19.157 & & & \\
\hline & Yes & 37 & 75.65 & 7.570 & LAB Grade & 0.004 & 0.000 \\
\hline & $\mathrm{DC}$ & 788 & 82.54 & 18.176 & VISIR & 0925 & 0034 \\
\hline Task DC or AC? & $\mathrm{AC}$ & 157 & 79.12 & 20.015 & Grade & & \\
\hline IASK DC or AC? & $\mathrm{DC}$ & 616 & 83.28 & 19.411 & IA B Grade & 0021 & 0000 \\
\hline & $\mathrm{AC}$ & 90 & 69.80 & 17.533 & LAB Grade & 0.021 & 0.000 \\
\hline & No & 788 & 82.54 & 18.176 & VISIR & 0.925 & 0.034 \\
\hline VISIR contents & Yes & 157 & 79.12 & 20.015 & Grade & 0.925 & 0.034 \\
\hline worked before? & No & 630 & 82.79 & 19.833 & Grode & 0001 & 0000 \\
\hline & Yes & 76 & 71.42 & 15.135 & LAB Grade & 0.001 & 0.000 \\
\hline & No & 44 & 87.68 & 15.707 & VISIR & 0036 & 0018 \\
\hline Students first time & Yes & 893 & 81.67 & 18.627 & Grade & 0.050 & 0.018 \\
\hline to use VISIR? & No & 41 & 53.76 & 27.341 & LAB Grade & 0000 & 0,000 \\
\hline & Yes & 664 & 83.27 & 17.786 & LAB Grade & 0.000 & 0.000 \\
\hline & $\mathrm{EE}$ & 193 & 82.33 & 23.322 & VISIR & 0000 & 0701 \\
\hline EE major or other & Other EE & 865 & 82.80 & 17.780 & Grade & 0.000 & 0.191 \\
\hline major & $\mathrm{EE}$ & 90 & 69.80 & 17.533 & & 0021 & 0,000 \\
\hline & Other EE & 616 & 83.28 & 19.411 & 3 Grade & 0.021 & 0.000 \\
\hline
\end{tabular}

